INTEGRATED BASELINE SYSTEM (IBS)

Version 1.03

\title{
USER GUIDE
}

\author{
B. M. Bailey \\ M. J. Burford \\ T. R. Downing \\ S. W. Matsumoto \\ E. E. Schrank \\ J. R. Williams \\ C. Winters
}

January 1993

Prepared for the Federal Emergency Management Agency under a Related Services Agreement with the U.S. Department of Energy Contract DE-AC06-76RLO 1830

Pacific Northwest Laboratory Richland, Washington 99352 


\section{NOTICE}

The Integrated Baseline System (IBS) is an emergency planning, training, and response tool intended to supplement existing resources for emergency planning, training, and management. IBS results must not be used as the sole basis for a decision regarding public safety. Although IBS is operational, not all IBS software/models have been verified. The assumptions of the IBS software must be reviewed to assure its appropriateness for an intended use. 


\section{Preface}

The Integrated Baseline System (IBS) is an emergency management planning and analysis tool being developed under the direction of the Federal Emergency Management Agency. The following documents were developed to support system users. The audience for each is identified.

This IBS User Guide explains how to start and use the IBS program, which is designed to help civilian emergency management personnel to plan for and support their responses to a chemical-releasing event at a military chemical stockpile. ${ }^{\text {(a) }}$ Audience: all users of the IBS, especially emergency management planners and analysts.

The IBS Utilities Guide explains how you can use IBS utility programs to manage and manipulate various kinds of IBS data. These programs include utilities for creating, editing, and displaying maps and other data that are referenced to geographic location. Audience: chiefly data managers but also system managers and some emergency management planners and analysts.

The IBS Models Guide summarizes the IBS use of several computer models for predicting the results of emergency situations. These include models for predicting dispersion/doses of airborne contaminants, traffic evacuation, explosion effects, heat radiation from a fire, and siren sound transmission. The guide references additional technical documentation on the models when such documentation is available from other sources. Audience: chiefly emergency management planners and analysts, but also data managers and system managers.

The IBS Data Management Guide provides the information needed to manage the data files and database used to support the administrative, userenvironment, database management, and operational capabilities of the IBS. Audience: chiefly database administrators and system managers, but also emergency management planners and analysts who want to know details of the emergency management data.

The IBS System Management Guide defines IBS hardware and software requirements and gives instructions for installing, upgrading, or transferring the IBS software package. Audience: system managers.

\footnotetext{
(a) The IBS program was developed as part of the U.S. Army's Chemical Stockpile Emergency Preparedness Program (CSEPP).
} 

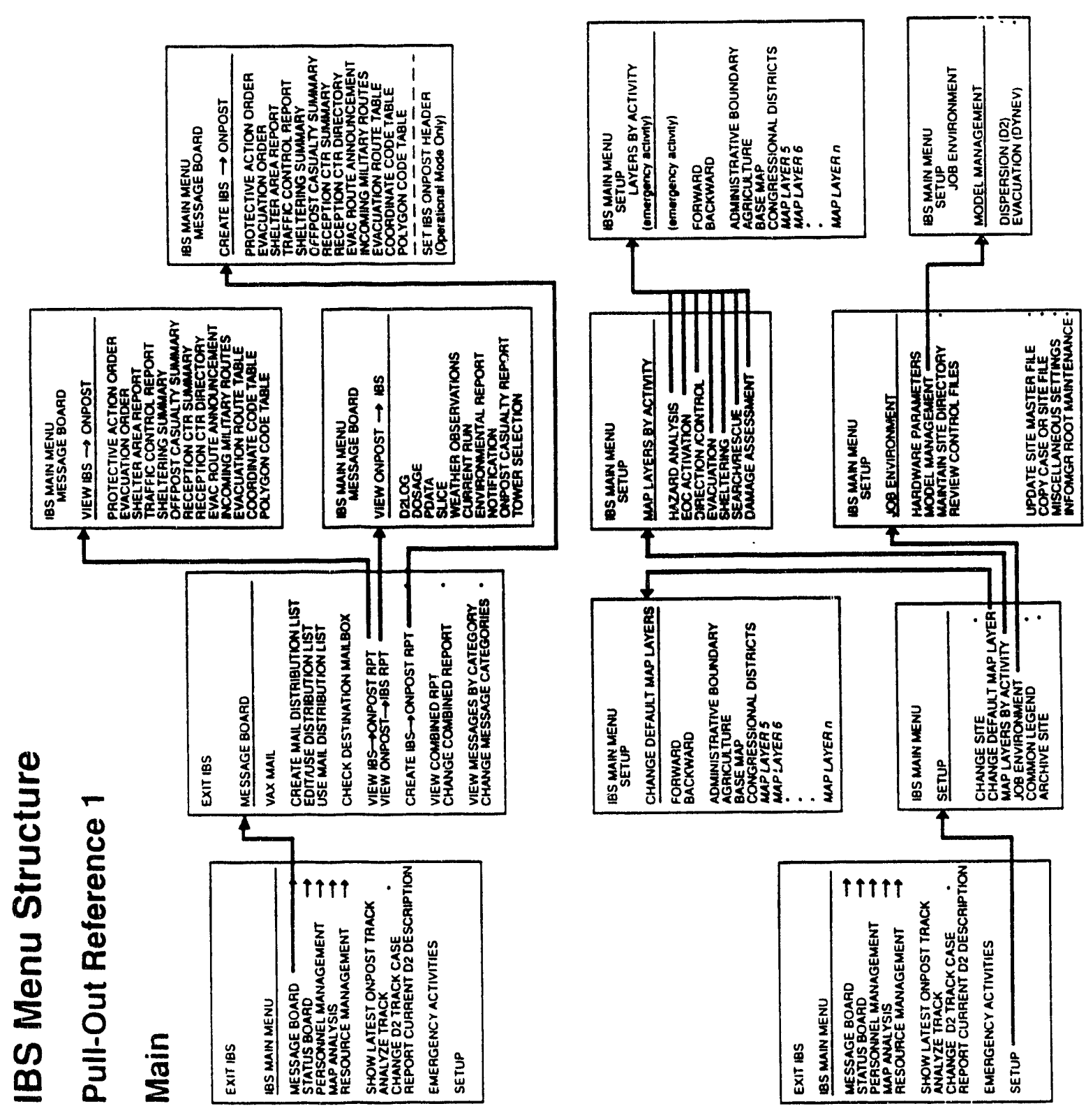


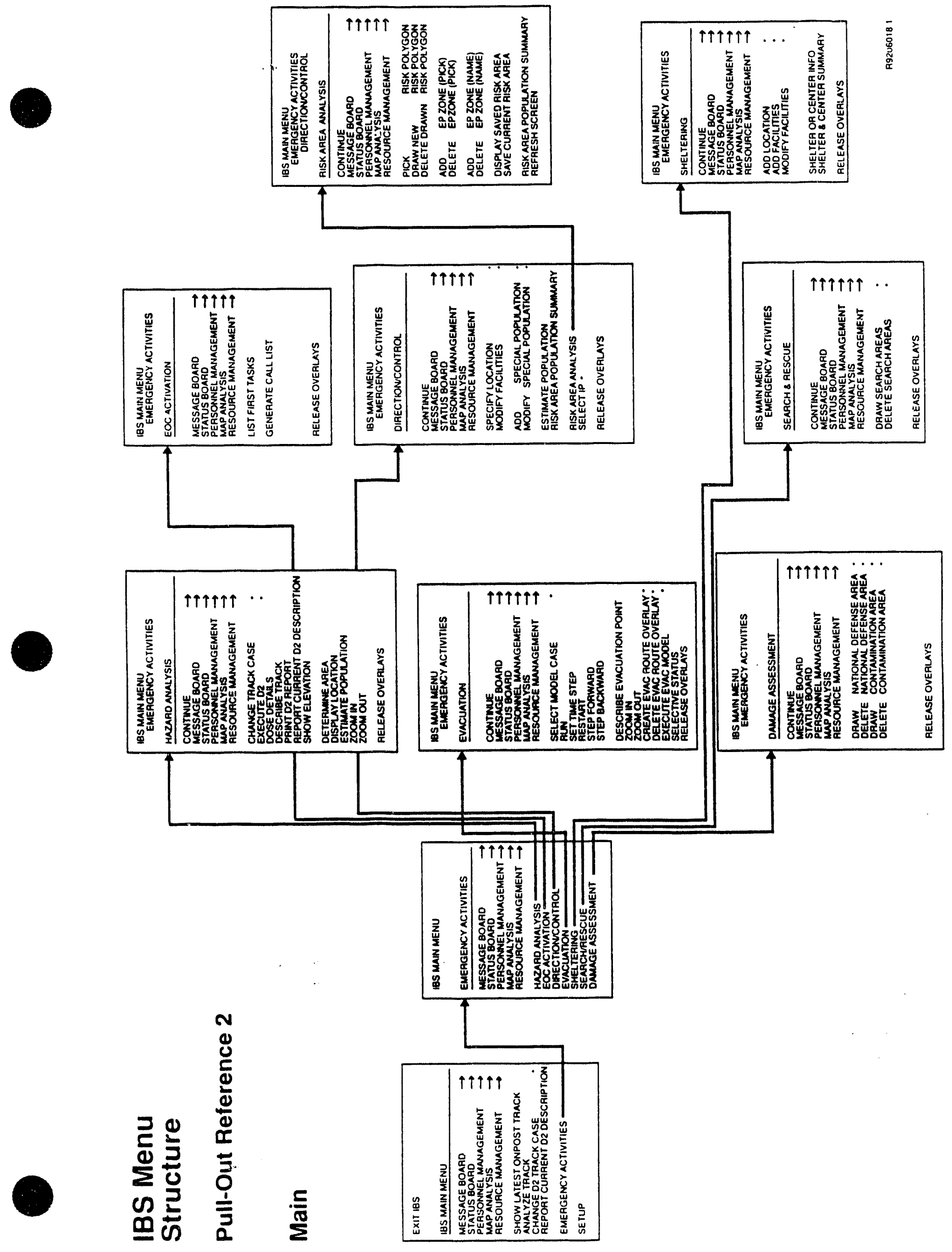




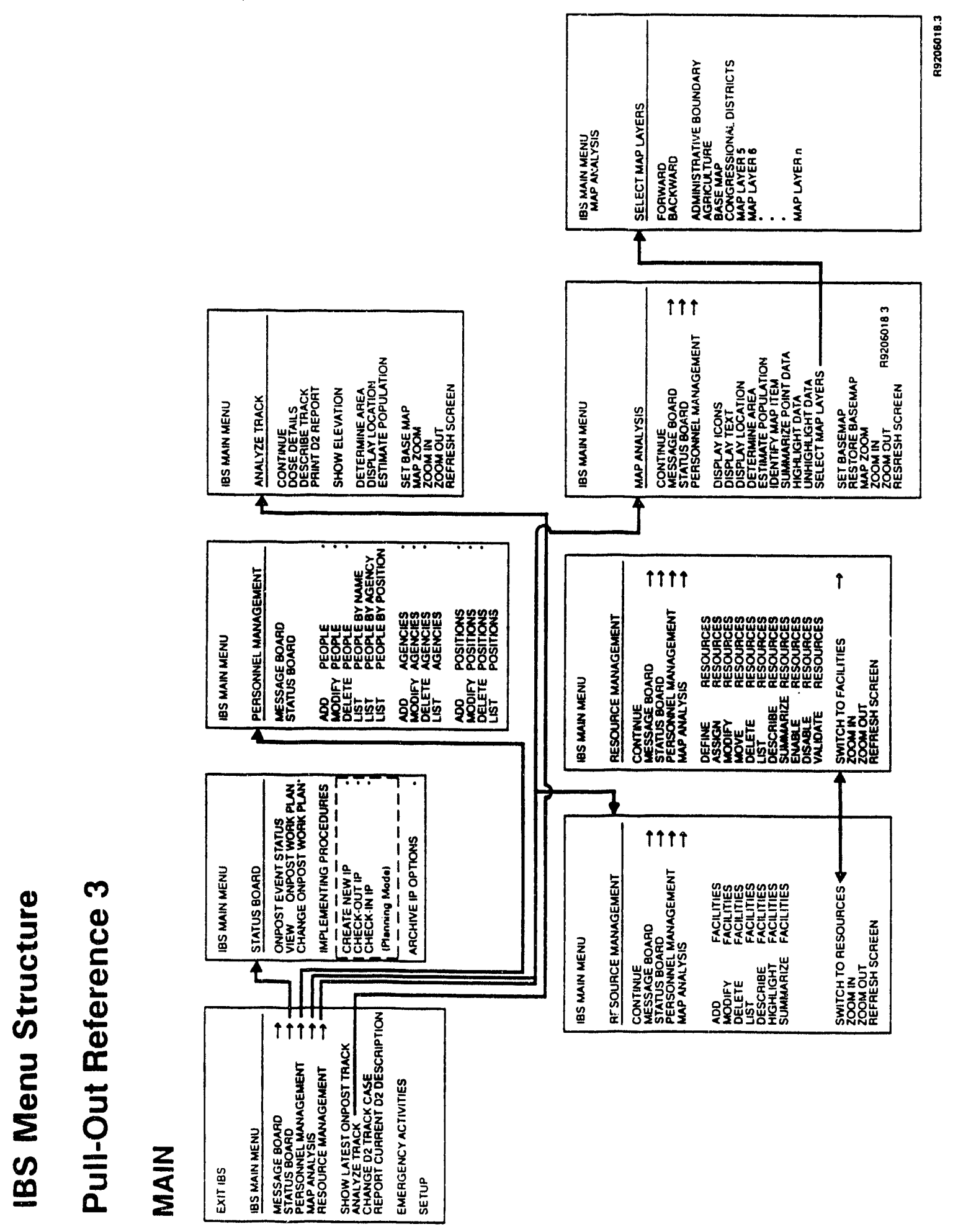




\section{About This Guide}

\section{Purpose}

The Integrated Baseline System (IBS), operated by the Federal Emergency

Management Agency (FEMA) ${ }^{(a)}$, is a system of computerized tools for emergency planning and analysis. This document is the user guide for the IBS and explains how to operate the IBS system.

\section{Scope}

This document provides information for the general system user, and is the primary reference for the system features of the IBS. It is designed for persons who are familiar with general emergency management concepts, operations, and vocabulary.

Although the IBS manual set covers basic and advanced operations, it is not a complete reference document set. Emergency situation modeling software in the IBS is supported by additional technical documents. Some of the other IBS software is commercial software for which more complete documentation is available. The IBS manuals reference such documentation where necessary.

IBS is a dynamic system. Its capabilities are in a state of continuing expansion and enhancement. However, if you have any questions related to the operation of IBS:

WRITE TO: $\quad$ Federal Emergency Management Agency NP-SE-AS (Attn: Ralph Sinnot)

$500 \mathrm{C}$ St. S. W.

Washington, D.C. 20472

OR TELEPHONE: (202) 646-3824

\section{Audience}

The primary audience for this document is composed of IBS general users, emergency planners and analysts, information managers, and geographic database administrators.

(a) The IBS is being developed by the Pacific Northwest Laboratory (PNL). PNL is operated for the U.S. Department of Energy by Battelle Memorial Institute under Contract DE-AC06-76RLO 1830. 


\section{Prerequisites}

Knowledge Requirements for Using the IBS. Users of the IBS software should receive training in the use of IBS capabilities for emergency management planning and operational tasks associated with CSEPP. For those users, this document is a reference guide to IBS capabilities. However, this document does not describe the overall context for using the IBS: it is expected that training and training materials will provide that context.

\section{Organization}

The chapters of this guide introduce IBS concepts and functions and explain how to navigate the menus and operate the various parts of the system.

\section{Section 1. Introduction and Overview}

A description of general system functions plus an introduction to the purpose and parts of the IBS and its use in developing emergency plans. Describes how to navigate the menu system, conventions for interacting with the IBS, and presents a series of exercises for the new user.

\section{Section 2. Message Board}

A reference guide to the IBS system functions and commands for the Message Board Main Menu function.

\section{Section 3. Status Board}

A reference guide to the IRS sysiem functions and commands for the Status Board Main Menu function.

\section{Section 4. Personnel Management}

A reference guide to the IBS system functions and commands for the Personnel Management Main Menu function.

\section{Section 5. Map Analysis}

A reference guide to the IBS system functions and commands for the Map Analysis Main Menu function.

\section{Section 6. Resource Management}

A reference guide to the IBS system functions and commands for the Resource Management Main Menu function. 


\section{Section 7. Show Latest Onpost Track}

A reference guide to the IBS system functions and commands for the Show Latest Onpost Track Main Menu Function.

Section 8. Analyze Track

A reference guide to the IBS system functions and commands for the Analyze Track Main Menu function.

\section{Section 9. Change D2 Track Case}

A reference guide to the IBS system functions and commands for the Change D2 Track Case Main Menu function.

\section{Section 10. Report Current D2 Description}

A reference guide to the IBS system functions and commands for the Report Current D2 Description Main Menu function.

\section{Section 11. Emergency Activities}

A reference guide to the IBS system functions and commands for the Emergency Activities Main Menu function.

\section{Section 12. Setup}

A reference guide to the IBS system functions and commands for the Setup Main Menu function.

\section{Appendix A. IBS Graphic Menus}

IBS Graphic Menus are summarized and illustrated.

Appendix B. Non-Graphic IBS

The use of the non-graphic IBS is summarized.

\section{Appendix C. People Location}

The People Location (LOCATE) program and its functions are described.

\section{Appendix D. Onpost Simulator}

The Onpost Simulator program and its functions are described.

\section{Appendix E. IBS and Onpost EOC Reports}


Descriptions of the formats for IBS and Onpost EOC reports.

Appendix F. System Icons

Descriptions and illustrations of the icons used in the graphic map display of the IBS. 


\section{How to Use this Document}

This guide is organized around the capabilities of the graphic IBS software. You will access most of these capabilities by picking them from menu listings on your terminal screen.

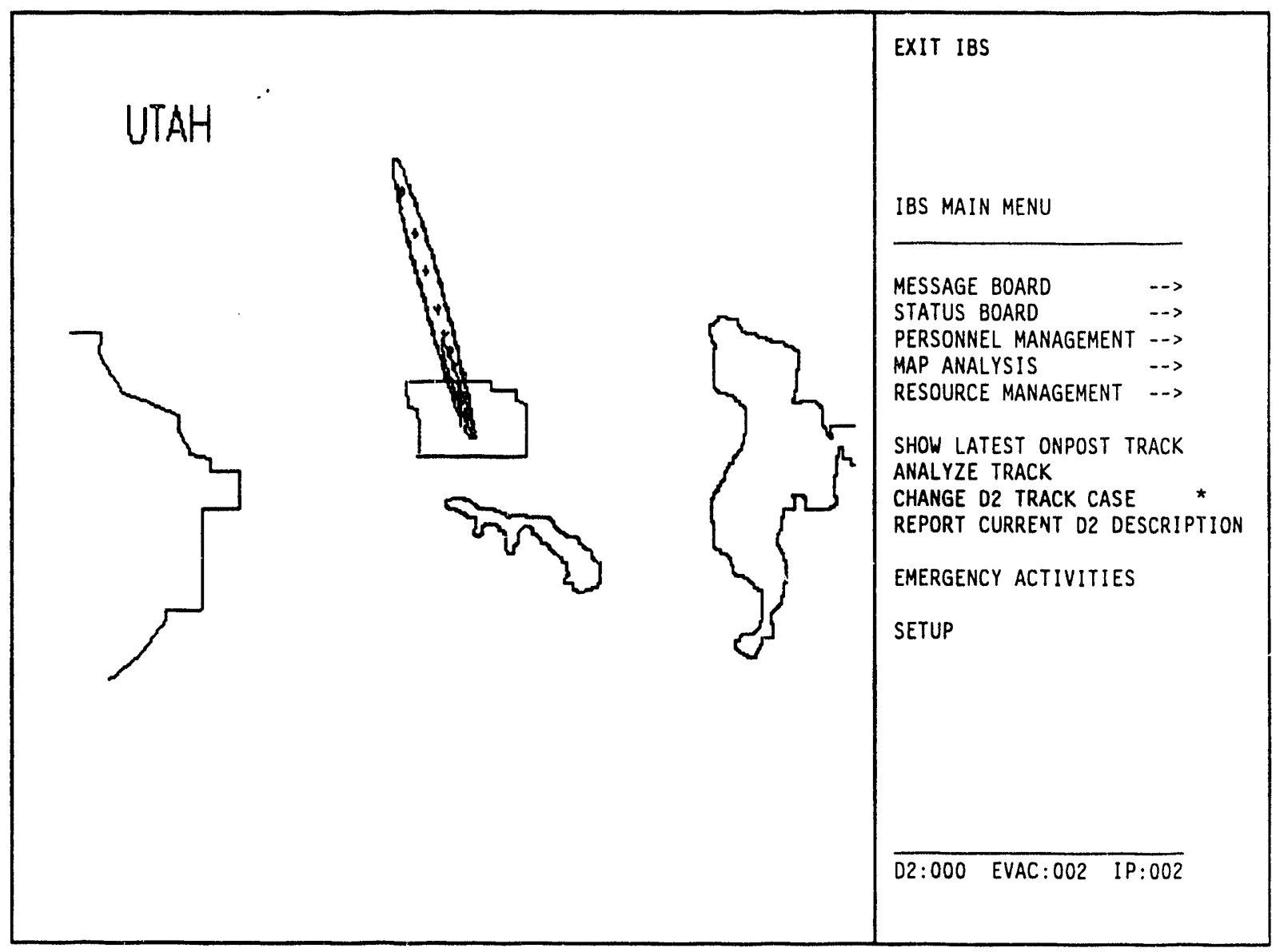

This is an illustration of the IBS main menu, which displays when you start the IBS. The screen display is split into two sections:

- Map display

- Menu display

The map display is on the left side of the screen, and is always visible except when you are in a report, a form, or other text function. The initial map display is the preset default established by the system manager. You can change the map display using the functions described in this guide. 
The menu display is on the right side of the screen. In this guide, the menu display is often shown without the accompanying map display, as in this example.

\section{EXIT IBS}

IBS MAIN MENU

\begin{tabular}{ll}
\hline & \\
MESSAGE BOARD & $->$ \\
STATUS BOARD & $->$ \\
PERSONNEL MANAGEMENT & $->$ \\
MAP ANALYSIS & $->$ \\
RESOURCE MANAGEMENT & $->$ \\
SHOW LATEST ONPOST TRACK & \\
ANALYZE TRACK & \\
CHANGE D2 TRACK CASE * \\
REPORT CURRENT D2 DESCRIPTION \\
EMERGENCY ACTIVITIES \\
SETUP
\end{tabular}

Each item on this menu represents a major category of capabilities. Picking items on this menu leads you to other menus (submenus) that list further capabilities.

Ke.erence Sections. The sections following Section 1 comprise the reference sections of this guide. The sections are organized by major function in the order in which they appear on the main menu. Each section explains one function on the IBS main menu and is pagenumbered independently. Within each section, descriptions of submenu items are ordered alphabet:cally

Page Heacings in the Reference Sections. The menu/submenu item names appear at the top of each page so you can look up most IBS capabilities as in a dictionary.

Asterisks $\left(^{*}\right)$ in this Guide. Asterisks indicate IBS menu items that require special privileges. These items appear as blank lines on the menus of users who lack the required privileges.

\section{Visual Conventions in this Guide}

- Bold italics mark special terms (defined in the text or Glossary).

- Menu items are upper case and bold: STATUS BOARD.

- Special headings mark the beginning of each menu item description:

O MAIN MENU ITEMS

IDSECOND-LEVEL MENU ITEMS

II. THIRD-LEVEL MENU ITEMS 
- Key Names. Keyboard key names are in upper-case letters. Special function key names are also in bold. Key combinations that require you to press keys simultaneously are hyphenated.

Examples: Instruction Meaning of Instruction

Press RETURN. Press the RETURN key once.

Press GOLD Z. Press the GOLD key once. Then press the $\mathrm{Z}$ key once.

Press CTRL-Z. Hold down the CTRL key and press the $\mathbf{Z}$ key once.

- Screen Text. Computer screen text appears in a different typeface than text that is typed in. Text that has been typed (or will be typed) at the keyboard is shown in bold.

Example: Enter the longitude $>-112.3386$

Enter the latitude $>40.2679$

- Data Input Forms. Some text screens are also forms that you will use for entering some system data. Forms in this guide are represented with the following graphic lines located before and after the text. Complete instructions for filling in IBS forms are presented in Section 1.

\section{Example:}

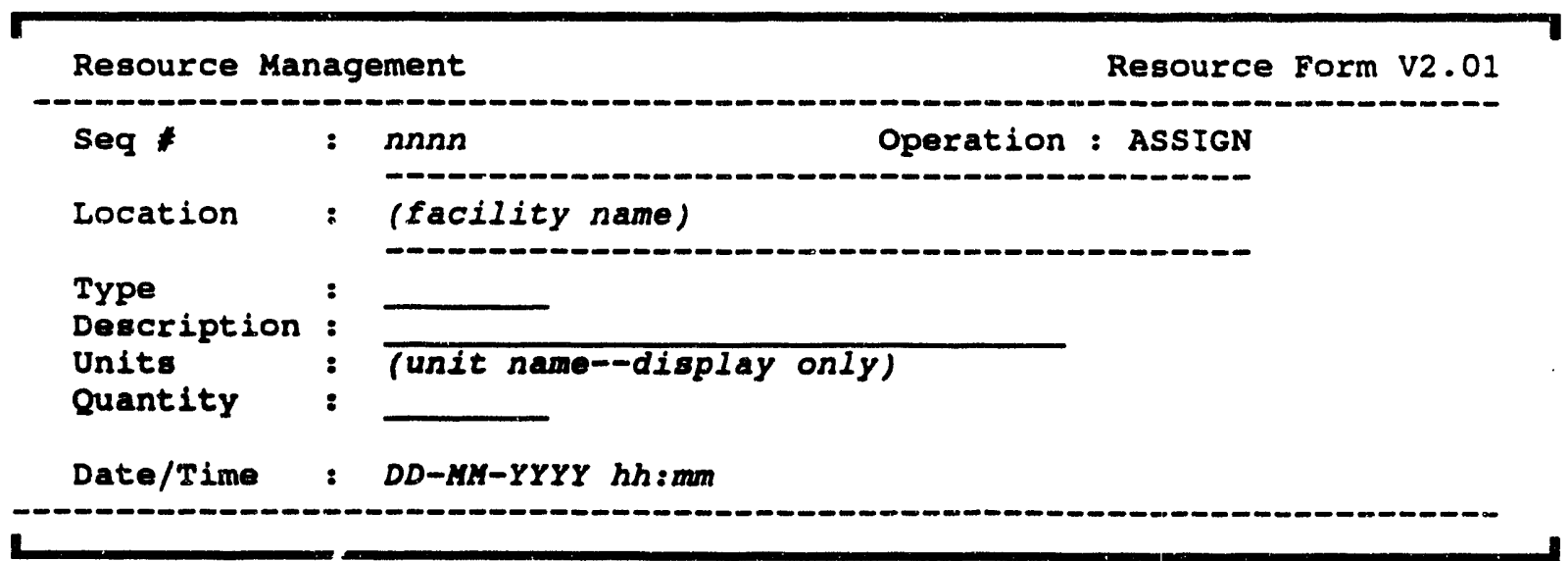

- Italics in screen displays indicate notes or variable items (examples on the screen above). 


\section{Contents}

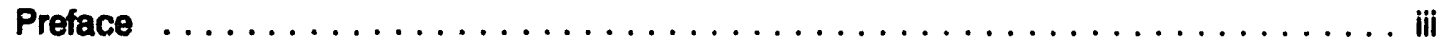

About This Gulde $\ldots \ldots \ldots \ldots \ldots \ldots \ldots \ldots \ldots \ldots \ldots \ldots \ldots$

\section{Section 1. Introduction and Overview}

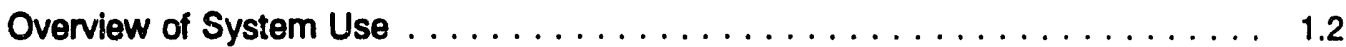

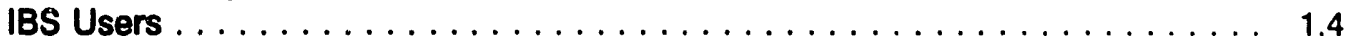

Getting Started (and Getting Stopped) $\ldots \ldots \ldots \ldots \ldots \ldots \ldots \ldots \ldots \ldots \ldots$

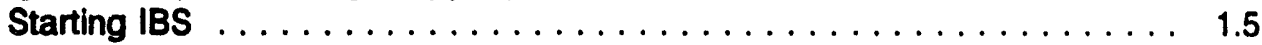

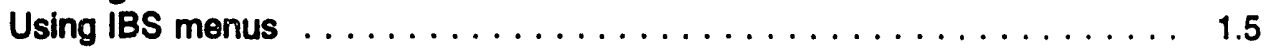

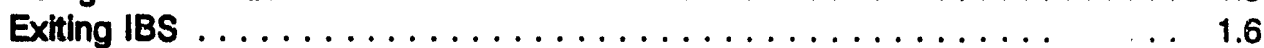

Conventions for Interacting with the IBS $\ldots \ldots \ldots \ldots \ldots \ldots \ldots \ldots \ldots$

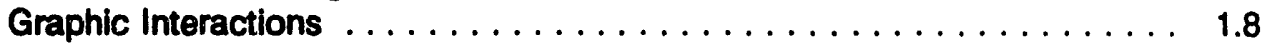

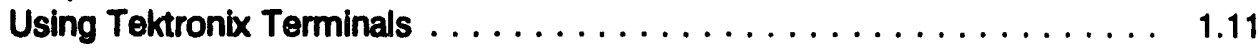

Using a VAXstation . . . . . . . . . . . . . . . . . . . .

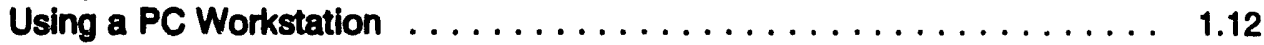

Defining Map Areas (Polygons) $\ldots \ldots \ldots \ldots \ldots \ldots \ldots \ldots \ldots \ldots \ldots \ldots$

Problems with Graphic Input $\ldots \ldots \ldots \ldots \ldots \ldots \ldots \ldots \ldots \ldots \ldots \ldots \ldots$

Text Interactions . . . . . . . . . . . . . . . . . . . 1.14

Vlewing Text Dlalog . . . . . . . . . . . . . . . . . . 1.14

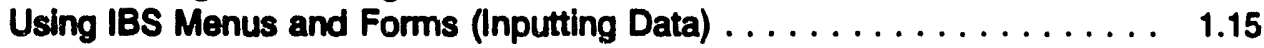

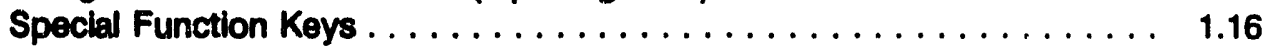

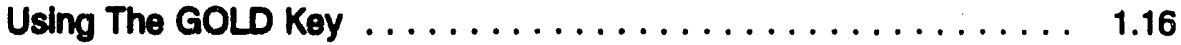

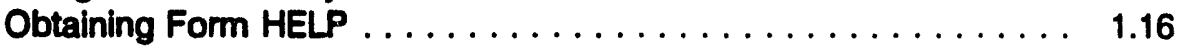

Selecting an Option from a Text Menu . . . . . . . . . . . . 1.20

To select an option from a text menu $\ldots \ldots \ldots \ldots \ldots \ldots$

Positioning the Input Cursor in a Form $\ldots \ldots \ldots \ldots \ldots \ldots \ldots 1.20$

Entering Numeric Values in a Form $\ldots \ldots \ldots \ldots \ldots \ldots \ldots \ldots$

Problems with Menus and Forms $\ldots \ldots \ldots \ldots \ldots \ldots \ldots \ldots \ldots$

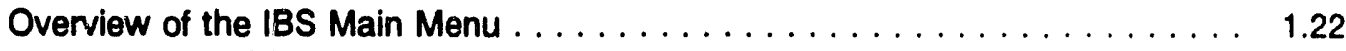

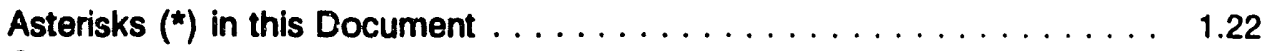

Order of the Reference Sections $\ldots \ldots \ldots \ldots \ldots \ldots \ldots \ldots \ldots \ldots, 1.22$

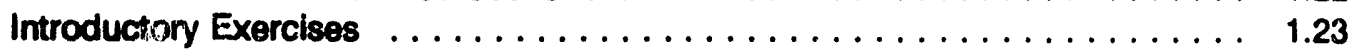

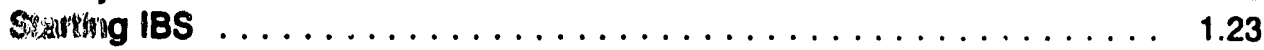

Exercise 1. Viewing the Onpost Work Plan .............. 1.25

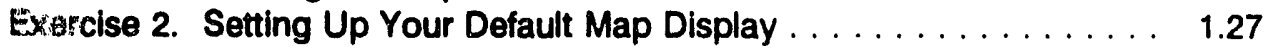

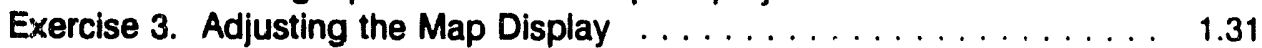

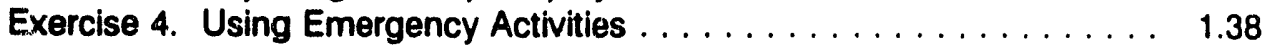

\section{Section 2. Message Board}

Onpost Emergency Event Notification $\ldots \ldots \ldots \ldots \ldots \ldots \ldots \ldots \ldots \ldots .2$

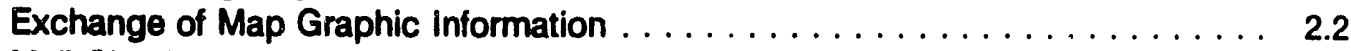

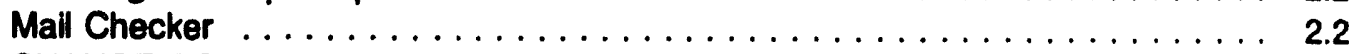

CHANGE COMBINED REPORT $\ldots \ldots \ldots \ldots \ldots \ldots \ldots \ldots \ldots \ldots \ldots .2$

IBS Usor Gi h $-1 / 25 / 93 \quad$ Xiii 
Preparing the VAX MAIL Messages $\ldots \ldots \ldots \ldots \ldots \ldots \ldots \ldots \ldots .4$

CHANGE MESSAGE CATEGORIES ${ }^{*} \ldots \ldots \ldots \ldots \ldots \ldots \ldots \ldots \ldots \ldots .4 .4$

CHECK SENT MAIL $\ldots \ldots \ldots \ldots \ldots \ldots \ldots \ldots \ldots \ldots \ldots \ldots \ldots \ldots \ldots \ldots$

CREATE/EDIT MAIL UST $\ldots \ldots \ldots \ldots \ldots \ldots \ldots \ldots \ldots \ldots \ldots \ldots \ldots \ldots \ldots$

CREATE IBS->ONPOST RPT ${ }^{2} \ldots \ldots \ldots \ldots \ldots \ldots \ldots \ldots \ldots \ldots \ldots . \ldots \ldots 2.10$

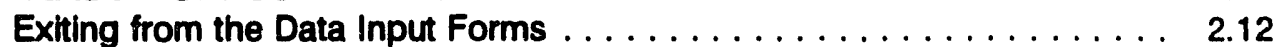

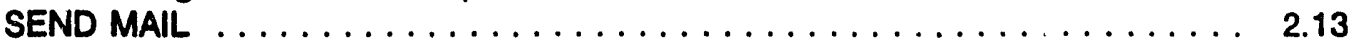

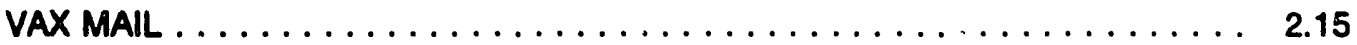

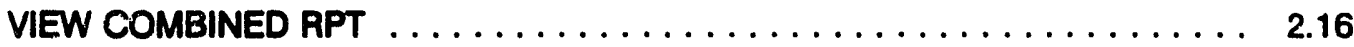

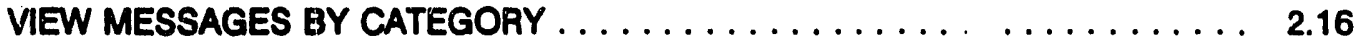

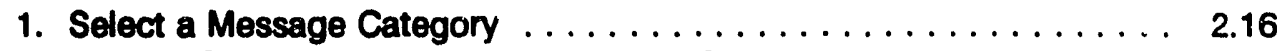

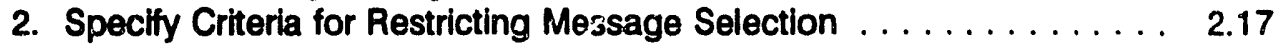

3. View the Selected Messages . . . . . . . . . . . . . . . . . . 2.18

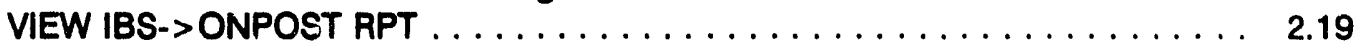

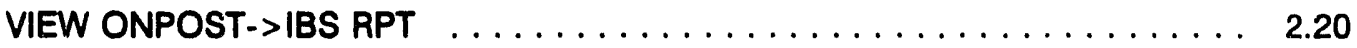

\section{Section 3. Status Board}

Understanding Implementing Procedures $\ldots \ldots \ldots \ldots \ldots \ldots \ldots \ldots .2$

ARCHIVE IP OPTIONS $\ldots \ldots \ldots \ldots \ldots \ldots \ldots \ldots \ldots \ldots \ldots \ldots . \ldots \ldots$

CHANGE ONPOST WORK PLAN * and VIEW ONPOST WORK PLAN $\ldots \ldots \ldots 3.6$

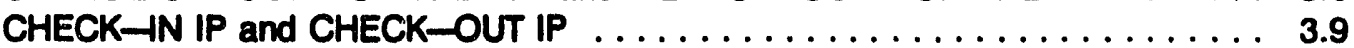

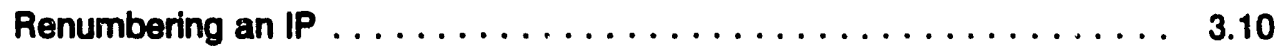

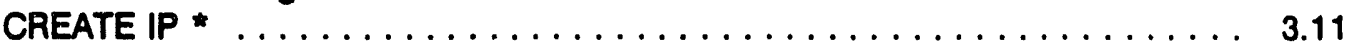

IMPLEMENTING PROCEDURES $\ldots \ldots \ldots \ldots \ldots \ldots \ldots \ldots \ldots \ldots \ldots .13$

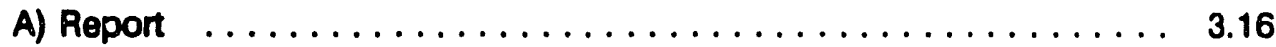

B) View IP Notes and Change IP Notes $\ldots \ldots \ldots \ldots \ldots \ldots \ldots \ldots .20$

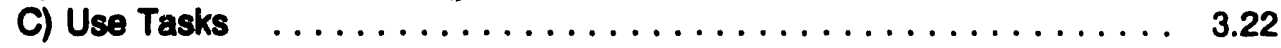

Listing Overdue Tasks . . . . . . . . . . . . . . . . . . 3.25

Listing Tasks by Description . . . . . . . . . . . . . . . . . . 3.25

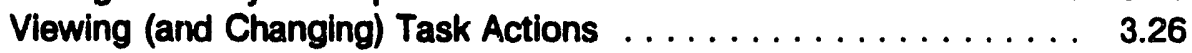

Viewing (and Changing) Task Resources . . . . . . . . . . . . . 3.27

Viewing (and Changing) Task/Action/Resource Notes . . . . . . . 3.28

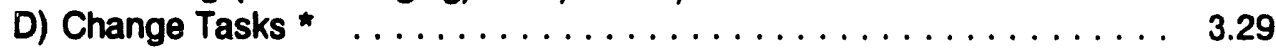

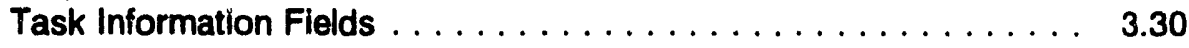

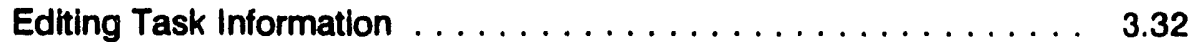

E) Select New IP * $\ldots \ldots \ldots \ldots \ldots \ldots \ldots \ldots \ldots \ldots \ldots .34$

Selecting a New IP in Operational Mode $\ldots \ldots \ldots \ldots \ldots \ldots . .3 .34$

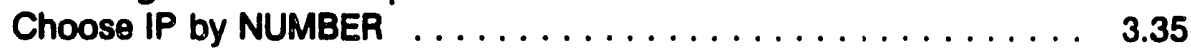

Chcose Whether to Retain Completed Tasks from the Previous IP . 3.36

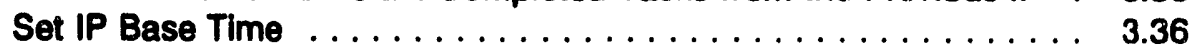

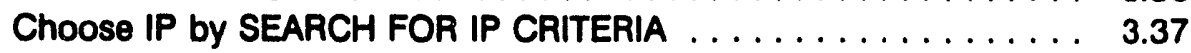

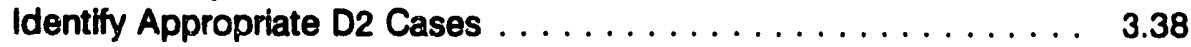

Select from a List of Identified D2 Cases . . . . . . . . . . . . 3.39

Select an IP that Contain the D2 Case . . . . . . . . . . . . . 3.39

Choose Whether to Retain Completed Tasks from the Previous IP . 3.40

Selecting a New IP in Plan Mode . . . . . . . . . . . . . . 3.40

ONPOST EVENT STATUS $\ldots \ldots \ldots \ldots \ldots \ldots \ldots \ldots \ldots \ldots \ldots \ldots \ldots . \ldots \ldots . \ldots \ldots$

SHOW USER ENVIRONMENT $\ldots \ldots \ldots \ldots \ldots \ldots \ldots \ldots \ldots \ldots \ldots \ldots \ldots ., 3.42$

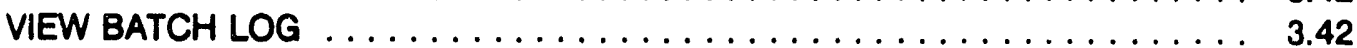

VIEW ONPOST WORK PLAN $\ldots \ldots \ldots \ldots \ldots \ldots \ldots \ldots \ldots \ldots \ldots . \ldots \ldots$ 


\section{Section 4. Personnel Management}

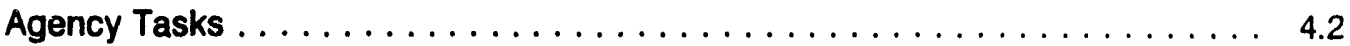

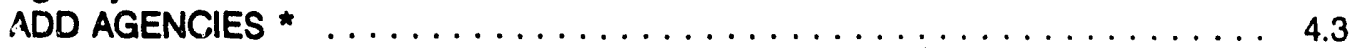

DELETE AGENCIES ${ }^{2} \ldots \ldots \ldots \ldots \ldots \ldots \ldots \ldots \ldots \ldots \ldots \ldots \ldots$

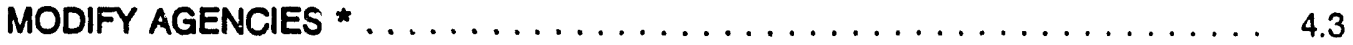

1. Specify Which Agency to Modify $\ldots \ldots \ldots \ldots \ldots \ldots \ldots \ldots \ldots$

2. Modify the Agency (Name and Code) . . . . . . . . . . . . 4.5

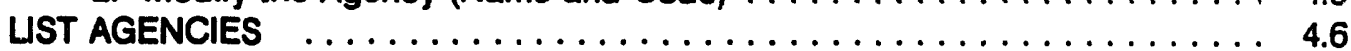

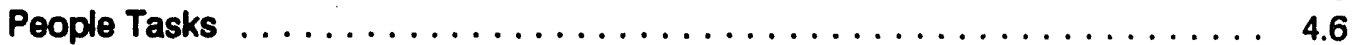

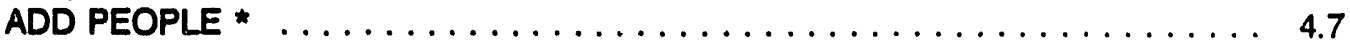

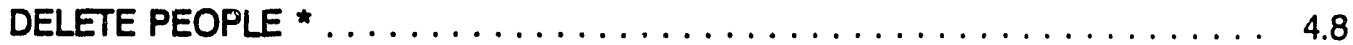

LIST PEOPLE BY NAME...AGENCY...POSITION $\ldots \ldots \ldots \ldots \ldots \ldots \ldots \ldots 4.9$

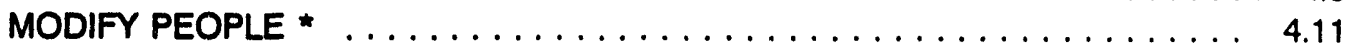

1. Specify Which Person to Modify . . . . . . . . . . . . . . . . . 4.11

2. Enter New Information about the Person . . . . . . . . . . . . . 4.12

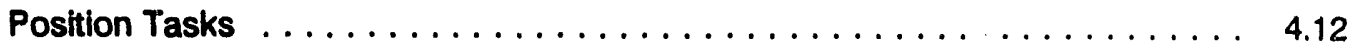

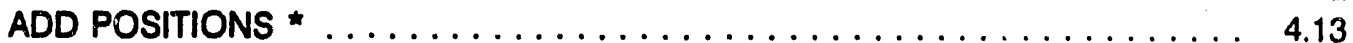

1. Specify Which Agency ..................... 4.13

2. Enter a New Position Name .................... 4.14

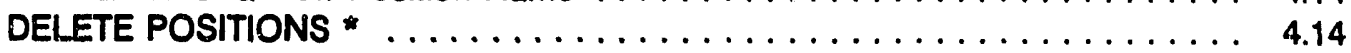

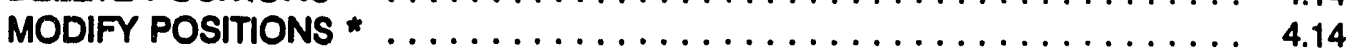

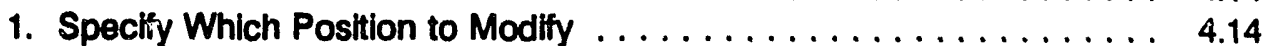

2. Enter a New Name for the Position . . . . . . . . . . . . . 4.15

LIST POSITIONS $\ldots \ldots \ldots \ldots \ldots \ldots \ldots \ldots \ldots \ldots \ldots \ldots \ldots . \ldots \ldots$

\section{Section 5. Map Analysis}

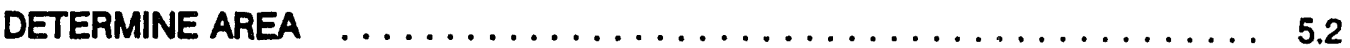

DISPLAY ICONS (TURN OFF ICONS) $\ldots \ldots \ldots \ldots \ldots \ldots \ldots \ldots \ldots . \ldots \ldots$

DISPLAY LOCATION $\ldots \ldots \ldots \ldots \ldots \ldots \ldots \ldots \ldots \ldots \ldots \ldots \ldots \ldots \ldots \ldots$

DISPLAY TEXT (TURN OFF TEXT) $\ldots \ldots \ldots \ldots \ldots \ldots \ldots \ldots \ldots \ldots \ldots . \ldots \ldots$

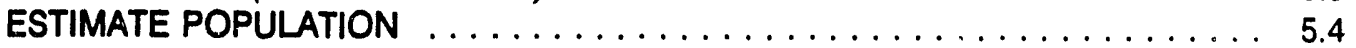

HIGHUGHT DATA $\ldots \ldots \ldots \ldots \ldots \ldots \ldots \ldots \ldots \ldots \ldots \ldots \ldots \ldots$

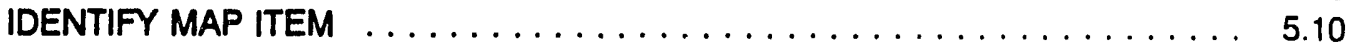

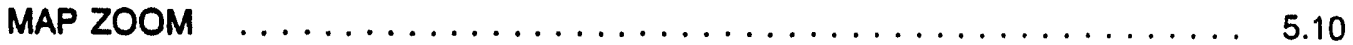

REFRESH SCREEN $\ldots \ldots \ldots \ldots \ldots \ldots \ldots \ldots \ldots \ldots \ldots \ldots \ldots \ldots . \ldots \ldots . \ldots \ldots \ldots$

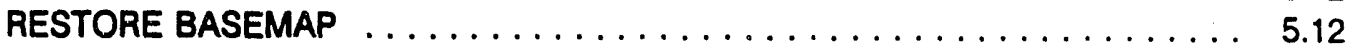

SELECT MAP LAYERS $\ldots \ldots \ldots \ldots \ldots \ldots \ldots \ldots \ldots \ldots \ldots \ldots \ldots \ldots . \ldots \ldots . \ldots \ldots \ldots$

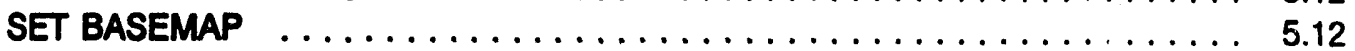

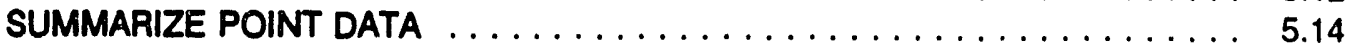

TURN OFF ICONS (DISPLAY ICONS) $\ldots \ldots \ldots \ldots \ldots \ldots \ldots \ldots \ldots . \ldots .16$

TURN OFF TEXT (DISPLAY TEXT) $\ldots \ldots \ldots \ldots \ldots \ldots \ldots \ldots \ldots \ldots . \ldots \ldots$

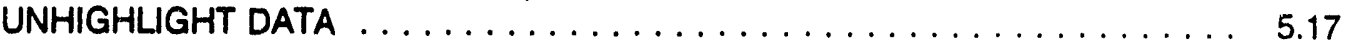

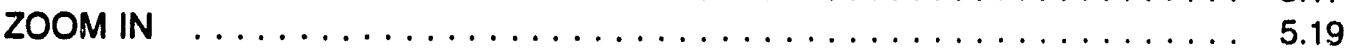

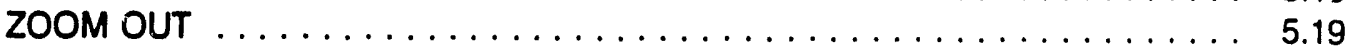

\section{Section 6. Resource Management}

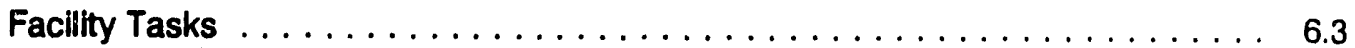

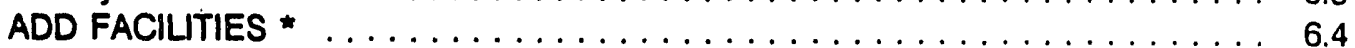

IBS User Guide $-12 / 7 / 92 \quad$ XV 
1. Specify a Facllity (Known Point) Location . . . . . . . . . . . . 6.4

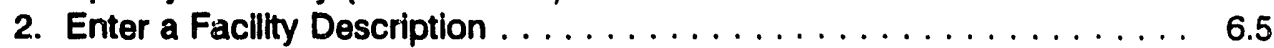

3. Enter Personnel Information about the Facility Contact Person . . . . . . 6.6 DELETE FACILITIES* $\ldots \ldots \ldots \ldots \ldots \ldots \ldots \ldots \ldots \ldots \ldots \ldots .6 .6$

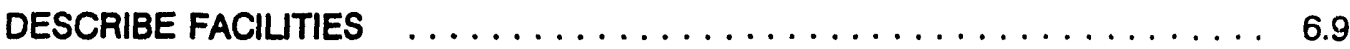
HIGHLIGHT FACILITIES $\ldots \ldots \ldots \ldots \ldots \ldots \ldots \ldots \ldots \ldots \ldots . \ldots \ldots . \ldots \ldots$

1. Specify an Area of Interest . . . . . . . . . . . . . . . . 6.11

2. Select Which Resources to Locate ... . . . . . . . . . . . 6.12

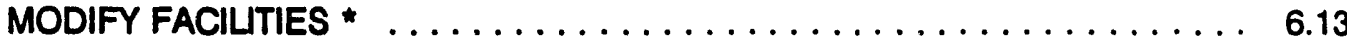

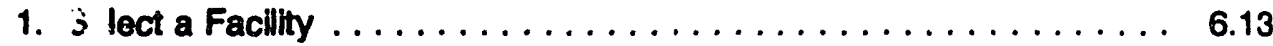

2. Modlfy the Facllity Description $\ldots \ldots \ldots \ldots \ldots \ldots \ldots \ldots \ldots . \ldots .13$

1. Select a Known Point . . . . . . . . . . . . . . . . . . 6.14

2. Modify the Known Point Location or Name . . . . . . . . . . . . . . . 6.14

Selecting a Facility $\ldots \ldots \ldots \ldots \ldots \ldots \ldots \ldots \ldots \ldots \ldots \ldots . \ldots \ldots \ldots$

Resource Tasks ......................... 6.18

ASSIGN RESOURCES * . . . . . . . . . . . . . . . . . . . . . . 6.20

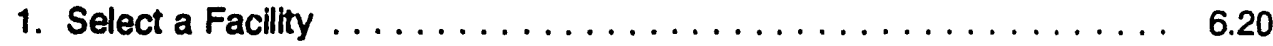

2. Enter the Resource Information $\ldots \ldots \ldots \ldots \ldots \ldots \ldots \ldots \ldots .6 .20$

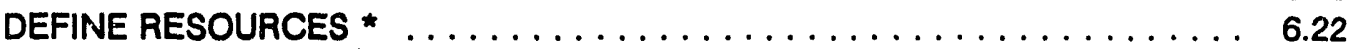

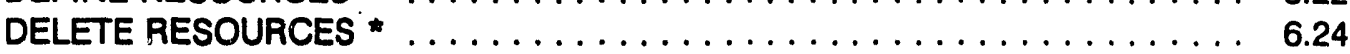

DESCRIBE RESOURCES $\ldots \ldots \ldots \ldots \ldots \ldots \ldots \ldots \ldots \ldots \ldots \ldots \ldots . \ldots \ldots$

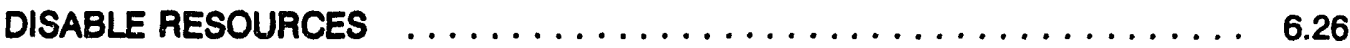

ENABLE RESOURCES $\ldots \ldots \ldots \ldots \ldots \ldots \ldots \ldots \ldots \ldots \ldots \ldots \ldots \ldots . \ldots \ldots \ldots$

LIST RESOURCES $\ldots \ldots \ldots \ldots \ldots \ldots \ldots \ldots \ldots \ldots \ldots \ldots \ldots \ldots \ldots \ldots \ldots \ldots \ldots .28$

MODIFY RESOURCES ${ }^{2} \ldots \ldots \ldots \ldots \ldots \ldots \ldots \ldots \ldots \ldots \ldots . \ldots \ldots . \ldots \ldots$

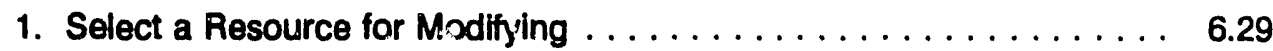

2. Modifying the Resource information ............... 6.30

MOVE RESOURCES * ........................... 6.32

1. Select a Resource to Move ... . . . . . . . . . . . . . . . . 6.32

2. Specify an Amount of Resource to Move $\ldots \ldots \ldots \ldots \ldots \ldots \ldots .6 .32$

3. Select a Destination Facility $\ldots \ldots \ldots \ldots \ldots \ldots \ldots \ldots \ldots . \ldots \ldots$

Resource Form Use $\ldots \ldots \ldots \ldots \ldots \ldots \ldots \ldots \ldots \ldots \ldots \ldots \ldots . \ldots \ldots . \ldots \ldots$

Selecting a Resource $\ldots \ldots \ldots \ldots \ldots \ldots \ldots \ldots \ldots \ldots \ldots \ldots \ldots . \ldots \ldots \ldots \ldots$

Selecting a Resource Type $\ldots \ldots \ldots \ldots \ldots \ldots \ldots \ldots \ldots \ldots \ldots . \ldots \ldots 6 . \ldots \ldots$

SUMMARIZE RESOURCES $\ldots \ldots \ldots \ldots \ldots \ldots \ldots \ldots \ldots \ldots \ldots \ldots . \ldots \ldots . \ldots \ldots$

1. Select an Area of Interest . . . . . . . . . . . . . . . . . . . 6.40

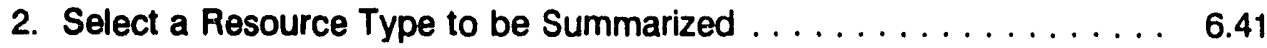

VALIDATE RESOURCES ${ }^{2} \ldots \ldots \ldots \ldots \ldots \ldots \ldots \ldots \ldots . \ldots . \ldots \ldots$

\section{Section 7. Show Latest Onpost Track}

Show (Remove) Latest Onpost Track . . . . . . . . . . . . . . . 7.1

\section{Section 8. Analyze Track}

DESCRIBE TRACK $\ldots \ldots \ldots \ldots \ldots \ldots \ldots \ldots \ldots \ldots \ldots \ldots . \ldots \ldots .2$

DOSE DETAILS $\ldots \ldots \ldots \ldots \ldots \ldots \ldots \ldots \ldots \ldots \ldots \ldots \ldots . \ldots \ldots . \ldots \ldots$

PRINT D2 REPORT $\ldots \ldots \ldots \ldots \ldots \ldots \ldots \ldots \ldots \ldots \ldots \ldots \ldots . \ldots \ldots$

SHOW ELEVATION $\ldots \ldots \ldots \ldots \ldots \ldots \ldots \ldots \ldots \ldots \ldots . \ldots \ldots$ 


\section{Section 9. Change D2 Track Case}

Choosing a D2 Case by Case Number . . . . . . . . . . . . . . . . . 9.1

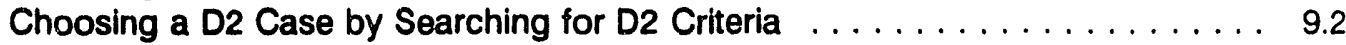

\section{Section 10. Report Current D2 Description}

REPORT CURRENT D2 DESCRIPTION

\section{Section 11. Emergency Activities}

DAMAGE ASSESSMENT $\ldots \ldots \ldots \ldots \ldots \ldots \ldots \ldots \ldots \ldots \ldots \ldots \ldots \ldots$

DELETE CONTAMINATION AREA * $\ldots \ldots \ldots \ldots \ldots \ldots \ldots \ldots \ldots \ldots$

DELETE NATIONAL DEFENSE AREA * $\ldots \ldots \ldots \ldots \ldots \ldots \ldots \ldots, 11.4$

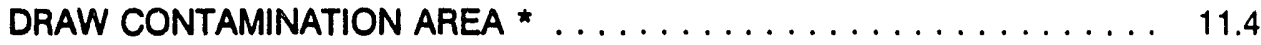

DRAW NATIONAL DEFENSE AREA $\star \ldots \ldots \ldots \ldots \ldots \ldots \ldots \ldots \ldots 11.5$

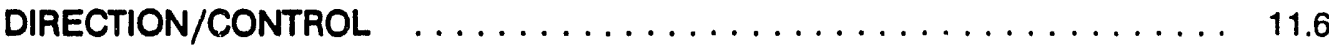

ADD SPECIAL POPULATION $\ldots \ldots \ldots \ldots \ldots \ldots \ldots \ldots \ldots \ldots \ldots$

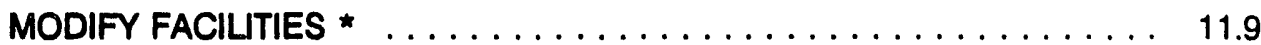

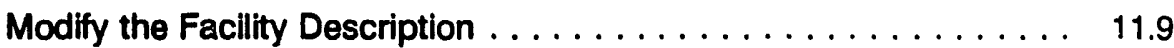

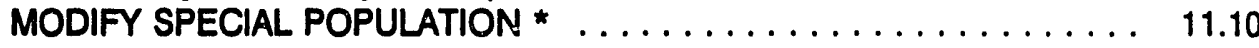

ESTIMATE POPULATION $\ldots \ldots \ldots \ldots \ldots \ldots \ldots \ldots \ldots \ldots \ldots, 11.11$

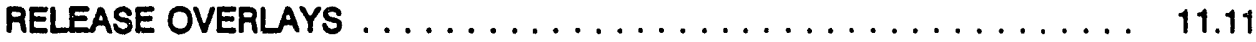

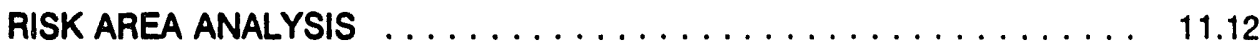

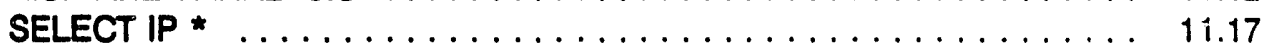

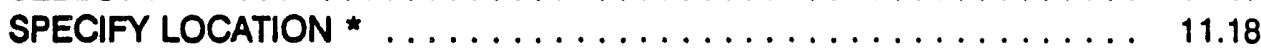

EOC ACTIVATION ........................... 11.19

GENERATE CALL LIST * $\ldots \ldots \ldots \ldots \ldots \ldots \ldots \ldots \ldots \ldots \ldots \ldots$

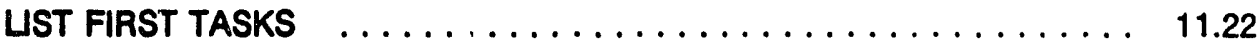

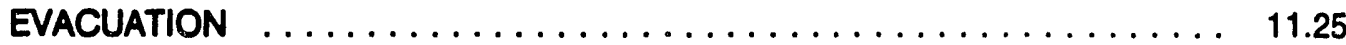

CREATE EVAC ROUTE OVERLAY $\ldots \ldots \ldots \ldots \ldots \ldots \ldots \ldots \ldots 11.26$

DELETE EVAC ROUTE OVERLAY $\ldots \ldots \ldots \ldots \ldots \ldots \ldots \ldots \ldots \ldots \ldots$

DESCRIBE EVACUATION POINT $\ldots \ldots \ldots \ldots \ldots \ldots \ldots \ldots \ldots, 11.27$

EXECUTE EVAC MODEL * $\ldots \ldots \ldots \ldots \ldots \ldots \ldots \ldots \ldots \ldots \ldots 11.28$

RELEASE/RETAIN OVERLAYS $\ldots \ldots \ldots \ldots \ldots \ldots \ldots \ldots \ldots \ldots, 11.31$

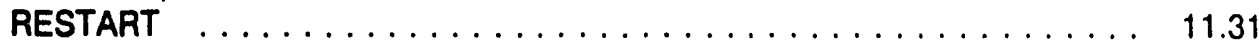

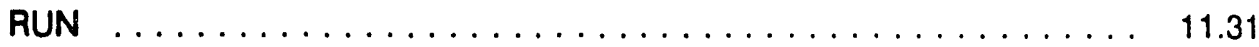

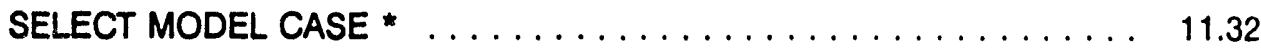

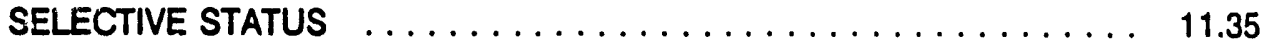

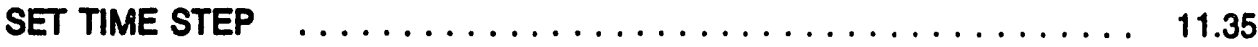

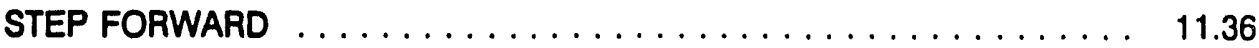

STEP BACKWARD $\ldots \ldots \ldots \ldots \ldots \ldots \ldots \ldots \ldots \ldots \ldots \ldots \ldots \ldots \ldots \ldots$

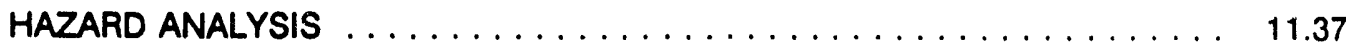

CHANGE TRACK CASE $* \ldots \ldots \ldots \ldots \ldots \ldots \ldots \ldots \ldots \ldots \ldots$

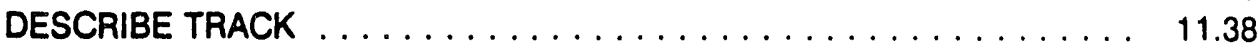

RELEASE/RETAIN OVERLAYS $\ldots \ldots \ldots \ldots \ldots \ldots \ldots \ldots \ldots \ldots \ldots \ldots$

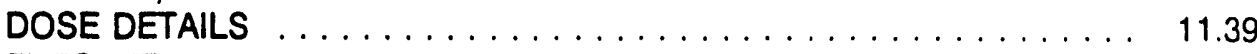

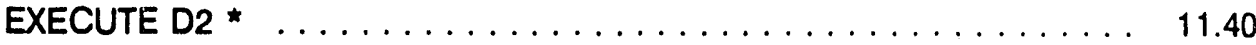

PRINT D2 REPORT $\ldots \ldots \ldots \ldots \ldots \ldots \ldots \ldots \ldots \ldots \ldots \ldots \ldots \ldots$

REPORT CURRENT D2 DESCRIPTION $\ldots \ldots \ldots \ldots \ldots \ldots \ldots \ldots .11 .49$

SHOW ELEVATION $\ldots \ldots \ldots \ldots \ldots \ldots \ldots \ldots \ldots \ldots \ldots \ldots \ldots \ldots$

IBS User Guide -12/7/92 X Xvii 


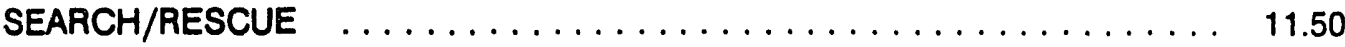

DRAW SEARCH AREAS $\ldots \ldots \ldots \ldots \ldots \ldots \ldots \ldots \ldots \ldots \ldots \ldots \ldots$

DELETE SEARCH AREA $\ldots \ldots \ldots \ldots \ldots \ldots \ldots \ldots \ldots \ldots \ldots \ldots \ldots$

RELEASE/RETAIN OVERLAYS $\ldots \ldots \ldots \ldots \ldots \ldots \ldots \ldots \ldots \ldots$

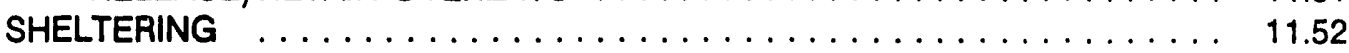

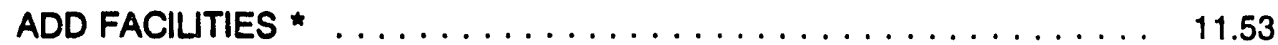

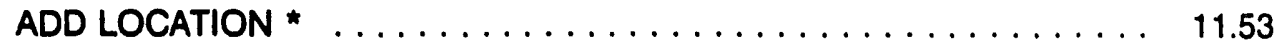

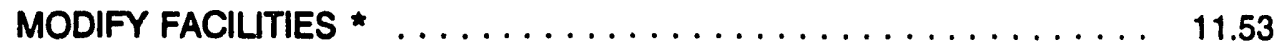

RELEASE/RETAIN OVERLAYS $\ldots \ldots \ldots \ldots \ldots \ldots \ldots \ldots \ldots \ldots 11.54$

SHELTER \& CENTER SUMMARY $\ldots \ldots \ldots \ldots \ldots \ldots \ldots \ldots \ldots 11.5 \mathrm{c}$

SHELTER OR CENTER INFO $\ldots \ldots \ldots \ldots \ldots \ldots \ldots \ldots \ldots \ldots .11 .55$

Section 12. Setup

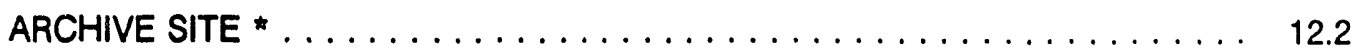

CHANGE DEFAULT MAP LAYER $\ldots \ldots \ldots \ldots \ldots \ldots \ldots \ldots \ldots \ldots \ldots . \ldots \ldots$

Restricting Map Layers Based on Display Size . . . . . . . . . . . . . . 12.3

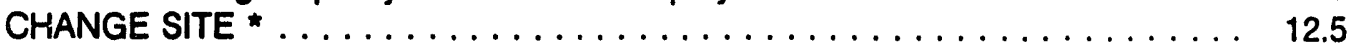

COMMION LEGEND * $\ldots \ldots \ldots \ldots \ldots \ldots \ldots \ldots \ldots \ldots \ldots \ldots \ldots \ldots$

JOB ENVIRONMENT $\ldots \ldots \ldots \ldots \ldots \ldots \ldots \ldots \ldots \ldots \ldots \ldots \ldots \ldots \ldots \ldots$

INFOMANAGER ROOT MAINTENANCE * $\ldots \ldots \ldots \ldots \ldots \ldots \ldots, 12.9$

MISCELLANEOUS SETTINGS $\ldots \ldots \ldots \ldots \ldots \ldots \ldots \ldots \ldots \ldots \ldots \ldots$

COPY CASE OR SITE FILE ${ }^{\prime} \ldots \ldots \ldots \ldots \ldots \ldots \ldots \ldots \ldots \ldots \ldots \ldots, 12.12$

Copying Site or Case Data FROM Another IBS User . . . . . . . 12.16

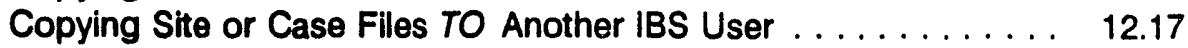

HARDWARE PARAMETERS $\ldots \ldots \ldots \ldots \ldots \ldots \ldots \ldots \ldots \ldots \ldots$

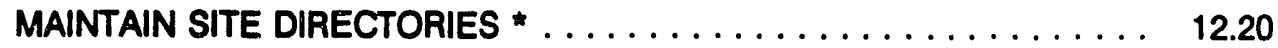

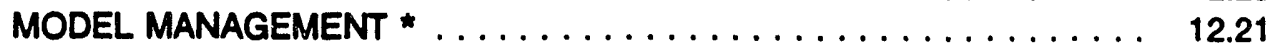

REVIEW CONTROL FILES $\ldots \ldots \ldots \ldots \ldots \ldots \ldots \ldots \ldots \ldots \ldots \ldots, 12.22$

UPDATE SITE MASTER FILE ${ }^{*} \ldots \ldots \ldots \ldots \ldots \ldots \ldots \ldots \ldots \ldots, 12.23$

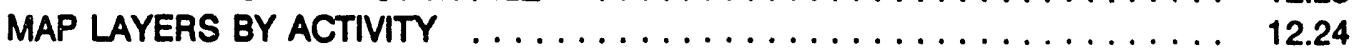

\section{Appendix A. IBS Graphic Menus}

Exampic of a Jubmenu with Layered Menu Selections . . . . . . . . . . . A.2

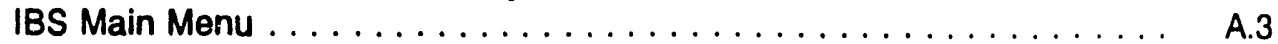

Message Board $\ldots \ldots \ldots \ldots \ldots \ldots \ldots \ldots \ldots \ldots \ldots \ldots \ldots \ldots \ldots \ldots$ A.4

View IBS->ONPOST Reports $\ldots \ldots \ldots \ldots \ldots \ldots \ldots \ldots$ A.5

View ONPOST->IBS Reports $\ldots \ldots \ldots \ldots \ldots \ldots \ldots \ldots \ldots$ A.6

Create IBS->ONPOST Reports $\ldots \ldots \ldots \ldots \ldots \ldots \ldots \ldots \ldots$ A.7

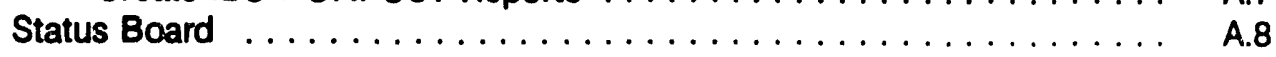

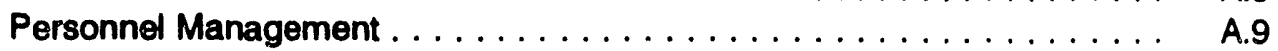

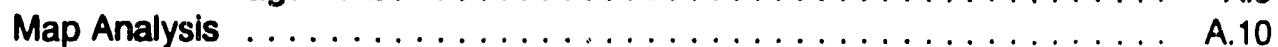

Select Map Layers . . . . . . . . . . . . . . . . . . . . . . . A.11

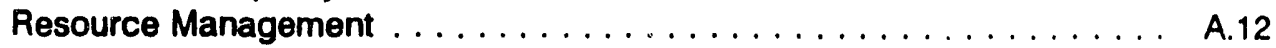

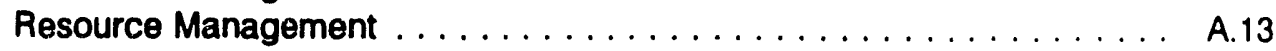

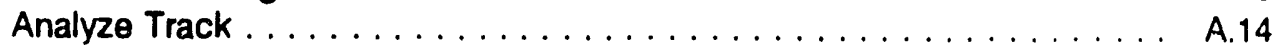

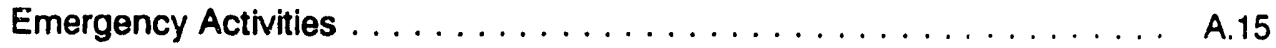

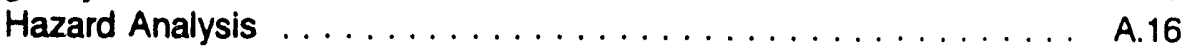

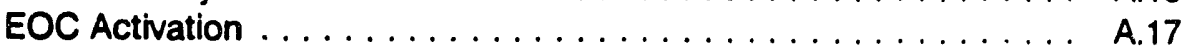

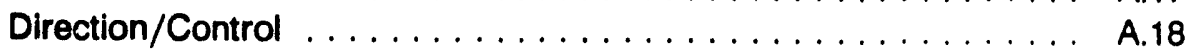




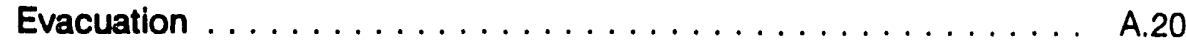

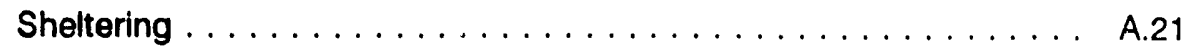

Search/Rescue . . . . . . . . . . . . . . . . . A.22

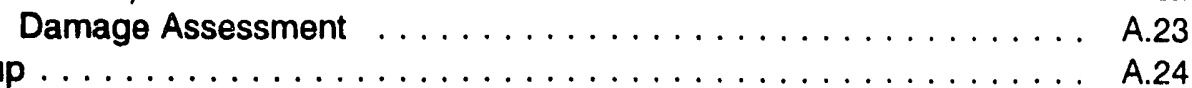

Change Default Map Layers . . . . . . . . . . . . . . . . . A.25

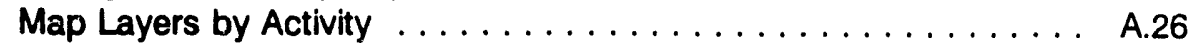

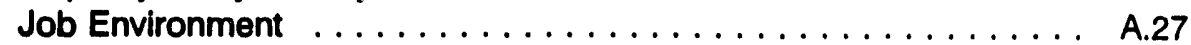

Map Layers by Activity/(emergency actlvity) $\ldots \ldots \ldots \ldots \ldots \ldots$ A.28

Mixdei Management * . . . . . . . . . . . . . . . A.29

\section{Appendix B. Non-Graphic IBS}

To Start NON-GRAPHIC IBS (IBS_NOGR) $\ldots \ldots \ldots \ldots \ldots \ldots \ldots \ldots \ldots$ B.1

\section{Appendix C. People Location}

To Start the People Location Program (LOCATE) . . . . . . . . . . . . . . . . C.1

PEOPLE LOCATION Menu $\ldots \ldots \ldots \ldots \ldots \ldots \ldots \ldots \ldots \ldots \ldots \ldots$ C.2

Option A. Enter Persons $\ldots \ldots \ldots \ldots \ldots \ldots \ldots \ldots \ldots \ldots \ldots \ldots \ldots$ C. 3

Option B. Update Persons $\ldots \ldots \ldots \ldots \ldots \ldots \ldots \ldots \ldots \ldots \ldots \ldots$ C.4

Option C. Search for Missing Persons $\ldots \ldots \ldots \ldots \ldots \ldots \ldots \ldots \ldots$ C.5

Option D. Enter Default Values for the Enter Persons Form . . . . . . . . . . C.6

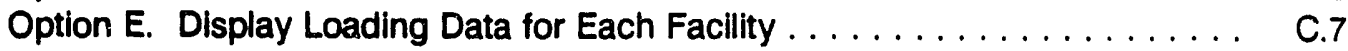

Option F. Select a Different Facility

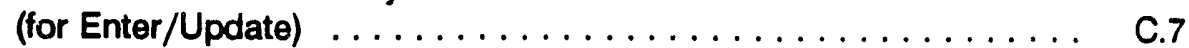

Option G. Deactivate the Current Facility $\ldots \ldots \ldots \ldots \ldots \ldots \ldots \ldots \ldots$ C.7

Option X. Exit, with Optional Facility Deactivation $\ldots \ldots \ldots \ldots \ldots \ldots \ldots$ C.8

\section{Appendix D. Onpost Simulator}

To Start the Onpost Simulator $\ldots \ldots \ldots \ldots \ldots \ldots \ldots \ldots$ D.1

\section{Appendix E. IBS and Onpost EOC Reports}

Reports from the IBS $\ldots \ldots \ldots \ldots \ldots \ldots \ldots \ldots \ldots \ldots \ldots$ E.2

Using the Report Selection Method Menu $\ldots \ldots \ldots \ldots \ldots \ldots \ldots$ E.2

Exiting After Creating an IBS Report $\ldots \ldots \ldots \ldots \ldots \ldots \ldots \ldots \ldots$ E.3

COORDINATE CODE TABLE $\ldots \ldots \ldots \ldots \ldots \ldots \ldots \ldots \ldots \ldots . \ldots .4$

EVAC ROUTE ANNOUNCEMENT $\ldots \ldots \ldots \ldots \ldots \ldots \ldots \ldots \ldots$ E.5

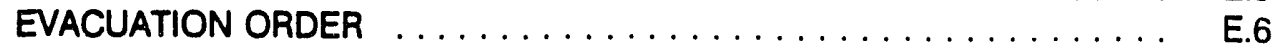

EVACUATION ROUTE TABLE $\ldots \ldots \ldots \ldots \ldots \ldots \ldots \ldots \ldots \ldots$ E.8

INCOMING MILITARY ROUTES $\ldots \ldots \ldots \ldots \ldots \ldots \ldots \ldots \ldots$ E.9

OFFPOST CASUALTY SUMMARY $\ldots \ldots \ldots \ldots \ldots \ldots \ldots \ldots \ldots$ E.10

POLYGON CODE TABLE $\ldots \ldots \ldots \ldots \ldots \ldots \ldots \ldots \ldots \ldots \ldots \ldots . \ldots \ldots$

PROTECTIVE ACTION ORDER $\ldots \ldots \ldots \ldots \ldots \ldots \ldots \ldots \ldots \ldots \ldots$ E.12

RECEPTION CTR DIRECTORY $\ldots \ldots \ldots \ldots \ldots \ldots \ldots \ldots \ldots \ldots$ E.13

RECEPTION CTR SUMMARY $\ldots \ldots \ldots \ldots \ldots \ldots \ldots \ldots \ldots \ldots \ldots$ E.14

SET IBS ONPOST HEADER $\ldots \ldots \ldots \ldots \ldots \ldots \ldots \ldots \ldots \ldots \ldots \ldots$ E.15

SHELTER AREA REPORT $\ldots \ldots \ldots \ldots \ldots \ldots \ldots \ldots \ldots \ldots \ldots \ldots \ldots$

SHELTERING SUMMARY $\ldots \ldots \ldots \ldots \ldots \ldots \ldots \ldots \ldots \ldots \ldots .17$

IBS User Guide $-12 / 7 / 92 \quad$ Xix 
TRAFFIC CONTROL REPORT $\ldots \ldots \ldots \ldots \ldots \ldots \ldots \ldots \ldots \ldots$ E.18

Reports from the Onpost EOC System $\ldots \ldots \ldots \ldots \ldots \ldots \ldots \ldots \ldots$.19

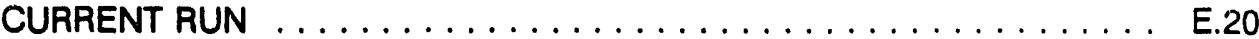

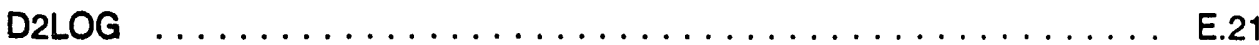

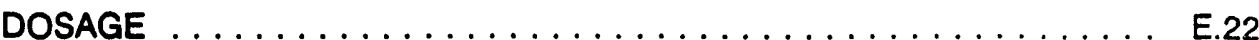

ENVIRONMENTAL REPORT $\ldots \ldots \ldots \ldots \ldots \ldots \ldots \ldots \ldots \ldots$ E.23

NOTIFICATION ......................... E.24

ONPOST CASUALTY REPORT $\ldots \ldots \ldots \ldots \ldots \ldots \ldots \ldots \ldots \ldots$ E.25

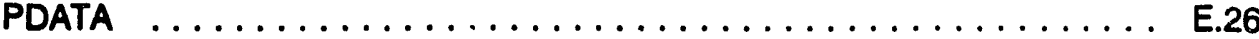

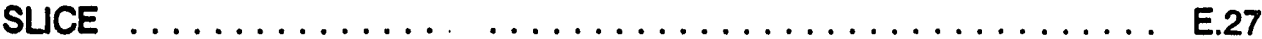

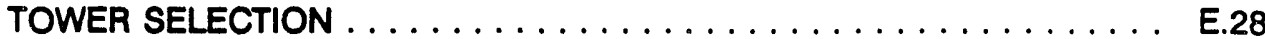

WEATHER OBSERVATIONS $\ldots \ldots \ldots \ldots \ldots \ldots \ldots \ldots \ldots \ldots \ldots$ E.29

Appendix F. IBS Icons

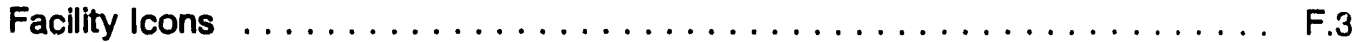

Resource Icons $\ldots \ldots \ldots \ldots \ldots \ldots \ldots \ldots \ldots \ldots \ldots \ldots \ldots \ldots \ldots$ F.8

Non-Facility/Resource Icons $\ldots \ldots \ldots \ldots \ldots \ldots \ldots \ldots \ldots \ldots \ldots$ F.14 


\section{Section 1 \\ Introduction and Overview}

The fundamental function of the IBS is to provide tools that civilian emergency management personnel can use in developing emergency plans and in supporting emergency management activities to cope with a chemical-releasing event at a military chemical stockpile.

Emergency management planners can evaluate concepts and ideas using the IBS system. The results of that experience can then be factored into refining requirements and plans.

In this introduction you will find:

- Overview of System Use - system concepts and terms

- IBS Users - general descriptions of IBS users

- Getting Started (and Getting Stopped) - basic operating procedures

- Conventions for Interacting with the IBS - conventions for interacting with various terminals, map displays, menus, and forms.

- Overview of the IBS Main Menu - an overview of IBS Main Menu functions.

- Introductory Exercises - a series of exercises to familiarize the new user with basic IBS system functions, commands, and options. 


\section{Overview of System Use}

The storage, movement, or disposal of chemical weapons materials at a military stockpile require emergency preparedness by both the military and the state and local governments. Prototypic systems are being implemented by both groups to support such preparedness by providing computerized data management, analysis, and monitoring tools that supplement traditional tools for emergency management.

The offpost system (IBS, in this case) is located at one or Iil: re Emergency Operations Centers (EOCs) that have primary responsibilities for preparedness and response from state and local authorities. The onpost system monitisrs ongoing chemical-related activities on the post.

The onpost and offpost systems exchange certain information so that the users of each kind of system are aware of both current conditions and planned activities. The Work Plan for current onpost activities (such as the transport or disposal of chemicals) is composed of data supplied by the onpost system. This data can include D2 runs and weather reports. Predefined reports of offpost emergency management activities are transmitted to the onpost system, especially after an actual event. Other offpost systems may also communicate with the IBS; for example, terminals and systems at some locations (such as hospitals, shelters) can update a people location database.

The IBS can help with many aspects of the Emergency

Management Components illustrated in Figure 1.1. These components include

- Planning for an emergency

- Readiness/ dealing with an emergency

- Recovering from an

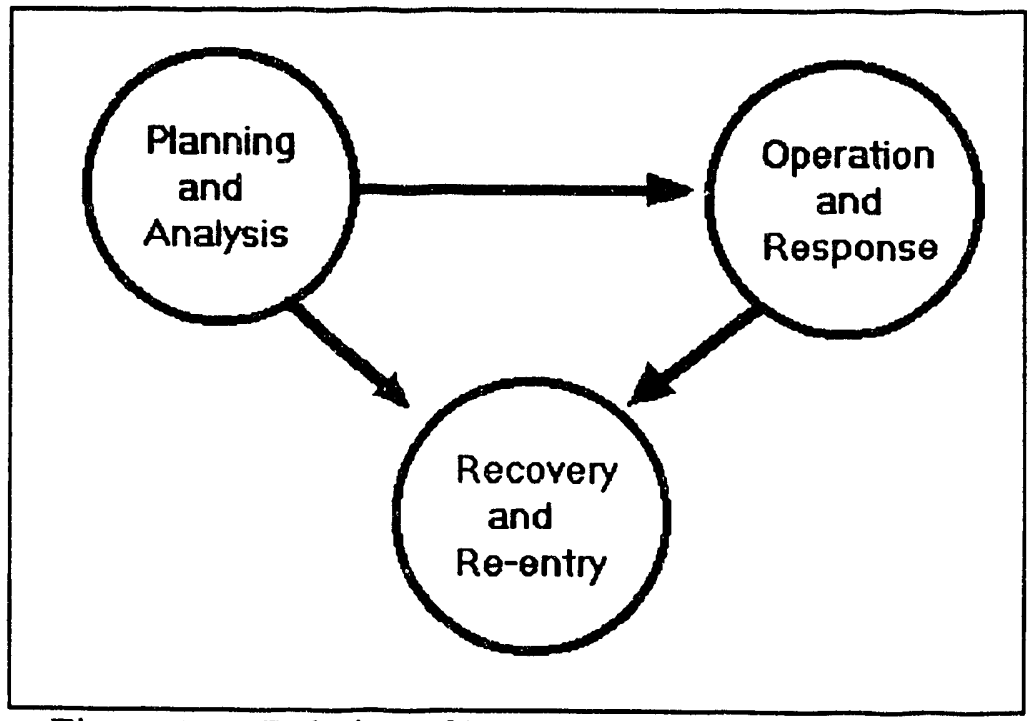

Figure 1.1. Relation of Emergency Management Components emergency

Emergency management personnel at the offpost EOC routinely evaluate the possible effects of the most likely event (chemical release), given the current onpost activities, weather situation, and population pattern (distribution of population around the post). Personnel at the EOC can use the IBS to build and maintain 
data that are related to particular chemical events and site conditions. At any specific time, a portion of that data is designated as the current event site databasethe operational data that would most probably apply if an event occurs.

Included in that event site database is the current Implementing Procedure (IP) for managing a specific set of Emergency Functions for a specific event situation. An IP has a basic structure similar to the following example.

\section{Implementing Procedure}

1. Emergency Function

A. Task

Responsible agencies/personnel

Required resources

B. Task

Required actions

Responsible agencies/personnel

Required resources

Required actions

2. Emergency Function

A. Task

Responsible agencies/personnel

Required resources

B. Task

Required actions

Responsible agencies/personnel

Required resources

Required actions

For each Emergency Function, the IP includes anticipated tasks and links them with the responsible personnel and required resources. The IBS enables emergency managers and planners to assemble a set of IPs that represent preplanned tasks and task actions for different event situations.

Even before an event occurs, an Operational IP (OPIP) is in effect at the EOC. The OPIP is updated, based on changing activities in the Work Plan, the weather, and the time of day (which is related to population pattern). Because the OPIP is in effect before an event actually occurs, it may contain precautionary activities that must be carried out before the occurrence of an event in order to ensure public safety. 


\section{IBS Users}

Personnel at the EOC and other offpost locations will have assigned roles for using the IBS. By using different program modules and user privilege controls, the system presents different capabilities to each type of user. The five principal categories of IBS users are the following:

1. Gener-1 Users: General users include emergency management decision maker., agency representatives, etc., who use and act on the information that the IBS provides. Generally, they can view but not change data.

2. Information Managers: At least one person on the EOC staff has responsibilities as the IBS Information Manager. If an event actually occurs, the Information Manager is responsible for selecting and activating an IP. The IP selected probably will be the OPIP, elevated to current event status. The Information Manager has full privileges to modify or delete data in the system databases.

The Information Manager also has special privileges to use the Onpost Simulator program, which can be used to send messages that are usually sent by the Army's onpost computer system in communication with the IBS. The Information Manager can set other user privileges.

3. Analyst/Planners: Information analysts and emergency management planners can own and use wholly independent sets of event site data. Although they can use the IBS to develop IPs and supporting information for their own use during planning stages, they cannot modify the official event site database. Analyst/planners have only general user privileges for viewing and using the event site database.

4. Communications Officer: During nighttime and other off hours (when an Information Manager might not be present), a Communications Officer at the EOC will have privileges to activate the EOC. EOC activation includes the notification of EOC personnel and the initiation of task lists.

5. Locators: Locators use only the LOCATE program to keep track of people at shelters, hospitals, and other special locations. Locators might be shelter managers, Red Cross volunteers, hospital personnel, or decontamination/reception center personnel. Although they can modify the people location database, locators have limited access to other IBS capabilities. 


\section{Getting Started (and Getting Stopped)}

The IBS is a multi-user system and can be operating on several computer terminals at once. Before starting the IBS at a terminal, you must be logged in to the computer system, and your terminal screen must be showing the VMS general system prompt, which is usually a dollar sign (\$).

\section{Starting IBS}

To start the main graphic IBS program, perform the following procedure.

1. At the general system prompt type IBS and press the Return key.

\$ IBS

The screen will clear and the following message will flash:

READING CONTROL FILES PLEASE WAIT

After a few moments, the IBS will display a map of the site and the IBS main menu, as shown in Figure 1.2.

\section{Using IBS menus}

Picking menu options will initiate specific operations or result in the display of further menus (submenus) for further refining selection of a desired operation. Appendix A contains complete listings of the IBS graphic menus.

To pick a menu optior , perform the following procedures.

1. Move the crosshairs displayed on the screen by pressing the joydisk or using a mouse. When using a joydisk, hold down the Shift key to speed up crosshair movement.

2. Place the crosshairs over the menu option you want.

3. Press the spacebar to finish picking the option. The system then performs the function you have requested.

In the actual operation of menus, some items will not be available to general users of the system. In particular, items that modify or update data will not appear on the menus of those who have no special privileges to modify information. 


\section{Exiting IBS}

To exit the IBS program, perform the following procedures.

1. If you are not currently at the main menu, return to the main menu by picking the IBS MAIN MENU option at the top of virtually all other menus.

2. Pick the EXIT IBS option at the top of the IBS main menu shown in Figure 1.2.

When you pick EXIT IBS, your screen returns to the general VMS system prompt. 
\begin{tabular}{l|l} 
A map title can appear here. & EXIT IBS
\end{tabular}

The upper part of the menu includes space for an ordered list of prior menu choices. To return directly to one of these earlier menus, just pick the menu title on the list.

The menu title is highlighted in yellow. $-\rightarrow$

IBS MAIN MENU

The graphic area on the left side of the screen automaticaliy shows the default map display.

$-\rightarrow$

Asterisks $(*)$ in this document indicate capabilities that require special privileges. These options will appear as blank lines on the menus of users who lack appropriate privileges.

MESSAGE BOARD

STATUS BOARD

PERSONNEL MANAGEMENT

MAP ANALYSIS

RESOURCE MANAGEMENT

SHOW LATEST POST TRACK

ANALYZE TRACK

CHANGE TPACK CASE

REPORT CURRENT D2 DESCRIPTION

EMERGENCY ACTIVITIES

SETUP

Notifications of mail messages and overdue tasks appear at the bottom of the graphics area on the left side of the screen.

Display screen labels: D2 model case \#; evacuation case \#; Implementing Procedure \#.-->

Figure 1.2. Map Display Screen and Main Menu of the Graphic IBS Software 


\section{Conventions for Interacting with the IBS}

In using the IBS, you will point at map locations, pick menu items, and fill in text forms, interacting with both graphic and text screen displays.

These interactions are described in the following sections. The IBS is designed to work on a VAX computer platform and is accessible through three types of devices for textual/graphic input and display:

- Tektronix graphics terminais Models 4107, 4109, 4207, 4208, 4209 4211)

- VAXstations emulating a Tektronix graphics terminal (with terminal emulation software: Grafpoint TGRAF-X software for emulating a Tektronix 4107)

- $\quad$ PC workstations emulating a Tektronix graphics terminal(with terminal ernulation software: Grafpoint TGRAF-07 software for emulating a Tektronix 4107).

When the hardware creates differences in interaction, the differences are noted.

\section{Graphic Interactions}

Except for file names and possibly some descriptive text, most input to the mapping and graphics software will be through your interaction with the menus and displays on the color graphics screen. Map graphics appear in a large display area on the left side of the screen, as indicated in Figures 1.1 and 1.2. Menu options appear in the menu area on the right side of the screen.

In a typical interaction, you will use a graphics input device to select an option from a menu of options and then pick screen locations at which to perform the task. For example, to display the coordinates of a point on a map, you select DISPLAY LOCATION on the MAP ANALYSIS menu and then pick a screen location. 
The following conventions apply to graphic menu interactions:

- The title of the current menu is displayed in yellow. The option items of the current menu are listed below the title.

- When you select a menu item, a submenu of further items can replace the current menu. The sequence of menu selections leading to this new menu is listed (in order) above the menu title.

- You can return to a previous menu in the sequence by picking any item that is listed above the current menu title: you will return directly to that level without seeing the intervening menus.

- Menu items normally appear in orange. Selected menu items appear in green. If the selected menu item starts blinking, the program is expecting further input, either from the graphics input device or from the keyboard.

- Menu options for adding or updating data are restricted to users who have special privileges (such as Information Managers and planners using the system in planning mode). Comparable menus seen by other general users with view only privileges will contain blank lines instead.

- Table 1.1 lists the locations of some standard menu items that occur on many IBS menus. 
Table 1.1. Location of Standard Items on the IBS Graphic Menus

Line

Number Menu Item or Line Use Notes on Use or Occurrence

IBS MAIN MENU

Returns you to the IBS main menu.

$2-6$

Previous menu

Selections leading to the current menu selections can be picked to return to a previous menu.

CURRENT MENU titLe Current menu title is displayed in yellow.

Horizontal bar separates the title from the options of the current menu.

Usually a blank line.

Needed by some menu items to complete an operation; occurs on menus only if needed-otherwise this line is blank.

$\begin{array}{ll}11 & \text { MESSAGE BOARD } \\ 12 & \text { STATUS BOARD } \\ 13 & \text { PERSONNEL MANAGEMENT ANALYSIS } \\ 14 & \text { RESOURCE MANAGEMENT } \\ 15 & \text { ZOOM IN } \\ 31 & \text { ZOOM OUT } \\ 31 & \text { REFRESH SCREEN }\end{array}$

The following sections explain how to:

- Pick an item on a menu or a point on the screen with the different input devices

- Define an area (polygon) 
- Troubleshoot, if certain problems occur with graphic interactions

\section{Using Tektronix Terminals}

When IBS is ready to accept graphics input, a graphics cursor (cross hairs) appears on the Tektronix terminal screen. Perform the following procedures to:
- Move the cursor
- Point with the cursor
- Select screen points or menu options

1. Bit Pad: If you have a bit pad (graphics tablet) and mouse, move the mouse across the bit pad to move the cross hairs on the screen.

Joydisk: If you do not have a bit pad, press the sides of the joydisk located on the keyboard to move the cross hairs. Press the Shift key at the same time to move the cross hairs rapidly.

2. Move the cross hairs over the graphics menu until they cross over the lettering of the desired menu item (or over the desired point on a map).

3. Bit Pad: Tap the yellow mouse button to select the menu item or point.

Joydisk: Tap the space bar to select the menu item or point.

If you have picked an operation for which no further graphics input is necessary, the cursor disappears while the operation is completed.

Note: If the space bar does not seem to be selecting correctly, press Ctrl-Q.

Avoid pressing the Return key to select items. Although this can work, heavy computer use can slow the system's response to input, making it appear as if the input was not received. Pressing Return repeatedly could enter an inadvertent keyboard response to a system request for input.

\section{Using a VAXstation}

The chief difference for graphic interactions on the VAXstation is the workstation has no joydisk for moving the cursor on the graphics display screen. Instead, the VAXstation (with Tektronix emulator) uses a mouse to position the cursor. When you press the left mouse button, it selects a menu item or point location. 


\section{Using a PC Workstation}

Like the VAXstation, the PC workstation (with Tektronix emulator) generally uses a mouse to position the cursor (cross hairs); pressing the mouse button selects a menu item or point location.

If the PC workstation does not have a mouse (or other input device), perform the following procedures to move the cursor:

1. To move the cursor, press one of the arrow keys on the numeric keypad ( $2=$ down, $4=$ left, $6=$ right, $8=$ up).

To increase the speed of cursor movement, hold down the Alt or Shift key while you press the arrow key. (The speed of keypad cursor movement is selectable through the emulation software-consult the TGRAF-07 software manual.)

2. Move the cursor until the center point of the cursor crosses over the desired menu item (or over the desired point on a map).

3. Press the space bar once to select the menu item (or point).

The same caution applies as for the Tektronix terminal: Avoid pressing the Return (Enter) key to select items. This will prevent an inadvertent response to other program interactions that require pressing Return (Enter).

\section{Defining Map Areas (Polygons)}

IBS sometimes prompts you to define an area of the map screen for use in an operation. For example, when you pick the ESTIMATE POPULATION option, the IBS prompts you to define the area in one of three ways:

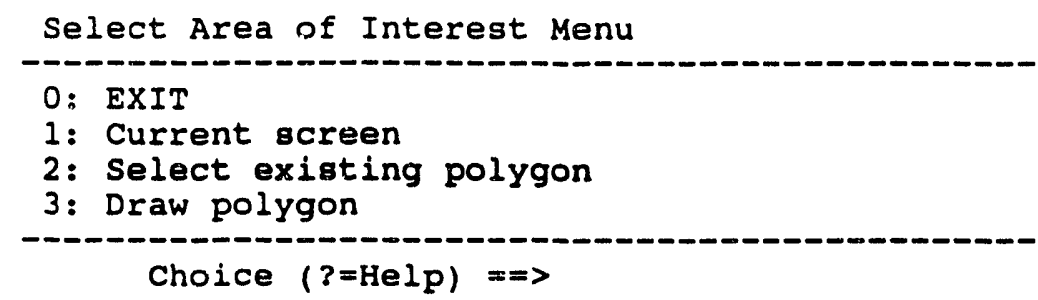

After you define an area by one of these three methods, the operation (ESTIMATE POPULATION) is then based on data within that area. Your choices of methods are:

1. Current Screen: Uses all data within the current screen map area. 
2. Select existing Polygon: Uses all data within the area bounded by the chosen polygon. If you choose this option, the system prompts you to pick a polygon:

Select Existing polygon using mouse or crosshair.

A. Pick any point on an existing polygon.

The polygon will blink in white to indicate a pick. If the wrong polygon is highlighted, pick again on the desired polygon until it blinks.

B. Pick CONTINUE from the menu to confirm the polygon selection.

3. Draw Polygon: Enables you to pick points to define a polygon around the desired area. The system prompts:

* * MSG: Draw a polygon. CONTINUE when done.

A. Pick points that define the sides of a polygon.

Line segments are drawn from point to point.

B. Pick CONTINUE from the menu to complete the final side of the polygon.

The system completes the polygon by drawing the final line segment between the first and last points that you picked.

The operation (ESTIMATE POPULATION in the above example) is then completed, based on data within the area you have defined.

\section{Problems with Graphic Input}

If you have problems with graphic screen interactions, try these suggested solutions:

- If the screen is static and the system does not accept input, press Ctrl-Q. Press the Dialog key to see if there are any error messages (see the following section on textual interactions).

- If the system is entirely locked up, press Ctrl-Y to exit IBS if you are stuck in a form or text screen. Restart IBS by typing IBS at the system prompt.

If you are stuck in graphics mode, perform the following procedures.

1. Press the Setup button on your keyboard. 
2. Type code ansi and press the Return key.

3. Type cancel and press the Return key.

4. Press the Setup button.

5. Press Ctrl-Y. The system prompt will display.

This meth', 1 of interrupting the program can cause you to lose the contents of your session, so use it only for the most severe system lockups.

- Call your system manager, if you continue to have difficulties. If you do not want to lose the contents of a work session, call your system manager before attempting any of the preceding procedures.

\section{Text Interactions}

The IBS usually prompts for text input through

- menus

- data forms

A menu is a list from which you can select options. A data form is a collection of related data items displayed on the screen with an input field for each item of data.

Text interactions occur within full-screen or partial-screen windows that overlay the normal display of map graphics.

\section{Viewing Text Dialog}

The IBS uses various mixes of graphics and text dialog. In some cases, the graphics and text may not appear on the screen of the Tektronix emulators exactly as they would appear on a Tektronix terminal. In other cases the dialog may disappear before you are through reading it. To toggle the text dialog on (or off), use the Dialog key:

- Tektronix terminals: You can press the Dialog key to view text that was replaced by graphics before you were through reading.

- VAXstations: Pick the D VIS (Dialog VISible) button in the row of on-screen buttons at the bottom of the TGRAF-X window.

- PC workstations: Press $[A L T-Z]$. (Refer to the TGRAF-07 reference manual for more information.) 


\section{Using IBS Menus and Forms (Inputting Data)}

The menus and data forms generally used in the IBS contain blank spaces or fields in which you select options or enter data. Generally a blinking input cursor (pointer) on the screen indicates which field is ready to accept an entry. The keyboard conventions used for operating the menus and forms presented by the IBS are described in the following paragraph. Table 1.2 summarizes the data entry conventions for data forms. 


\section{Special Function Keys}

The IBS uses two special function keys:

- Help key

- GOLD key

\section{Using The GOLD Key}

The GOLD key is used with other keys for completing and exiting data forms. See Table 1.2.

The identity and placement of the GOLD key on your keyboard depends on the type of workstation/emulator:

\begin{tabular}{cl} 
Terminal Type & GOLD Function Key \\
\cline { 1 - 1 } Tektronix 4107, & F5, Home \\
4109, 4208 & PF1 \\
VAXstation & PF1 \\
PC & \\
Workstation $^{(2)}$ & NumLock
\end{tabular}

\section{Obtaining Form HELP}

If you have a question about a particular item on a data form, you can press the Help key.

The identity and placement of the Help key on your keyboard depends on the type of workstation/emulator:

$\begin{array}{cll}\text { Terminal Type } & & \text { HELP Function Key } \\ \begin{array}{cl}\text { Tektronix 4107, } \\ \text { 4109, 4208 }\end{array} & & \text { Help, F6 } \\ \text { PF2 } & \\ \text { VAXstation } & \text { Help } \\ \text { PC workstation } & \text { [Alt-ScrollLock] }\end{array}$

(a) The setup mode of the TGRAF-07 software allows you to define the PC keyboard's function keys. It might be helpful to assign function keys to a few IBS functions. Refer to the TGRAF-07 reference manual for details on function key definitions and how to assign them. 
On all types of keyboards you can also use the ? key (question mark) to get help information. Pressing Help yields two types of information.

- $\quad$ Field Information: Pressing Help the first time produces specific help information pertaining to the current input field.

- Form/Menu Information: Pressing Help a second time produces general help information pertaining to the entire data form or menu.

In both cases, more than one page (screenful) of help information may be available. Press Return to page through the available information and return to the data form or menu. 
Table 1.2. Summary of Data Entry Conventions for Data Forms - Tektronix and [PC] Keypresses

Keypress(es) Cursor Movement

\% RETURN Advance past a scrolling block of items on a form

CTRL-D

CTRL-F

Move left one character without altering the text

Up F1 [8]

Down F2 [2]

Left F3 [4]

Right F4 [6]

Move right one character without altering the text

Move to preceding line

Move tr: next line

Backup horizontally to preceding field

Advance horizontally to next field

Form Editing or Operation

HELP, F6, PF2

? + RETURN and ??

[ALT-ScrollLock]
In fields with Help, first press: Show information about the current field.

Second press: Show info about the current form or menu. In selected fields, ?? + RETURN will display a list of possible choices to enter in the field.
GOLD Z

[NumLock] [Z]

GOLD Y

[NumLock] [Y]

RETURN

\section{BACKSPACE}

CTRL-E or CTRL-Z

\section{Complete and exit one form:}

Checks and accepts current entries in field and form; Signals completion of the current form;

Moves to the next form (in a set of forms); or Exits to the previous higher-level form or menu (from a single-page form)

\section{Exit from a form or set of forms:}

Restores the original contents of the current field; Signals completion of the current set of forms; Exits to the previous higher-level form or menu.

Accept the current field entry and advance:

If the cursor is in the final field of a form, pressing RETURN acts like GOLD Z.

\section{Delete the previous character.}

Refresh the screen. Use these to redraw your screen, for example, after a broadcast message prints over your form use CTRL-E to redraw the form. These keystrokes work only on forms, not menus. Some complex forms may not refresh completely. If you have trouble refreshing a form, exit the form by pressing GOLD Y and restart the form.

Delete character. 
CTRL-R

CTRL-W

CTRL-X
Insert a blank. Inserts a blank character into the current field.

Provide an option to abort current field or form: A prompt at the bottom of the scre:n will ask you whether you want to abort the field $(F)$, the whole form $(\mathrm{W})$, or nothing $(\mathrm{N})$.

- An F aborts the current entry and restores the original contents of the field-the contents before you started changing it.

- A W aborts the current form and restores the original contents of the form.

- An $\mathbf{N}$ enables you to continue without aborting.

Clear the current field. Clears the field you are currently working in of any characters. 


\section{Selecting an Option from a Text Menu}

Text menus generally consist of a list of options and a single input field:

Highlight Data Menu
$0:$ ExIT
$1:$ List attributes for current screen
$2:$ Enter attribute description
Choice $(?=$ lielp) $m=>$

\section{To select an option from a text menu}

Type the character corresponding to the desired option and press Return. If you need help, type a ? at the prompt and press the Return key. For the above menu, the foliowing help screen will display.

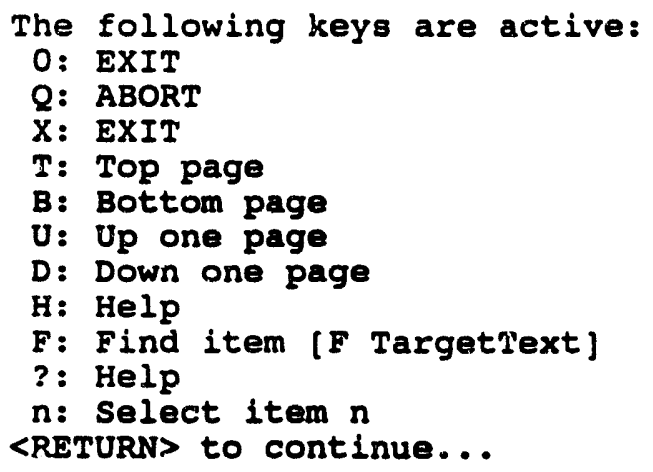

\section{Positioning the input Cursor in a Form}

When the IBS first displays a data form, the input cursor is at the beginning of the first entry field. Use the arrow keys to move the cursor to the various fields of the form. When the cursor is at the beginning of a field, Return also advances the input cursor to the next field. These cursor movements do NOT affect any entries already in the entry fields unless you have started to make a new entry in the field where the cursor resides. When the form is not large enough to contain all the necessary items, some items may be scrolled several lines (c „le block) at a time to reveal nore input fields. You can enter a percent (\%) symbol at the beginning of an entry field to advance the input cursor past the scrolling block area of the form.

\section{Entering Numeric Values in a Form}

The data forms accept floating point input in some cases. Type numeric values (positive or negative) to fit the entry fields. When you press Return or an arrow key to accept the numeric entry, the IBS rewrites the entry to fit the field, sometimes reformatting the value in scientific notation. 


\section{Problems with Menus and Forms}

If you have one of the following problems with text menus or data forms, try the suggested solution(s):

- If the following messages display: "Input too long for this field." or "Value out of range for this field.", check your entry. Use the Delete key ([Backspace] on the PC) to delete the current value, and type your entry again. Press the Help key to get information about acceptable field values.

- If the screen is static and the system does not accept keyboard input, try pressing Ctrl-Q to free up the keyboard.

- If no system response follows a menu selection or completion of a form, try the following. If you pressed Return while the system was updating the display, you may need to press Return again to continue. 


\section{Overview of the IBS Main Menu}

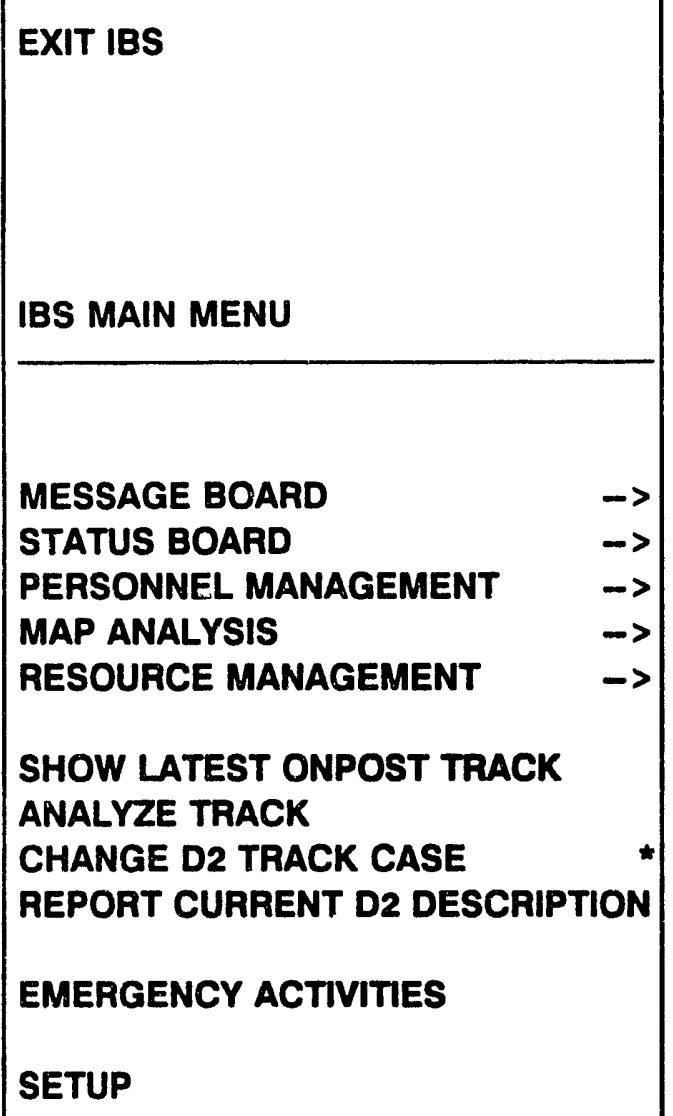

\section{Asterisks $\left(^{*}\right)$ in this Document}

In this document the asterisks on the graphic menus indicate options that require special privileges. These options will be blank lines on the menus of General Users.

\section{Order of the Reference Sections}

The reference sections of this guide are arranged in the same order as the major options appear on the main menu. Capabilities within each section are arranged in alphabetical order. planning and tracking capabilities with computerized map display and modeling of emergency events (such as the dispersion of a chemical agent or the evci: ation of a population).

<-- Map computed time-release concentrations.

<-- Show computed information about track.

$<$-- Switch between track data sets.

<-- Show text description of current track.

<-- Carry out emergency support activities and computer modeling activities.

<-- Tailor various system features that are to be used as default conditions. 


\section{Introductory Exercises}

The following exercises have been developed to give you a practical introduction to the IBS. After performing these exercises, you will be able to:

- Start IBS

- Navigate the menu system

- Select options

- Set up default map layers

- View data

- Work with Emergency Planning Zones (EPZs)

- Change map displays

- Exit IBS

The exercises are not intended as a substitute for formal training. Formal training provides in-depth methodologies and procedures tailored for your work site.

To do the exercises, you must have a user account on the VAX computer system. You must be able to login with a username and password. If you do not have a user account, contact your system manager.

Note: The graphic displays shown in these exercises are examples included for instructional purposes. The map displays and system data included on your system can vary. Even though your map display may look different, the IBS commands still work in the same way.

\section{Starting IBS}

To do these exercises perform the following procedures.

1. Login to the VAX.

2. Start IBS by typing ibs at the system prompt and press the Return key. The system will display the following message:

READING CONTROL FILES

PLEASE WAIT. 
After a few moments, the IBS Main Menu and default map graphic displays as shown.

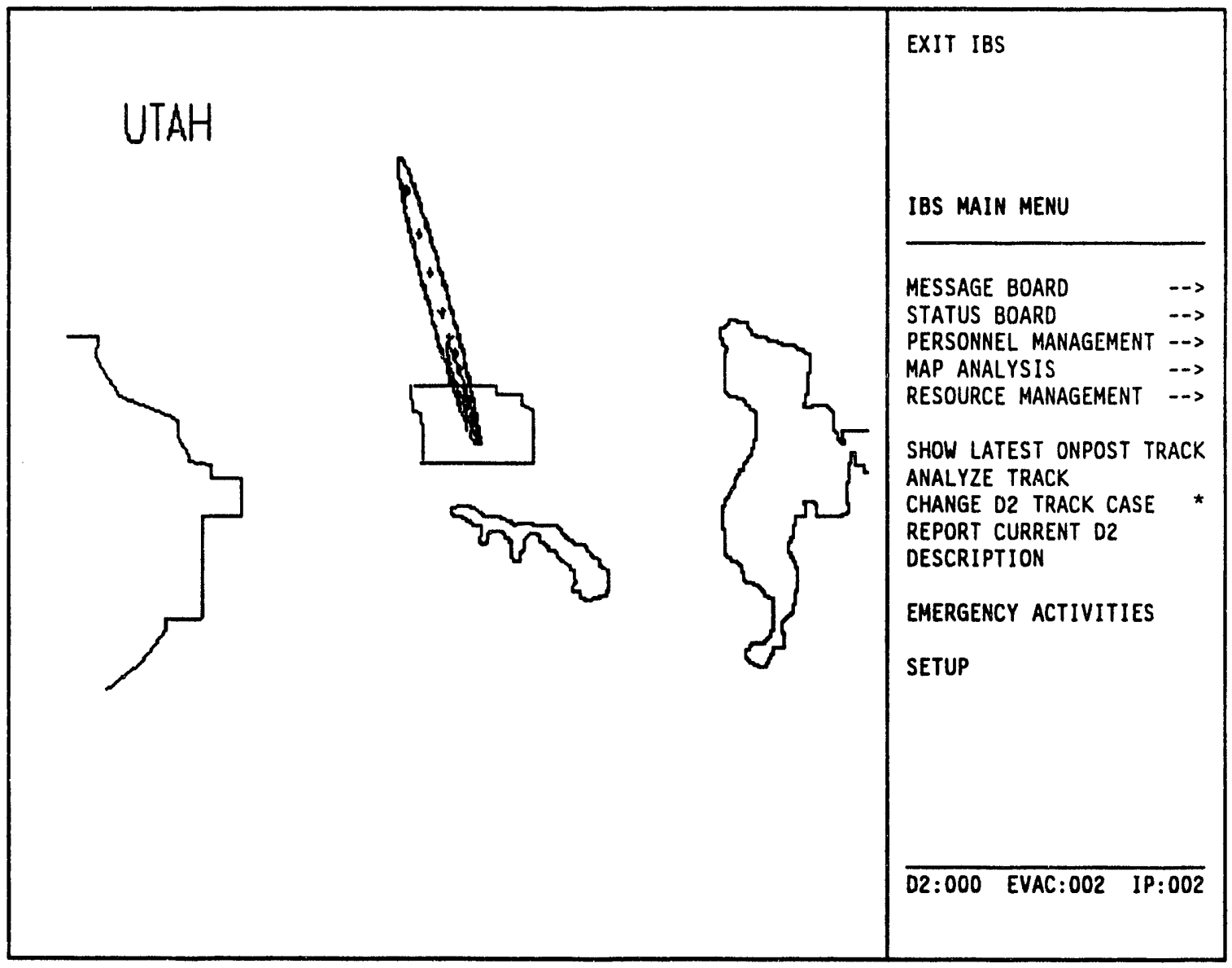

You are now ready to begin any of the following exercises.

1. Viewing the Onpost Work Plan

2. Setting Up Your Default Map Display

3. Adjusting the Map Display

4. Using Emergency Activities

For detailed information on pointing and selecting with the graphic cursor (cross hairs), and working with text displays and forms, see the preceding heading Getting Started and Conventions for Interacting with the IBS earlier in this section. 


\section{Exercise 1. Viewing the Onpost Work Plan}

To view the current Onpost Work Plan, perform the following procedures.

1. From the IBS Main Menu, select the Status Board command with the cross hairs and press the Space bar. The Status Board menu displays as shown.

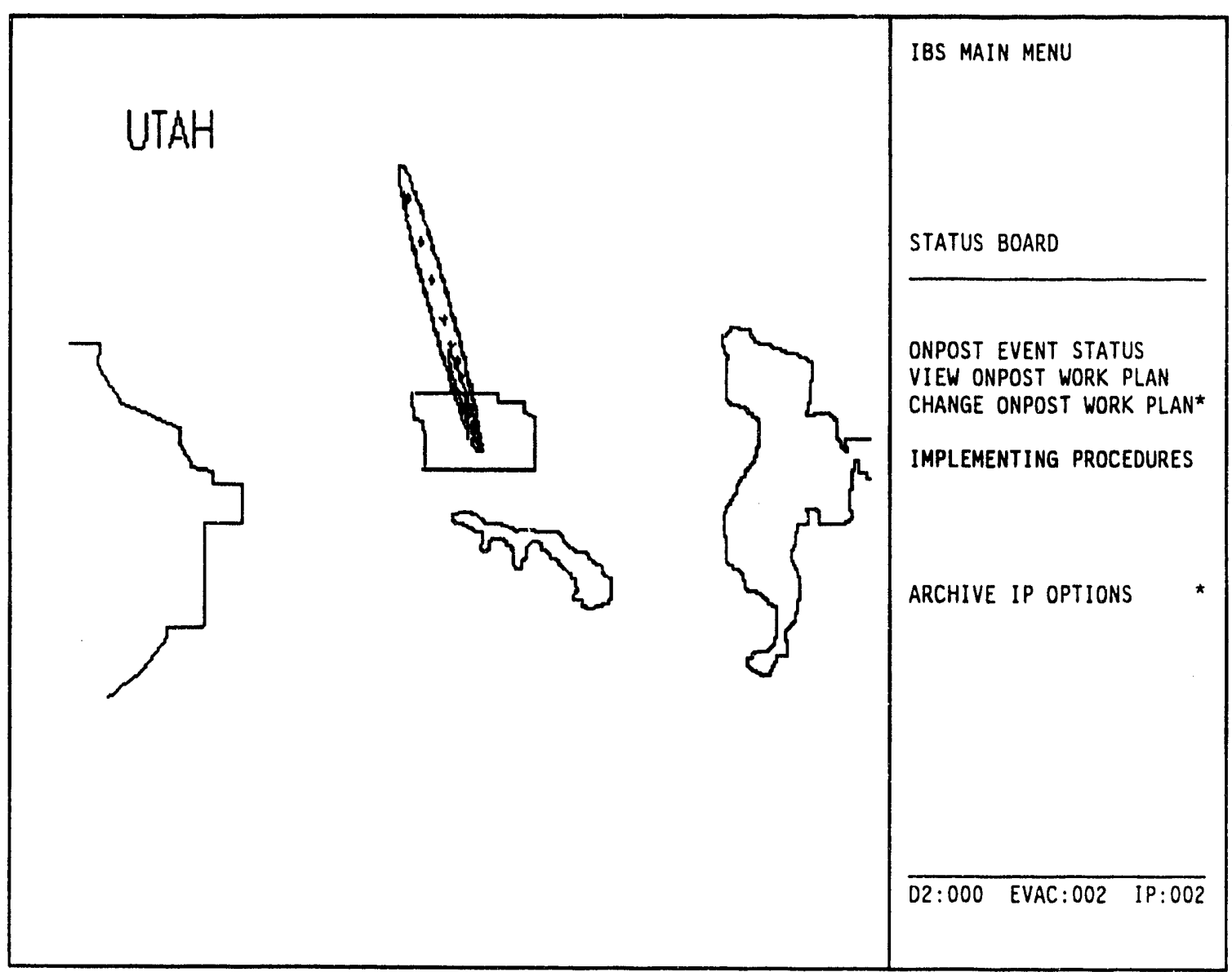


2. From the Status Board menu, select the View Onpost Work Plan command.

The Onpost Work Plan displays, as shown. This text screen overlays the graphic map display.

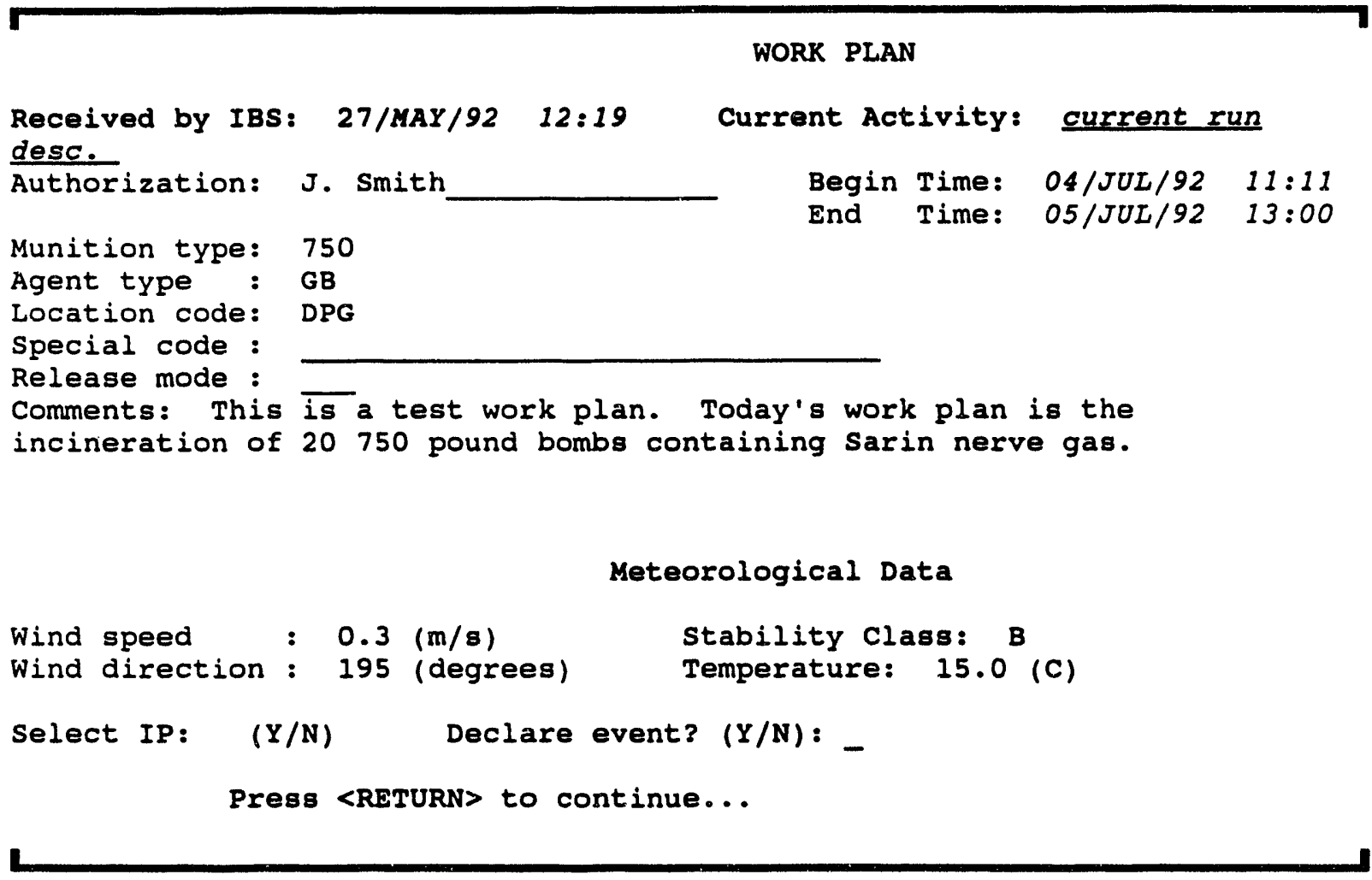

3. Exit the current Onpost Work Plan by pressing the Return key. The Status Board menu displays.

4. From the top of the Status Board menu, select the IBS Main Menu command. The system returns you to the Main Menu.

For detailed information on the Onpost Work Plan and Implementing Procedures, see Section 3. 


\section{Exercise 2. Setting Up Your Default Map Display}

Each time you start IBS, you can set up the map display to show you the map layer infomation you want. To set up the map display, perform the following procedures.

1. From the IBS Main menu, select the Setup comand. The Setup menu will display as shown.

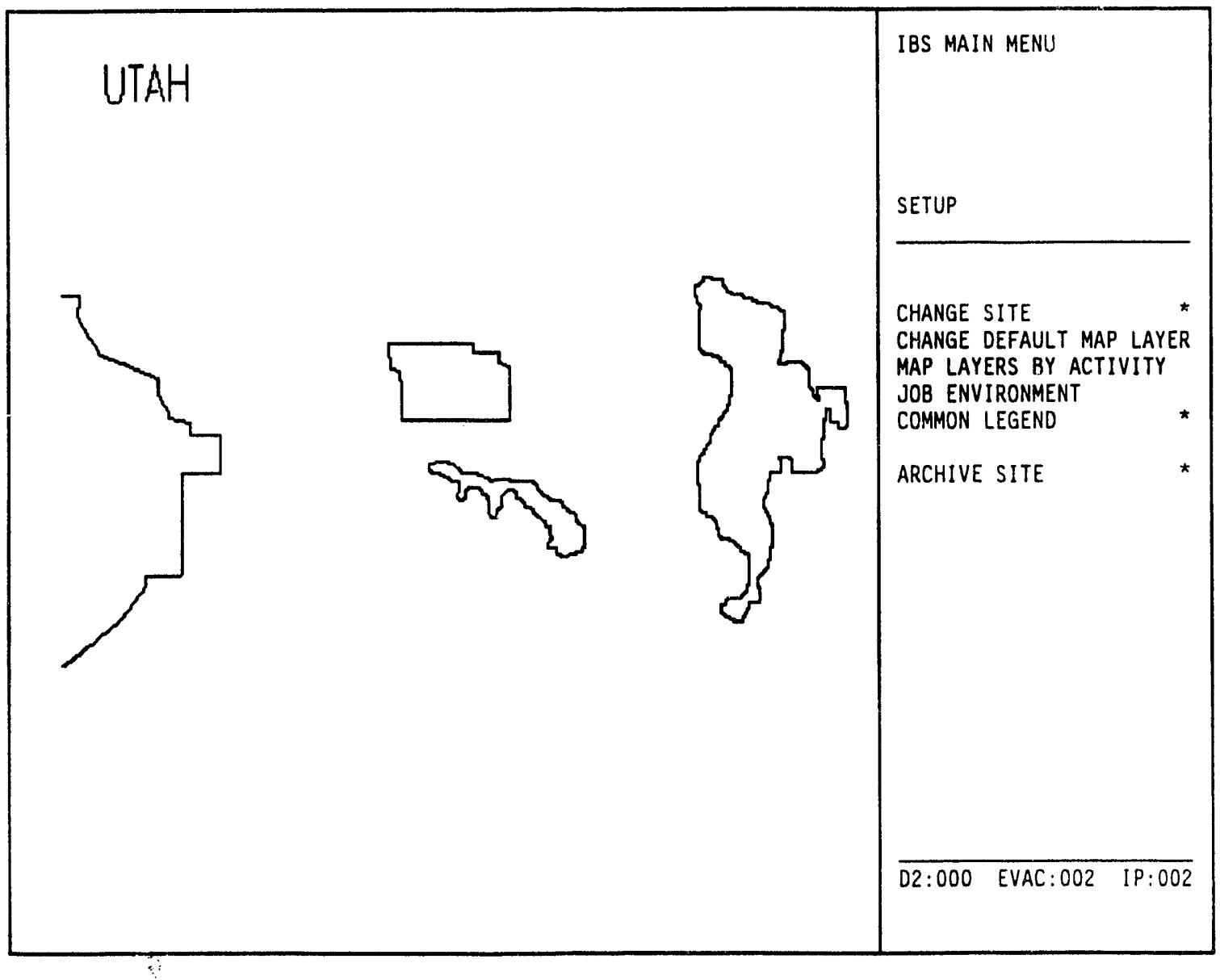

2. From the Setup menu, select the Change Default Map Layer comand. The Change Default Map Layers menu will display, as shown. 


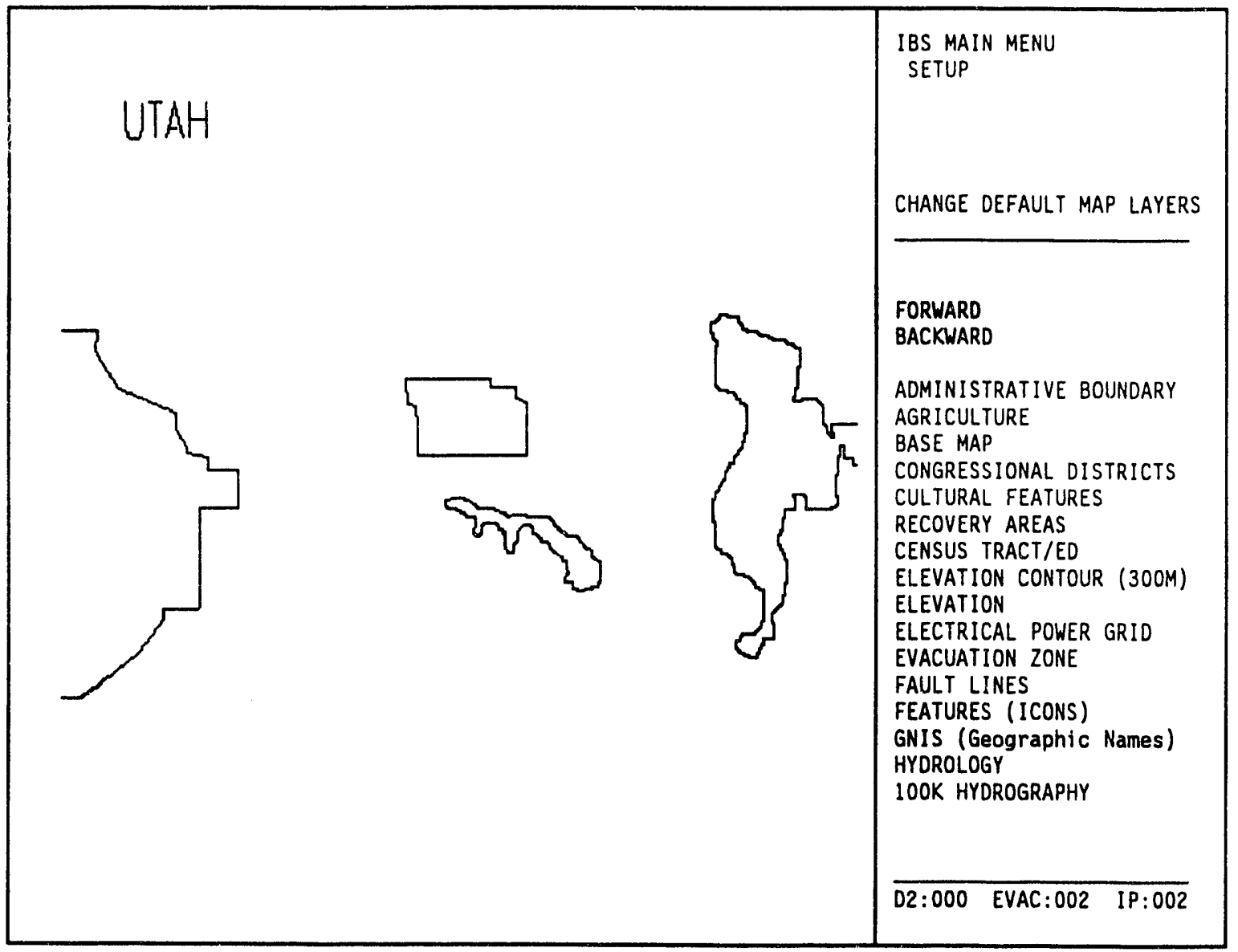

The Change Default Map Layers menu consists of several lists of map layers from which you can pick the layers you want to view. For this exercise you will pick the following layers:

- Hydrology

- $100 \mathrm{~K}$ Roads

- Railroads

- Roads

These map layers may not all be contained in the first map layer list.

Note: The user list of map layers supplied with your system can be slightly different from the examples shown.

3. Use the Forward command to page through the lists by selecting the command with the cursor (cross hairs).

4. Select the map layers when they display on the list. As you select the map layers, they will highlight in green. Keep paging through the list and picking map layers until all four listed map layers have been selected. 
Default map layers (such as Evacuation zone) will display in green on the list. Leave these as they are. After paging forward several times, you will eventually return to the first page of the list.

5. Select the Setup command to exit Select Default Map Layers. The Restrictions of Map Layers by Display Size menu will display, as shown.

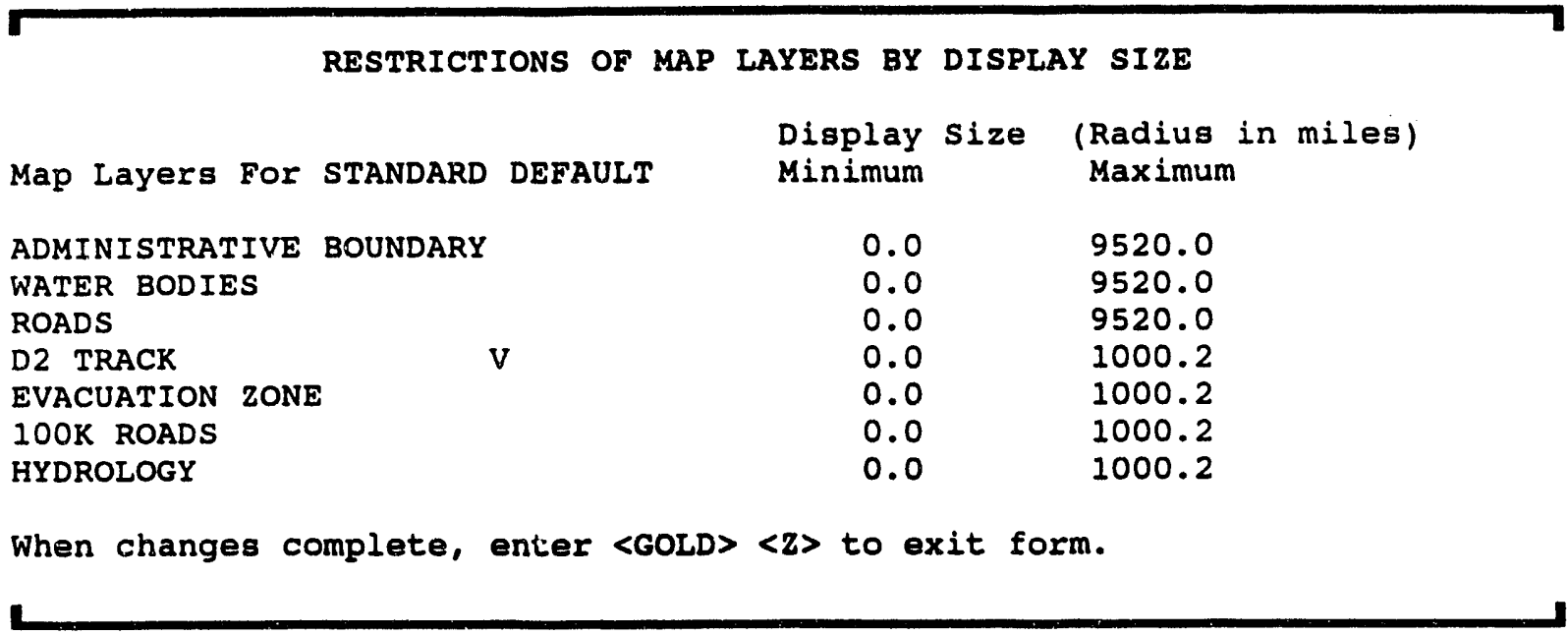

6. Use this menu to restrict the display of certain data-rich map layers. In many cases, the default setting is fine. In this exercise, you were instructed to turn on the display of both Roads and $100 \mathrm{~K}$ Roads. Use the Return key to move through the Minimum and Maximum fields and change the settings for Roads and $100 \mathrm{~K}$ Roads to the following:

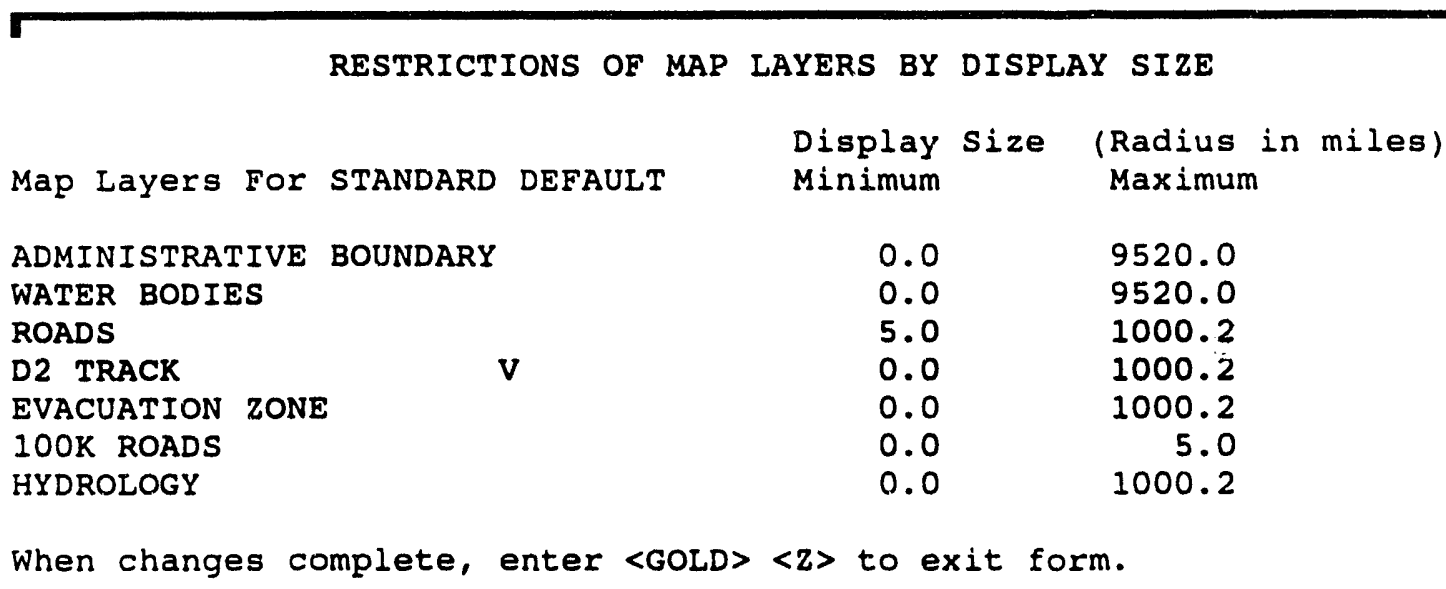

Notice that you have now restricted $100 \mathrm{~K}$ Roads so that they will display only when you have zoomed in your map display to a radial distance of five miles or less. This makes sense, as the $100 \mathrm{~K}$ Roads layer is a very data-rich map layer. If you try to display the $100 \mathrm{~K}$ Roads map layer over a large area (for 
instance, 30-50 miles), the system would spend too much time trying to display all the tiny roads in the area. In some cases, the system can run out of memory while trying to display all the details, resulting in a system lockup. Check with your system manager for more details concerning which map layers need to be restricted to small areas.

7. When you have finished typing in the new restrictions, press GOLD-Z to exit the menu. This will cruse the system to display the chosen map layers. The graphic screen will go sank for a moment, then the map will display with the new layers, as shown. These layers will now display each time you start IBS.

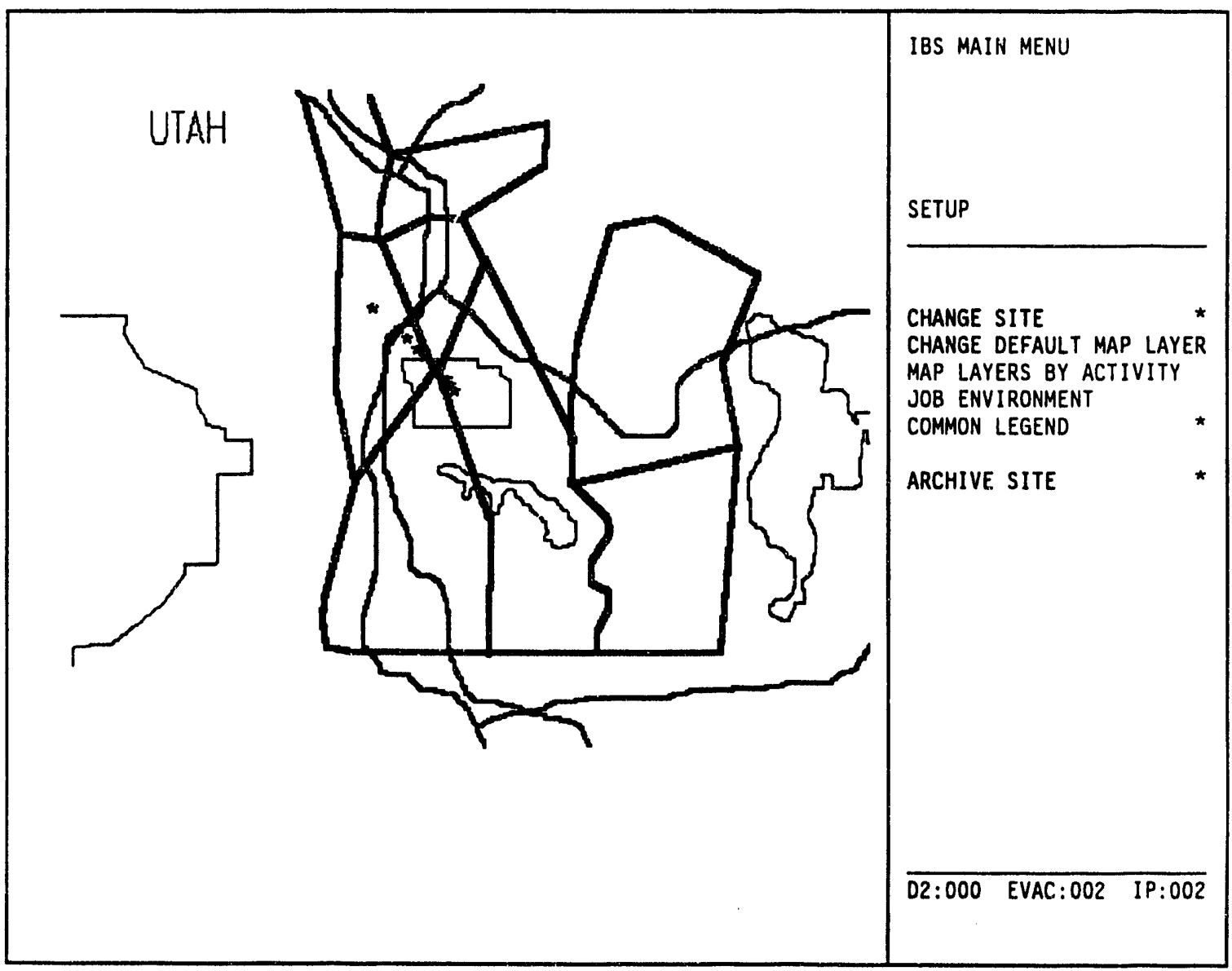




\section{Exercise 3. Adjusting the Map Display}

To change and adjust the map display, perform the following procedures.

1. From the IBS Main Menu, select the Map Analysis command with the cross hairs and press the Space bar. The Map Analysis menu will display, as shown.

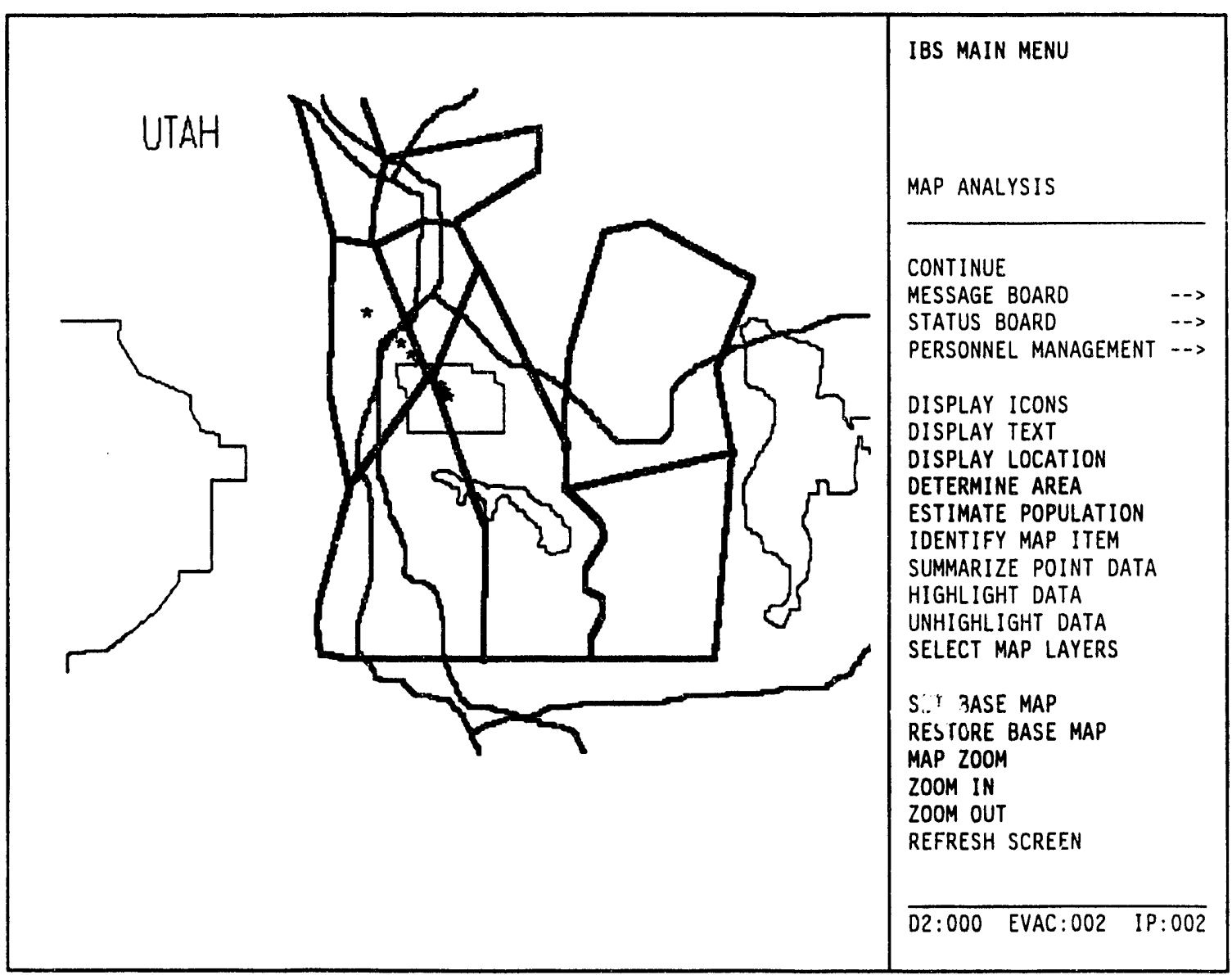


2. From the Map Analysis menu, select the Display Text command. Descriptive text will display on the base map, as shown. This command toggles between Display Text and Turn Off Text each time you select it. Now that you have selected the Display Text command, the Turn Off Text command displays in its place.

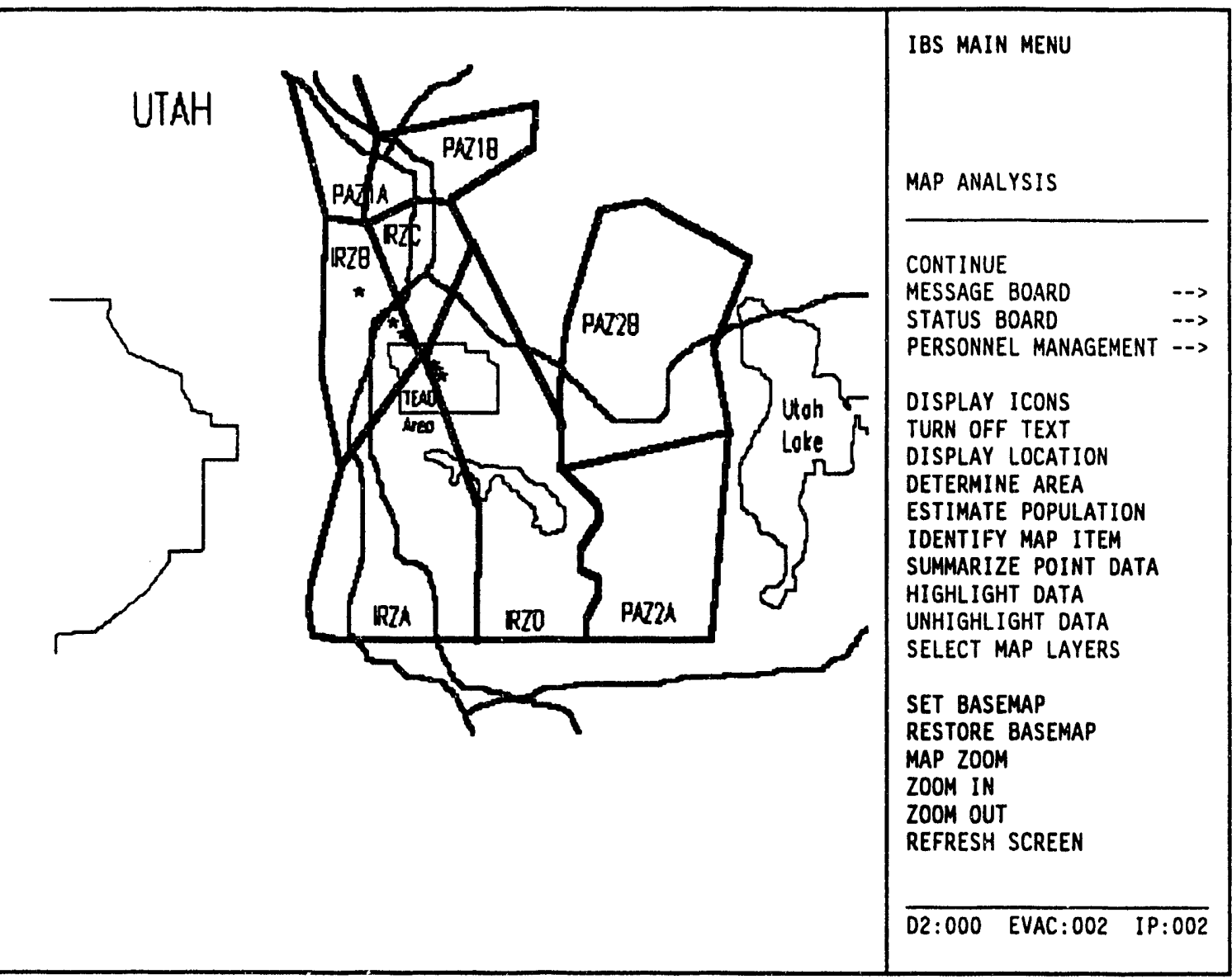

3. For a closer view of an area, select the Zoom In command from the Map Analysis menu.

The Zoom In command will highlight in green and blink, while the following text message will display in the upper left corner of the screen:

* * * MSG: Select center and one edge $w /$ mouse

4. Move the cross hairs on your screen so that they cross over the center of the area where you want to zoom in. Press the Space Bar once.

5. Move the cross hairs out to a spot which will become the new corner or edge of the zoomed in display. Press the Space Bar. A red square will display momentarily to show the area you have marked, then the screen will blank out 
as the system zooms in on the map. The new area you indicated will display, as shown in the following example.

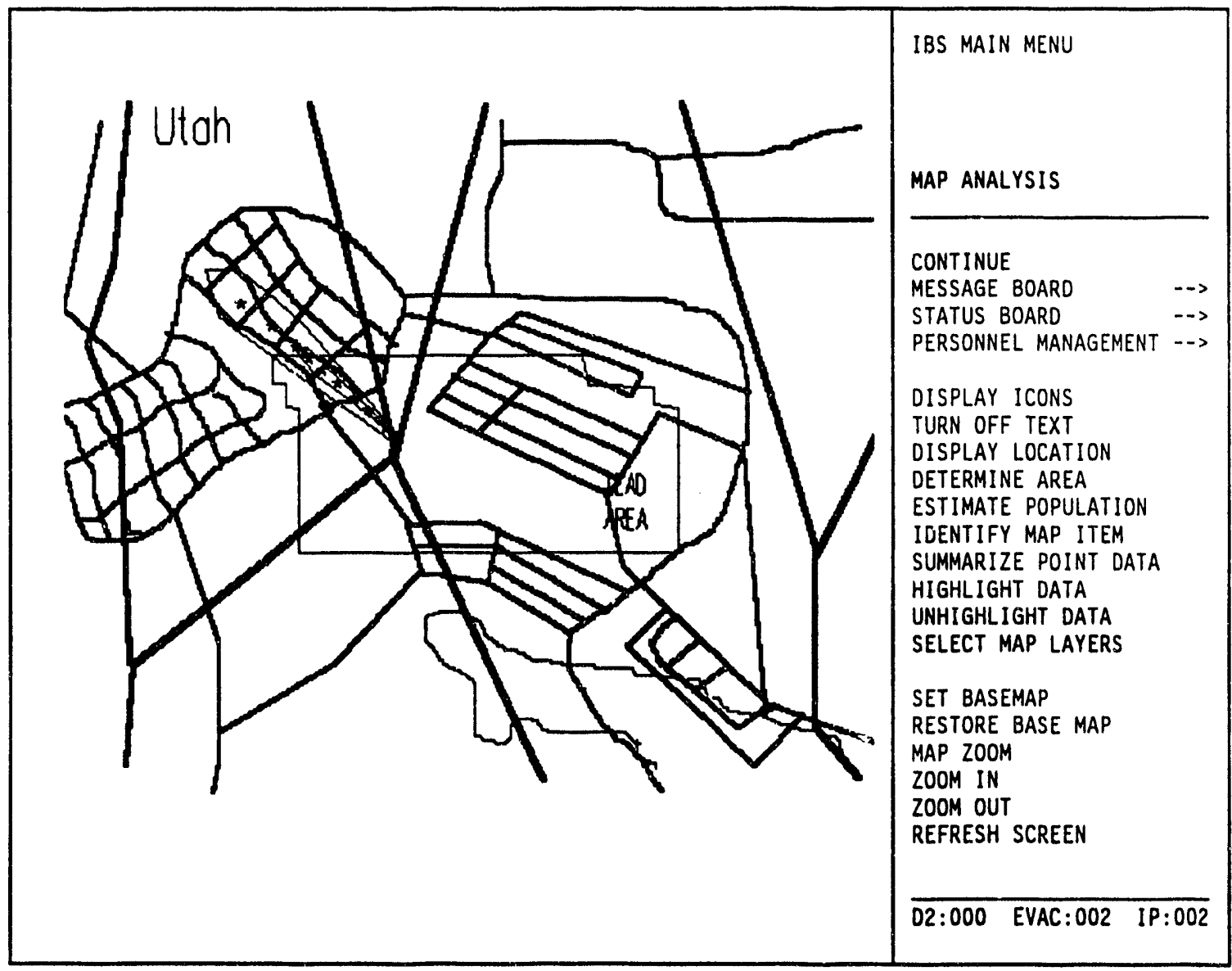

You can repeat this procedure to get as close a view as you wish. Use the Zoom Out command in a similar way to move your view back.

Note: If you have used the Select Map Layers option to display a map layer with data-rich information while you are zoomed in, you may get the message:

\section{Data Exceeds Memory}

when you try to zoom out or restore the base map. The system may not draw all the information on the larger area, or it may take too much time trying to draw the information. To avoid this problem, use the Default Map Layers option under the Setup command to restrict the areas on which data-rich map layers will display (as described in Exercise 2). 
6. To return to your original viewpoint on the map, select the Restore Basemap command from the Map Analysis menu.

7. From the top of the Map Analysis menu, select the IBS Main Menu command. The IBS Main Menu will display.

8. From the IBS Main Menu, select the Resource Management command. The system will display the various standard facility icons on the map, as shown.

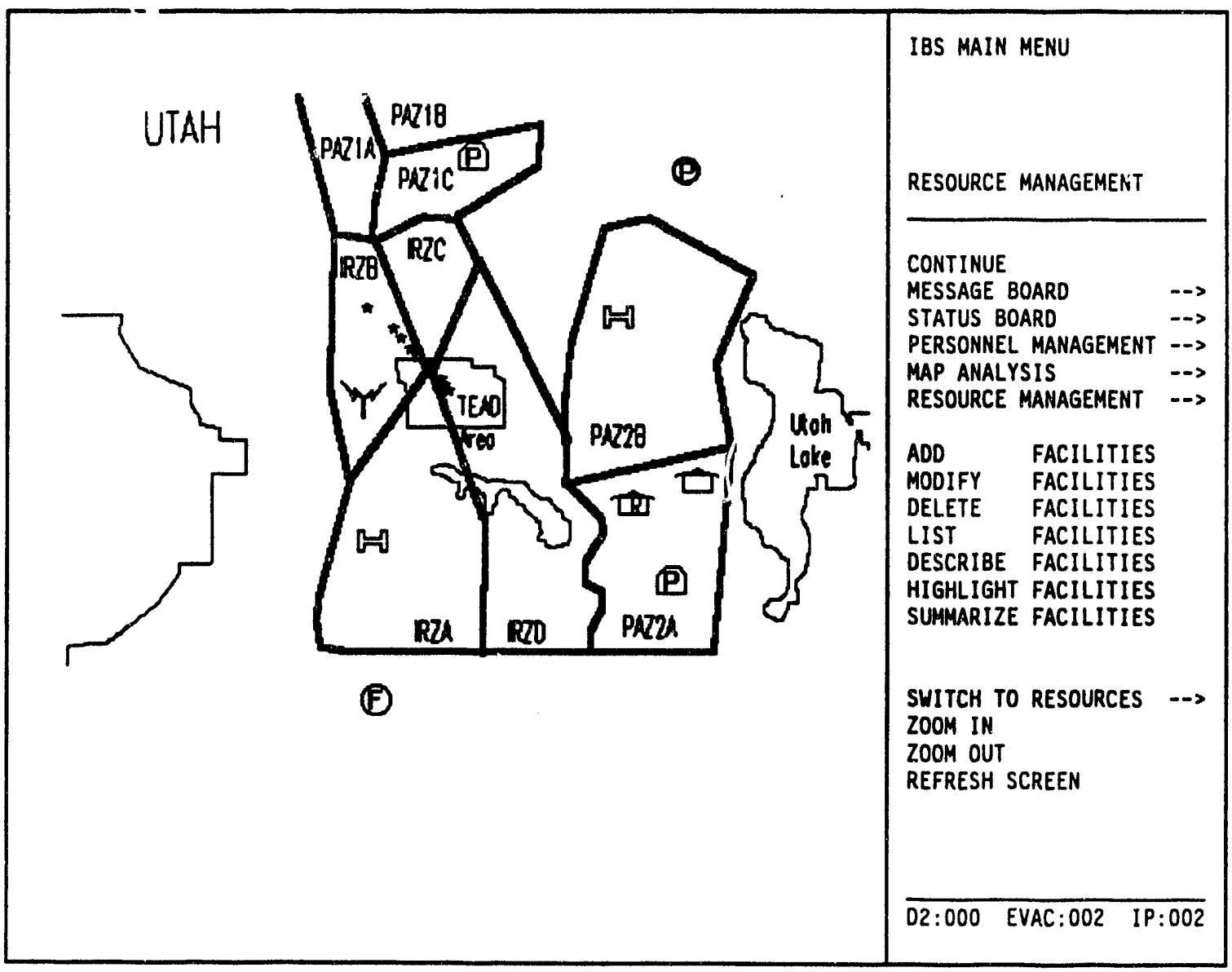

The Resource Management menu will display.

9. Select the List Facilities command from the Resource Management menu. The List Facilities command will highlight in green, then the system will overlay the map display with a text listing of the facilities represented by the icons. 
Note: If your system has not been set up for default screen display of reports, you will be presented with the Ouput Redirection Menu:

Output Redirection Menu

Output Redirection Menu
0 : ExIT
1 : Display on screen
2 : Print on default printer
3 : Mail to other user (s)
$4:$ Save to an AscII file
Choice $(?=$ Help) $==>$

At the Choice prompt, type 1 and press the Return key. The facilities listing will display. 
An example of the facilities listing follows.

A-CORE CONCRETE CUTTING SPEC. PRIVATE BUSINESS

5360 SOUTH RILEY LANE

MURRAY UT 84107

JOHNSON JACK 801-261-5552

O F

ALBERTSONS FOOD CENTER PRIVATE BUSINESS

250 N. MAIN

TOOELE UT

$$
801-882-6338
$$

O F

ALLEN'S FOOD TOWN PRIVATE BUSINESS

$47 \mathrm{~S} 1 \mathrm{~W}$

TOOELE UT 84074

O F

$801-882-6348$

ARNOLD MACHINERY CO. 2975 WEST 2100 SOUTH

SALT LAKE CITY UT 84130

HAMMOND FRANK 801-972-4000

$0 \mathrm{~F}$

CARLSON CONSTRUCTION INC. PRIVATE BUSINESS

14800 SOUTH ST.

WEST VALLEY CITY UT

801-254-3339

$0 \mathrm{~F}$

LEHI HIGH SCHOOL

SHELTER

LEHI

UT

$801-882-6338$

$700 \mathrm{~F}$

Press <RETURN> to continue... 
10. Press the Return key to page through the listings. When you have displayed all the facilities, the system returns to the map display and the Resource Management menu.

The listings can continue for several pages. To exit the listing without scrolling through every page, press Ctrl-Z.

11. Select the IBS Main Menu command to return to the top level of IBS. Notice that the facility icons remain on the map display. 


\section{Exercise 4. Using Emergency Activities}

1. From the IBS Main Menu, select the Emergency Activities command with the cross hairs and press the Space bar. The Emergency Activities menu displays, as shown.

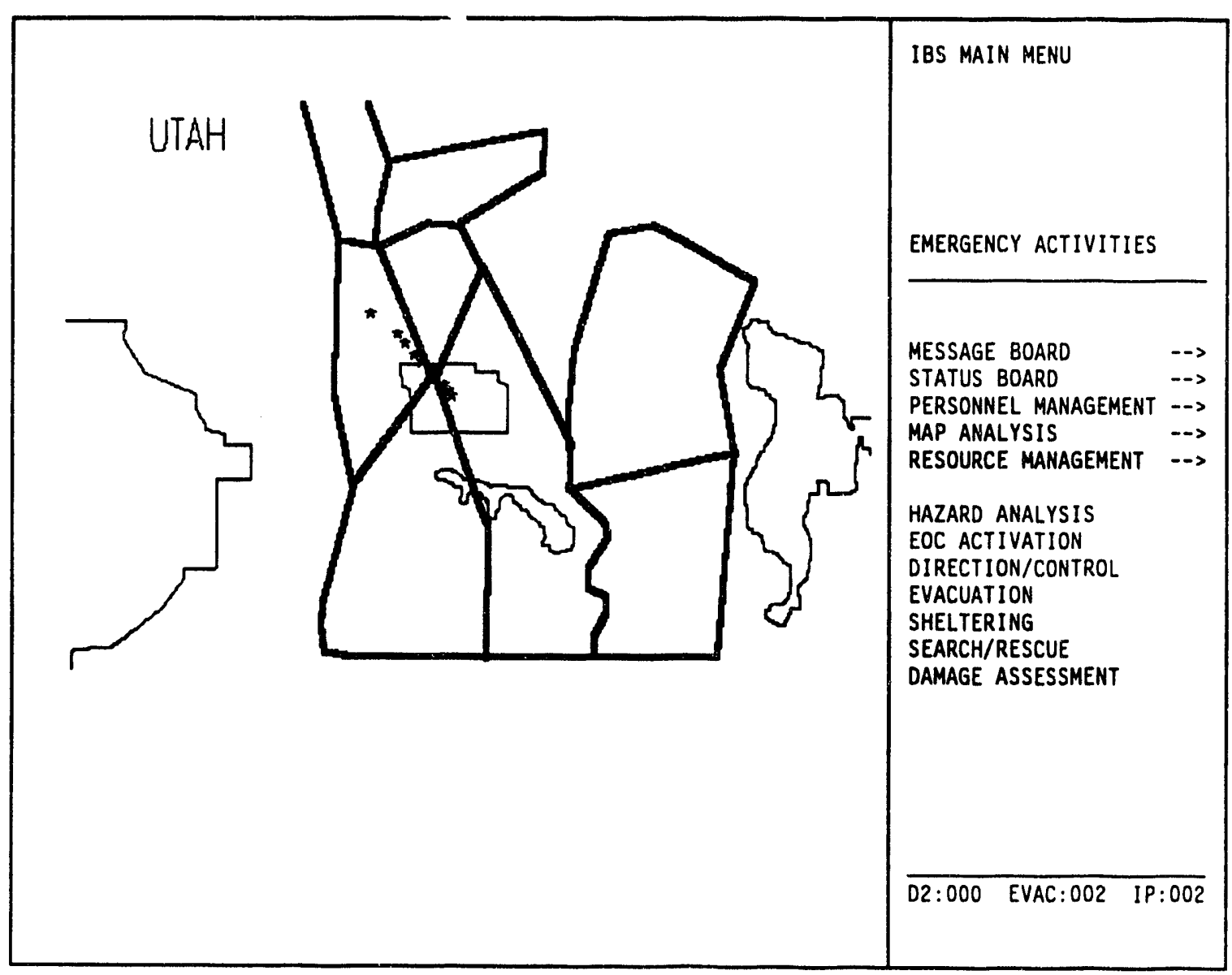


2. From the Emergency Activities menu, select the Direction/Control command. The Direction/Control menu displays, as shown.

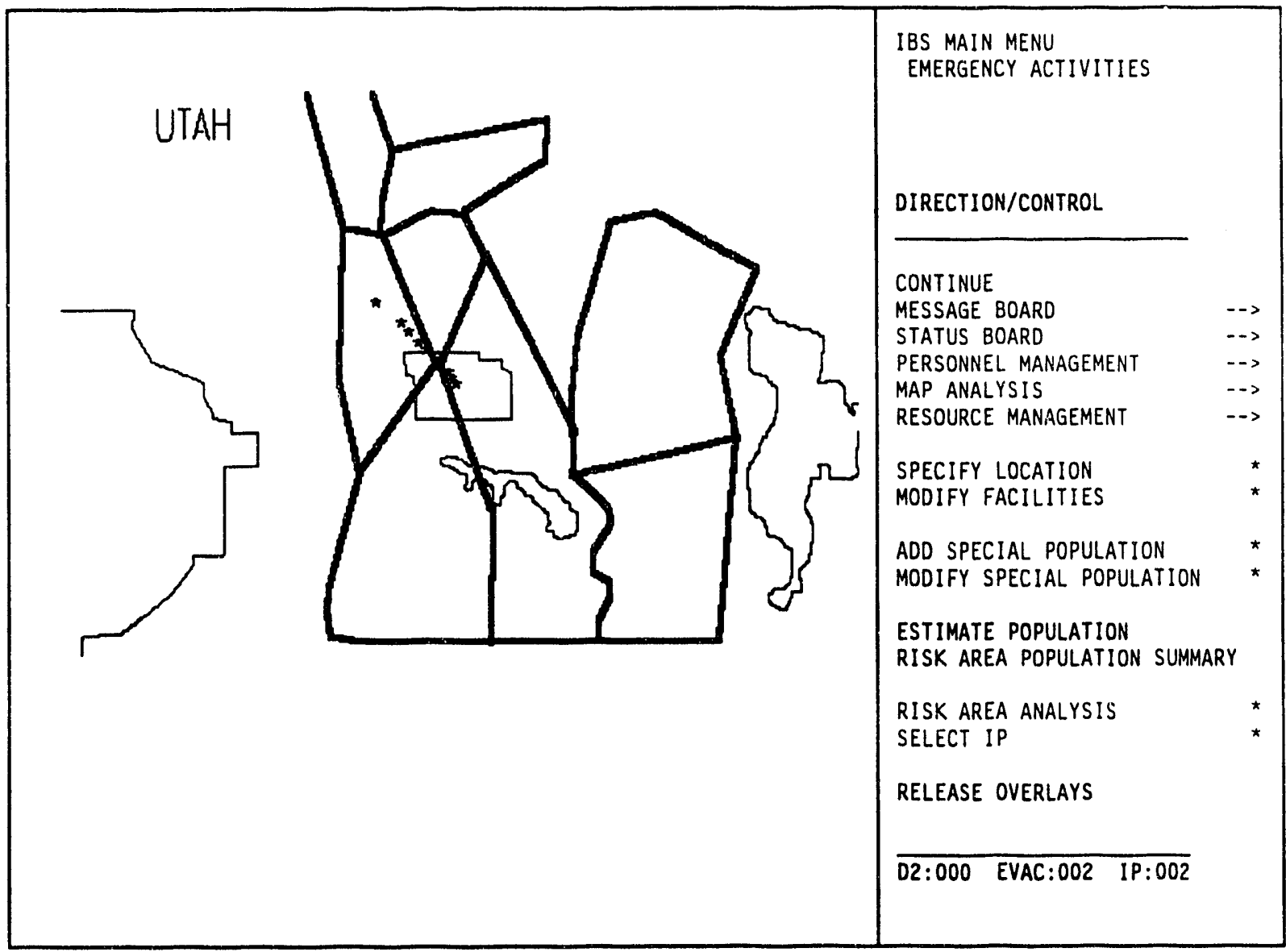


3. From the Direction/Control menu select the Risk Area Analysis command. The system draws in any existing risk polygon in bold white lines over the base map display, as shown. The Risk Area Analysis menu displays.

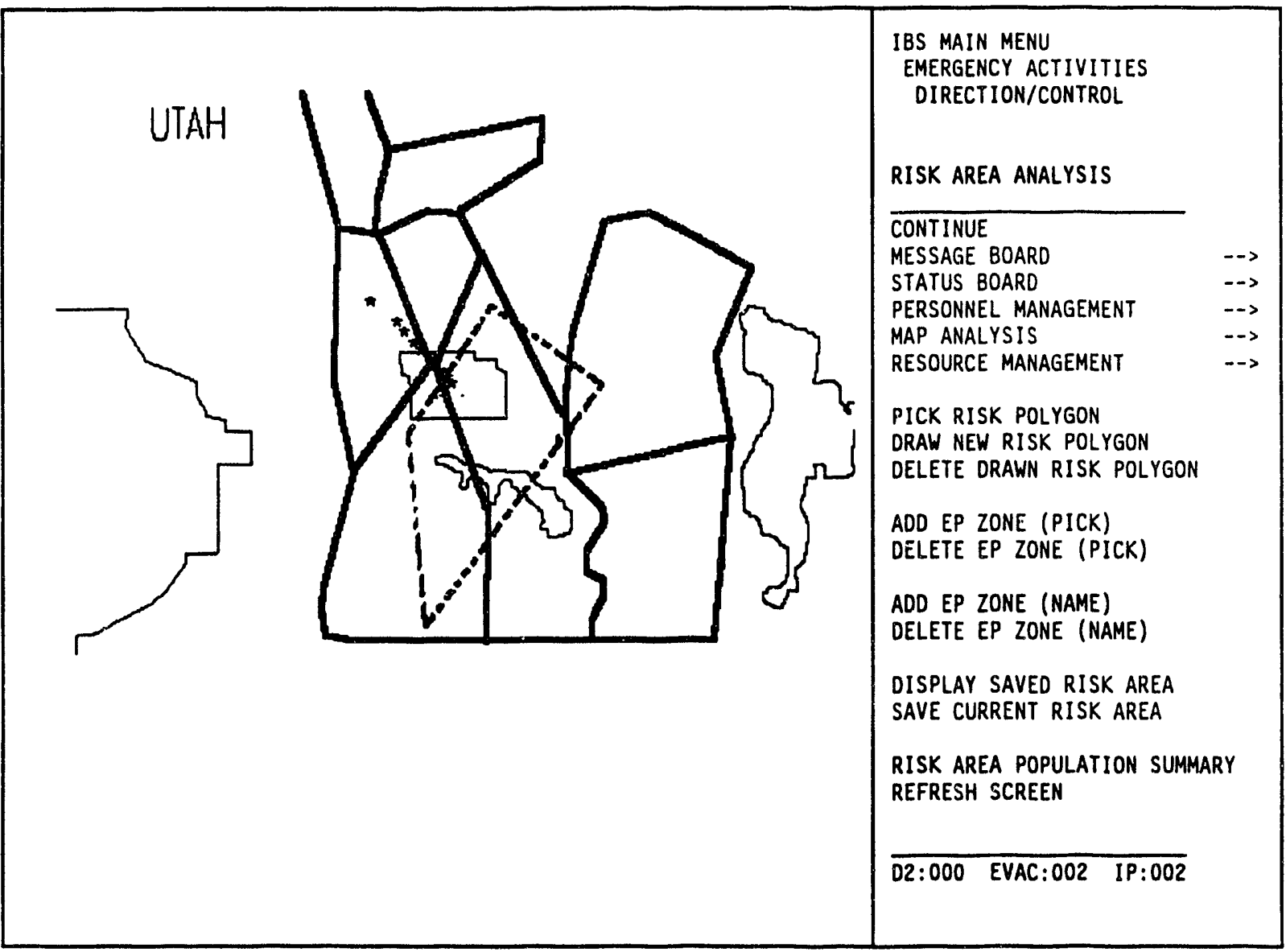

4. From the Risk Area Analysis menu, select the Draw New Risk Polygon command. The system displays the following message:

* * * MSG: Draw a new Risk polygon. ContINUE when done

5. Use the cursor (cross hairs) to draw a risk polygon on the map display. Press the Space bar to indicate the point of each corner. The polygon lines are initially drawn in green. 
6. When you have drawn the polygon, select the Continue command to close the polygon. The new risk polygon is redrawn in bold white lines. The evacuation zones that intersect or are contained in the new risk area will be redrawn in bold lines. Those zones not touched by the risk polygon are redrawn in thin lines.

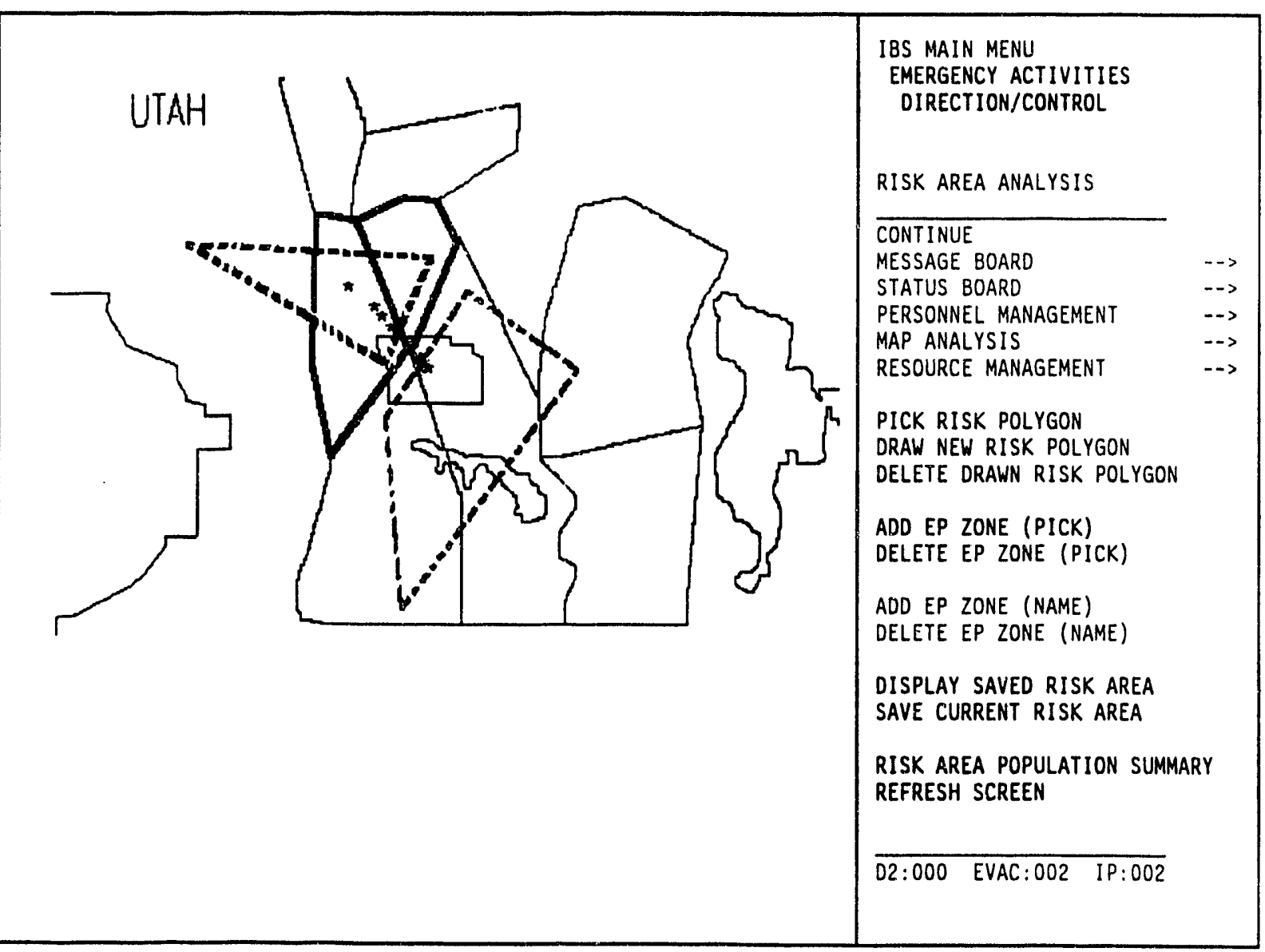

Delete the old risk polygon and leave the new risk polygon on your map display.

7. To delete the old risk polygon, select the Delete Drawn Risk Polygon command from the Risk Area Analysis menu. The system displays the following message:

* * MSG: Select Risk Polygon to delete. CONTINUE when done.

8. Use the cursor to select any point on the polygon you want to delete. Move the cursor over the polygon and press the Space bar. The polygon you have selected will blink. If you select the wrong polygon, move the cursor and select a point on the correct polygon.

9. Delete the polygon by selecting the Continue command from the menu. The blinking polygon is deleted. 
The polygons outlined in bold orange are EPZs. These EPZs compose the risk area. Now you can add or delete EPZs to the risk area.

10. To add an EPZ to your risk area, select the Add EP Zone (Pick) command from the Risk Area Analysis menu. The system displays the following message:

* * * MSG: Select EPZ to add to Risk Area. CONTINUE when done

11. Use the cursor to select an orange EPZ polygon it $m$ those displayed on the map. The selected zone is highlighted in white and blinks.

12. Select the Continue command to add the zone to the Risk Area. The zone will highlight, flash once, then redisplay in bold orange. The population data from this zone is then included in the Risk Area.

13. From the Risk Area Analysis menu select the Risk Area Population Summary command. The Output Redirection Menu displays, as shown (unless you have used the Setup command to set a default). See Section 12 for more information.

Dutput Redirection Menu

$\begin{aligned} & 0: \text { ExIT } \\ & 1: \text { Display on screen } \\ & 2: \text { Print on default printer } \\ & 3: \text { Save to an ASCII file } \\ & \text { Choice }(?=\text { Help) }=m\end{aligned}$

14. Type a 1 at the Choice prompt and press the Return key. The Risk Area Population Selection Menu displays, as shown.

Risk Area Population Selection Menu

Risk Area Population Selection Menu
0: ExIT
1: Total Population (Census)
2: Special population summary (Special Population)
3: Special population by EPz (Special Population)
Choice (?=Help) $=>$


15. Select the Total Population option by typing a $I$ at the $==>$ prompt. Press the Return key.

The population summary displays, as shown.

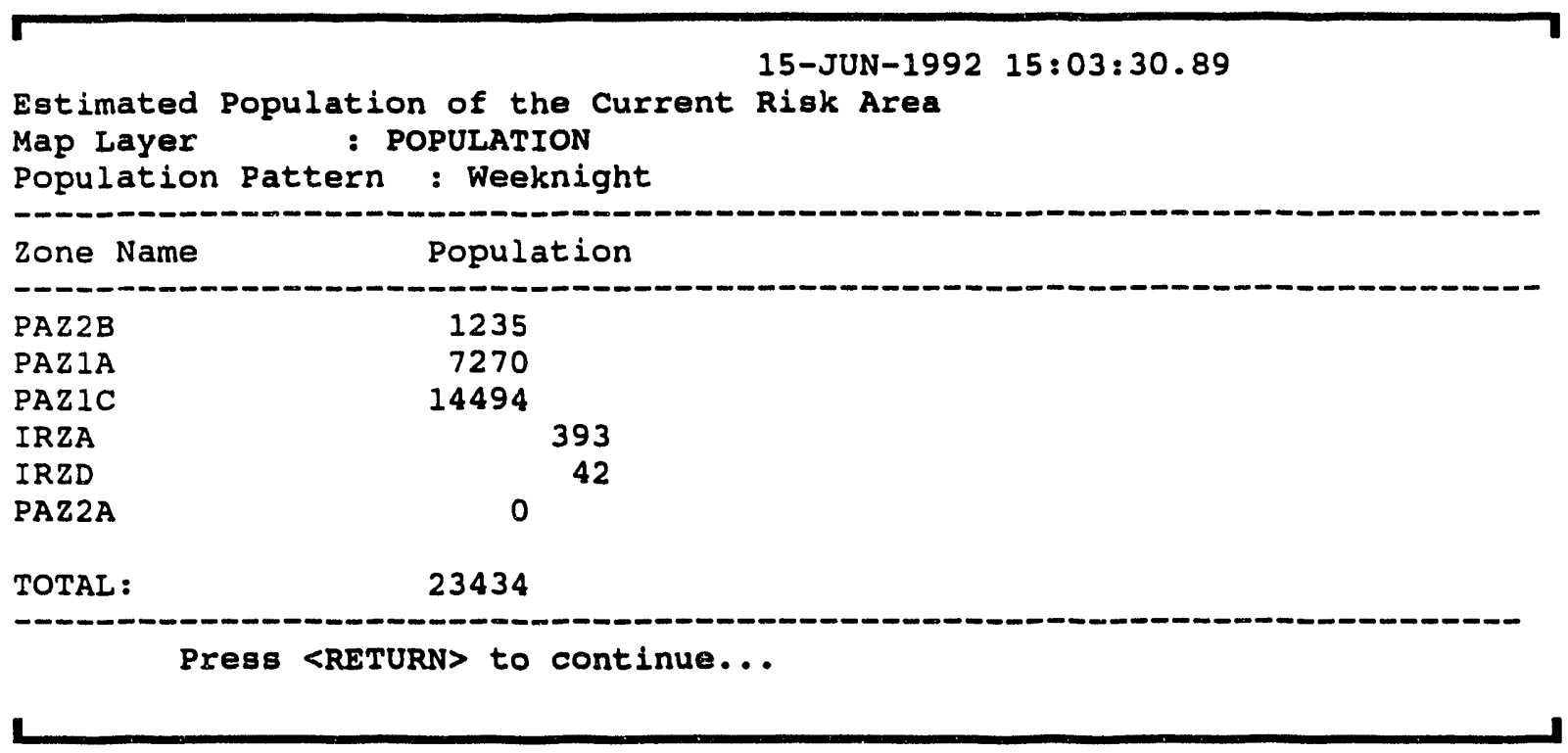

16. Press the Return key to return to the Risk Area Analysis menu.

17. From the top of the Risk Area Analysis menu select the Emergency Activities command. The system displays the following message.

Save Risk Area $[Y] ?=>$

Press the Return key to save the new risk area. The Emergency Activities menu displays.

18. From the Emergency Activities menu select the Sheltering command. The Sheltering menu displays.

19. From the Sheltering menu select the Shelter or Center Info command.

Note: In some cases, you will have a better view of facility icons if you first use the zoom in function on an area of interest. If you are in an extreme zoom out view, the icons may be so crowded together that the map display is difficult to interpret. 
The Shelter or Center Info command will highlight in blinking green. If you do not have a default Selection method (see Section 12 for details on defaults), the system displays the Facility Selection method menu.

Facility selection method menu
$0:$ ExIT
$1:$ Type in Facility name
$2:$ Select Facility name from a list
3 : Type in long/lat coordinates
$4:$ Use mouse to select Facility
Choice $(?=H e l p)==>$

20. At the Choice prompt, type a 4 and press the Return key. The system displays the following prompt.

Draw facilities onscreen? [Y] ==>

Press the Return key. The system draws the facility icons and displays the following message:

* * * MSG: Select a Facility w/mouse

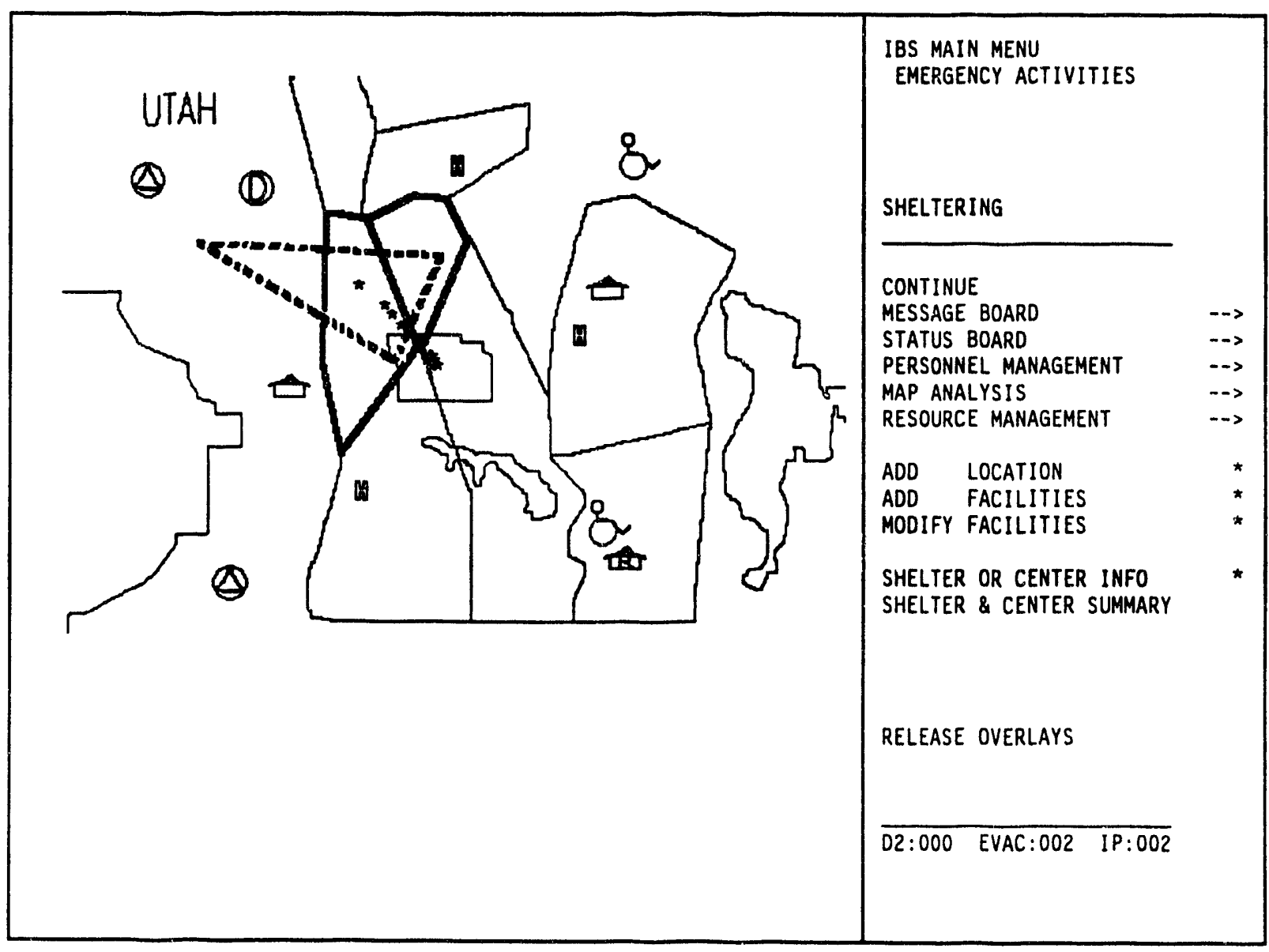


21. Use the cross hairs to select a shelter facility icon and press the Space bar. The system displays a full screen text Facility Form, as shown in the following example.

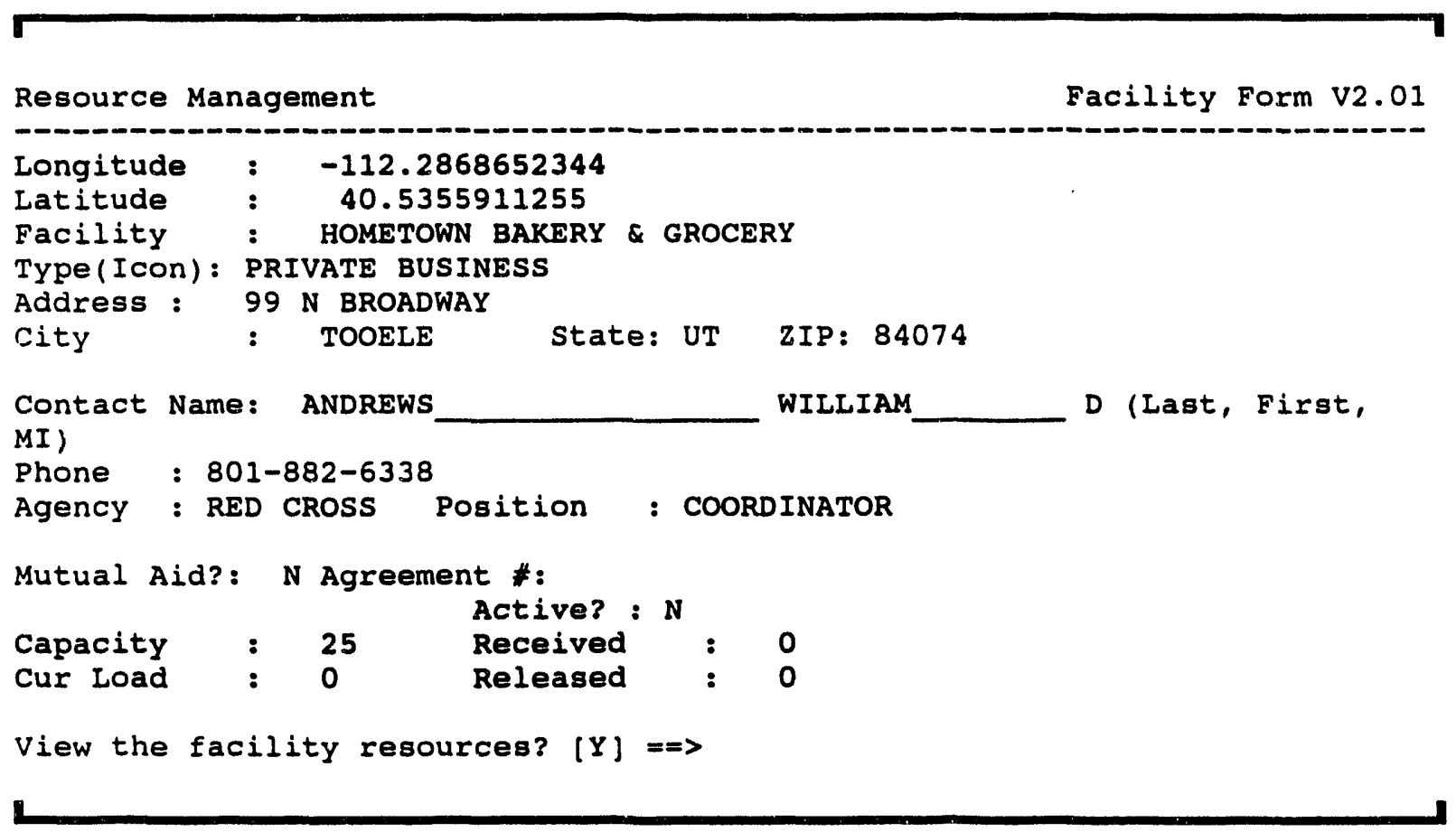

22. Press the Return key to answer yes to the View the facility resources? prompt. A Facility Resource report will display following the Facility Form, as shown. 


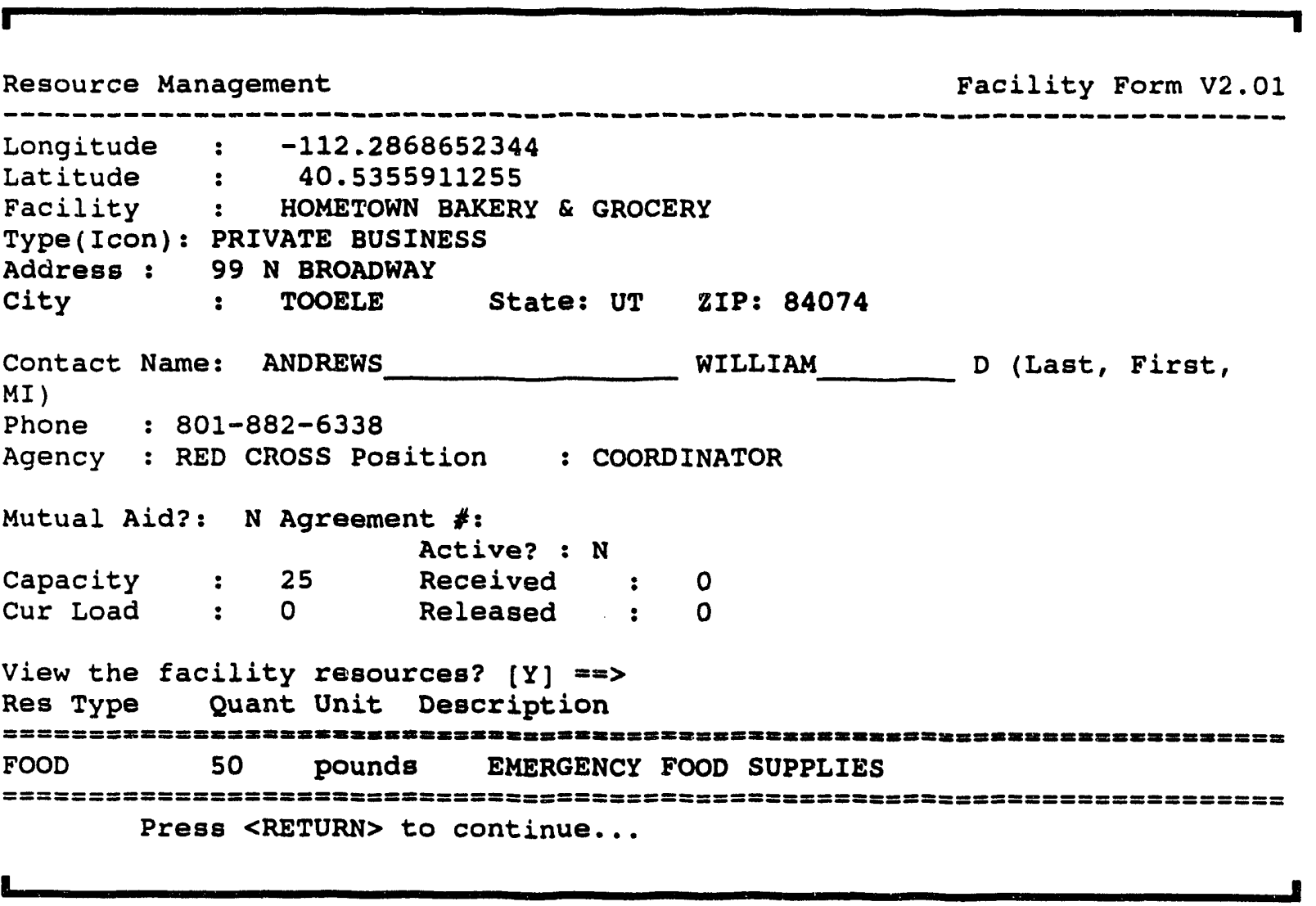

Press the Return key to return to the Facility Selection method menu. You can repeat the preceding procedures to view more facility information, or you can exit.

23. To exit, select 0 : EXIT and press the Return key. The Sheltering Menu displays.

24. From the top of the Sheltering menu select the IBS Main Menu command. The IBS Main Menu displays.

25. From the IBS Main Menu, select the Exit IBS command to return to the system prompt. 


\section{Section 2 \\ Message Board}

\section{MESSAGE BOARD}

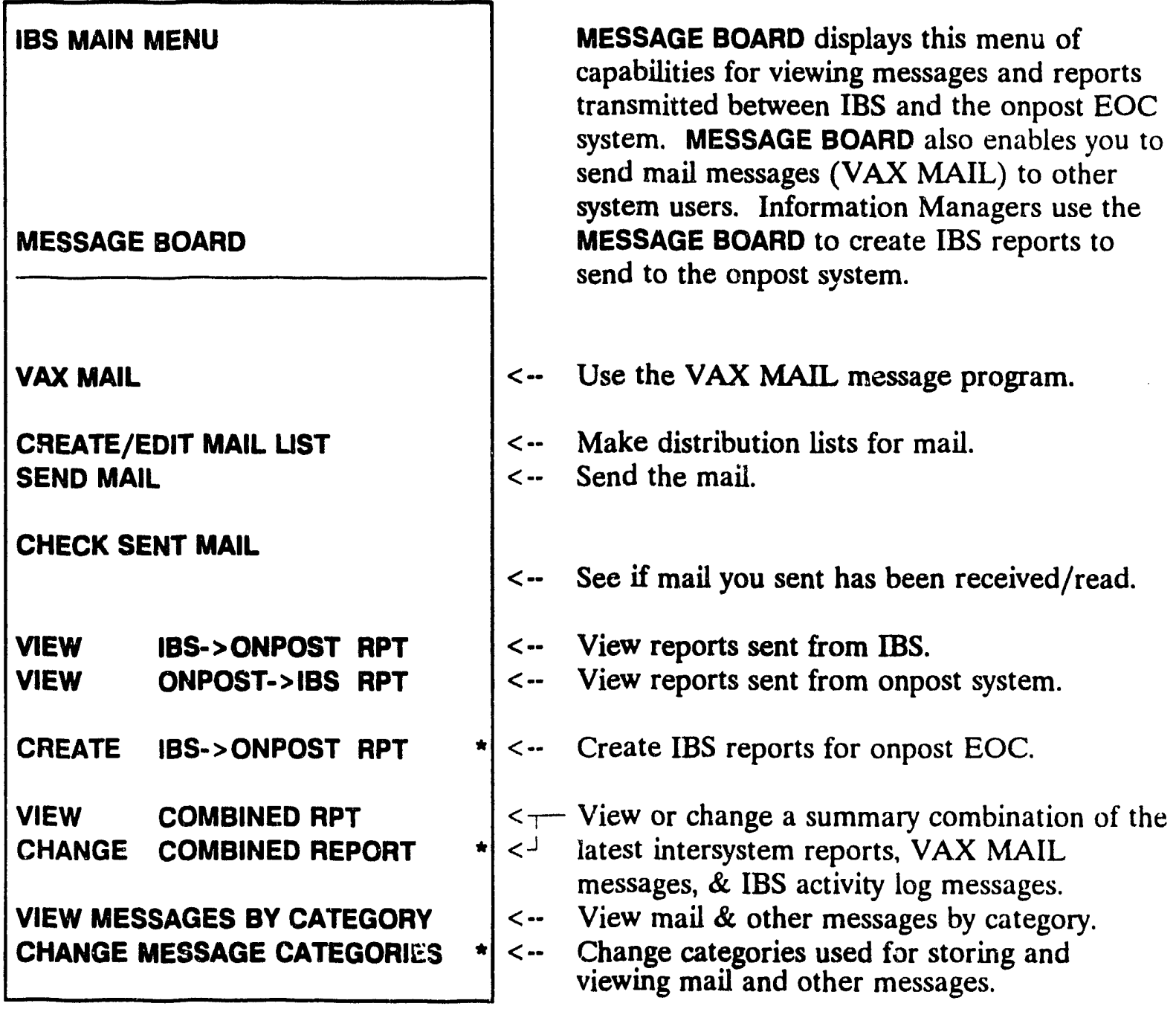

The MESSAGE BOARD option occurs on most IBS menus, so you can view messages at any time without returning to the IBS main menu. The MESSAGE BOARD capabilities in this section are described in alphabetical order. 


\section{Onpost Emergency Event Notification}

If an event occurs onpost, you will immediately see an Onpost Emergency Event Notification. (See Section 3, Status Board, ONPOST EVENT STATUS for a depiction of the information on this screen.) If you are using IBS, just press RETURN to remove the notification message and continue with whatever you were doing. Event notifications and other reports from the onpost system can be reviewed by using VEW ONPOST->IBS RPT.

\section{Exchange of Map Graphic Information}

All graphic map overlays exchanged between IBS and the onpost system are passed as ASCII files using the "optional" Digital Line Graphics (DLG) data format (as defined in the US GeoDatu Users Guide 2). Conversions to and from IBS's normal Digital Mapping Structure (DMS) format is accomplished without special user interactions for normal IBS inputs and products.

\section{Mail Checker}

An automatic program called Mail Checker runs on the VAX without user intervention. Once every minute the program will check all user mail files. If you get new mail, or if your mail arriv's late, the program will display a message across the bottom of the IBS graphic menu. For example, if you have new mail, the system will display the message:

NEW MAIL

\section{CHANGE COMBINED REPORT}

This option enables you to view the most recent messages recorded in the following locations and to generate a COMBINED REPORT file:

- VAX MAIl messages (a collection of important messages)

- the IBS event $\log$ (reports from IBS to the onpost system)

- the onpast event $\log$ (reports from the onpost system to IBS)

- the IBS activity log (resource management activities, Event

Management Plan selection, updates to the people locate database, etc.) 
Extraction of information from these sources is largely automatic: when you select CHANGE COMBINED REPORT, the system displays a menu similar to the following.

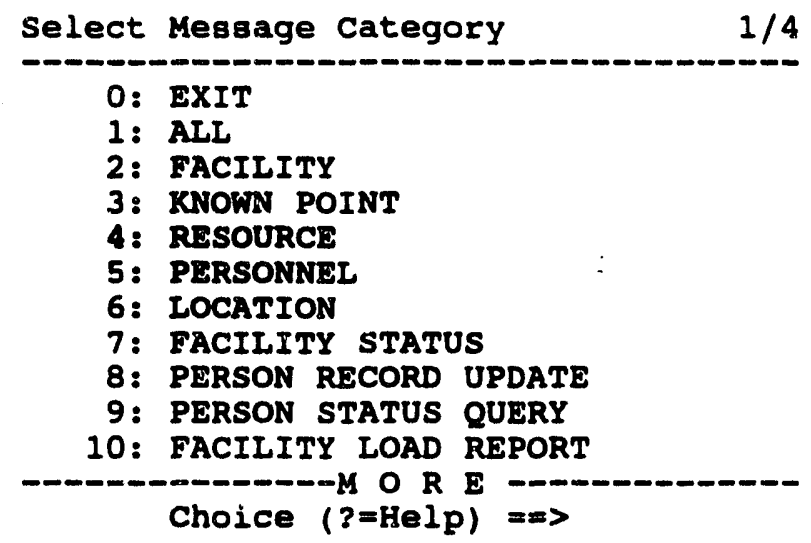

Select a cacegory and press the Return key.

The system then displays the following Report Selection Method menu.

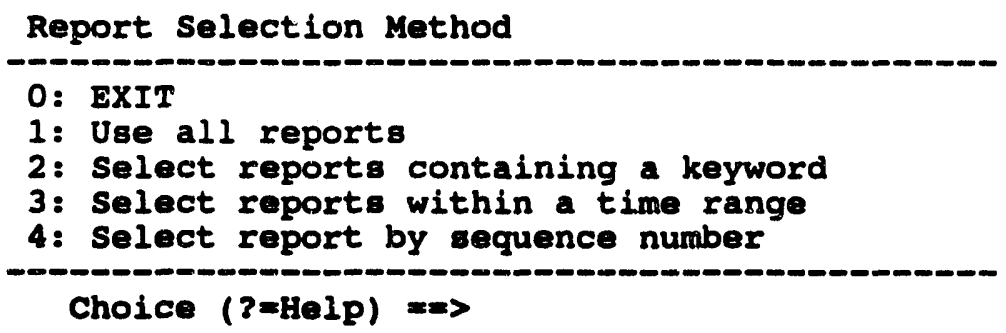

If you select items 2,3 , or 4 , the system will display additional prompts which will enable you to enter a keyword, time range or sequence number.

IBS takes a moment to assemble the information and then displays up to 500 lines of messages, one screen at a time. The messages start with the most recent messages (regardless of the source) and continue in reverse chronological order. Any messages which are new (have not previously been printed) are routed to the system printer. 


\section{Preparing the VAX MAIL Messages}

The preceding VAX MAIL messages are ones that have been sent to Message Control and extracted. Currently, this is accomplished by a procedure such as the following:
Aaent
Activity
Result
Information
Enter the system command:
Manager
set folder [foldername] (usually the folder
name is mail)
Sets the default to the mail folder
Information Periodically enter the following
MAIL command:
or MAIL
Monitor
EXTRACT/AII OFF\$DIR: IMPMAIL.LOG
Puts all the mail Manager messages into the specific file where they can be extracted by CHANGE COMBINED REPORT.

You can also use the plain extract command to extract just the current mail messages to the log file, or you can use the extract/append command to append any current messages onto the log file.

See the VAX MAIL manual for full instructions on all commands and options available to VAX MAIL users.

General users can select VIEW COMBINED RPT to obtain the latest complete log on their screen. It is displayed in read-only mode, but can be scrolled.

\section{CHANGE MESSAGE CATEGORIES *}

VAX MAIL messages and some automatically logged reports are stored and categorized so that they can be viewed later with the VIEW MESSAGES BY CATEGORY option. If you are an Information Manager, you can use the CHANGE MESSAGE CATEGORIES option to specify a list of categories, and whether all messages of a category are reported or only the most recent message.

When you select CHANGE MESSAGE CATEgories, IBS starts the system text editor and enables you to edit a special file, (IEMIS\$SYSFILES:EVENT_SUBJECTS.DAT) that contains the information about each subject category. For example, if the VAX EDT text editor is used, the screen clears and presents the EDT editor's command line prompt, an asterisk $\left({ }^{*}\right)$.

To begin editing: type $c$ and press RETURN. The text of the message category file is then shown on the screen. The following text is an example (default) file, which you may edit to tailor the reporting requirements. 
Note: Message categories are limited to 25 characters, as shown. Do not use tabs when editing, use spaces. Do not change the coluinn location of the (L) or (A) fields.

\begin{tabular}{|c|c|}
\hline MESSAGE CATEGORY & (L)AST or (A)LL \\
\hline ALL & A \\
\hline FACILITY & A \\
\hline KNOWN POINT & A \\
\hline RESOURCE & A \\
\hline PERSONNEL & A \\
\hline LOCATION & A \\
\hline FACILITY STATUS & A \\
\hline PERSON RECORD UPDATE & A \\
\hline PERSON STATUS QUERY & A \\
\hline FACILITY LAND REPORT & A \\
\hline PROTECTIVE ACTION ORDER & A \\
\hline EVACUATION ORDER & A \\
\hline SHELTER AREA REPORT & A \\
\hline SHELTERING SUMMARY & A \\
\hline OFFPOST CASUALTY SUMALARY & A \\
\hline RECEPTION CTR SUMMLARY & A \\
\hline RECEPTION CTR DIRECTORY & A \\
\hline EVAC ROUTE ANNOUNCEMENT & A \\
\hline $\begin{array}{l}\text { INCOMING MILITARY ROUTES } \\
\text { EVACUATION ROUTE TABLE }\end{array}$ & $\begin{array}{l}\text { A } \\
\text { A }\end{array}$ \\
\hline ECORDINATE CODE TABLE & A \\
\hline POLYGON CODE TABLE & A \\
\hline D2LOG & A \\
\hline DOSAGE & A \\
\hline PDATA & A \\
\hline SLICE & $\ddot{A}$ \\
\hline WEATHER OBS & A \\
\hline CURRENT-RUN & A \\
\hline ENVIRONMENT & $\ddot{A}$ \\
\hline NOTIFICATION & A \\
\hline CAS_SUM & A \\
\hline TOWER_SEL & A \\
\hline ERROR̄̄ ??????? EVENT & A \\
\hline $\begin{array}{l}\text { OTHER } \\
\text { BMB CAT }\end{array}$ & $\begin{array}{l}\mathbf{A} \\
\mathbf{A}\end{array}$ \\
\hline
\end{tabular}

To quit editing, press CTRL-Z. The asterisk prompt will reappear. Then:

- To save the new edited file: type EXIT and press RETURN.

- To cancel without saving any changes: type QUIT and press RETURN. 


\section{CHECK SENT MAIL}

This option enables you to check the list of unread messages you sent to a specific user. By doing this you can find out if a particular message has been received and read.

The following menu displays.

MAII LIST CRITERIA
0: EXIT
1: Mail distribution by USERNAME
2: Mail distribution by NAME
3: Mail distribution by TITLE
4: Mail distribution by POSITION
Choice (?=Help) mm

If you select option 2, Mail distribution by NAME, the following menu will display.

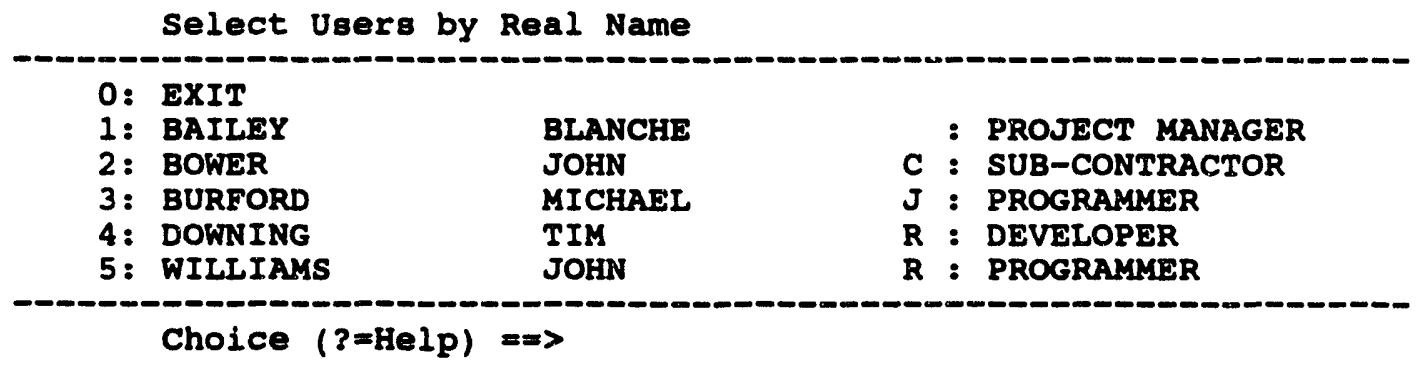

Select the user you want by typing the number corresponding with the name. Press the Return key. $A=>$ will display by the selected name. Continue to select names from the list until you have selected all the users you want. To see if the selected users have read the mail sent by you, select the 0: EXIT option and press the Return key. The system will display messages similar to the following for each user you selected. In this example the user had read all the mail.

Listing unread mail messages for COLLEEN WINTERS...

All messages you sent have been read.

Pregs <RETURN> to continue...

Check more users? [N] $=\Rightarrow$

If you want to check more users, type a $Y$ (yes) at the prompt and press the Return key. The Mail List Criteria menu will redisplay. 


\section{CREATE/EDIT MAIL LIST}

This option enables you to

- Create a new mail distribution list

- Change an existing list

After you select Create/Edit Mail List, the following menu displays.

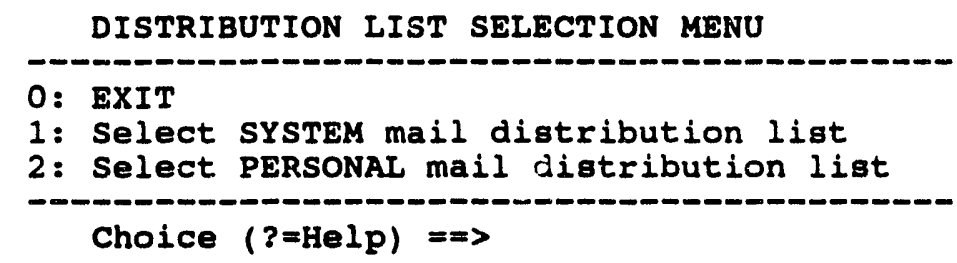

Select the type of mail distribution list you want to work with: System, or Personal.

Option 1, Select SYSTEM mail distribution list, will enable you to edit one of the System mail distribution lists. A copy of the System Mail list you select will be placed in your own directory and will reflect any changes you make. You can not change the master System mail distribution list.

Option 2, Select PERSONAL mail distribution list, will enable you to edit an existing distribution list in your directory, or to create a new distribution list which will be placed in your directory.

After you select either of the two options, the following menu will display.

Select Distribution List
0: EXIT
1: Create New Mail Distribution List
2: FIRE DEPT
3: POLICE
4: RED_CROSS
Choice $(?=\mathrm{Help})=\mathrm{P}$

Note: Option 1, Create New Mail Distribution List will not display if you selected the SYSTEM mail distribution list option from the preceding menu. 
You can select an existing distribution list to edit from the menu, or select option 1, Create New Mail Distribution List to create a new list. Press the Return key. The following prompt will display.

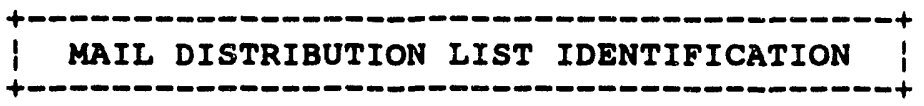

Please input new mail distribution filename:

At the prompt, type the name of the distribution list you want to create and piess the Return key.

The following menu will display once you have selected a distribution list to edit, or entered the name of a new distribution list.

MAII LIST CRITERIA
0: EXIT
1: Mail distribution by USERNAME
2: Mail distribution by NAME
3: Mail distribution by TITLE
4: Mail distribution by POSITION
Choice (?=Help) =m

Options 1, 2, and 3 each enable you to select people from a menu. These menus will display people listed by:

\section{- System username}

\section{- Real name}

- Title

After you select any of the above options $(1,2$, or 3$)$ a menu similar to the following will display.

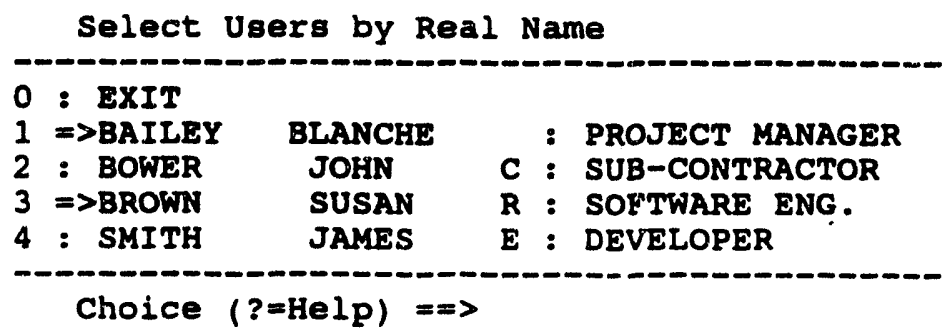

This menu and the similar menus for username or title enable you to make several selections at a time. When a person is selected, $a=>$ appears in place of the : symbol in the list. In the above example, both Blanche Bailey and Susan Brown have been selected. To deselect an item from the menu, select it again and the $=>$ symbol will be removed. 
If you are creating a new distribution list, the above menu will display with no people preselected. If you are editing an existing list, the people on the list will display preselected on the menu. You can then select or deselect people to add or delete them from the list.

When you have selected all the people you want to add to your list, select option 0 : EXIT.

Option 4, Mail distribution by POSITION will display the same menu shown in Personnel Management, List People by Position. From this menu you can select one or more positions. Any personnel in the personnel database with the selected position and an account on the system will display on a menu list similar to the example shown above. This list will be sorted by real name. You can then select the people you want to add to your distribution list.

Note: $\quad$ For this method to work, the name of the person must appear exactly the same in both the personnel database and Systein mail lists (see UPDATE_MAIL_LIST in the IBS Utilities Guide).

When using the VAX MAIL message capability, you can address messages to distribution lists as well as individual addressees. Contact your system manager for the names of distribution lists that have already been set up on your system. 


\section{CREATE IBS-> ONPOST RPT*}

\author{
IBS MAIN MENU \\ MESSAGE BOARD
}

CREATE IBS-> ONPOST RPT

PROTECTIVE ACTION ORDER

EVACUATION ORDER

SHELTER AREA REPORT

TRAFFIC CONTROL REPORT

SHELTERING SUMMARY

OFFPOST CASUALTY SUMMARY

RECEPTION CTR SUMMARY

RECEPTION CTR DIRECTORY

EVAC ROUTE ANNOUNCEMENT

INCOMING MILITARY ROUTES

EVACUATION ROUTE TABLE

COORDINATE CODE TABLE

POLYGON CODE TABLE

SET IBS ONPOST HEADER
This option displays the menu shown here for creating reports (messages) transmitted from IBS to the onpost computer system.

Each menu item corresponds to one type of report. Information Managers can use the menu to select which types of reports are generated and sent to the onpost system.

After one type of report is selected, IBS displays one or more screen forms for your information input and approval. After your approval, that report is generated, logged in the IBS event log, and copied to the onpost system.

The specific report formats are shown in Appendix E.

- SET IBS ONPOST HEADER Enables you to set the report header that identifies the created report as an exercise, a test, or a real report.

After you select this option, the following menu displays.

HEADER MODE OPTIONS
$0:$ EXIt
$1:$ EXER
$3:$ TEST
Choice $(?=\mathrm{Help})==\mathrm{S}$


Enter the number of the header option you want. The following menu cisplays.

\begin{tabular}{l} 
HEADER DEPOT Options \\
\hline $0:$ EXIT \\
$1:$ ANAD \\
$2:$ APG \\
$3:$ LBAD \\
$4:$ NAAP \\
$5:$ PBA \\
$6:$ PUDA \\
$7:$ TEAD \\
$8:$ UMDA \\
\hline Choice $($ ?=Help) $==>$
\end{tabular}

Enter the number of the depot option you want. The following prompt displays.

Enter description $==>$

Enter any description you want (up to 70 characters). The mode, depot, and description are combined to form the first record of all reports sent to the post. 


\section{Exiting from the Data Input Forms}

Exiting from a form is handled similarly for all report formats:

- Exiting normally (with approval): If you press RETURN in the last field of the form (or GOLD $\mathrm{Z}$ in any field), you can approve the report for transmittal:

Send report to onpost? $(Y / N /\langle C t r 1-z\rangle=A b o r t) \Rightarrow$

- $\quad$ : If you approve transmittal, the system prompts you for:

Onpost computer name

Onpost user name

Onpost password

After you respond to these prompts, the report is generated, logged, and sent to the onpost system. IBS then returns to the CREATE IBS$>$ ONPOST RPT menu and displays a confirming message that the report was generated and sent.

Note: The system will not send you an error message if the report is not sent, for example, if you mistyped a password.

If the report being sent has a graphic file or files attached to it, the system will prompt you in a similar fashion for each graphic file. Confirming messages will display as each graphic file is sent.

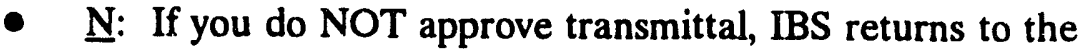
CREATE IBS-> ONPOST RPT menu and displays a message indicating the report was NOT generated.

- Cancelling directly (without approval): If you press GOLD Y, the report is NOT sent, no prompt appears, and IBS returns to the CREATE IBS$>$ ONPOST RPT menu with a message confirming the report was NOT generated. 


\section{SEND MAIL}

This option enables you to send a mail message to the mail distribution list created by CREATE/EDIT MAIL LIST, or to a selection of users. The following menu will display:

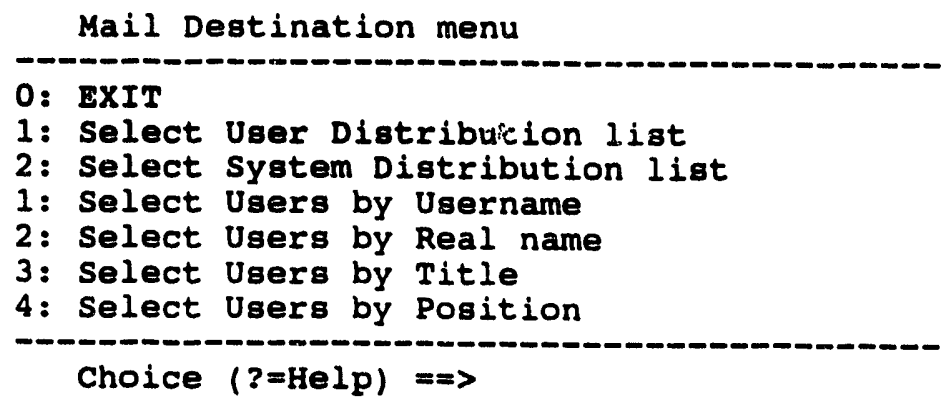

Options 1 and 2 will display a menu of the available distribution lists similar to those shown under the CREATE/EDIT MAIL UST command in this section. Select a distribution list from the menu and press the Return key. Mail will be sent to all users appearing on the selected distribution list.

Options 3, 4, 5, and 6 enable you to select a set of users to which you can send mail. The selection process is the same as that described under the CREATE/EDIT MAIL LIST command. Mail will be sent to all users selected on the menu lists.

After you have selected the mail recipients, the following menu displays:

MAIL FILE SELECTION MENU

\begin{tabular}{l}
\hline 0 EXit \\
$1:$ CREATE NEW FILE to send \\
$2:$ ENTER FILENAME to send \\
\hline Option $(?=$ Help) $==>$
\end{tabular}

1. CREATE NEW FILE to send - enables you to create a new file using the VAX EDT editor. 
2. ENTER FILENAME to send - enables you to send an already existing file, which may be edited before sending.

After you have created a new file or identified an edited and existing file, this form requests that you enter the following information:

MAIL SUBJECT FORM

Subject :

Priority: -

Expiration time (optional)

Hours: -1 Minutes: -1

- Subject: Enter a subject or title for the message. (If you wish this message to be listed within one of the IBS message categories, enter the category name as part of the subject line. See VIEW MESSAGES BY CATEGORY for a list of category names.

- Priority: Enter one character to indicate message priority. (This can be any character: message priority levels have not yet been established.)

- Expiration time ( 0 to 16 hours; -1 cancels the feature): To set an alarm that tells the message recipient the content of a message is about to become obsolete, enter a number of hours and minutes as the expiration time. When that time expires the message " $\star \star$ LATE MAIL $\star \star "$ displays at the bottom of the menu area. After the recipient reads the mail, the message disappears.

- To show the expiration message immediately: enter zeros for both the hours and minutes.

- To cancel any expiration message: enter the default values $(-1)$ for both the hours and the minutes.

After you complete this form, the message is sent, and the screen returns to the MESSAGE BOARD menu. 


\section{VAX MAIL}

When you select VAX MAIL, the system starts the electronic mail program, VAX MAIL, which operates as explained in the documentation supplied by Digital Equipment Corporation. You will see the following MAIL prompt where you can enter MAIL commands:

\section{MAIL>}

To exit from mail, enter the command QUIT or EXIT, returning the screen to the MESSAGE BOARD menu.

Frequently Used Commands. In getting started, you will probably use these commands most frequently:

- HELP

Show MAIL commands and information on how to use MAIL.

- HELP command Show information about a specific MAIL command.

- SEND

Compose and send a message to one or more people.

- READ

Display the next available message (or page of the message).

- READ/NEW Display the next new message (not previously read).

- DIRECTORY List your messages.

- DELETE Delete the current message.

- EXIT Exit from the MAIL utility.

- QUIT Leave the MAIL utility and cancel any message deletions.

One-Time Setup Commands. Use the HELP command to find out more about the following commands, which you can use to set up some convenient MAIL features.

- SET PERSONNEL_NAME name Specify the "From:" name or title in your messages.

- SET COPY_SELF

- SET CC_PROMPT
Send yourself a copy of any message that you REPLY to, SEND, or FORWARD.

Set up MAIL to prompt for the names of people to be sent "carbon copies" of the message (in addition to the "To:" addressee). 
You may address messages to distribution lists, as well as to individual addressees. You may create distribution lists or use lists that have already been set up on your system. See CREATE/EDIT MAIL LIST.

\section{VIEW COMBINED RPT}

This option enables you to view the most recent messages recorded in the COMBINED REPORT file. The complete log appears as scrollable, read-only infori. ation. (See CHANGE COMBINED REPORT.)

\section{VIEW MESSAGES BY CATEGORY}

This option enables you to display or print messages and reports that are listed within certain predefined event subjects or categories. Each category is a potential subject area for messages sent by VAX MAIL and messages automatically logged by the system.

After first selecting a category of messages, you may then further restrict the choice of messages within that category by key words, time ranges, or sequence numbers within a specific message journal.

\section{Select a Message Category}

You will first see a menu that contains a list of message categories. (The Information Manager can modify the categories shown on this menu by using the CHANGE MESSAGE CATEgories option)

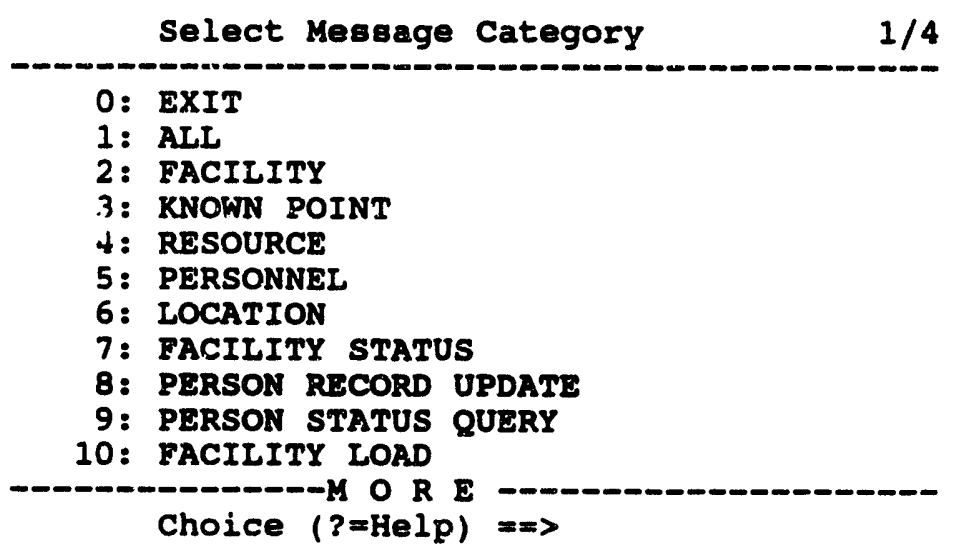

Type the number that corresponds to the desired category.

- The "Other" category contains only messages that have been designated as "Other" (for example, as the subject of a mail message).

- The "ALL" category contains all messages and reports, including those not contained in the listed categories. 
Note: Use the ALL category when you want to specify the desired message by sequence number (see Step 2 below.)

\section{Specify Criteria for Restricting Message Selection}

After selecting the message category, use the following menu to select messages that meet special criteria within the selected category:

1) Use all reports

2) Select reports containing a key word

3) Select reports within a time range

4) Select report by sequence \#

Enter choice >

The following table shows how you can either view all reports in the selected category or specify criteria for restricting the selection of messages.

Table 2.1. Criteria for Restricting Message/Report Selection

Your Response Selection of Reports

1) All reports

All reports of the chosen type are selected, from the most

2) Key word recent to the earliest.

Enter key word >

Enter any string of characters (up to 40 characters). The string may include blanks and is sensitive to upper- and lower-case lettering. All messages containing exactly those characters are selected, from the most recent to the earliest.

3) Time range

Choose the time of creation or time of recording:

1) Select based on date/time range when records were entered or

2) Select based on date/time range of recorded actions

Enter choice >

Then, specify the time range itself:

Enter begin date $(\mathrm{mm} / \mathrm{dd} / \mathrm{yy})>$
Enter begin time $(\mathrm{hh}: \mathrm{mm})$
Enter end date $(\mathrm{mm} / \mathrm{dd} / \mathrm{yy})>$
Enter end time $(\mathrm{hh}: \mathrm{mm})>$

All messages within that time range are selected, from the most recent to the earliest. 
Your Response

4) Sequence \#
Selection of Reports

Select the journal you want to check:

1) IBS Event Journal

2) IBS Activity Journal

3) Post Event Journal

Enter Journal ID $(1,2$, or 3) >

This "journal"

IBS Event Journal

IBS Activity Journal

Post Event Journal
Contains these messag:

IBS reports to onpost EUC

Miscellaneous updates to

IBS database

Onpost EOC reports to IBS

Then specify the sequence number within that journal:

Enter sequence $*>$

The message or report matching that sequence number is selected.

\section{View the Selected Messages}

After a few moments to load the message journal (and to search for messages that meet any criteria specified in Step 2), the IBS displays the selected messages on your screen.

- To scroll through the messages: use the UP and DOWN arrow keys.

- To quit and return to the MESSAGE BOARD menu: press GOLD Z or GOLD Y.

Note: Because some mail messages may contain an embedded end of file marker, it is necessary to substitute another character for this marker. You may see a message indicating that such substitutions have been made. 


\section{VIEW IBS-> ONPOST RPT}

\section{IBS MAIN MENU \\ MESSAGE BOARD}

VIEW IBS->ONPOST RPT

PROTECTIVE ACTION ORDER

EVACUATION ORDER

SHELTER AREA REPORT

TRAFFIC CONTROL REPORT

SHELTERING SUMMARY

OFFPOST CASUALTY SUMMARY

RECEPTION CTR SUMMARY

RECEPTION CTR DIRECTORY

EVAC ROUTE ANNOUNCEMENT

INCOMING MILTARY ROUTES

EVACUATION ROUTE TABLE

COORDINATE CODE TABLE

POLYGON CODE TABLE
VIEW IBS->ONPOST RPT displays this menu for reviewing reports (messages) that have been transmitted from IBS to the onpost system. Each menu item corresponds to one type of report. The actual contents of each type of report are described in Appendix E.

After selecting a report type, you may restrict the instances of those reports to reporis that contain a key word, reports that apply to a certain time range, or reports that have a specific sequence number.

In the final step, you can specify how the reports are output: displayed on the screen or sent to a printer.

To view IBS reports:

1. Select one of the report types listed on the menu.

2. Use the following menu to specify which specific instances of the selected report type are desired:

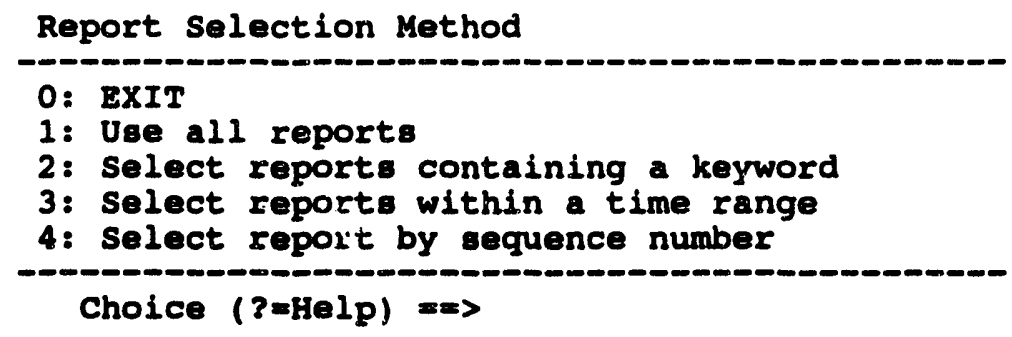

Table 2.1 shows how to use these options to select reports by key word, time range, or sequence number.

The reports selected in Steps 1 and 2 are then sent to the specified output device. If you have not selected a default output device such as a printer or the screen, an output selection menu displays. To set up a default output device, see Section 12. 


\section{IBS MAIN MENU \\ MESSAGE BOARD}

VIEW ONPOST->IBS RPT

D2LOG

DOSAGE

PDATA

SLICE

WEATHER OBSERYATIONS

CURRENT RUN

ENVIRONMENTAL REPORT

NOTIFICATION

ONPOST CASUALTY REPOAT

TOWER SELECTION
VIEW ONPOST->IBS RPT displays this menu for reviewing reports (messages) that have been transmitted from the onpost system to IBS. Each menu item corresponds to one type of report. The formats for reports from the onpost system are shown in : ppendix $E$.

After selecting a type of report, you have an opportunity to restrict the instances of those reports to reports that contain a key word, reports that apply to a certain time range, or reports that have a specific sequence number. (This occurs as described for VIEW IBS-> ONPOST RPT on the previous page.)

In the final step, you can specify how the report(s) are output: displayed on the screen, sent to a printer, or saved as a printable ASCII file. 


\section{Section 3 \\ Status Board}

ISTATUS BOARD

IBS MAIN MENU

STATUS BOARD

ONPOST EVENT STATUS

VIEW

CHANGE

ONPOST WORK PLAN ONPOST WORK PLAN *

IMPLEMENTING PROCEDURES

CREATE NEW IP

CHECK-OUT IP

CHECK-IN IP

ARCHIVE IP OPTIONS

VIEW BATCH LOG

SHOW USER ENVIRONMENT
The STATUS BOARD option on the IBS main menu is used to view the onpost event status report and access the Implementing Procedures (IPs). The IPs are an automated aid to the planning and tracking of emergency function tasks and task actions.

STATUS BOARD is a general option that occurs on many IBS menus.

<-- View current report of onpost event status.

<-- View current report of onpost Work Plan.

<-- View or modify the onpost Work Plan and allow selection of an IP.

<-- View or modify details of the current IP.

<-- Create a new IP for planning work.

<-- Record check-out of IP for planning work.

<-- Record check-in of IP after planning work.

<-- Options to archive, retrieve, or reset IP.

$<-$ View batch log after an event.

Many of the STATUS BOARD capabilities concern the IBS IPs. The following discussion of the IPs and IP operating conditions provides information needed for understanding the use of IPs.

Following this background information on IPs, the STATUS BOARD options in this section are explained in alphabetical order. 


\section{Understanding Implementing Procedures}

In the IBS, an Implementing Procedure is a set of preplanned emergency actions that are designed to cope with one or more chemical release situations or scenarios. The IBS allows emergency managers and planners to create and assemble a set or library of IPs that can be applied in different event situations. The Implementing Procedures supply an automation-assisted means of defining and tracking specific emergency actions that are needed to accomplish the more general objectives of an Emergency Operations Plan (EOP).

Each IP includes time-ordered tasks, which are grouped by Emergency Function. Each task consists of a numbered set of actions and requires certain resources (materials and equipment at certain locations or facilities) to accomplish task goals. A descriptive IP note can be entered for each IP, and three descriptive notes can be entered for each task: one general task note, one action note, and one resource note.

This structure is described in Table 3.1 and illustrated by Figure 3.1.

IP Development Conditions. In general, it is expected that IPs will be developed by planners under planning conditions; this means that a planner would create or modify an IP as a part of the planner's own planning site database. When the IP is ready for general use, the planner copies the IP into the reference database for the local site.

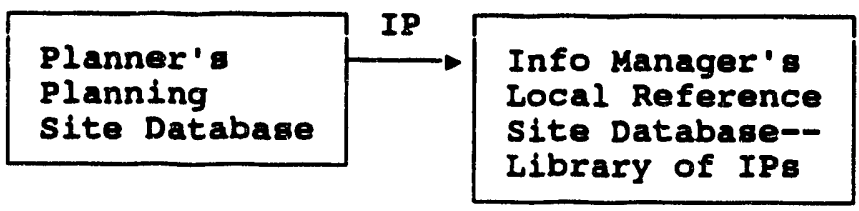

TABLE 3.1. Descriptions of IP Structures and Components

IP Structure

\section{Implementing Procedure} (+ Note)

\section{Emergency Functions}

Tasks

(+ Note)

Actions

(+ Note)

Resource

(+ Note)
Description

Up to 1000 IPs (less than 20 expected) 1 IP Note per IP (up to 99 lines of text)

Up to 36 Emergency Functions

Up to 99 tasks per Emergency Function

1 Task Note per task (up to 99 liktes)

Up to 99 actions per task

1 Action Note per task (up to 99 lines:

Up to 99 resources per task

1 Resource Note per task (up to 99 lines) 


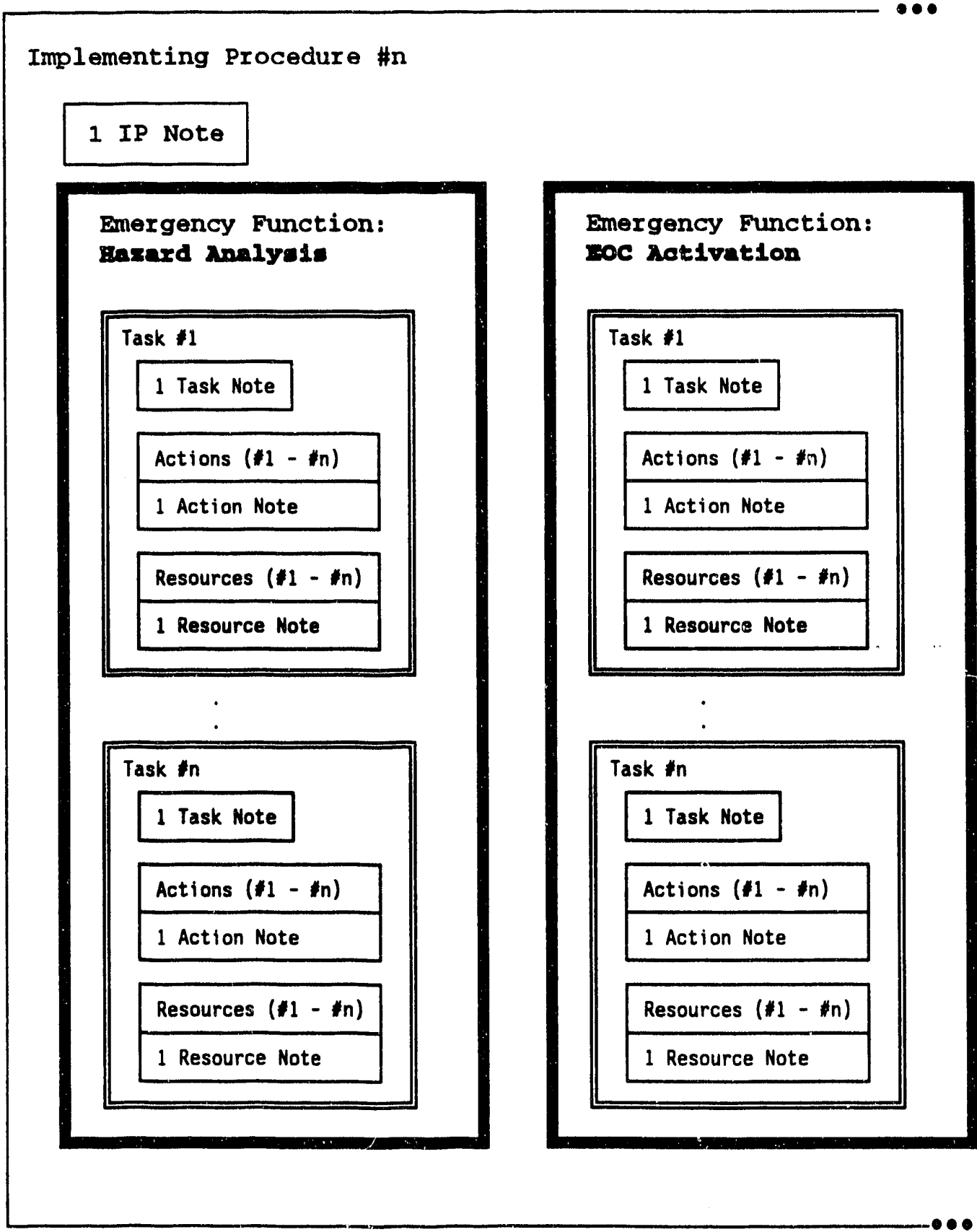

Figure 3.1. Components or an Implementing Procedure

The operation of STATUS BOARD IP options varies, depending on whether the IPs are being used under planning conditions or under other (operational/exercise) conditions. The conditions of operation are denendent on which site database is selected as the current site database. General users usually use the event site database under operational conditions. Planners may own and use other site data sets, changing between site databases by using SETUP-CHANGE SITE (for more 
information, see Section 12). Some IP screens have labels that identify the IP activity as PLANNING, OPERATIONAL, or EXERCISE.

If you are in Operational mode and the selected IP case has been checked out by a planner, a message similar to the following will display.

* * MSG: The selected case has been checked out by a planner. They will be

* * MSG: unable to check in their case while it is aelected as the current

* * MSG: Operational case.

The planner who has checked out this case will not be able to check it back in as long as it is selected as the current Operational IP case. 


\section{ID ARCHIVE IP OPTIONS}

ARCHIVE IP OPTIONS enables users to make an archival copy of the current IP, retrieve this copy at a later time, or reinitialize the current IP.

When you select Archive IP, the system displays the following menu.

IMPLEMENTING PROCEDURES ARCHIVE OPTIONS
O: EXIT
1: Archive Current IP
2: Retrieve Archived IP to Current IP
3: Reinitialize Current IP
Choice $(?=\mathrm{Help})=>$

1. Archive Current IP: (Operational or planning mode) enables you to archive the current IP to a backup file. If you select Option 1, hie following message displays.

This function will archive the current IP for future access. There can only be one archive on any given IP at one time. If you archive this IP, it will replace any previous archived copies of the current IP.

Do you wish to continue? [Y] $=>$

2. Retrieve Archived IP to Current IP: (Operational or planning mode) enables you to retrieve an archived IP and use it in place of the current IP. If you select Option 2, the following message displays.

This function will retrieve $t$. last archived copy of the current IP, and use it to replace the carrent IP. All changes to the current IP since the

last archive will be deleted.

Do you wish to continue? [Y] ==>

3. Reinitialize Current IP: (operational mode only) enables you to reinitialize the current IP. If you select Option 3, the following message displays.

This function reinitializes an IP for operational mode. To do this, it will erase all actual start and done times from the current IP, and

mark all tasks as being NOT dore.

This function should only be used when work with the current IP is complete,

and it is time to reinitialize the IP for a future run. This function will not be performed if one or more users are currently looking at the IP.

Do you wish to continue? [Y] $=\Rightarrow$ 


\section{ID CHANGE ONPOST WORK PLAN * and VIEW ONPOST WORK PLAN}

Both CHANGE ONPOST WORK PLAN and VIEW ONPOST WORK PLAN display information from the current Work Plan as shown in the following screen.

Using VIEW ONPOST WORK PLAN, general users may view the current Work Plan description and exit (GOLD Z).

Using CHANGE ONPOST WORK PLAN, those with Information Manager privileges may view and modify the current work plan description, declare an event, and select an IP based on the current Work Plan.

If you select CHANGE ONPOST WORK PLAN and have the privilege to do so, the following prompt will display before you enter the WORK PLAN form:

Fill in work plan with current run and latest meteorological data? [Y] $==>$

If you answer $\mathbf{N}$ to this prompt, no updates will be made, and the main Work Plan form will display for manual editing. If you answer $Y$ by pressing the Return key; the following menu will display before the WORK PLAN:

Pick Current Run
$0:$ ExIT
$1:$ Use scheduled Current Run Data
$2:$ Select Current Run From List
Choice $(?=$ Help) $==>$

1. Use Scheduled Current Run Data: If you select option 1, the work plan will be filled in with the current run information sent by the post for the current time period. This information includes:

- The chemical agent to be worked with

- The type of munition

- A location

- A one-line description

2. Select Current Run From List: If you select option 2, you can select a current run from a list of current run post data.

Regardless of which option you select, the latest weather information will automatically be filled in. Once this data has been used to update the Work Plan, you will enter the Work Plan form for any manual updating you want to perform. 


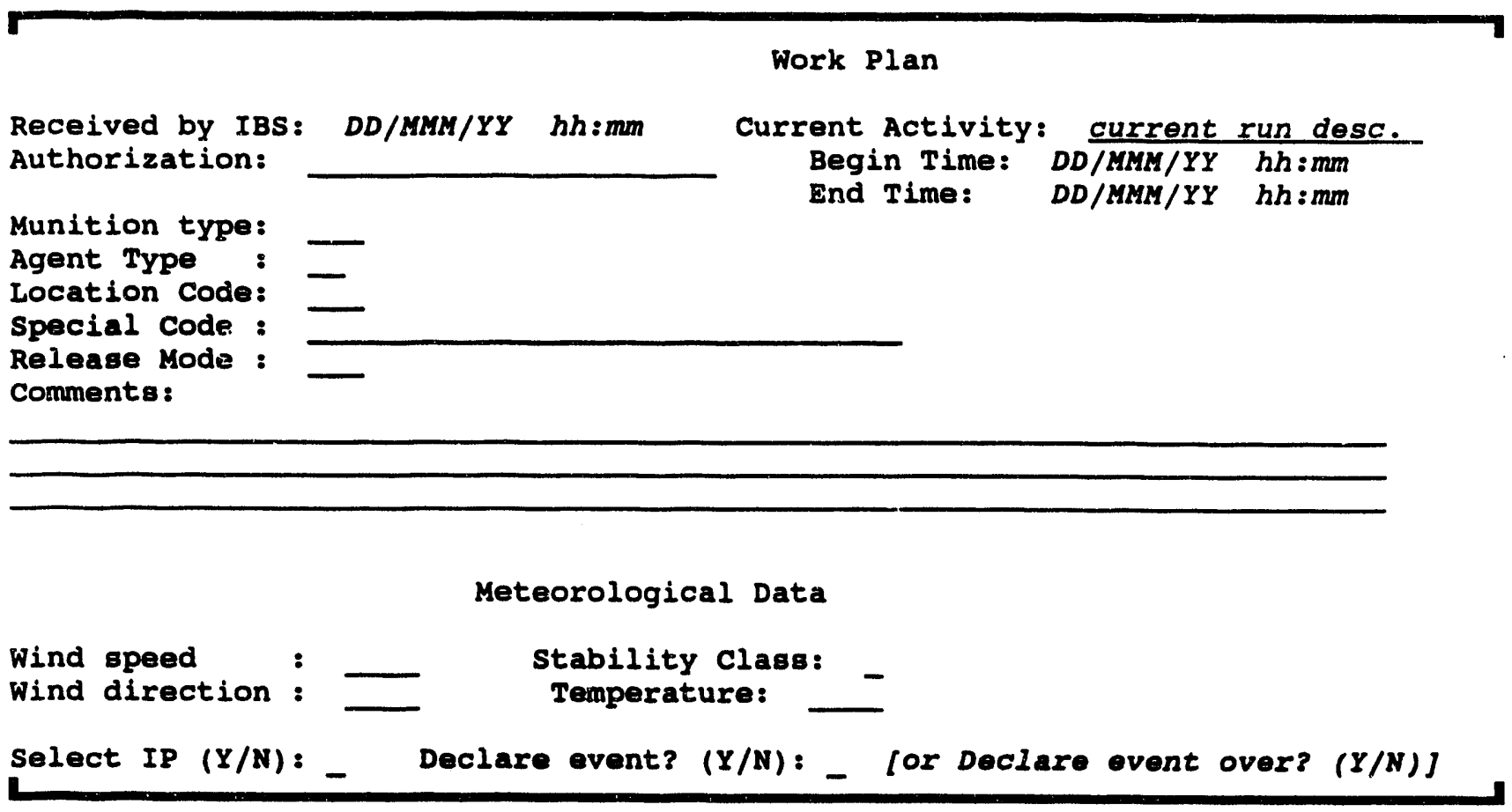

Only those with Information Manager privileges can modify the foll nwing information on the Work Plan screen.

- Work Plan: Information from the onpost current run report or the most recent version of the work plan (edited by the Information Manager) is displayed automatically in the upper part of the screen.

- Meteorological Data: You may enter meteorological data from whatever data sources are available.

- Select IP: If you wish to use the Work Plan data as the basis for selecting an IP, enter $\mathbf{Y}$. A response of $\mathbf{N}$ simply saves the form data for the current Work Plan.

If you choose to select a new IP, you do so by searching for scenarios that closely match the current event situation, based on the current Work Plan. This method is described in detail under STATUS BOARD-IMPLEMENTING PROCEDURE-D) Select New IP. It is expected that you will use this method most frequently to select the IP and the Operational Preparedness IP (OPIP).

An alternative method for selecting the IP based on Emergency Planning Zones (EPZs) is described in Section 11, Emergency Activities, Direction/Control. 
- Declare event?: A Y answer declares an event and notifies IBS users. If an event is already under way, a different inquiry appears: Declare event over?. In that case, a $\mathbf{Y}$ answer declares the event over and notifies IBS users the event is finished. When an event is declared over, the system will display a sequence of messages similar to the following.

The event has been declared over. Following is a list of things you may wish to consider:

1) It is STRONGLY suggested that you archive the operaticil al site by selecting ARCHIVE SITE from the setup menu.

2) If you wish to restore your IP/OPIP to its pre-event status, you should retrieve the previously archived copy. On the other hand, if you wish to incorporate changes made to the IP during the event, you should archive your current IP/OPIP. You may also wish to reset your current IP/OPIP.

3) You should verify that your IP/OPIP, D2 dispersion case, and evacuation case reflect current conditions.

4) You should change the onpost work plan to reflect current conditions.

5) You may wish to delete the people location database and make all shelters inactive by typing DELPTDB at the command line prompt.

6) You may wish to restart the IBS logs by typing RST_Logs at the command line prompt.

Press <RETURN> to continue ... 


\section{ID CHECK - IN IP and CHECK - OUT IP}

The CHECK-IN IP and CHECK-OUT IP options are used by planners who may be updating or refining an IP in the local reference site database (or in another site database).

If you are a planner, CHECK-OUT IP allows you to "check out" an IP from the library of IPs incorporated in the local reference site database (or another site database).

Note: Before checking out an IP with CHECK-OUT IP, make sure your current site is set to an appropriate planning site database. It does not make sense to check out an IP for one site and use it with data from a physically different site.

When you select CHECK-OUT IP, the system displays the following series of prompts

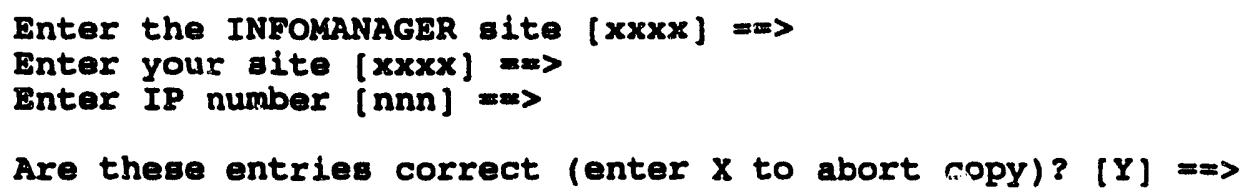

After you specify which IP to use, the system checks to see whether or not the specified IP is already checked out (that is, already assigned to another planner).

- If the IP is already checked out, the system cannot check it out to you until the IP has been checked back in.

- If the IP is available, the system copies the IP and associated records from the scenario table to your current planning site database.

When you check out an IP, the system notes the IP is assigned to you. No one els can check out the same IP until you check it in again.

CHECK-IN IP copies the IP and scenario table records back into the local reference site database while leaving you a copy in your planning database. 
When you select CHECK-IN IP, the system displays the following series of prompts

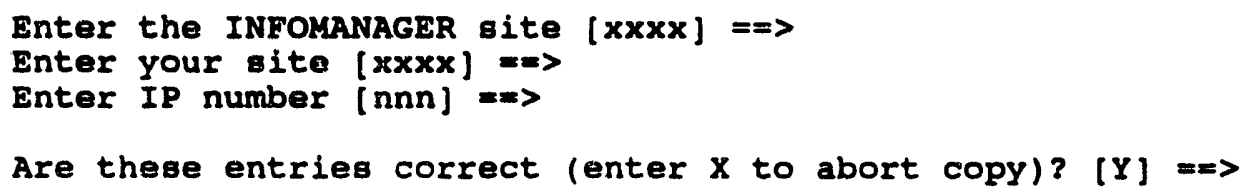

The system then returns you to the Status Board menu, leaving a copy of your modified IP in ynur planning database, as well as in the corresponding INFOMANAG ? site database. The modified IP then becomes available for check-out by planners once again.

Until you change your planning IP, you will still be set to the IP you just ckecked in. If you want to make changes to this IP and then check it in with the same number, you need to check it out again before making the changes. If you want to make changes to your private copy, you can check it in again under a new IP number (see Renumbering an IP). In this way, you can base a new IP on an existing one.

\section{Renumbering an IP}

In some circumstances, you may want to check in an IP from your planning database, and you discover the IP number is checked out to someone else. (This may happen if you create the IP from scratch in your planning site or if you checkin an IP and continue to make changes to the copy in your planning site.) If, for whatever reason, the IP is checked out to someone else, you will get the following message on check-in:

IP case nnn is not checked out to you.

Would you like to renumber your case? $[Y] \Rightarrow$

If you answer $Y$, the software will prompt you to pick a new number. The given IP will then be renumbered and checked into the specified site under the new number. If you answer $\mathrm{N}$, nothing will happen and you will be returned to the STATUS BOARD menu. 


\section{ID CREATE NEW IP *}

The CREATE NEW IP option allows planners to create a new "blank" IP, which can be filled in by using other IBS capabilities for editing IPs. The system displays the following menu.

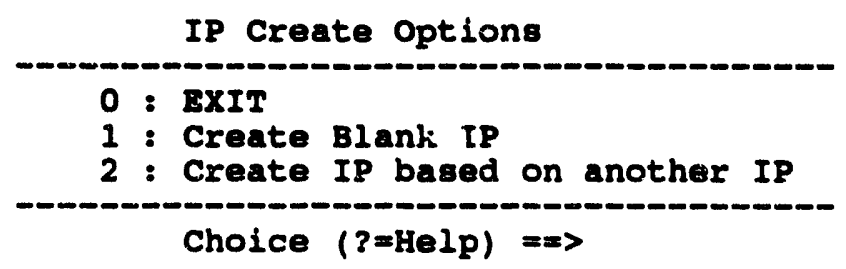

If you select option 1, the system will prompt you to enter a new IP number.

Please enter the IP number you wish to create $=\Rightarrow$

Type a new IP number and press the Return key. If that IP number is not already used in your planning site, the system creates a blank template for the new IP, informs you that the new IP is your current IP, and returns the screen to the STATUS BOARD menu.

If you select option 2, the system will prompt you to select an IP on which to base the new IP from a list.

\begin{tabular}{|c|c|c|c|}
\hline IP & DESCRIPTION & & \\
\hline $\begin{array}{r}1 \\
7 \\
11\end{array}$ & $\begin{array}{l}\text { One line description } \\
\text { One line description } \\
\text { One line description }\end{array}$ & $\begin{array}{l}\text { of OPIP } \\
\text { of OPIP } \\
\text { of OPIP }\end{array}$ & $\begin{array}{l}1 \\
7 \\
11\end{array}$ \\
\hline
\end{tabular}

You can select an IP from the list or press $\langle$ GOLD $><Y>$ to escape IP selection. If the list is too long to fit on one page, you can use the following commands to scroll the through list:

Key Result

D Scrolls Down to the next page of tasks

D* Scrolls Down \# pages

U Scrolls Up to the previous page of tasks

U* Scrolls Up \# pages

T Scrolls to the Top of the list (first page)

B Scrolls to the Bottom of the list (last page)

After you select a base IP, the system will request that you enter a new IP number.

Please enter the IP number you wish to create mm> 
Type in the number of the new IP. The system will create the new IP based on the existing IP you selected.

To add task details to the new IP use IMPLEMENTING PROCEDURE-C)

Change Tasks. 


\section{IMPLEMENTING PROCEDURES}

This option of the STATUS BOARD allows you to view details of the current IP. Information Managers may also modify the IP or switch between existing IPs.

When you choose IMPLEMENTING PROCEDURES, the following menu screen displays information about the current IP and enables you to start activities for using the procedure. (The screen shows 12 Emergency Function categories at a time. The categories shown are the default examples. Your local system may have up to 36 Emergency Function categories with different names chosen specifically for the system.) The following screen is labeled for operational use; for planning use, the screen and the menu options are somewhat different (as shown on the next page).

Implementing Procedures Menu (nonplanning modes)

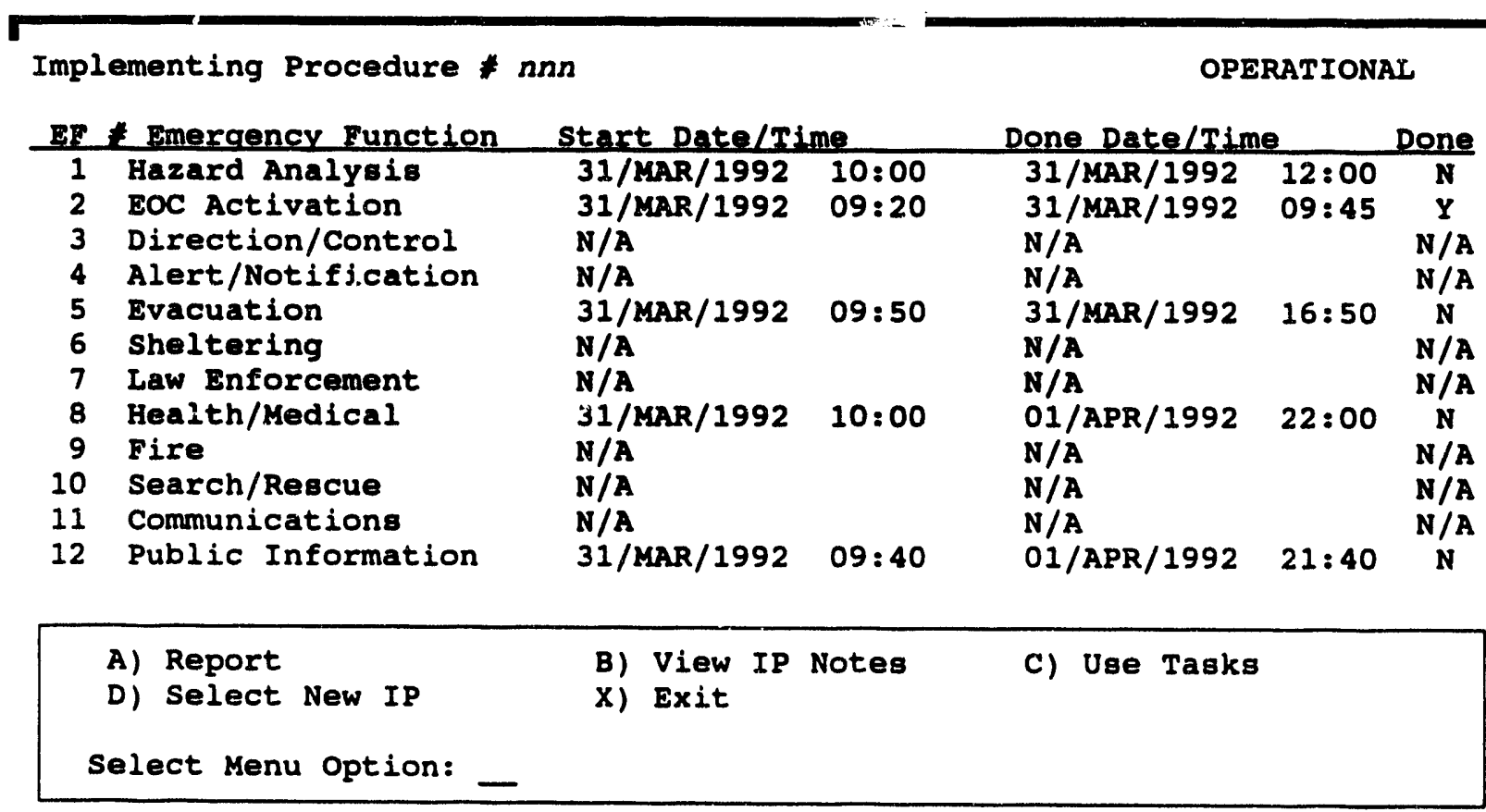

Operational/Exercise Mode Display Items - The upper part of the screen is filled in automatically:

- The IP number is the number of the current IP (actually an OPIP unless an event has occurred).

- The Start/Done times and the Done flags are filled in, based on the progress of the tasks. If no tasks exist for a particular Emergency Function, these times are labeled as N/A (not applicable). 


\section{Implementing Procedures Menu (planning mode)}

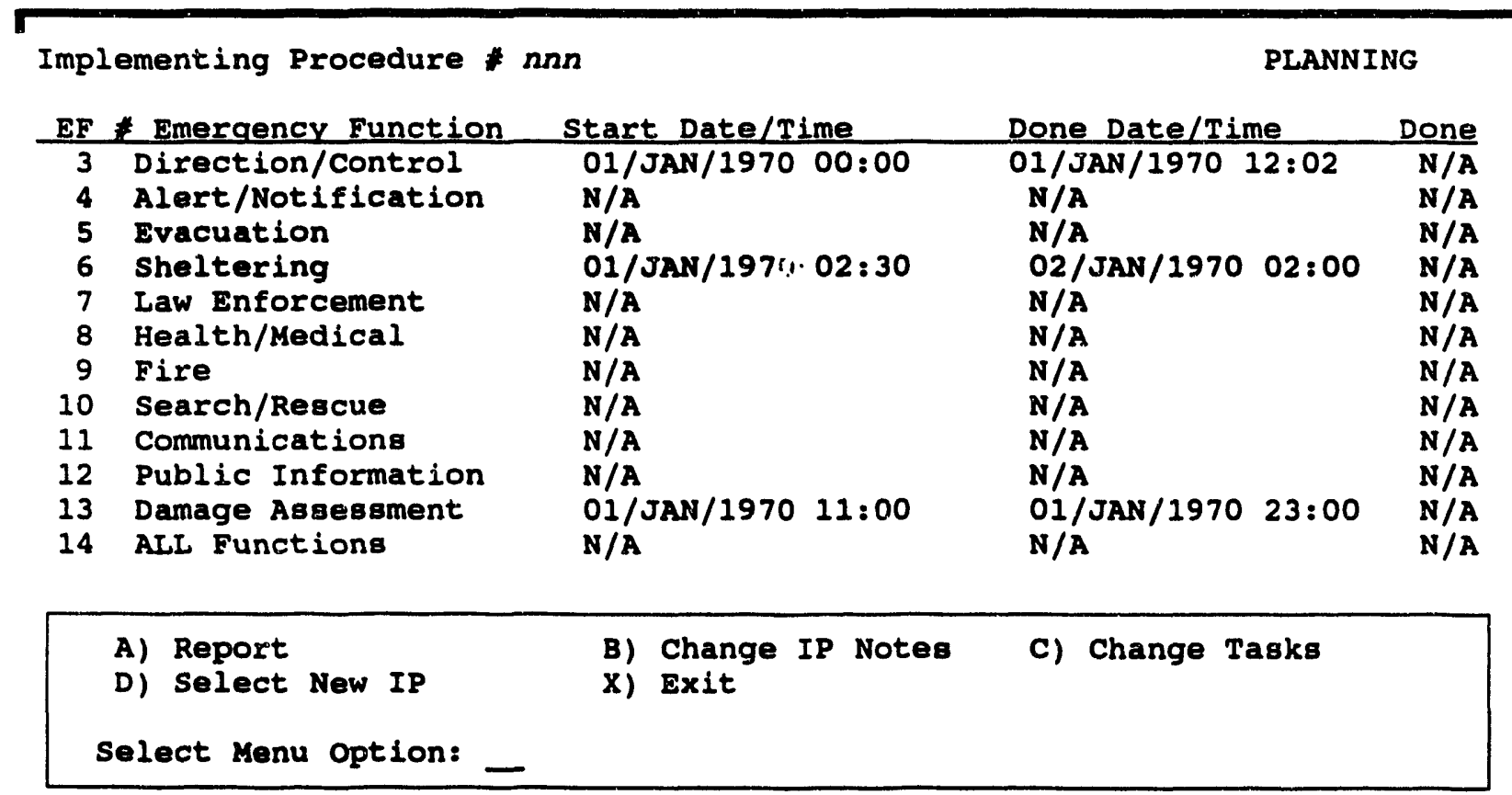

Planning Mode Display Items - The upper part of the screen is filled in automatically:

- The IP number is the number of the current IP.

- In planning mode, the Done flags are always listed as N/A (not applicable).

Selecting IP Options - To initiate an activity, select one menu option (A-D) or X to exit. If you choose A) Report, C) Use Tasks, or F) Add Tasks, another prompt requests a specific Emergency Function: Emergency Function *:

To choose an Emergency Function, enter the index number of the function. If the total number of Emergency Functions are more than 12, you can show the other functions by using the following key commards at the Emergency Function number prompt:
Key Result
D Scrolls Down to the next page of functions
U Scrolls Up the previous page of functions
$T$ Scrolls to the Top of the list (first page)
B Scrolls to the Bottom of the list (last page)

Selecting ALL Functions applies only for Option A) Report. 
The IP options are summarized in the following table and described in detail in the following sections.

TABLE 3.1. Summary of IMPLEMENTING PROCEDURES Options

Option

A Report presents the IP report production options.

B View IP Notes (operational mode only) (a) displays the notes (up to 99 lines) for the current IP. These are general descriptions and explanatory notes associated with the IP. Action and resource notes associated with specific tasks can be accessed through Option C.

$B^{(b)} \quad$ Change IP Notes (planning mode only) displays the IP notes for editing by planners.

C Use Tasks (operational mode only) displays details of the tasks for the chosen Emergency Function. All users may view tasks, actions, and resources in the IP. Users with appropriate privileges may enter task starting and completion times and mark tasks as done. Users with appropriate privileges may also insert tasks and edit any part of the task, action, and resource information.

C Change Tasks (planning mode only) displays details of the tasks for the chosen Emergency Function. Planners can modify the IP by changing tasks, actions, resources, and the notes associated with each.

$D^{(c)} \quad$ Select New IP (operational mode only) allows you to select a different IP based on event criteria. (This capability is identical to Select IP under the STATUS BOARD-CHANGE ONPOST WORK PLAN option.)

X EXIT exits this IP screen and returns to the STATUS BOARD menu.

(a) The IP capabilities for Operational, Exercise, and Backup use are all the same. The IP capabilities and menu options for Planning use are different.

(b) Planner or Information Manager privileges required.

(c) Information Mariager privileges required. 


\section{A) Report}

This option allows you to produce predefined or user-defined reports about an IP. Reports can be displayed, printed, or written to a file.

When you select the A) Report option, the second prompt requests you identify an Emergency Function by entering an Emergency Function number on the IP menu.

After the Emergency Function(s) are identified, the system displays the following menu screen for choosing reports about the current IP.

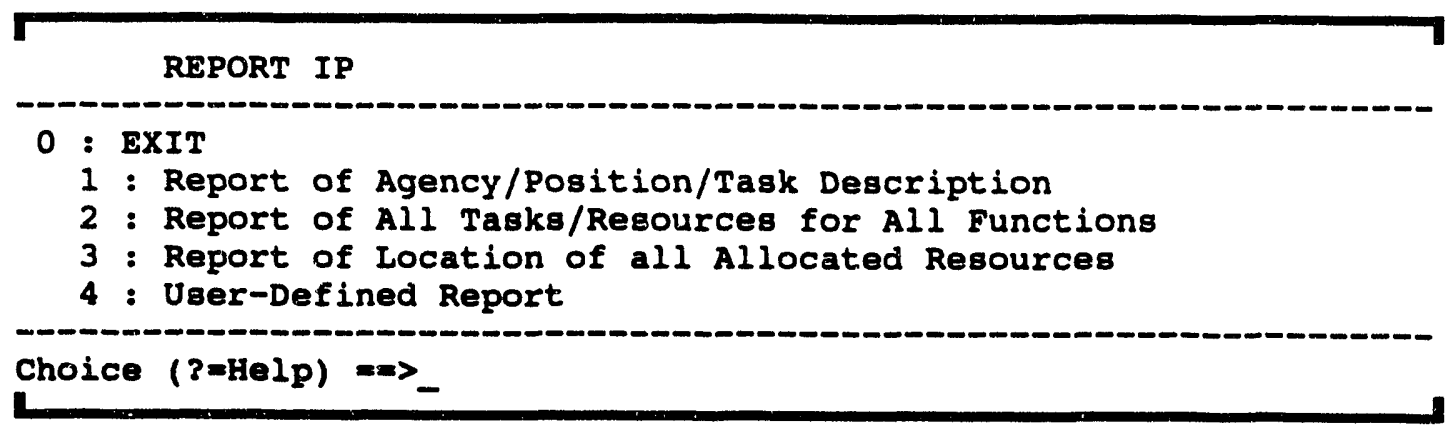

Options 1, 2, and 3 provide predefined reports that include the items specified in the report type title. Remember the resources in these reports are the planned or required resources, and NOT the actual resources. For tracking actual resources, see Section 6, Resource Management.

Option 4 displays the following screen for tailoring the contents of a report of IP information. 
User-Defined Reports

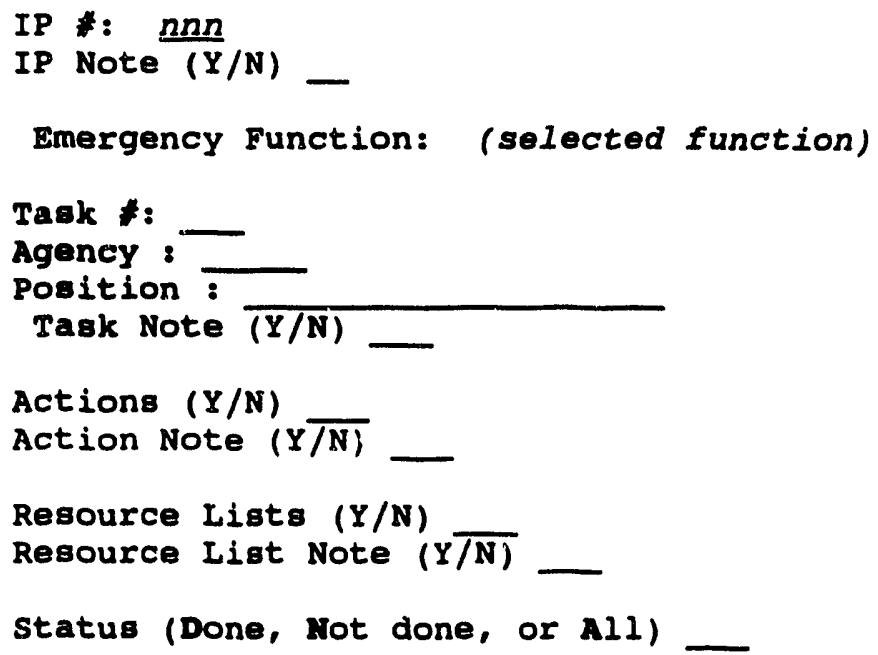

To tailor the report, specify your choices for each item in the screen fields. The IP information that you specify is then assembled for the report. The fields of the screen are explained here.

- IP \#: The current IP \# is displayed. You may accept this value, specify a different IP \#, or enter a -1 (negative one) to produce a report for ALL IPs in the current database. (If an event has been declared, only the current IP is searched or displayed.)

- Emergency Function: The Emergency Function selected on the previous screen is displayed. You may accept this choice, enter a different Emergency Function, or enter a -1 to indicate ALL Emergency Functions. (Entering two question marks ?? in this field displays a list of all Emergency Functions.)

- Task \#. Enter a specific task number or a $\mathbf{- 1}$ to indicate ALL tasks in the specified Emergency Function.

- Agency. Enter a specific 5-character agency code to request a report containing information on a specific agency. Leave this field blank to get a report containing information on all agencies.

- Position. Enter a specific 20-character position code to request a report containing information on a specific agency position. Leave this field blank to get a report containing information on all positions.

- Note (Task, Action, Resource List): To include these notes in the IP report, enter a $Y$ in the corresponding NOTE field. 
- Action and Resource List: To include actions or resource lists, enter a Y in the corresponding field.

- Status: Enter $\mathbf{D}, \mathbf{N}$, or $\mathbf{A}$ for the following results.

D Done : Only tasks that ARE done are reported.

N Not done: Only tasks that are NOT done are reported.

A All : If Status is A (or is left blank), ALL tasks are reported (done or not) and a done/not done indi; tor is included in the report.

After choosing reports, (if a default output specified is not specified) you then specify how the report(s) are output:

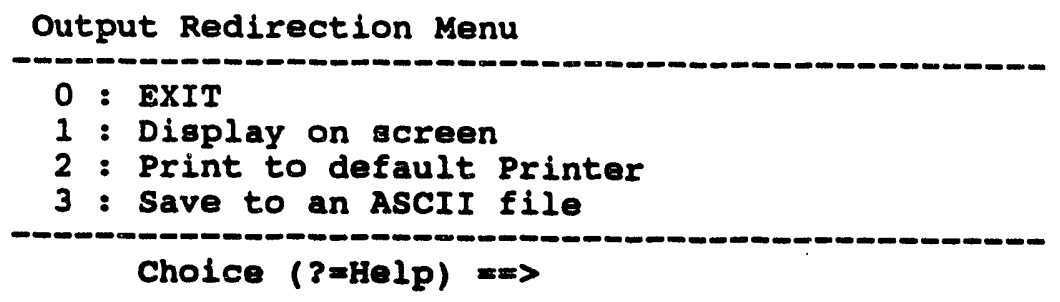

See Figure 3.2 for the hierarchy of elements in the format for the IP report. The actual elements included in a specific report depend on your previous choices. 


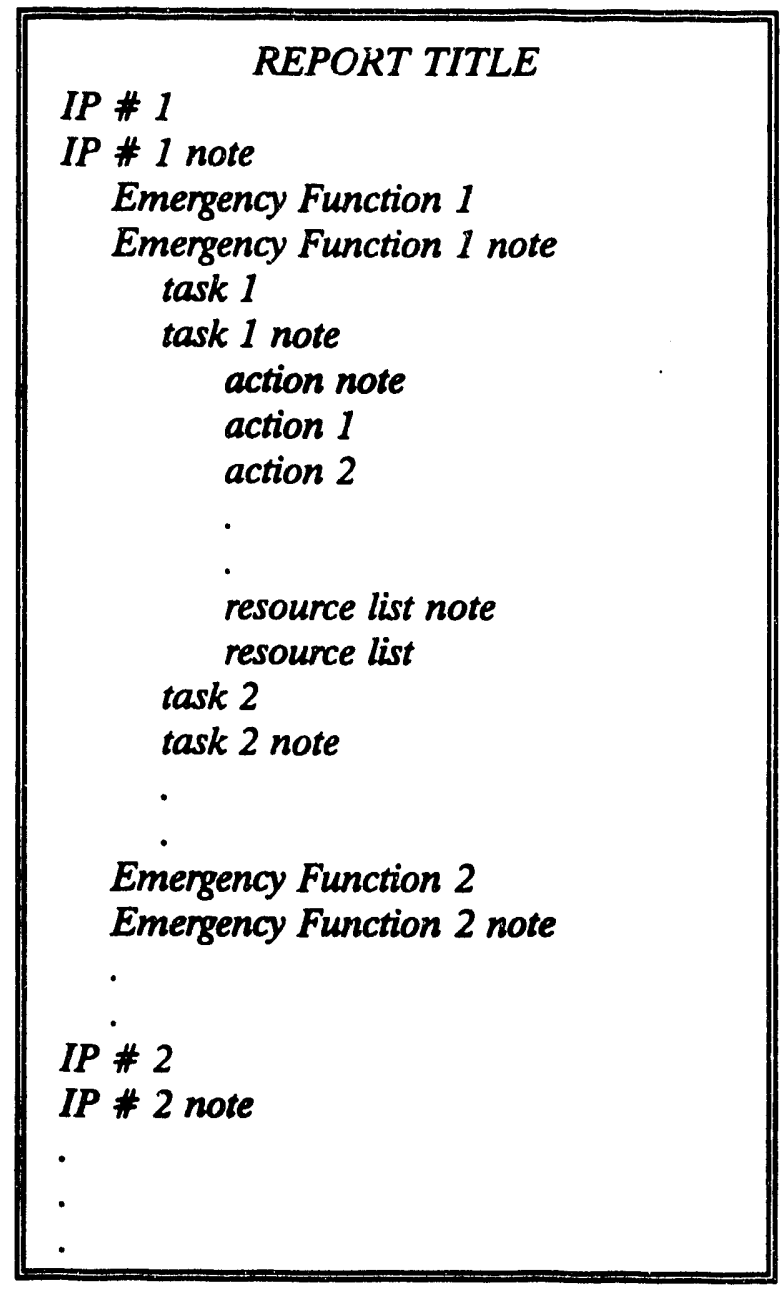

Figure 32. Format for Implementing Procedure Reports 


\section{B) View IP Notes and Change IP Notes}

The View IP Notes (in operational mode) and Change IP Notes (in planning mode) options on the Implementing Procedure menu display the IP-level note lines for the current IP. (a) The operational IP note screen appears as shown.

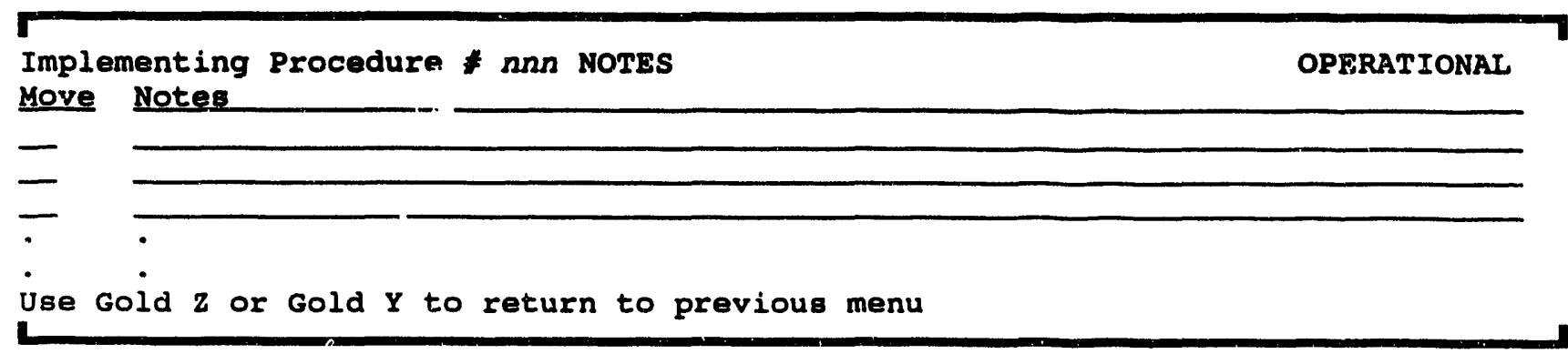

Enter each line of the note independently by pressing RETURN at the end of each line. Each line is preceded by an initial Move field.

To scroll through the note lines: use the arrow keys OR enter one of the following key commands in a Move field:

Key Result

D Scrolls Down to the next page of tasks

D\# Scrolls Down \# pages

U Scrolls Up to the previous page of tasks

U\# Scrolls Up \# pages

T Scrolls to the Top of the list (first page)

B Scrolls to the Bottom of the list (last page)

If you have privileges to add or modify notes, you can enter up to 99 lines of notes.

- To edit an existing line, type over the existing text.

- To delete a line, enter a blank at the beginning of the line.

- To add a line, move the cursor to the first blank line and type new information.

- GOLD $\mathrm{Z}$ exits and saves any changes.

(a) To view notes for a task, action, or resource list, you must first select D) Use Tasks (operational) or Thange Tasks from the IP menu and then choose to view notes, as described in following sections. You may also view notes using the A) Report option. 
- GOLD Y exits and leaves the note in its original form.

\section{C) Use Tasks}

Use Tasks (in operational mode) on the Implementing Procedure menu displays a task list screen for the selected Emergency Function, similar to the following example screen. All users can retrieve information about tasks, actions, resources, and the notes for each in the boxed working area of the screen.

If you have appropriate privileges, you may also indicate tasks as started or done, mark tasks as crucial or not, insert new tasks, or edit any task information (task, action, resource, or notes associated with each).

Use Tasks Screen (operational mode)

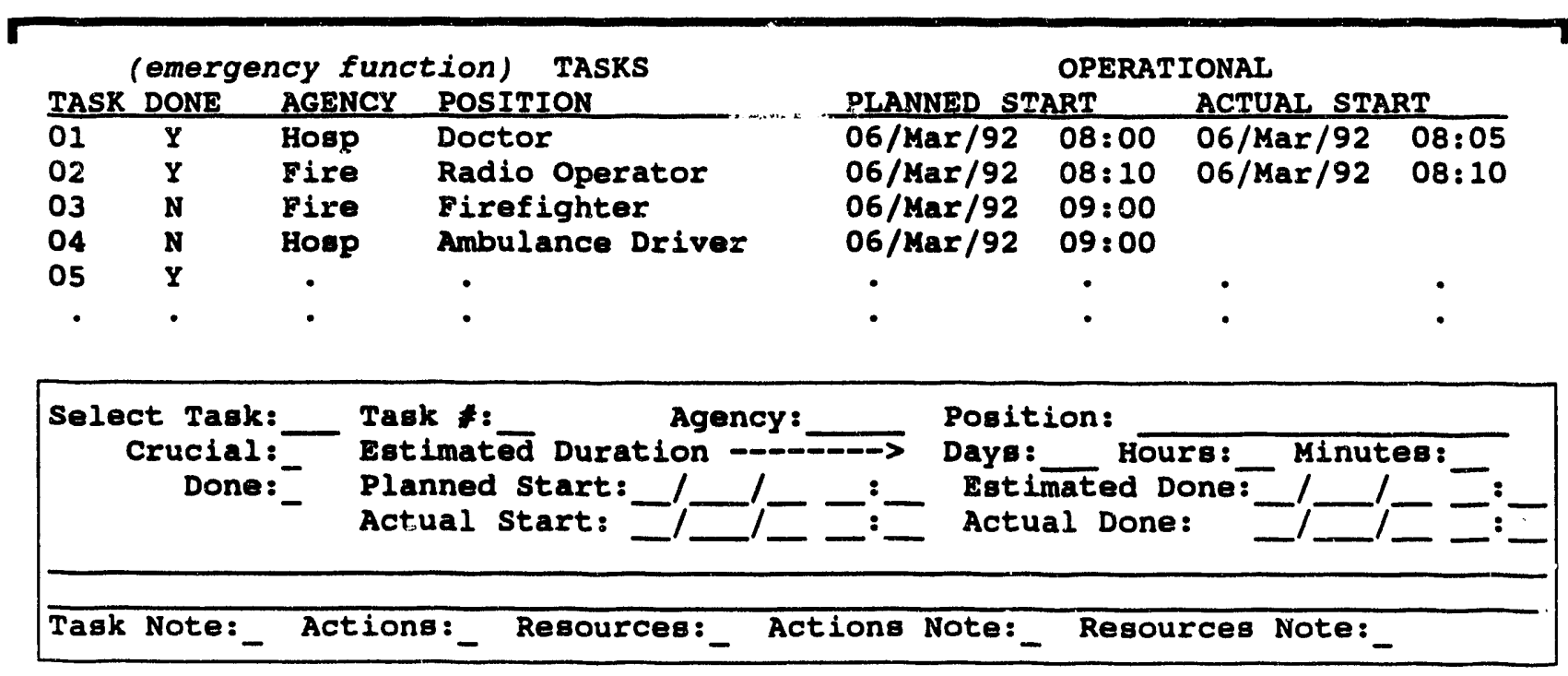


To select tasks for viewing and use: Enter a tast number (or one of the following key commands) in the Select Task field.

$\begin{array}{ll}\text { Key } & \text { Result } \\ \text { ? } & \text { Displays HELP information on screen functions } \\ \text { C } & \text { Cancels and clears information from the boxed working area } \\ \text { O } & \text { Displays a list of overdue tasks (nonplanning modes only) } \\ \text { H } & \text { Switches between alternative Headings and task information } \\ \text { I } & \text { Switches to INSERT mode for adding tasks } \\ \text { D } & \text { Scrolls Down to the next page of tasks } \\ \text { D\# } & \text { Scrolls Down pages } \\ \text { U } & \text { Scrolls Up to the previous page of tasks } \\ \text { U\# } & \text { Scrolls Up \# pages } \\ \text { T } & \text { Scrolls to the Top of the list (first page) } \\ \text { B } & \text { Scrolls to the Bottom of the list (last page) } \\ \text { RS } & \text { Refreshes the screen display } \\ \text { P } & \text { Lists personnel responsible for the current task. }\end{array}$

After you enter a task number in the Select Task field, the system retrieves the IP information on that task and clears the Select Task field for another key command. The Task \# field displays the selected task number: this task number is for display only and cannot be changed directly. The other fields on the Use Tasks screen are modifiable only by those who have privileges to do so. When you enter a number in the Select Task field, the system saves the current task information before retrieving information on the next task.

- Date and Time Fields. Type the complete date and time, or enter T in each field to get the current system date and time. The hours are entered on a 24 -hour clock $(1 \mathrm{pm}=13: 00)$.

The following fields are ones modified during normal operational use.

- Done: Enter Y (yes), N (no), or I (ignore). If you enter I to ignore the task, it does not appear on the list of overdue tasks when the estimated completion time is past.

- Actual Start: Enter the actual start date and time.

- Actual Donc: Enter the actual completion date and time.

- Crucial: Enter Y (no) or N (no).

- Actions and Resources: To immediately display a list of actions or resources for the selected task, enter $\mathbf{Y}$ in either of these fields. 
- Task Notes and Action Notes and Resource Notes: To immediately display a list of any of the three kinds of notes, enter a $Y$ in the corresponding fields.

The remaining fields are normally entered only during planning: Agency, Position, Planned Start, Estimated Done, and Estimated Duration.

If you enter a new agency or position code, the system will enable you to create it.

- If you enter a new position code, the system will prompt you to confirr 'he creation of the new position. If you answer yes to the prompt, the sysiem will add the new position.

- If you enter a new agency code, the system will prompt you to confirm the creation of the new agency. If you answer yes to the prompt, the system will prompt you to enter the new agency name. Type the agency and press the Return key. The system will create the new agency. (Ses Section 4, Personnel Management for more information on agencies and positions.)

Those with appropriate privileges are able to edit any task information and even insert new tasks: they are able to do everything that a planner can do during planning use, except remove a task from the task list. For specific instructions on editing, planning, and inserting new tasks, see Editing Task Information under C) Change Tasks.

Note: Changing the planning information and inserting new tasks during operational use have a potential for serious confusion, unless the people responsible for executing the modified or new tasks are immediately aware of the changes.

To exit the Use Tasks screen: press GOLD $Z$ to exit and SAVE modifications of the current task OR press GOLD $Y$ to exit and CANCEL modifications (of the current task only). You will return to the Implementing Procedure menu. 


\section{Listing Overdue Tasks}

To see a list of overdue tasks: enter $O$ in the Select Task field ( $O$ for Overdue).

The list part of the screen displays only tasks that are overdue to start or to finish.

To switch back to the rürmal task list, press RETURN.

Use Tasks Screen - Overdue Tasks (operational mode)

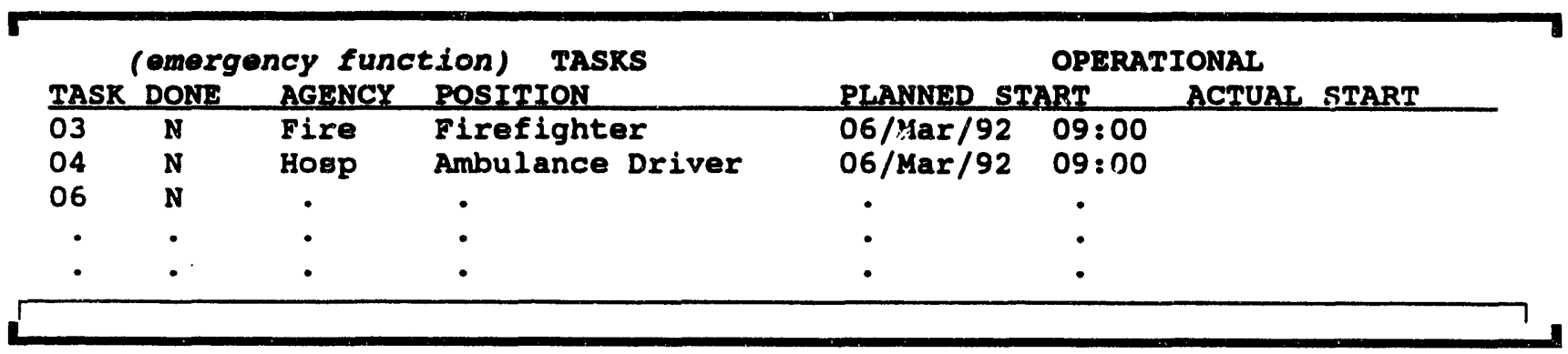

The following Use Task capabilities are also available through the Change Tasks capability.

- Listing tasks by description (alternative heading)

- Viewing (and changing) task actions

- Viewing (and changing) task resources

- Viewing (and changing) task/action/resource notes.

\section{Listing Tasks by Description}

To switch to a task list with alternative headings: enter $\mathbf{H}$ in the Select Task field ( $\mathrm{H}$ for Heading). This switches the column headings from Agency, Position, and task times to the task Description, as in the following example. Enter $\mathbf{H}$ again to switch back.

Tasks Screen with Alternative Heading (any mode)

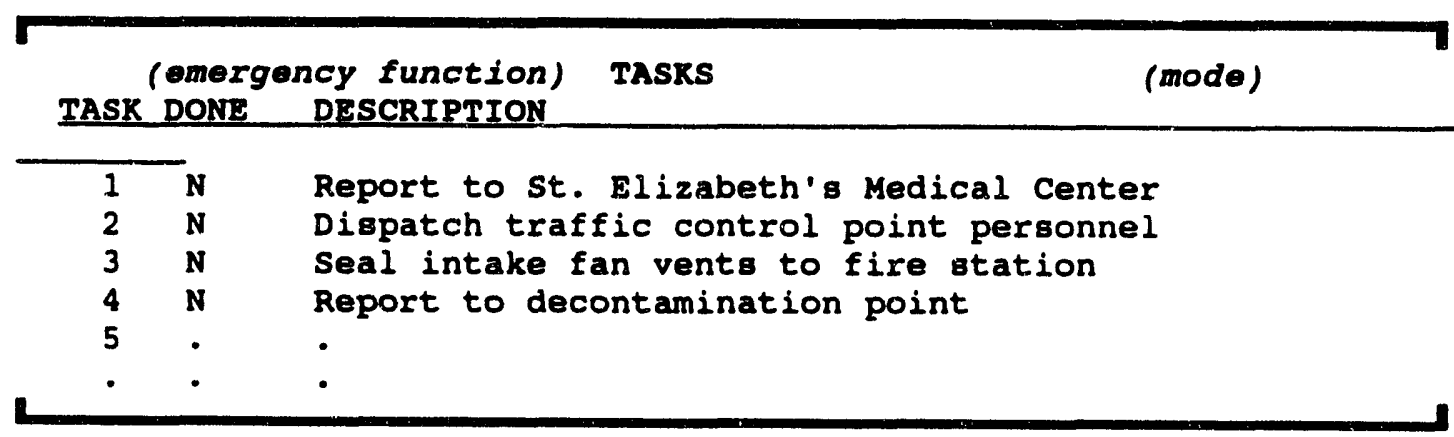




\section{Vlewing (and Changing) Task Actions}

If you enter a $\mathbf{Y}$ in the Actions field of the Use Tasks screen or the Change Tasks screen, the actions for the selected task are immediately displayed in another screen that can be scrolled to view additional actions for this task.

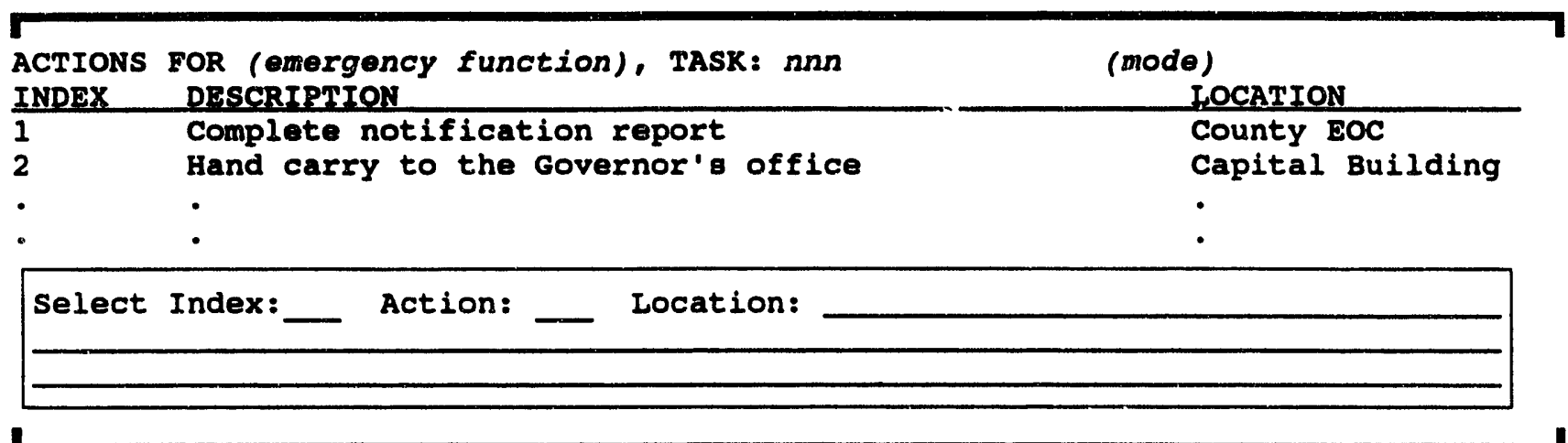

To process actions: In the Select Index field, enter an action number OR one of the following key commands:

Key Result

? Displays HELP info on key commands for scrolling resources:

Up, Down, Top, Bottom (U, U\#, D, D*, T, B)

$\mathrm{H}$ Switches between alternative Headings

I\# Inserts an action at position \# on the action list

$\mathrm{R}$ \# Removes action \# from the action list

When you enter an action number, the system puts that number in the Action field and displays the action information in the boxed area. If you have privileges to do so, you can modify the action information:

- Location: Enter a facility location (or enter two question marks ??) to see a list of the available locations.

- Description: Enter two lines of description.

To insert an action into the task action list: Enter I\# in the Select Index field, where \# is the index position where you want to insert the new action. Enter data in the appropriate fields. The new information is shown in the action list as you press RETURN after entering each value.

To remove an action from the task action list: Enter $\mathbf{R} \#$ in the Select Index field, where \# is the index of the action that you want to delete. 


\section{Vlewing (and Changing) Task Resources}

If you enter a $\mathbf{Y}$ in the Resources field of the Use Tasks screen or the Change Tasks screen, the resources for the selected task are immediately displayed on another screen that can be scrolled to view additional resources for this task.

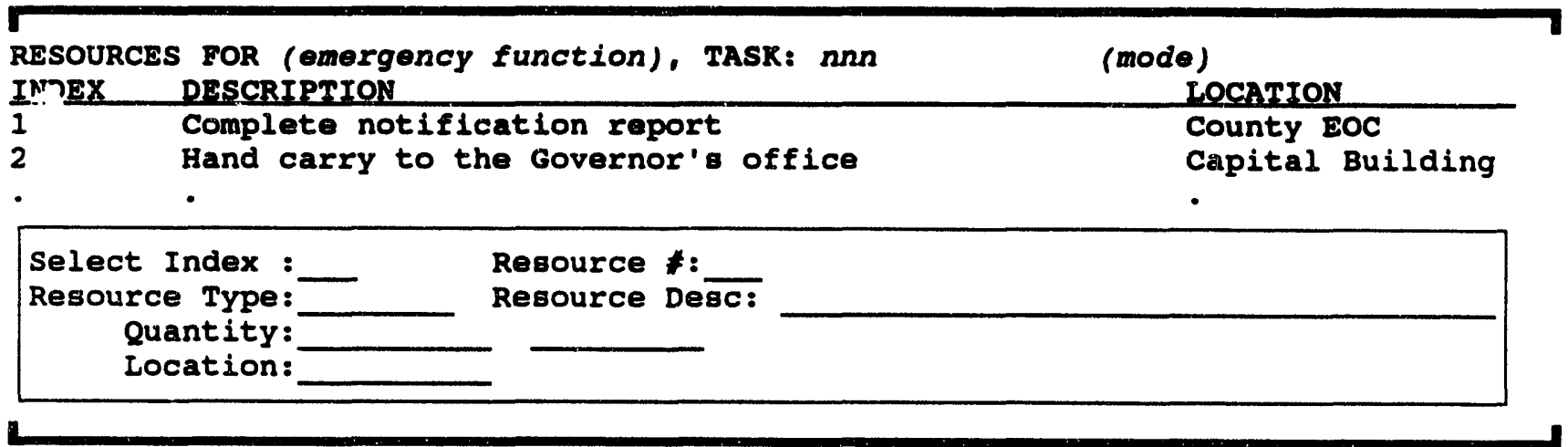

To process resources: In the Select Index field, enter a resource number OR one of the following key commands:

Key Result

? Displays HELP info on key sommands for scrolling resources: Up, Down, Top, Bottom (I) U* D, D\#, T, B)

H Switches between alternative Headings

I\# Inserts a resource at position \# on the resource list

R\# Removes resource \# from the resource list

When you enter a resource number, the system puts that number in the Resource \# field and displays the resource information in the boxed area. If you have privileges to do so, you can modify the resource information:

- Resource Type: Enter the general resource type (or enter two question marks ??) to see a list of resource types.

- Resource Description: Enter the description of the individual resource (or enter ??) to see a list of resource descriptions.

- Quantity: Enter a nonzero quantity.

- Location: Enter a facility location (or enter ??) to see a list of locations.

To insert a resource into the resource list: Enter I\# in the Select Index field, where \# is the index position where you want to insert the new resource. Enter data in the appropriate fields. The new information is shown in the resource list as you press RETURN after entering each value. 


\section{Viewing (and Changing) Task/Action/Resource Notes}

If you enter a $Y$ in one of the Notes fields of the Use Tasks screen or the Change Tasks screen, the task note, action note, or resource note for the selected task is immediately displayed on another screen that can be scrolled to view additional lines of the note. The heading for the Task Note follows:

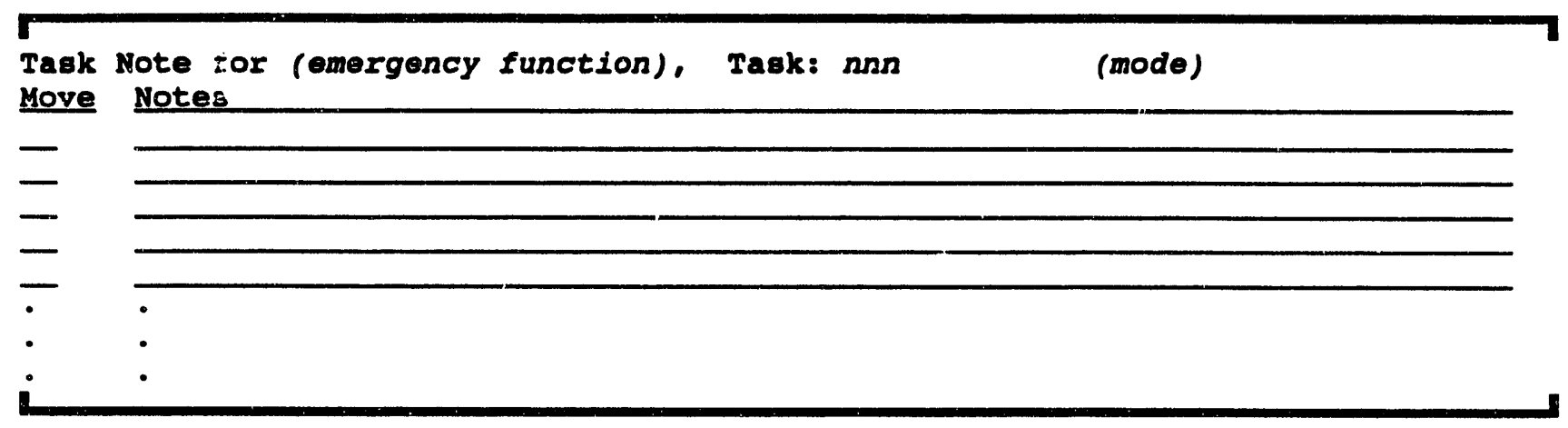

Enter each line of the note independently by pressing RETURN at the end of each line. Each line is preceded by an initial Move field.

To scroll through the note lines: use the arrow keys OR enter one of the following key commands in a Move field:

Key Result

D Scrolls Down to the next page of tasks

D\# Scrolls Down \# pages

U Scrolls Up to the previous page of tasks

U\# Scrolls Up \# pages

T Scrolls to the Top of the list (first page)

B Scrolls to the Bottom of the list (last page)

If you have privileges to add or modify notes, you can enter up to 99 lines of notes.

- To edit an existing line, type over the existing text.

- To delete a line, enter a blank at the beginning of the line.

- To add a line, move the cursor to the first blank line and type new information.

- GOLD Z exits and saves any changes.

- GOLD Y exits and leaves the note in its original form. 


\section{D) Change Tasks *}

Change Tasks (in planning mode) on the Implementing Procedure menu displays a task list screen for the selected Emergency Function, similar to the example Change Tasks screen shown. Planners or other authorized users may modify tasks, actions, resources, and notes associated with any of these in the boxed working area of the screen. General users do not use this screen.

The Change Tasks screen is nearly identical to the Use Tasks screen except that it lacks a few nonplanning fields (Done, Actual Start, Actual Done) and lists the estimated completion time instead of the actual start time in the task list.

Change Tasks Screen (planning mode)

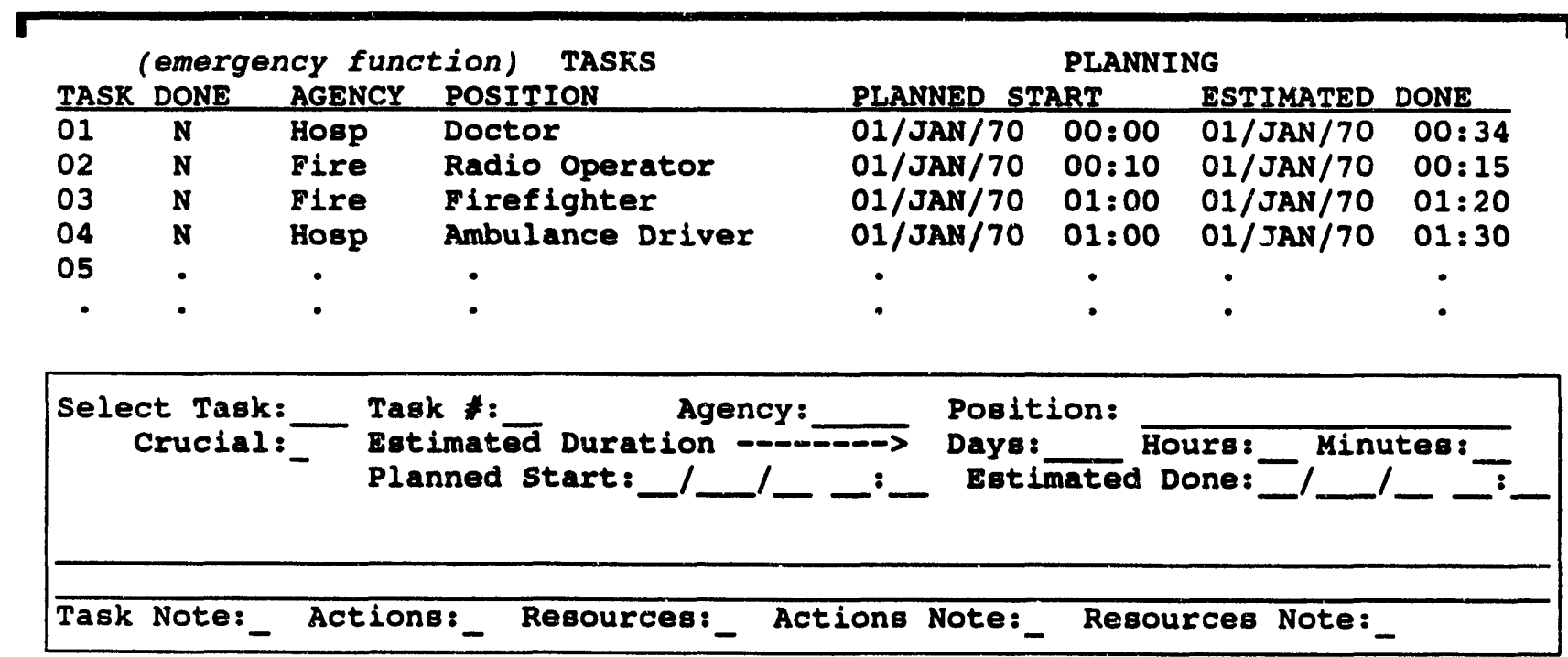


To select tasks for viewing and use: Enter a task number (or one of the following key commands) in the Select Task field.

Key Result

? Displays HELP information on screen functions

\# Select a task number to edit

C Cancels and clears information from the boxed working area

H Switches between alternative Headings and task information

I Switches to INSERT mode for adding tasks

R\# Removes task number \# from the task list

D Scrolls Down to the next page of tasks

D\# Scrolls Down \# pages

U Scrolls Up the previous page of tasks

U\# Scrolls Up \# pages

$\mathrm{T}$ Scrolls to the Top of the list (first page)

B Scrolls to the Bottom of the list (last page)

O Lists overdue tasks

RS Refresh screen

P Show personnel responsible for a task. A + indicates the person is scheduled to be on duty.

\section{Task Information Flelds}

The fields of the task area of the Change Tasks screen are explained in following paragraphs.

- Date and Time Fields. Type the complete date and time, or enter T in each field to get the default base event time for planning mode: 01/JAN/70 00:00 (see Planned Start and Estimated Done). The hours are entered on a 24 -hour clock $(1 \mathrm{pm}=13: 00)$.

- Agency and Position: Enter the agency code (up to five characters) and the position of the contact person for the task. To see a numbered list of possible agencies (or positions), enter two question marks ?? in the Agency (or Position) field.

- Crucial: Enter $\mathbf{Y}$ (no) or N (no).

If you enter values for any two of the following three time periods, the system calculates the third value.

- Estimated Duration: Enter the number of days, hours, and minutes expected as necessary to complete the task.

- Planned Start: During the planning phase, it is established that each task must occur some period after an event is declared. The planned start time for a task is that number of days/hours/minutes 
added to an arbitrary base event time (01/JAN/70 00:00 on a 24hour clock).

- Estimated Done: The estimated task ending time is the planned start time plus the estimated task duration (established during planning). Like the planned start time this is shown relative to the arbitrary base "event" time of 01/JAN/70 00:00.

- Task : Tescription: Enter two lines of task description, which will appean in the task description lists.

After a task has been added, you can use the following fields for adding task actions, task resources, and notes.

- Actions and Resources: To immediately display a screen for adding actions or resources for the selected task, enter $\mathbf{Y}$ in either of these fields.

- Task Notes and Action Notes and Resource Notes: To immediately display a screen for entering any of the three kinds of notes, enter a $\mathbf{Y}$ in the corresponding fields. 


\section{Editing Task Information}

The following capabilities are available to planners from the Change Tasks screen (in planning mode): inserting, removing, and changing a task on the task list. Users with appropriate privileges may also insert and change (but not remove) tasks from task list on the Use Tasks screen (in operational mode).

To insert a new task:

1. Enter I in the Select Task field.

This puts you in insert mode for adding tasks. The screen displays the following message

You are in INSERT mode

2. Fill in the screen information.

Required

- Agency and Position

- Two of Planned Start, Estimated Done, and Estimated

Duration: After two of these values are entered, the third value is calculated.

\section{Recommended}

- Crucial: Indicate whether the task is crucial ( $\mathbf{Y}$ or $\mathbf{N})$.

- Task Description: Enter two lines of task description, which then appear in the task description lists.

3. Do one of the following:

Action

Enter I in the Select Task field again.

Enter $\mathbf{C}$ in the Select Task field.

Press GOLD Y.
Result

Inserts the new task into the task list in chronological order and takes you out of insert mode.

Cancels the insert operation, clears the task information box, and cancels insert mode.

Cancels the current insert operation and exits the Change Task screen.

After the new task has been inserted, you can add the other task information:

- $\quad$ task actions 
- task resources

- task notes, action notes, and resource notes

To remove a task from the task list: Enter $\mathbf{R} \#$ in the Select Task field, where \# is the number of the task. The chosen task is then deleted from the task list. Task removal is available only during planning; under nonplanning conditions, unwanted tasks can be ignored by entering an I in the Use Task screen's Done field.

To change a task:

1. Enter the task number in the Select Task field.

When you press RETURN, the form box on the screen fills with that task's information.

2. Change the task information.

3. Do one of the following:

Action

Press GOLD Z.

Enter another task number for editing.

Press GOLD Y.

\section{Result}

Saves the modified task information and exits the Change Task screen. Updates the task listing, if necessary.

Saves the modified task information before filling in the box with the next task's information. Updates the task listing, if necessary.

Cancels any changes you have made (for the current task only) and exits the Change Task screen.

To exit the Change Tasks screen: press GOLD $Z$ to exit and SAVE modifications of the current task OR press GOLD Y to exit and CANCEL modifications (of the current task only). The screen returns to the Implementing Procedure menu. 


\section{E) Select Now IP *}

Only a user with Information Manager privileges can select the system IP in operational mode.

Note: All planners have the privilege to select an IP in planning mode under their personal planning site.

\section{Selecting a New IP In Operational Mode}

In operational mode, you are given the option of selecting an IP directly by IP number or by searching the scenario table based on the current work plan. In planning mode, you can only select an IP by number.

To select an IP in operational mode, perform the following procedures:

1. Choose IP selection method and select IP.

A. Choose IP by NUMBER: from a list of IPs, select one IP.

\section{B. Choose IP by SEARCH FOR IP CRITERIA}

1) Identify appropriate D2 cases by using a D2 Track Qualification screen to search for and identify D2 cases that most nearly match the D2 track that you describe on the screen.

2) From a list of the D2 cases identified, select one case.

3) From a list of IPs that use the selected D2 case, select one IP.

2. Now that the new IP number has been selected, choose whether to retain completed tasks from the previous IP.

3. Set IP base time.

This procedure is detailed in the following sections. 
When you select Option D) Select New IP in operational mode, the Choose IP menu displays.

\begin{tabular}{l} 
CHOOSE IP MENU \\
\hline $0:$ EXIT \\
$1:$ ChOOse IP by NUMBER \\
$2:$ ChOOBe IP bY SEARCH FOR IP CRITERIA \\
Choice $(?=H E l p)=m$
\end{tabular}

\section{Choose IP by NUMBER}

If you select Choose IP by NUMBER, a list of all possible IPs (if an event has been declared) or OPIPs (if an event has not been declared) displays:

\begin{tabular}{ll} 
IP & DESCRIPTION \\
\hline 7 & One line description of OPIP 1 \\
11 & One line description of OPIP 7 \\
One line description of OPIP 11
\end{tabular}

Select desired IP:

You can select an IP from the list or press $\langle$ GOLD $>\langle Y\rangle$ to escape IP selection. If the list is too long to fit on one page, you can use the following commands to scroll the through list:
Key Result
D Scrolls Down to the next page of tasks
D\# Scrolls Down \# pages
U Scrolls Up to the previous page of tasks
U\# Scrolls Up \# pages
T Scrolls to the Top of the list (first page)
B Scrolls to the Bottom of the list (last page) 


\section{Choose Whether to Retain Completed Tasks from the Previous IP}

If you have already been checking off tasks in the previous IP (such as in an OPIP before an event) you can retain the completed tasks as part of the current data. The system gives you a number of options by displaying the following menu:

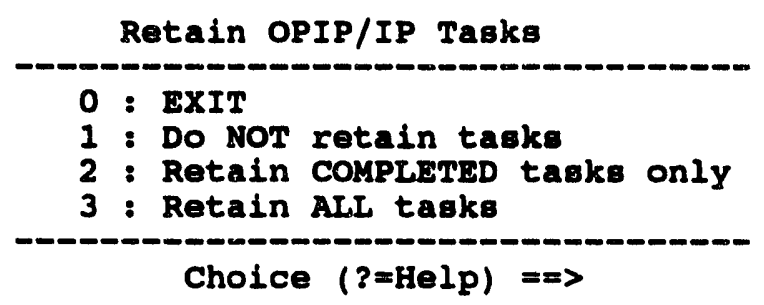

Select an option based on your current situation:

0. EXIT. Exit the current menu.

1. Do NOT retain tasks. In this case, the IBS removes all files from the current event database. The "empty" event database is then ready to receive the files for the new IP or OPIP. Example: When the Work Plan changes, you might want to change to a new OPIP, responding $\mathbf{N}$, so that a fresh OPIP can be started to match the new Work Plan.

2: $\quad$ Retain COMPLETED tasks only. The completed tasks are merged with the tasks of the newly selected IP for each Emergency Management category. Example: When an event occurs that necessitates escalation from OPIP to IP, you can select this option, so that the completed OPIP tasks remain as a part of the overall preparation for and response to the event.

3: Retain ALL tasks. All tasks, completed or incomplete, are merged with the tasks of the newly selected IP for each Emergency Management category.

\section{Set IP Base Time}

Finally, you will need to set a base time for your IP. In planning mode, planners creating an IP assumed an arbitrary base time of 01-JAN-1970 00:00, and all task times were set relative to this time. When this IP is selected for use, it is up to the person selecting the IP to input an appropriate base time. This time can be when people are supposed to begin work on the plan; it can be when an event occurs; it can be the current time. It is left to the user to decide what is appropriate.

When the new base time is specified, all tasks in the IP will be changed relative to this new base time. 


\section{Choose IP by SEARCH FOR IP CRITERIA}

The following method for selecting a new IP is based on using information from the current onpost Work Plan. This IP selection method is also accessible through CHANGE ONPOST WORK PLAN. It is expected that you will use this method most frequently to select the IP and the Operational Preparedness IP (OPIP). An alternative method for selecting the IP based on Emergency Planning Zones (EPZs) is described under EMERGENCY FUNCTIONS-DIRECTION/COONTROL

if no actual event has occurred, you will be using an OPIP based on the Work Plan for the day. (It is expected that information about the day's Work Plan will be obtained from onpost sources such as the current run report.) If an event occurs, the system defaults to the IP, which is based on the Work Plan. 


\section{Identify Appropriate D2 Cases}

You will see the following D2 Track Qualification screen for describing the current chemical and weather situation for a D2 model track. This screen contains fields that serve as search criteria for identifying D2 cases that match or approximate the release situation described in the fields. Information from the Work Plan screen (when the information is available) automatically appears in the corresponding fields of the D2 Track Qualification screen. (See the Work Plan screen)

You can modify the fields, which are used as search keys into the D2 cases included in the scenario table:

- The default tolerances for wind direction, wind speed, and agent quantity are displayed. You can change these values for this particular search.

- You can remove one or more criteria from the search by leaving blank the text fields (agent, munition, release type, stability class) or by entering a negative one $(-1)$ in the numeric fields. If all fields are removed from the search, you must then select one case from a list of all $D 2$ cases in the scenario table.

- If any criteria are used, the IBS compares these case input criteria with D2 cases in the scenario table. (If no perfect matches can be found, the IBS displays a message to indicate how many criteria were actually matched.) You must then select from a list of D2 cases that match the greatest number of criteria (see the next screen).

- If no cases match the specified criteria, you will see this message:

No D2 case matching specified criteria found.

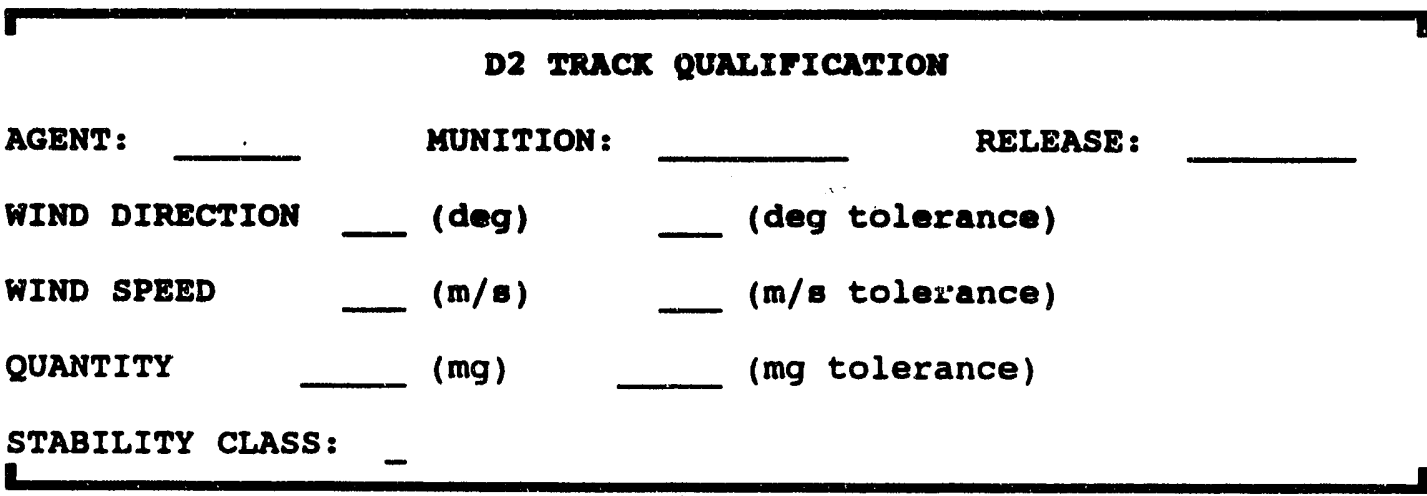




\section{Select from a List of Identified D2 Cases}

If the search identifies a set of possible D2 cases, a screen similar to the following one lists the cases (in numerical order by $D 2$ case number).

If the cases are too many to fit on one screen, you can scroll through the remaining case descriptions by entering a key command at the Select Case \#: prompt (U, U\#, D, D\#, T, B). (Or enter H to switch the heading display to show the D2 case description instead of the D2 case qualifications shown here.)

To select a case, enter the case number at the Select Case \#: prompt. The next step is to actually choose an IP that contains the selected D2 case.

\begin{tabular}{|c|c|c|c|c|c|c|c|}
\hline \multicolumn{4}{|l|}{ D2 } & \multicolumn{2}{|c|}{ Wind } & \multirow[b]{2}{*}{ ouantity } & \multirow[b]{2}{*}{ stability } \\
\hline Case* & Agent & Munition & Release & Dir & Speed & & \\
\hline $\begin{array}{l}123 \\
124\end{array}$ & $\begin{array}{l}\mathbf{V X} \\
\mathbf{V X}\end{array}$ & $\begin{array}{l}\text { M55 } \\
\text { M55 }\end{array}$ & $\begin{array}{l}\text { INS } \\
\text { INS }\end{array}$ & $\begin{array}{l}90 \\
180\end{array}$ & $\begin{array}{l}15 \\
40\end{array}$ & $\begin{array}{l}100 \\
100\end{array}$ & $\begin{array}{l}\text { D } \\
\text { C }\end{array}$ \\
\hline - & - & - & • & - & - & - & - \\
\hline Select & Case & - & - & • & - & - & - \\
\hline
\end{tabular}

\section{Select an IP that Contains the D2 Case}

After you select a D2 case, a screen similar to the following one lists the IPs that contain that case.

If the IP are too many to fit on one screen, you can scroll through the remaining IP descriptions by entering a key command at the Select IP \#: prompt (U, U\#, D, D\#, T, B). (Or enter $\mathbf{H}$ to switch the heading display to show a longer D2 case description line instead of the case numbers and population patterns shown here.)

To select an IP, enter the IP number.

\begin{tabular}{lllll}
\hline IP & EVAC & D2 & Population & Description \\
\hline 008 & 222 & 123 & Seasonal & Eiret day of Hunting season \\
009 & 400 & 123 & Weeknight & Nighttime \\
010 & 401 & 123 & Weekday & Regular Day \\
- & & & - & \\
Select IP : : & &
\end{tabular}


After selecting a new IP, the only remaining step is to choose whether to retain in completed tasks from the previous IP (or OPIP).

\section{Choose Whether to Retain Completed Tasks from the Previous IP}

This option is the same as described in Select IP by NUMBER.

\section{Set IP Base Time}

This option is the same as described in Select IP by NUMBER.

This concludes the process of selecting an IP in operational mode, which is initiated by choosing the D) Select New IP option on the Implementing Procedure menu or on the Work Plan screen.

\section{Selecting a New IP in Plan Mode}

Following is a discussion of selecting an IP in planning mode.

If you select option D) Select New IP in plan mode, you a list of all possible IPs and OPIPs in your planning database is displayed.

$\begin{array}{ll}\text { IP } & \text { DESCRIPTION } \\ 7 & \text { One line description of OPIP } 1 \\ 8 & \text { One line description of OPIP } 7 \\ \text { One Iine description of IP } 8\end{array}$

Select desired IP:

You can select a number from the list or press GOLD-Y to escape IP selection. In planning mode you do not have the option of selecting an IP by searching the scenario table. It is also not possible to retain tasks from the previous IP. Your base date and time is assumed to be 01/JAN/1970 00:00 in planning mode, so you need not specify a base date and time as you would in operational mode. 


\section{ONPOST EVENT STATUS}

This option displays the Onpost Emergency Event Notification screen, which is shown in the example below.

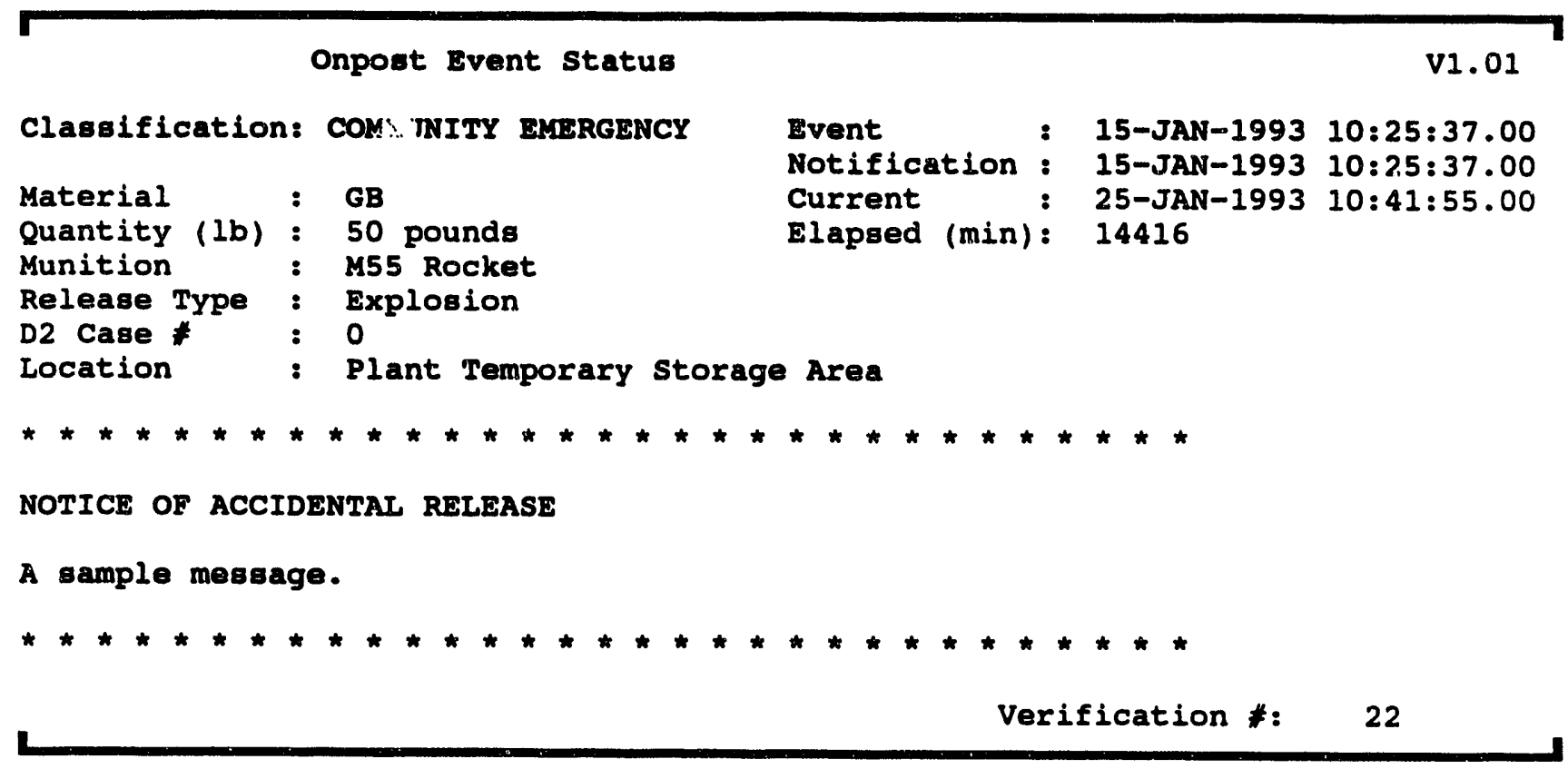

The entire screen is for display only: you cannot alter any of the information here.

- EVENT CLASSIFICATION on the form is one of four types of emergencies:

- $\quad$ Non-Surety Emergency

- $\quad$ Limited Area Emergency

- $\quad$ Post Only Emergency

- $\quad$ Community Emergency.

- VERIFICATION \# is the number that is assigned to one set of the screen information as it is received and recorded.

If an event has not been declared, the system will display the following message.

* * *SG: An event has not been declared

Press <RETURN> to continue... 


\title{
I.. SHOW USER ENVIRONMENT
}

The SHOW USER ENVIRONMENT option is used by planners want to view their current operating environment. This option displays a screen similar to the following.

USER ENVIRONMENT

\begin{abstract}
EVENT: DECLARED / NOT DECLARED
TIME DECLARED: 01-DEC-1992 i3:04:00.00 (Blank if Event not declared)

MODE: PLANNING / OPERATIONAL MY CURRENT SITE: TOOE

You have new mail. / You have late mail. (blank if no mail)

CURRENT OPERATIONAL SITE: TEST

CURRENT OPERATIONAL CASES

CURRENT PLANNING CASES (shown in planning

D2 008

$\mathrm{C888}$

IDYNEV 000

$\mathrm{COOO}$

IP $\quad 000$

$\mathrm{COOO}$

Press <RETURN> to continue.

Use this option to see if an event has been declared or not declared. This option is also useful for planners who want to check whether or not they are in planning or operational mode, and which cases they are using. This screen is for display only. Press the Return key to return to the Status Board menu.
\end{abstract}

\section{VIEW BATCH LOG}

The VIEW BATCH LOG option is used by planners who want to view the batch log file generated by the Event program. This can be useful after an event for planning purposes. The batch log will be similar to the following sample (an actual batch log can be considerably larger).

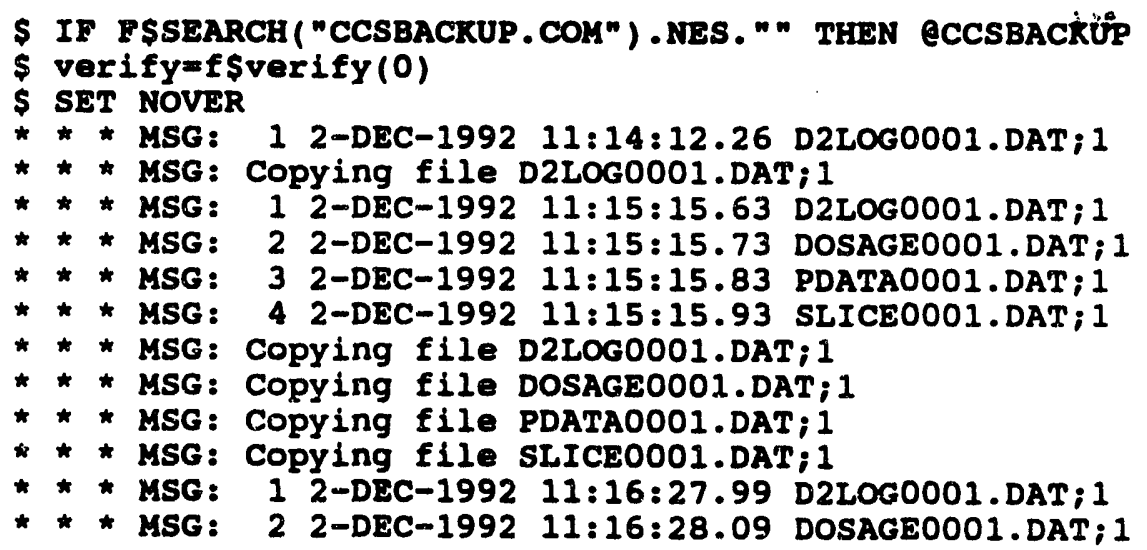




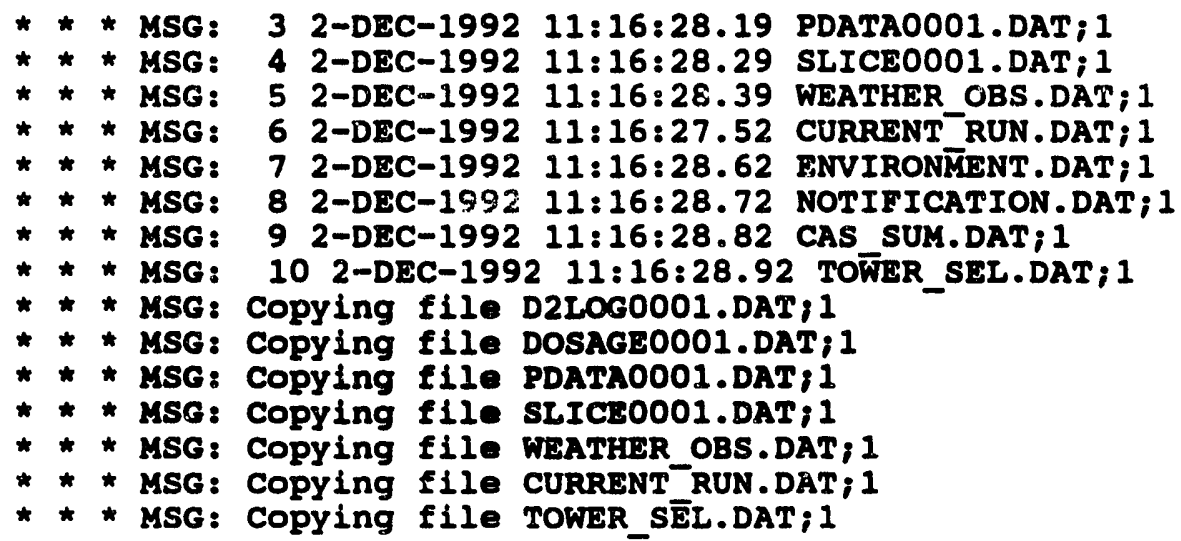

\section{VIEW ONPOST WORK PLAN}

(SEe CHANGE ONPOST WORK PLAN) 


\section{Section 4 \\ Personnel Management}

\section{PERSONNEL MANAGEMENT}

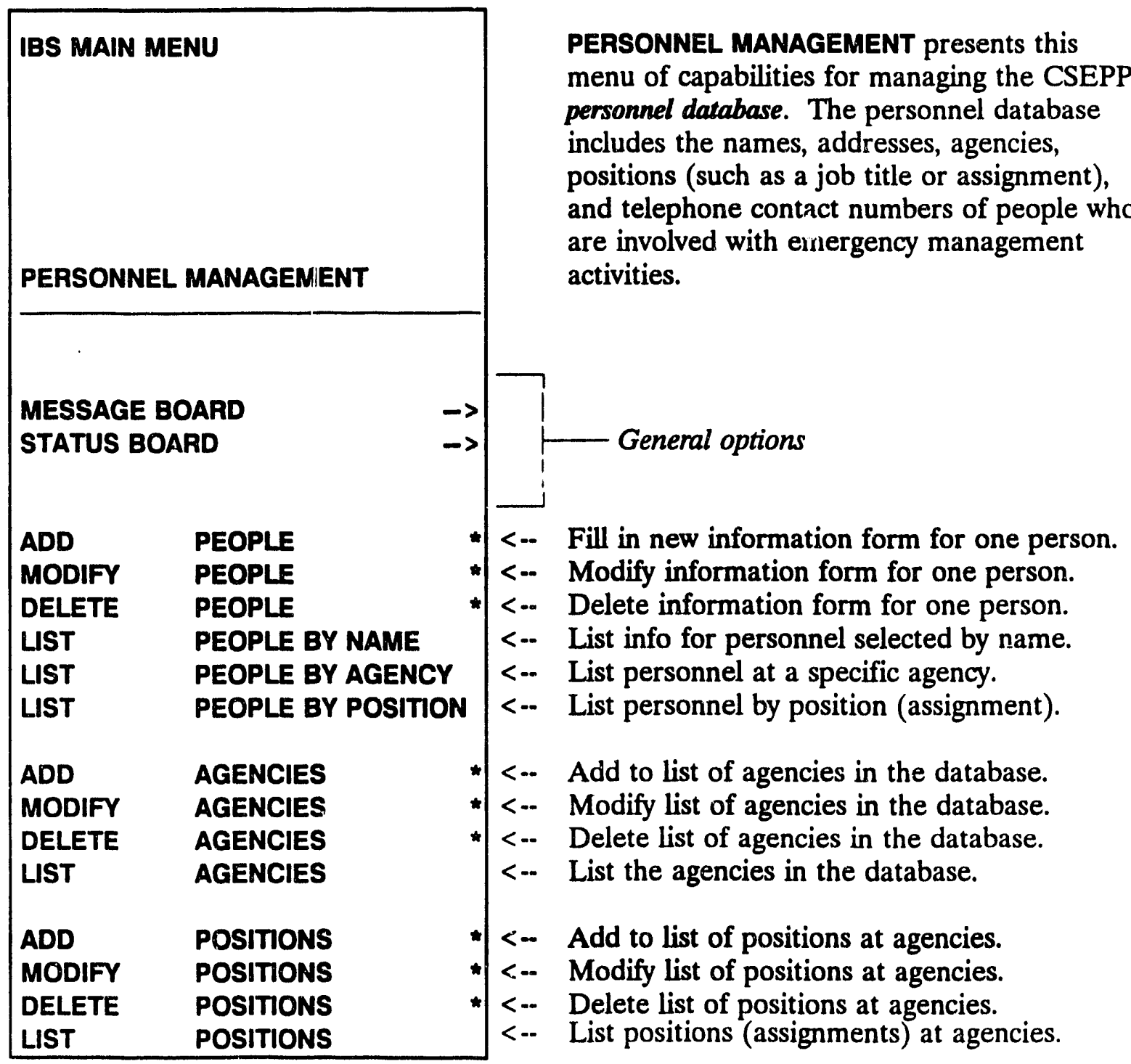


The PERSONNEL MANAGEMENT menu options are explained on the following pages in alphabetical order within three general categories:
- Agency Tasks
- People Tasks
- Position Tasks

\section{Agency Tasks}

Different agencies or organizations employ personnel involved in emergencyrelated activities. The IBS agency lookup table is a list of agency acronyms and the associated agency names. The listing looks similar to the following example.

\begin{tabular}{ll} 
COde & Agency Name \\
NES & NATIONAL FOREST SERVICE \\
PNL & PACIFIC NORTHWEST LABORATORY \\
FEMA & FEDERAL EMERGENCY MANAGEMENT AGENCY \\
OEM & OREGON EMERGENCY MANAGEMENT \\
\hline & Press <RETURN> to cOntinue...
\end{tabular}

The agency lookup table is used throughout Personnel Management and Resource Management, and also in the Implementing Procedures.

The complete list of options available in Personnel Management for using the agency lookup table are:
- $\quad$ ADD AGENCIES
- MODIFY AGENCIES
- DELETE AGENCIES
- LIST AGENCIES

Any IBS user can look at the table by using the LIST AGENCIES option, but only an Information Manager can change the contents of the table, either through ADD AGENCIES, MODIFY AGENCIES, or DELETE AGENCIES. 


\section{ADD AGENCIES *}

This option enables an Information Manager to add information to the agency lookup table.

The system prompts:

Enter new Agency code =>

1. Enter the acronym for the agency (or press CTRL-Z to quit).

You are restricted to only five characters, so you may need to truncate the acronym. If that acronym is already in the lookup table, you must try again.

The system prompts:

Enter new Agency name $==>$

2. Enter the full name of the agency.

You are restricted to 64 characters, so once again, you may need to truncate your input. If that name is already in the lookup table, you must try again.

After the new agency code and name information are saved, the system returns to Step 1 and prompts you again. Use GOLD-Z to exit the prompt when you are finished.

\section{ID DELETE AGENCIES *}

This option enables an Information Manager to delete information from the agency lookup table. The system displays the Agency Selection method menu as described in Modify Agencies. Use the menu in the same way as in MODIFY AGENCIES to choose the agencies you want to delete.

\section{MODIFY AGENCIES * : I}

This option enables an Information Manager to modify information already in the agency lookup table. This consists of 1 ) specifying which agency (by code or by name) and 2) entering a new agency code and name. 


\section{Specify Which Agency to Modify}

The system prompts:

\begin{tabular}{l} 
Agency Selection method menu \\
0: ExIT \\
1: Type in Agency code \\
2: Select Agency code from a list \\
3: Type in Agency name \\
4: Select Agency name from a list \\
\hline Choice (?=Help) $=\Rightarrow$
\end{tabular}

Use one of these four methods to select an agency to modify:

1. Type in Agency code: Prompts you to enter the agency code (up to five characters).

Enter Agency code =>>

Enter the acronym for the agency you wish to modify. If it is not in the table, you must try again.

2. Select Agency code from a list: Prompts you to choose one agency from a numbered list of agencies (ordered by agency code).

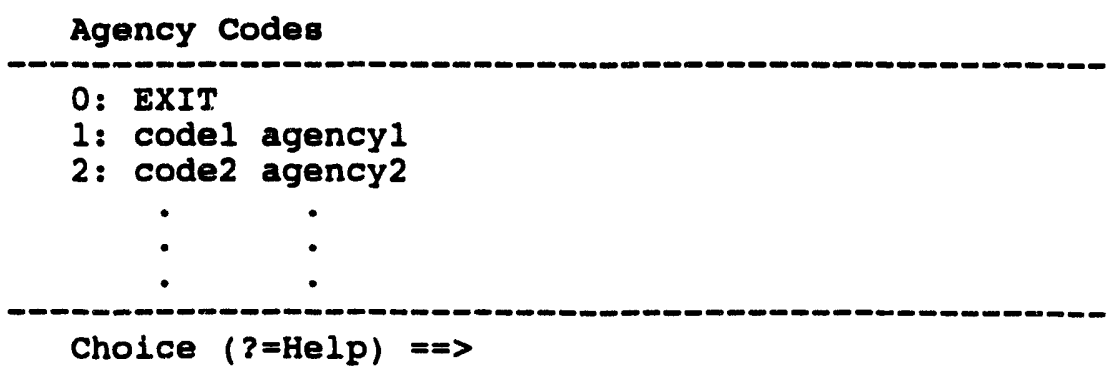

3. Type in Agency name: Prompts you to enter the agency name.

Enter Agency name $=>$

If the name you enter is not in the table, you must try again. 
4. Select Agency name from a list: Prompts you to choose one agency from a numbered list of agencies (ordered by agency name).

$\begin{array}{ll}\text { AgenCY Names } & \\ \text { 0: EXIT } & \text { NFS } \\ \text { 1: NATIONAL FOREST SERVICE } & \text { PNL } \\ \text { 2: PACIFIC NORTHWEST LABORATORY } & \text { FEMA } \\ \text { 3: FEDERAL EMERGENCY MANAGEMENT AGENCY } & \text { OEM } \\ \text { 4: OREGON EMERGENCY MANAGEMENT } & \end{array}$

Choice $(?=\mathrm{Help})=\geq$

After selecting an agency, you then enter into the actual modification phase.

\section{Modify the Agency (Name and Code)}

The system prompts:

Modify the Agency name? $[Y]=>$

You must now $\therefore$ :ide whether you want to modify the agency acronym or the agency name - you cannot do both at once.

Y To change the agency name: Enter Y. The system prompts:

Enter new Agency name [Code] $=m$

Enter the full name of the agency. You are restricted to 64 characters, so once again, you may need to truncate your input. If that name is already in the lookup table, you must try again.

$\mathrm{N}$ To change the agency code: Enter $\mathrm{N}$ to skip the agency name and get this prompt for the agency code:

Enter new Agency code [Code] $==>$

Enter the acronym for the agency. You are restricted to only five characters, so you may need to truncate the acronym. If that acronym is already in the lookup table, you must try again.

After the modified agency code or name information are saved, the system returns to Step 1 and prompts you again. To exit, press CTRL $-Z$. 


\section{LIST AGENCIES}

This option enables you to list and view the contents of the agency lookup table, one screen at a time.

\section{People Tasks}

The personnel database inci 'des the names, addresses, agencies, positions (such as a job title or assignment), and telephone contact numbers of people who are involved with emergency management activities.

The complete set of Personnel Management options for creating and reviewing this information for using the position lookup table are:
- ADD PEOPLE
- MODIFY PEOPLE
- DELETE PEOPLE
- LIST PEOPLE BY NAME
- LIST PEOPLE BY AGENCY
- LIST PEOPLE BY POSITION

Any IBS user can look at this information by using the LST PEOPLE BY... options, but only an Information Manager can change the contents of this information, either through ADD PEOPLE, MODIFY PEOPLE, or DELETE PEOPLE. 


\section{ADD PEOPLE *}

ADD PEOPLE displays the following form for entering information about CSEPP personnel:

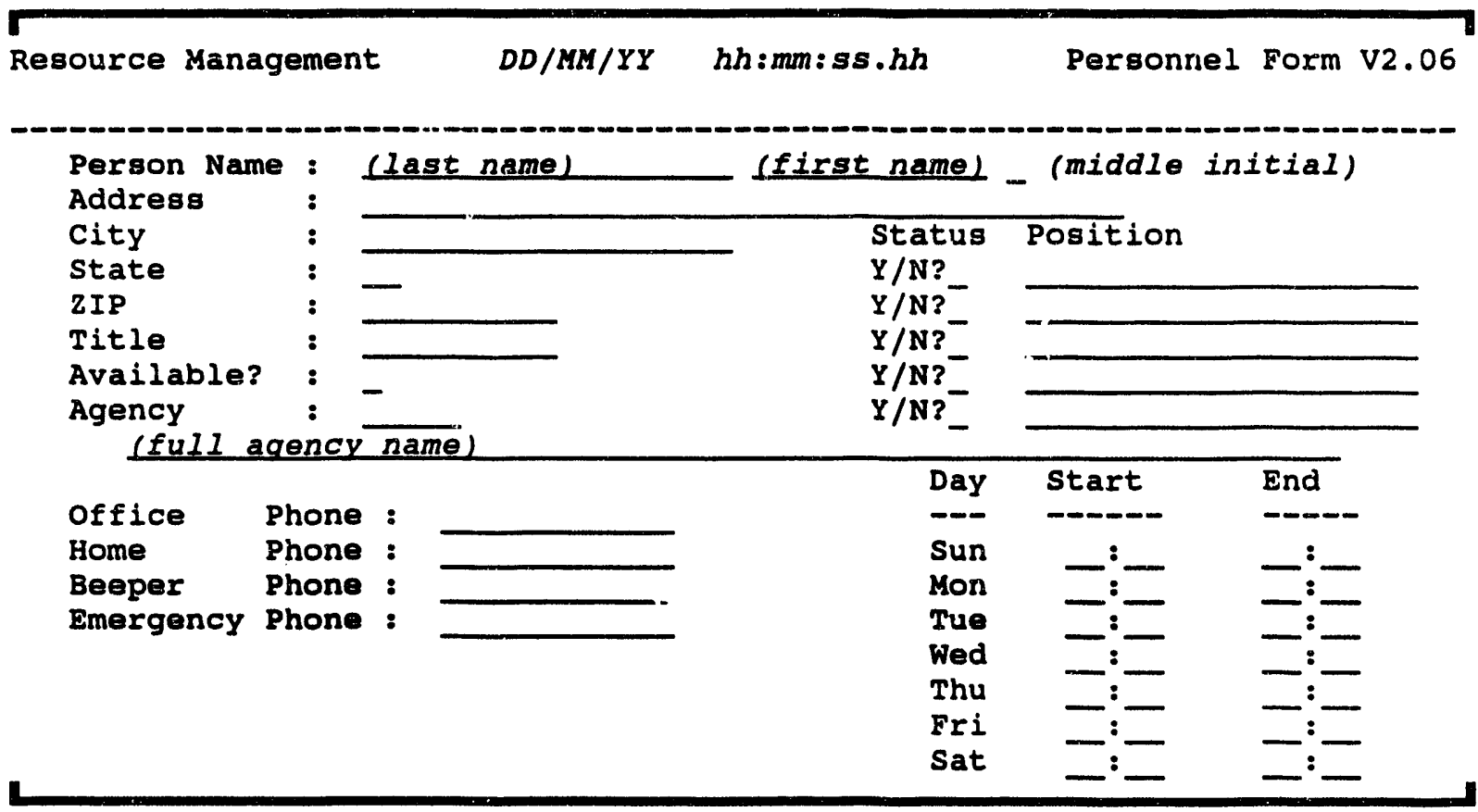

The date and time are the system date and time. Yuu can add information in any of the other fields.

- Available? (Y or $\mathrm{N}$ ): Is the person available $(\mathrm{Y})$ or unavailable for some reason, such as travel. (N). The person must be available to have active status in any of the positions for which the person is qualified.

- Status and Position: A list of up to five position titles can be entered to indicate emergency positions for which the person is qualified. Status indicates whether the person is currently active in the corresponding position ( $\mathrm{Y}$ or $\mathrm{N}$ ).

- Ofrice Phone: If the person is the designated contact person for a particular facility, it is expected that the "Office Phone" is the contact phone number included in the facility database. (For more information on the facility database, see RESOURCE MANAGEMENT. -ADD A FACILITY.) 
- Schedule: The schedule is a scrolled area for indicating the person's scheduled work times for each day of the week. Enter times for a 24-hour clock; for example, 13:00 is 1 p.m.

Use GOLD-Z to save the information, GOLD-Y to exit without saving. Use GOLD-Y in a blank form to exit the Add People option when you have finished adding,

\section{DELETE PEOPLE *}

This option enables an Information Manager to delete information about a specific person in the personnel database. The system displays the Personnel Selection method menu as described in MODIFY PEOPLE. Use the menu in the same way to choose the people you want to delete. 


\section{LIST PEOPLE BY NAME...AGENCY...POSITION}

These three options allow you to produce three different lists of personnel. You can list personnel by

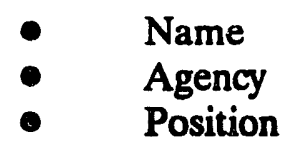

You must specify the information necessary to generate the personnel list by selecting an option from the following menu.

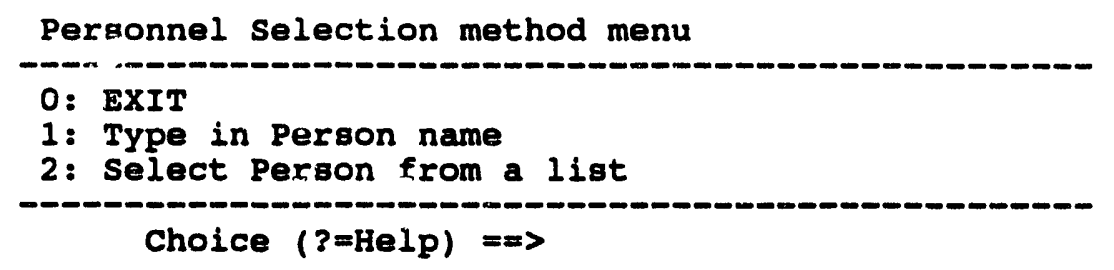

If you select Option 1: Type in Person name. The system then displays the following prompts.

Enter Person's last name $==>$

Enter Person's first name $==>$

Enter Person's middle initial $==>$

After you have entered the name of the person you want listed, the system displays the Personnel Selection method menu again. Continue selecting people until you are finished.

If yo" select Option 2: Select Person from a list, a menu similar to the following displays.

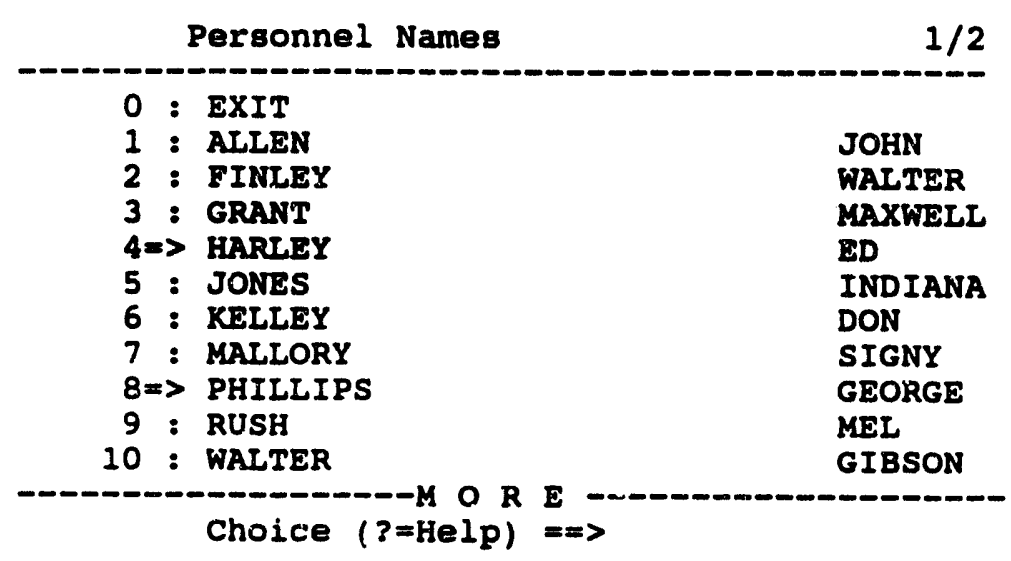

You can select multiple people from this menu. Enter the number of the person you want to select at the $==>$ prompt. The system will indicate the selection by 
displaying $\mathrm{a}=>$ symbol by the selected names. To finish your selection, select the 0: EXIT option. The Personnel Selection method menu will display.

Select the 0: EXIT option and the system displays the report listing the people you requested. The report looks similar to the following example.

$$
\text { Personnel Report (By Name) 8-JUL-1992 15:20:28.41 }
$$

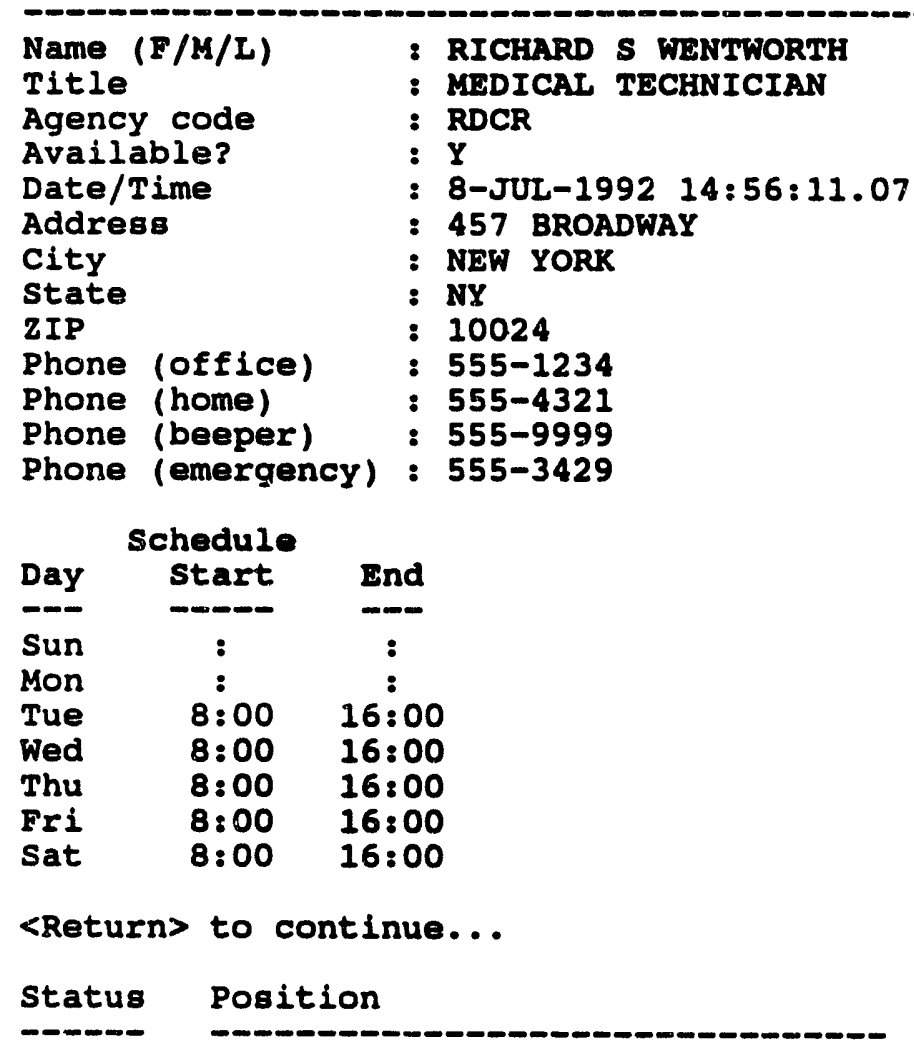




\section{MODIFY PEOPLE *}

This option enables an Information Manager to modify information about a specific person in the personnel database. Modifying personnel information consists of 1) specifying the person name and 2) entering new information about the person.

\section{Specify Which Person to Modify}

The system prompts:

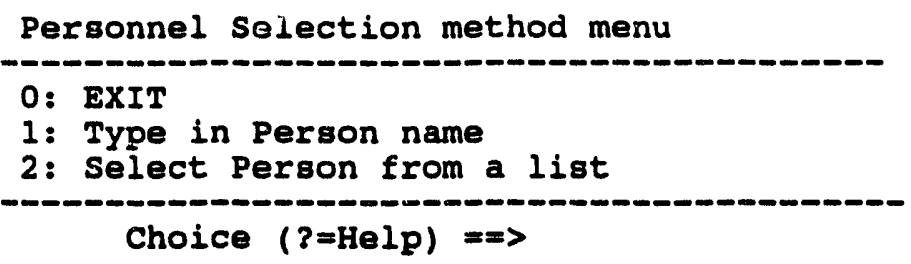

Use one of these two methods to specify the person for whom to modify information:

1. Type in Person name: Prompts you to enter the three parts of the person's name. For example:

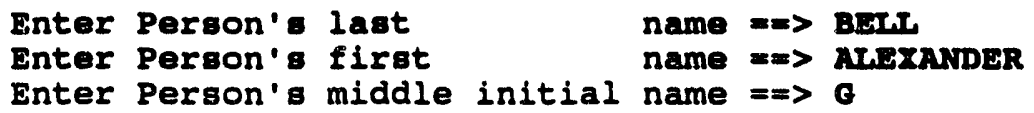

If the name is found in the personnel database, proceed to Step 2.

2. Select Person from a list: Prompts you to choose one name from a numbered list of personnel names. For example:

\begin{tabular}{|c|c|c|}
\hline $\begin{array}{l}0: \\
1: \\
2: \\
3:\end{array}$ & $\begin{array}{l}\text { EXIT } \\
\text { ASTOR } \\
\text { BELL } \\
\text { EDISON }\end{array}$ & $\begin{array}{l}\text { JOHN } \\
\text { ALEXANDER } \\
\text { THOMAS }\end{array}$ \\
\hline
\end{tabular}

Enter the number that corresponds to the desired name, or select 0 to exit. Proceed to modify information in Step 2. 


\section{Enter New Information about the Person}

The personnel data form is then presented for updating or modification. You can modify any fields except the system date and time. For example:

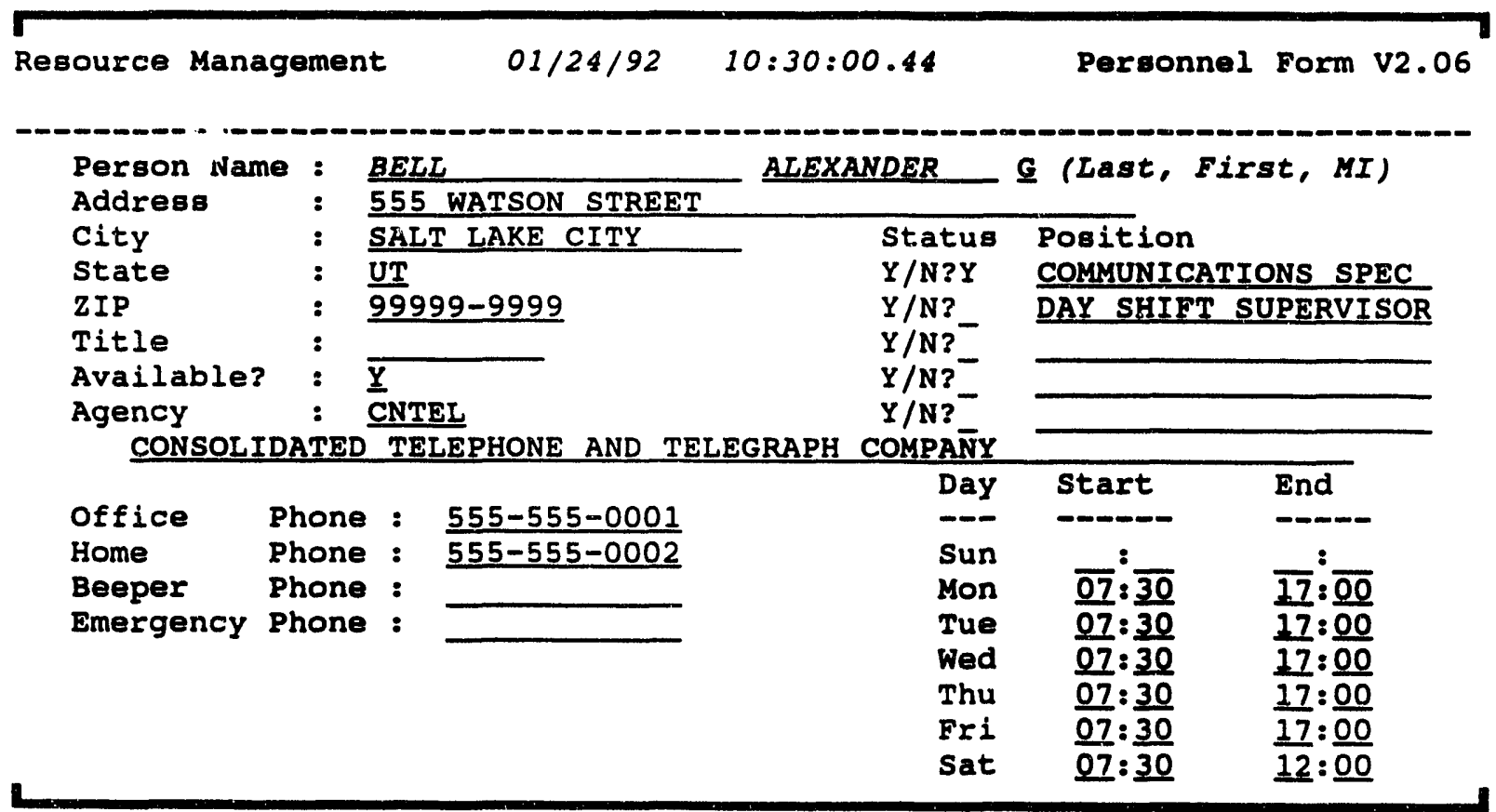

Exit the form and save the changes by pressing GOLD-Z. Exit the form and do not save the changes by pressing GOLD-Y.

\section{Position Tasks}

Within different agencies or organizations, personnel can hold one or more position (job titles, assignments, etc.). The IBS's position lookup table is a list of agency acronyms and positions associated with that agency. For example,

$\begin{array}{ll}\text { Agency } & \text { Position } \\ \text { PNL } & \text { PROJECT MANAGER } \\ \text { PNL } & \text { GIS PROGRAMMER } \\ \text { OEM } & \text { COMMUNICATIONS OFFICER }\end{array}$

The position lookup table is used throughout Personnel Management and Resource Management, and also in the Implementing Procedures.

While any General User can look at the table by using the LST POSITIONS option, only an Information Manager can change the contents of the table, either through ADD POSITIONS, DELETE POSITIONS, or MODIFY POSITIONS. 
The complete list of options available in Personnel Management for using the position lookup table are:

$\begin{array}{lll}- & \text { ADD } & \text { POSITIONS } \\ - & \text { MODIFY } & \text { POSITIONS } \\ - & \text { DELETE } & \text { POSITIONS } \\ - & \text { LIST } & \text { POSITIONS }\end{array}$

\section{ADD POSITIONS *}

This option enables an Information Manager to add information to the position lookup table. This consists of

1. Specifying which agency is associated with the position.

2. Entering a new position name.

\section{Specify Which Agency}

The system prompts:

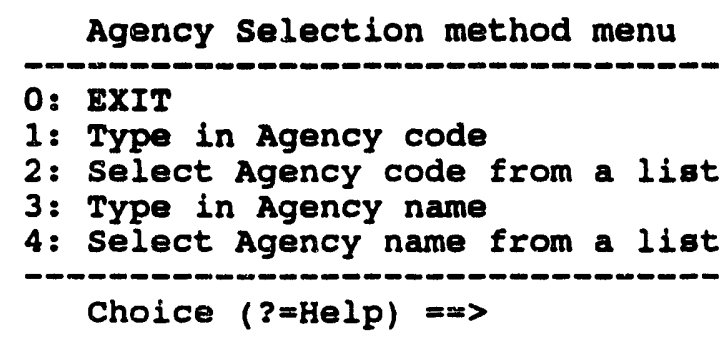

Use one of these four methods to select the agency associated with the position(s) that you wish to add. Refer to MODIFY AGENCIES for more information on selecting an agency from this menu.

After doing so, you are ready to add the new position to the table. 


\section{Enter a Now Position Name}

The system prompts:

Enter new Position $==>$

Enter the name of the position you want associated with the agency.

You are restricted to only 20 characters, so you may need to truncate you. input.

After the new position information is saved, the system returns to Step 1 and prompts you again.

\section{DELETE POSITIIONS *}

This option enables an Information Manager to delete a position associated with an agency. The system displays the Agency/Position Selection method menu as described in MODIFY POSITIONS. Use the menu in the same way to choose the positions you want to delete.

\section{MODIFY POSITIONS *}

This option enables an Information Manager to modify information already in the position lookup table. This consists of 1) selecting which position to modify and 2) entering a new name for the position.

\section{Specify Which Position to Modify}

The system prompts:

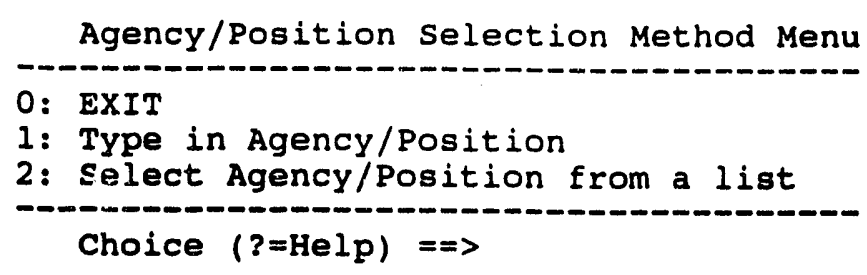

Use one of these two methods to select a position to modify.

1. Type in Agency/Position: Prompts you to enter the agency acronym and then the position at that agency.

Enter Agency Code $==>$

Enter Position $==>$ 
Enter the agency acronym and the position you wish to modify. If either are not in the position lookup table, you must try again.

2. Select Agency/Position from a list: Prompts you to select a position from a numbered list of positions at different agencies.

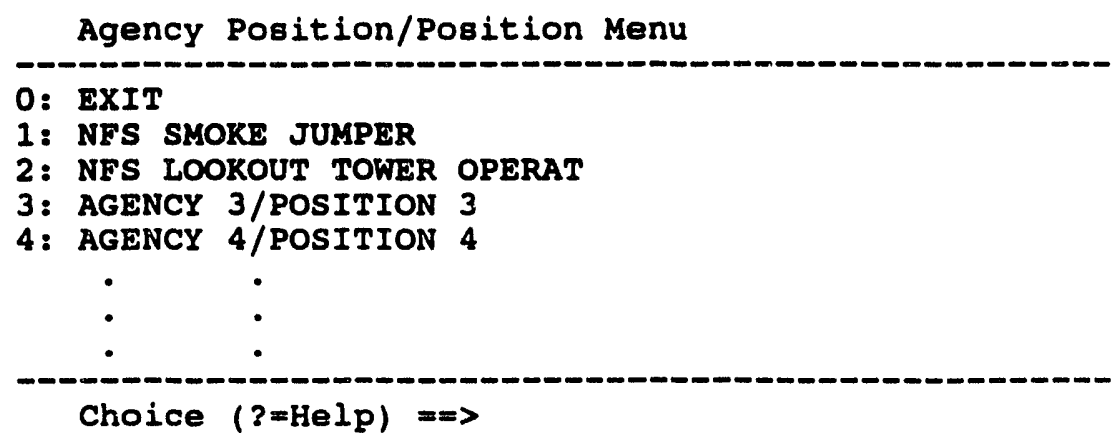

Enter the number of the position you wish to modify.

\section{Enter a New Name for the Position}

The system then prompts:

Enter new Position $==>$

Enter the new name for the position. If it is already in the table, you must try again.

To quit any of these prompts, press GOLD-Z or CTRL-Z.

After the modified position information is saved, the system returns to the Agency/Position Selection method menu. To quit, select option 0: EXIT.

\section{ID LIST POSITIONS}

This option enables you to list and view the contents of the position lookup table, one screen at a time. 


\section{Section 5 \\ Map Analysis}

\section{- MAP ANALYSIS}

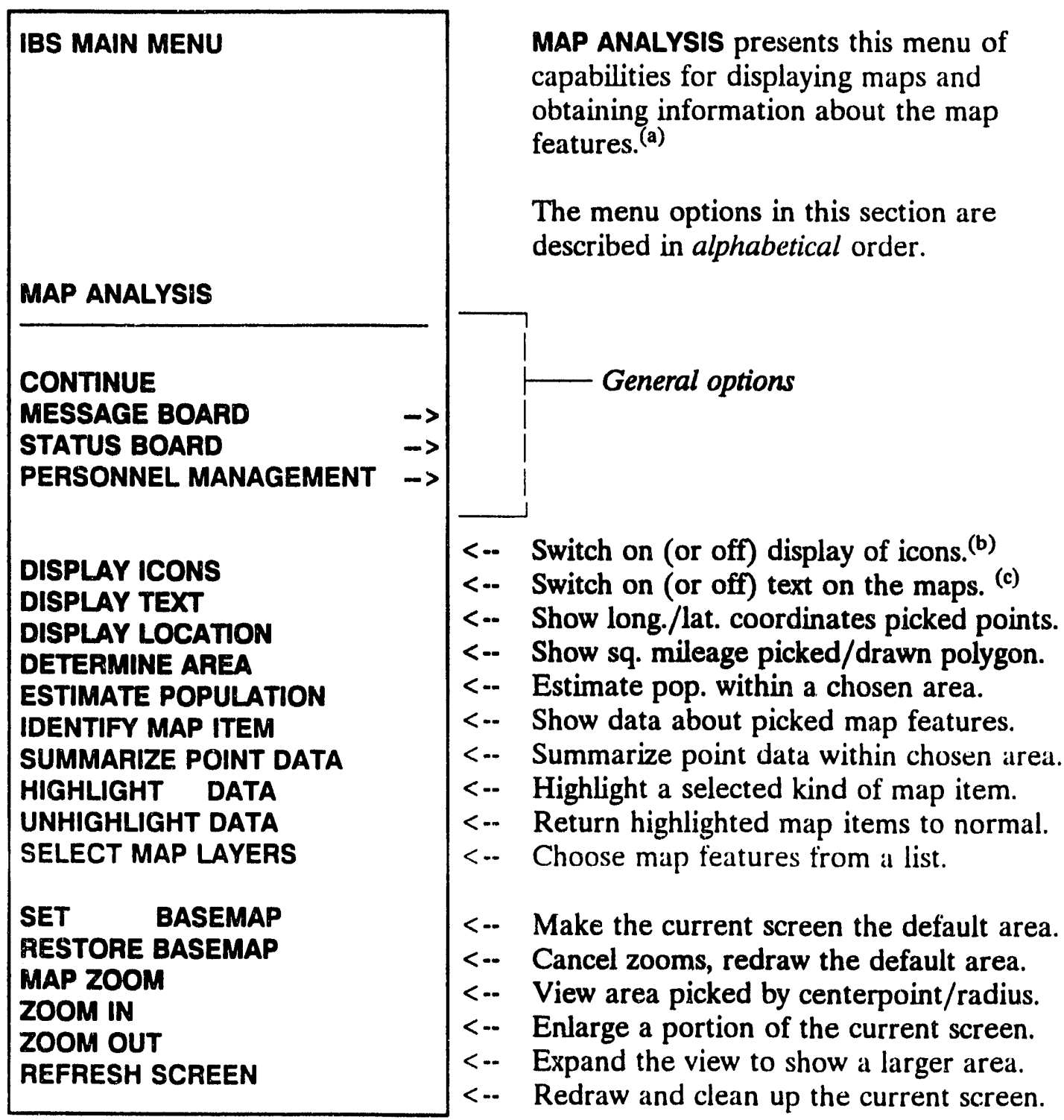

\section{DETERMINE AREA}

(a) An independent utility program, GEDIT, provides map editing capabilities. GEDrr is documented in the IBS Utilities Guide.

(b) When chosen. DISPLAY ICONS switches to TURN OFF ICONS at the same position.

(c) When chosen, DISPLAY TEXT switches to TURN OFF TEXT at the same position. 
DETERMINE AREA displays the area (in both acres and square miles) of a polygonal region. The region's perimeter is also displayed (in both feet and miles).

When you select DETERMINE AREA, the program prompts you to define the region in one of three ways:

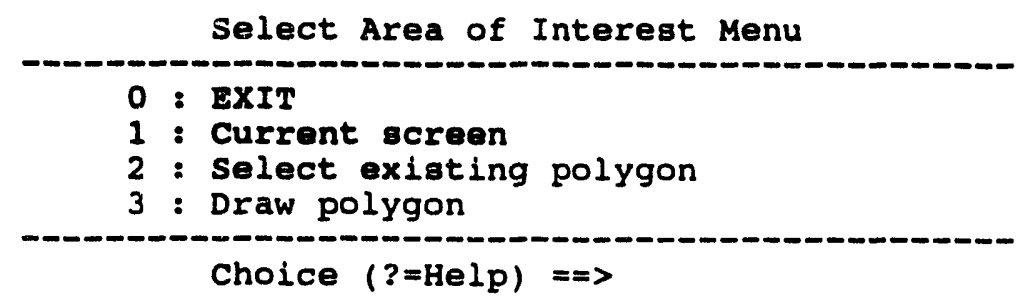

Your choices are these:

1. Current screen: Determines the area of the current screen.

2. Select existing polygon: Enables you to pick an existing polygon to define the desired region.

3. Draw polygon: Enables you to pick points that define a polygon around the desired region.

These methods for defining a region are fully described in Section 1.

Note: Remember to select the Continue option after you have defined an area.

After the polygon is defined, the requested data are displayed:

\begin{tabular}{cccc}
$\begin{array}{c}\text { Area } \\
\text { (Sq. Miles) }\end{array}$ & $\begin{array}{c}\text { Area } \\
\text { (Acres) }\end{array}$ & $\begin{array}{c}\text { Perimeter } \\
\text { (Miles) }\end{array}$ & $\begin{array}{c}\text { Perimeter } \\
\text { (Feet) }\end{array}$ \\
\hdashline 167.657 & -106020.314 & 50.430 & 266269.033
\end{tabular}




\section{IDISPLAY ICONS (TURN OFF ICONS)}

DISPLAY ICONS is a switch that turns on the display of any icons included in the current map display data. (When you pick DISPLAY ICONS, the menu item switches to TURN OFF ICONS.)

TURN OFF ICO $\$$ is the reverse operation that cancels the display of any icons included in the current map display data. (When you pick TURN OFF ICONS, the menu item switches back to DISPLAY ICONS.) Select REFRESH SCREEN to finish removing the icons.

\section{DISPLAY LOCATION}

DISPLAY LOCATION displays the following information about a point (or sequence of points) that you pick:

- Longitude, latitude

- Delta miles, or the miles from the last point you picked

- Total miles accumulated along the chain of points you pick

- Miles to the center of the screen

When you select DISPLAY LOCATION, the program prompts:

* * MSG: Use crosshair to pick a known point.

After you pick a point, the information is displayed in a table. For example:

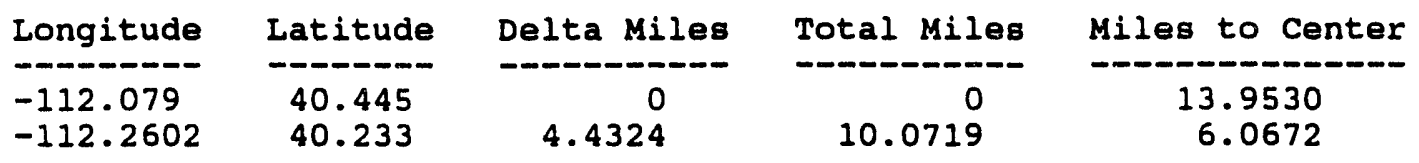

As you continue to pick points, the information about previous points remains on the screen. Choosing CONTINUE or picking another menu item ends the capability and removes the information from the screen.

\section{ID DISPLAY TEXT (TURN OFF TEXT)}

DISPLAY TEXT immediately displays the text labels associated with items on the current map screen. When you select DISPLAY TEXT, the menu item switches to TURN OFF TEXT.

TURN OFF TEXT enables you to cancel the display of text labels on the screen. To remove the text, select REFRESH SCREEN after selecting TURN OFF TEXT. 


\section{ESTIMATE POPULATION}

ESTIMATE POPULATION provides an estimate of the population within a defined area. There are two sources of data for population reports within ESTIMATE POPULATION:

- Census data

\section{- People Locate data}

Census data (if present in the site database) comes from static census database map layers chosen using SELECT MAP LAYERS in MAP ANALYSIS, or CHANGE DEFAULT LAYERS in SETUP. People Locate data is generated by the People Location (LOCATE) program (see Appendix C). When you select Estimate Population, the system displays the following menu.

Select Area of Interest Menu
0: ExIT
2: Current screen
3: Draw polygon
Choice $(?=$ Help) $==$

Use one of these three methods to specify which items on the graphic display screen are used to calculate population.

1. Current screen: Will calculate population for the entire display area.

2. Select existing polygon: Prompts you to select a polygon from the screen with the cross hairs.

Note: If you select a polygon which is partly offscreen, the following message will display:

* * * MSG: Polygon selected is partially off the current screen.

* * * MSG: The population shown may not be accurate.

Any population information you receive after viewing this message should be verified by using the zoom out option so the polygon is completely onscreen, then estimating the population of the polygon again.

3. Draw polygon: Prompts you to draw an area on the screen with the cross hairs.

After you select an area, the system will display the following menu. The source of population data accessed within ESTIMATE POPULATION depends on the type of population report selected. 


\begin{tabular}{ll} 
Estimate Population Selection Menu \\
0: ExIT & (Census) \\
1: Total population & (Census) \\
3: Population by age group & (People Locate) \\
a: Facility summary & (People Locate) \\
\hline Choice (?=Help) &
\end{tabular}

Select the type of report data you wish to see from these choices. The choices marked with Census will use census daia for calculaticit. The choices marked with People Locate will use the Locate database for calculation.

Your choices are:

1. Total population (Census): Produces a report of the total population for the selected area. Census population data is used to generate this report.

\begin{tabular}{l} 
Estimated Population Based on Census Data \\
Map Layer \\
Population Pattern : Weeknight \\
Total Population : XXXXX \\
\hline Return> to continue...
\end{tabular}

If no population map layer was selected, the program displays the following message:

* * * MSG: No population topography selected

If this happens, use SELECT MAP LAYERS in MAP ANALYSIS, or CHANGE DEFAULT LAYERS in SETUP to select a population map layer.

2. Population by age group (Census): Produces a report of the population in the selected area summarized into age categories. Census demographic data is used to generate this report.

\begin{tabular}{|c|c|c|c|}
\hline $\begin{array}{l}\text { Map Layer } \\
\text { Population } \\
\text { Total Age } \\
\text { Total Age } \\
\text { Total Age } \\
\text { Total Age } \\
\text { Total Popu. }\end{array}$ & $\begin{array}{l}\text { Pattern } \\
0-5 \\
6-19 \\
20-64 \\
>65 \\
\text { lation }\end{array}$ & $\begin{array}{l}: \\
: \\
: \\
: \\
:\end{array}$ & $\begin{array}{l}\text { DEMOGRAPHIC } \\
\text { Weeknight } \\
\text { XXXX } \\
\mathrm{XXXX} \\
\mathrm{XXXX} \\
\mathrm{XXXX} \\
\mathrm{XXXX}\end{array}$ \\
\hline
\end{tabular}

DD-MMM-YYYY HH: MM:SS

<Return> to continue ... 
If no demographic map layer was selected, the program displays the following message:

* * * MSG: No demographic topography selected

If this happens, use SELECT MAP LAYERS in MAP ANALYSIS, or CHANGE DEFAULT LAYERS in SETUP to select a demographic map layer.

3. Population by facility (People Locate): Produces a report of the number of people received, released, and remaining at emergency-related facilities. These facilities are of the following type: 1) shelters, 2) reception centers, 3) decontamination centers, 4) hospitals, and 5) morgues. People Location data is used to generate this report.

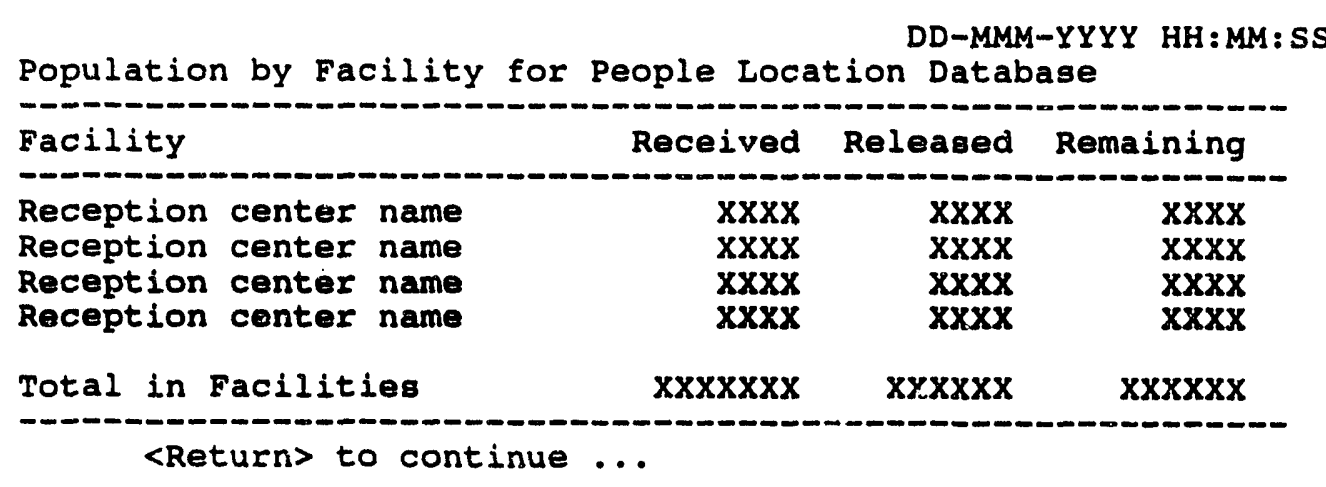

4. Facility summary (People Locate): Produces a facility summary report for number of facilities, total number of people remaining, and percent load (people remaining/capacity) for emergency-related facilities. People Location data is used to generate this report.

\begin{tabular}{|c|c|c|c|c|c|c|}
\hline Facility & (ive) & $\begin{array}{l}\text { umber } \\
\text { (Total) }\end{array}$ & $\begin{array}{l}\text { Popu } \\
\text { (Active) }\end{array}$ & $\begin{array}{l}\text { lation } \\
\text { (Total) }\end{array}$ & $\begin{array}{r}\text { Load/ } \\
\text { (Active) }\end{array}$ & $\begin{array}{c}\text { Cap }(z) \\
(\text { Total) }\end{array}$ \\
\hline Shelter & $X X X$ & $\mathrm{xxx}$ & $x \times x$ & $x \times X$ & $x \times X$ & $\mathrm{xxx}$ \\
\hline Reception centers & $\mathbf{X X X}$ & $\mathrm{xxx}$ & $x \times x$ & $\mathbf{X X X}$ & $\mathrm{XXX}$ & $\mathrm{XxX}$ \\
\hline Decontamination centers & $\mathbf{X X X}$ & $\mathrm{xxX}$ & $\mathbf{x x X}$ & $\mathbf{X X X}$ & $\mathbf{X X X}$ & $\mathrm{XXX}$ \\
\hline Hospital & $\mathbf{X X X}$ & $\mathrm{xxx}$ & $\mathbf{x x x}$ & $\mathbf{X X X}$ & $\mathbf{x x}$ & $\mathrm{xxx}$ \\
\hline Morgue & $\mathbf{X X X}$ & $\mathbf{X X X}$ & $\mathbf{x x X}$ & $\mathbf{X X X}$ & $\mathbf{X X X}$ & $\mathbf{X X X}$ \\
\hline Other & $\mathbf{x} \mathbf{x}$ & $\mathbf{x x x}$ & $\mathbf{x x x}$ & $\mathbf{X X X}$ & $\mathbf{X X X}$ & $\mathbf{x x x}$ \\
\hline TOTAL: & $\mathrm{xxxx}$ & $\operatorname{xxxx}$ & $x \times x x$ & $\mathrm{xxx}$ & $\mathrm{XxXXX}$ & $\mathrm{XXXX}$ \\
\hline
\end{tabular}

The report lists:

A. The number of total and active facilities. 
B. The number of people remaining at active facilities, and combined inactive and active facilities.

C. The percent load (people remaining/facility capacity) for active, and combined inactive and active facilities.

\section{HIGHLIGHT DATA}

HIGHLGHT DATA enables you to highlight specific types of graphic items (lines, points, icons, etc.) within the map display area. The graphic items must be visible within the display area. ZOOM IN or ZOOM OUT first, as required, before selecting Highlight Data. (See also-UNHIGHLIGHT DATA.)

After you select HIGHLIGHT DATA, the system prompts with the following menu:

\begin{tabular}{l} 
Highlight Data Menu \\
0 : ExIT \\
1 : Enter attribute description \\
2 : Iist attributes for current screen \\
\hline Choice $=>$ -
\end{tabular}

Use one of these two methods to specify which items on the graphics display screen are to be highlighted:

1. Enter attribute description: Prompts you to enter an attribute description:

Enter data description $=m$

Enter any text that describes the feature you are interested in (from 1 to 60 characters). You can enter the entire attribute description (example, NATIONAL FOREST OR GRASSLAND), or only part of the attribute description (FOREST).

2. List attributes for current screen: Presents a list of attributes for all data items within the current screen display area. 
After you select a method, a listing of the attributes on the screen is presented. An example of such a listing follows:

Attribute Description MENu
0 : EXIT
$1:$ EMERGENCY PLANNING ZONE BOUNDARY
$2:$ INDIAN RESERVATION
$3:$ NATIONAL FOREST OR GRASSLAND
$4:$ NATIONAL SCENIC WATERWAY OR WILDERNESS AREA
$5:$ SHELTER
$6:$ EMERGENCY PLANNING ZONE BOUNDARY
$7:$ INTERSTATE
ChOICE $(?=\mathrm{Help})==>$

Select an attribute from the list of attributes. All data with this attribute description are then highlighted. Lines are redrawn as wide lines and the location of points or icons are shown as highlighted white asterisks.

To highlight additional types of data, select HIGHLIGHT DATA again. Highlighted areas remain onscreen until you cancel the highlighting. To cancel highlighting, use the UNHIGHLGHT DATA option. 


\section{IDENTIFY MAP ITEM}

IDENTIFY MAP ITEM displays attribute information about a graphic item (or sequence of items) that you pick on the map screen. When you select IDENTIFY MAP ITEM, the following prompt appears:

* * * MSG: Pick a map item using mouse or crosshair.

After you pick an item on the map, attributes for that item are listed as shown in the following example. Graphic notes for that item, (such as Known Polygon ID) are displayed also. The most recently entered note is displayed first.

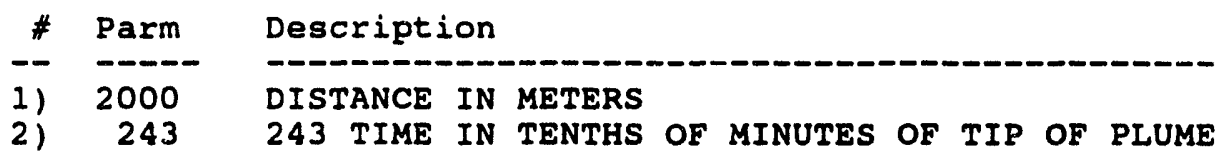

As you continue to pick graphic items, the information about previous items is superseded. Picking Continue or another menu item ends the capability and removes the information from the screen.

\section{ID MAP ZOOM}

The zoom capabilities change or affect the size of the region shown in the map display area of the graphics screen. MAP ZOOM enables you to specify the center point and radius of an area displayed on the screen. (See also ZOOM IN, ZOOM OUT, SET BASEMAP, RESTORE BASEMAP.)

MAP ZOOM prompts you to define the center in one of three ways:

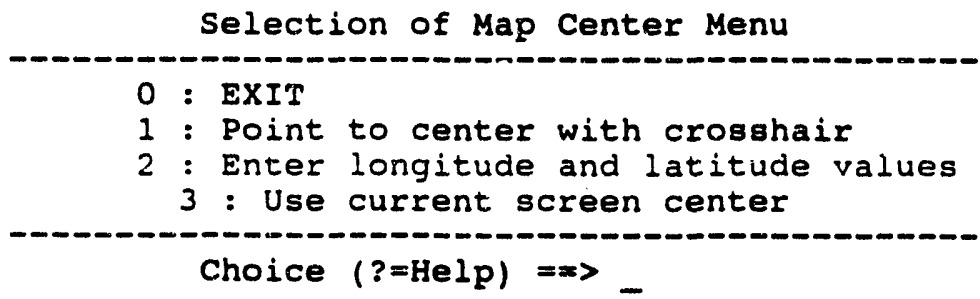

Your choices are:

1. Point to center with crosshair: Enables you to point to the location that you wish to be screen center. The system prompts:

* * * MSG: Use the crosshair to pick center of new display

After you pick the center with the cross hairs, the system will prompt:

Enter the radius (in miles) $\Rightarrow>>$ 
2. Enter longitude and latitude values: Enables you to enter specific longitude and latitude values. The system prompts:

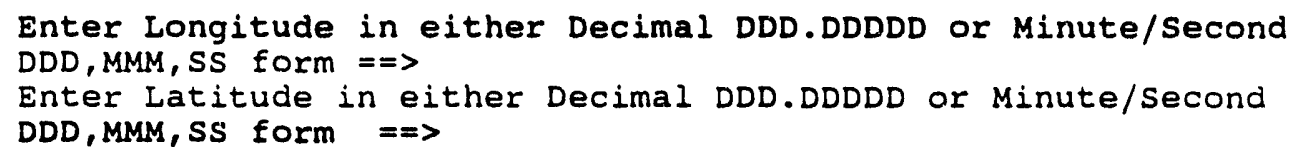

3. Use current screen center: Enables you to use the current center point of the screen.

In all of these cases, you are then prompted for the desired radius:

Enter the radius (in miles) $=\Rightarrow$

When you have entered all required information, the map screen is redrawn with the center and radius as you have specified. 


\section{REFRESH SCREEN}

REFRESH SCREEN redraws the current map display screen. This may be needed after text or graphic items have been erased, redrawn, or overdrawn: these operations sometimes create "holes" in the displayed data.

\section{ID RESTORE BASEMAP}

RESTORE BASEMAP enables you to refresh the display and restore the original extents of the map to the area displayed before any zoom operations. However, if you have used SET BASEMAP, then RESTORE BASEMAP resets the display size to the area that was displayed after SET BASEMAP was last picked.

\section{ID SELECT MAP LAYERS}

\section{IBS MAIN MENU \\ MAP ANALYSIS}

SELECT MAP LAYERS

FORWARD

BACKWARD

MAP LAYER 1

MAP LAYER 2

.

•

•

MAP LAYER $n$
SELECT MAP LAYERS produces this submenu, which lists the different groups of map features (layers) available for display in the map database. The currently displayed map layers are already selected (listed in green) when you first see this menu.

You can select additional map layers for temporary display or cancel some of those already selected. When you exit this menu, the selected map layers are drawn on the map screen and remain for the rest of your work session unless you change them again here.

Note: As soon as you exit Map Analysis and redraw the screen, default map layers defined in SETUP will supersede any map layers you alter in MAP ANALYSIS. 
Not all map layers than can be shown on a single menu. Use the FORWARD and BACKWARD options to display other pages of the map layer list:

- FORWARD shows the next page of map layers. When you reach the end of the list, the next FORWARD returns you to the first page.

- BACKWARD shows the previous page of map layers. When you reach the first page of the list, the next BACKWARD sends you to the last page.

\section{SET BASEMAP}

This enables you to reset the base map-the default display area for this session-to be the area currently displayed on the screen. If you later use RESTORE BASEMAP, the display is redrawn to show this default display area. 


\section{SUMMARIZE POINT DATA}

SUMMARIZE POINT DATA produces a summary of information about the point data within a defined area.

The program prompts you to define the area in one of three ways:

Select Area of Interest Menu
$0:$ ExIT
$1:$ Current screen
$2:$ Select existing polygon
$3:$ Draw polygon
$4:$ Select point
Choice $(?=$ Help $)=m$

Your choices are these:

1. Current area: Produces summary information for all point data within the current screen map area.

2. Select existing polygon: Enables you to choose an existing polygon to define the desired area.

3. Draw polygon: Enables you to pick points to define a polygon around the desired area.

4. Select point: Prompts you to select a point with the cross hairs or mouse. You can use the HIGHLIGHT DATA command to make the point easier to see before selecting it with the SUMMARIZE POINT DATA command. If you select this option, the following message displays.

* * * MSG: Pick a data point using mouse or crossiair

After you have selected an area, the following menu displays.

List Attribute Description Menu
0: EXIT
2: List attributes for selected area
Choice $(?=$ Help) $==>$


Use one of these two methods to specify which attributes from the selected area are to be displayed.

1. List attributes for selected area: Presents a list of attributes for all data items within the previously selected area.

\begin{tabular}{l} 
Select Attribute Description Menu \\
\hline $0:$ EXIT \\
$1:$ CEMETERY \\
$2:$ FLOWING WELL \\
$3:$ MINE \\
$4:$ MINE SHAFT \\
$5:$ MINE TUNNEL \\
ChOice $==>$
\end{tabular}

Each description is associated with one or more point(s) on the screen. Enter the index number that corresponds to the data that you want summarized.

2. Enter attribute description: The system prompts you to enter an attribute description:

Enter data description $==>$

Enter any text (from 1 to 60 characters). You can enter the entire attribute description (example, NATIONAL FOREST OR GRASSLAND), or only part of the attribute description (FOREST). All attribute descriptions that match the entered text and are within the selected area of interest are listed.

After you have selected an attribute, the IBS summarizes information for all point data within the selected area which have that attribute. For example:

Pcint Data Summary for Selected Area

DD-MMM-YYYY HH:MM:SS

Description: DAY FOR TAIL OF PLUME

\# of Points Attribute Parameter statistics Maximum Minimum Aumerage

Press <RETURN> to continue... 
The point data summary includes:

- The number of points with the selected attribute

- The SUM, MINIMUM, MAXIMUM, and AVERAGE of the attribute parameter values associated with those points.

\section{TURN OFF ICONS (DISPLAY ICONS)}

TURN OFF ICONS is a switch that cancels the display of any icons included in the current map display data. Select REFRESH SCREEN to finish removing the icons. When you pick TURN OFF ICONS, the menu item switches to DISPLAY ICONS.

DISPLAY ICONS is the reverse operation that turns on the display of any icons included in the current map display data. When you pick DISPLAY ICONS, the menu item switches back to TURN OFF ICONS.

\section{ITURN OFF TEXT (DISPLAY TEXT)}

TURN OFF TEXT enables you to cancel the display of text on the screen. Select REFRESH SCREEN after selecting TURN OFF TEXT to complete the removal of text from the screen.

When you select TURN OFF TEXT, the menu item switches to DISPLAY TEXT. DISPLAY TEXT immediately redraws the text on the map screen. 


\section{ID UNHIGHLIGHT DATA}

UNHIGHLIGHT DATA can be used to cancel the effect of HIGHLIGHT DATA, which highlights all instances of a particular type of map item. UNHIGHLIGHT DATA returns one type of highlighted map item to normal.

After you select UNHIGHLIGHT DATA, the system prompts you with the following menu:

UnHighlight Data Menu

$\begin{aligned} & 0: \text { ExIT } \\ & 1: \text { Enter attribute description } \\ & 2: \text { List all highlighted attributes } \\ & 3: \text { UnHighlight all Highlighted items } \\ & \text { Choice }(?=\text { Help) }==>\end{aligned}$

Use one of these three methods to specify which items on the graphics display screen are to be unhighlighted:

1. Enter attribute description: Prompts you to enter a data attribute description:

Enter data description $==$

Enter any text (from 1 to 60 characters). You can enter the entire attribute description (example, NATIONAL FOREST OR GRASSLAND), or only part of the attribute description (FOREST). All highlighted attribute descriptions that match the entered text are listed.

2. List all highlighted attributes: Presents a list of attributes which are currently highlighted.

3. Unhighlight all highlighted items: Selecting this menu item unhighlights all of the data which is currently highlighted.

After selecting a method, a listing of the highlighted attributes (which match the input description, if the user entered an attribute description) is presented. An example of such a listing follows: 


Highlighted Attribute Description Menu
$0:$ EXIT
$1:$ EMERGENCY PLANNING ZONE BOUNDARY
$2:$ INDIAN RESERVATION
$3:$ NATIONAL FOREST OR GRASSLAND
$5:$ NATIONAL SCENIC WATERWAY OR WILDERNESS AREA
5 SHELTER
Choice $(?=\mathrm{Help})=\equiv$..

Select an attribute from the list of attributes. All data with this attribute description are then unhighlighted and returned to normal.

To unhighlight additional types of data, select UNHIGHLIGHT DATA again.

Restoring map items to their original appearance with UNHIGHLIGHT DATA may produce graphic fragments where the map items are redrawn. If this happens, pick REFRESH SCREEN to clean up the screen.

\section{IIZOM IN}

ZOOM IN enables you to enlarge a square portion of the current display screen. (See also MAP ZOOM.)

The program prompts:

* * * MSG: Select center and one edge $w /$ mouse

1. Position the graphics cursor (cross hairs) on the center of the area you want to zoom in and press the Return key.

2. Position the graphics cursor on the edge of the zoom region and press the Return key.

A square zoom in box is drawn by the system, indicating the zoom in area. The screen is refreshed, and the zoom in area is expanded to fit the entire map graphics area. 


\section{ZOOM OUT}

ZOOM OUT enables you to view a larger area of interest on the screen. (See also MAP ZOOM.)

The program prompts:

* * * MSG: Select center and one edge w/mouse

1. Position the graphics cursor (cross hairs) on the center of the area you want to zoom out and press the Return key.

2. Position the graphics cursor on the edge of the zoom out region and press the Return key.

A square zoom out box is drawn by the system, indicating the zoom out area. The screen is refreshed, and the previous map display area is compressed and redrawn within the zoom out box area. The zoom out box area is centered in the new map display screen. 


\section{Section 6 \\ Resource Management}

\section{RESOURCE MANAGEMENT}

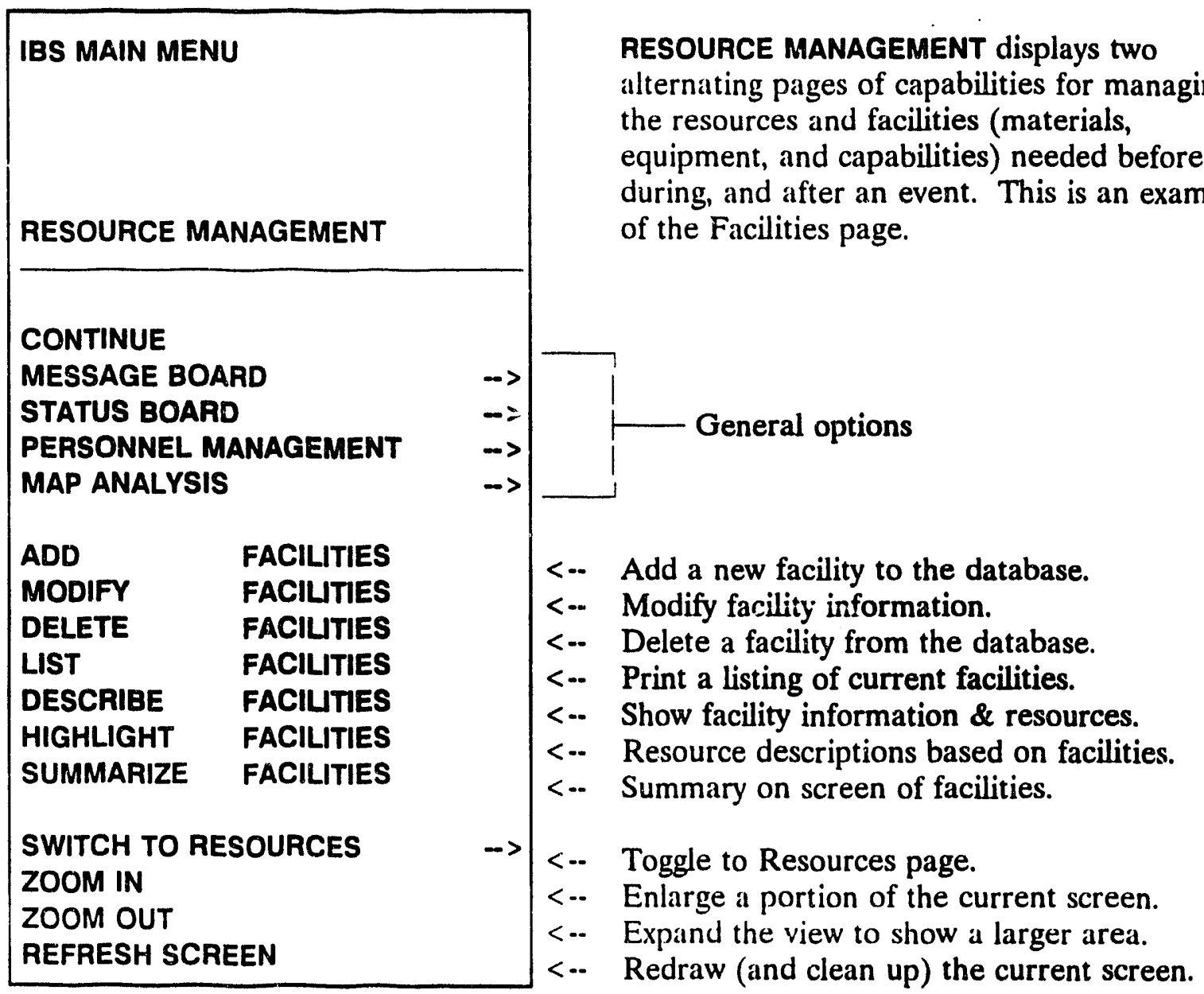

The locations of resources and facilities are depicted by graphic icons. Each of these resource and facility icons represents a major resource type. Each facility can include any number of unique resources. Thus, a facility icon often depicts the location of one or more individual resources within one resource type. 


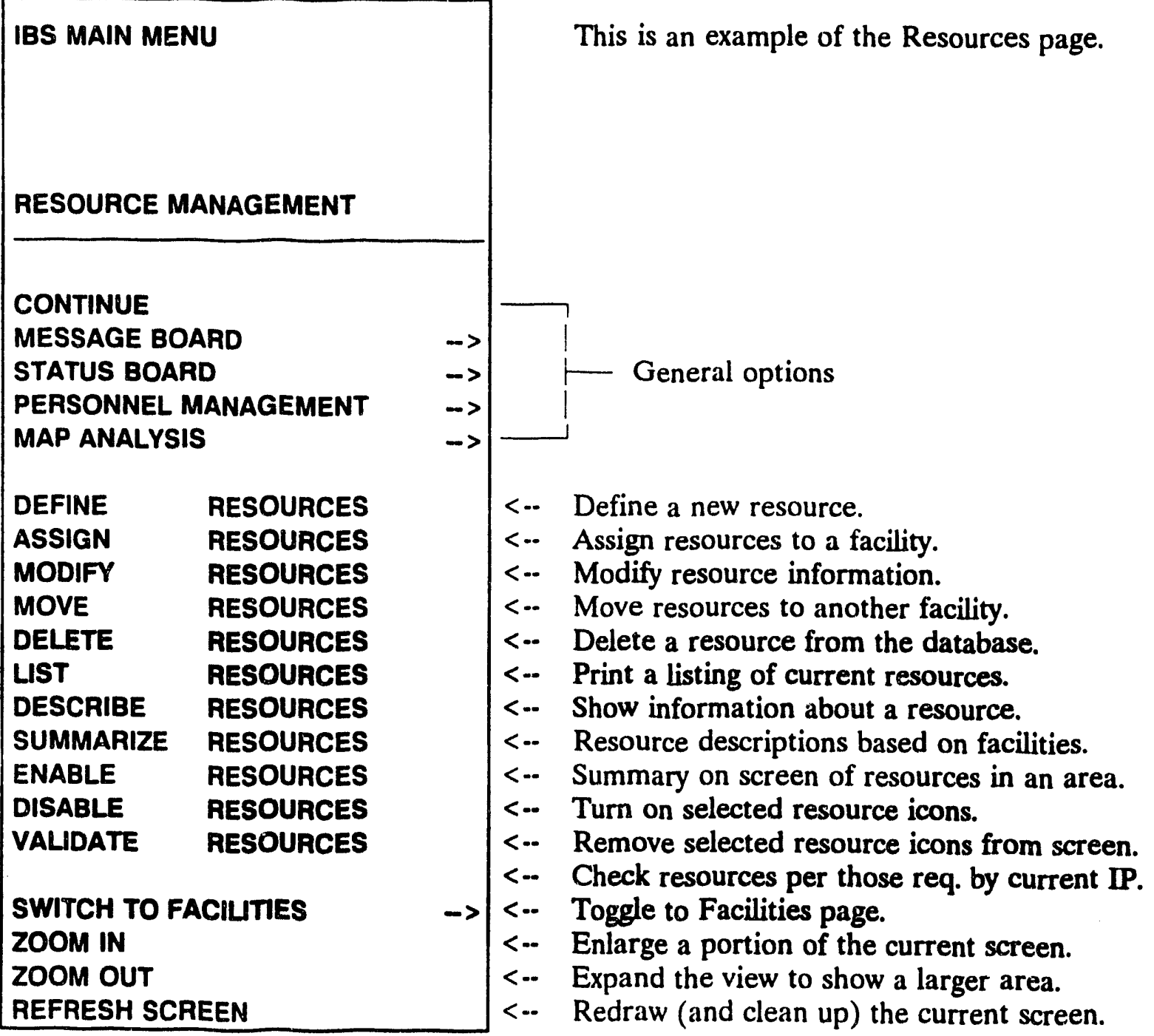

Facility icons that graphically depict the locations of facilities are automatically displayed when you start RESOURCE MANAGEMENT. Each facility can have up to 60 resource types associated with it. All IBS users can view facility information and list the resources located at the facilities. Information Managers can also define resources, define facility locations, assign quantities of resources at facilities, update this information in the resource database, and check (validate) the available resources against the resources required by the current Implementing Procedure.

The RESOURCE MANAGEMENT menu options are described in alphabetical order within two general categories:

- Facility Tasks 
- Resource Tasks

REFRESH SCREEN and ZOOM IN/OUT are explained as options of MAP ANALYSIS in Section 5.

\section{Facility Tasks}

The tasks of adding a new facility, updating facility information, and viewing information about a facility share some procedures in common. The following figure illustrates these common elements:

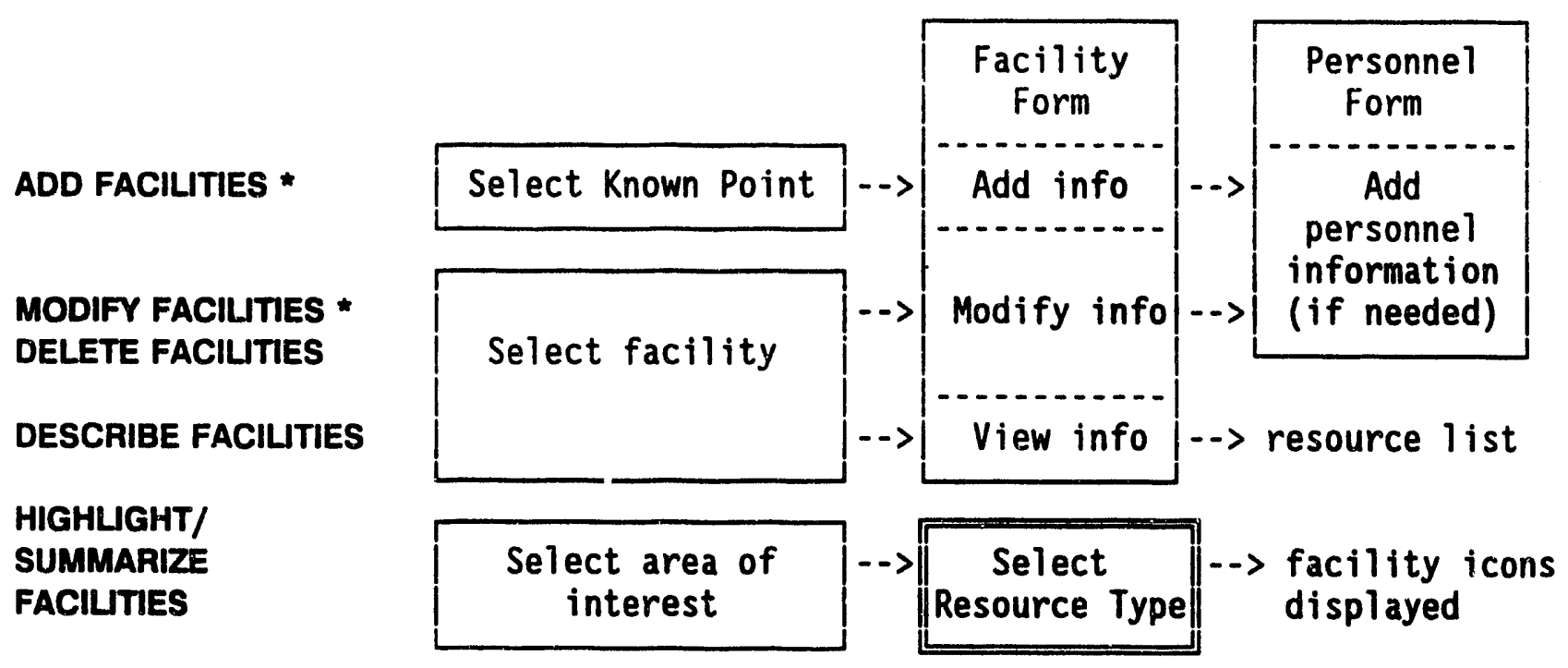

- Three : iptions (ADD FACILITIES, MODIFY FACILITIES, and DESCRIBE FACILITIES) present facility information in the same facility form. (See ADD FACILITIES for a complete description of this information form.)

' $थ$

- MODIFY FACILITIES and DESCRIBE FACILITIES allow you to first select which facility to modify or describe. Selecting a Facility is explained as an independent facility task.

- ADD FACILITIES and MODIFY FACILITIES can involve the use of a personnel form for entering the information about the facility contact person ints the personnel database.

- HIGHLIGHT FACILITIES is used to highlight (flash) the icons of facilities that contain resources of a selected type. Selecting a Resource Type is explained as an independent resource task. 


\section{ADD FACILITIES *}

This option enables an Information Manager to add a new facility. Adding a facility consists of 1) specifying a facility location, 2) entering a facility description, and 3 ) entering personnel information about the facility contact person (if necessary).

\section{Specify a Facility (Known Point) Location}

The system displays the following menu

Known Point Selection Method menu

$0:$ ExIT
1 : Type in known Point name
$2:$ Select known Point name from a list
3 : Type in long/lat coordinates
$4:$ Use mouse to select known Point
Choice $(3=\mathrm{Help})=>$

Use the Known Point Selection Method menu to choose the method you want to use to select a known point. For example, if you select Option 4 : Use mouse to select Known Point, the following message will display.

* * MSG select Rnown Point location w/mouse

If you select a point near an existing facility, the system will display a message similar to the following example.

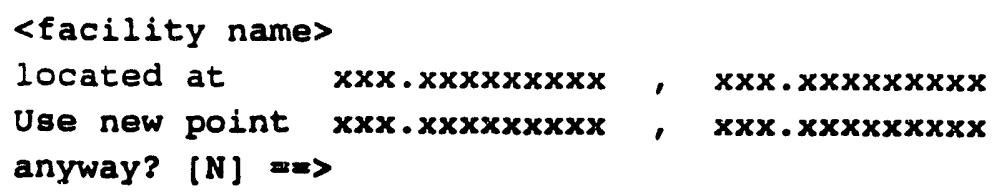

If you select a point with no preexisting facility, the system displays a message similar to the following example.

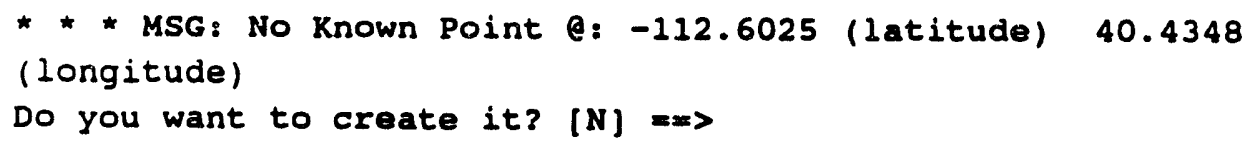

If you enter a $\mathrm{Y}$ for yes at the prompt, the system displays the following prompt.

Enter new known Point name $=>$ 
You can enter the name (up to $\mathbf{4 0}$ characters) of a point location. After you enter the new known point name, the system displays the Resource Management Facility Form as shown in 2. Enter a Facility Description.

\section{Enter a Facility Description}

After specifying the facility location, enter facility information in the following facility form (also used for DESCRIBE FACILITIES and MODIFY FACILITIES).

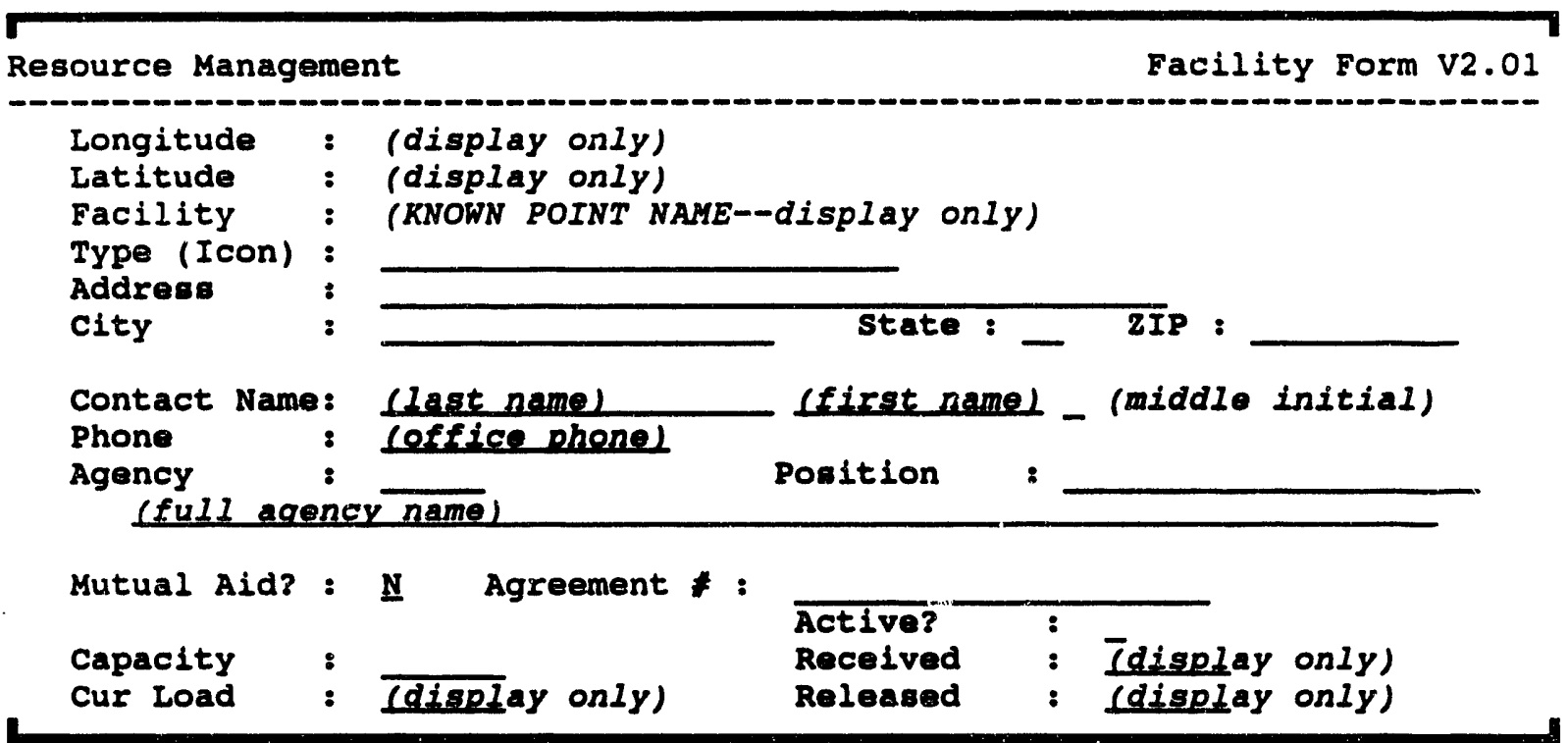

The location coordinates, facility name, current load, received and released information are for display only. Enter the following information on this form:

- Type (Icon): the name of the icon associated with this facility. This field has some special features to help you:

Enter this:
$? ?$

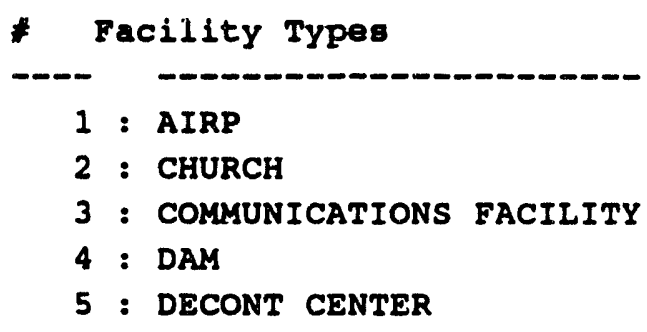

More... 
Press RETURN to display more icon names, or CTRL-Z to exit this list.

$? x x x$

$?^{*} x x x$

>icon number a numbered list of all icon names starting with $x x x$

a numbered list of all icon names containing $x x x$

- Address/City/State/ZIP: the complete mailing address of the facility, including ZIP code

- Contact Name: the name of the contact person for this facility. If the contact person is already in the current personnel database, the rest of the contact fields are prefilled. If the contact person is NOT in the current CSEPP personnel database, the system informs you that you need to supply additional personnel information for the CSEPP personnel database:

* * MSG: Name not in porsonnel database

- Phone: the contact person's office phone number

- Agency: the agency code (an acronym, up to five characters) and the full agency name with which the contact person is affiliated

- Position: the contact person's job position

- Mutual Aid?: Y or N--Is there a mutual aid agreement in force?

- Agreement \#: the mutual aid agreement number (if agreement exists)

- Capacity: the number of people this facility can hold (if the facility is a shelter or care facility)

When you finish and exit this form, you will return to the Known Points Selection method menu, where you can continue to add facilities.

\section{Enter Personnel Information about the Facility Contact Person}

If the contact person is not in the personnel database, the following message will display after you finish entering information in the Facilities Form.

\footnotetext{
* * MSG: Need to add a personnel record

Press <RETURN> to continue...
} 
To modify the personnel file, press RETURN to continue and then complete the personnel information on the following screen form. The Person Name and Office Phone are taken from the facility form. When you exit this personnel form, you will return to the Known Points Selection method menu, where you can continue to add facilities.

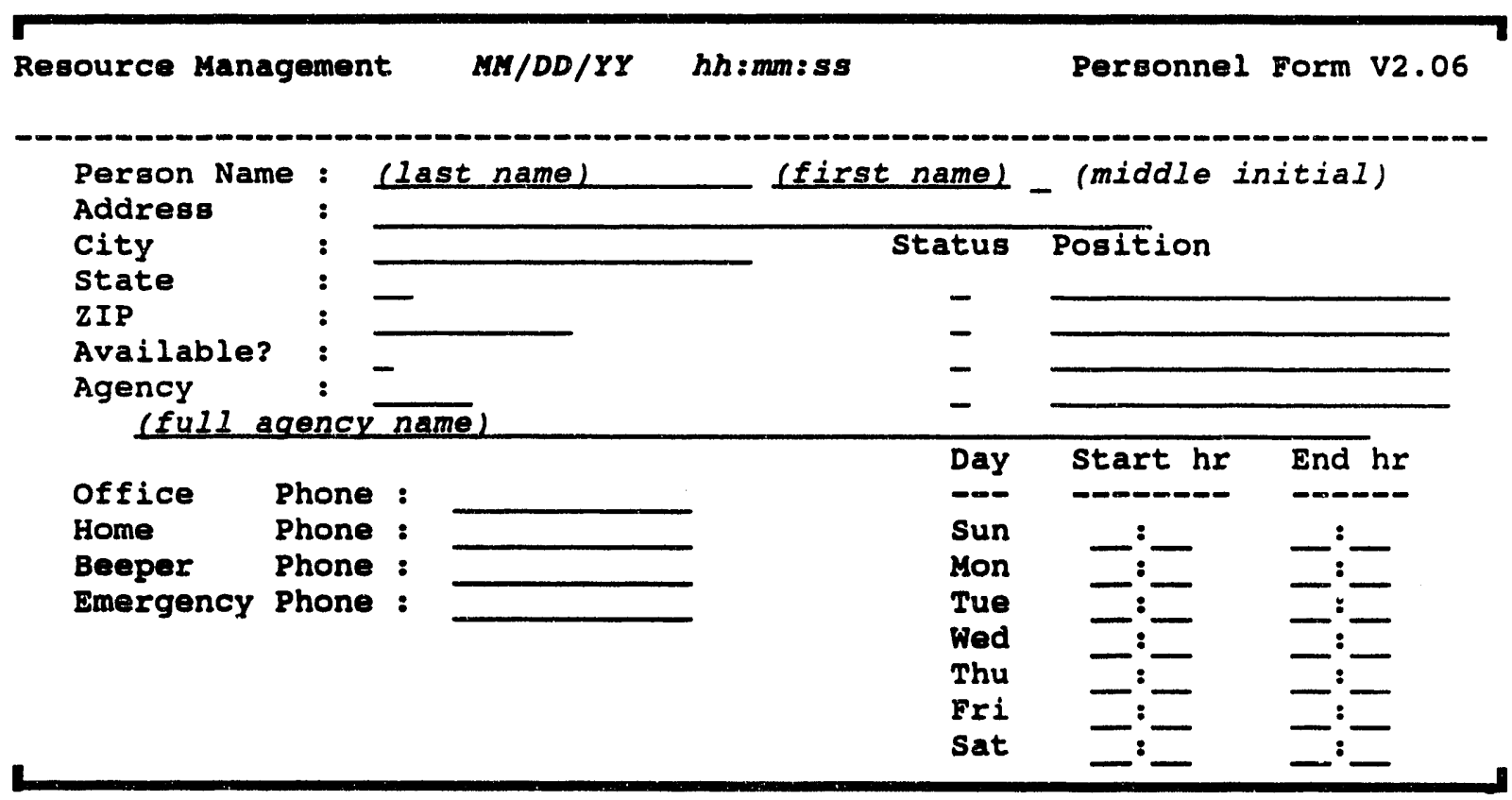




\section{DELETE FACILITIES*}

This option enables an Information Manager to delete a selected facility. The system displays the Facility Selection Method menu. You can use this menu to select facilities to delete.

Facility selection method menu
0: ExIT
1: Type in Facility name
2: Select Facility name from a list
3: Type in long/lat coordinates
4: Use mouse to select Facility
Choice $(?=H e l p)==$

When you have selected a facility, the system displays the Facility Form associated with that icon for you to check.

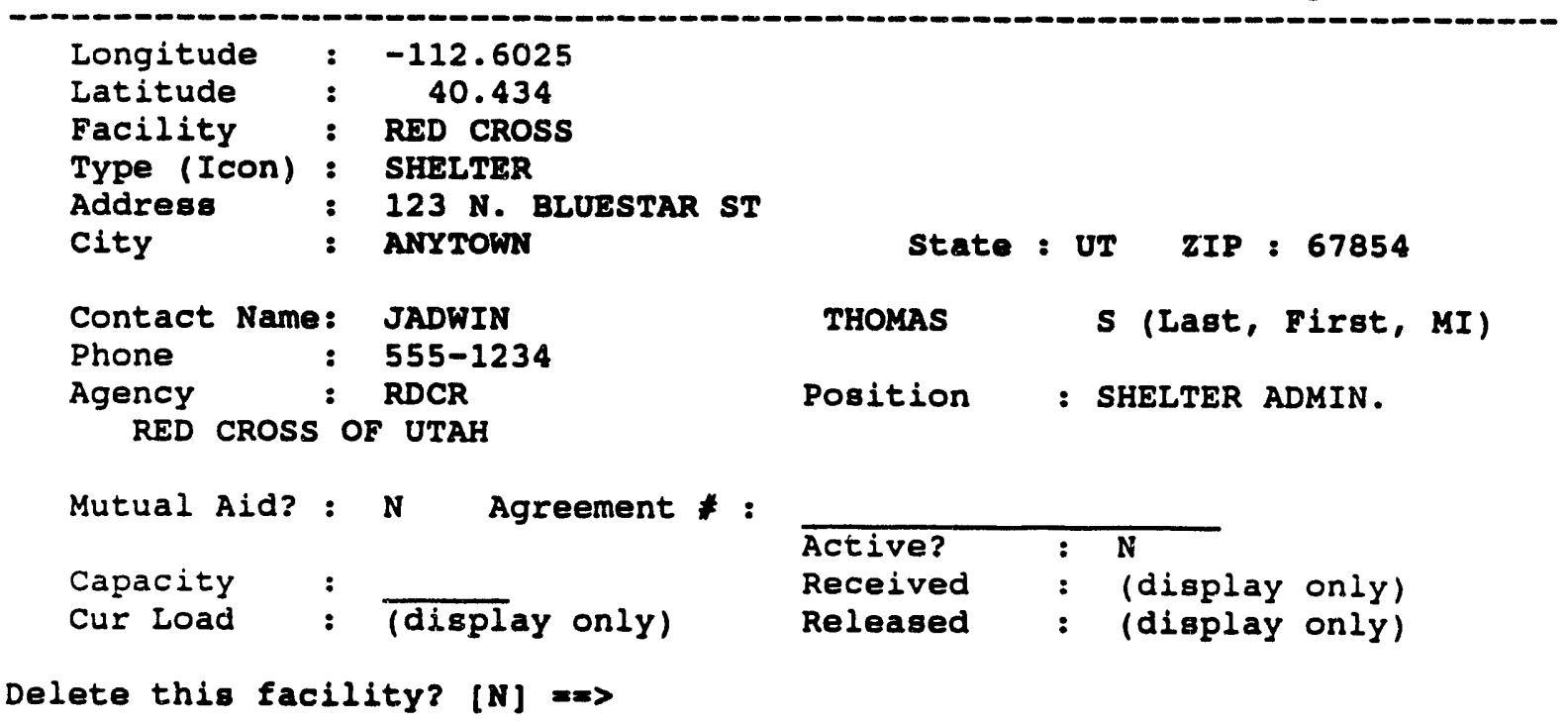

If you are certain this is the facility you want to delete, type a $\mathrm{Y}$ at the Delete this facility? prompt and press the Return key. The system then returns the screen to the Facility Selection Method menu. Using this method, you can delete as many facilities as you want.

Exit the Modify Facilities function by selecting 0: EXIT from the menu. 


\section{ID DESCRIBE FACILITIES}

This option displays the description of a selected facility and gives you the option of listing the resources of the facility. The system displays the Facility Selection Method menu.

Facility selection method menu

0: ExIT
1: Type in Facility name
2: Select Facility name from a list
3: Type in long/lat coordinates
4: Use mouse to select Facility
Choice $(?=$ Help $)==>$

Use one of these four methods to select a facility, as described under the heading Selecting a Facility.

After you have selected a facility, the Facility Form displays, as shown in the following example. All fields are for display only.

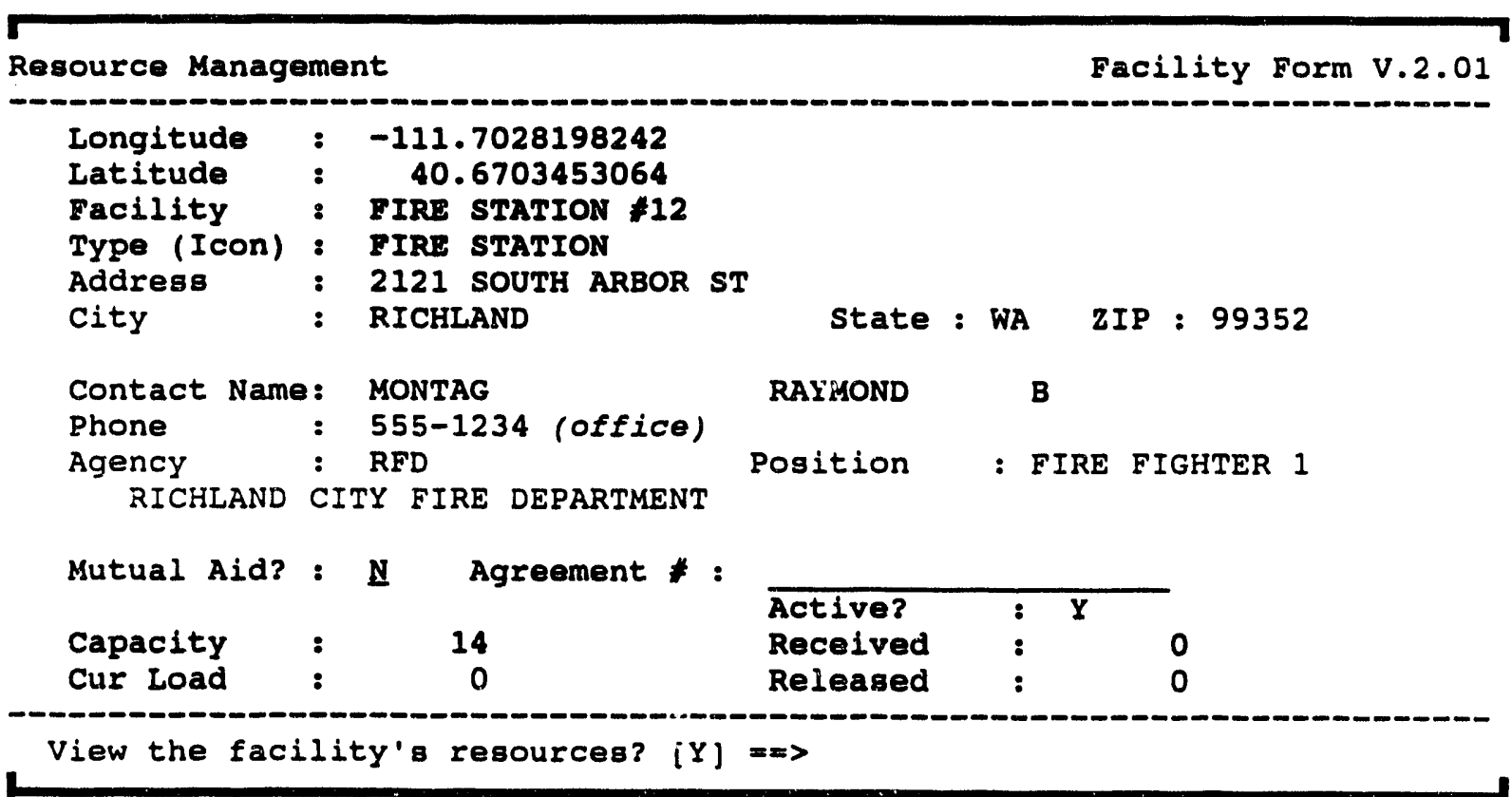


To view the resources at that facility, type $Y$ or press the Return key. The resources are then listed in alphabetical order by resource type:

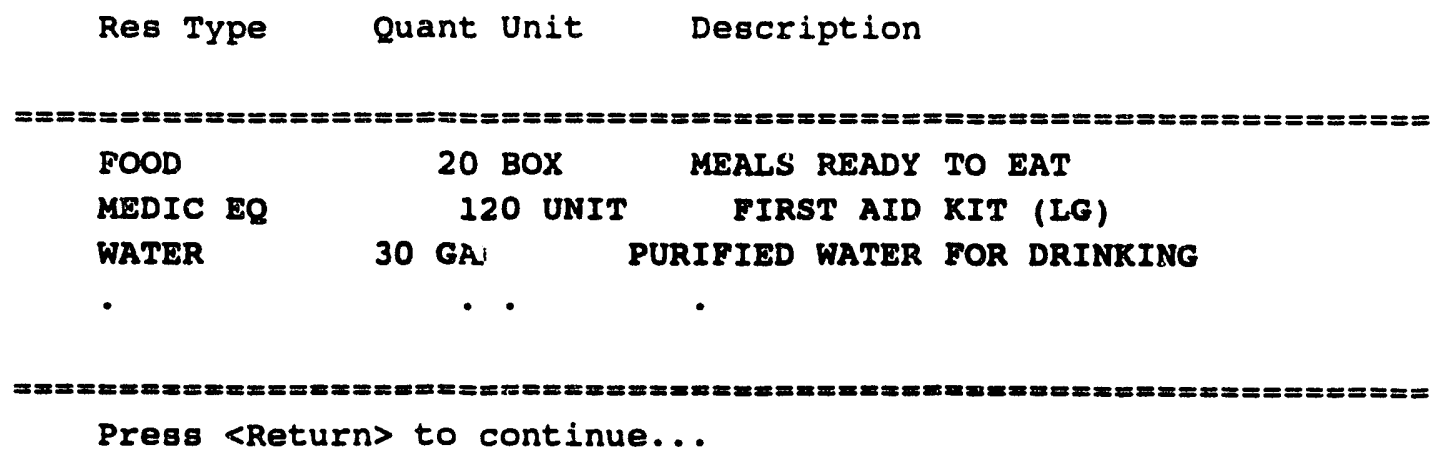




\section{HIGHLIGHT FACILITIES}

This option enables you to highlight facility icons that show the locations of certain resources within a specified area of interest. This involves 1) specifying an area of interest and 2) selecting the resource(s) to be noted at facilities within that area. The facilities that have the selected resources in that area then flash until you choose another menu option.

\section{Specify an Area of Interest}

The system prompts:

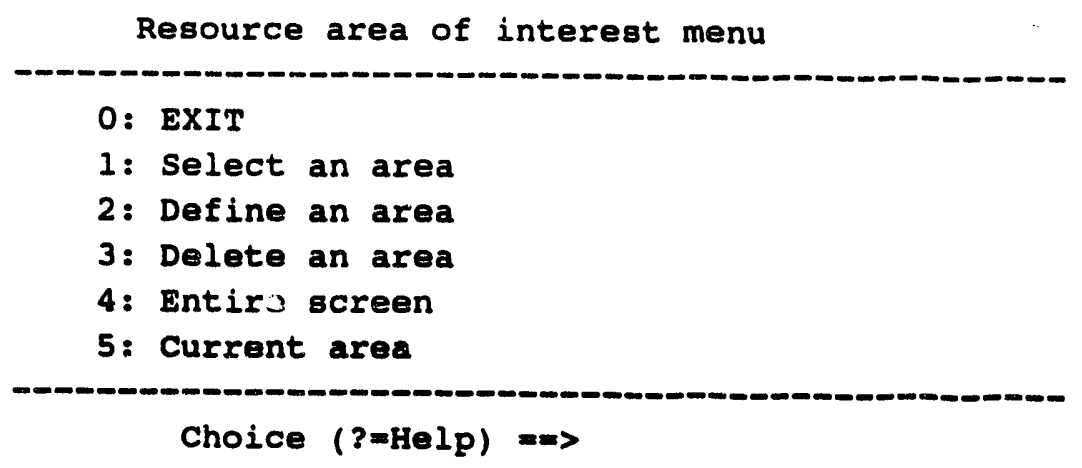

Use one of these methods to identify the area of interest:

1. Select an area: Prompts you to select an existing area by picking a polygon. For example, you could pick the outer polygon of the D2 model track output.

2. Define an area: Prompts you to define an area by drawing a polygon around the desired area.

When you pick CONTINUE to finish the last side of the polygon, the polygon lines are redrawn in white. The polygon remains on the screen until you use the Delete an Area option to erase it, or you exit Resource Management.

3. Delete an area: Prompts you to pick a polygon to.be deleted from the area of interest. The polygon must be one that you have drawn by using the Define an Area option.

When you pick CONTINUE to confirm the deletion, the polygon is erased (redrawn in the background color). You may need to use REFRESH SCREEN.

4. Entire screen: Uses the entire current map area as the area of interest.

5. Current area: Uses the current polygon you picked using option 1: Select an area. This option only displays after you have selected a polygon by using option 1: Select an area. 
After you have specified the area, the subsequent selection of facilities by resource then applies only to facilities in that area.

\section{Select Which Resources to Locate}

The system displays the Resource Description Selection method menu.

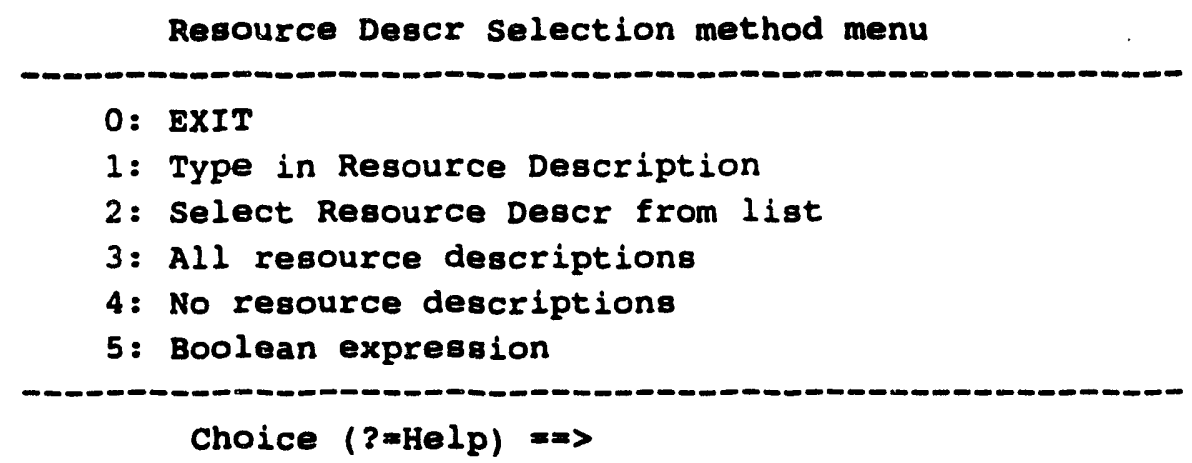

Use one of the following five methods to identify individual resources.

1. Type in Resource Description: Type in the name of a resource.

2. Select Resource Description from list: Displays the Resources Descriptions list.

3. All resource descriptions: Select any facilities with resources.

4. No resource tescriptions: Unselect all selected (blinking) facilities.

5. Boolean expressim: Presents a numbered list of resources (as in number 2) and prompts you for an expression that defines a set of resources:

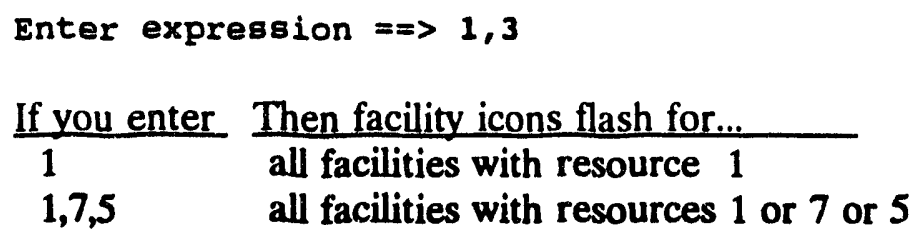

The system will then highlight any resources matching the selected description. The Resource Descr Selection method menu continues to display. Continue to select resources.

6. When you have finished selecting resources, select 0: EXIT to return to the Resource area of interest menu.

7. Select 0: EXIT to return to the Resource Management menu. 


\section{MODIFY FACILITIES *}

This option enables an Information Manager to modify facility information. Updating a facility consists of 1) deciding whether to update the facility itself (address, contact name), or 2) the known point of the facility (name and locition).

Updating the facility consists of: 1) selecting a facility and 2) modifying the facility description.

Updating a known point consists of: 1) selecting a known point and 2) modifying either the location or the name.

\section{Select a Facility}

The Facility Selection method menu displays. For details on using this menu, see the heading Selecting a Facility.

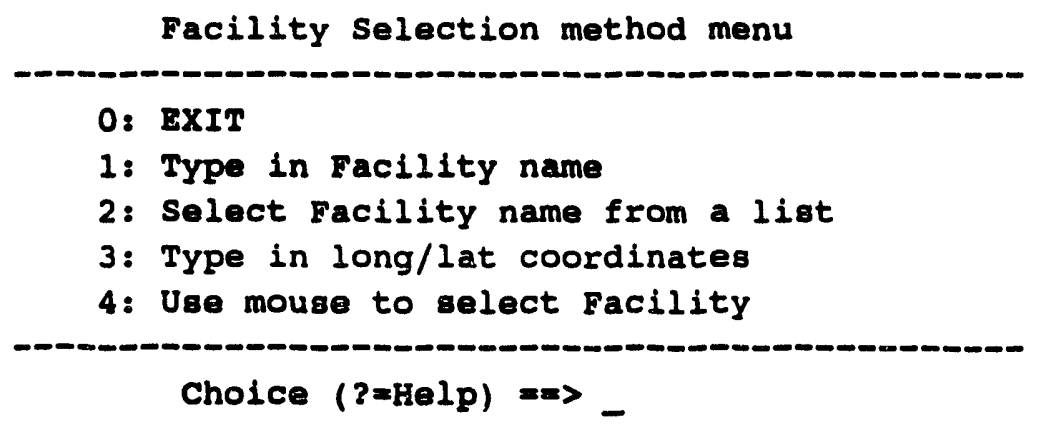

\section{Modify the Facility Description}

The facility form description of the selected facility is then presented for updating (for details on using or updating the form, see ADD FACILITIES, Entering a Facility Description). 


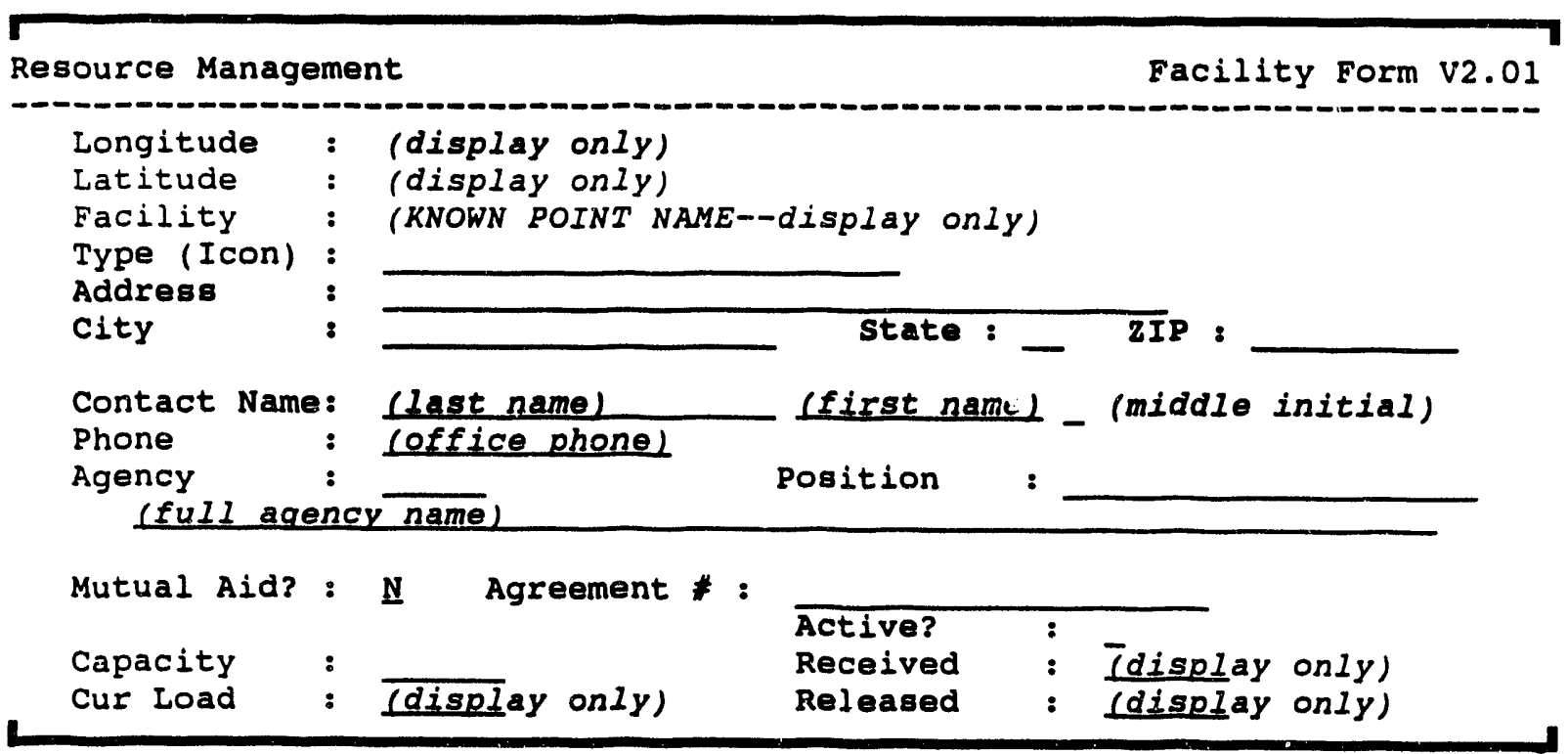

When you exit the facility form, the screen returns to the Facility Selection method menu, where you can choose another facility for modification.

Exit the Modify Facilities function by selecting 0: EXIT from the menu.

\section{Select a Known Point}

The Known Point menu displays. This menu works the same as the Facility Selection method menu described above. The only difference is that there can be known points with no associated facility that can be selected with this menu.

Known Point selection method menu

0: EXIT
1: Type in known Point name
2: Select known Point name from a list
3: Type in long/lat coordinates
4: Use mouse to select known Point
Choice $(3=\mathrm{Holp})=>$

\section{Modify the Known Point Location or Name}

The Known Point name will display in a prompt similar to the following example.

Known Point: HIGH SCHOOL

Modify the known Point location? $[Y]=m$ 
Press the Return key (Yes) to modify the location. You will be prompted to select a new location for the Known Point with the mouse (or joydisk). After you select the new location, the facility will be moved.

If you enter $\mathrm{N}$ (No) at the prompt you can then modify the Known Point name. The following warning prompt will display.

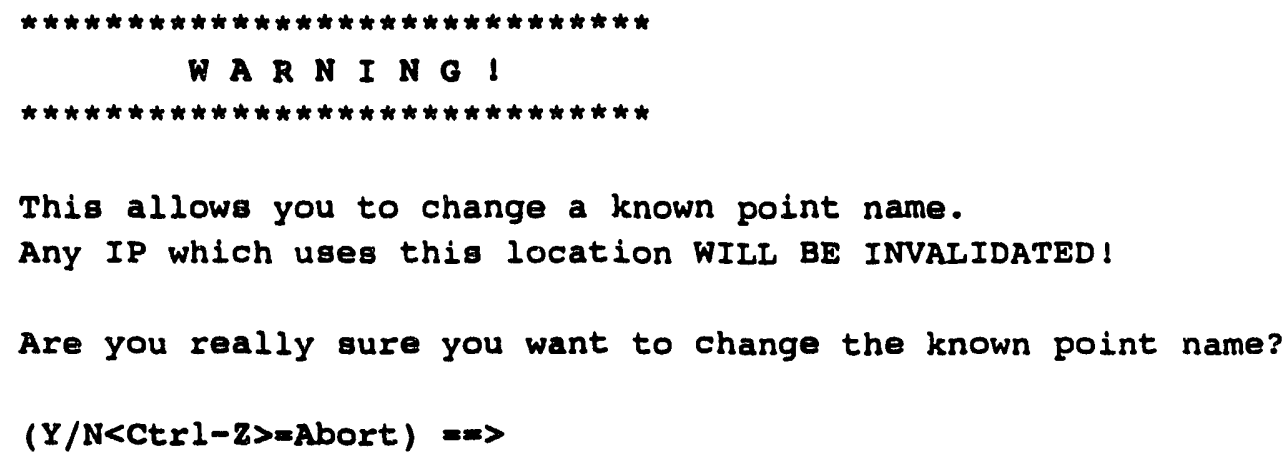

You can corrupt a lot of data if you change a Known Point name. Be sure of the consequences before you commit to the change.

If you choose to continue, the following prompts will display.

Known Point: HIGH SCHOOL

Enter naw known Point name: $=>$

Type in the new name at the prompt and press the Return key to change the name.

Known Point: HIGH scHOOL

Enter new known point name: =m GRADE SCHOOL 


\section{Selecting a Facility}

The following RESOURCE MANAGEMENT menu options require you to select a particular facility:

- MODIFY FACILITIES

- DELETE FACILITIES

- DESCRIBE FACILITIES

- ASSIGN RESOURCES

- DELETE RESOURCES

- DESCRIBE RESOURCES

- iVIOVE RESOURCES

In each case, the general sequence for selecting a facility is the same. The system displays the following menu:

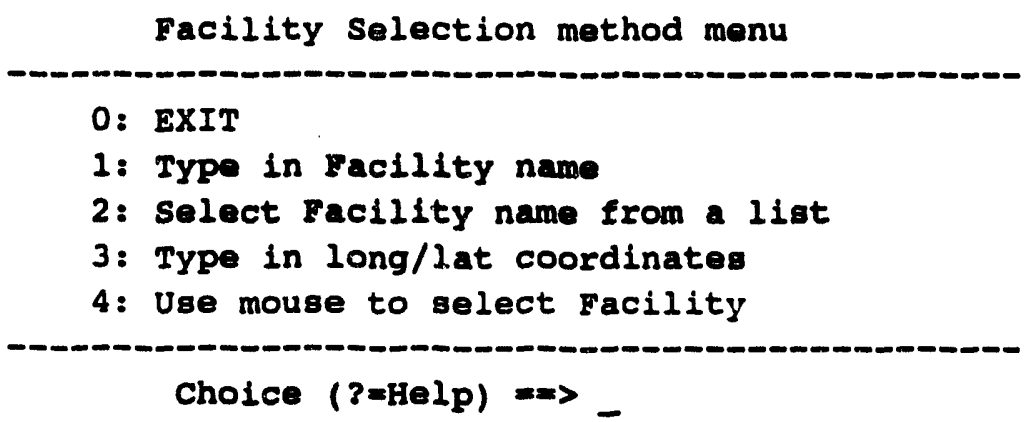

Select one of these four methods to identify the facility:

1. Type in Facility name: Prompts you to enter the name of an existing facility. For exa:nple:

Enter Facility name $\Rightarrow$ PIRe smapION \#3

2. Select Facility name from a list: Prompts you to choose one from a numbered list of facility names. For example:

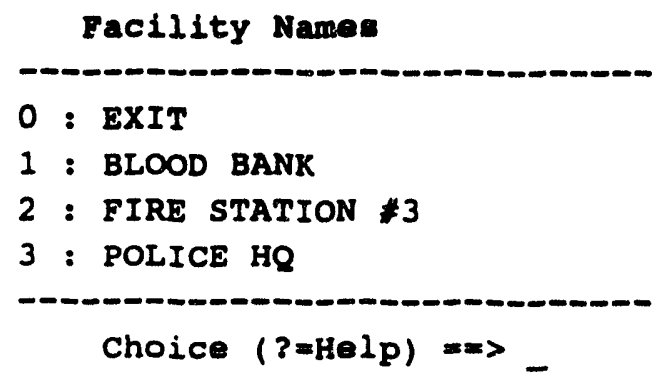

Enter the facility's number, or exit. 
3. Type in long/lat coordinates: Prompts you for the longitude and then the latitude coordinates of the facility location.

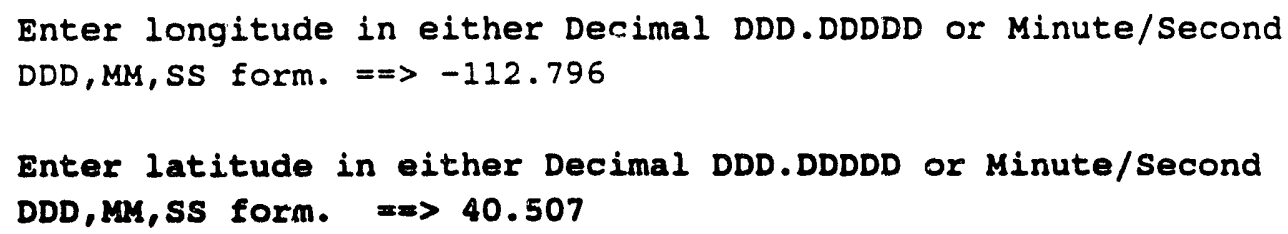

4. Use mouse to select Facility: Enables you to pivk a facility icon on the screen by using the cross hairs.

The selected facility is then used in completing the current operation. 


\section{Resource Tasks}

The following figure illustrates that many of the resource tasks share common procedural elements:

DEFINE RESOURCES

ASSIGN RESOURCES

MODIFY RESOURCES

DELETE RESOURCES

MOVE RESOURCES

DESCRIBE RESOURCES

SUMMARIZE RESOURCES

ENABLE RESOURCES

HIGHUGHT

FACILITIES

\section{Resource form}

Select facility $-->$ Resource Form

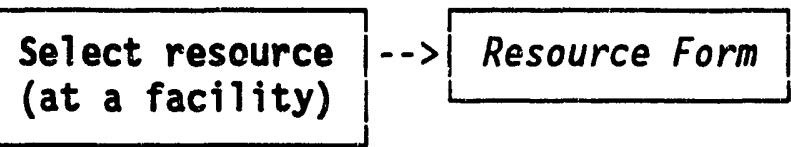

\begin{tabular}{|c|c|c|c|c|}
\hline $\begin{array}{l}\text { Select resource } \\
\text { (at a facility) }\end{array}$ & $|-->|$ & $\begin{array}{l}\text { Resource Form } \\
\& \text { Amt to move }\end{array}$ & $->$ & $\begin{array}{l}\text { Select (2nd) } \\
\text { facility }\end{array}$ \\
\hline
\end{tabular}
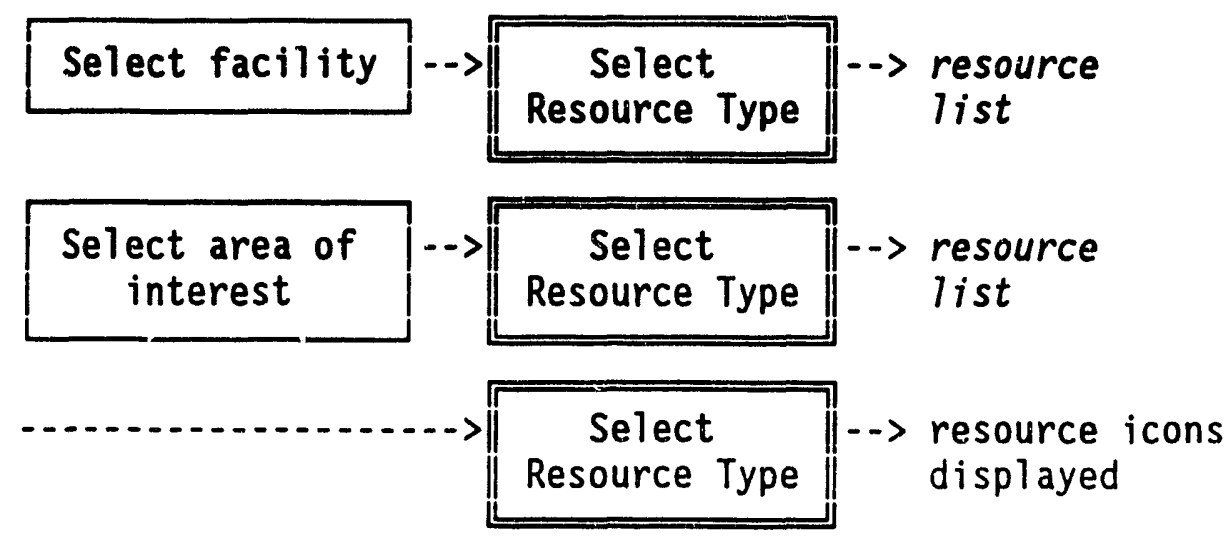

$\begin{gathered}\begin{array}{c}\text { Select area of } \\ \text { interest }\end{array} \\ \text { Resource Type }\end{gathered}-\rightarrow \begin{aligned} & \text { Select } \\ & \text { displayed }\end{aligned}$


- The Information Manager tasks-DEFINE RESOURCES, ASSIGN RESOURCES, MODIFY RESOURCES, DELETE RESOURCES, and MOVE RESOURCES--present facility information in the same resource form. (See Resource Form Use for a summary description of how to use this information form.)

- Selecting a Resource is explained independently as a resource task.

- Selecting a Resource Type is explained independently as a resource task.)

- Solecting a Facility is explained independently as a facility task.

- Note that HIGHLIGHT FACILITIES is a facility task that relates to locating resources. 


\section{ID ASSIGN RESOURCES *}

This option enables an Information Manager to assign a quantity of a resource to a specific facility. (The resource type and description must have been already defined with DEFINE RESOURCES.) Assigning resources consists of 1) selecting the facility where the resource is to be assigned and 2) entering the resource information.

\section{Select a Facility}

The Facility Selection method menu will display.

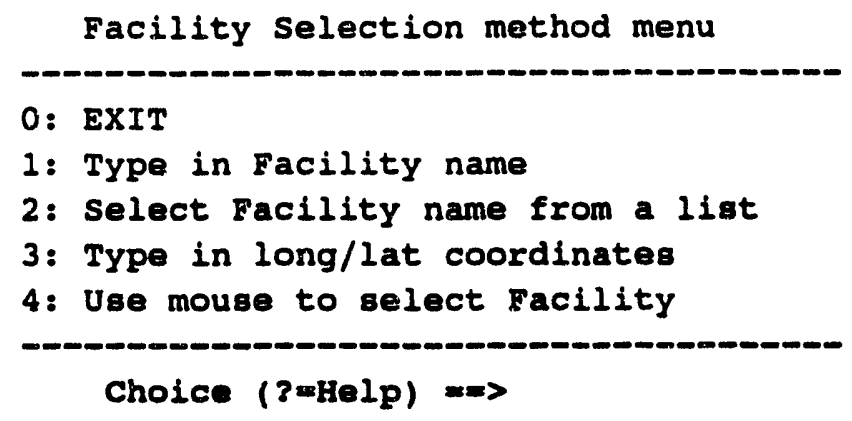

Use one of these four methods to select a facility, as described under the heading Selecting a Facility.

After you have selected a facility, the Resource Form displays, as shown in the following example.

\section{Enter the Resource Information}

After selecting the facility, enter resource information in the Resource Management Resource Form.

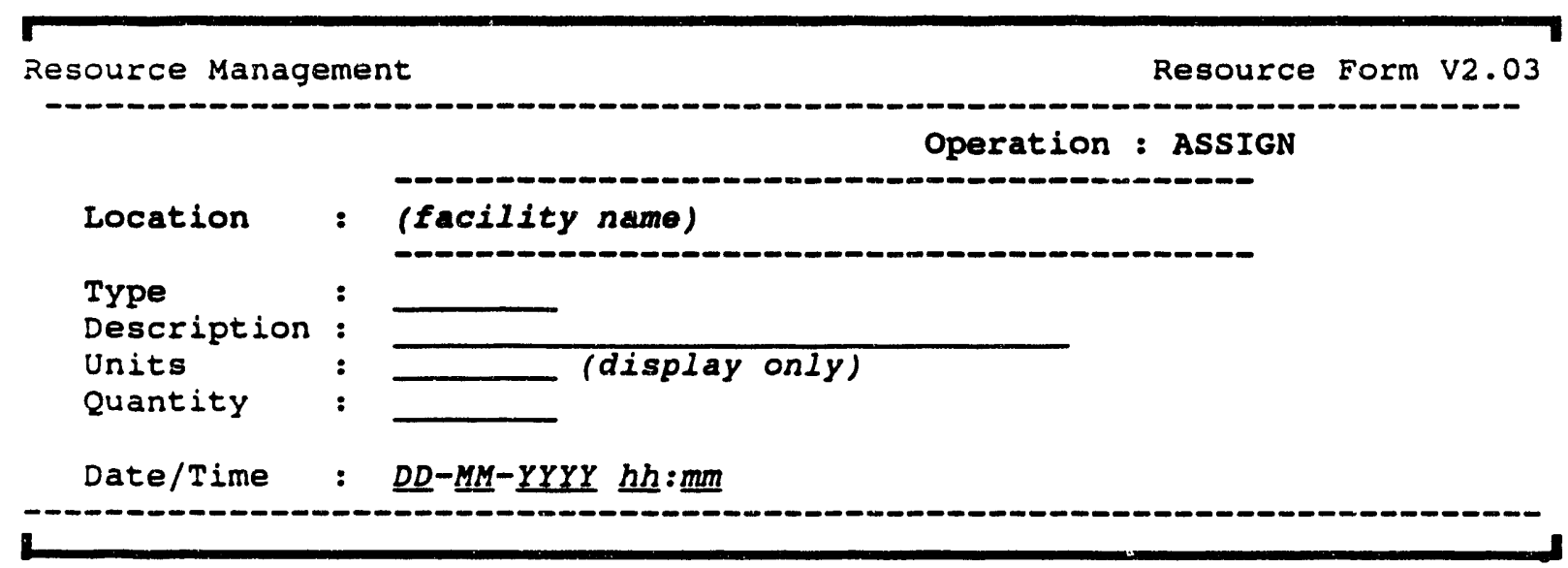


The Operation, Location, and Units fields are automatically filled and cannot be modified.

Enter the following information on this form. (For details on special entry features, see Resource Form Use under the heading Resource Tasks.)

- Type: the general type of resource (or ?? to see a list of resource types)

This must be a defined resource type or the system ignores your input.

- Description: the name of a specific resource of the selected Type (or ?? to see a list of resource descriptions)

If you enter a resource description that is NOT defined for the entered resource type, the system ignores your input.

- Quantity: a number of units greater than zero.

- Date/Time: the date and time at which the resource was assigned.

When you approve the information and exit the form with GOLD-Z, the screen returns to the Facility Selection method menu, where you can choose another facility for assigning resources. 


\section{ID DEFINE RESOURCES *}

This option enables an Information Manager to define individual resources within general resource types. The defined resources can then be assigned in various quantities to facilities. A resource is defined by its

\section{- Type}

- Description

- Units of measure

These fields are in the following resource form. (For details, see Resource Form Use under the heading Resource Tasks.)

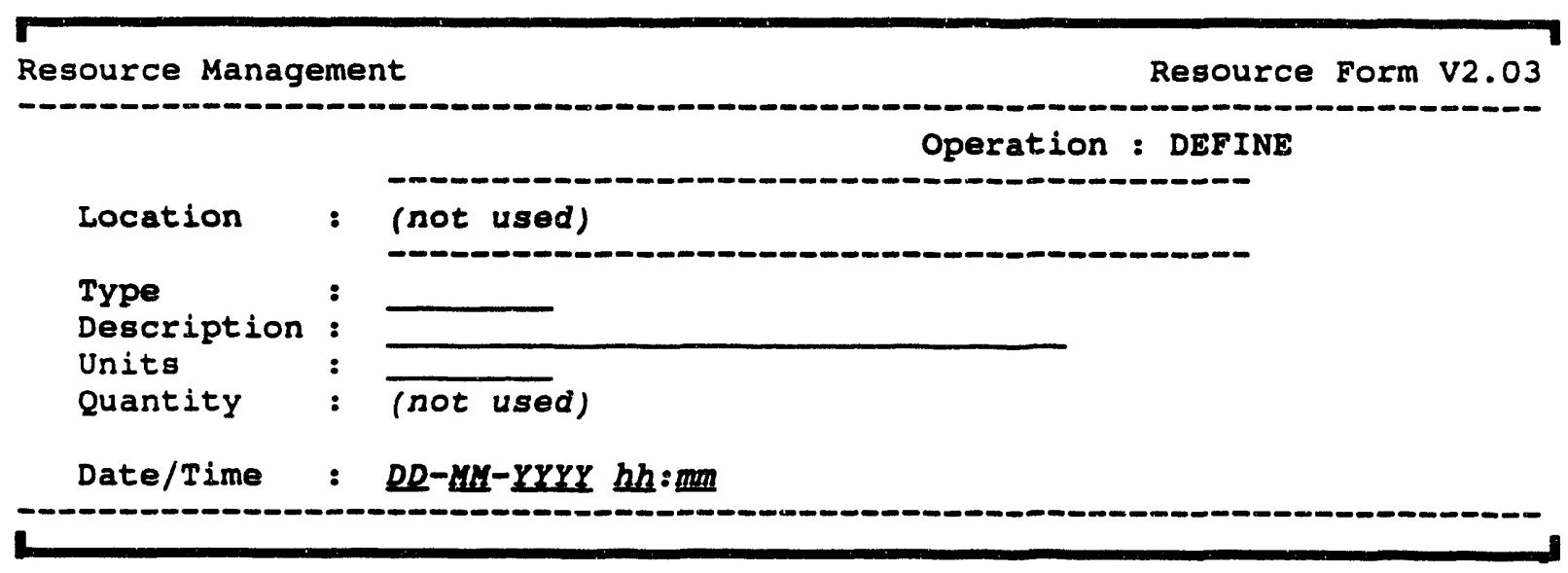

The Operation field is automatically filled in. The Location and Quantity fields do not apply to resource definition.

Enter the following information on this form:

- Type: the general type of resource (up to eight characters) or ?? to see a list of resource types. This type of help list is similar to the following example.

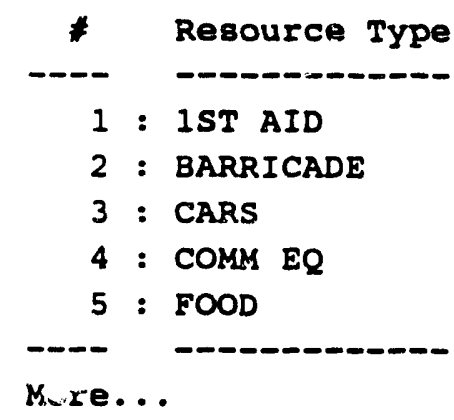


- Description: a unique description (up to 32 characters).

If you enter a resource description that is already defined, the system informs you and enables you to enter a different description.

- Units: any units of resource quantity (up to eight characters).

- Date/Time: the date and time when the resource was defined.

When you approve the information and exit the form by pressing the RETURN key or GOLD-Z, another blank resource form is presented so you can continue to define resources. To quit when you are finished, press GOLD-Y. 


\section{IDDELETE RESOURCES}

This option enables an Information Manager to delete individual resources from the resource database. The Resource Selection method menu displays as shown.

\begin{tabular}{l} 
Resource Selection method menu \\
\hline $0:$ EXIT \\
$1:$ Type in Resource Location \& Namis \\
2 : Select Resource from a list \\
$3:$ Type in long/lat coordinates \\
$4:$ Use mouse to select Resource \\
Choice $(?=$ Help) $=>$
\end{tabular}

Use one of these four methods to select a resource type, as described under the heading Selecting a Resource.

After you select a resource using one of the above methods, it is deleted from the database and the screen is returned to the Resource Selection method menu. You can continue to delete resources, or you can select option 0 to exit.

If you have deleted resources, the following message appears when you exit the delete function.

\footnotetext{
* * MSG: RUn VALIDATE RESOURCEs since you have deleted resources Prese <RETURN> to continue...
} 


\section{DESCRIBE RESOURCES}

DESCRIBE RESOURCES enables you to view a list of resources of a specific type at a specific facility. Describing a resource consists of 1) selecting a facility and 2) selecting a resource type. The Resource Selection method menu displays as shown.

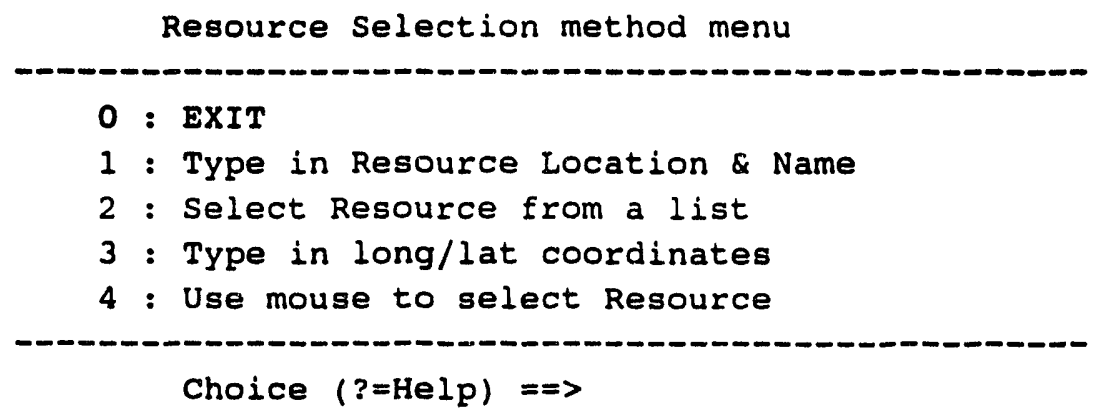

Use one of these four methods to select a resource type, as descrived under the heading Selecting a Resource.

After you select a resource using one of the above methods, the system displays a list of the resources of that type located at that facility:

\begin{tabular}{lr} 
Facility Name: TOOLE FIRE DEPT. \\
Resource Type: MEDICAL \\
Description & Quantity Units \\
\hline BANDAGES & 20 BOXES \\
SUTURES & 5 CASES \\
r & $\cdot$ \\
- & $\cdot$
\end{tabular}

Press the Return key to exit the list and return to the Resource Selection method menu. Select 0 : EXIT to exit the menu. 


\section{IDISABLE RESOURCES}

This option enables you to erase resource icons that show the locations of selected resources (icons that have been drawn on the screen by using the ENABLE

RESOURCES option). When you select Disable Resources, the system displays the Resource Type Selection method menu.

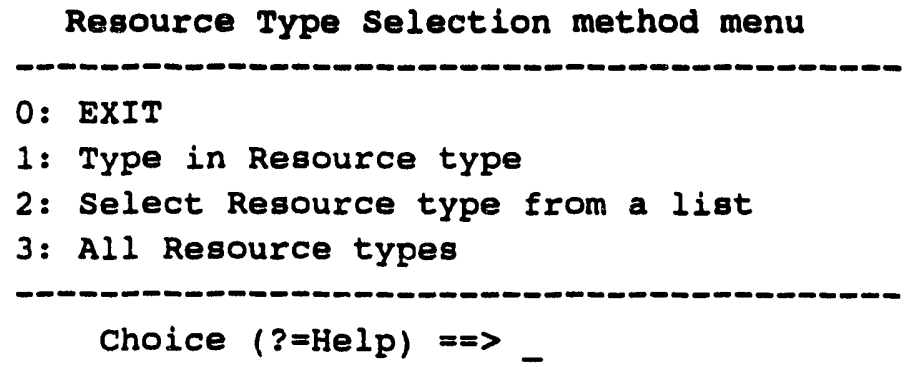

Use one of the three options to select resource type(s).

The selected icons are then erased. Erasing is done by drawing the icons in black (the background color), which can obscure other map features. If this occurs, use REFRESH SCREEN to clean up the display. 


\section{ID ENABLE RESOURCES}

This option enables you to display resource icons that show the locations of selected resources. When you select Enable Resources, the system displays the Resource Type Selection method menu.

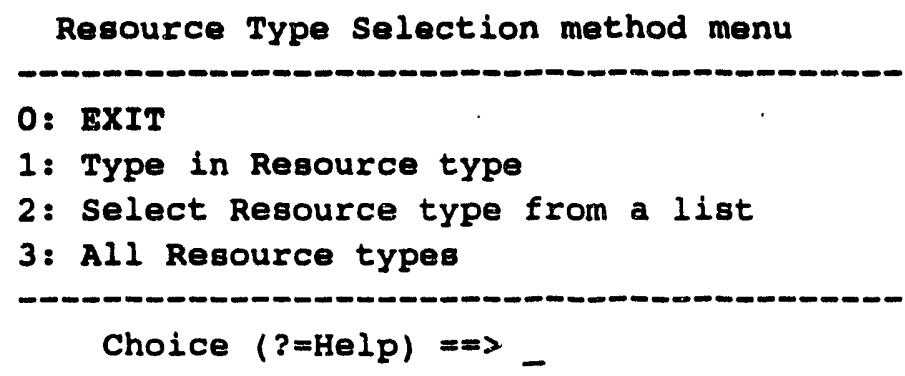

Use one of the three options to select resource type(s).

The selected icons are then displayed at the locations of that resource. Each icon represents a major resource type, which can include any number of unique resources. 


\section{LIST RESOURCES}

This option enables you to list all

- Resources

- Resource types

- Quantities

- Units

- Facility where the resources are located

When you select this command, the system displays a report similar to the following example.

\begin{tabular}{llrl} 
LIGHTS & PROPANE LANTERNS & 1 UNIT & USED CAR DEALERSHIP \\
CARS & TAXIS & 5 UNIT & USED CAR DEALERSHIP \\
TRUCKS & CEMENT MIXERS & 1 UNIT & USED CAR DEALF' UHIP \\
MEDIC EQ STRETCHERS & 34 UNIT & USED CAR DEALE SHIP \\
EMERG EQ BLANKETS & 5 UNIT & FIRE STATION \\
LIGHTS & PROPANE LANTERNS & 5 UNIT & FIRE STATION \\
IST AID & SUTURES & 6 BOXES & FIRE STATION \\
\hline
\end{tabular}

Press <ReTURN> to continue...

Page through the list by pressing the Return key. When all resources have been listed, the system returns you to the Resource Management menu. 


\section{ID MODIFY RESOURCES *}

This option enables an Information Manager to modify the:

- Quantity of a resource that is already assigned to a facility

- Description or Units of any resource

Modifying the quantity consists of 1) selecting a resource at a particular facility and 2) modifying the quantity information for one resource assigned to that facility. This change will be updated in the resource database.

Modifying the Description or Units consists of 1) selecting a resource at a particular facility and 2) modifying the Description or Units of the resource. All facilities that contain this resource will be updated in the resource database.

Note: You must have enabled resources (turned on their icons) before using this option. Use the Enable Resources option to do this.

\section{Select a Resource for Modifying}

The system prompts:

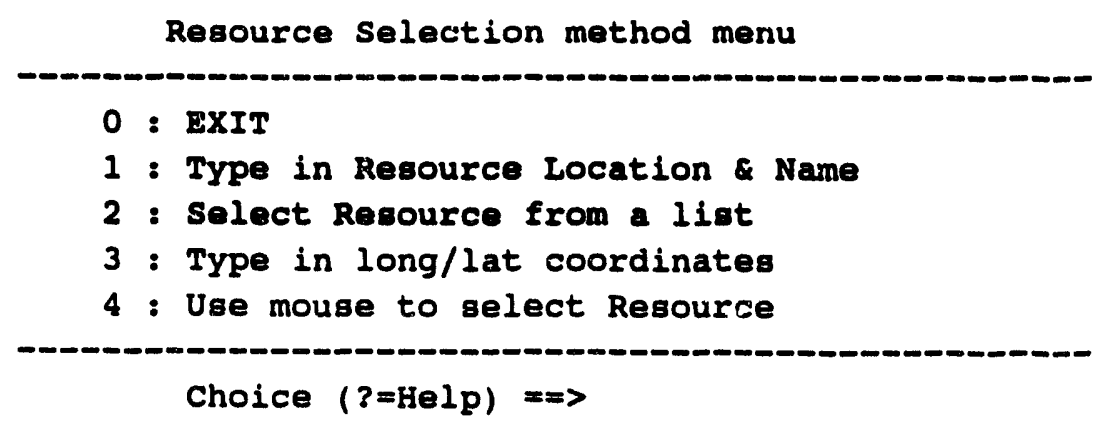

Use one of these four methods to identify a resource as described under the heading Selecting a Resource.

When you select a resource to modify the Description or Units, tiie system will display the following warning prompt. 


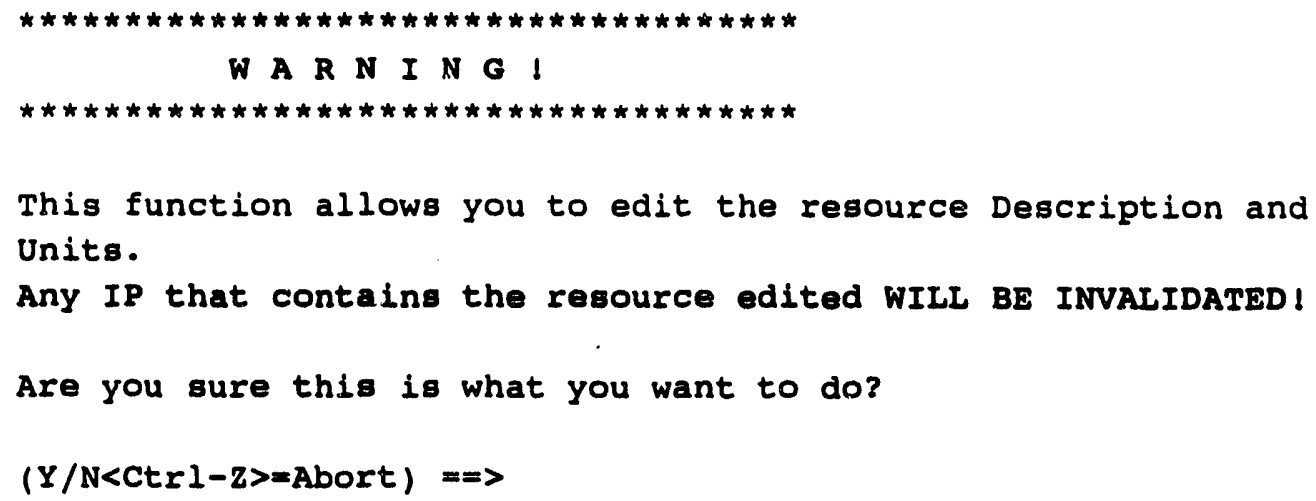

Be sure you understand the consequences of changing the data before you answer yes $(\mathrm{Y})$ to the prompt.

\section{Modifying the Resource Information}

After identifying a resource, you can modify the Description and Units information in the resounce form. (For details, see Resource Form Use under the heading Resource Tasks.) With the exception of Description, Units, and date/time, all items in the Resource Form are Read Only.

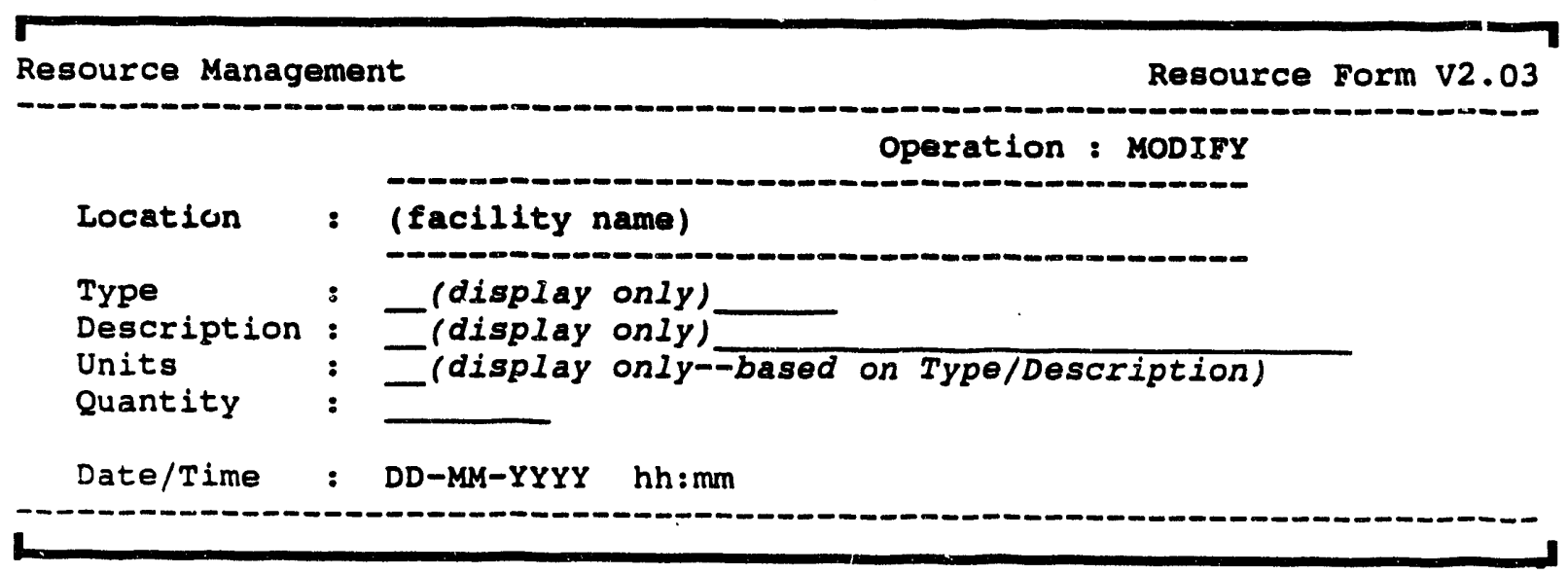

All form fields are filled in automatically, based on the resource and facility that you selected. You can modify only the Quantity and Date/Time fields to update the resource at that facility:

- Type (display only): the general type of resource

- Description (display only): the description of an individual resource

- Units (display only): the units of measure that apply to the resource narned by the Description field. Units cannot be changed in this field. 
- Quantity: the current quantity of the resource named by Description. The quantity cannot be less than zero.

If you decrease the quantity of an existing resource so the quantity is less than that required by the correct IP, the sy'stem prompts

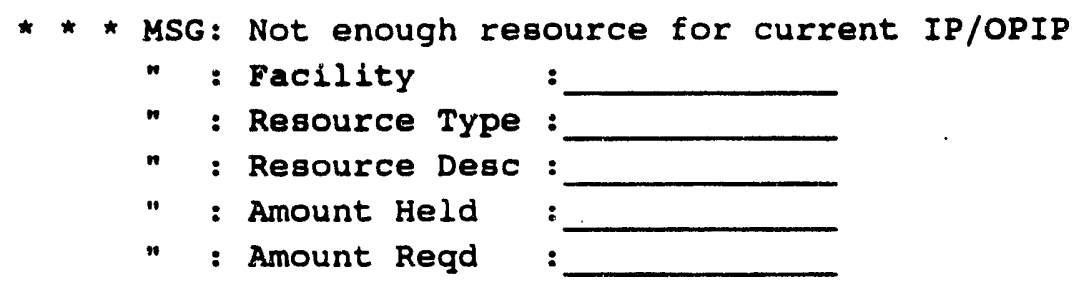

When you exit the resource form, the screen returns to the Resource Selection method menu, where you can continue to select other resources for modification.

To exit, select the 0: EXIT option. 


\section{In MOVE RESOURCES *}

MOVE RESOURCES enables you to move currently assigned resources between facilities. Moving a resource consists of 1) selecting a resource that is associated with a particular facility, 2) specifying the quantity to be moved and 3) selecting a destination facility for the moved resource.

\section{Select a Resource to Move}

The system displays the Resource Selection method menu.

Resource Selection method menu
0 : ExIT
1 : Type in Resource Location \& Name
2 : Select Resource from a list
3 : Type in long/lat coordinates
4 : Use mouse to select Resource
Choice (?=Help) =>

Use one of these four methods to identify a resource, as described under the heading Selecting a Resource.

\section{Specify an Amount of Resource to Move}

After selecting the resource to be moved, the resource form appears on the screen:

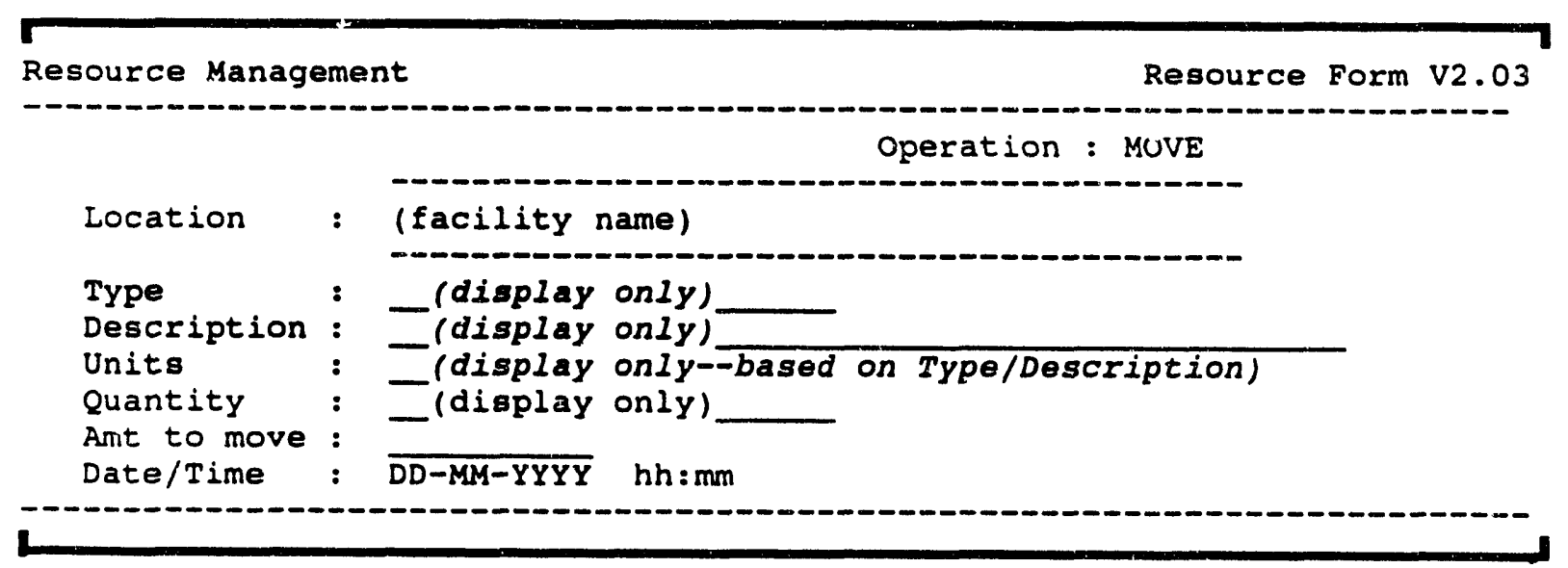

The Operation, Location, Type, Description, Units, and Quantity fields are automatically filled in and cannot be changed. 
- Amt to Move: The amount moved must be less than the current quantity.

- Date/Time: Change the date and time, if necessary, to reflect the date of the change.

\section{Select a Destination Facility}

The system displays the Facility Selection method menu.

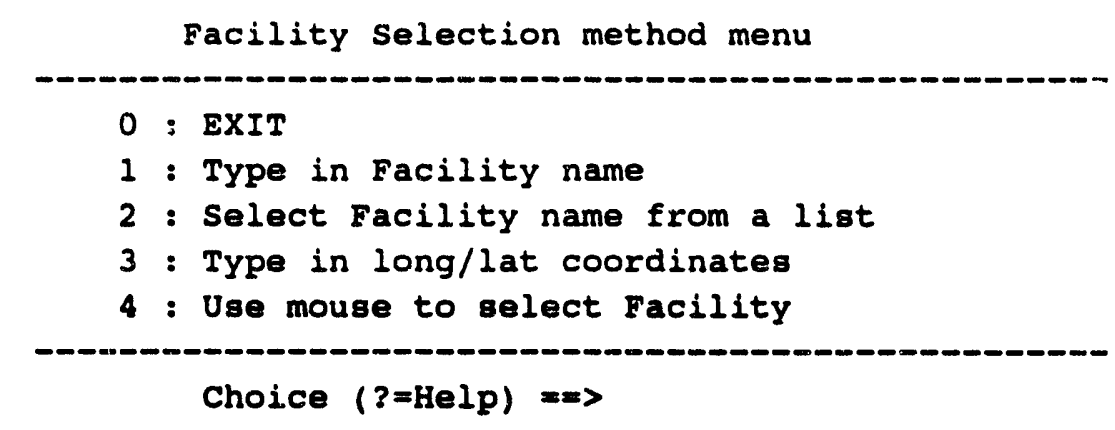

Use one of these four methods to identify a resource as described under the heading Selecting a Facility.

After you have selected a destination facility, the system makes the desired changes in the resource database and returns to the Select a Resource prompt, where you can continue with another move.

If you try to move more resources than the facility has in stock, the system displays the following message:

* * * ERR: Cannot move more than is held

If you need to adjust quantities, use the Define Resources or Modify Resources options.

When you exit the resource form, the screen returns to the Resource Selection method menu, where you can continue to select other resources for modification.

To exit, select the 0: EXIT option. 


\section{Resource Form Use}

Many RESOURCE MANAGEMENT options present the following form for specifying resource information.

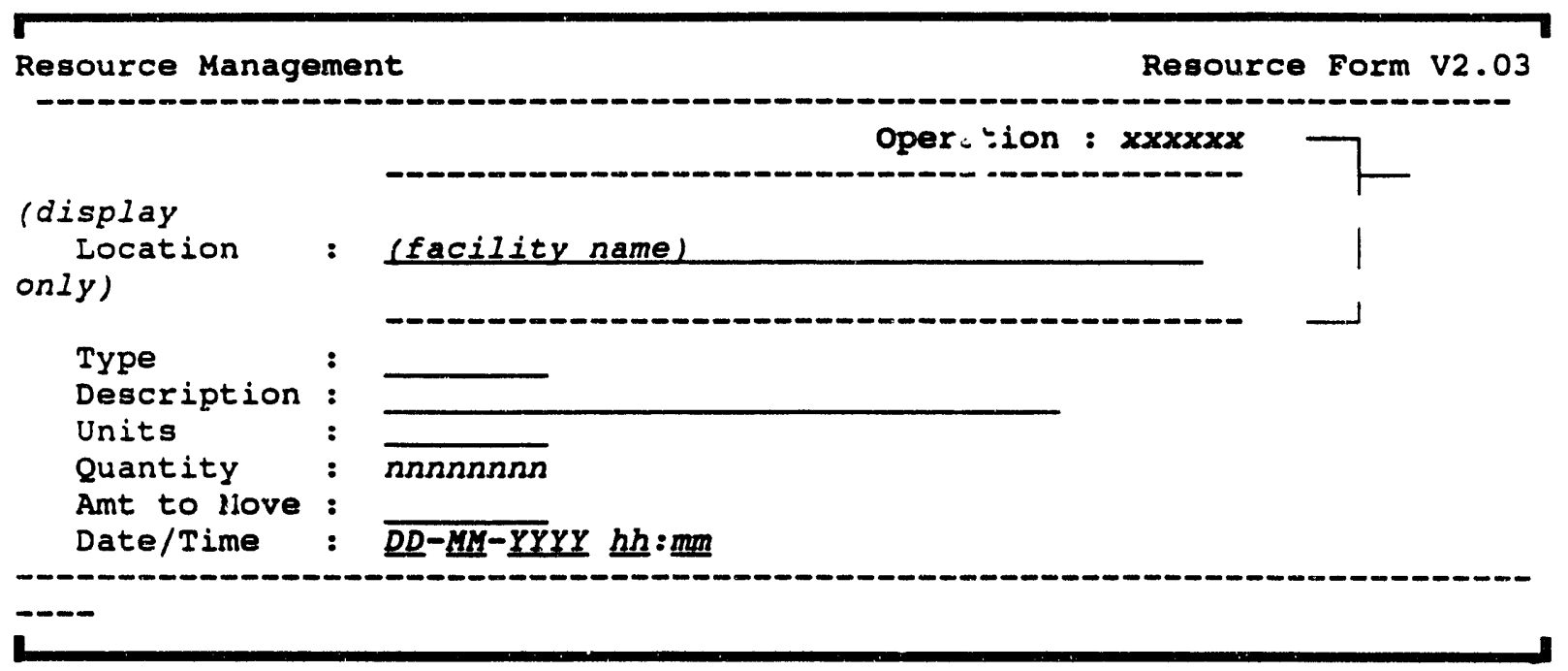

The form fields are described here.

- Operation (display only): DEFINE, ASSIGN, MODIFY, or MOVE

- Location (display only): the name of the facility where the resource is located. (During the DEFINE operation, this field is blank.)

- Type: the general type of resource (up to eight characters). This field includes special help features (see the following page).

- Description: a unique description (up to 32 characters). This field includes special help features (see the following page).

- Units: the units of resource quantity (up to eight characters). Units are entered only during the Define Resources operation. At other times, the units are an automatic display, based on the Type and Description values.

Units are coordinated with the resource description. The units of some resources can be simply "units". For example:

$\begin{array}{ll}\text { Resource Description } & \text { Units } \\ \text { Rice }(50-\mathrm{lb}) & \text { Sacks } \\ \text { Blankets } & \text { Units } \\ \text { Gas Masks } & \text { Units } \\ \text { Sutures } & \text { Boxes }\end{array}$


- Quantity: the number of units of the resource at the designated facility. (For the DEFINE and MOVE operations, the quantity is for display only.)

- Amt to move: amount of resource to move between facilities. This appears only during the Move Resources operation.

- Date/Time: the date and time the resource was actually defined, assigned, modified, or moved. 
Help Features for Type and Description

These fields have identical special features to help you:

Field Enter this: To get this result:

Type

??

a numbered list of all resource types. For example:

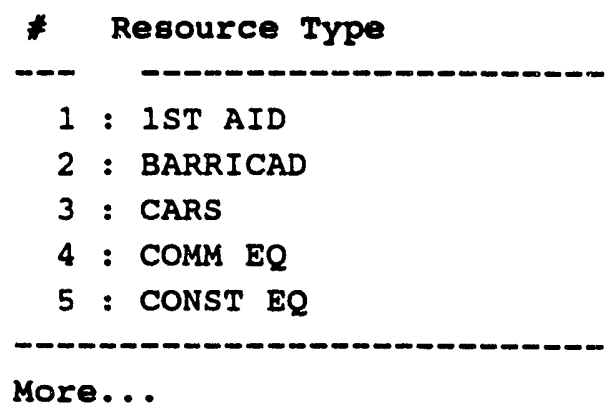

Press RETURN to display more resource names, or CTRL-Z to exit this list.

?xxx a list of all resource types starting with $x x x$

?*xox a list of all resource types containing $x x x$

>index \# resource type from the numbered list autornatically

(from list) entered in the "Type" field

Descrip. ??

a numbered list of all resource descriptions. For example:

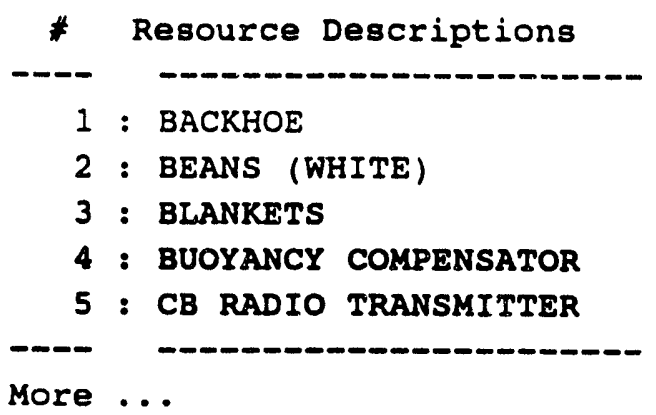

Press RETURN to display more resource descriptions, or CTRL-Z to exit this list.

?xx a list of all descriptions starting with $x x x$

$>$ index \# $\quad$ resource description from the numbered list

(from list) automatically entered in the "Description" field 


\section{Selecting a Resource}

The following RESOURCE MANAGEMENT menu options require you to select a specific resource within a general resource type:

\section{MOVE RESOURCES MODIFY RESOURCES DELETE RESOURCES}

In each case, the general sequence for selecting a resource type is similar. The system prompts:

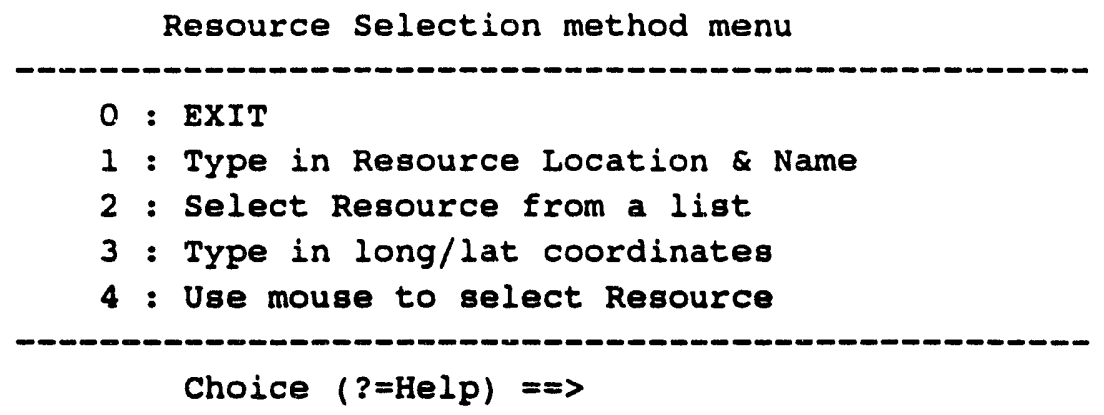

Use one of these four methods to identify a resource at a facility:

1. Type in Resource location and name: Prompts you to enter the name of an existing facility and a resource description.

Enter Resource location $=>$
Enter Resource description $=>$

2. Select Resource from a list: Prompts you to choose one from a numbered list of resources at various facilities. For example:

\begin{tabular}{|c|c|c|}
\hline \multicolumn{3}{|c|}{ Resources } \\
\hline 0 & : EXIT & \\
\hline 1 & : POLICE HEADQUARTERS & SQUAD CARS \\
\hline 2 & : SHELTER 1 & BLANKETS \\
\hline 3 & : FRANKLIN SCHOOL & FIRST AID KITS \\
\hline 4 & : FIRE STATION & HOOK AND LADDER \\
\hline
\end{tabular}

Enter the number that corresponds to the desired facility and resource, or press CTRL-Z to exit.

3. Type in long/lat coordinates: Prompts you for the longitude and then the latitude coordinates of the resource location. 
4. Use mouse to select Resource: Enables you to pick a resource icon on the screen by using a mouse (or other pointing device).

Note: You must first have enabled (turned on the icons) the resources hefore you can select them with the mouse. Use the Enable Resources option to do this.

The selected resource description is then used in completing the current operation.

\section{Selecting a Resource Type}

The following RESOURCE MANAGEMENT menu options require you to select a general resource type:

\section{DESCRIBE RESOURCES ENABLE RESOURCES SUMMARIZE RESOURCES}

In each case, the general sequence for selecting a resource type is similar. The system prompts:

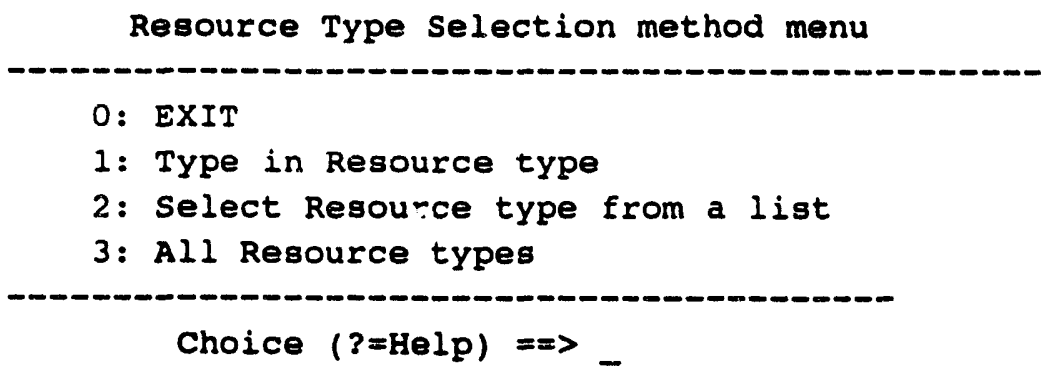

Use one of these three methods to select the resource type:

1. Type in Resource type: Prompts you to enter the name of an existing resource. For example:

Enter Resource type ==> FOOD

2. Select Resource type from a list: Prompts you to choose one from a numbered list of resource types. For example:

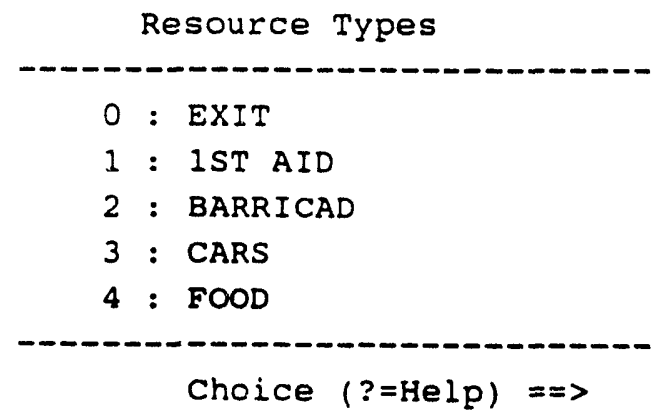


Enter the number corresponding to a resource type, or exit.

3. All resource types: Will select all resource types in a defined area of interest.

The selected resource type is then used in completing the current operation. 


\section{SUMMARIZE RESOURCES}

SUMMARIZE RESOURCES enables you to view a list of all resources of one resource type within a specified area. Producing this summary of resources consists of 1) selecting an area of interest and 2) selecting a resource type.

\section{Select an Area of Interest}

The system prompts:

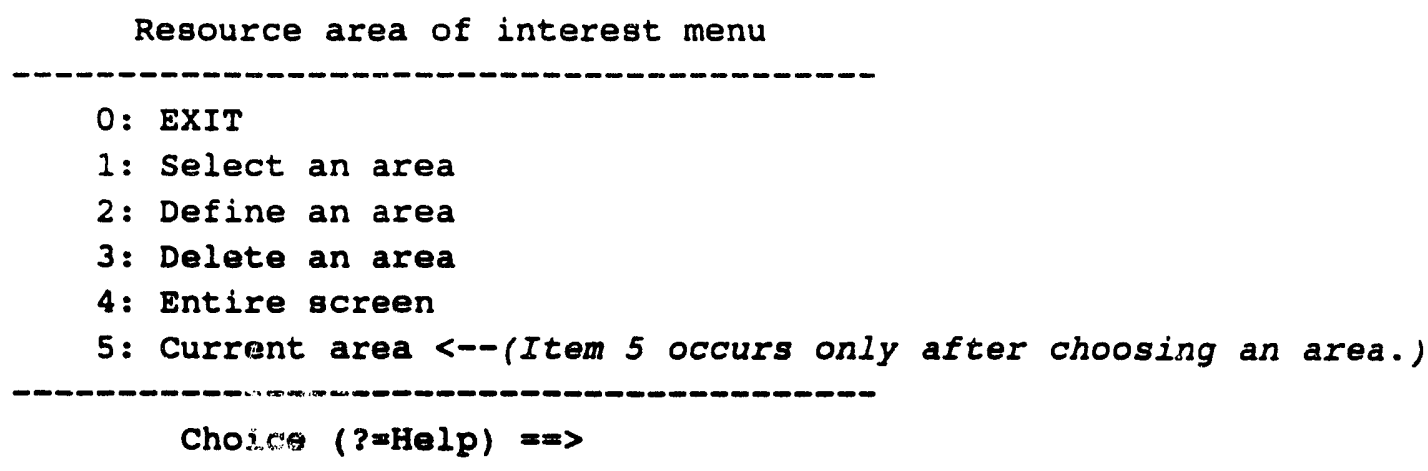

Use one of these five methods to identify the area of interest:

1. Select an area: Prompts you to select an existing area by picking a polygon. For example, you could pick the outer polygon of the D2 model track output.

2. Define an area: Prompts you to define an area by drawing a polygon around the desired area.

When you pick CONTINUE to finish the last side of the polygon, the polygon lines are redrawn in white. The polygon remains on the screen until you use the "Delete an area" option to erase it, or exit the Summarize Resources option.

3. Delete an area: Prompts you to pick a polygon to be deleted. The polygon must be one that you have drawn by using the "Define an area" option.

When you pick CONTINUE to confirm the deletion, the polygon is erased (redrawn in the background color). You may need to use REFRESH SCREEN.

4. Entire screen: Uses the entire current map area as the area of interest.

5. Current area: "Re-uses" the last-specified area. This option appears on the menu only after you have selected an area of interest once.

After you have specified the area, the subsequent selection of resource type applies only to resources within that area. 


\section{Select a Resource Type to be Summarized}

The system prompts with the Resources Types, list as shown in the following example.

\begin{tabular}{l} 
Resources TYPes \\
0: EXIT \\
1: 1 ST AID \\
2: CARS \\
3: COMM EQ \\
4: CONST EQ \\
5: DRY GOOD \\
6: EMERG EQ \\
7: FOOD \\
8: GENERATOR \\
9: HAND TL \\
10: MEDIC EQ \\
\hline ChOICe (?=Help) $x=$
\end{tabular}

You can select a resource type directly from the list or press the Return key to display the Resource Type Selection method menu.

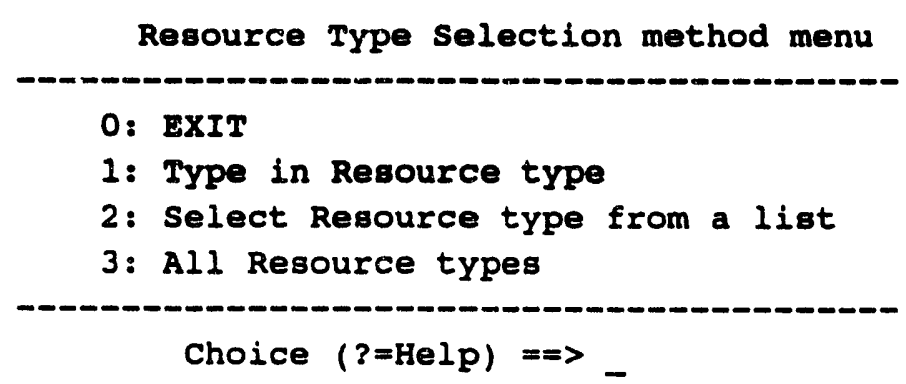

Use one of the three options to select resource type(s). For detailed instructions on using this menu, see the heading Selecting a Resource Type. 
All resources for that resource type within the specified area are then listed in a summary table. For example:

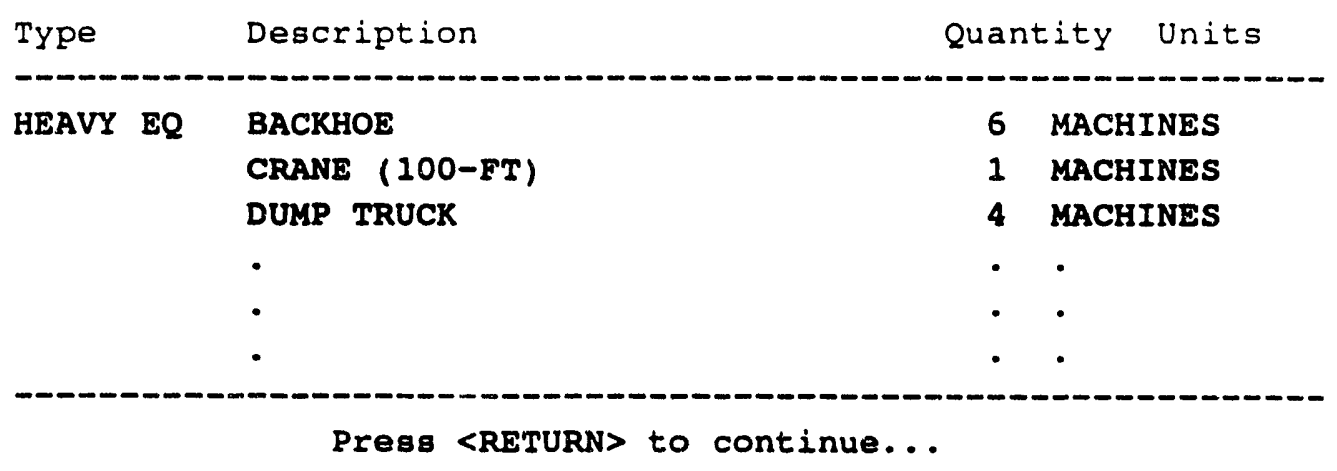




\section{ID VALIDATE RESOURCES *}

This option is used to deter ine whether resources are sufficient to meet the requirements of all Implementing Procedures. (For example, this is important in checking the available resources, if there is a switch to a different IP.)

This option takes some time to perform because it checks through all the IPs you specify. When you select this option, the system displays the Output Redirection menu, or it will send any output to your default printer or display (if you set up your system default under the Setup option).

After you have chosen the output device, the Select IP Menu displays, as shown in the following example.

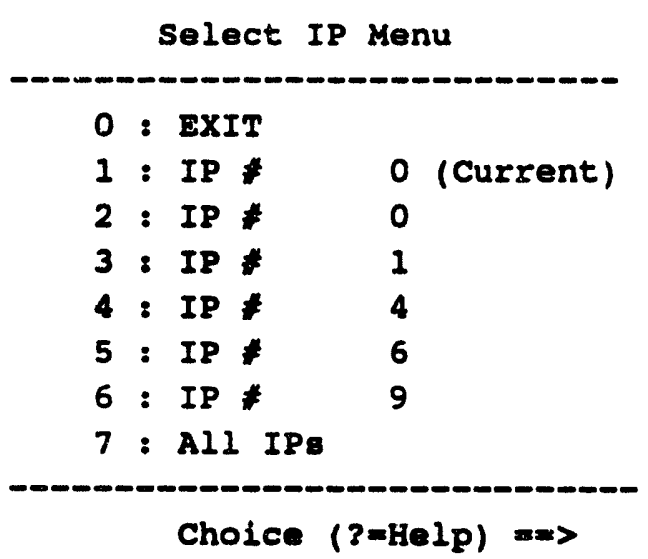

If any specific resource is in short supply (that is, if the amount required by any IP exceeds the amount available), a paged validation report either displays on the screen or is printed to your default printer. 
For each facility, the validation report for the each IP lists the total amounts required and available for each specific resource that is in short supply. These amounts and resource description are shown in bold in the example. For each resource, the report then shows a breakdown of the required amounts by task number within each applicable Emergency Function.

For example:

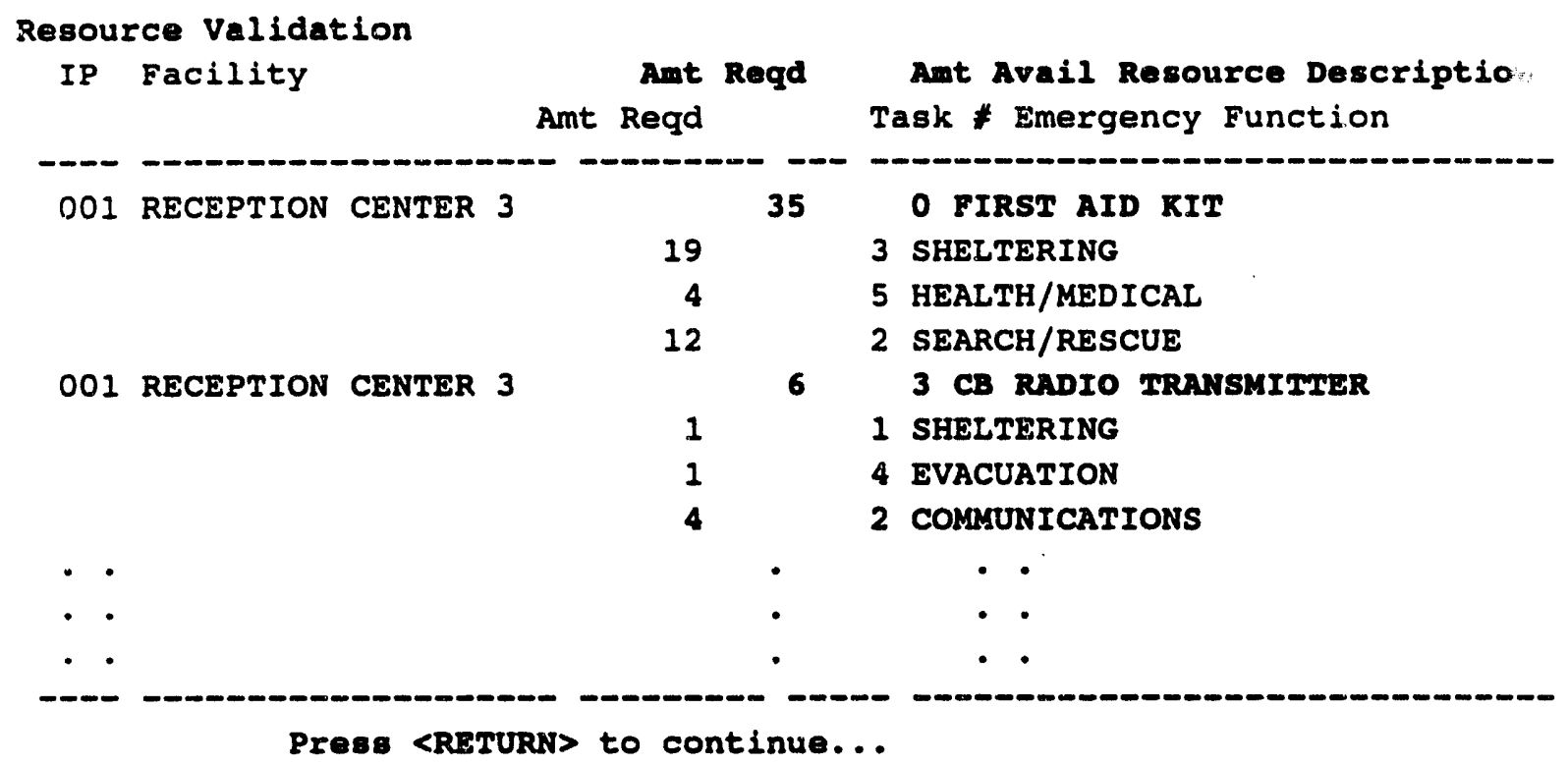




\section{Section 7 \\ Show (Remove) Latest Onpost Track}

\section{DHOW (REMOVE) LATEST ONPOST TRACK}

SHOW LATEST ONPOST TRACK displays the latest D2 track from the onpost system, overlaying it on the current D2 track for the IBS event database. This allows two tracks to be displayed simultaneously. To make it clear that you are viewing both tracks, the menu item then changes to REMOVE LATEST ONPOST TRACK.

When REMOVE LATEST ONPOST TRACK is selected, the screen is refreshed, removing the onpost track from the display. The current D2 case track continues its display.

Whenever new information is received from the onpost system, the IBS displays a single-line message at the bottom of your screen. If the information received from the onpost system is adequate for the generation of a new D2 model case, the system creates the new case, assigns it a model number, and puts the output file in the appropriate directory, where it can be used by SHOW/REMOVE LATEST

ONPOST TRACK. You can use the MESSAGE BOARD at any time to view other textual information for the latest onpost system case.

When you receive a notification message concerning new D2 output from the onpost system, you may ignore it or choose SHOW LATEST ONPOST TRACK to display the new information in addition to the track from the current D2 case. 


\section{Section 8 \\ Analyze Track}

ANALYZE TRACK

IBS MAIN MENU

ANALYZE TRACK

CONTINUE

DOSE DETAILS

DESCRIBE TRACK

PRINT D2 REPORT

SHOW ELEVATION

DETERMINE AREA

DISPLAY LOCATION

ESTIMATE POPULATION

SET BASEMAP

MAP ZOOM

ZOOM IN

ZOOM OUT

REFRESH SCREEN
The output of the D2 dispersion model is expressed graphically on the map screen as track contours of time-weighted concentration. ANALYZE TRACK presents a menu of options for obtaining information about the current track from the current event database.

The track analysis and elevation options on this menu are also available under EMERGENCY ACTIVITIES-HAZARD ANALYSIS.

<-- Check doses along the track center line.

<-- View the label of a selected track contour.

<-- Display or print D2 output reports.

<-- Show elevation of point locations.

<- Show area/perim. of a region (polygon).

<-- Show coordinates of picked points.

$<-$ Estimate population within a region (polygon) based on population pattern.

<-- View area picked by center point/radius.

<-- Make the current screen the default area.

$<-$ Enlarge a portion of the current screen.

<-- View current area within a larger area.

$<-$ Redraw (and clean up) the current screen.

The track analysis and elevation options in this section are described in alphabetical order.

(a) These options are explained as menu items on the MAP ANALYSIS menu and are NOT duplicated in this section. 
D2 Track. The time-weighted concentration track on the map screen consists of three contour lines. Each contour represents a constant level of dose or concentration (depending on the original inputs to the D2 model). A series of asterisks $\left(^{*}\right)$ along the track center line (if they appear) indicate slice points along the track where the DOSE DETAILS option can be used to display dose or concentration information about those locations. Some chemical agents do NOT result in the generation and appearance of these points.

\section{ID DESCRIBE TRACK}

DESCRIBE TRACK enables you to pick one or more of the three contours displayed in the current D2 track. When you select Describe Track, the system will display the following message at the top of the screen.

select TRACK boundary with crosshairs

As you pick a track contour, a text description of the contour is displayed at the top of your screen. For example:

$\begin{array}{lll}\text { LOW DOSAGE TRACK : } & n n n . n n & (M G-M I N / M * * 3) \\ \text { MEDIUM DOSAGE TRACK: } & n n n . n n & (M G-M I N / M * * 3) \\ \text { HIGH DOSAGE TRACK : } & n n n . n n & \end{array}$

Be sure to place the cross hairs insicie the track when you make your selection. The selected contour highilights in white and also blinks. You can pick more than one contour. Information from the previous pick remains visible on the screen until you choose another menu option. When you have finished selecting contours, select Continue to stop.

\section{IDOSE DETAILS}

Asterisks (*) are used to mark locations of changing dose along the D2 track center line. DOSE DETAILS enables you to select an asterisk on the track center line to display dose information for that location. When you select Dose Details, the system displays the following message at the top of the screen.

Select dose site (*) with crosshairs 
You can pick more than one asterisk location. The information includes details such as those in the following example:

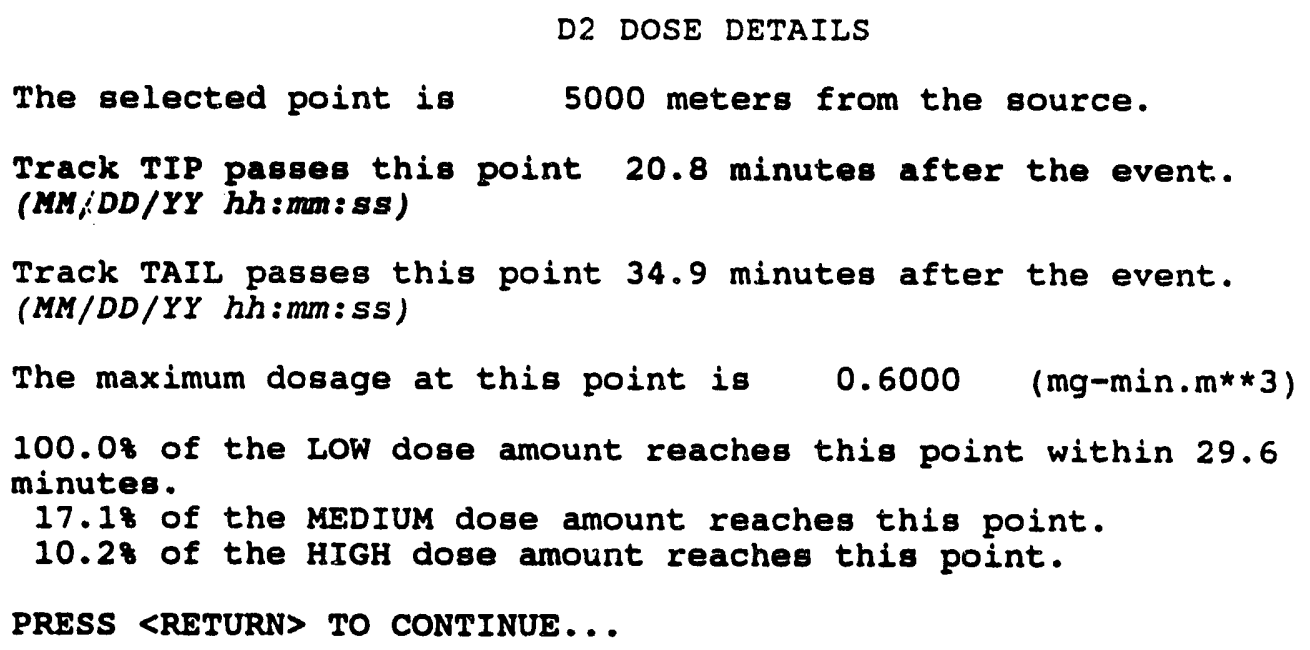

When you have finished selecting asterisks, select CONTINUE to stop the selection process.

The information provided can vary somewhat, depending on the input parameters selected for the D2 cases. For example, dosage information is not available when the D2 input requests concentrations.

\section{ID PRINT D2 REPORT}

This option enables you to display or print the output reports produced by the IBS implementation of D2.

The system first prompts you to identify the desired report:

Select report type
0: EXIT
1: D2log
2: Pdata
3: Dosage
4: Slice
Choice $($ ?=Help) $==>$

To select the type of report, enter the number associated with the desired report. To exit without selecting a report, type 0 and press the Return key.

When you select one of these reports, you choose whether to display or print the report. Refer to the discussion of the MESSAGE BOARD capability for illustrations of the report outputs. 


\section{SHOW ELEVATION}

SHOW ELEVATION displays the elevation (meters above sea level) associated with the point location you pick with the graphic cursor. You can pick more than one point location. The information from the previous picks remains visible on the screen until you choose another menu option. 


\section{Section 9 \\ Change D2 Track Case}

\section{- CHANGE D2 TRACK CASE *}

CHANGE D2 TRACK CASE is" used to select an existing D2 case as the "current" D2 case for the IBS event database. This erases the currently displayed track from the map screen and replaces it with the track for the "new" current D2 case. To assure the replacement case has a track to display, CHANGE D2 TRACK CASE enables you to switch only to D2 cases with available output.

When an Information Manager switches between D2 cases, other system users see a message that instructs them to pick REFRESH SCREEN to see the current D2 track case.

If you are in Operational mode and the selected case has been checked out by a planner, a message similar to the following will display.

\footnotetext{
* * MSG: The selected case has been checked out by a planner. They will be * * * MSG: unable to check in their case while it is selected as the current

* * * MSG: Operational case.
}

The planner who has checked out this case will not be able to check it back in as long as it is selected as the current Operational D2 case.

CHANGE D2 TRACK CASE gives you the options of entering a case number directly or specifying a set of case description criteria:

Choose D2 Case Menu
0: EXIT
2: CHOOSE D2 CASE BY CASE NUMBER
: CHOOSE D2 CASE BY SEARCH FOR D2 CRITERIA
Choice $(?=$ Help) $=\Rightarrow$

\section{Choosing a D2 Case by Case Number}

If you know the number of the D2 case that you want to use, choose this option. When you see the following form, enter the D2 case number you want from the listing as shown. 


\begin{tabular}{|c|c|c|c|c|c|c|c|}
\hline \multicolumn{8}{|c|}{ CHANGE CASE } \\
\hline $\mathrm{D} 2$ & AGENT & MUNITION & RELEASE & WIND DIR & WIND SPEED & QUANTITY & STAB \\
\hline & & & & & & & \\
\hline 0 & GA & $81 N$ & INS & 180.0 & 3.2 & 1 & A \\
\hline 1 & GA & $81 \mathrm{~N}$ & INS & 90.0 & 8.0 & 1 & B \\
\hline 2 & GB & M23 & INS & 150.0 & 5.0 & 1 & B \\
\hline 10 & GB & M23 & INS & 180.0 & 3.0 & 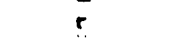 & A \\
\hline 20 & GB & M23 & INS & 90.0 & 5.3 & 2 & B \\
\hline
\end{tabular}

To move around in the form, you can type in the following options at the Select desired IBS D2 case prompt.

$\mathrm{H}=$ Display alternate headers. This option will enable you to toggle between the above form and a one-line description of each case.

$D=$ Move down the list to see more cases.

$\mathrm{U}=$ Move up the list.

$?=$ Help.

$\mathrm{D \#}=\quad$ Move down number $(\#)$ of pages.

$\mathrm{U} \#=\quad$ Move up number $(\#)$ of pages.

\section{Choosing a D2 Case by Searching for D2 Criteria}

When you select option 2, the system displays a message similar to the following.

You are in operational mode, looking at the system database.

Your current D2 case is $910^{\circ}$

Press <RETURN> to continue...

After you press the Return key, the system displays the following brief message.

Loading D2 case data. Please wait...

This second option displays the following screen for specifying a set of case description criteria. The IBS then generates a selection list of D2 cases that match (or approximately match) the criteria. 
On this screen you can modify the fields, which serve as "search keys" into the database of D2 cases:

- The default tolerances for wind direction, wind speed, and agent quantity are displayed. You can change these values for this particular search.

- You can remove one or more criteria from the search by leaving blanks in the text fields (agent, munition, release type, stability class) or by entering a negative one $(-1)$ in the numeric fields.

If you enter a non-existent case number in the IBS D2 Case Number field, the following message displays.

Case not found. Please specify another case or input search criteria by hand.

D2 Track QuAIFICATION

IBS D2 CASE NUMBER:

AGENT:

MUNITION:

RELEASE :

WIND DIRECTION (deg) (deg tolerance)

WIND SPEED $(\mathrm{m} / \mathrm{s})$ ( $\mathrm{m} / \mathrm{s}$ tolerance)

QUANTITY (mg) (mg tolerance)

STABILITY CLASS:

- If all fields are removed from the search by entering 0 or -1 in each field, you must instead select one case from a list of all D2 cases (see the next screen).

- If any criteria are used, the IBS compares these case input criteria with the database of D2 cases. (If no identical matches can be found, the IBS displays a message to indicate how many criteria were actually matched.) You must then select from a list of D2 cases that match the greatest number of criteria (see the next screen).

- Press the Return key in the Stability Class field to complete the form and start the search.

- If all fields are removed from the search, the system displays a list of all D2 cases. Select one case from the list. 
The selection list of D2 cases looks like the following example:

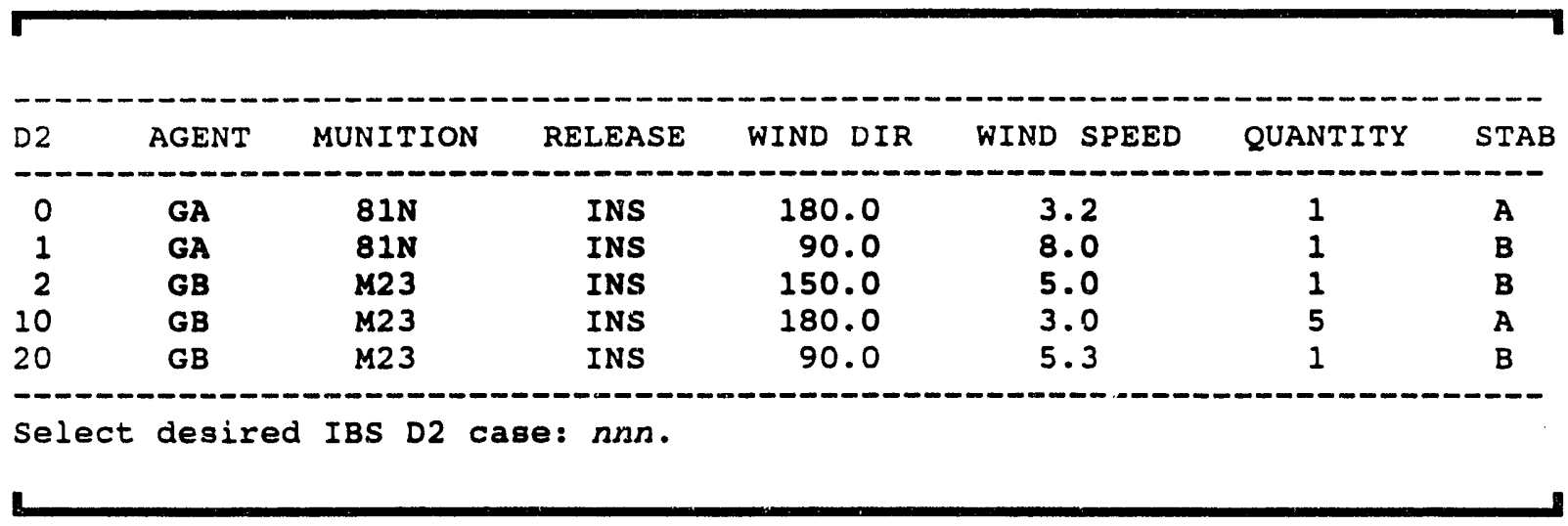

If the cases are too numerous to fit on one screen, you can scroll through the remaining case descriptions by entering a key command at the Select desired IBS case: prompt (U, U\#, D, D\#, T, B). (Enter $\mathbf{H}$ to switch the heading display to show the D2 case description instead of the D2 case qualifications shown here.)

To select a case, enter the case number at the Select desired IBS case: prc mpt. The IBS program then removes the previous track contours and displays the D2 results for the selected D2 case. 


\section{Section 10 \\ Report Current D2 Description}

\section{REPORT CURRENT D2 DESCRIPTION}

This opiion displays a description of the current D2 case. This description consists of the two lines entered on the D2 Standard Input form shown for the HAZARD ANALYSIS emergency activity. For more information, see Section 11, Emengency Activities.

When you select Report Current D2 Description, a message similar to the following example displays.

Current D2 Description:

Case number 002. Agent GB, munition 8 in shell, release type INS. Wind direction 10 degrees. Wind speed $15 \mathrm{~m} / \mathrm{s}$. Release quantity $0.060 \mathrm{mg}$.

F cegs <RETURN> to continue...

Press the Return key to return to the IBS Main menu. 


\section{Section 11 \\ Emergency Activities}

DEMERGENCY ACTIVITIES

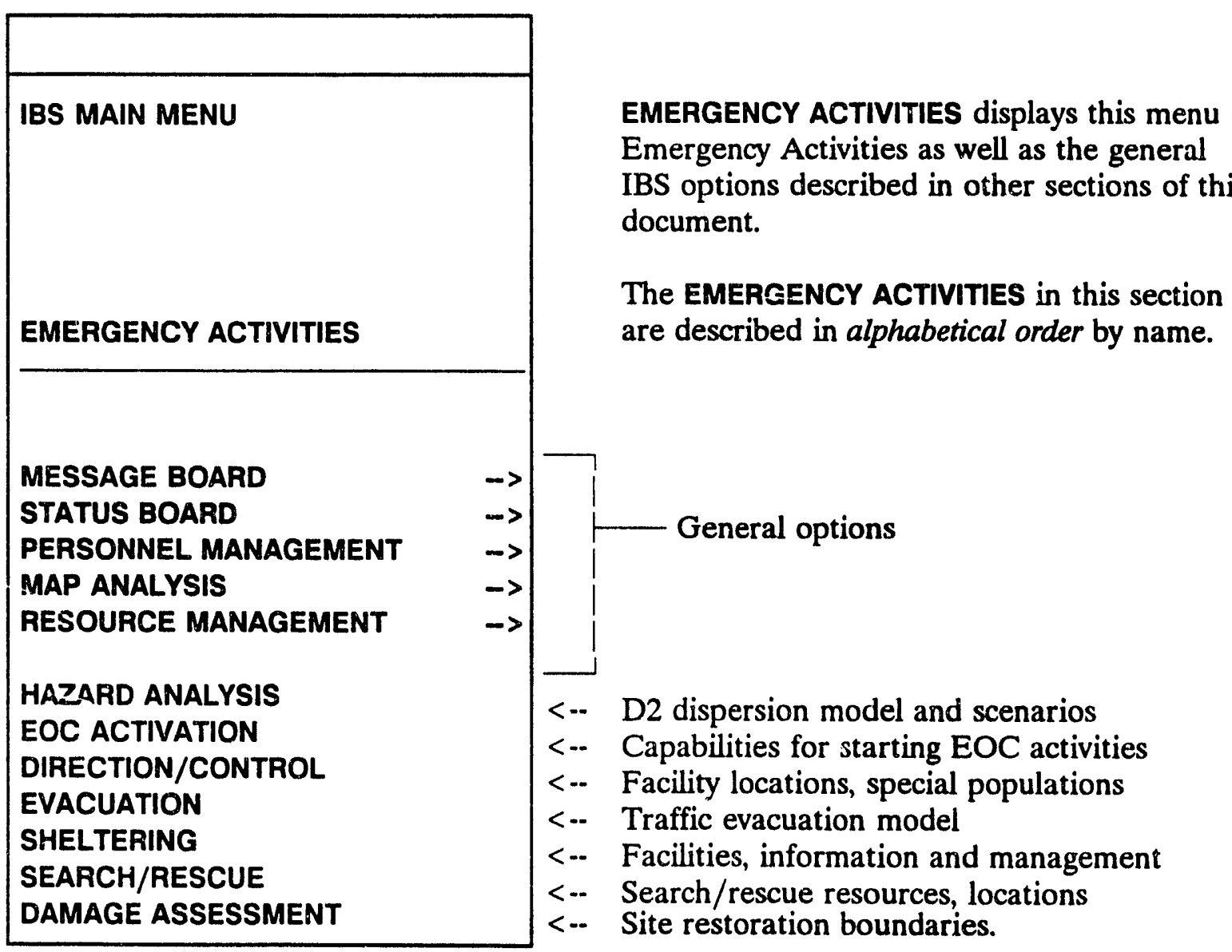

When you select any one of the seven Emergency Activities, the IBS presents a submenu of capabilities for that function. These Emergency Activities submenus usually include an overlay option that is similar from one function to another:

- RELEASE OVERLAYS (RETAIN OVERLAYS). The map layers associated with an Emergency Activity are automatically overlaid on the screen map when you first use that function. These overlays continue to be displayed (both in and out of Emergency Activity operations) until you cancel their display. 
To cancel their display, pick RELEASE OVERLAYS (the menu item then switches to RETAIN OVERLAYS). To redisplay them, pick RETAIN OVERLAYS (the menu item switches back to RELEASE OVERLAYS). To choose the overlay map layers for each Emergency Activity, use SETUP-MAP LAYERS BY FUNCTION. 


\section{ID DAMAGE ASSESSMENT}

\author{
IBS MAIN MENU \\ EMERGENCY ACTIVITIES
}

DAMAGE ASSESSMENT

\section{CONTINUE}

MESSAGE BOARD

STATUS BOARD

PERSONNEL MANAGEMENT

MAP ANALYSIS

RESOURCE MANAGEMENT
This Emergency Activity currently includes boundary drawing options to be used in developing and evaluating strategies for restoring a contaminated area.
DRAW NATIONAL DEFENSE AREA DELETE NATIONAL DEFENSE AREA * DRAW CONTAMINATION AREA DELETE CONTAMINATION AREA
<-- Draw boundary of Nat. Def. Area.

<-- Pick/delete a INat. Def. Area boundary.

<-- Draw boundary of a contamination area.

<-- Pick/delete a contam. area boundary.
RELEASE OVERLAYS
<-- Cancel display of DAMAGE ASSESSMENT map layers.

The DAMAGE ASSESSMENT menu options are described in alphabetical order. 


\section{DELETE CONTAMINATION AREA *}

This option enables you to pick and delete a boundary that identifies a contamination area (see DRAW CONTAMINATION AREA) by selecting it on the screen:

1. After picking DELETE CONTAMINATION AREA, the system displays the following message.

* * MSG: Select Contaminated Area to delete. CONTINUE when wone Use the mouse (or joydisk) to pick any point on the boundary that you want to delete.

The selected boundary blinks to indicate your selection.

2. Pick CONTINUE to confirm the deletion.

The selected boundary is then removed from the screen.

\section{DELETE NATIONAL DEFENSE AREA *}

This option enables you to pick and delete a boundary that identifies a National Defense Area (see DRAW NATIONAL DEFENSE AREA) by selecting it on the screen.

After picking DELETE NATIONAL DEFENSE AREA, the system displays the following message.

* * * MSG: Select National Defense Boundary to delete. CONTINUE when done

Use the same procedures described under DELETE CONTAMINATION AREA to complete the deletion.

\section{DRAW CONTAMINATION AREA *}

This option enables you to plot points that define the boundaries of a contamination area. Selecting this menu item causes it to highlight and flash in? green. The system displays the following message.

* * MSG: Draw a Contaminated Area. Contrnus when done

Move the cursor to the first point of the area you want to draw. Select this point and then move the cursor to the next point. Select this point and a green line is drawn between the two points. Continue this selection process until you are ready to select the last segment to close the area. Select the CONTINUE option from the menu. The area automatically is redisplayed with the last segment completed and the Contamination area boundary drawn in white. 


\section{DRAW NATIONAL DEFENSE AREA *}

This option enables you to plot points that define the boundaries of a National Defense Area. Selecting this menu item causes it to highlight and flash in green. The system displays the following message.

* * MSG: Draw a National Defense Boundary. ConTINUE when done

Move the cursor to the first point of the area you wan: to draw. Select this point and then move the cursor to the next point. Select this point and a green line is drawn between the two points. Continue this selection process until you are ready to select the last segment to close the area. Select the CONTINUE option from the menu. The area automatically is redisplayed with the last segment completed and the National Defense Area boundary drawn in white. 
DIRECTION/CONTROL

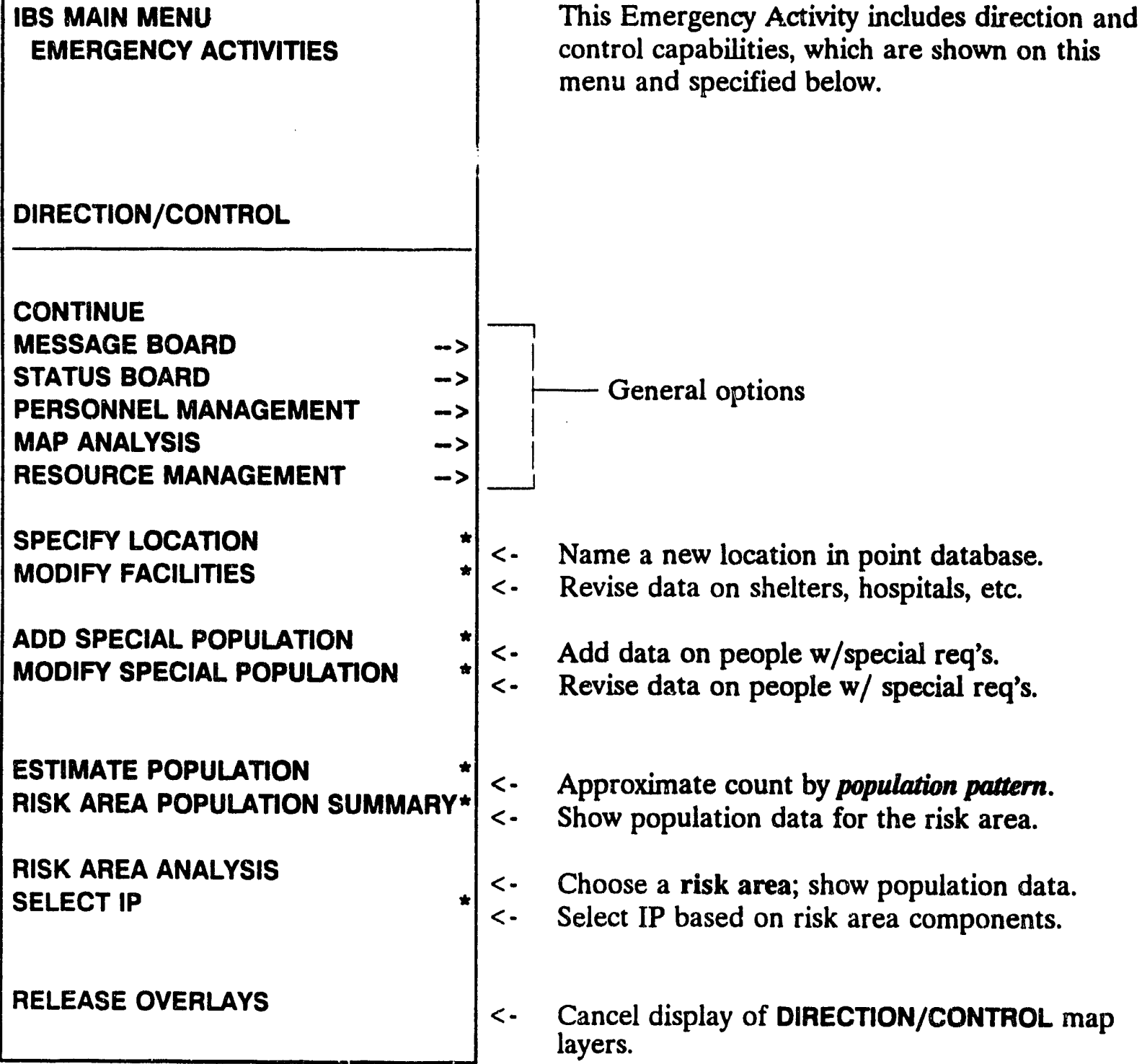

IBS MAIN MENU EMERGENCY ACTIVITIES

DIRECTION/CONTROL

CONTINUE

MESSAGE BOARD

STATUS BOARD

PERSONNEL MANAGEMENT

MAP ANALYSIS

RESOURCE MANAGEMENT

SPECIFY LOCATION

MODIFY FACILITIES

ADD SPECIAL POPULATION

MODIFY SPECIAL POPULATION

ESTIMATE POPULATION

RISK AREA POPULATION SUMMARY*

RISK AREA ANALYSIS

SELECT IP

RELEASE OVERLAYS

This Emergency Activity includes direction and control capabilities, which are shown on this menu and specified below.

<- Name a new location in point database.

<- Revise data on shelters, hospitals, etc.

<- Add data on people w/special req's.

<- Revise data on people w/ special req's.

<- Approximate count by population pattern.

$<-\quad$ Show population data for the risk area.

<- Choose a risk area; show population data.

<- Select IP based on risk area components.

<- Cancel display of DIRECTION/CONTROL map layers. 


\section{ADD SPECIAL POPULATION}

This option is used to enter data about populations with special requirements (such as transportation dependence). Special population data must be added to an existing facility, or a new facility must be created prior to adding the special population data.

After selecting ADD SPECIAL POPULATION, the system prompts with the following menu:

Add Special Population Menu

Add Special Population Menu
0 : ExIT
1 : Add special population to existing facility
$2:$ Create new facility and add special population
Choice $(?=H e l p)==>$

Use one of these two methods to specify adding a special population:

1. Add special population to existing facility: The system displays the Facility Selection method menu, as described in Section 6, Resource Management.

2. Create new facility and add special population: Prompts you for information to create a new facility. When you select this option, the system displays the Known Point Selection method menu, as described in Section 6, Resource Management.

You can now create a new Known Point, or add facilities to an existing Known Point. The procedures you use to add the facility are similar to those described in Section 6, Resource Management, under ADD FACILITIES.

After a facility has been selected, or created, the following special population form displays: 


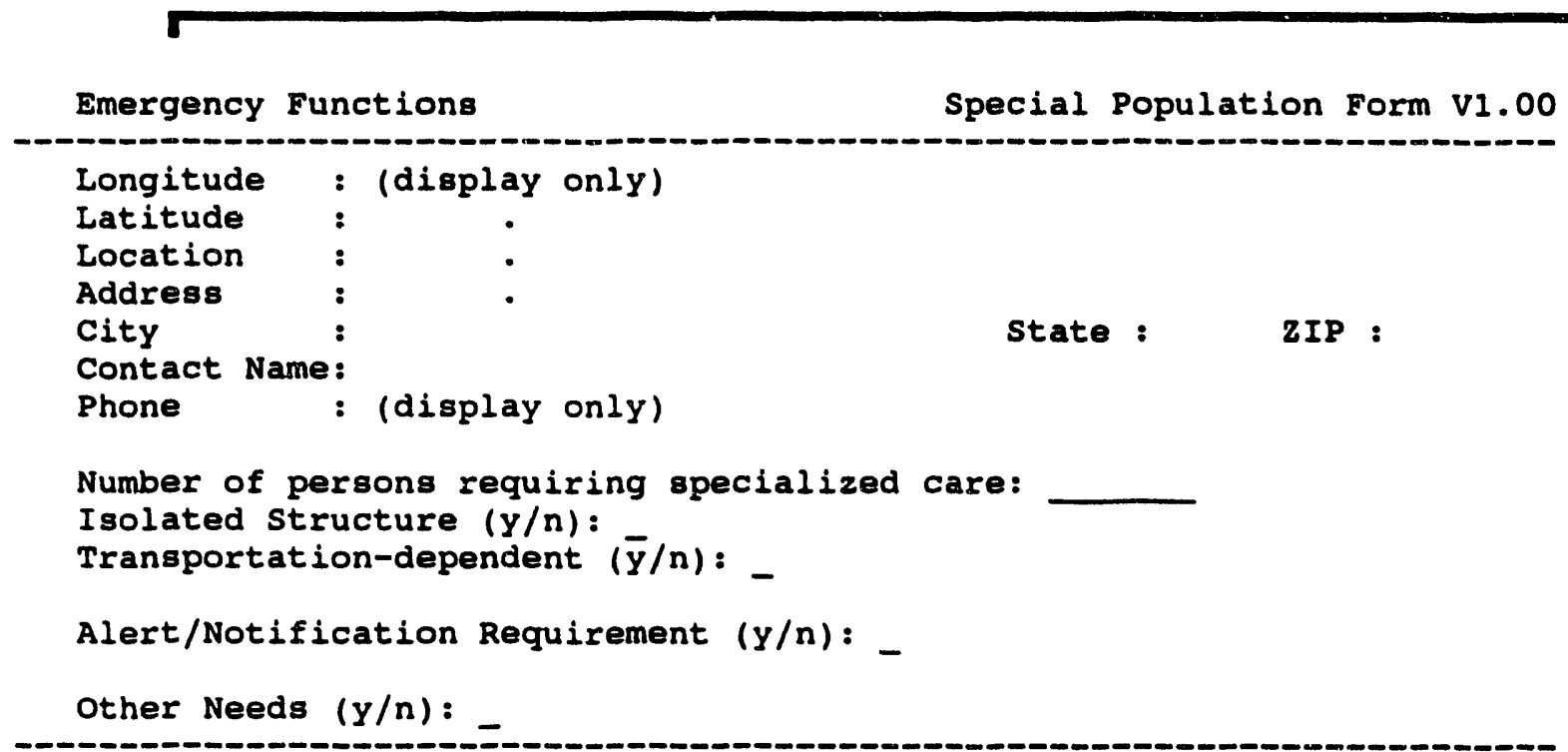

The upper part of the special population form is for displaying facility information only. The lower part of the form is used to enter special population data. Enter the following information on this form:

Number of persons requiring specialized care: Enter the number of persons at the facility requiring specialized care (special population).

Isolated Structure $(\mathbf{y} / \mathbf{n}): \mathrm{Y}$ or $\mathrm{N}$-- Is the special population located at an isolated structure?

Transportation-dependent $(\mathbf{y} / \mathbf{n}): \mathrm{Y}$ or $\mathrm{N}$-- Is the special population transportation dependent? Use the following line for adding comments.

Alert/Notification Requirement (y/n): $\mathrm{Y}$ or $\mathrm{N}$-- Is an alert/notification required for the special population? Use the following line for adding comments.

Other Needs $(y / n): Y$ or $N$-- Are there other additional needs? Use the following line for adding comments. 


\section{MODIFY FACILITIES *}

This option enables an Information Manager to modify facility information by 1) selecting a facility and 2) modifying the facility description.

After selecting MODIFY FACILITIES, the system displays the Facility Selection method menu.

Facility selection method menu
0: ExIT
1: Type in Facility name
2: Select Facility name from a list
3: Type in long/lat coordinates
4: Use mouse to select Facility
Choice $(3=\mathrm{Help})=\mathrm{C}$

Select a facility using this menu.

\section{Modify the Facility Description}

The facility form description of the selected facility is then presented for updating (for details, see the heading Entering a Facility Description in Section 6, Resource Management, under the Add Facility option). When you exit the facility form, you return to the Facility Selection method menu above, where you can choose another facility for updating.

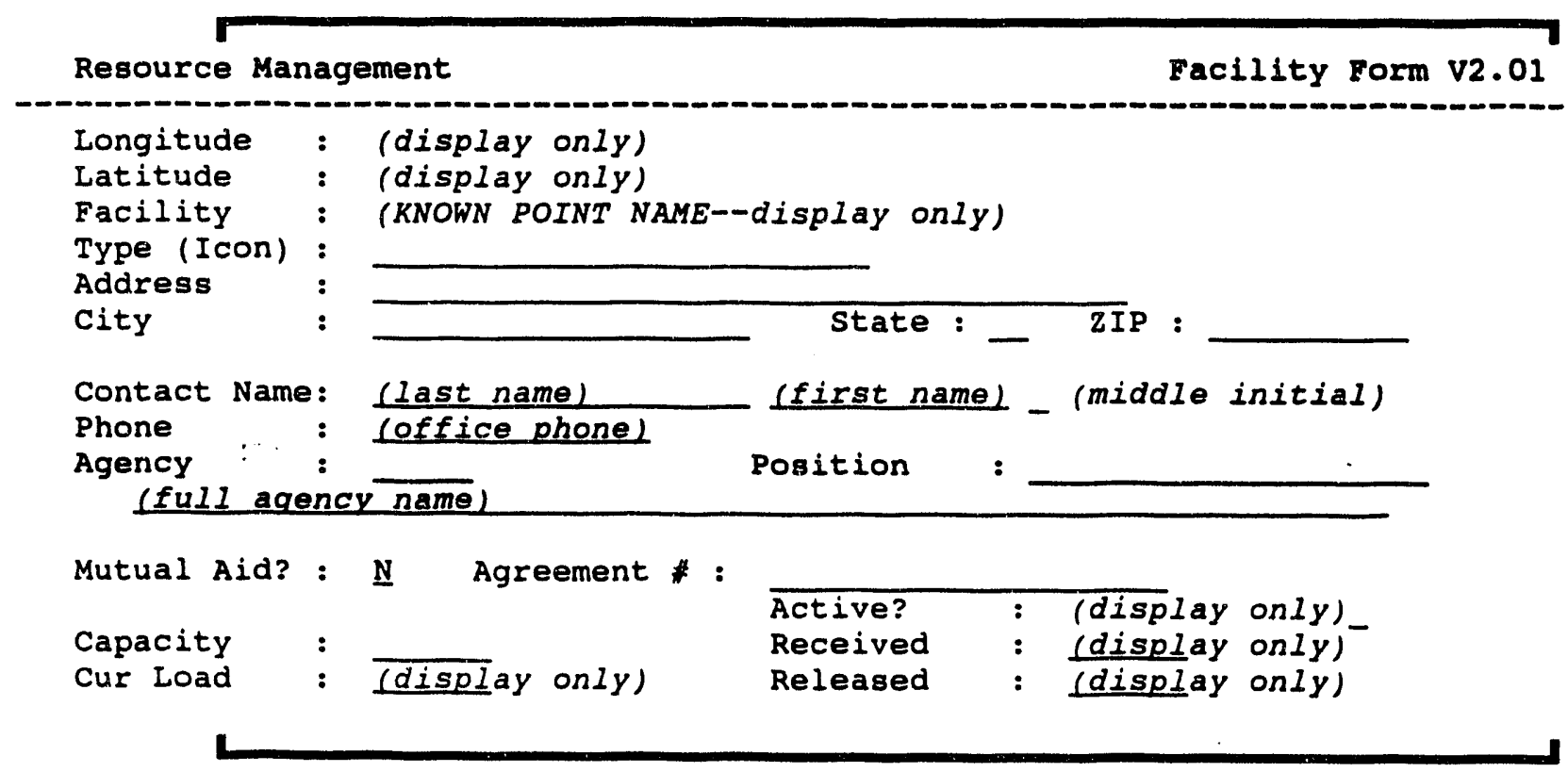

If you cannot find the facility you want to modify, or want to quit modifying facilities, select CONTINUE from the menu. The system returns you to the Facility Selection method menu. 


\section{MODIFY SPECIAL POPULATION *}

This option is used to modify special population data that has been previously enteren.

After selecting MODIFY SPECIAL POPULATION, the system prompts with the following menu:

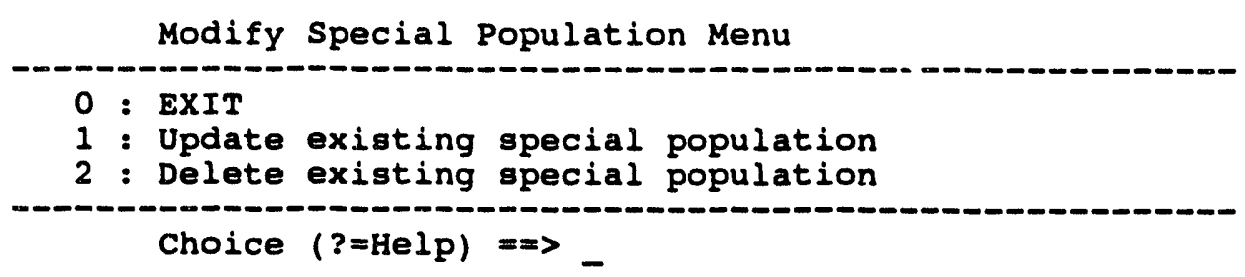

Use one of these two methods to specify adding a special population:

1. Update existing special population: The system displays the Facility Selection method menu, as described in Section 6, Resource Management.

After selecting the facility, the special population form (see ADD SPECIAL POPULATION) appears for modifying the special population data at the facility.

2. Delete existing special population: Prompts you to select an existing facility by displaying the Facility Selection method menu.

After the facility has been selected, a prompt appears verifying that you want to delete the special population data at this facility:

Delete special population at this facility? [Y] ==>

Enter ' $\mathrm{Y}$ ' or <ENTER > to delete the special population data at the facility. 


\section{ESTIMATE POPULATION}

ESTIMATE POPULATION provides an estimate of the population within a defined area. The two sources of data for population reports within ESTIMATE POPULATION are:

- Census data

- People Locate data

To use this option, see the complete procedures in Section 5, Map Analysis, under Estimate Population.

\section{RELEASE OVERLAYS}

This option enables you to switch on or switch off the display of the map layers associated with DIRECTION/CONTROL. (To choose these map layers, see Section 12, Setup, under MAP LAYERS BY ACTIVITY.) 


\section{RISK AREA ANALYSIS}

An Information Manager can establish the risk area, which is made up of one or more Emergency Planning Zones (EPZs). (EPZs are areas defined during emergency planning. Generally, the risk area includes any EPZs where the D2 model predicts the chemical track.) The Information Manager can establish a risk area by Jefining a risk polygon: any EPZ that overlaps a part of this risk polygon is considered to be part of the initial risk area. If a risk area is chosen or modified, the I: jrmation Manager must inform the general users. The general users can then display the boundaries of the risk area, as well as determine the populations of the EPZs within the risk area.

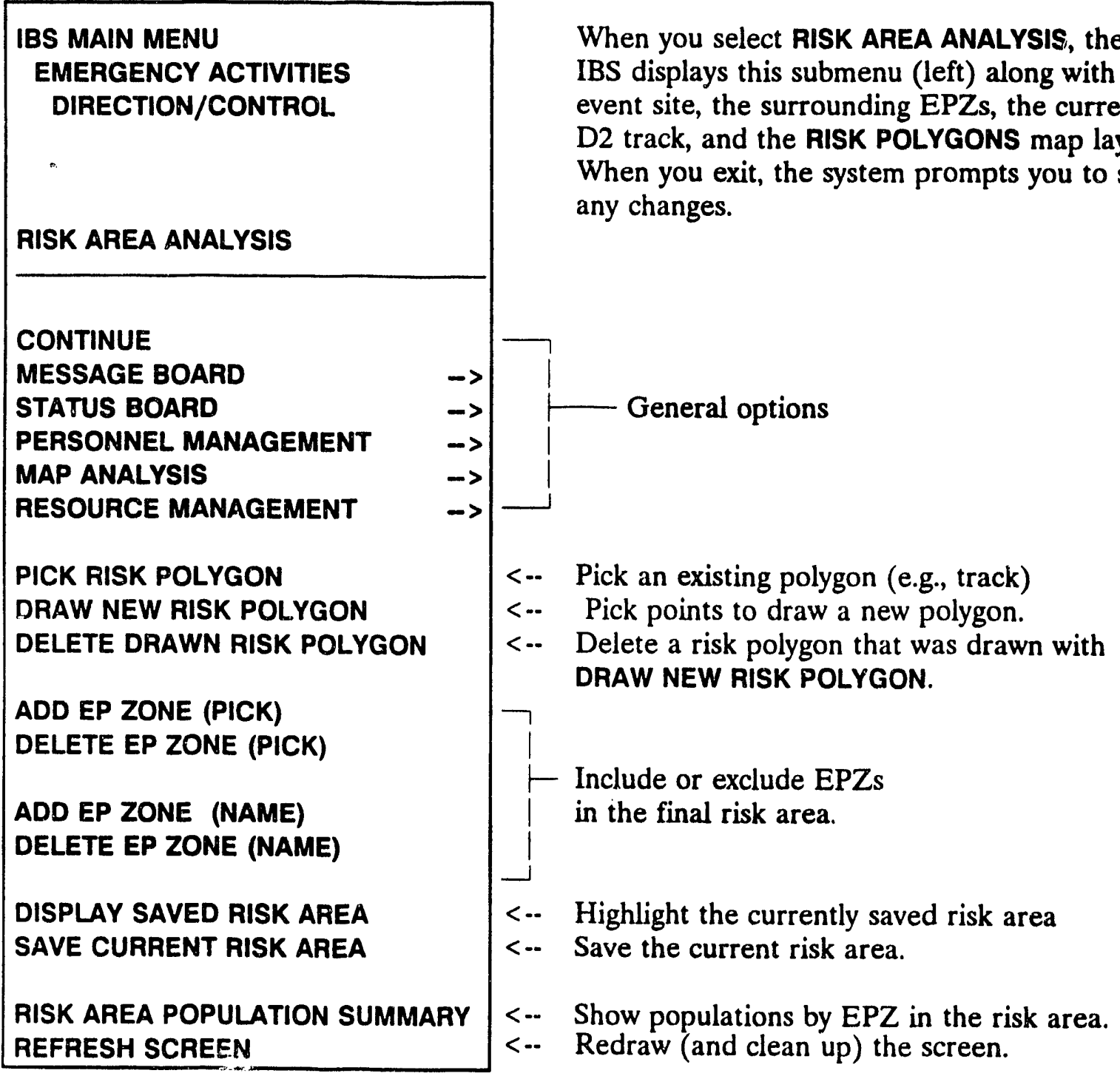


These RISK AREA ANALYSIS options are explained in the following paragraphs.

PICK RISK POLYGON enables you to pick an existing polygon as the risk polygon that is used to specify which Emergency Planning Zones compose the risk area. (For example, a convenient choice might be to pick the polygon that represents the outer contour of the D2 track.) When you pick the desired polygon (and finish by picking CONTINUE), the boundaries of the risk area (all EPZs that intersect the chosen polygon) are drawn with bold lines.

DRAW NEW RISK POLYGON enables you to plot points that define a new risk polygon. As you use the cursor to plot points on the screen, line segments are drawn between the points. When you draw the final line segment between the first and last points (by picking CONTINUE), the boundaries of the risk area (all EPZs that intersect the drawn polygon) are then drawn with bold lines. Risk polygons that are defined in this way are then stored as a map layer named Risk Polygons.

DELETE DRAWN RISK POLYGON enables you to pick a risk polygon for removal from the Risk Polygons map layer.

The ADD and DELETE options enable you to include or exclude specific EPZs within the risk area:

- ADD EP ZONE (PICK) enables you to use the cursor to pick the boundary of an EPZ to be included. When you pick the desired EPZ boundary (finishing by picking CONTINUE), the boundary is then redrawn with bold lines like the rest of the risk area.

- DELETE EP ZONE (PICK) enables you to use the cursor to pick the boundary of an EPZ to be excluded. When you pick the desired EPZ boundary (finishing by picking CONTINUE), the boundary lines are then restored to lines of normal width.

- ADD EP ZONE (NAME) prompts you to enter the name of the ETZ, to be included. (For EPZ names, see POPULATION SUMMARY.) The boundary of the identified EPZ is then redrawn with bold lines like the rest of the risk area.

- DELETE EP ZONE (NAME) lists the EPZs in the current risk area (by ID number and by name) and then prompts you to enter the ID number of the EPZ to be excluded. The boundary lines of the identified EPZ are then restored to lines of normal width.

DISPLAY SAVED RISK AREA displays the most up-to-date risk area by drawing the EPZ boundaries with bold lines. General users of the IBS must use this option to update the current risk area when the Information Manager changes the risk area boundaries. Usually this option is used after receiving a message from the Information Manager. 
SAVE CURRENT RISK AREA saves the currently defined risk area to the system database.

RISK AREA POPULATION SUMMARY provides an estimate of the population within the current risk area.

REFRESH SCREEN redraws the current screen and cleans up any graphic debris left from selecting a risk polygon or from manipulating the EPZs that are included in the risk area.

RISK AREA POPULATION SUMMARY provides an estimate of the population within the current risk area. The two sources of data for risk area population reports are:

- Census data

- Special Population data

Census data (if present in the site database) comes from static census database map layers chosc.. using SELECT MAP LAYERS in MAP ANALYSIS, or CHANGE DEFAULT LAYERS in SETUP. Special population data is generated by the functions ADD SPECIAL POPULATION and MODIFY SPECIAL POPULATION within DIRECTION/CONTROL and contains data for people with special requirements (such as transportation dependence)

After selecting RISK AREA POPULATION SUMMARY, the system displays the Output Redirection menu if you have not specified a default output. The system then prompts with the following menu:

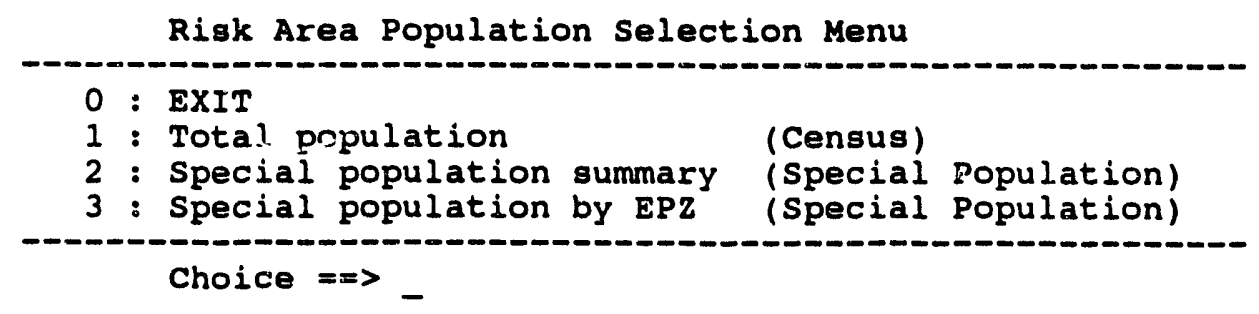

Your choices are these: 
1. Total population (Census): Produces a report of the total population within the current risk area. Census population data is used to generate this report.

\begin{tabular}{l} 
Estimated Population of the Current Risk Area \\
Map Layer \\
Population Pattern : Weeknight \\
\hline Zone Name
\end{tabular}

If no population map layer has been selected, the program displays the following message:

* * MSG: No population topography selected

If this happens, use SELECT MAP LAYERS in MAP ANALYSIS, or CHANGE DEFAULT LAYERS in SETUP to select a population map layer.

2. Special population summary (Special Population): Produces a report of the total special population in the current area of interest. Special population data is used to generate this report.

Special Population Summary status

DD-MMM-YYYY HH:MM:SS

All Special Populations in Risk Area

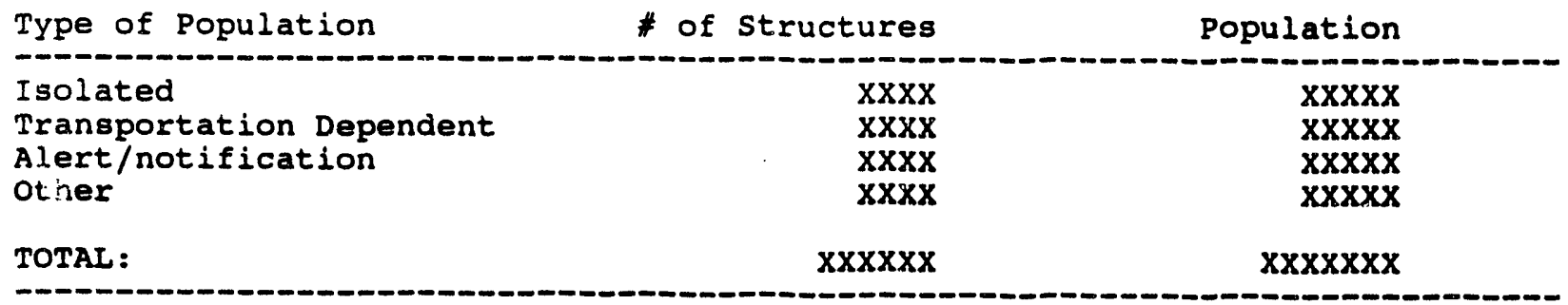

<Return> to continue ...

Note: Some special population facilities can be counted more than once in the \# of Structures or Population columns. A special population facility can qualify for more than one category of facility. For example, the same facility can have transportation dependent people and be isolated. 
3. Special population by EPZ (Special Population): Produces a report of the special population for each emergency planning zone within the current risk area. Special Population data is used to generate this report.

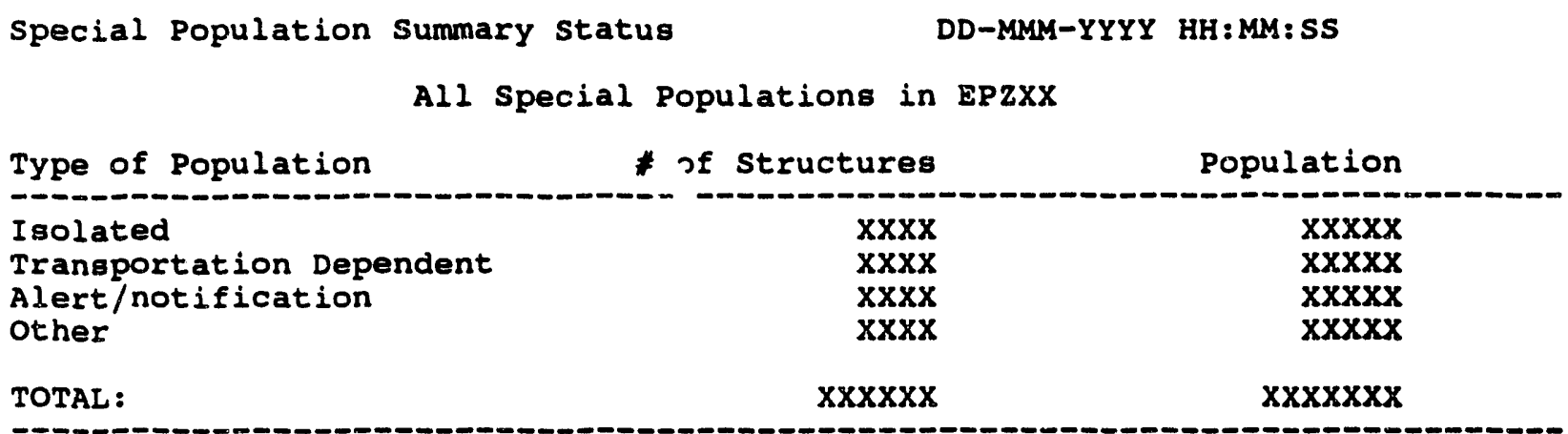

<Return> to continue ...

Note: Some special population facilities can be counted more than once in the \# of Structures or Population columns. A special population facility can qualify for more than one category of facility. For example, the same facility can have transportation dependent people and be isolated.

\section{SAVE CURRENT RISK AREA}

This option enables you to save the current risk area to the system database. The risk area then displays whenever you start the IBS and select the RISK AREA ANALYSIS option.

When you select this option, the system prompts you to define a risk area, if one has not been defined earlier.

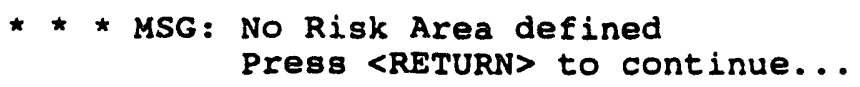

If a risk area has been drawn on screen, the system displays the following message. Do you wish to save the RISK AREA? [Y] $=\Rightarrow$

Press the Return key to complete the option and save the risk area. If you decide you do not want to save the risk area, type $\mathrm{N}$ at the prompt and press the Return key. 


\section{SELECT IP *}

The Select IP option enables you to change your current IP. This option is only used by information managers, planners, and others with appropriate authorization.

For more information on IPs and their use, see Section 3, Status Board, under the heading Implementing Procedures.

When you select the Select IP option, the system displays a message similar to the following example.

You are in planning mode, looking at your own database.

Your current IP number is 000

Press <RETURN> to continue...

After you press the Return key, the system displays a listing of the Eniergency Planning Zones.

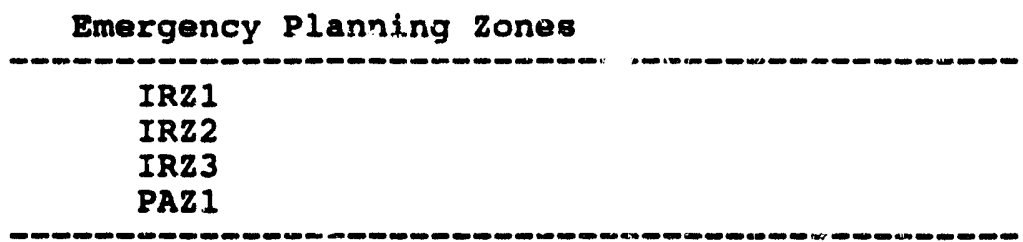

Are emergency zones correct: $(Y / N)\{Y\}:=>$

If you answer yes ( $\mathrm{Y}$ ) at the prompt, the system displays a list..'g of all IPs in the database (Planning or Operational, depending on which mode you are in).

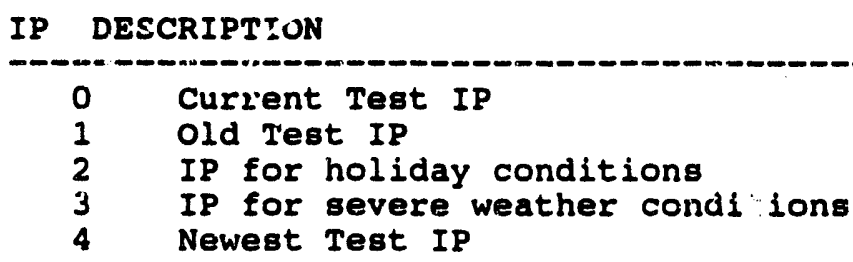

Select desired IP :

Type the number of the IP you want to use at the Select desired IF prompt and press the Return key. The system displays a message similar to the following example.

Your old IP number was 000
Your new IP number is 001
Press <RETURN> to rentinue... 
You will now be using the new IP.

If you answer no $(\mathrm{N})$ at the prompt, the system directs you to select new Emergency Planning Zones using RISK AREA ANALYSIS.

\section{SPECIFY LOCATION}

SPECIFY LOCATION adds a new location to the database of Known Points. The following prompt appears first:

Enter riew known Point name ==>

Enter any name (up to 40 characters) or press CTRL-Z to exit.

This location name serves as the facility name for any facility that is added at that location.

If you enter a name that is already used for a location, the system prompts you to enter another name. After you enter a valid new location name, the following prompt appears:

* * * MSG: Select new Known Point location using mouse

Pick a location on the map screen.

If you pick a location that is already specified as a Known Point locution, the systcm prompts you to select another point.

After you pick a valid location, that location is placed in the database of Known Points. The system then returns to the previous step where you can continue to add noint locations until you quit by pressing CTRL-Z. 


\section{EOC ACTIVATION}

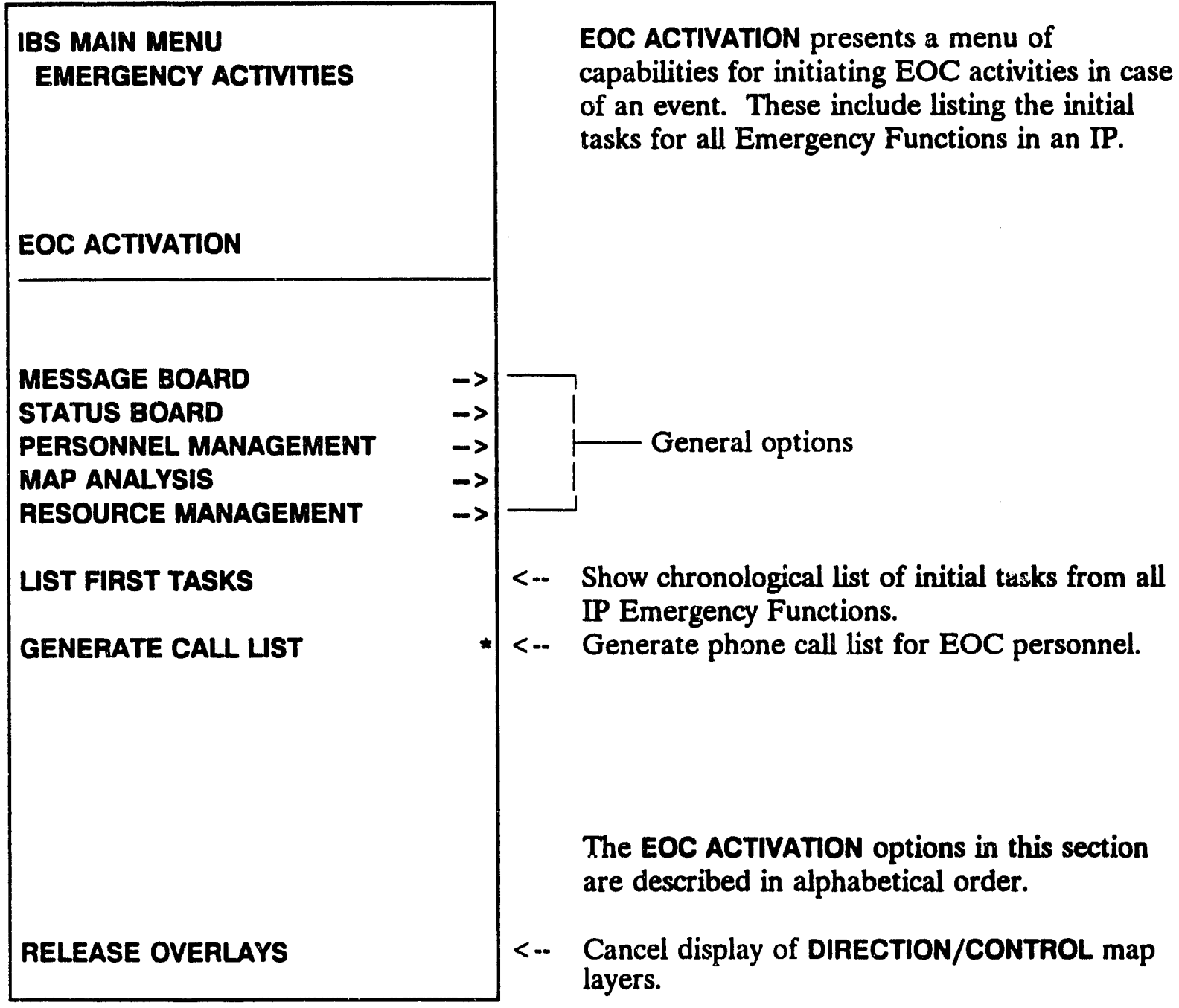




\section{GENERATE CALL LIST *}

This option generates a phone call list for emergency management personnel. This list can be sent to the default printer or displayed on the screen. When you select GENERATE CALL LIST, the system prompts you to select one of three types of lists.

Generate Call List

1: Make call list of ALL Ip tasks
2: Make call list of IP tasks for a specified duration
3: Make call list of ALL positions in database
Choice $(?=H e l p)==>$

1. Make call list of ALL IP tasks. The following prompt displays.

Include task description in call list [N]?

After you answer the prompt, the Generate Call list menu displays.

2. Make call list of IP tasks for a specified duration. The following prompt displays.

Inciude task description in call list [N]?

After you answer the prompt, the system displays the following message.

IBS will now generate a call list of personnel responsible for the current IP tasks. Only personnel required for those tasks to be started in the time period you specify will be listed.

Please specify the number of hours after an event=m

After you specify the number of hours after an event and press the Return key, the system displays the following menu.

3. Make call list of ALL positions in database. The following menu displays.

Generate Call List

0: ExIT
1: List only those on duty
2: List those on duty and alternates
Choice $(?=$ Help) $=\Rightarrow$

Your choices are:

1. List only those personnel on duty.

2. List those personnel on duty and their alternates, if any. 
If you have not specified a default output (which you can define under SETUP, JOB ENVIRONMENT, MISCELLANEOUS SETTINGS), the following menu displays.

Output Redirection Menu

0: ExIT
1: Display on screen
2: Print on default printer
3: Save to an ASCII file
Choice $(?=H e l p) \Rightarrow=>$

After you select an option, the system displays the following prompt.

Include task description in call list [N]?

After you type $\mathrm{Y}$ (Yes) or $\mathrm{N}$ (No) at the prompt and press the Return key, the system displays or prints a report similar to the following.

\begin{tabular}{|c|c|c|}
\hline $\begin{array}{l}\text { AGENCY : FEMA } \\
\text { LAST HAME } \\
+ \text { SMITH }\end{array}$ & $\begin{array}{l}\text { POSITION: EMERG TECH. } \\
\text { FIRST HAME } \\
\text { JAMES }\end{array}$ & $\begin{array}{l}\text { OFFICE \# } \quad \text { BEEPER \# } \\
609-555-1234 \quad 609-555-4567\end{array}$ \\
\hline $\begin{array}{l}\text { AGENCY : FEMA } \\
\text { LAST NAME } \\
\text { JOHNSON } \\
+ \text { STANDISH } \\
\text { BARR }\end{array}$ & $\begin{array}{l}\text { POSITION: EMERG PLANNER } \\
\text { FIRST MAME }\end{array}$ & $\begin{array}{ll}\text { OFFICE \# } & \text { BEEPER } \\
609-555-4321 & 609-555-1243 \\
609-555-4321 & 609-555-1243 \\
609-555-4321 & 609-555-1243\end{array}$ \\
\hline
\end{tabular}




\section{LIST FIRST TASKS}

This option displays a list of the initial tasks that must be completed for all Emergency Functions. The list is shown in chronological order by the start time of the task.

The system prompts:

Li j:ing tasks by planned starting time-Lisi tasks for how many hours? $\Rightarrow$

After entering a time period, you then specify the type of report:

REPORT IP
0: EXIT
1: Report of Agency/Position/Task Description
2: Report of All Tasks/Resources for All Functions
3: Report of Location of All Allocated Resources
4: User-Defined Report
Choice $(?=H e l p)==$

Tasks that must be started within the specified time period are listed. Those tasks that have the earliest start times are listed first. 
After you have selected a report, the system displays a report similar to the following example.

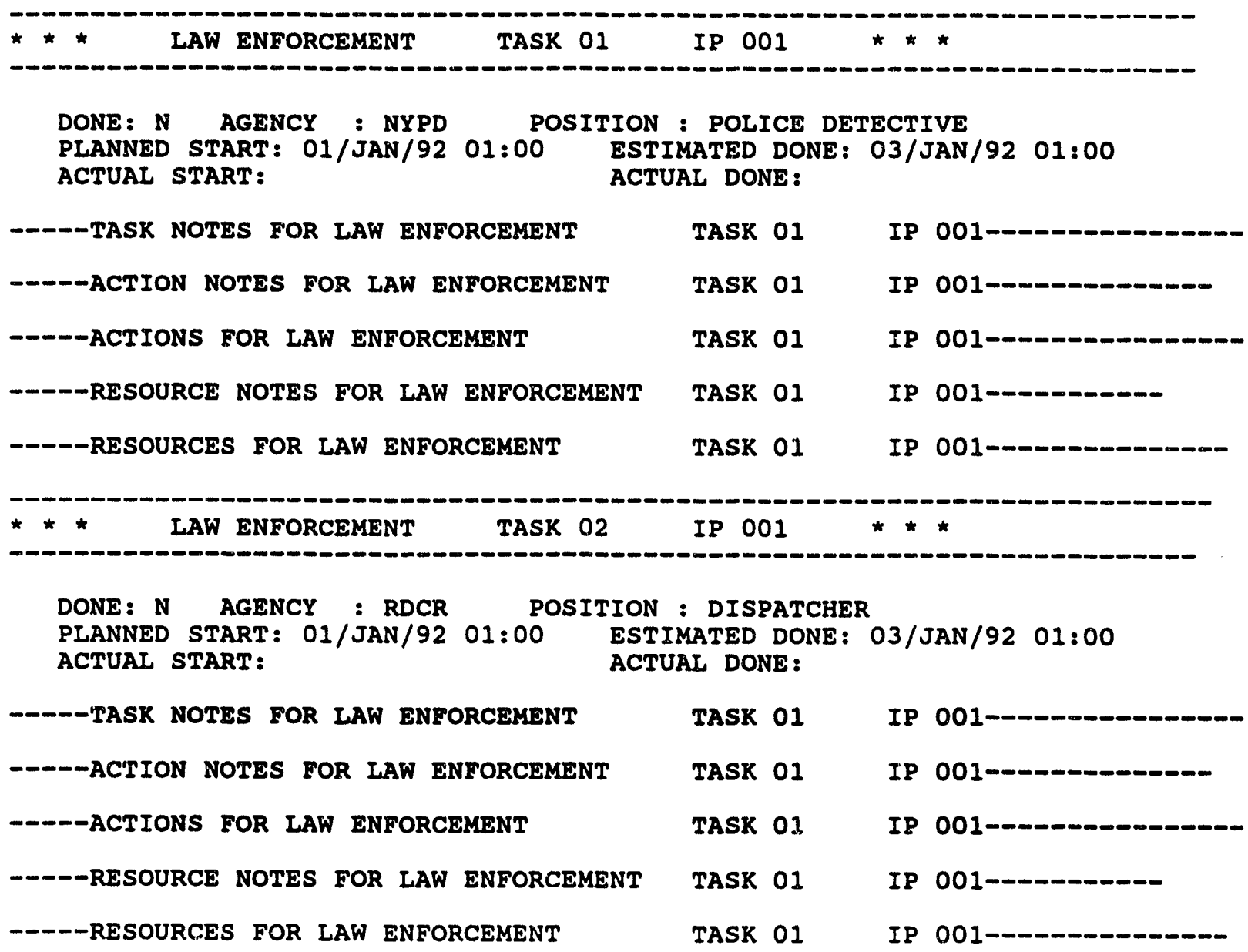

END OF IMPLEMENTING PROCEDURES REPORT

$<$ Return $>$ to continue... 
Figure 11.1 shows the general list format.

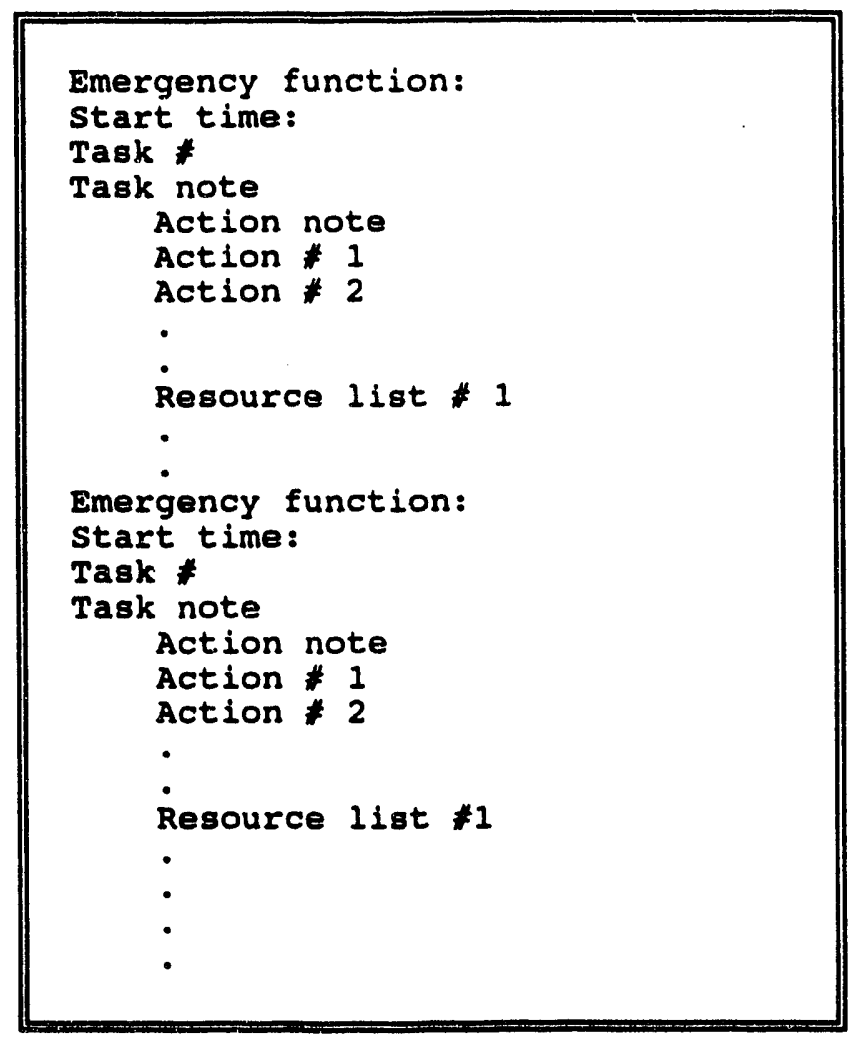

Figure 11.1. List Format for First Tasks of All Emergency Functions 


\section{EVACUATION}

\begin{tabular}{|c|c|}
\hline $\begin{array}{l}\text { IBS MAIN MENU } \\
\text { EMERGENCY ACTIVITIES }\end{array}$ & $\begin{array}{l}\text { EVACUATION incorporates a modeling progr } \\
\text { for evacuation planning that predicts the pro } \\
\text { of area evacuations by indicating the changi } \\
\text { conditions of population movement over a } \\
\text { roadway network. EVACUATION displays thi } \\
\text { menu along with the default map layers that } \\
\text { include population, roads, and trails. }\end{array}$ \\
\hline $\begin{array}{l}\text { CONTINUE } \\
\text { MESSAGE BOARD } \\
\text { STATUS BOARD } \\
\text { PERSONNEL MANAGEMENT } \\
\text { MAP ANALYSIS } \\
\text { RESOURCE MANAGEMENT }\end{array}$ & General options \\
\hline $\begin{array}{l}\text { SELECT MODEL CASE * } \\
\text { RUN } \\
\text { SET TIME STEP } \\
\text { RESTART } \\
\text { STEP FORWARD } \\
\text { STEP BACKWARD }\end{array}$ & $\begin{array}{l}\text { <-- Change the current case to another case. } \\
<- \text { Show evacuation output sequence on map. } \\
\text { <-- Enter a time step for evac. output. } \\
\text { <-- Restart output sequence at first time step. } \\
\text { <-- Show the next step of evac. output. } \\
\text { <-- Show the previous step of evac. output. }\end{array}$ \\
\hline $\begin{array}{l}\text { DESCRIBE EVACUATION POINT } \\
\text { ZOOM IN } \\
\text { ZOOM OUT } \\
\text { CREATE EVAC ROUTE OVERLAY * } \\
\text { DELETE EVAC ROUTE OVERLAY * } \\
\text { EXECUTE EVAC MODEL * } \\
\text { SELECTIVE STATUS } \\
\text { RELEASE/RETAIN OVERLAYS }\end{array}$ & $\begin{array}{l}\text { <-- Show information on picked evac. item. } \\
\text { <-- Enlarge a portion of the current screen. } \\
\text { <-- View the current area within a larger area. } \\
\text { <-- Pick road segments for one evac. route. } \\
\text { <-- Delete one evacuation route overlay. } \\
\text { <-- Execute evac. model for the current case. } \\
\text { <-- Show status of some icon items. } \\
\text { <-- Cancel display of EVACUATION map layers. }\end{array}$ \\
\hline
\end{tabular}

The evacuation model produces several measures of evacuation effectiveness, including travel times, vehicle counts, queues and delays, and person throughput over the links (street segments) and nodes (intersections) of the roadway network. Many of the model results are shown graphically: the network is overlaid on the site map, and you can visualize the results by stepping through the time sequence of the evacuation. Red bars on the network links indicate the extent of traffic lineups near intersections. When you pick EVACUATION, the evacuation network overlay (or link-node diagram) is automatically displayed for the current evacuation case. 
Note: In some cases, a message similar to the following can display when you initially select Evacuation from the Emergency Activities menu.

The current case does not include record type 6 . One will now be created. Enter the current site origin longitude $(-112.34010315)=\mathrm{m}$

Press the Return key to accept the default longitude, or enter a new longitude. Another prompt will display.

Enter the current sits origin latitude $(40.29669952)=>$

Press the Return key to accept the default latitude, or enter a new latitude. A final prompt will display.

Enter the current site radius in miles $(37.40000153)==>$

Press the Return key to accept the default radius, or enter a new radius.

This message and sequence of prompts indicates that the current evacuation case is incomplete. If you are a planner, select Execute Evac Model from the Emergency Activities menu. Select A: Change Input Data from the Evacuation Model menu to complete the evacuation case.

If you are not a planner, you must notify the person responsible for the evacuation cases that the current case is incomplete. If the case is left incomplete, the message will display whenever you select a command or option requiring evacuation case input data.

ZOOM IN and ZOOM OUT operate as described in Section 5, Map Analysis. The EVACUATION options are described in alphabetical order. 


\section{CREATE EVAC ROUTE OVERLAY}

This option enables you to create a graphic overlay showing an evacuation route that applies to the current evacuation case. This evacuation route overlay is made available to the onpost system as a map graphics file. The only purpose of this option is to pass evacuation-related information to the onpost system. The system prompt.

Ent: : route name (single word - no special characters) Im

1. Enter any name (up to 40 characters).

If you enter a route name that already exists, the system informs you and prompts again. After obtaining an appropriate name, the system prompts:

Trace the evacuation route by picking roadway segments. After picking the last segment, select CONTINUE.

2. Pick a sequence of roadway segments, as instructed.

Each picked roadway segment blinks continuously to indicate selection. When you pick CONTINUE, the screen is redrawn to show its normal display. To unselect any segment, pick on it again and it will stop blinking.

\section{DELETE EVAC ROUTE OVERLAY}

This option enables you to delete one of the evacuation route overlays (created by CREATE EVAC ROUTE OVERLAY) by selecting from a list:

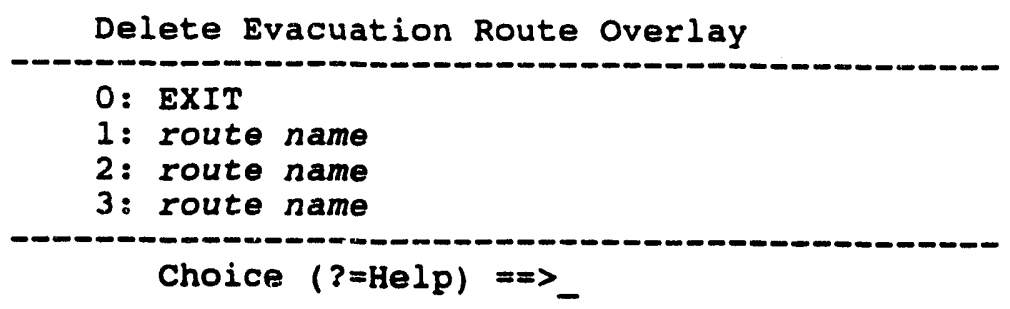

The system draws the route with blinking roadway segments and prompts:

Is this the route you want to delete? $(Y / N)==>$

- $\underline{Y}$ deletes the evacuation route overlay (graphics file).

- $\quad \mathbf{N}$ returns you to the EVACUATION menu without deleting the route overlay. 


\section{DESCRIBE EVACUATION POINT}

This option enables you to graphically pick a part of the evacuation network overlay (the link-node diagram) and display model information for that part. You can obtain information about:

- links (roadway segments)--Link information includes, for example, Level of Service (LOS) codes that indicate traffic conditions from free-flow (code A) to unmoving (code F). To obtain link information, the model output must be stepped at least through the first time step (see RUN, STEP FORWARD, and STEP BACKWARD).

- nodes (intersections)

- exit nodes (intersection of a link and the evacuation boundary)

- centroids (traffic loading and exit points internal to the network). 


\section{EXECUTE EVAC MODEL *}

EXECUTE EVAC MODEL displays the following short menu, which enables Information Managers or planners to prepare evacuation data or run the evacuation model.

Note: This option is available only in Planning mode. To change from Operational to Planning mode, use the Setup option under the IBS Main Menu. For complete instructions co changing modes, see Section 12, Setup.

$r$

EVACUATION MODEL

A Change Input Data

B Run Evacuation Model

C Update Evacuation Case Header

$x$ Return to Evacuation Menu

Enter option selection:

Option A Change Input Data enables you to modify the input data for the evacuation model. The IBS Models Guide describes background and procedures for modifying evacuation model input.

Option B Run Evacuation Model first displays a check list for the current evacuation case. For example:

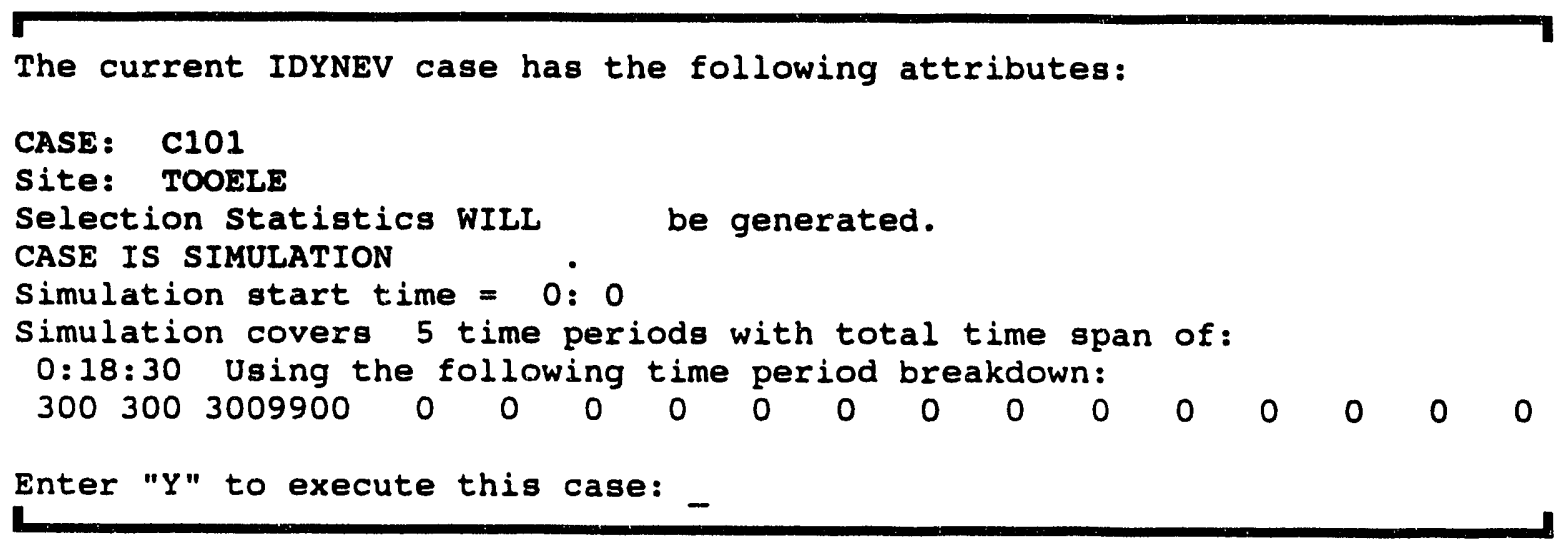


The check list is for your information only: you cannot change any of the information shown. Read the check list to be sure that the case is set up to run as you wish.

At your approval, the IBS executes the model. While the model is running, you CANNOT interact with the modeling program or with any other IBS capability.

After the evacuation model has finished exec! 'ing, the IBS draws the roadway network on the site map and prompts you to enter two items that serve as additional case descriptors:

Enter percent of population evacuated $==>$

This refers to the population inputs to the model as a portion of the population expected in the evacuation area. That is, what part of the estimated population data set was supplied to the model as the total number of people to be evacuated? (This should be 100 percent unless you: 1) decided that some people within the evacuation boundary did NOT have to be evacuated and 2) adjusted the model inputs accordingly.)

Enter population pattern $==>$

This refers to the population pattern: WEEKDAY, WEEKEND, WEEK NIGHT, or SEASONAL. Each population pattern defines a data set that estimates the number and distribution of people for that time period.

As the evacuation case modeler, you must supply these two case descriptors here because they are considerations that are outside the actual inputs to the model. They can later serve as a basis for categorizing evacuation cases (for example, see SELECT MODEL CASE in this section).

If the model needs further information, you can be presented with one or all of the following prompts.

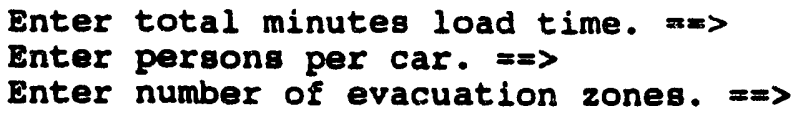

The following prompt will display once for each evacuation zone specified.

Enter evacuation zone name for zone nnn. $\mathrm{n}=>$

After you enter the name of the last evacuation zone, press the Return key and the model will begin to run.

Stopping the Model. No clean way is provided to halt the evacuation model while it is running. Pressing CTRL-Y is a standard system interrupt command 
that halts model execution, but it does not guarantee where you will regain control. The model can be restarted only from the beginning of its execution.

Evacuation Model Report. If the model is executed for a traffic simulation, and if one or more time steps of the simulation are completed, the IBS produces a summary report of the evacuation following model completion. This report file contains various statistics extracted from the last simulation time period reported by the evacuation model: vehicie miles, vehicle minutes, vehicle trips, average sijeed, percentage of vehicles that stopped, average number of vehicles per queue, average delay per vehicle, etc. The report file is named as follows:

\section{[username.SITES_site.OUTPUT.DYNEV]CnnnCOD.RPT}

where username is your system username, site is a four-character site code, and $n n n$ is the evacuation ce number.)

Option C Update Evacuation Case Header enables you to change or update the case header for the current evacuation case. The system displays the following prompts.

Enter percent of popuiation evacuated. $=\Rightarrow$

Enter population type. $==>$ 


\section{RELEASE/RETAIN OVERLAYS}

The appearance of this option on the menu switches back and forth between RELEASE OVERLAYS and RETAIN OVERLAYS. When you use the EVACUATION Emergency Activity for the first time, the default map layers associated with evacuation are automatically overlaid on the map screen and RELEASE OVERLAYS appears on the EVACUATION menu.

Pick this option

RELEASE OVERLAYS
To see this effect on your map screen

Removes all the map layers associated with this emergency activity

Re-displays the map layers-The map layer overlays continue to be display until you select RELEASE OVERLAYS.

To choose which map layers are the ones associated with the emergency activity, see Section 12, Setup - MAP LAYERS BY ACTIVITY.)

\section{RESTART}

RESTART resets the model output display at the first time step.

\section{RUN}

This option displays the evacuation model output, showing changes in the traffic network as the output steps from the first time step to the last.

Red bars on the network links (street segments) indicate the extent of traffic lineups near nodes (intersections). 


\section{SELECT MODEL CASE *}

SELECT MODEL CASE enables you to change the current evacuation model case. You are asked to supply selection criteria for searching through the existing set of evacuation cases. All cases matching the specified criteria are then displayed in a list from which you can select one.

If you are in Operational mode and the selected evacuation model case has been checked out by a planner, a message similar to the following will display.

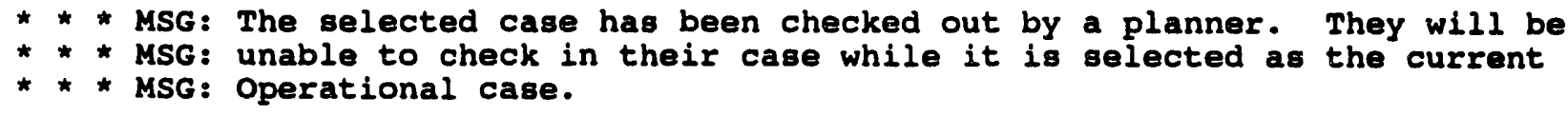

The planner who has checked out this case will not be able to check it back in as long as it is selected as the current Operational evacuation case.

SELECT MODEL CASE gives you the options of entering a case number directly or specifying a set of case description criteria:

CHANGE EVACUATION CASE MENU

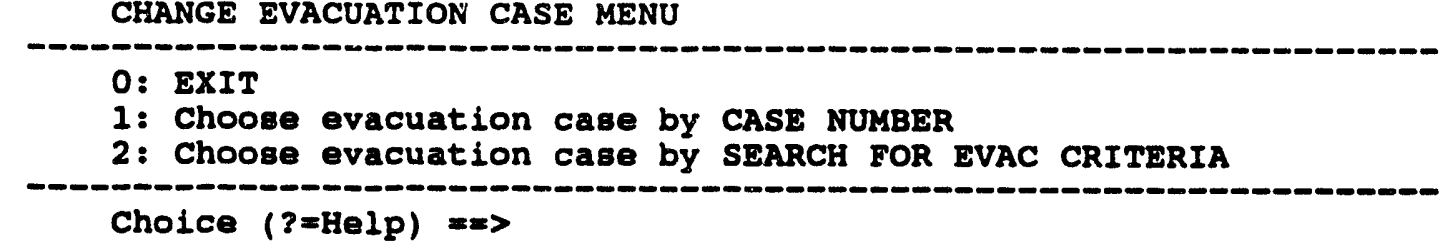

These options are explained here.

Option 1. Choosing an Evacuation Case by Case Number. Choose this option if you know the number of the evacuation case that you want to use. The system displays the following prompt.

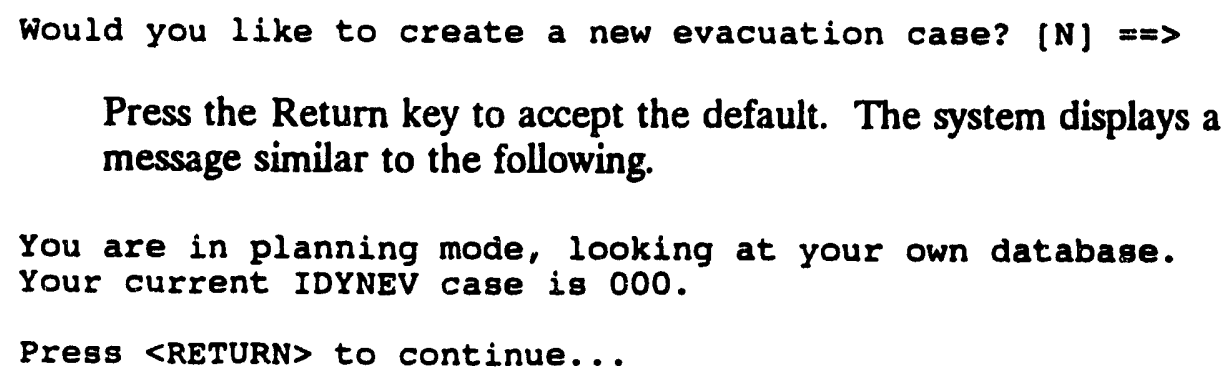


Press the Return key. The system displays a listing of evacuation cases.

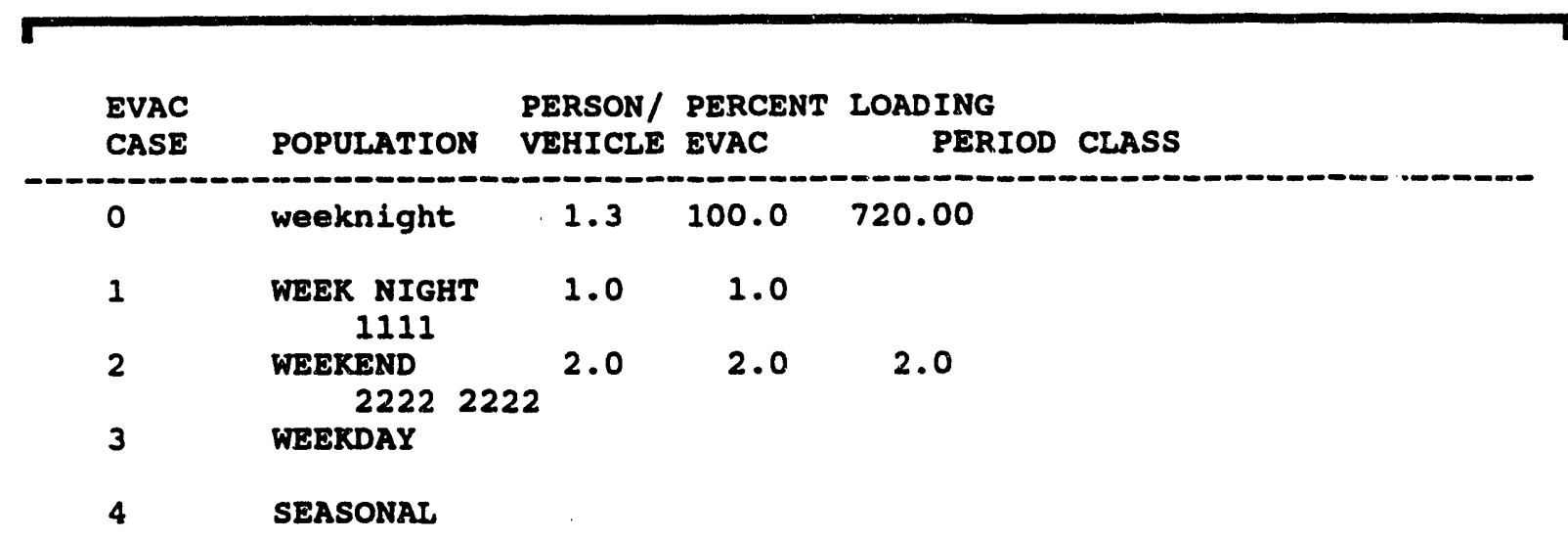

Select Evacuation Case :

To scroll through the cases on the list, use the U, D, T, B keys as described in Section 1, Introduction and Overview. Select an evacuation case by typing the Evac Case number at the prompt.

Option 2. Selecting an Evacuation Case by Search for Evac Criteria. Choose this option if you want to search the evacuation criteria to select an evacuation case. The system displays the following prompt.

Would you like to create a new evacuation case? [N] $=\Rightarrow$

Press the Return key to accept the default. The system displays the following message.

You are in planning mode, looking at your own database. Your current IDYNEV case is 000.

Press <ReturN> to continue...

This second option displays the following screen where you can specify criteria for selecting the evacuation case. The IBS then generates a selection list of evacuation cases that match (or approximately match) the criteria. For example: 


\section{EVACUATION CASE SELECTION CRITERIA}

IDYNEV Case number 000

Population pattern: weeknight

Persons/vehlcle: 1.3 with 0.5 people/vehicle tolerance $(+/-)$

Percent evacuation: 1008 with .05 tolerance $(+/-)$

Loading period class: 1.0 hour(s) with 0.5 hours of tolerance $(+1-1$

ZONES: IREB PAZ1A

$\longrightarrow$

<GOLD $\mathrm{Z}>$ to exit and continue, <GOLD $Y>$ to quit.

The entry fields serve as search keys into the database of evacuation cases:

- The default tolerances are displayed. You can also change these values for this particular search.

- You can remove one or more criteria from the search by entering blanks in the text fields or a negative one $(-1)$ in the numeric fields. If all fields are removed from the search, you must instead select one case from a list of all evacuation cases.

- If any criteria are used, the IBS compares these case input criteria with the database of evacuation cases. (If no identical matches are found, the IBS displays a message to indicate how many criteria were actually matched.) You must then select from a list of evacuation cases that match the greatest number of criteria (see the next screen).

After the search, the resulting set of evacuation cases are listed by Evacuation case number, as shown in the following screen example.

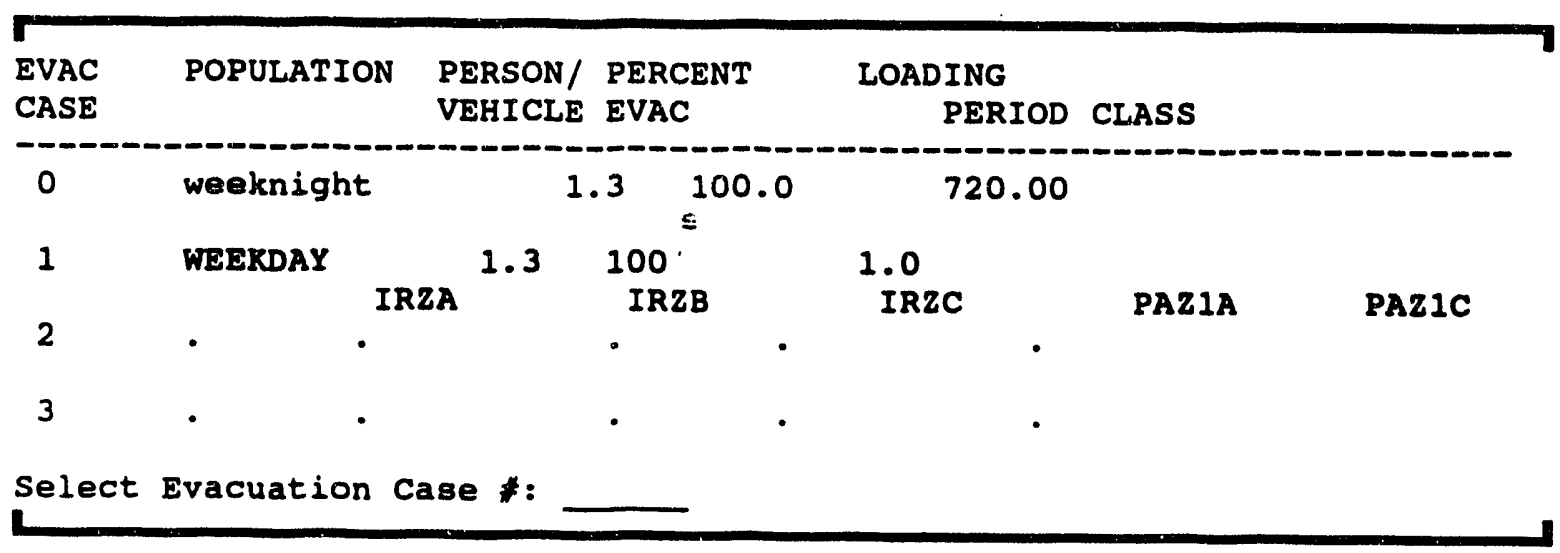




\section{SELECTIVE STATUS}

This option enables you to use the mouse to pick an icon that identifies a point associated with evacuation: sirens, EBS stations, traffic control points, and reception centers.

Note: You must have turned on the correct map layers (FACILITIES/RESOURCES under the MAP ANALYSIS option) for this option to ". rk. If the needed map layers are not turned on, the system displays the following message.

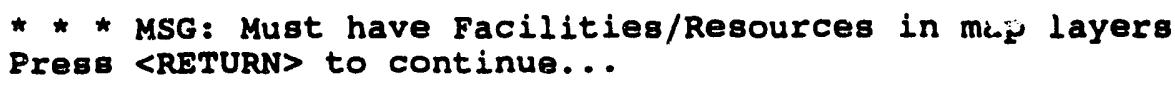

If the map layers have been selected, but are not on the map display, the following prompt displays

Draw selected Icons onscreen? [Y]

Press the Return key to accept the default. The Facilities/Resources icons display. The system then displays the following message.

* * MSG: Select Item with Mouse

Select an icon with the mouse.

The system responds by displaying information about the status of the item (retrieved from the IBS real-time database related to that item.) The information displayed is similar to the following example.

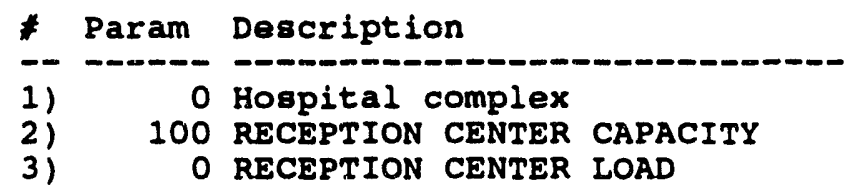

You can continue to select one icon at a time. The new icon information replaces the previous information on the screen. When you are finished viewing information, select the CONTINUE option from the menu.

\section{IIE SET TIME STEP}

This option enables you to set the display of model results to a specific time step. Enter a time step number in response to the following prompt.

Enter Time Step $(0-4)>$

The time displays in white on the menu. 


\section{STEP FORWARD}

This displays the traffic network results for the next sequential time step in the model output. The step forward is calculated from your currently displayed time step.

\section{STEP BACKWARD}

This displays the traffic network results for the previous sequential time step in the model output. The step backward is calculated from your currently displayed time step. 
II HAZARD ANALYSIS

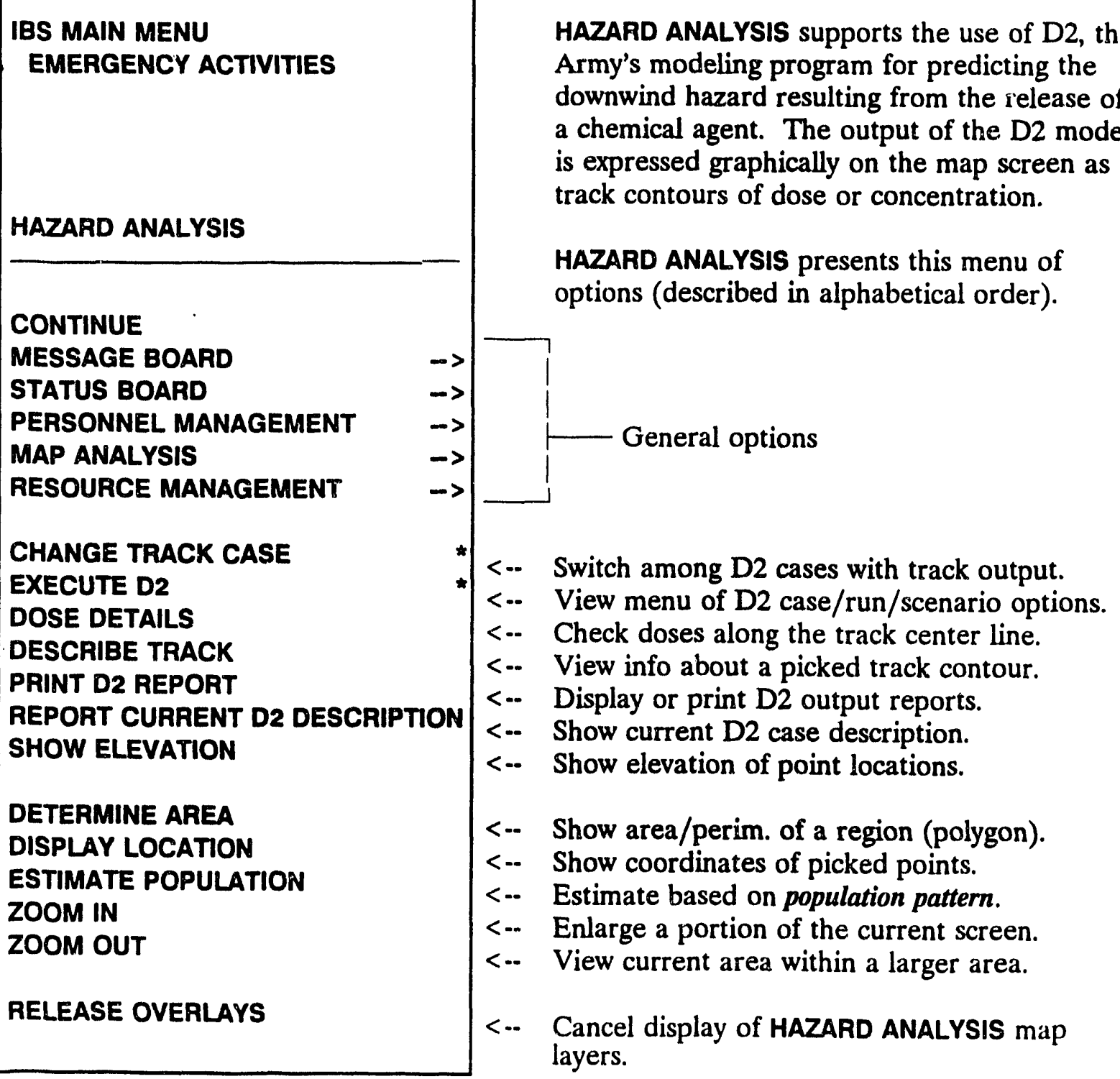

When you begin HAZARD ANALYSIS, the map screen automatically displays the default map layers associated with this function. These map layers should include POPULATION and D2 TRACK for the current D2 case.

D2 Track. The D2 output track on the map screen consists of three contour lines. Each contour represents a constant level of dose or concentration (depending on the original inputs to the D2 model). A series of asterisks $\left({ }^{*}\right)$ appearing along the track center line indicate slice points along the track where the DOSE DETAILS option can be used to display dose or concentration information about those 
locations. Some chemical agents do NOT result in the generation and appearance of these points.

\section{CHANGE TRACK CASE *}

This option for identifying the current D2 case is identical to the option of the same name on the IBS main menu (see Section 9, Change D2 Track Case). CHANGE TRACK CASE is available only to the Information Manager and P'anners (for their planning site databases).

\section{DESCRIBE TRACK}

DESCAIBE TRACK enables you to pick one more of the three contours displayed in the current D2 track. When you select this option, the Describe Track command highlights in blinking green and the following message displays.

Select TRACK boundary with crosshairs

As you pick a contour, a text description of the contour is displayed at the top of your screen. For example:

$\begin{array}{lll}\text { LOW DOSAGE TRACK : } & n n n . n n & (\text { MG-MIN/M**3) } \\ \text { MEDIUM DOSAGE TRACK: } & n n n . n n & (M G-M I N / M * * 3) \\ \text { HIGH DOSAGE TRACK : } & n n n . n n & \end{array}$

You can pick more than one contour. The information from the previous picks remains visible on the screen until you choose another menu option. To stop, select the CONTINUE command from the menu.

\section{RELEASE/RETAIN OVERLAYS}

The appearance of this option on the menu switches back and forth between RELEASE OVERLAYS and RETAIN OVERLAYS. When you use the HAZARD ANALYSIS Emergency Activity for the first time, the default map layers associated with hazard analysis are automatically overlaid on the map screen and RELEASE OVERLAYS appears on the HAZARD ANALYSIS menu.

$\begin{array}{ll}\text { Pick this op:ion } & \begin{array}{l}\text { To see this effect on your map screen } \\ \text { RELEASE OVERLAYS }\end{array} \\ \begin{array}{l}\text { Removes all the map layers associated with } \\ \text { this emergency function }\end{array} \\ \text { RETAIN OVERLAYS } & \begin{array}{l}\text { Re-displays the map layers-The map layer } \\ \text { overlays continue to be displayed until you } \\ \text { select RELEASE OVERLAYS. }\end{array}\end{array}$


To choose which map layers are the ones associated with the emergency function, use SETUP-MAP LAYERS BY ACTIVITY.)

\section{DOSE DETAILS}

Asterisks (*) are used to mark intervals of predetermined length along the D2 track center line. DOSE DETAILS enables you to pick one asterisk on the track center line to see a report of dosage information ? or that location. When you select this option, the Dose Details command highlights in blinking green and the following message displays.

Select dose site (*) with crosshairs

You can pick more than one asterisk location to see further reports. For each pick you will see information details similar to those shown in the following example report. The report provided can vary somewhat, depending on the input parameters selected for the D2 cases.

Note: If the D2 model input requests concentrations instead of dosage information, dose details and asterisks along the track center line are NOT generated. Also, it is possible that some chemical agents will not result in the generation of dose details.

Example Report:

D2 DOSE DETAILS

The selected point is 5000 meters from the source.

Track TIP passes this point 20.8 minutes after the event.

Track TAIL passes this point 34.9 minutes after the event.

The maximum dosage at this point is 0.6000 (mg-min.m**3)

100.0\% of the LOW dose amount reaches this point within 29.6 minutes.

17.18 of the MEDIUM dose amount reaches this point.

10.28 of the HIGH dose amount reaches this point.

PRESS RETURN TO CONTINUE...

To stop, select the Continue command from the menu. 


\section{EXECUTE D2 *}

This option displays the following text-screen menu of D2 RUN Capabilities. The menu includes options for creating a new case (based on an existing case), modifying the input, executing the model, and maintaining the model cases (input and output data). Also included is a key capability for creating scenarios: scenarios are unique combinations of situational data that link the D2 case output with an evacuation model case, meteorological conditions, and population pattern for a specific Implementing Procedure.

\section{Caution}

The D2 model inputs are easy to change; however, the knowledge of what those changes will be is left up to you. ${ }^{(0)}$ For other than testing purposes, you probably should NOT change D2 model input unless you have a clear understanding of the model. The many input parameters are interrelated in nonstraightforward ways. Also, please interpret the D2 model results cautiously. The D2 model itself is unchanged from previous implementations: data that caused aborted runs in the D2PC model will do so in the IBS as well.

\section{D2 RUN Capabilities}

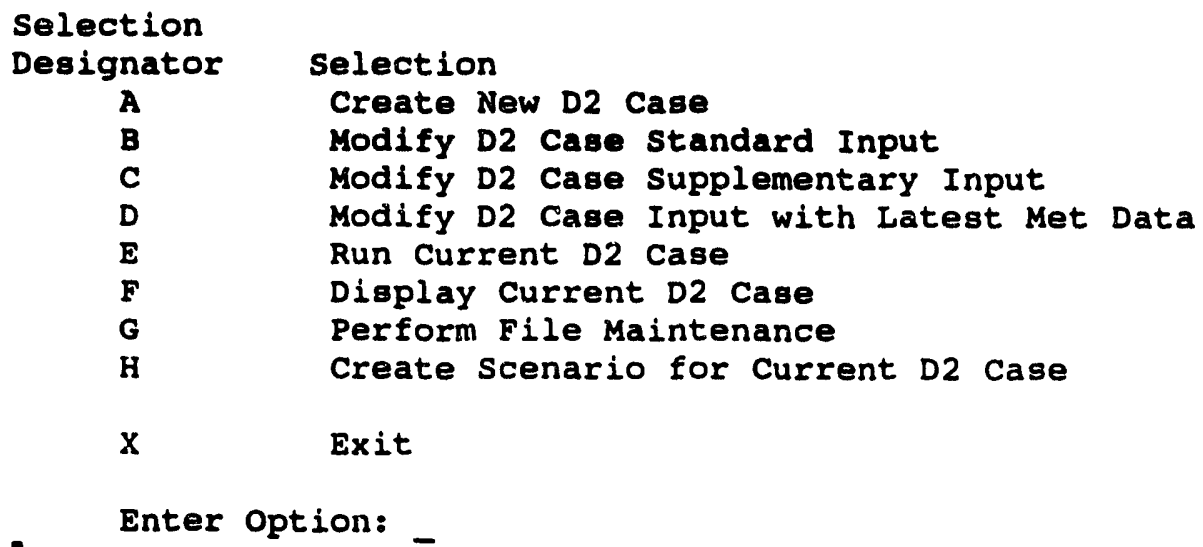

Note: For Options B, C, and D: A case marked as a Maximum Credible Event cannot be edited. This setting can be changed by using the INFOMANAGER ROOT MAINTENANCE command under the SETUP main menu option.

(a) See Whitacre, C.G., J.H. Griner III, M.M. Myirski, and D.W. Sloop. 1987. Personal Computer Program for Chemical Hazard Prediction (D2PC). CRDEC-TR-87021, U.S. Army Munitions Chemical Command, Aberdeen Proving Ground, Maryland. 
The options of the D2 RUN Capabilities menu are described in the following paragraphs.

Option A. CREATE NEW D2 CASE enables you to create a new case based on an existing case. The existing case is then referred to as the base case.

You select the case to be used as a base case by either: 1) entering a D2 case number directly, or 2) searching the agent, munition, and meteorological data for the cases-as explained for CHANGE D2 TRACK CASE on the IBS main menu. After selecting a case the following form is displayed.

CREATE D2 CASE $<$ GOLD $>Y Y>$.

To exit and save inputs press <GOLD><z>. To abort press

Option B. MODIFY D2 CASE STANDARD INPUT presents the following input screen for entering D2 input data:

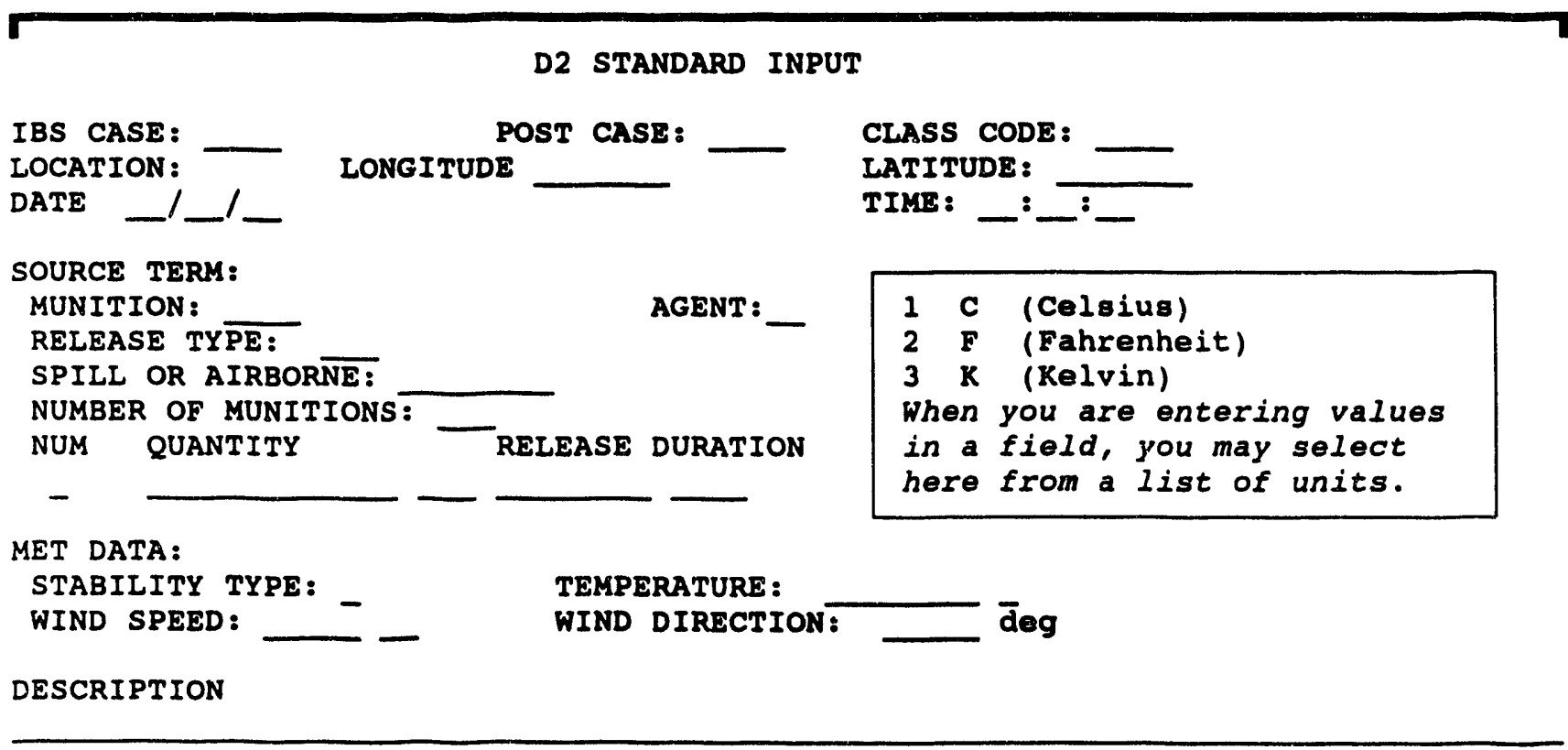

To view information about the possible inputs on this screen, press? (or the HELP key) at each field. To exit and save, press GOLD-Z, to exit without saving, press GOLD-Y. 
Option C. MODIFY D2 CASE SUPPLEMENTARY INPUT allows you to change some basic D2 input parameters listed as shown in the following screen example. These parameters are not expected to change frequently.

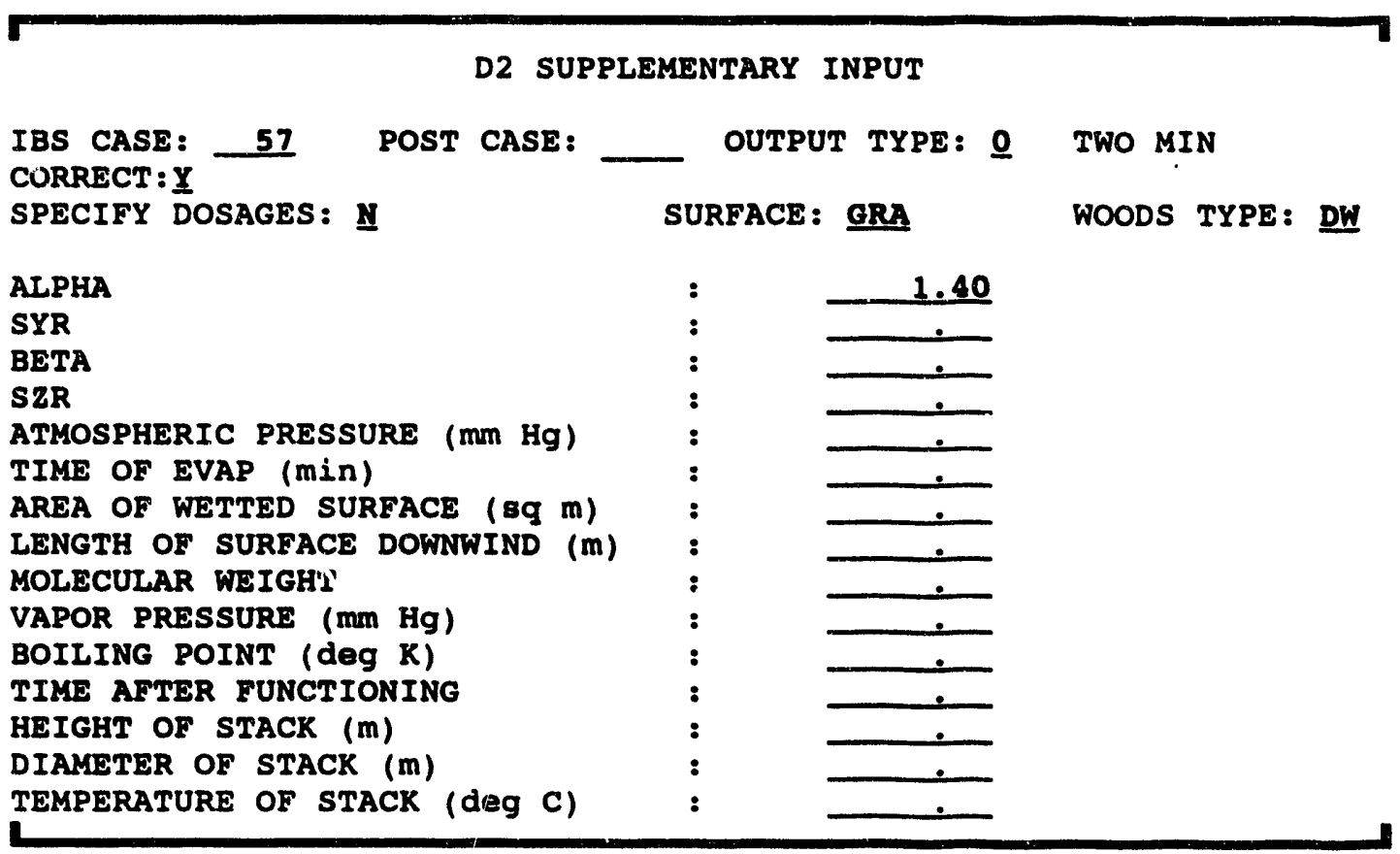

When you reach the end of the screen, the parameters list scrolls forward to show further parameters. To view information about the possible inputs on this screen, press ? (or the HELP key).

Option D. MODIFY D2 CASE INPUT WITH LATEST MET DATA allows you to alter the meteorological input to the model. When you select this option, the IBS reads a file report of current weather conditions and extracts information that is used as input for the current D2 case. The weather conditions file (named WEATHER_OBS.DAT) is created by the onpost system and is periodically transmitted to the IBS for updating of the current weather conditions.

Option E. RUN THE CURRENT D2 CASE executes the D2 model for the current case inputs. Based on the case results, the IBS creates output files that are identified with the current IBS D2 case number. The IBS also creates one graphic output file that contains polygons depicting the D2 track contours. Note that the amount and type of information contained in this graphic output file depends on the D2 input. If possible, the model produces information on dose slice points along the track. Those points appear as asterisks along the track center line. Some chemical agents do NOT result in the generation and appearance of 
these points. In that case, this message is displayed after D2 execution:

SLICE FILE NOT CREATED. DOSAGE ATTRIBJTES WILL NOT BE GENERATED.

Option F. DISPLAY CURRENT D2 CASE displays the current D2 track contours. If a track already appears in the graphics area, it is erased before the new current track is displayed.

Option G. PERFORM FILE MAINTENANCE displays the following menu. The menu options allow you to list the directories of evacuation cases for the current site. You also can delete selected input and output files from the system (if you own the files). Exercise care here, especially in deleting input files, because recreating files can be time consuming.

\section{$\mathbf{r}$}

PERFORM FILE MAINTENANCE

Selection

Designator selection

A Display Directory of Cases

B Delete Case Output for a Specified Case

C Delete Input and Output for a Specified Case

$x$ Exit to Previous Menu

Enter selection designator:

Option H. CREATE SCENARIO FOR CURRENT D2 CASE enables you to create scenarios to be included in the scenario table for the current D2 case: this scenario applies to the current Implementing Procedure (IP). The following illustration is a compressed example of the scenario table. 


\section{Scenario Table}

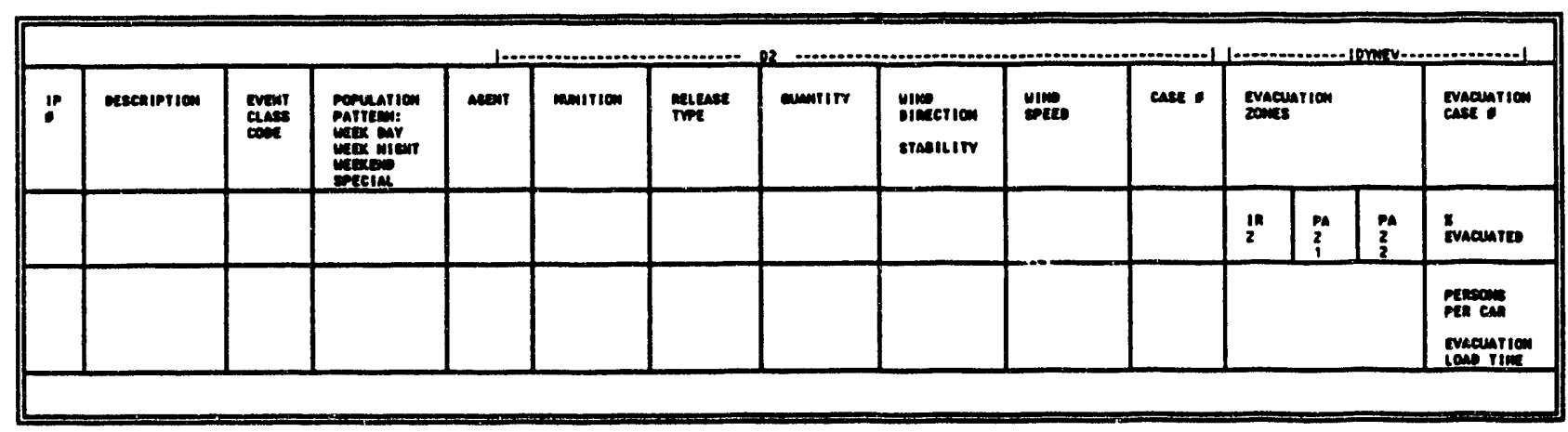

Each record in the scenario table represents a unique combination of

- D2 case

- Evacuation case (IDYNEV)

- Meteorological conditions

- Population pattern

A single, IP can apply to several different scenarios, but each scenario maps to only one IP.

The case number of the current D2 case is assigned to the new scenario(s). If you want to create scenarios that are based on a different D2 case, use the CHANGE D2 TRACK CASE option before creating a new scenario.

This Create Scenario option is used extensively in the planning phase. It allows you to Add, Modify, Delete, or Print records in the scenario table by using the following text menu:

SCENARIO TABLE
1: EXIT
2: Modify Scenario Records
3: Delete Scenario Records
4: Print Scenario Table
Choice $(?=$ Help) $=>$


The options of the scenario table menu are explained in the following paragraphs.

Option 1. Add Scenario Records - The IBS prompts for the number of the IP for which you wish to add a scenario:

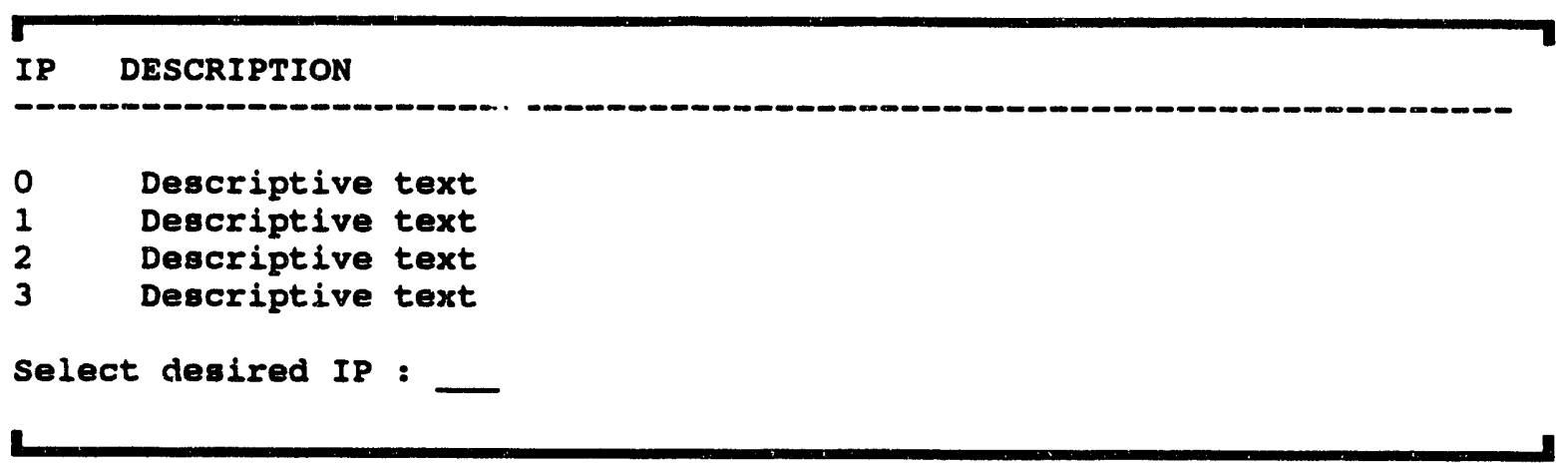

You must already know the number of the IP for which you wish to add a scenario record. IP numbers are always even numbers; OPIP numbers are always odd (one greater than the corresponding IP numbers).

After entering the IP number, add the scenario table records during several stages in which you must define or select the following:

risk area: one or more Emergency Planning Zones that intersect either the current D2 case track or a polygon that you draw

population pattern (for both the IP and the OPIP): the number and distribution of people at a specific time of week and day

evacuation model case (for the IP and the OPIP): the number of the evacuation model case associated with the current D2 case

The current D2 case is automatically entered in the scenario record for both the OPIP and IP. (The records also include data used in creating the D2 case: munition, agent, quantity, wind direction, wind speed, release type, and stability class. This allows searching of the scenario table to find matching cases during selection of an IP at a later date.) 
A. Defining a risk area: The risk area consists of a number of Emergency Planning Zones (EPZs) that are affected by the event. To help you define the risk area, the system directly displays the RISK AREA ANALYSIS menu from the DIRECTION/CONTROL Emergency Activity. After defining the risk area and picking CONTINUE SCENARIO CREATION, you have an opportunity to save the risk area before continuing.

B. Associating population pattern with the IP/OPIP: You are then asked to select the population pattern for the IP and OPIP:

SELECTION OF POPULATION PATTERN FOR IP\# nnn AND OPIP\# nnn+1
A) WEEKDAY (MONDAY-FRIDAY 8AM-5PM)
B) WEEK END (FRIDAY 5PM - MONDAY 8AM)
C) WEEK NIGHT (MONDAY-FRIDAY 5PM-8AM)
D) SEASONAL

SELECT POPULATION PATTERN

C. Associating an evacuation case with the D2 case (for the IP and OPIP): After selecting the D2 case and population, you must select an evacuation case. The IBS first presents a screen on which you can specify criteria for selecting the evacuation case. The entry fields on this screen serve as search keys into the database of evacuation cases. For example:

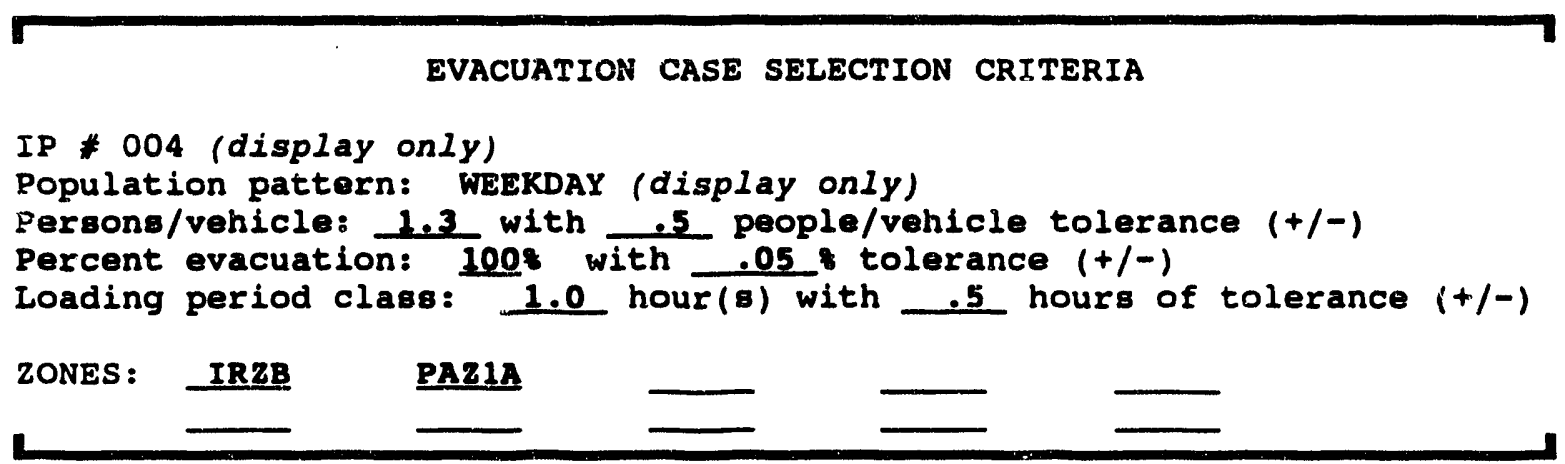

- The default tolerances are displayed. You can also change these values for this particular search. 
- You can remove one or more criteria from the search by leaving blanks in the text fields or by entering a negative one $(-1)$ in the numeric field(s).

- If all fields are removed from the search, then no search is made. You must then select one case from a list of all evacuation cases (see the next screen).

- If entries are made in one or more fields, the IBS compares these case input criteria with the database of evacuation cases. (If no identical matches can be found, the IBS displays a message to indicate how many criteria actually matched.) You must then select from a list of evacuation cases that match the greatest number of criteria (see the next screen).

After the search, the IBS lists the resulting set of cases in numeric order by IBS case number:

\begin{tabular}{|c|c|c|c|c|c|c|}
\hline $\begin{array}{l}\text { EVAC } \\
\text { CASE }\end{array}$ & POPULATION & $\begin{array}{l}\text { PERSON/ } \\
\text { VEHICLE }\end{array}$ & $\begin{array}{l}\text { PERCENT } \\
\text { EVAC }\end{array}$ & 1 & CLASS & \\
\hline \multirow[t]{2}{*}{101} & WEEKDAY & 1.3 & 100 & & & \\
\hline & & IRZA & IRZB & IRZC & PAZ1A & PAZ1C \\
\hline 102 & - & - & - & - & & \\
\hline Selec & Evac Case : & & - & - & & \\
\hline
\end{tabular}

To scroll through the cases on the list, enter a command key in the field after Select Evac Case \# (U, U\#, D, D\#, T, B). To select an evacuation case, enter the case number in the same field. Note that a single evacuation case can be mapped to several different IPs (because the particular combination of the D2 case, meteorological data, and/or population pattern is different for each IP).

After finishing the scenario, the system displays the following message.

Enter a one line description for this scenario record:

After you enter the description, the system displays the record you have created and prompts you to verify its addition. Press the 
Return key to add the scenario record. The system returns you to the Scenario Table menu.

Option 2. Modify Scenario Records - You can search the scenario table using IP \#, D2 case \#, and Evac case \#. The matching records are then displayed, and you can select one record to modify. You can modify the IP \#, D2 case \#, Evac case \#, population pattern, and the scenario record description. This action creates a new scenario record. An example of the Scenario Record Form follows.

Scenario Record Form

(scenario record description)

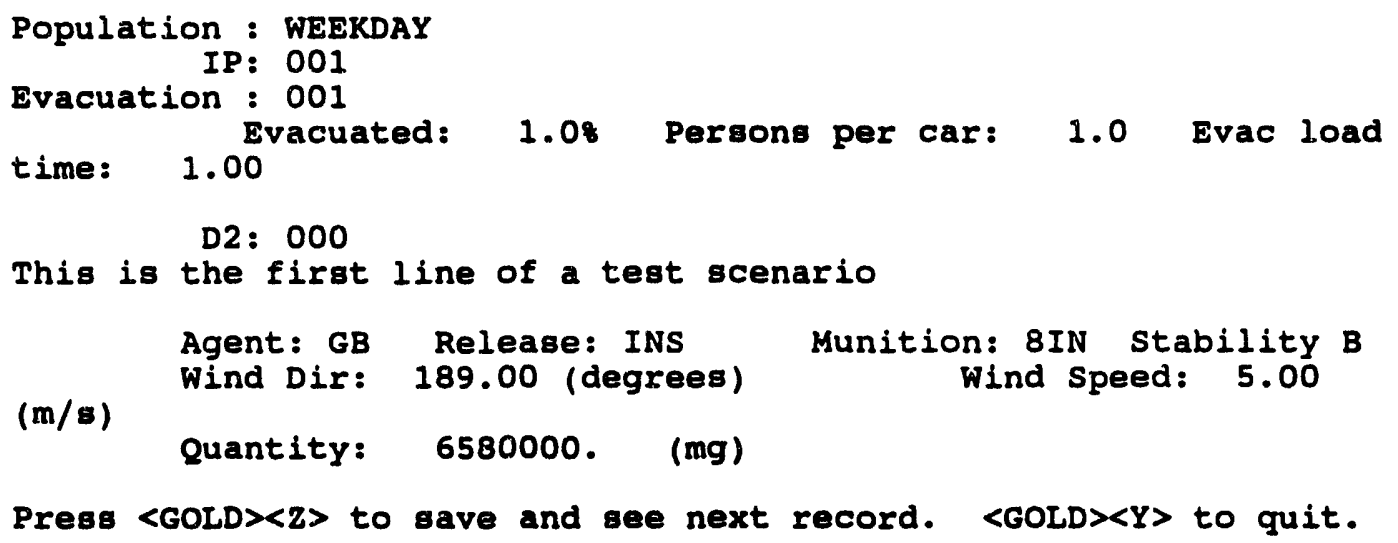

After you exit the form, the system displays the following prompt:

Modify more records? $[Y]=\Rightarrow$

If you press the Return key, or type a $\mathrm{Y}$, the system enabled you to modify more records. If you type $\mathrm{N}$, the system returns you to the Scenario Table menu.

Option 3. Delete Scenario Records - Is similar in function to Modify Scenario Records. You can search the scenario table using IP \#, D2 case \#, and Evac case \#. You can delete a scenario record by specifying the record number. After you confirm the deletion of the selected record, that record is removed from the scenario table.

Option 4. Print Scenario Records - If you have not specified a default out ${ }_{\text {f }}$ at, the Output Redirection menu displays. After you select the type of output you want, the IBS prints a list of all scenario table records, one page at a time. 


\section{PRINT D2 REPORT}

This option allows you to display or print the output reports produced by the IBS implementation of D2.

The system prompts you to identify the desired report:

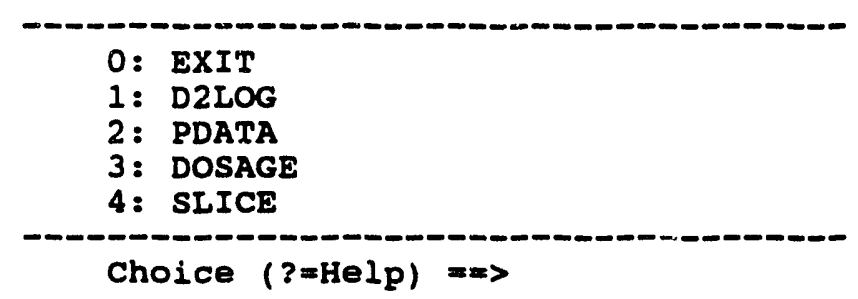

To select the type of report, enter the number of the type of report you want. To exit without selecting a report, press Ctrl-Z.

You can have these reports displayed on the screen, or sent to a printer. See Section 12, Setup for a complete description of setting up your system for default printing.

\section{REPORT CURRENT D2 DESCRIPTION}

This option displays a description of the current D2 case at the top of the screen. This description consists of the two lines entered on the D2 Standard Input form illustrated in EXECUTE D2.

\section{IID SHOW ELEVATION}

SHOW ELEVATION displays the elevation (meters above sea level) associated with one or more point locations that you pick with the graphic cursor. The information from previous picks remains visible on the screen until you quit by selecting another menu option. To use this option, you must have the Elevation map layer selected under either the Setup or Map Analysis options. 


\section{SEARCH/RESCUE}

\section{IBS MAIN MENU \\ EMERGENCY ACTIVITIES}

SEARCH/RESCUE

CONTINUE

MESSAGE BOARD

STATUS BOARD

PERSONNEL MANAGEMENT

MAP ANALYSIS

RESOURCE MANAGEMENT

DRAW SEARCH AREAS

DELETE SEARCH AREA
The SEARCH/RESCUE activity supports search and rescue planning and operations. The default map layers for this Emergency Activity include roads and trails as well as search and rescue resources. See Section 12 for more information on activating default map layers.

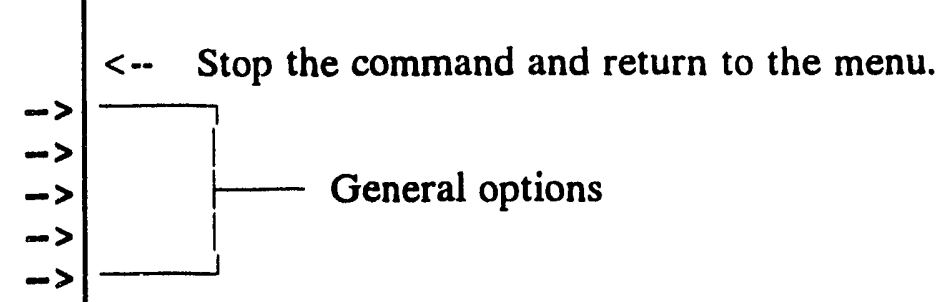

* <-- Draw a search area boundary.

* <-- Delete a search area boundary.

\section{DRAW SEARCH AREAS}

This option enables you to draw boundary lines that define a search area.

1. After picking DRAW SEARCH AREAS, the system displays the following message.

* * MSG: Draw a Search \& Rescue Area. CONTINUE when done

Use the mouse (or joydisk) to pick three or more points that define the sides of the search area. 
A boundary line segment is drawn between each new point and the previous point.

2. Pick CONTINUE to complete the search area.

The final boundary line segment is then drawn between the first and last points picked. The entire search area redisplays in white.

\section{IID DE!. ETE SEARCH AREA}

This option enables you to delete an existing search area boundary by selecting it on the screen:

1. After picking DELETE SEARCH AREA, the system displays the following message.

* * MSG: Select Search \& Rescue Area to delete. CONTINUE when done

Use the mouse (or joydisk) to pick any point on the boundary that you want to delete.

The selected boundary blinks to indicate your selection.

2. Pick CONTINUE to confirm the deletion.

The selected boundary is then removed from the screen.

\section{RELEASE/RETAIN OVERLAYS}

This appearance of this option on the menu switches back and forth between RELEASE OVERLAYS and RETAIN OVERLAYS. When you use the SEARCH/RESCUE Emergency Activity for the first time, the default map layers associated with search/rescue are automatically overlaid on the map screen and RELEASE OVERLAYS appears on the SEARCH/RESCUE menu.

Pick this option

RELEASE OVERLAYS

RETAIN OVERLAYS

\section{To see this effect on your map screen}

Removes all the map layers associated with this emergency activity

Redisplays the map layers-The map layer overlays continue to be displayed until you select RELEASE OVERLAYS.

To choose which map layers are the associated with the emergency activity, see Section 12, Setup under the heading MAP LAYERS BY ACTIVITY. 


\section{SHELTERING}
IBS MAIN MENU
EMERGENCY ACTIVITIES
SHELTERING enables you to display information about shelters and reception centers. If you have appropriate privileges, you can also designate the locations of these facilities and store the locations as map information.
SHELTERING
CONTINUE
MESSAGE BOARD
STATUS BOARD
PERSONNEL MANAGEMENT
MAP ANALYSIS
RESOURCE MANAGEMENT
ADD LOCATION
ADD FACILITIES
MODIFY FACILITIES
SHELTER OR CENTER INFO
SHELTER \& CENTER SUMMARY
RELEASE OVERLAYS
<-- Cancel display of SHELTERING map layers. 


\section{ADD FACILITIES *}

This option allows an Information Manager to add a new facility. Adding a facility consists of: 1) specifying a facility location, 2) entering a facility description, and 3) entering personnel information about the facility contact person, if necessary. Details for this task are described in Section 6, Resource Management, under ADD FACILITIES.

\section{ADD LOCATION *}

ADD LOCATION adds a new location to the database of Known Points. The following prompt appears first:

Enter new Known Point name $=\approx>$

1. Enter any name (up to $\mathbf{4 0}$ characters) and press the Return key or press CTRL-Z to exit.

This location name serves as the facility name for any facility that is added at that location.

If you enter a name that is already used for a location, the system prompts you to enter another name. After you enter a valid new location name, the following prompt appears:

* * MSG: Select new known Point location w/ mouse

2. Pick a location on the map screen.

If you pic a location that is already specified as a Known Point location, the system prompts you to select another point.

After you pick a valid location, that location is placed in the database of Known Points. The system then returns to Step 1 where you can continue to add point locations until you quit by pressing CTRL-Z.

\section{IID MODIFY FACILITIES *}

This option enables an Information Manager to modify facility information. Updating a facility consists of: 1) selecting a facility and 2) modifying the facility description. Details for this task are described in Section 6, Resource Management, under MODIFY FACILITIES. 


\section{RELEASE/RETAIN OVERLAYS}

The appearance of this option on the menu switches back and forth between RELEASE OVERLAYS and RETAIN OVERLAYS. When you use the SHELTERING Emergency Activity for the first time, the default map layers associated with search/rescue are automatically overlaid on the map screen and RELEASE OVERLAYS appears on the SHELTERING menu.

Pick this option

RELEASE OVERLAYS

RETAIN OVERLAYS
To see this effect. on your map screen

Removes all the map layers associated with this emergency activity

Redisplays the map layers-The map layer overlays continues to display until you select RELEASE OVERLAYS.

To choose which map layers are the associated with the emergency activity, see Section 12, Setup, under MAP LAYERS BY ACTIVITY.)

\section{SHELTER \& CENTER SUMMARY}

SHELTER \& CENTER SUMMARY enables you to view a table of information about the shelters and reception centers within a specified area.

Resource area of interest menu
0: ExIT
1: Select an area
2: Define an area
3: Delete an area
4: Entire screen
Choice $(?=$ Help) $==>$

For example, if you select Option 1, the system displays the following message.

* * MSG: Select an area. CONTINUE when done 
Select an area with the mouse or cross hairs. The area you have picked highlights in white and blinks. Select the Continue command when you have finished. The system then displays a shelter and center summary report similar to the following example.

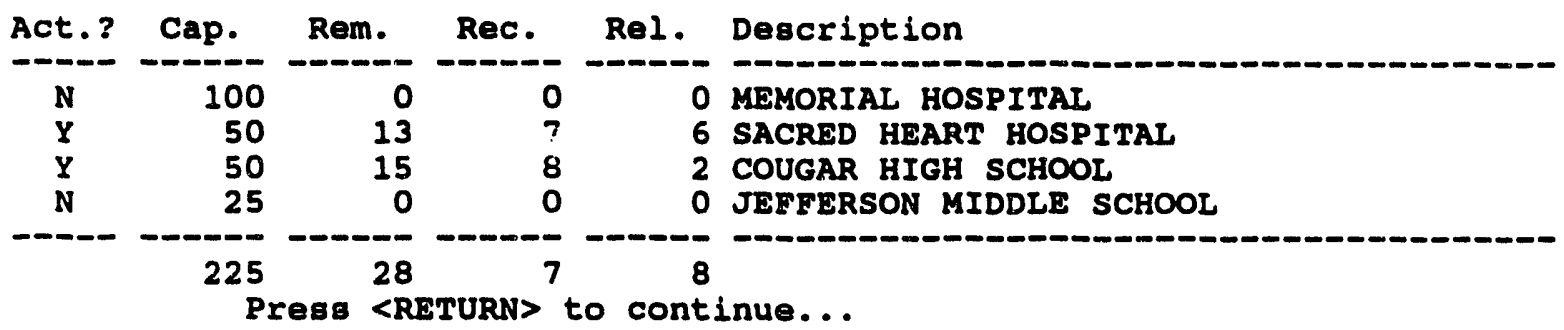

Press the Return key to return to the Resource area of interest menu. You can continue to select and view summary reports, or exit by selecting Option 0 .

\section{SHELTER OR CENTER INFO}

This option displays the description of a selected shelter or reception center and gives you the option of listing the resources of the facility. Details for this task are described in Section 6, Resource Management, under DESCRIBE FACILITIES. 


\section{Section 12 Setup}

\section{GETUP}

\begin{tabular}{|c|c|c|}
\hline IBS MAIN MENU & & $\begin{array}{l}\text { SETUP displays this submenu of capabilities for } \\
\text { tailoring the default map layers, site, and job } \\
\text { environment to your needs. Most users are not } \\
\text { expected to need the SETUP capabilities. It is } \\
\text { anticipated that the System Manager has tailored } \\
\text { these defaults when setting the user up as an IBS } \\
\text { user. For those users whose requirements can }\end{array}$ \\
\hline $\begin{array}{l}\text { CHANGE SITE } \\
\text { CHANGE DEFAULT MAP LAYER } \\
\text { MAP LAYERS BY ACTIVITY } \\
\text { JOB ENVIRONMENT } \\
\text { COMMON LEGEND }\end{array}$ & 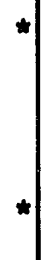 & $\begin{array}{l}\text { <-- Switch between site databases. } \\
\text { <-- Choose which map layers are displayed. } \\
\text { <-- Choose map layers for Emergency Activities. } \\
\text { <-- Control setups of hardware, software, data. } \\
\text { <-- Place a title at the top of the screen. }\end{array}$ \\
\hline ARCHIVE SITE & * & $<-$ Save the current site database. \\
\hline
\end{tabular}

SETUP displays this submenu of capabilities for tailoring the default map layers, site, and job environment to your needs. Most users are not expected to need the SETUP capabilities. It is anticipated that the System Manager has tailored user. For those users whose requirements can differ, such as emergency planners, SETUP enables them to adjust the IBS environment to their needs.

<-- Switch between site databases.

<-- Choose which map layers are displayed.

$<-$ Choose map layers for Emergency Activities. <-- Control setups of hardware, software, data. $<-$ Place a title at the top of the screen.

$<-$ Save the current site database.

The SETUP menu options and capabilities are specified in alphabetical order in the following sections. 


\section{ID ARCHIVE SITE *}

This option enables you to archive the site database.

\section{Caution}

This opticn begins immediately to archive the entire current site database. This is a time intensive activity and could take $h$. urs. Because there is no graceful way to exit this function after the proces, begins, it is recommended that you run this activity during system "off hours".

When you select ARCHIVE SITE, the following message displays.

Archiving database. Please wait...

Note: If you unintentionally start liis process, you can force an exit by performing the following procedure.

1. Press Ctrl-Y to stop the process. The stop can take 10 minutes or more.

2. Have your system manager delete any half-completed backup files from the archive directory. 


\section{CHANGE DEFAULT MAP LAYER}

\begin{tabular}{l} 
IBS MAIN MENU \\
SETUP \\
CHANGE DEFAULT MAP LAYERS \\
\hline \\
FORWARD \\
BACKWARD \\
RISK AREA POLYGONS \\
SEARCH/RESCUE POLYGONS \\
DAMAGE ASSESSMENT POLYS \\
IOOK ROADS \\
ROADS \& TRAILS \\
RAILROADS \\
ADMINISTRATIVE BOUNDARY \\
D2 TRACK \\
1OOK HYOROGRAPHY \\
TRAFFIC CONTROL \\
WATER BODIES \\
CONGRESSIONAL DISTRICTS \\
POLITICAL BOUNDARIES \\
TRACT POPULATION \\
APA SECTORS \\
\end{tabular}

This option presents a menu that lists the different groups of map features (layers) available in the current map database. Any menu items displayed in green are the currently selected default map layers: the map layers that are automatically displayed when you start using the IBS. You can select additional map layers or cancel some of those already selected. The selected map layers then appear on the map screen throughout this session-unless you cancel map layers by using this menu again.

The map layers are too numerous to show on a single screen. The menu shown here is the first of several "pages" of map layers. The actual list of map layers can change as map layers are added or subtracted from the menu. Use the FORWARD and BACKWARD options to display other pages of the map layer menu:

- FORWARD shows the next page of map layers. If you reach the end of the list, the next FORWARD returns you to the first page.

- BACKWARD shows the previous page of map layers. If you reach the first page of tie list, the next BACKWARD sends you to the last page.

\section{Restricting Máp Layers Based on Display Size}

When you exit the menu, you see a screen for restricting the display of map layers based on display size ( 0 to 30,000 miles). For example:

RESTRICTIONS OF MAP LAYERS BY DISPLAY SIZE

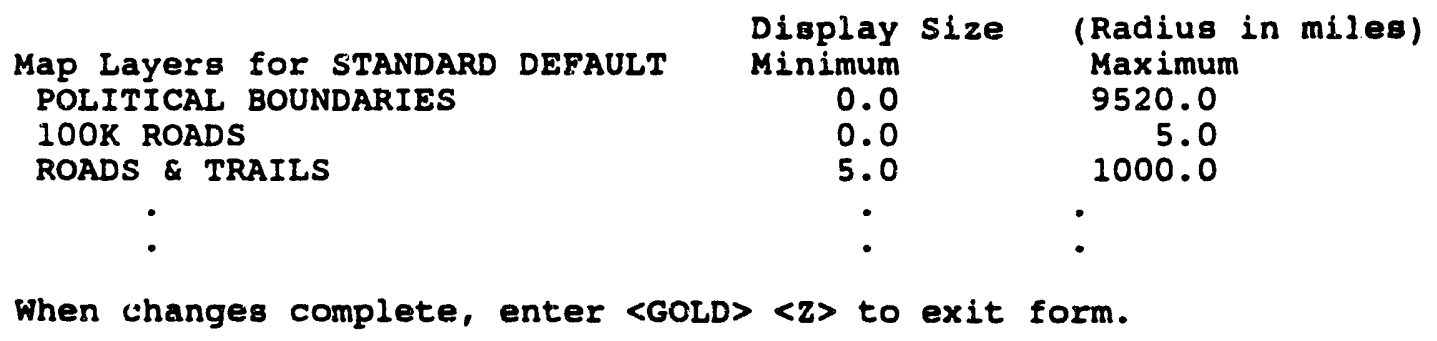


This screen enables you to make the display of map layer data dependent on the size of the displayed area. For each map layer listed, you can specify a range of display sizes (radius in miles) within which that map layer will be shown.

You can use this capability to customize the use of data sets that have different resolutions. For example, you might specify that $1: 2$ million-scale road data be shown for displays from 5 to 1000 miles across while 1:100,000-scale data is used for displays 0 to 5 miles across. This enables you to avoid the display of high-resolution data that night be appropriate for smaller areas but which are too detailed and time consuming to display for large areas.

Note: Some data rich map layers such as $100 \mathrm{~K}$ Roads will cause the system to hang if you try to display the map layer over a large map area. Restrict such layers using the previous screen example. Recommended settings for $100 \mathrm{~K}$ Roads can be a minimum of $\mathbf{0 . 0}$ miles and a maximum of $\mathbf{5 . 0}$ miles. If you zoom out your map display to anything larger than a 5mile radius, the $100 \mathrm{~K}$ Roads layer does not display. This keeps your system up and running.

If you see blank map layer descriptions that have minimum and maximum display sizes listed, this is because your Job Environment file contains one or more map layers that are not in the current map database. This should not interfere with the operation of the IBS program.

After you exit this screen, the new set of map layer defaults are immediately displayed. 


\section{CHANGE SITE *}

CHANGE SITE enables planners, and others who have appropriate privileges, to switch their current default sites between the

- Operational site database (OPER)

- Other site databases (such as a planner's planning site database)

General users do NOT have this option: most users use only the operational site database assigned by the Information Manager.

After you select this option, the system displays the following prompt if you have Information Manager privilege.

Do you want to change the operational site? ( $Y / N<C t r l-z\rangle=A b o r t)=3$

Depending on which option you pick, you can change either the system-wide operational site database or your personal site database at this point. If you change the operational site database, the default site database for everyone on the system is changed.

If you enter $Y$ (yes) at the prompt, the system will enable you to change the operational site database. If you enter $\mathbf{N}$ (no) at the prompt, the system will enable you to change your personal site database. Press CTRL-Z to exit without changing sites.

If you answered $\mathbf{N}$ (no) at the prompt, a menu similar to the following displays.

Select new site
0: EXIT
1: TOOE [Plan] -> TOOE [Real]

Select the new site you want to use from the menu listing. This menu indicates which site is your current site, and which site is the operational site. A site which is both the current and operational site will be marked (Current/Oper). The other designations are:

Plan Planning database

Real Real database

Exer Exercise database

If you selected a new site, the systems stops and resets to the new site database. Changing planning sites will not affect other users of the system.

If you have Information Manager privilege and entered $Y(Y e s)$ at the prompt: Do you want to change the operational site? $(\mathrm{Y} / \mathrm{N} /\langle\mathrm{Ctrl}-\mathrm{Z}\rangle=\mathrm{Abort})==>$, the following message displays. 
* * MSG: If other users are using the system, changing the operational

* * MSG: site May cause them to lose changes they have made.

Do you really want to change the operational site? (Y/N/<Ctrl-Z>=Abort) ==>

Type a Y (Yes) at the prompt to change the operational site and press the Return key.

You will be given a menu similar to the one shown previously. Select a new operational site or 0 to exit. If you selected a new operational site, the system then stops and resets to the new site database. Users in operational mode are $c_{i}$ anged to the new site database. Planners working in planning mode remain in planning mode looking at their own data; however, references to any shared data are directed to the new operational site.

Note: Use caution before changing the operational site database. You should normally only change the operational site when no other people are using the IBS program. A privileged user can change the operational site while others are using the program even though this can cause them to lose some recent changes. 


\section{COMMON LEGEND *}

This option enables you to display a title legend or other information at the top of the display screen. You can choose from two predefined legends or define your own. The legend appears in tall white lettering and can obscure some map information. The legend appears in Operational mode on all terminal screens tied into the system, so its use is restricted to the Information Manager.

Note: $\quad$ This option is available only 12 Operational mode. To change from Planning to Operational mode, use the CHANGE SITE option described in this section.

The system prompts:

TITLE OPTIONS

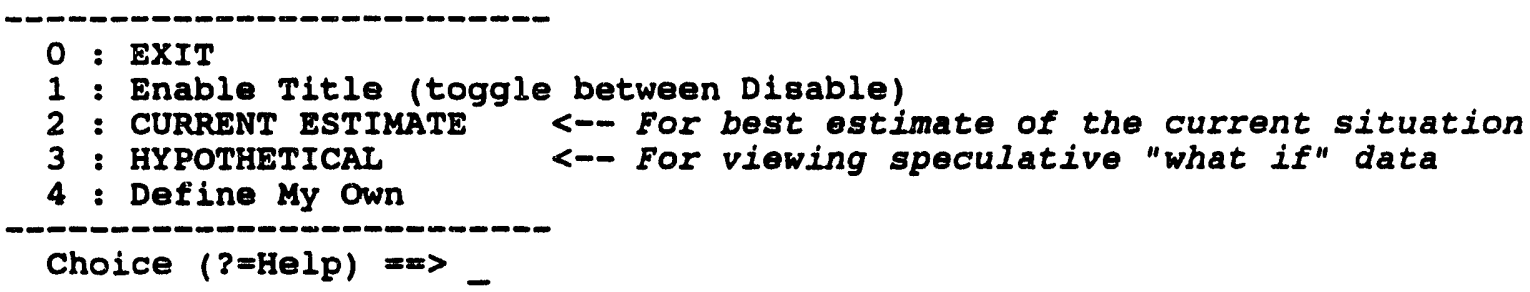

Your options are these:

1. DISABLE TITLE: Removes any currently displayed title text from the screen. This can leave breaks in the map information where the title occurred; REFRESH SCREEN restores the missing information.

2. CURRENT ESTIMATE: Displays the title, "CURRENT ESTIMATE." This is intended as a standard way of identifying the display as the most up-to- date information and modeling estimates about the current situation.

3. HYPOTHETICAL: Displays the title, "HYPOTHETICAL." This is intended as a quick way of indicating the display contains speculative modeling results or other information that does necessarily reflect the current situation.

4. Define My Own: Enables you to enter a title of your own choosing.

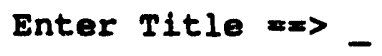




\section{JOB ENVIRONMENT}

\begin{tabular}{l}
\hline IBS MAIN MENU \\
SETUP \\
\\
JOB ENVIRONMENT \\
\hline \\
HARDWARE PARAMETERS \\
MODEL MANAGEMENT \\
MAINTAIN SITE DIRECTORIES \\
REVIEW CONTROL FILES \\
UPDATE SITE MASTER FILE \\
COPY CASE OR SITE FILE \\
MISCELLANEOUS SETTINGS \\
INFOMANAGER ROOT MAINTENANCE
\end{tabular}

The IBS job environment is the current overall setup of equipment, software, and data that you can use. JOB ENVIRONMENT on the SETUP menu provides a consistent means of identifying what general data sets you wish to use and how you wish to use them.

$<-$ Identify your graphics hardware devices.

$<-$ Specify the current cases for IBS models.

$<-$ List model cases with options to delete.

$<-$ List graphics control files (or others).

<- Edit the list of a user's site data sets.

$<-$ Copy site or case data to another IBS user.

$<-$ Set up system defaults for printing, etc.

$<-$ Maintain the Caseindex file.

The job environment affects both mapping (graphic) interactions and modeling functions. For example, the job environment defines which graphics input device you can use.

For most users of the IBS, most parts of the job environment are fixed. Only those with special privileges (an Information Manager) are able to modify the files that define the job environment. In general, it is the responsibility of the system or data manager to supply general users with the appropriate job environment. 


\section{IIIINFOMANAGER ROOT MAINTENANCE *}

This option enables you to make corrections to the Infomanager CASEINDEX.DAT file.

Note: Infomanager authorization is required to access and use this option.

When you select the INFOMANAGER ROOT MAINTENANCE option, the following form ilisplays:

\section{INFOMANAGER ROOT MAINTENANCE \\ SITE IDENTIFICATION}

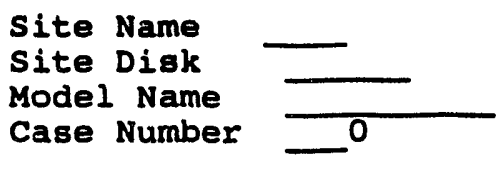

FUNCTION

The first four fields must be filled in to identify the particular Infomanager site/disk/model/case to be updated or corrected.

Use the following commands in the FUNCTION field:

$\mathrm{X}$ : Exit

D: Delete the case (both input and output). The system then prompts:

Are you sure?

O: Delete case output. The system then prompts:

Are you sure?

A: Assign the case. The system displays the following menu, liscing the options for the assignment.

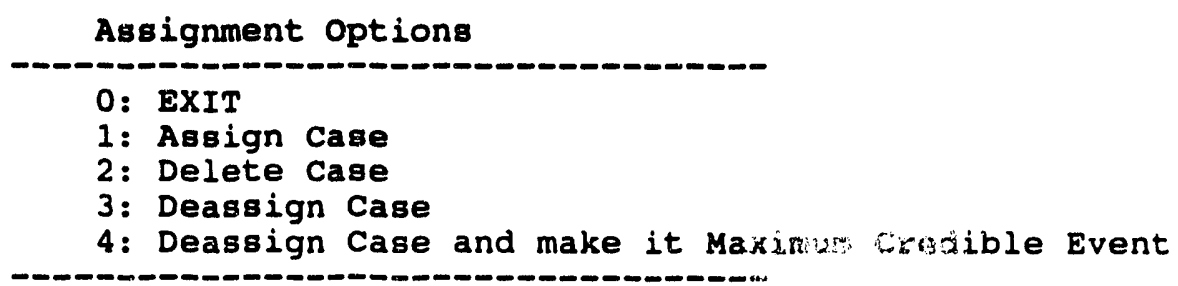

The assignment options are:

1. Assign Case: Sets the code haracter in the CASEINDEX.DAT file for the specified case to " $A$ ", indicating the case is available but is assigned to a 
planner for modification. It cannot be assigned to another planner at this time.

2. Delete Case: Sets the code character in the CASEINDEX.DAT file for the specified case to " $n$ ", indicating the case does not exist.

3. Deassign Case: Sets the code character in the CASEINDEX.DAT file for the specified case to " $Y$ ", indicating the case exists and is not assigned.

4. Deassign Case and make it Maximum Credible Event: Sets the code character in the CASEINDEX.DAT file for the specified case to " $\mathrm{M}$ ", indicating the case exists, is not assigned, and is one which represents a Maximum Credible Event.

L: List a directory of cases based on the first three fields of the form.

Use GOLD-Y to exit the form without saving the changes. 


\section{MISCELLANEOUS SETTINGS}

This option enables you to specify the default

- Selection mode

- Report destination

When you specify a default selection mode, the system offers you that mods of selecting an item. This occurs whenever you have to select an item as part of another IBS option. The options for selecting (picking) are:

1. List

2. Mouse

3. Name

When you specify a default report destination, the system sends any generated report to your preferred destination. The destination can be:

1. Screen

2. Printer

3. Mail

4. File

If you select no defaults, the system displays the general selection and report destination menus whenever you select an option that requires these actions.

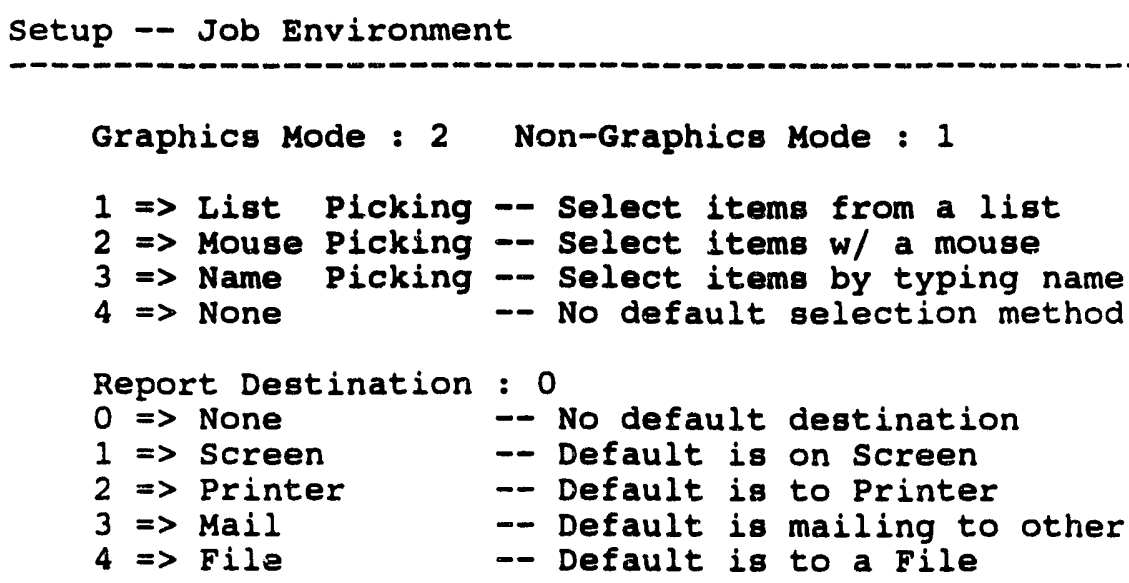




\section{COPY CASE OR SITE FILE *}

This option enables you to

- Copy site or case data from another person's directories to your own

- Copy similar information from your directories to another person

These operations require special authorizations ii $d$ password use, especially when data are copied between different systems (nodes). You should have Information Manager or Planner privileges to use this option. At some point in the copying process, you are prompted to enter a user name and password.

When you select the COPY CASE OR SITE FILE option, the following message displays.

\section{REMINDERS}

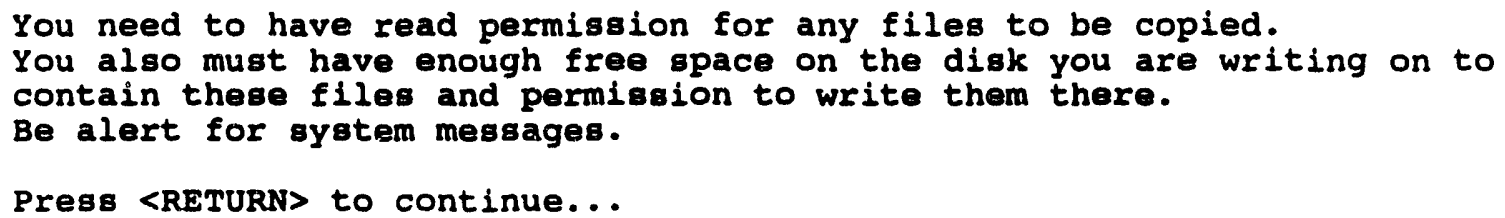

Press the Return key to display the COPY CASE SITE OPTIONS menu.

\begin{aligned} COPY CASE SITE OPmTONS \\ \hline $0:$ EXIT \\ $1:$ Check-out IP \\ $2:$ Check-in IP \\ $3:$ Check-out D2 \\ $4:$ Check-in D2 \\ $5:$ Check-out Evac \\ $6:$ Check-in Evac \\ $7:$ Copy Topo \\ $8:$ Copy Pop Set \\ $9:$ General Copy Case Site \\ $10:$ Deleto Site \\ \hline \\ \hline Choice (?=Help) $==-\end{aligned}$

The following examples show the typical prompts for various menu selections. 
When you select Option 1: Check-out IP, the following series of prompts display.

Note: Before checking out an IP with Check-out IP, make sure that your current site is set to an appropriate planning site database. It would not make sense to check out an IP for one site and use it with data from a physically different site.

When you select Check-out IP, the system displays the following series of prompts

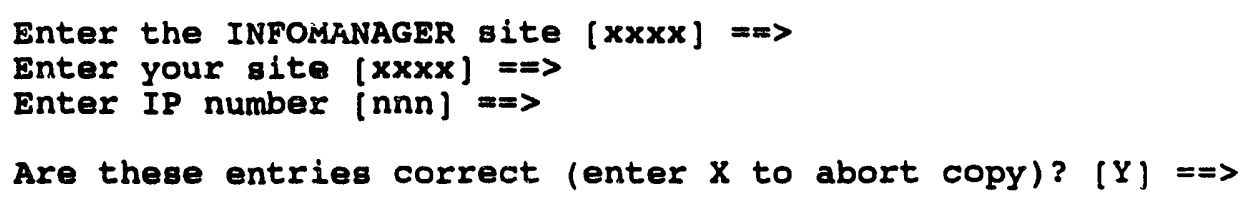

After you specify which IP to use, the system checks to see whether the specified IP is already checked out (that is, already assigned to another planner).

- If the IP is already checked out, the system cannot check it out to you until the IP has been checked back in.

- If the IP is available, the system copies the IP and associated records from the scenario table to your current planning site database.

When you check out an IP, the system notes the IP is assigned to you. No one else can check out the same IP until you check it in again.

If you select Option 2: Check-in IP, the following series of prompts display.

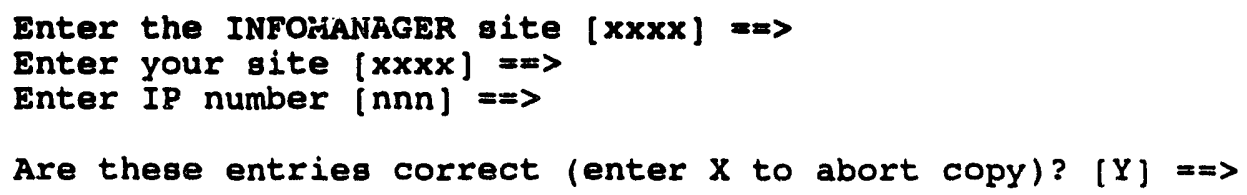

The system returns you to the Copy Case Site Options menu, leaving a copy of your modified IP in your planning database, as well as in the corresponding INFOMANAGER site database.

For more detailed information on CHECK-OUT IP and CHECK-IN IP, see Section 3. Status Board. 
If you select Option 7: Copy Topo (Copy Topographies), the following series of prompts display.

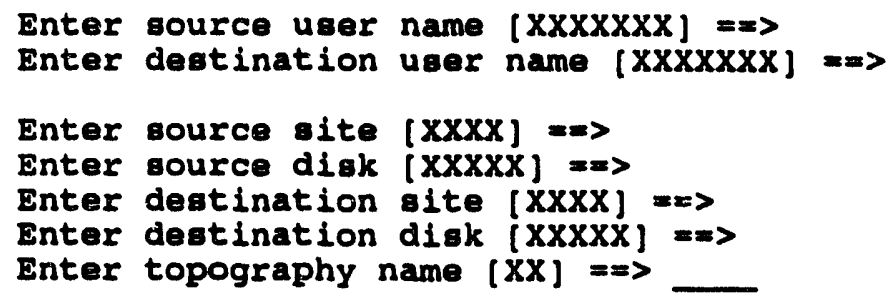

To see a menu listing of possible entries for a field of the screen: enter ?? in the field. A menu appears so that you can select the file, model, or data set name.

For example, if you need a reminder of the possible infomanager sites, type ?? at the Enter the INFOMANAGER site prompt. A listing of source sites similar to the following example displays.

\begin{tabular}{ll} 
* SITE NAME \\
\hline 1 & TOOE \\
2 & JCB1 \\
3 & JCB2 \\
4 & OPER \\
5 & EXER
\end{tabular}


When you select Option 9: General Copy Case Site, the following input screen displays.

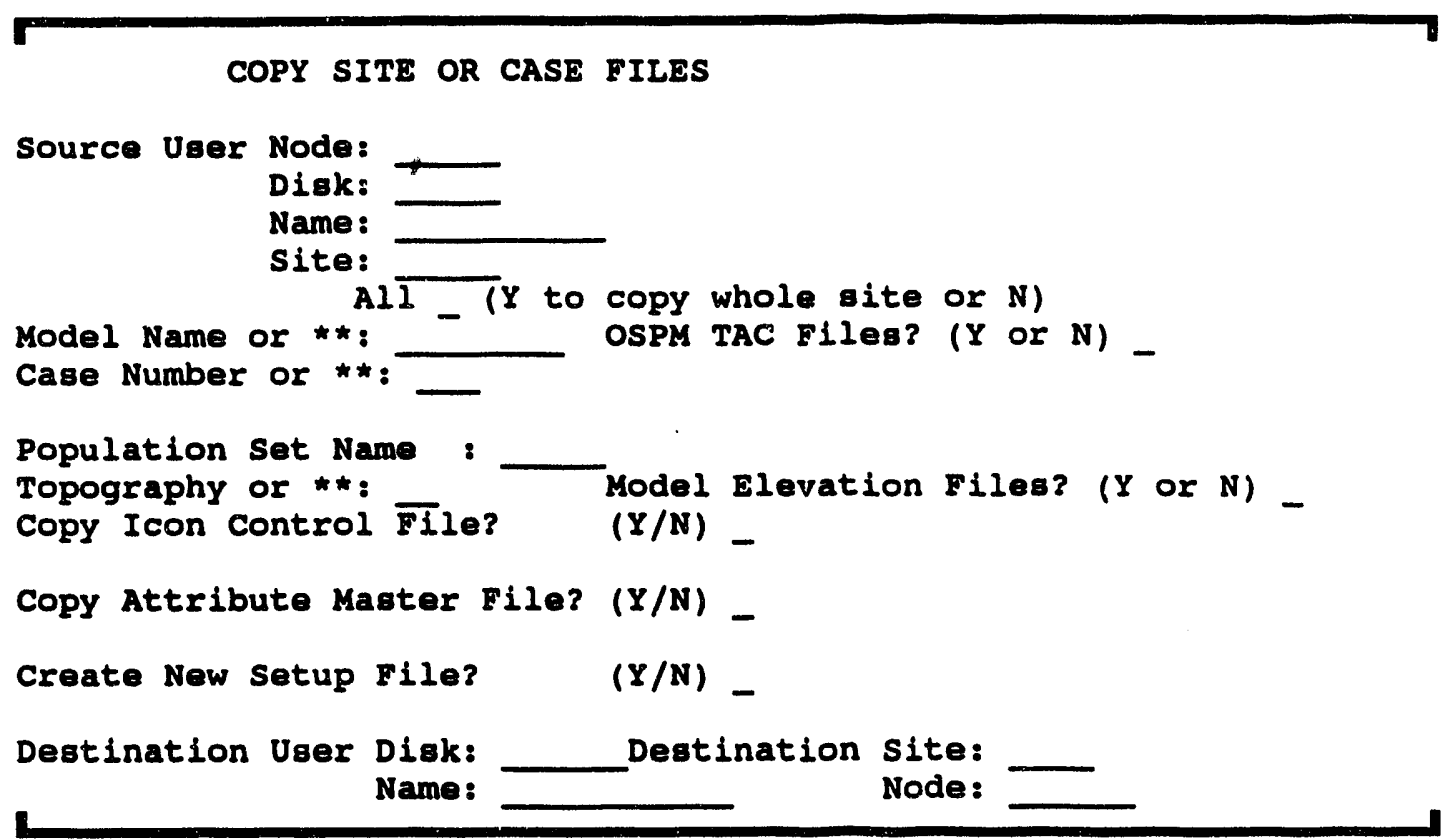

The same screen is used for copying data to or from another IBS user. These two processes are explained in the following sections. In general, you must know what kinds of data you want to copy (which fields to use on the screen). The IBS provides specific help with the names of files, models, and data sets:

To see a menu listing of possible entries for a field of the screen: enter ?? in the field. A menu appears so that you can select the file, model, or data set name.

If you enter file names directly: enter the complete file specification, including disk, directories, and file name-disk:[directories]filename. 


\section{Copying Site or Case Data FROM Another IBS User}

For example, if you were working with a planner to create evacuation scenarios for a specific site, you can copy case data from that person's directories directly into your own directories.

The fields of the COPY CASE OR SITE FILES screen are explained here. A bullet $(\bullet)$ appears next to each input item. Remember: for some fields you can enter ?? to see a menu list of possible inputs.

- Source User Node: Enter the name of the node (system) from which you wish to copy data.

- Source User Disk: Enter the name of the disk used by the person whose files you want to copy.

- Source User Name: Enter the "user name" of the person whose files you want to copy.

- Source User Site: Enter the 4-character site name of the site from which you wish to copy data.

- ALL?: Enter $\mathbf{Y}$ to copy a complete site. If necessary, site directories are created on the destination disk. All model data, mapping data, and other support files are then copied from the source disk to the destination disk. The site master file in your login directory is also updated.

- Model Name or **: Enter a specific model name (such as D2 or IDYNEV)-or ** (two asterisks) to signify all models for the chosen site.

- OSPM TAC Files? ( $\mathbf{Y}$ or $\mathbf{N}$ ): Enter $\mathbf{Y}$ to copy TAC (cell data) files associated with the OSPM model. These files must comply with IEMIS naming conventions for OSPM TAC data files.

- Case Number or **: Enter a case number-or ** (two asterisks) to signify all cases for the chosen model.

- Population Set Name: Enter the name of the population set to be copied with the chosen site.

- Topography or **: Enter a two-character topographic code to identify one topography-or ** (two asterisks) to signify all topographies (map layers) from the chosen site.

- Model elevation files? ( $\mathbf{Y}$ or $\mathbf{N}$ ): Enter $\mathbf{Y}$ to copy TAC (cell data) elevation files associated with the modcls. These files must comply with IEMIS naming conventions for model elevation data files. 
- Copy Icon control file? (Y/N): Enter $Y$ to copy Icon control files associated with the models.

- Copy Attribute Master File? (Y/N): Enter the name of the attribute master file that applies to the chosen site.

- Create New Setup File? (Y/N): Enter $\mathbf{Y}$ to create a new setup control file based on the previous selections in the form. Enter $\mathbf{N}$ to avoid creating a new setup control file.

If you choose to create a new setup control file, the IBS creates a new file nanned SETUP.COM in your user directory on the specified destination disk. You must check and edit this file to be sure that it meets your needs before using it.

- Destination User Disk: Enter the name of the destination disk device to which IBS is to copy the desired files. Be careful: the IBS searches the destination disk for a top directory corresponding to your system user name. If no such directory exists, results are uncertain but errors are likely.

- Destination Site: Enter the 4-character site name of the site to which you want to copy data.

- Destination User Name: Enter the user name of the person who will receive the data.

- Destination Node: Enter the name of the node to which you want to copy data).

Regardless of what you copy, the settings for such things as the current case, site, and population set remain unchanged in your job environment. You must explicitly set these items to the new data using SETUP-JOB ENVIRONMENT, if that is what you wish to do.

\section{Copying Site or Case Files TO Another IBS User}

In this situation, you use the same input screen to specify that site or case files be directed to another IBS user. 


\section{IIIHARDWARE PARAMETERS}

The purpose of modifying hardware parameters is to tell the system what kind of hardware devices you are using. When you select this option, the IBS displays the following input screen for modifying hardware parameters. The current hardware selections are indicated by the letters that appear in the input fields.

Note: Most users use a workstation with standard hardware parameters and shouli $i$ VOT change them from the defaults that apply to most users:

J-Joydisk

T-Tektronix

B-Bit Pad (see the following example).

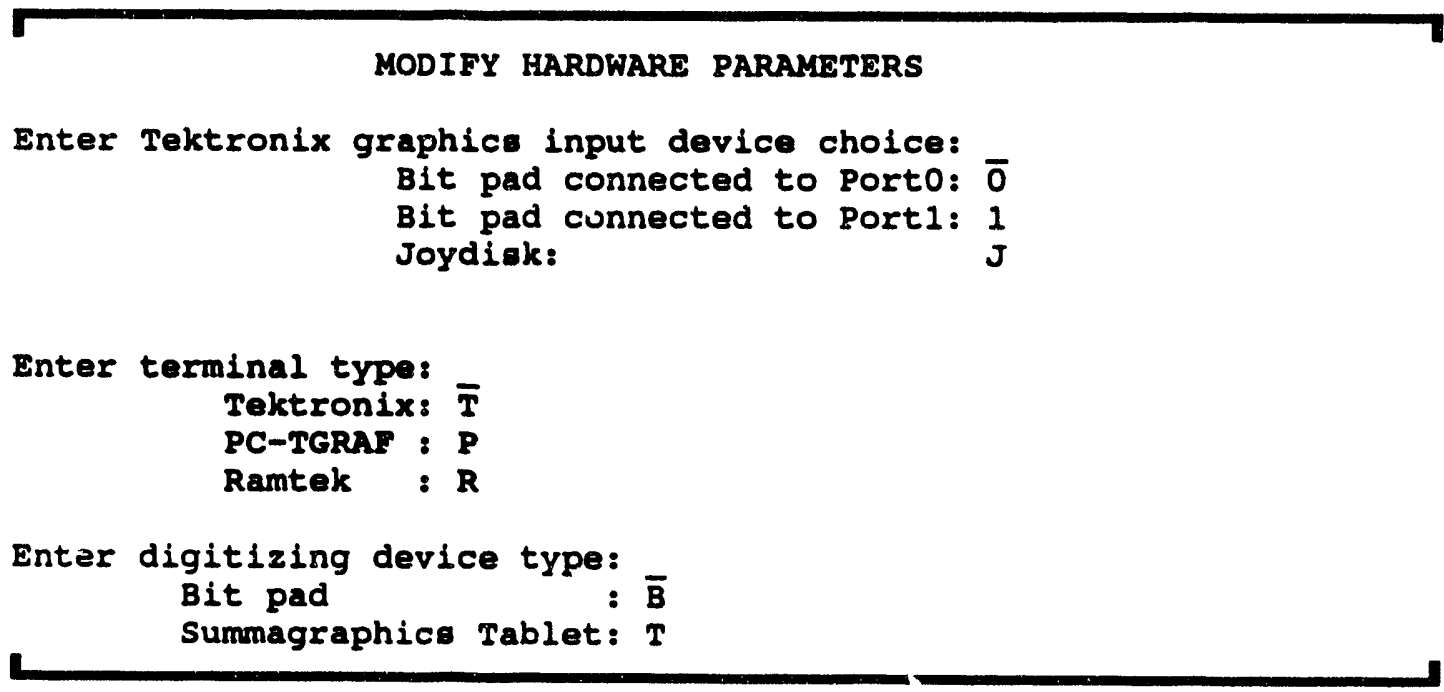

The fields of the form are explained here. A bullet $(\bullet)$ appears next to each input item. If you modify a hardware choice and accept the modification (when you exit the form), the system tells you that the previous value of the device's logical name has been superseded by your new choices.

- Tektronix graphics input device: This applies only to Tektronix workstations (or workstations that emulate a Tektronix terminal).

Enter:
O - (zero) to use a bit pad connected to Port 0
1 - (one) to use a bit pad connected to Port 1 
J - to use the terminal's joydisk for graphics input.

If you have a workstation that is emulating the Tektronix terminal, use J-Joydisk.

- Terminal (display device) type: Enter:

$\mathbf{T}$ - to use the Tektronix terminal monitor (or other terminal emulating a Tektronix monitor)

P - to use the Tektronix emulation provided by TGRAF software on personal computer

- Digitizing device : This refers to the graphics input device that can be used with the software to digitize graphic information, such as from a paper map. Enter:

B - to use a bit pad

T - to use a Summagraphics digitizing tablet. 


\section{MAINTAIN SITE DIRECTORIES *}

This option enables you to list and delete case data for any model in the IBS. Do this periodically to eliminate old data you no longer need.

When you select this option, the system displays the menu screen shown here.

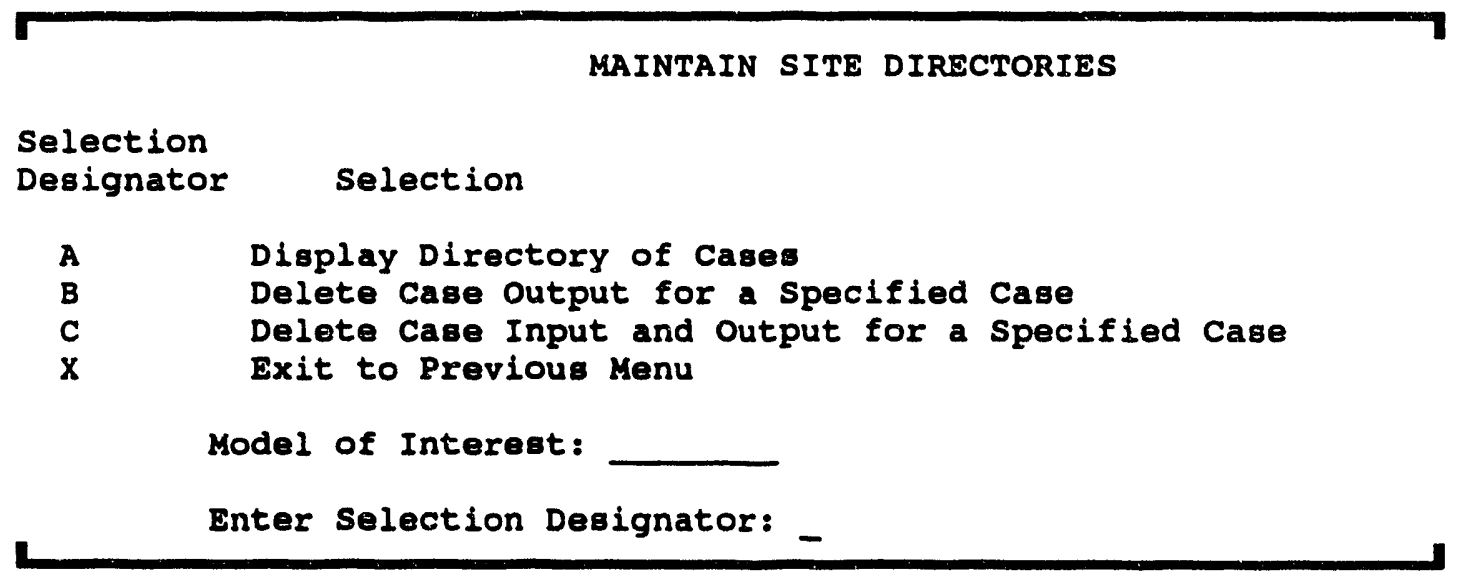

The screen has only one data input field:

- Model of Interest: Enter the name of the model for which you wish to list or delete case files (for example, D2 or IDYNEV).

After choosing a model, select one of the file maintenance activities by entering the corresponding letter. The three main options of this menu are:

Option A. Display Directory of Cases: This option displays a list of all the case files (inputs and outputs) for the selected model.

Option B. Delete Case Output for a Specified Case: This option enables you to delete case output by specifying a case number from a list of case outputs.

Option C. D $\quad$ Case Input and Output for a Specified Case: This option enables you . Nolete both the inputs and outputs of a case by specifying a case number trom a list of cases. 


\section{MODEL MANAGEMENT *}

\begin{tabular}{|l|}
\hline IBS MAIN MENU \\
SETUP \\
JOB ENVIRONMENT \\
MODEL MANAGEMENT \\
\hline DISPERSION (D2) \\
EVACUATION (DYNEV)
\end{tabular}

MODEL MANAGEMENT is a capability for centrally specifying which cases (data sets) are currently in effect for each emergency-related model in the IBS.

MODEL MANAGEMENT lists the models in this central menu; you can pick one at a time. After you pick a model, the IBS enables you to enter a case number or to specify criteria for generating a list of cases (from which you can choose one).

DISPERSION (D2) is identical to CHANGE D2 TRACK CASE on the IBS main menu.

EVACUATION (DYNEV) is identical to SELECT MODEL CASE on the EMERGENCY ACTIVITIES-EVACUATION menu. 


\section{IID REVIEW CONTROL FILES}

This option enables you to print or display the contents of any specified text file. This is helpful when you are planning to use special control files and wish to first see their contents.

When you select this option, the system displays the following prompt:

REVIEW GRAPHICS CONTROL FILES

Enter name of control file to review:

Enter the file specification of a control file (or any text file).

After the file is displayed or sent to the printer, you return to the JOB ENVIRONMENT menu. 


\section{UPDATE SITE MASTER FILE *}

This option enables an Information Manager to edit the site master file (SITE.DAT). Your site master file, located in your top-level directory, contains a list of all the sites owned by you. The most probable reasons for editing this file are to add a site that you have copied or to remove an unneeded site. This requires some knowledge of SITE.DAT (for further information on SITE.DAT, ste the IBS Data Management Gluide) and of the system text editor (of which you must have prior knowledge.)

When you select UPDATE SITE MASTER FILE, the system displays this menu:

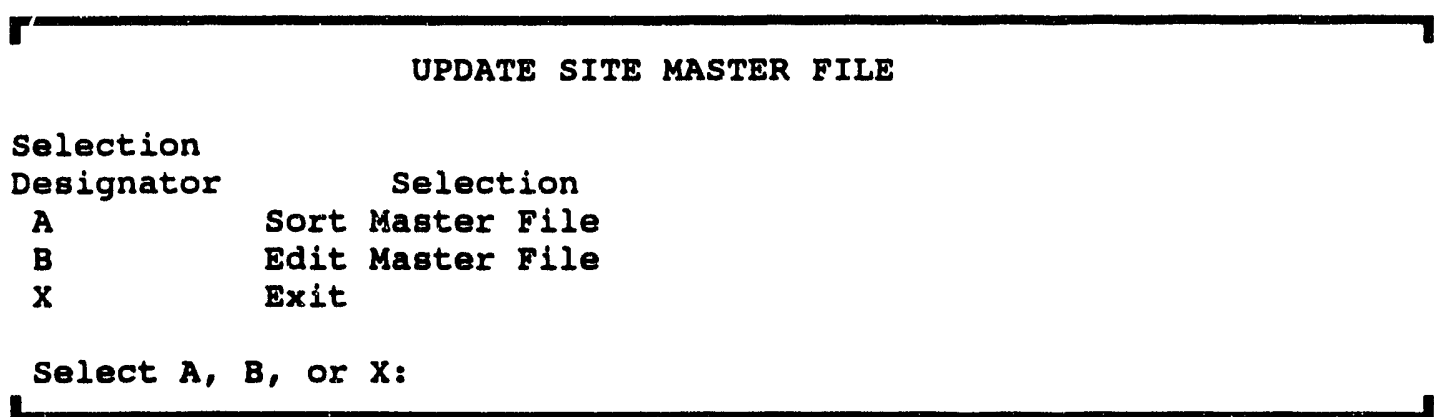

The two main options of this menu are to $\mathbf{A}$ ) sort the site master file and B) edit the site master file:

Option A. Sort Master File: This option alphabetically sorts the sites in the site master file according to site name. This is automatic and causes no screen display. If two sites have the same name, the system informs you; you must then edit the site master file to remove one of the sites.

Option B. Edit Master File: When you select this option, the IBS starts the system text editor (EDT) and enables you to edit the site master file.

To exit from the editor: Type EXIT or QUIT in response to the asterisk $\left(^{*}\right)$ prompt.

- EXIT saves the new edited site master file as a new version of SITE.DAT.

- $\quad$ OUIT ignores your editing and does NOT save a new version of SITE.DAT. 


\section{IDAP LAYERS BY ACTIVITY}

\begin{tabular}{l} 
IBS MAIN MENU \\
SETUP \\
\\
MAP AYERS BY ACTIVITY \\
\hline \\
HAZARD ANALYSIS \\
EOC ACTIVATION \\
DIRECTION/CONTROL \\
EVACUATION \\
SHELTERING \\
SEARCH/RESCUE \\
DAMAGE ASSESSMENT
\end{tabular}

\begin{tabular}{|l} 
IBS MAIN MENU \\
SETUP \\
MAP LAYERS BY ACTIVITY \\
(emergency actlvity) \\
(emergenCy activity) \\
\hline FORWARD \\
BACKWARD \\
ADMINISTRATNE BOUNDARY \\
AGRICULTURE \\
BASE MAP \\
MAP LAYER 4 \\
MAP LAYER 5 \\
- \\
- \\
MAP LAYER N \\
\hline
\end{tabular}

MAP LAYERS BY ACTIVITY enables you to choose which map layers you wish to display for each Emergency Activity. You can select one Emergency Activity at a time from the menu list.

After selecting an Emergency Activity, a submenu of map layers for that function displays, similar to the one lower left.
The initial default map layers (see CHANGE DEFAULT LAYERS) and any map layers already defined as default layers for the chosen Emergency Activity are already selected (shown in green). You can select additional map layer(s) to be included in the set of default map layers for this Emergency Activity. The new map layers also are highlighted in green. To deselect a map layer, pick on a highlighted map layer, so it returns to its original color.

When you exit from the menu, you see the screen for restricting the display of map layers based on display size. As described for CHANGE

DEFAULT MAP LAYERS, this screen enables you to make the display of map layer data dependent on the size of the displayed area. For each Emergency Activity map layer listed on the form, you can specify a range of display sizes within which that map layer is shown. The following screen example shows map layers that were selected for the HAZARD ANALYSIS Emergency Activity. 


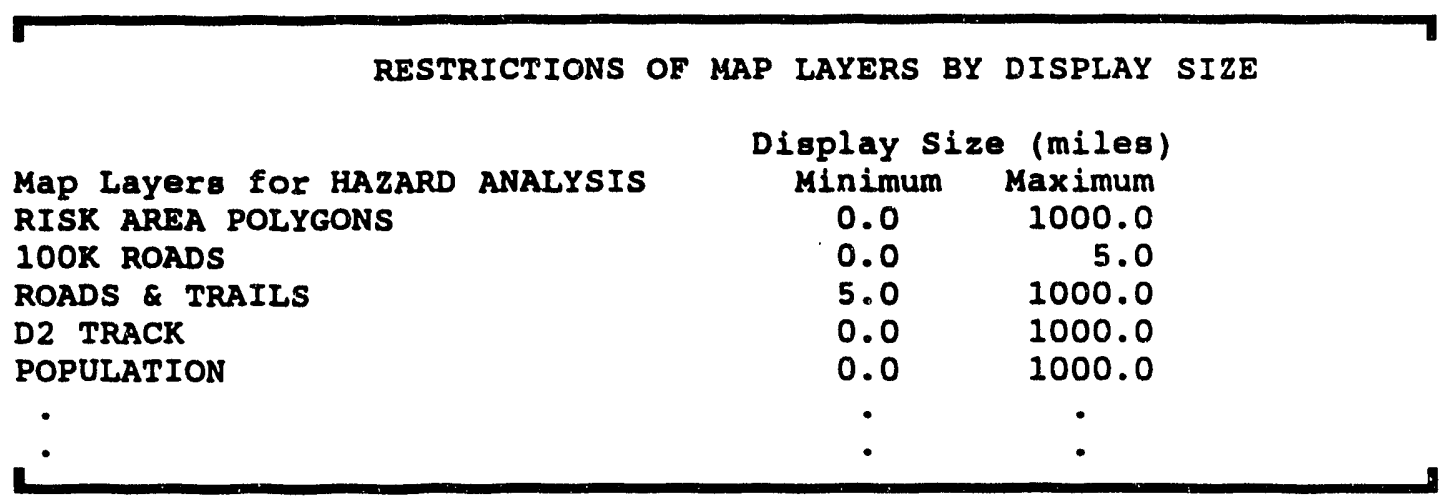

After you exit this screen, the new set of default map layers can be displayed within that emergency activity. To display the new map layers, return to the IBS Main menu and select the desired emergency activity. The new map layers display when the graphic display is refreshed. 


\section{Appendix A IBS Graphic Menus}

This appendix shows the appearance and structure of the graphic-screen menus used by the IBS. Most of the options listed on the IBS Main Menu result in the display of further submenus. These submenus are presented in the order in which they appear on the IBS Main Menu.

This appendix contains a series of menu diagrams which you can remove from the book and use for handy reference. The IBS Menu Structure is located at the back of this appendix. The menu structure reads from left to right; the first menu on the left is always the IBS Main Menu.

As you select options that result in further submenus, each level or layer of menu selection is listed in the upper area of the menu. The hierarchy of selections is indireted by indentation. You may go directly to any of the previous menus by selecting an item in the hierarchy of selections. For detailed information on salecting from a graphic menu, see Section 1, Introduction and Overview. 


\section{Example of a Submenu with Layered Menu Selections}

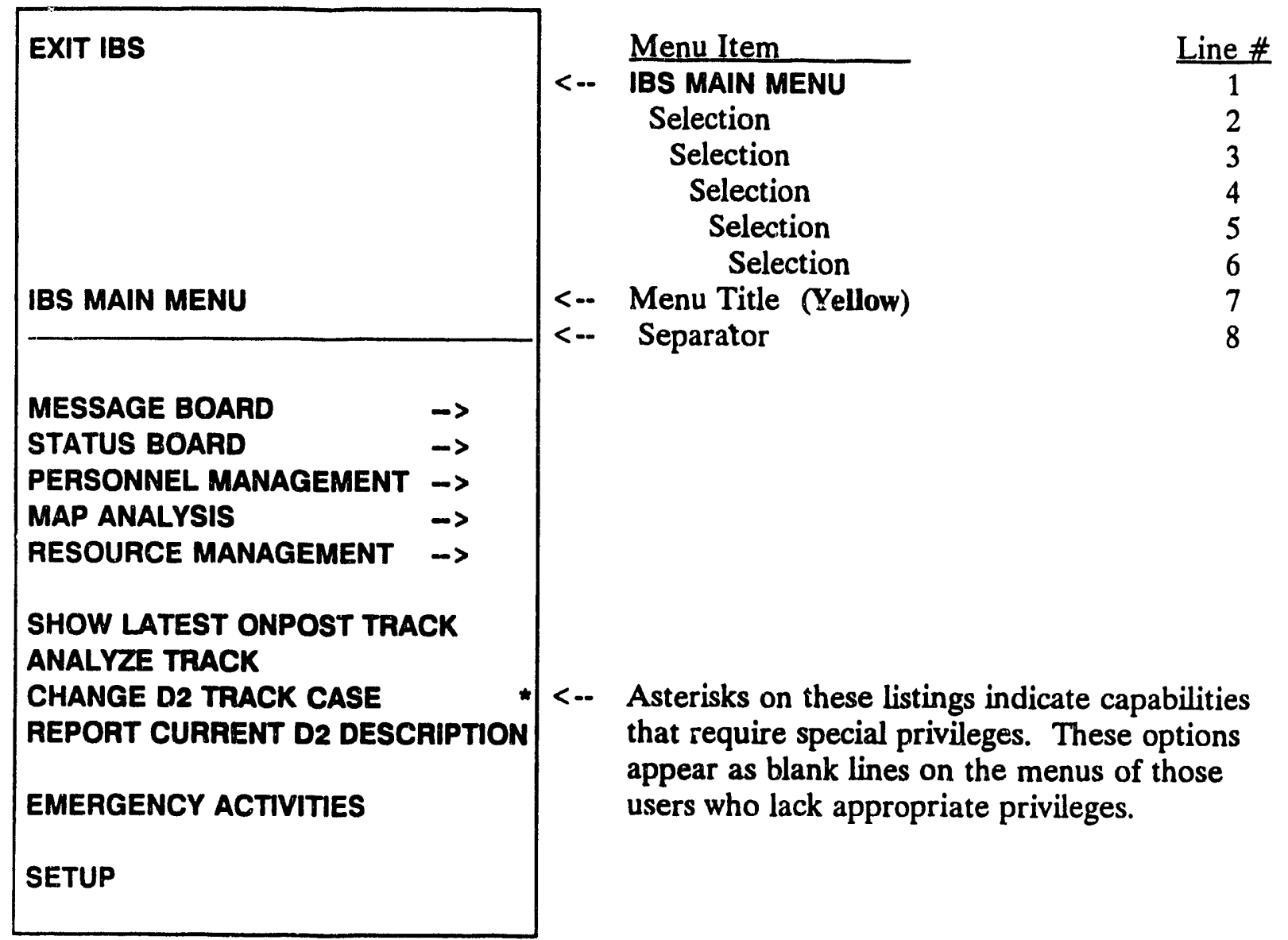




\section{IBS Main Menu}

$$
\text { EXIT IBS }
$$

IBS MAIN MENU

\begin{tabular}{ll}
\hline & \\
& \\
MESSAGE BOARD & $->$ \\
STATUS BOARD & $->$ \\
PERSONNEL MANAGEMENT & $->$ \\
MAP ANALYSIS & $->$ \\
RESOURCE MANAGEMENT & $->$ \\
SHOW LATEST ONPOST TRACK \\
ANALYZE TRACK \\
CHANGE D2 TRACK CASE \\
REPORT CURRENT D2 DESCRIPTION \\
EMERGENCY ACTIVITIES \\
SETUP
\end{tabular}

$<$ - Alternates between SHOW LATEST ONPOST TRACK and REMOVE LATEST ONPOST TRACK. 
Message Board

IBS MAIN MENU

MESSAGE BOARD

VAX MAIL

CREATE/EDIT MAIL UST

SEND MAIL

CHECK SENT MAIL

VIEW IBS -> ONPOST RPT

VEW ONPOST $\rightarrow>$ IBS RPT

CREATE IBS -> ONPOST RPT

VIEW COMBINED RPT

CHANGE COMBINED REPORT

VIEW MESSAGES BY CATEGORY

CHANGE MESSAGE CATEgoRIES* 
View IBS->ONPOST Reports

IBS MANN MENU
MESSAGE BOARD

VIEW IBS -> ONPOST


PROTECTIVE ACTION ORDER
EVACUATION ORDER
SHELTER AREA REPORT
TRAFFIC CONTROL REPORT
SHELTERING SUMMARY
OFFPOST CASUALTY SUMMARY
RECEPTION CTR SUMMARY
RECEPTION CTR DIRECTORY
EVAC ROUTE ANNOUNCEMENT
INCOMING MIITARY ROUTES
EVACUATION ROUTE TABLE
COORDINATE CODE TABLE
POLYGON CODE TABLE


View ONPOST->IBL Reports

IBS MAIN MENU

M:: ISAGE BOARD

VIEW ONPOST -> IBS

D2LOG

DOSAGE

PDATA

SLICE

WEATHER OBSERVATIONS

CURRENT RUN

ENVIRONMENTAL REPORT

NOTIFICATION

ONPOST CASUALTY REPORT

TOWER SELECTION 
Create IBS->ONPOST Reports

IBS MAIN MENU

MESSAGE BOARD

CREATE IBS $->$ ONPOST

PROTECTIVE ACTION ORDER EVACUATION ORDER

SHELTER AREA REPORT

TRAFFIC CONTROL REPORT

SHELTERING SUMMARY

OFFPOST CASUALTY SUMMARY

RECEPTION CTR SUMMARY

RECEPTION CTR DIRECTORY

EVAC ROUTE ANNOUNCEMENT

INCOMING MILTARY ROUTES

EVACUATION ROUTE TABLE

COORDINATE CODE TABLE

POLYGON CODE TABLE

SET IBS ONPOST HEADER

(Operational mode oniy) 
Status Board

IBS MAIN MENU

STATUS BOARD

ONPOST EVENT STATUS

VIEW ONPOST WORK PLAN

CHANGE ONPOST WORK PLAN*

IMPLEMENTING PROCEDURES

CREATE NEW IP

CHECK-OUT IP

CHECK-IN IP

ARCHIVE IP OPTIONS

VIEW BATCH LOG

SHOW USER ENVIRONMENT 


\section{Personnel Management}

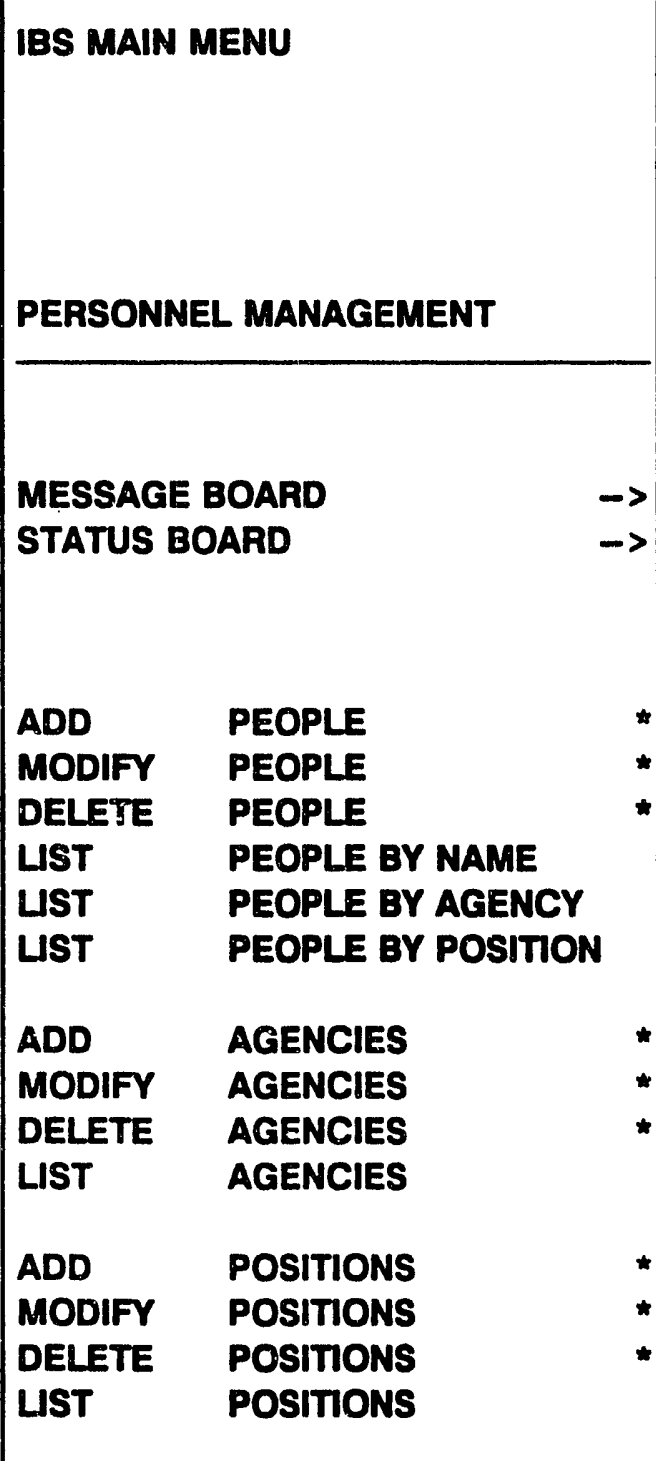




\section{Map Analysis}

IBS MAIN MENU

MAP ANALYSIS

CONTINUE

MESSAGE BOARD

STATUS BOARD

PERSONNEL MANAGEMENT

DISPLAY ICONS

DISPLAY TEXT

DISPLAY LOCATION

DETERMINE AREA

ESTIMATE POPULATION

IDENTIFY MAP ITEM

SUMMARIZE POINT DATA

HIGHLIGHT DATA

UNHIGHLIGH" DATA

SELECT MAF :AYEAS

SET BASEMAP

RESTORE BASEMAP

MAP ZOOM

ZOOM IN

ZOOM OUT

REFRESH SCREEN 
Select Map Layers

\begin{tabular}{l} 
IBS MAIN MENU \\
MAP ANALYSIS \\
SELECT MAP LAYERS \\
\hline \\
FORWARD \\
BACKWARD \\
ADMINISTRATIVE BOUNDARY \\
AGRICULTURE \\
BASE MAP \\
CONGRESSIONAL DISTRICTS \\
MAP LAYER 5 \\
MAP LAYER 6 \\
. \\
. \\
MAP LAYER $n$
\end{tabular}


Resource Management

(Facilities)

\begin{tabular}{|c|c|c|}
\hline \multicolumn{3}{|c|}{$\begin{array}{l}\text { IBS MAIN MENU } \\
\text { RESOURCE MANAGEMENT }\end{array}$} \\
\hline \multicolumn{2}{|c|}{$\begin{array}{l}\text { CONTINUE } \\
\text { MESSAGE BOARD } \\
\text { STATUS BOARD } \\
\text { PERSONNEL MANAGEMENT } \\
\text { MAP ANALYSIS }\end{array}$} & $\begin{array}{l}\rightarrow \\
\overrightarrow{ } \\
\rightarrow\end{array}$ \\
\hline $\begin{array}{l}\text { ADD } \\
\text { MODIFY } \\
\text { DELETE } \\
\text { LIST } \\
\text { DESCRIBE } \\
\text { HIGHLGHT } \\
\text { SUMMARIZE }\end{array}$ & $\begin{array}{l}\text { FACIIITIES } \\
\text { FACIIITIES } \\
\text { FACIIITIES } \\
\text { FACIITIES } \\
\text { FACIIITIES } \\
\text { FACIIITIES } \\
\text { FACILITIES }\end{array}$ & \\
\hline $\begin{array}{l}\text { SWITCH TO } \\
\text { ZOOM IN } \\
\text { ZOOM OUT } \\
\text { REFRESH SC }\end{array}$ & $\begin{array}{l}\text { RESOURCES } \\
\text { REEN }\end{array}$ & $\rightarrow$ \\
\hline
\end{tabular}


Resource Management

(Resources)

\begin{tabular}{|c|c|c|}
\hline \multicolumn{3}{|c|}{$\begin{array}{l}\text { IBS MAIN MENU } \\
\text { RESOURCE MANAGEMENT }\end{array}$} \\
\hline \multicolumn{2}{|c|}{$\begin{array}{l}\text { CONTINUE } \\
\text { MESSAGE BOARD } \\
\text { STATUS BOARD } \\
\text { PERSONNEL MANAGEMENT } \\
\text { MAP ANALYSIS }\end{array}$} & $\begin{array}{l}-> \\
-> \\
-> \\
->\end{array}$ \\
\hline $\begin{array}{l}\text { DEFINE } \\
\text { ASSIGN } \\
\text { MODIFY } \\
\text { MOVE } \\
\text { DELETE } \\
\text { UST } \\
\text { DESCRIBE } \\
\text { SUMMARIZE } \\
\text { ENABLE } \\
\text { DISABLE } \\
\text { VALIDATE }\end{array}$ & $\begin{array}{l}\text { RESOURCES } \\
\text { RESOURCES } \\
\text { RESOURCES } \\
\text { RESOURCES } \\
\text { RESOURCES } \\
\text { RESOURCES } \\
\text { RESOURCES } \\
\text { RESOURCES } \\
\text { RESOURCES } \\
\text { RESOURCES } \\
\text { RESOURCES }\end{array}$ & \\
\hline \multicolumn{2}{|c|}{$\begin{array}{l}\text { SWITCH TO FACILITIES } \\
\text { ZOOM IN } \\
\text { ZOOM OUT } \\
\text { REFRESH SCREEN }\end{array}$} & $\rightarrow$ \\
\hline
\end{tabular}




\section{Analyze Track}

\begin{tabular}{|l|}
\hline IBS MAIN MENU \\
ANALYZE TRACK \\
\hline CONTINUE \\
DOSE DETAILS \\
DESCRIBE TRACK \\
PRINT D2 REPORT \\
SHOW ELEVATION \\
DETERMINE AREA \\
DISPLAY LOCATION \\
ESTIMATE POPULATION \\
SET BASEMAP \\
MAP ZOOM \\
ZOOM IN \\
ZOOM OUT \\
REFRESH SCREEN \\
\hline
\end{tabular}




\section{Emergency Activities}

\begin{tabular}{l} 
IBS MAIN MENU \\
\\
EMERGENCY ACTIVITIES \\
\hline \\
\\
MESSAGE BOARD \\
STATUS BOARD \\
PERSONNEL MANAGEMENT \\
MAP ANALYSIS \\
RESOURCE MANAGEMENT \\
HAZARD ANALYSIS \\
EOC ACTIVATION \\
DIRECTION/CONTROL \\
EVACUATION \\
SHELTERING \\
SEARCH/RESCUE \\
DAMAGE ASSESSMENT
\end{tabular}


Hazard Analysis

\begin{tabular}{|l|}
\hline IBS MAIN MENU \\
i: IERGENCY ACTIVITIES \\
\\
\\
HAZARD ANALYSIS \\
\hline \\
CONTINUE \\
MESSAGE BOARD \\
STATUS BOARD \\
PERSONNEL MANAGEMENT \\
MAP ANALYSIS \\
RESOURCE MANAGEMENT \\
CHANGE TRACK CASE \\
EXECUTE D2 \\
DOSE DETAILS \\
DESCRIBE TRACK \\
PRINT D2 REPORT \\
REPORT CURRENT D2 DESCRIPTION \\
SHOW ELEVATION \\
DETERMINE AREA \\
DISPLAY LOCATION \\
ESTIMATE POPULATION \\
ZOOM IN \\
ZOOM OUT \\
RELEASE OVERLAYS \\
\end{tabular}


EOC Activation

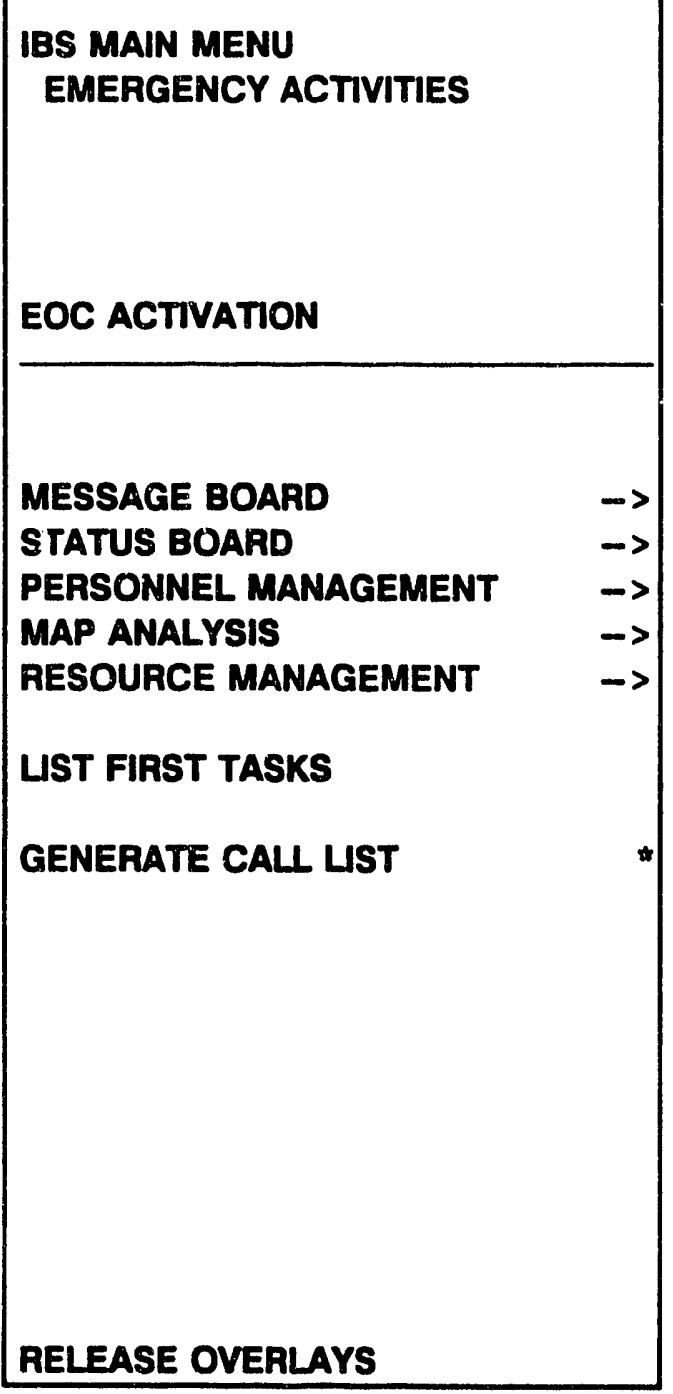


Direction/Control

IBS MAIN MENU

EMERGENCY ACTIVITIES

DIRECTION/CONTROL

CONTINUE

MESSAGE BOARD

STATUS BOARD

PERSONNEL MANAGEMENT

MAP AMALYSIS

RESOURCE MANAGEMENT

SPECIFY LOCATION

MODIFY FACILTIES

ADD SPECLAL POPULATION

MODIFY SPECLAL POPULATION

ESTIMATE POPULATION

RISK AREA POPULATION SUMMARY

RISK AREA ANALYSIS

SELECT IP

RELEASE OVERLAYS 
Risk Area Analysis

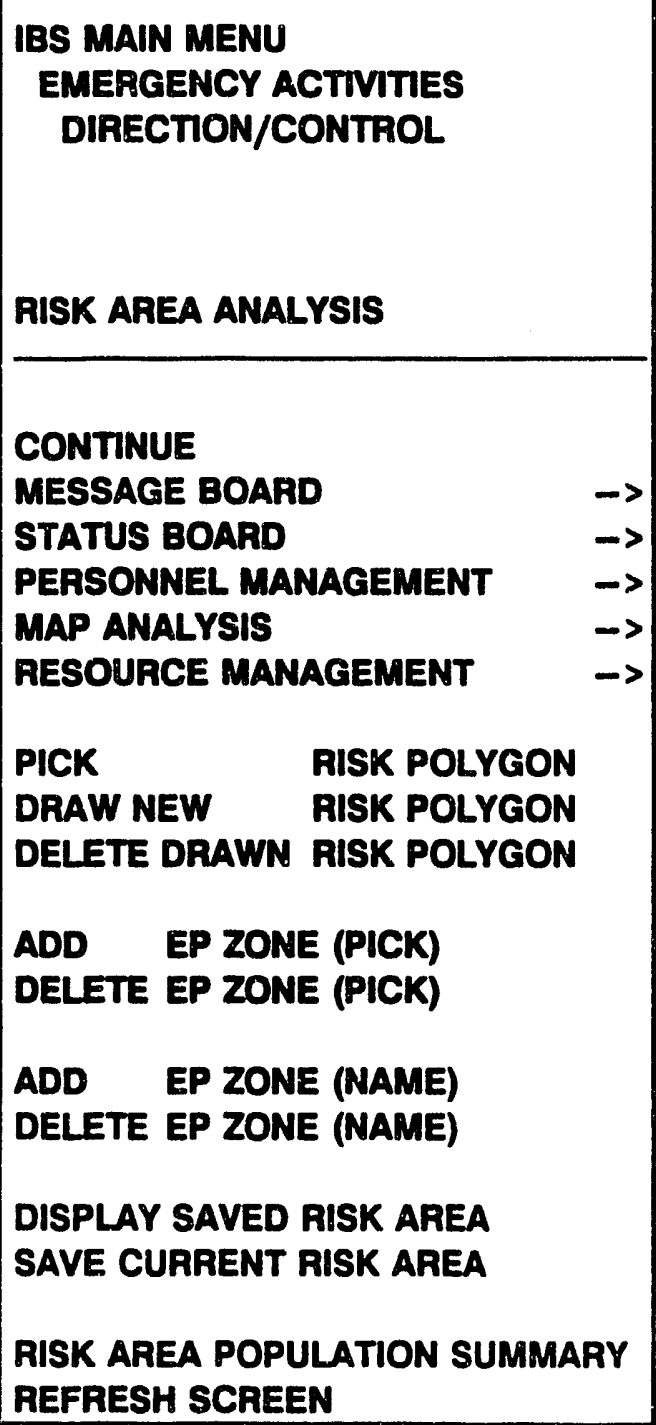

IBS MAIN MENU

EMERGENCY ACTIVITIES

DIRECTION/CONTROL

CONTINUE

MESSAGE BOARD

STATUS BOARD

MAP ANALYSIS

$\rightarrow$

PICK

RISK POLYGON

DRAW NEW RISK POLYGON

DELETE DRAWN RISK POLYGON

ADD EP ZONE (PICK)

DELETE EP ZONE (PICK)

ADD EP ZONE (NAME)

DELETE EP ZONE (NAME)

DISPLAY SAVED RISK AREA

SAVE CURRENT RISK AREA

RISK AREA POPULATION SUMMARY

REFRESH SCREEN 
Evacuation

IBS MAIN MENU

EMERGENCY ACTIVITIE:

EVACUATION

CONTINUE

MESSAGE BOARD

STATUS BOARD

PERSONNEL MANAGEMENT

MAP ANALYSIS

RESOURCE MANAGEMENT

SELECT MODEL CASE

RUN

SET TIME STEP

RESTART

STEP FORWARD

STEP BACKWARD

DESCAIBE EVACUATION POINT

ZOOM IN

ZOOM OUT

CREATE EVAC ROUTE OVERLAY

DELETE EVAC ROUTE OVERLAY

EXECUTE EVAC MODEL

SELECTIVE STATUS

RELEASE OVERLAYS 
Sheltering

IBS MAIN MENU

SHELTERING

CONTINUE

MESSAGE BOARD

STATUS BOARD

$\rightarrow$

PERSONNEL MANAGEMENT

MAP ANALYSIS

RESOURCE MANAGEMENT

ADD LOCATION

ADD FACIUTIES

MODIFY FACIUTIES

$\rightarrow$

$\rightarrow$

$\rightarrow$

SHELTER OR CENTER INFO

SHELTER \& CENTER SUMMARY

Release OVERLAYS 
Search/Rescue

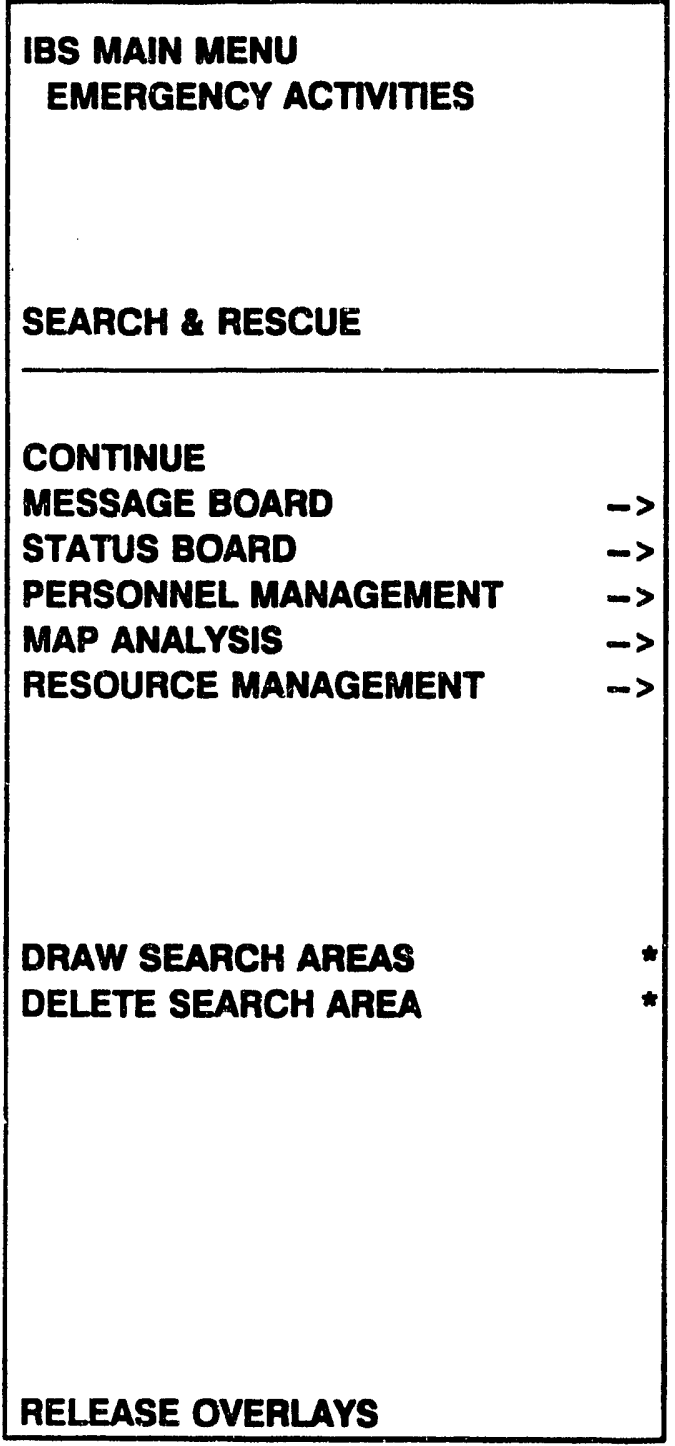


Damage Assessment

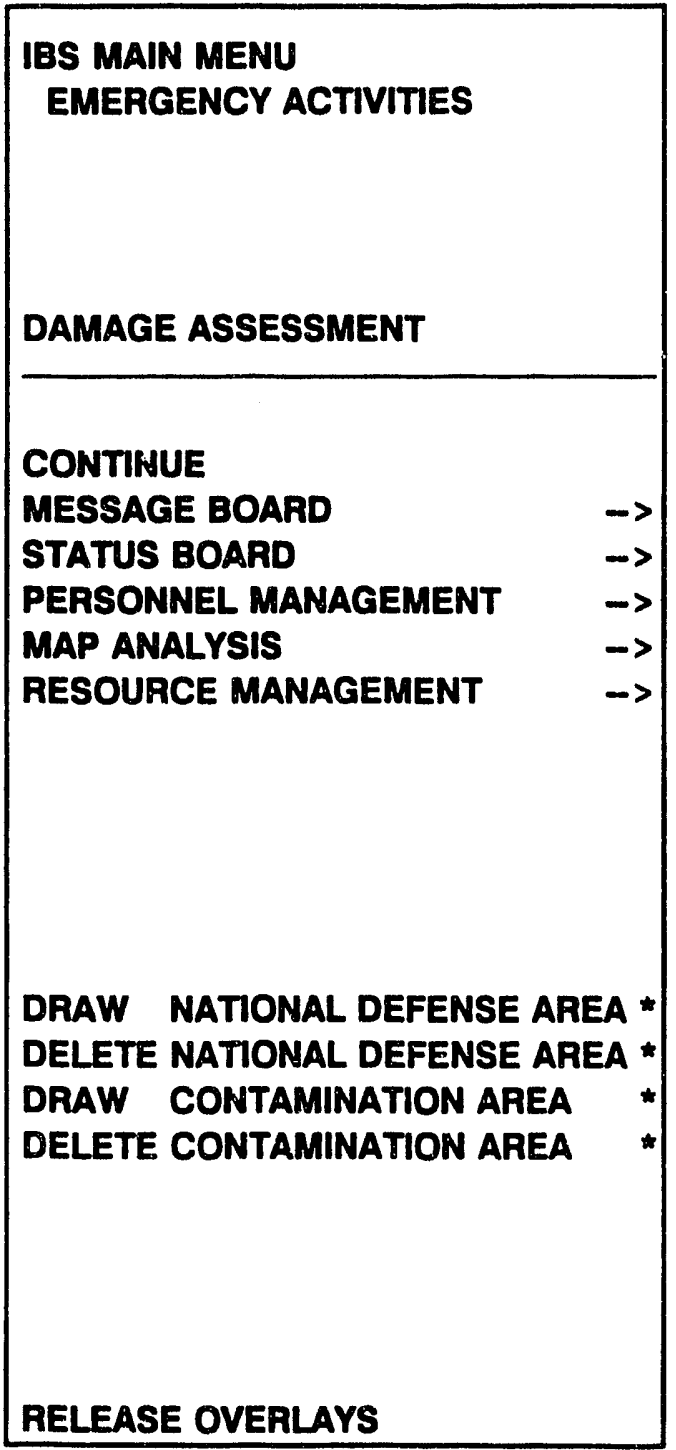


Setup

IBS MAIN MENU

SETUP

CHANGE SITE

CHANGE DEFAULT MAP LAYER

MAP LAYERS BY ACTIVITY

JOB ENVIRONMENT

COMMON LEGEND

ARCHIVE SITE 
Change Default Map Layers

\section{IBS MAIN MENU}

SETUP

CHANGE DEFAULT MAP LAYERS

FORWARD

BACKWARD

BASE MAP

RISK AREA POLYGONS

SEARCH/RESCUE POLYGONS

DAMAGE ASSESSMENT POLYS

MAP LAYER 5

MAP LAYER 6

$\cdot$

MAP LAYER $n$ 
Map Layers by Activity

IBS MAIN MENU

iETUP

MAP LAYERS BY ACTIVITY

HAZARD ANALYSIS

EOC ACTIVATION

DIRECTION/CONTROL

EVACUATION

SHELTERING

SEARCH/RESCUE

DAMAGE ASSESSMENT 
Job Environment

\begin{tabular}{l}
\hline IBS MAIN MENU \\
SETUP \\
JOB ENVIRONMENT \\
\\
HARDWARE PARAMETERS \\
MODEL MANAGEMENT \\
MAINTAIN SITE DIRECTORIES \\
REVIEW CONTROL FILES \\
UPDATE SITE MASTER FILE \\
COPY CASE OR SITE FILE \\
MISCELLANEOUS SETTINGS \\
INFOMANAGER ROOT MAINTENANCE
\end{tabular}


Map Layers by Activity/(emergency activity)

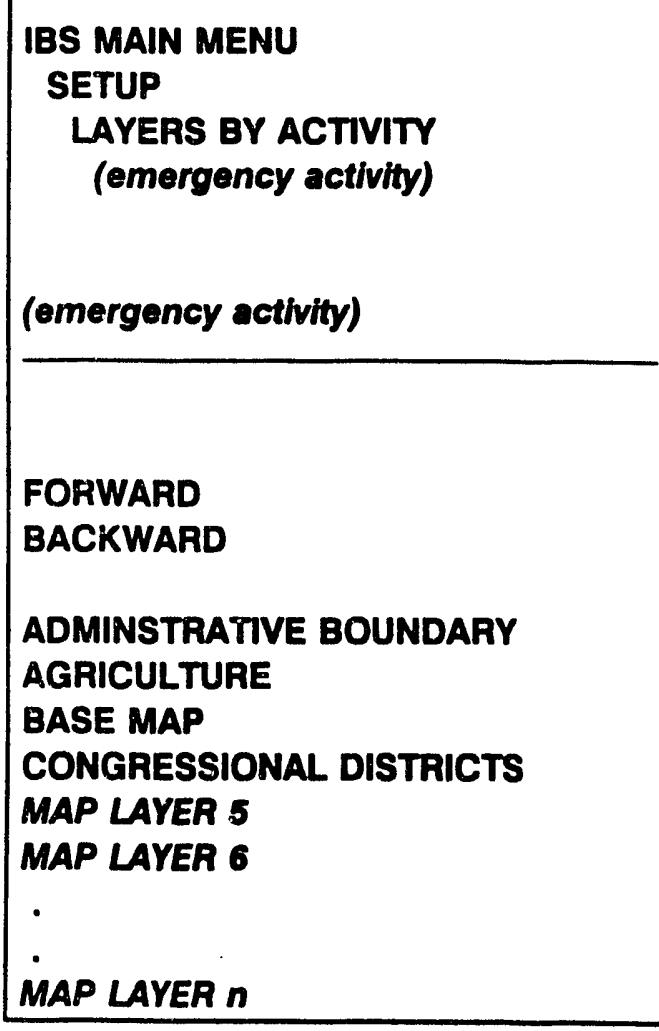




\section{Model Management *}

\begin{tabular}{|l|}
\hline IBS MAIN MENU \\
SETUP \\
JOB ENVIRONMENT \\
MODEL MANAGEMENT \\
\hline DISPERSION (D2) \\
EVACUATION (DYNEV
\end{tabular}




\section{Appendix B Non-Graphic IBS}

Although the IBS is designed to be used with a terminal for displaying map graphics, you can also use the non-graphic capabilities of the IBS from a nongraphic terminal by using a separate utility program called IBS_NOGR.

\section{To Start NON-GRAPHIC IBS (IBS_NOGR)}

Enter IBS_NOGR at the system prompt and press the Return key.

The system presents the following menu of IBS capabilities:

Non-Graphic IBS Main Menu
1: ExIT
2: Sesagge Board
3: Personnel Management
4: Reoource Management
5: Current D2 Description
6: Emergency Activities
7: Setup
Choice (z=Help) $=>$

With minor changes to accommodate making selections with numbers instead of the graphics cursor (cross hairs), these options are implemented as they are described in the body of this document. Both versions of the IBS act on the same database; therefore, any changes made using one version of the IBS are rellated in the other. 


\section{Appendix C People Location}

The people location program (LOCATE) enables personnel at various emergencyrelated facilities to record the names and whereabouts of people who enter or leave the facilities (shelters, reception centers, hospitals, etc.). If you are a Locator (an authorized operator of the LOCATE program), you can search the facility records in the IBS database to find information about specific persons or to determine the currently recorded loading status of facilities. The aggregate data are available in the main IBS program through the SUMMARY and SELECTION options on the emergency Function menus.

The people location program is designed to be used with an alphanumeric (textonly) workstation; it does NOT require a graphics workstation.

\section{To Start the People Location Program (LOCATE)}

Enter LOCATE at the system prompt.

The system presents the following title screen and a list of the facilities in the IBS database:

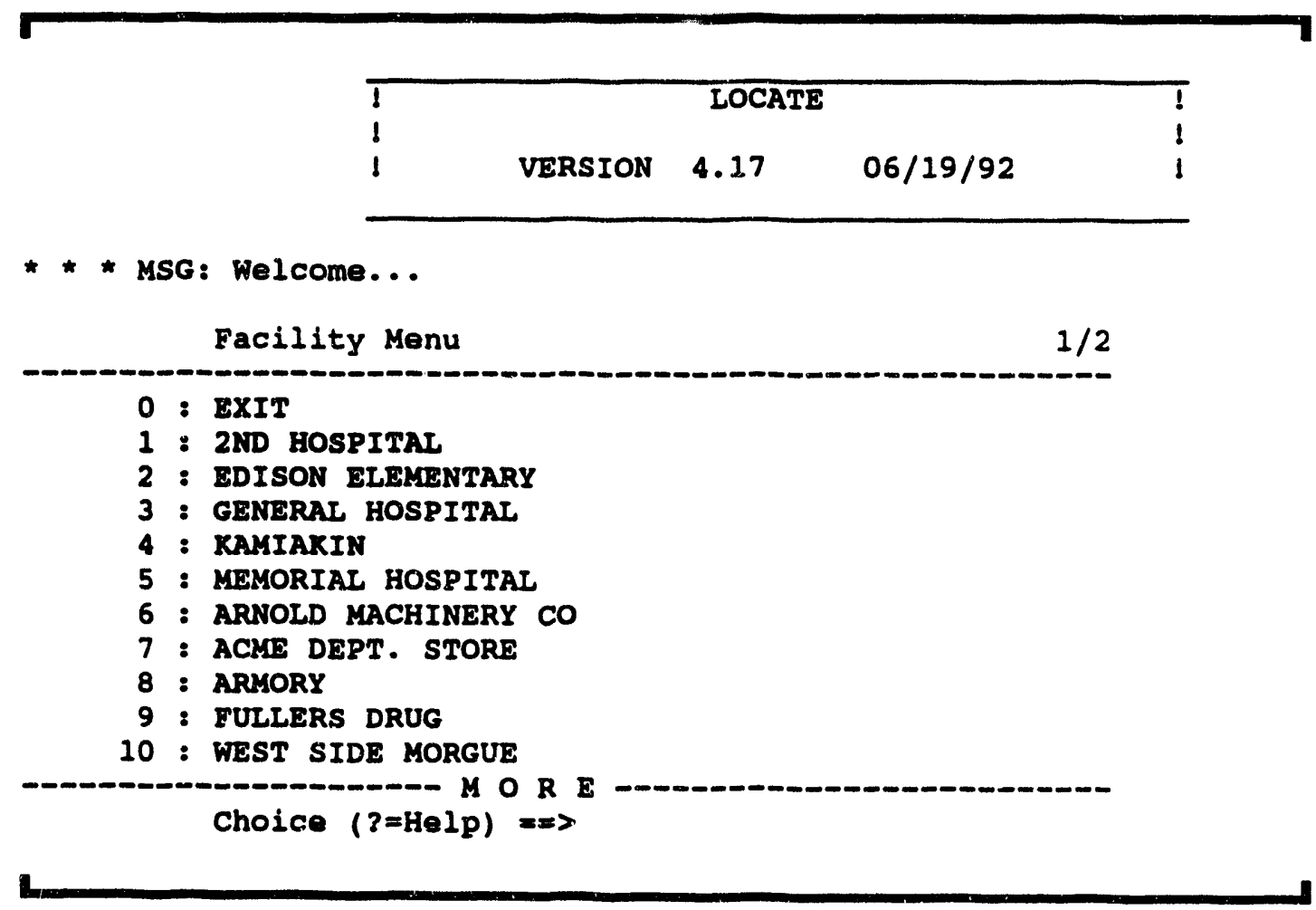


The facilities list is displayed one page at a time.

The facility that you select is the initial facility for which person information is entered or updated.

\section{PEOPLE LOCATION Menu}

After you select a facility for making inquiries, the following general PEOPLE LOCATION menu displays.

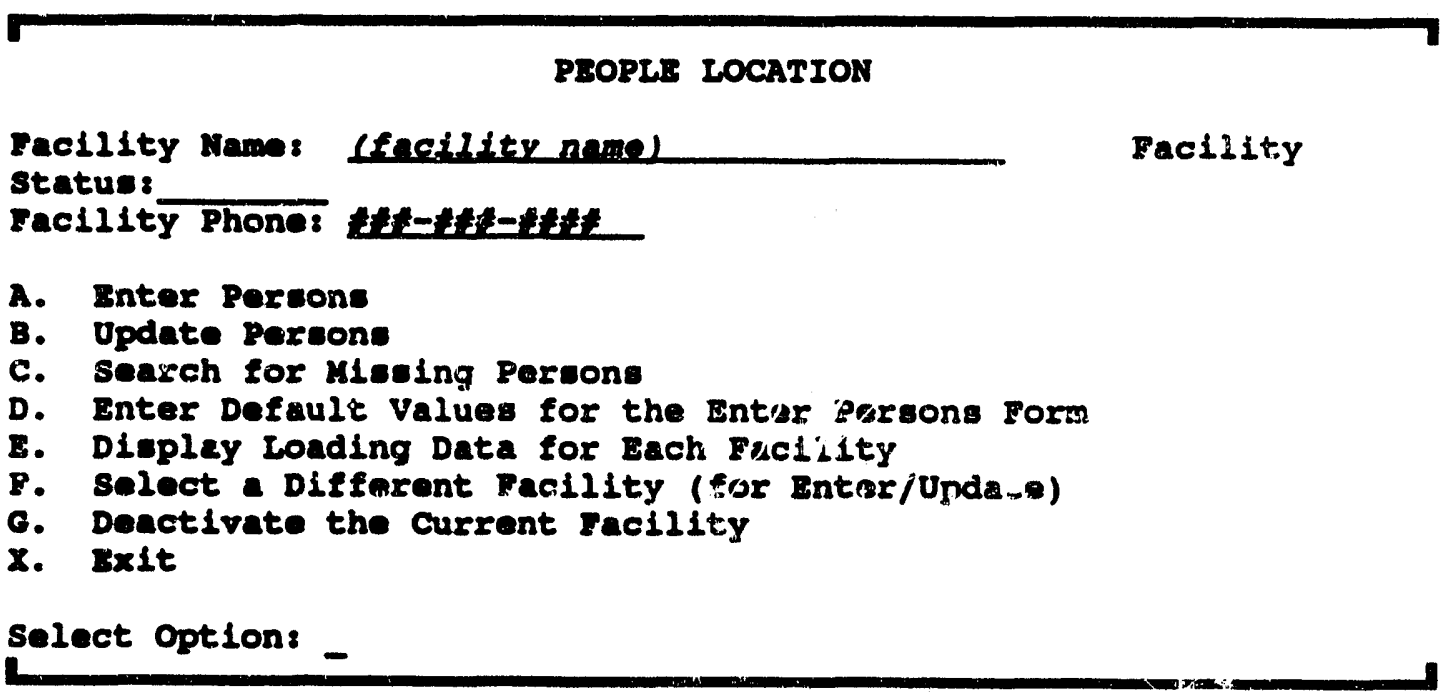

The facility named at the top of the form is the facility entered or updated for each person chosen when you use the Enter Persons or Update Persons options. You can change this default by using Option $F$ above. The options of the menu are explained on the following pages in the order in which they appear on this menu.

The facility status displays for each facility you select. The status can be:

- Active

- Inactive 


\section{Option A. Enter Persons}

This first option enables you to record personal data on the following blank form, which is based on the Red Cross shelter registration form.

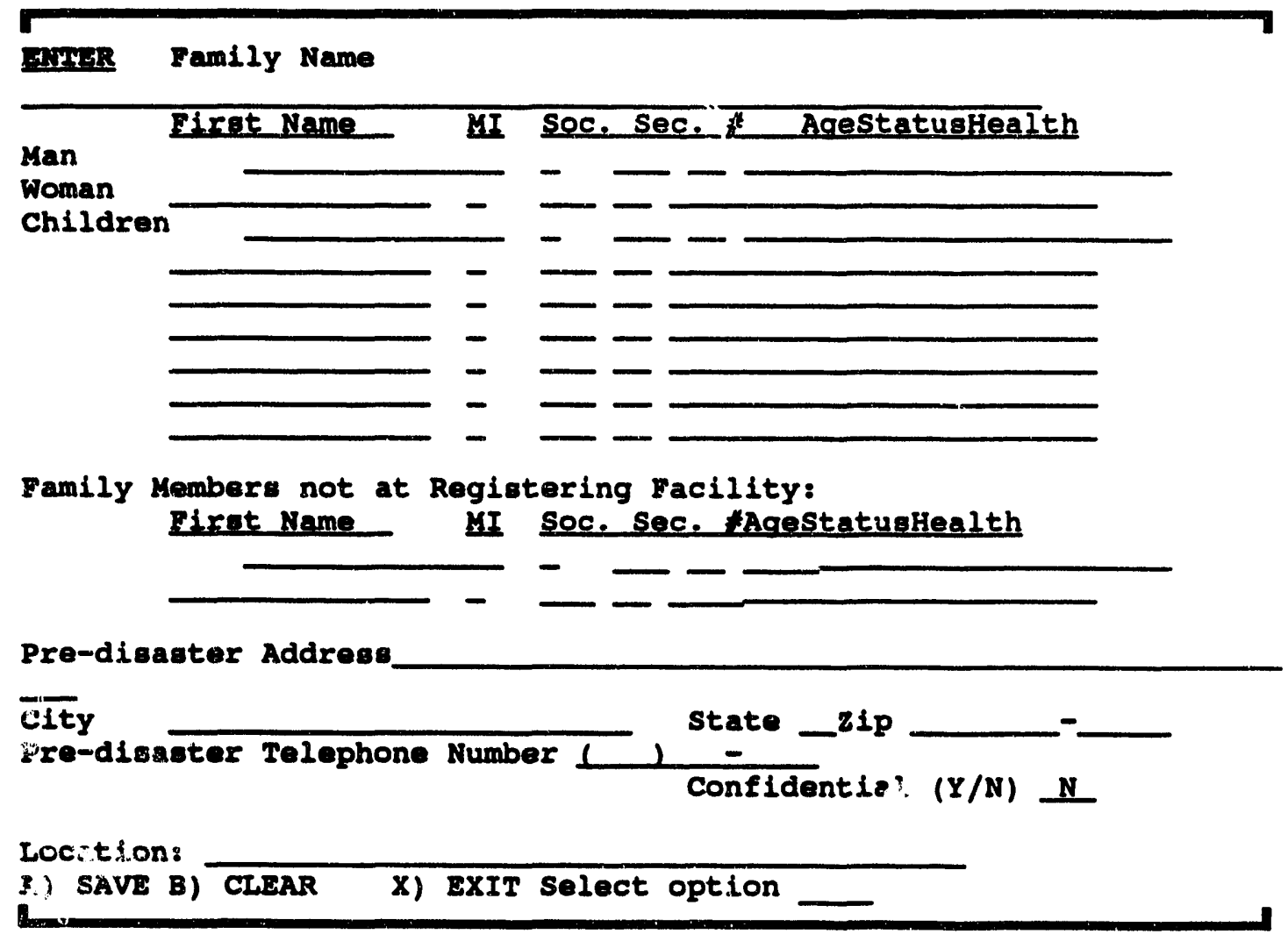

Unknown Names: If the name of a person at the facility is unknown, enter XXXXX as the name. The counts of persons at various facilities include these unnamed persons.

Default Values: If default values are already set for the city, address, and the telephone area code by using option D on the PEOPLE LOCATION menu, they appear on this form. All entries apply to the current facility.

To select one of the form's operative functions, enter the associated letter:

A SAVE - After modifying the data in an existing form or entering data in a blank form, you can select SAVE to add the data to the database. After selecting SAVE, a blank form appears for a new entry.

B CLEAR discards data entered on the current form and provides another blank form. 
$X$ EXIT returns you to the previous PEOPLE LOCATION menu.

\section{Option B. Update Persons}

This option enables you to modify personal data using the same registration form with different operative functions. When you choose Update Persons, you see the following form, which is also blank until you specify which record you wish to update. All updates apply to the current facility.

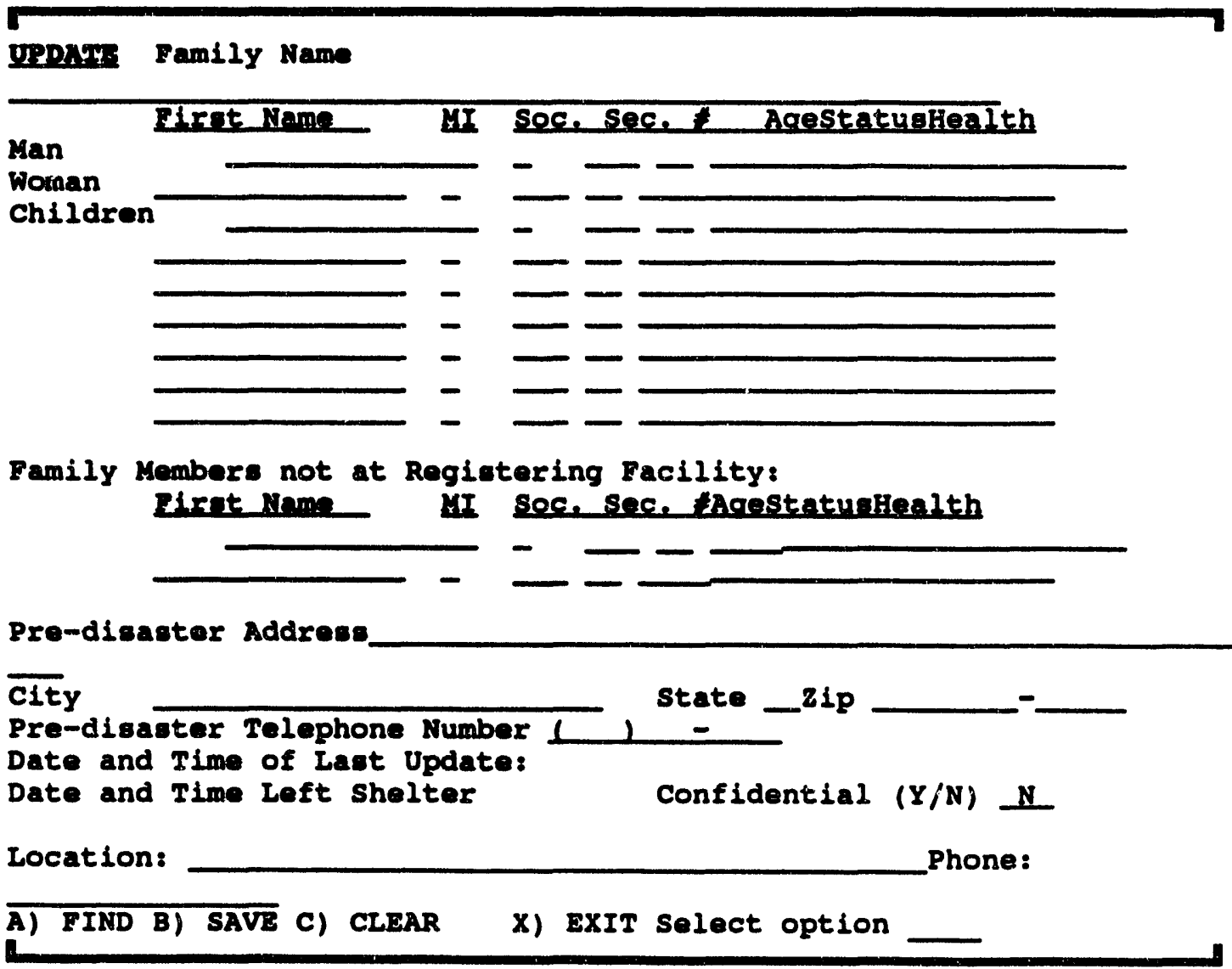

A FIND enables you to enter any known data in the name and address fields. The system then searches the database for matching records. Information from the selected record is then displayed in the form. If you have appropriate privileges, you can modify any field. Press GOLD-Z to see the next matching record, if any.

Searching with Inexact Names or Addresses. Note that partial names such as BRO* are valid search keys that match all names containing the specified string. The asterisk $\left({ }^{*}\right)$ serves as a wild card character that matches any string of characters. 
To enter any changes in the database, you must use the SAVE option.

B SAVE - After modifying the data in an existing form or entering data in a blank form, you can select SAVE to add the data to the database. After selecting SAVE, a blank form appears for a new operation.

C CLEAR discards data entered on the current form and provides another blank form.

X EXIT returns you to the PEOPLE LOCATION menu.

\section{Option C. Search for Missing Persons}

This option enables you to search the people location database to find information about a person. When you choose Search for Missing Persons, you see the following form for identifying the source of the query. This information is required before you can search for the person.

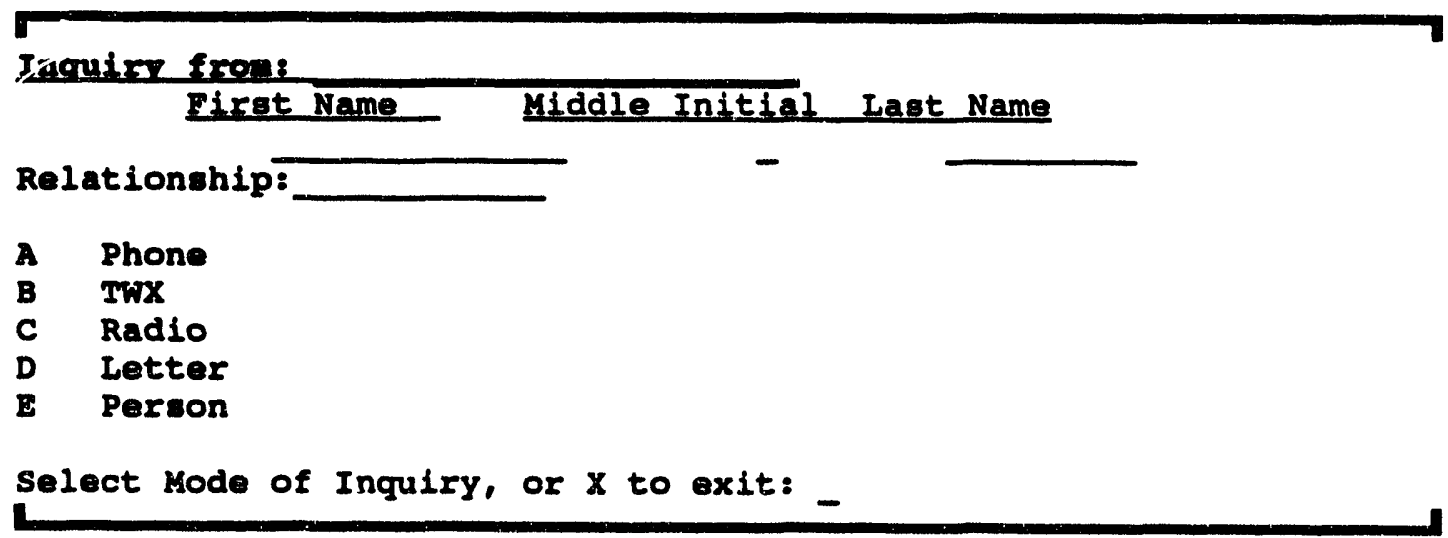

After identifying who made the query and how the query was made, you see another registration-type form similar to the form for Update Persons data. You can enter any or all information on this form (shown on the next page).

The system searches the database for matching records. Information from the selected record is then displayed in a form similar to that used for data entry.

Note: If the record has been marked confidential, no information is displayed. Press GOLD-Z to view the next matching record, if any. 


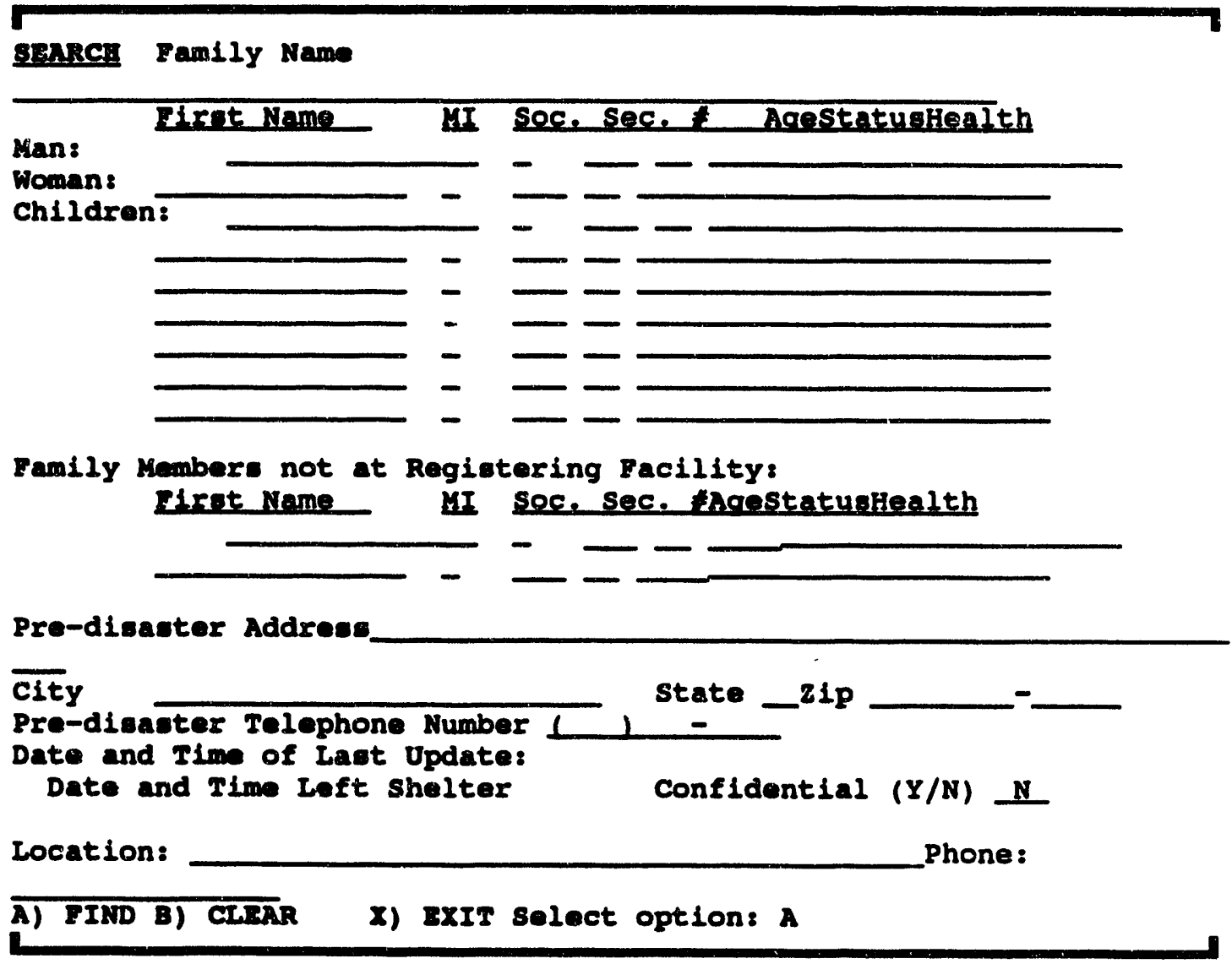

\section{Option D. Enter Default Values for the Enter Persons Form}

This option enables you to enter default values that automatically appear in the Enter Persons form when a blank form appears. Because the city address and telephone area code are likely to remain the same for entries made at any one facility, this feature saves time and makes these entries consistently accurate. (Or consistently inaccurate-check this information carefully when you enter it.)

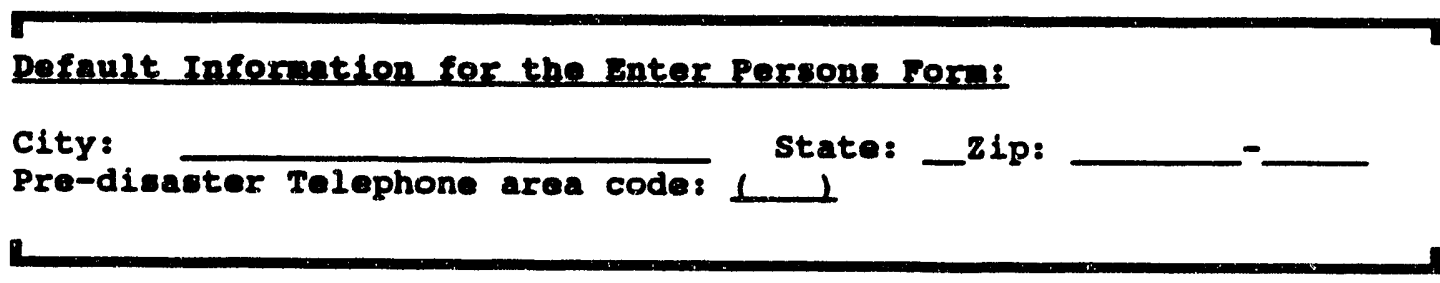

Use GOLD-Z to exit the form without filling in information. 


\section{Option E. Display Loading Data for Each Facility}

This option presents a scrolled tabular report of the capacities, status, and currently recorded loadings of emergency-related facilities in the IBS database. The report is similar to the following example:

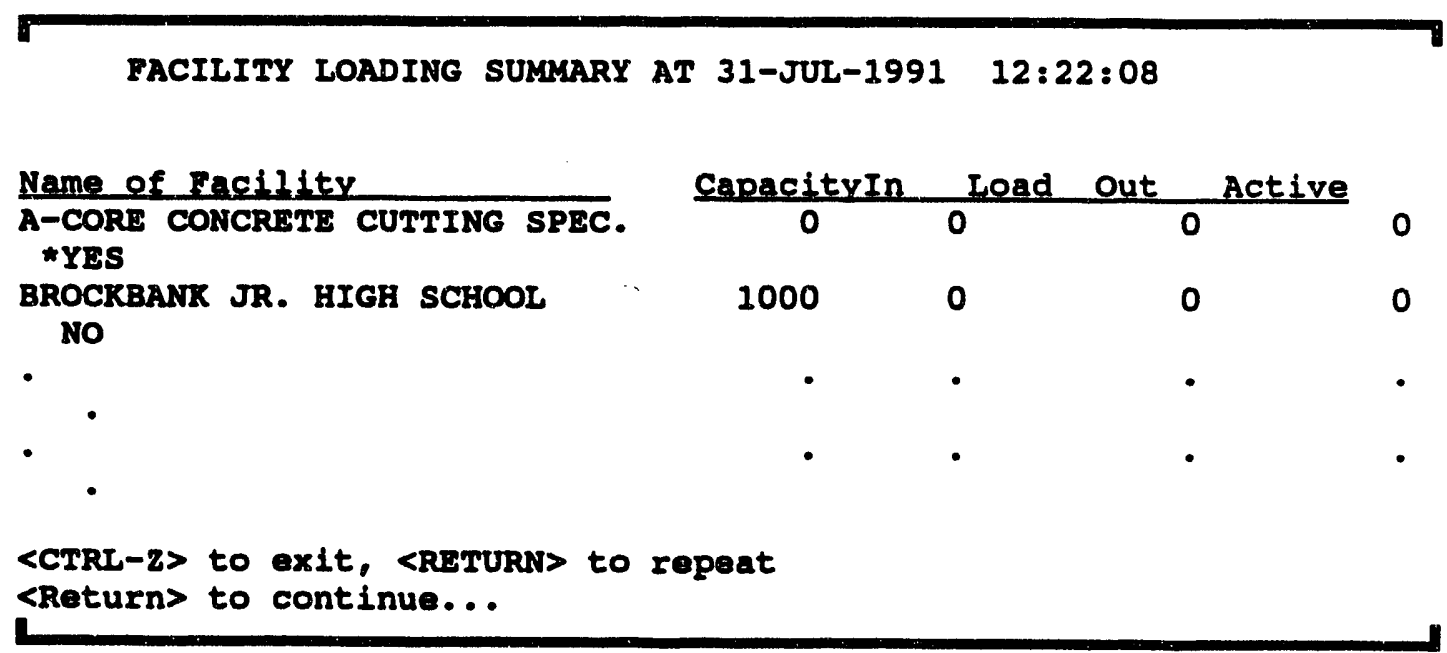

\section{Option F. Select a Different Facility (for Enter/Update)}

This option enables you to switch to a different default facility for entering or updating person records. You choose from the same scrolled list of facilities that displays when you first start the LOCATE program.

\section{Option G. Deactivate the Current Facility}

This option enables you to deactivate a facility.

The program displays the following prompt:

* * MSG: Facility has been deactivated: (facility name) Press <Return> to continue ...

The same scrolled list of facilities that occurs when you first start the LOCATE program is displayed. After you choose another facility, the program displays the message

* * MSG: Activating Facility: (facility name)

and returns to the initial PEOPLE LOCATION menu. 


\section{Option X. Exit, with Optional Facility Deactivation}

This option enables you to exit the LOCATE program.

The program displays the following information and prompt:

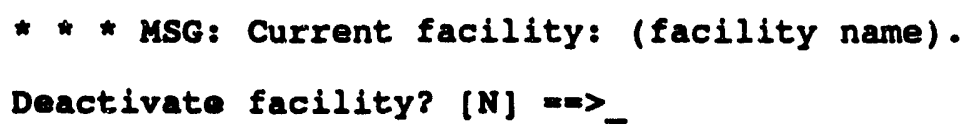

When you answer $Y$ (yes), the program displays the message

* *SG: Facility was deactivated: (facility name)

* * MSG: Good bye

and exits to the system prompt.

When you answer $\mathrm{N}$ (no) the program displays the following message:

* * MSG: Good Bye

and exits to the system prompt. 


\section{Appendix D Onpost Simulator}

The Onpost Simulator program allows privileged IBS users to send messages that are usually sent by the Army's onpost computer system in communication with the IBS $^{(\omega)}$. The Onpost Simulator enables testing and exercising of IBS, independent of onpost participation. Also, if the IBS/onpost interface were inoperable, an IBS user could trigger a simulated onpost notification or other onpost-type ireports.

The use of the Onpost Simulator program is restricted to authorized users, such as an IBS Information Manager.

\section{To Start the Onpost Simulator}

Enter ONPOSTSIM at the system prompt.

The Onpost Simulator copies onpost-type files to the appropriate IBS directory just as the onpost system does. You have the opportunity to modify the files before copying them. After you start the Onpost Simulator, the main menu displays as shown.

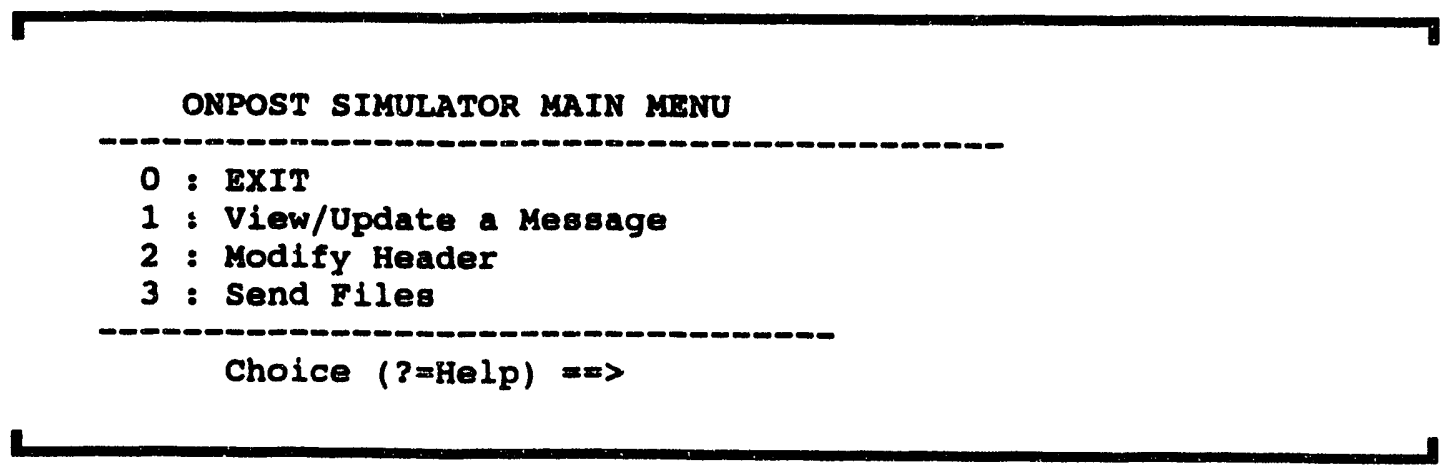

(a) This program was created specifically for the IBS system at Tooele, Utah where the WATCHI sy,tem (Warning Against Toxic Chemical Hazards) is the onpost system. 
Option 1. Use this option to view or update files. The system displays the following menu.

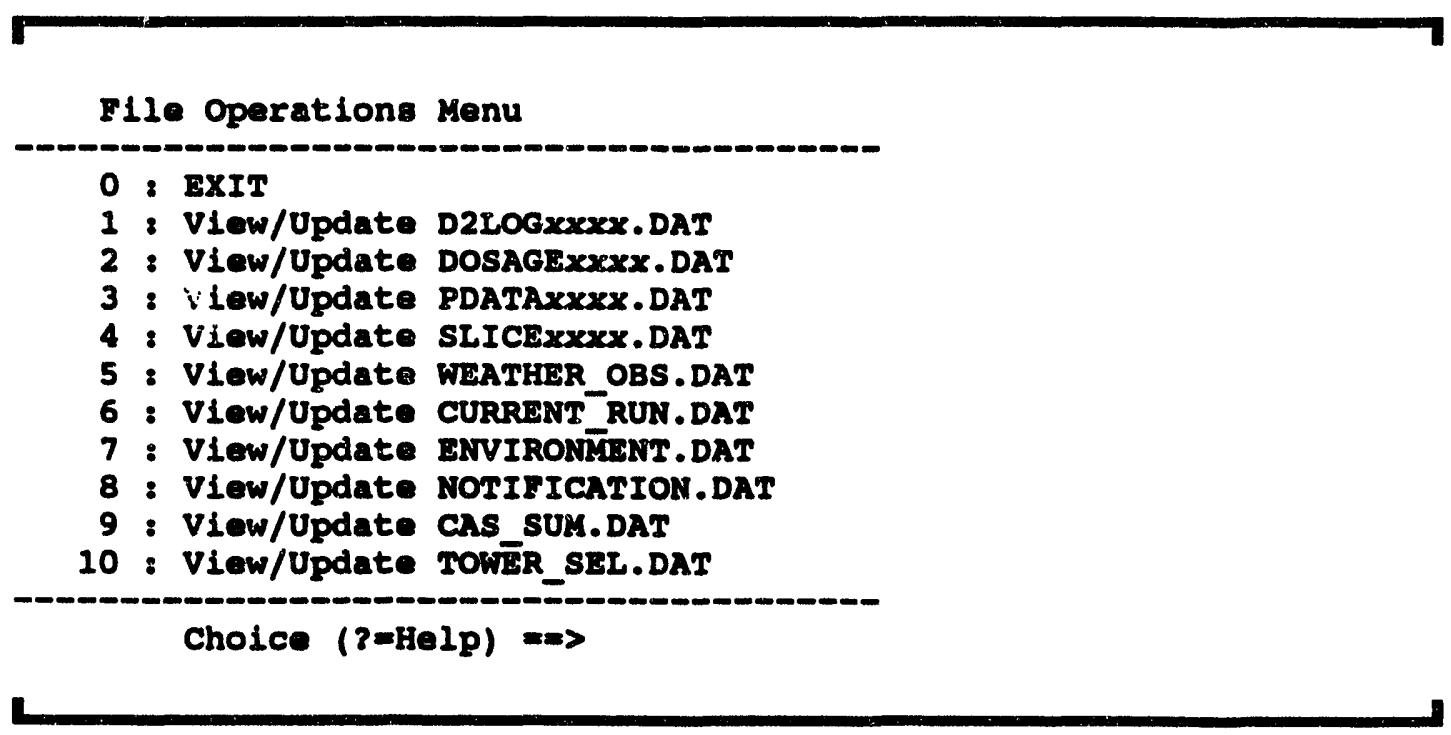

Select the file you want to view or update. These files are described in Section 2 under the heading VIEW ONPOST->IBS REPORTS and in Appendix $E$.

Option 2. The system displays the following messages:

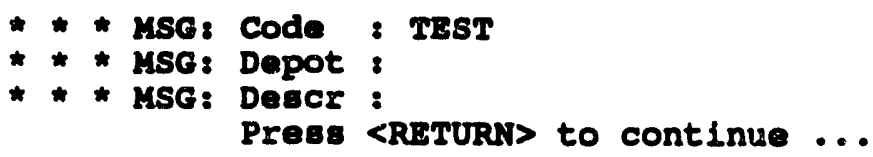

After viewing the messages, press the RETURN key to display the following menu.

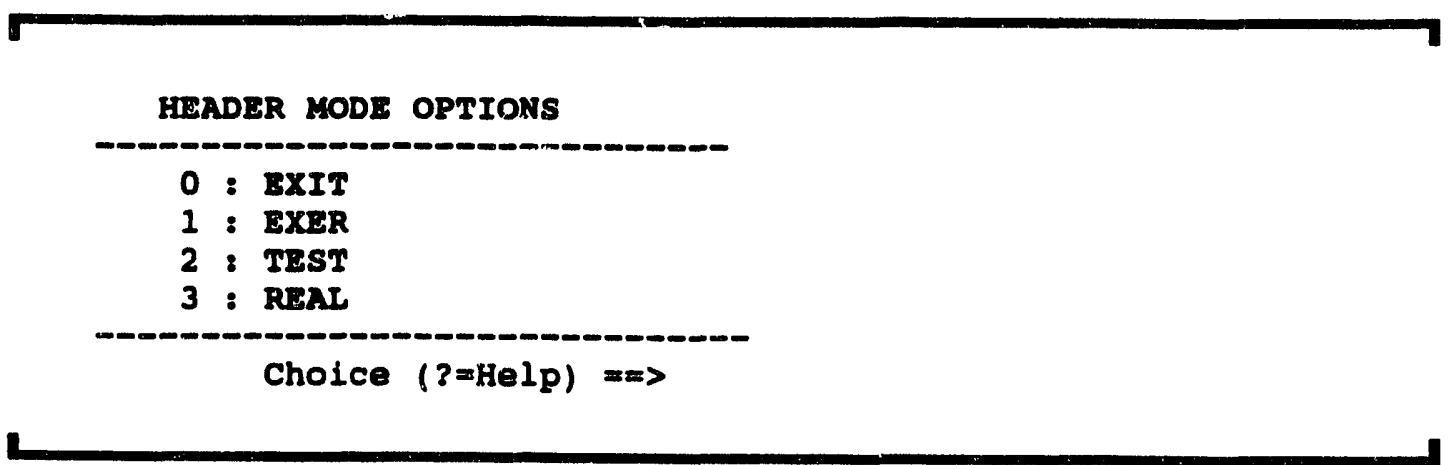


Select the number of the header mode you want to use. After you select the header mode, the system displays the following menu.

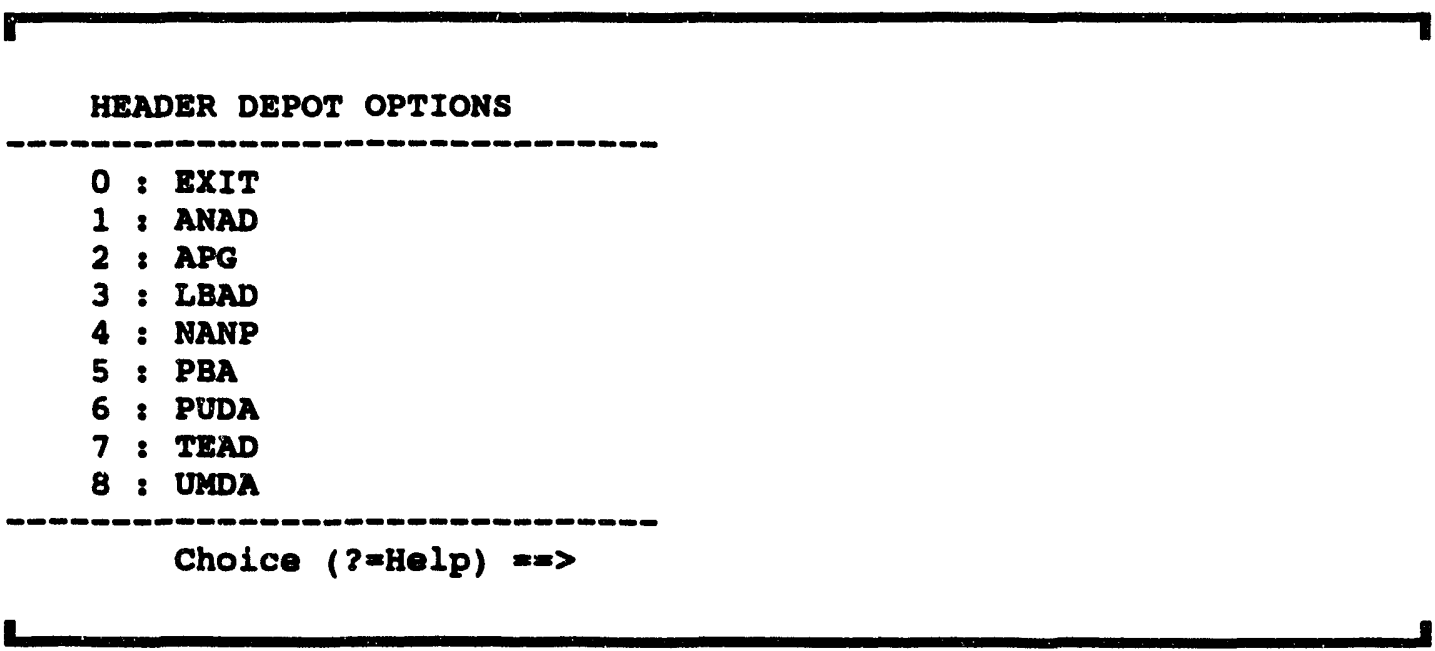

Your responses to these menus are used by the system in constructing the header record. The header record is the first record of each file sent by the Onpost Simulator.

Option 3. The system displays the following menu.

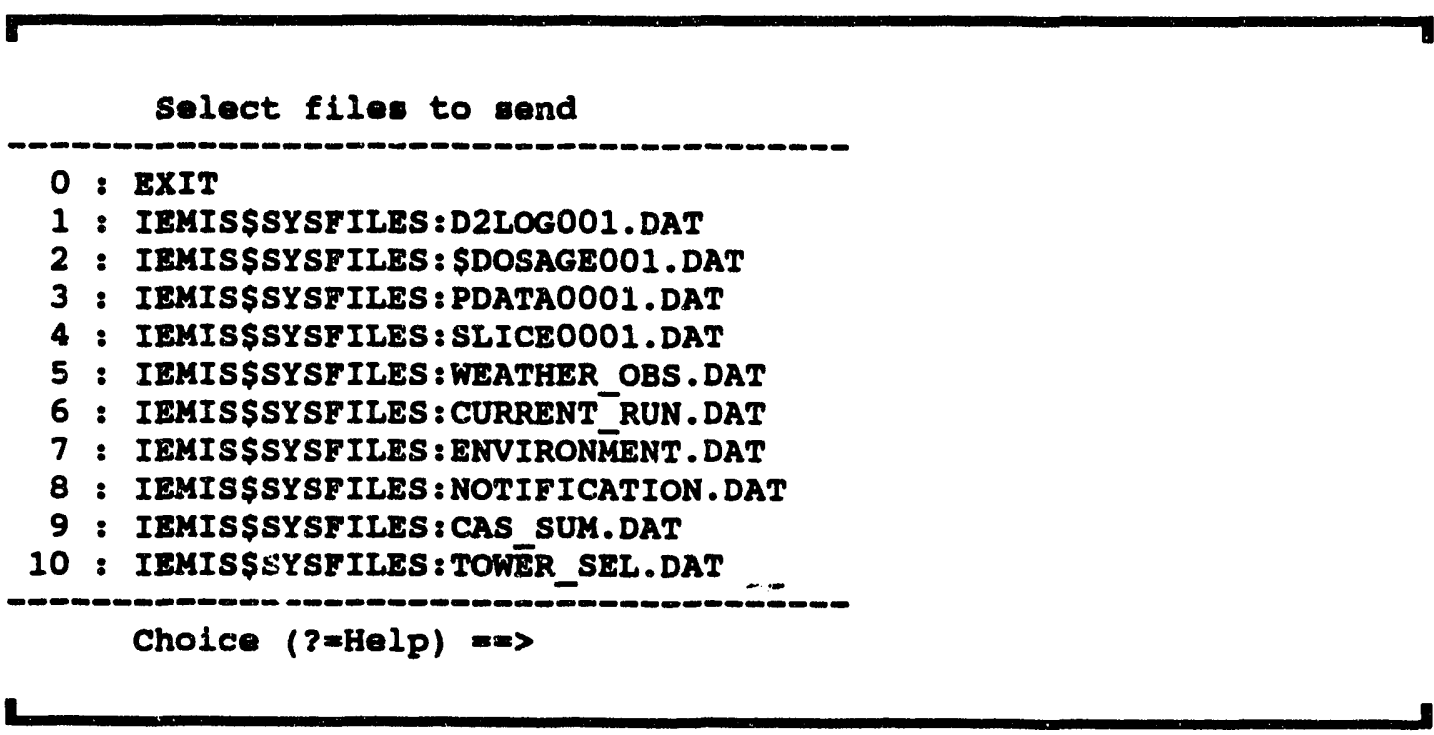

Select the number of the file you want to send. Selected files (those previously selected or reviewed/updated) will be marked with an asterisk (*). You can select as many files as you want. After you have selected the file or files, select the 0:EXIT option. 
After you exit, the system will display the report (XFERLIST.DAT) for the files to be transferred.

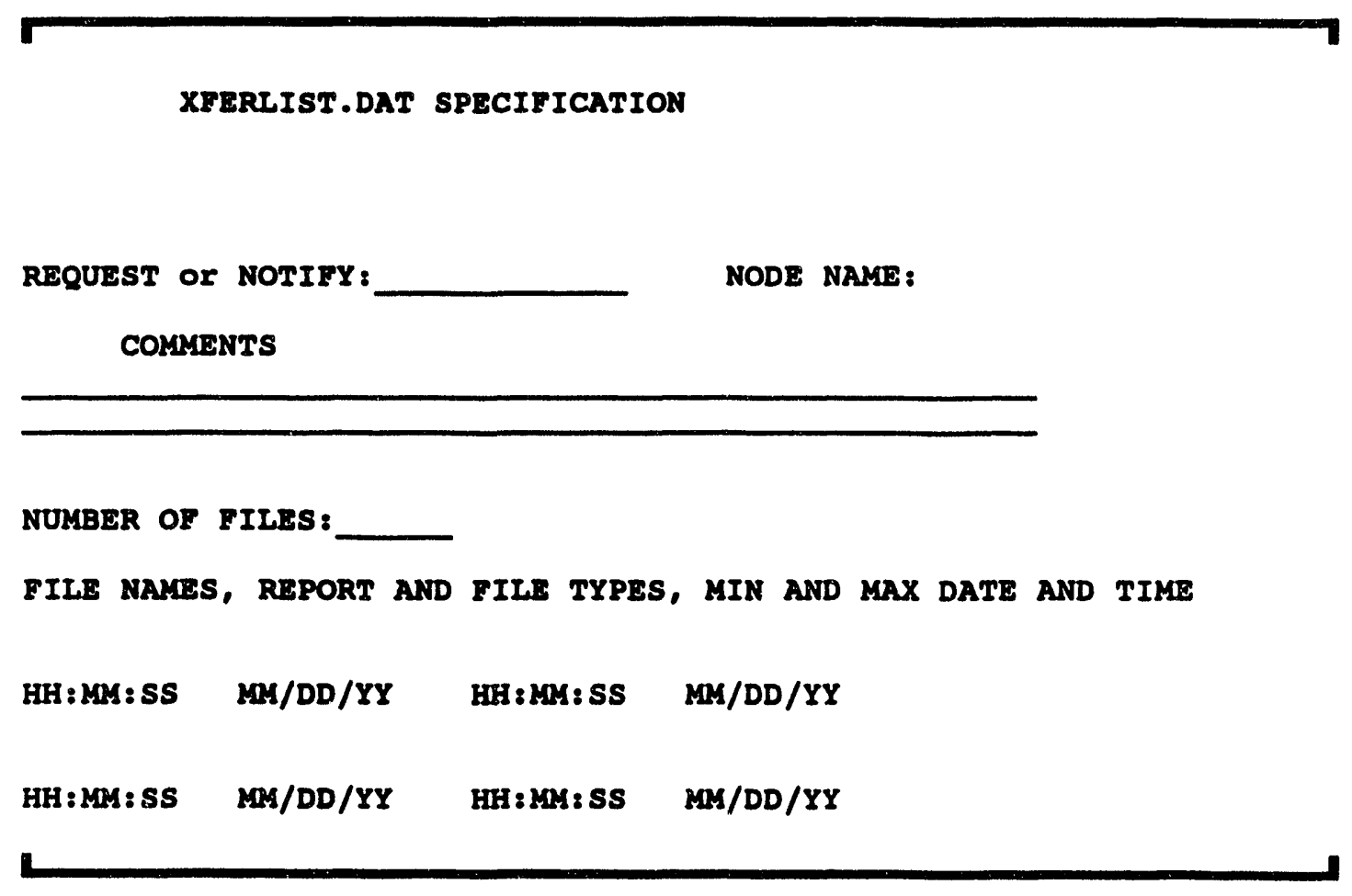

Use the techniques described in Section 1, under the heading Conventions for Interacting with the IBS, to move around in this report.

Exit the report and send the listed files by pressing GOLD-Z. To exit the report without sending the files, press GOLD-Y. The Onpost Simulator Main Menu will display. 


\section{Appendix $\mathrm{E}$ IBS and Onpost EOC Reports}

This appendix shows the formats of the reports exchanged between the IBS and the onpost emergency operations center EOC. These reports are accessible through options on the MESSAGE BOARD menu:

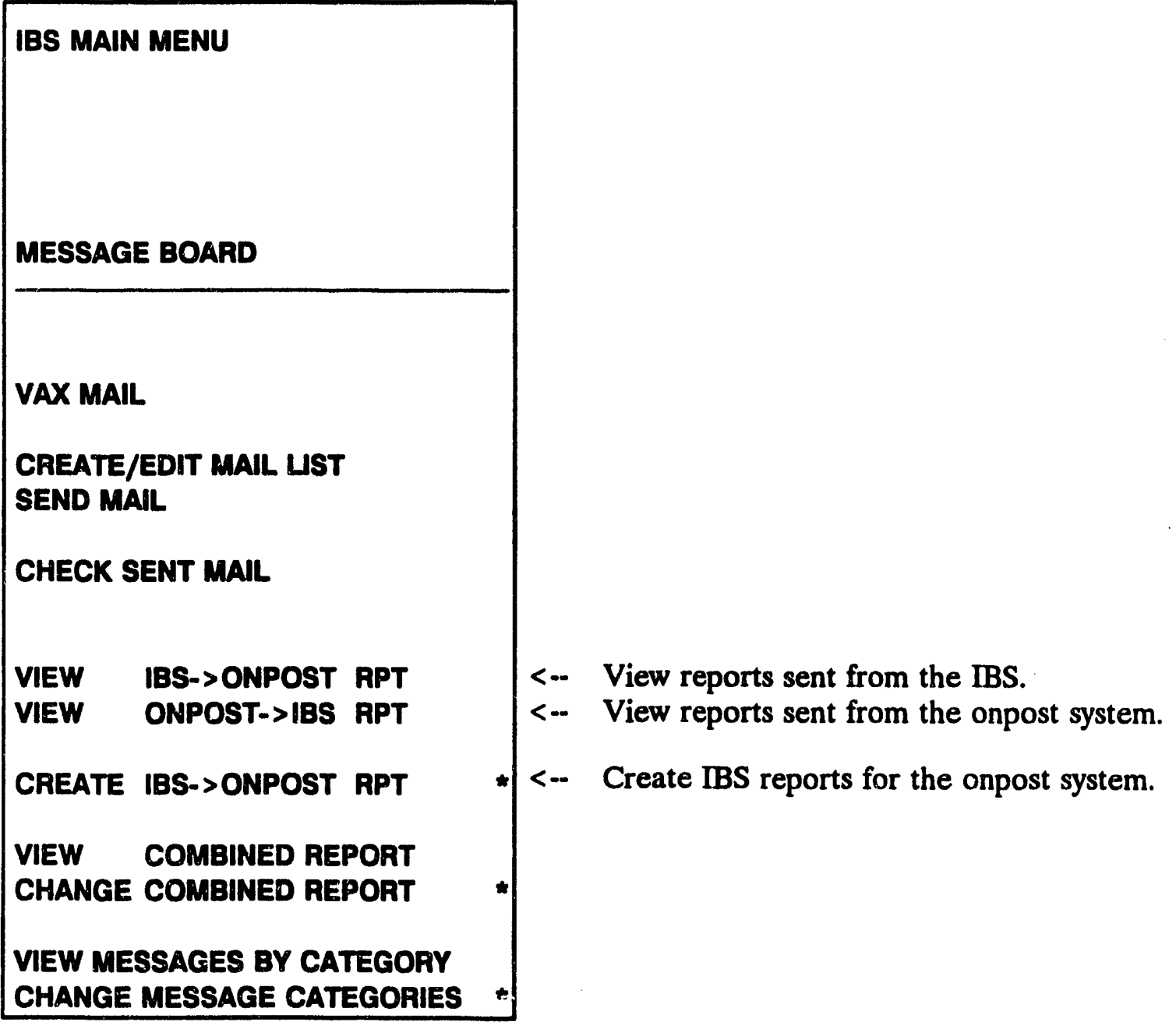




\section{Reports from the IBS}

\author{
IBS MAIN MENU \\ MESSAGE OARD
}

CAEATE IBS->ONPOST

PROTECTIVE ACTION ORDER

EVACUATION ORDER

SHELTER AREA REPORT

TRAFFIC CONTROL REPORT

SHELTERING SUMMARY

OFFPOST CASUALTY SUMMARY

RECEPTION CTR SUMMARY

RECEPTION CTR DIRECTORY

EVAC ROUTE ANNOUNCEMENT

INCOMING MILTTARY ROUTES

EVACUATION ROUTE TABLE

COORDINATE CODE TABLE

POLYGON CODE TABLE

SET IBS ONPOST HEADER
The menus for both CREATE IBS->POST REPORTS and VIEW IBS->POST REPORTS list the reports that are transmitted from the IBS to the onpost computer system. On those menus (as in the illustration here) each menu item corresponds to one type of report. The IBS report formats are shown on the following pages in alphabetical order by menu item name.

If you are just viewing the IBS reports (VIEW IBS->POST REPORTS), you can restrict the instances of those reports to those that contain a key word, reports that apply to a certain time range, or reports that have a specific sequence number. See the procedures in Using the Report Selection Method Menu sample that follows.

If you are an Information Manager who is generating a report (with CREATE IBS->POST REPORTS), selecting a menu item displays report screens for your information input and approval. Additional interactions for creating reports are described in the following paragraphs and with the report formats.

\section{Using the Report Selection Method Menu}

When you view reports, you can restrict the quantity of those reports by selecting from the Report Selection Method menu that initially displays when you pick a report.

Report Selection Method

0: ExIT
1: Use all reporta
2: Select reports containing a keyword
3: Select reports within a time range
4: Select report by sequence number
Choice $(?=\mathrm{Help})=>$




\section{Exiting After Creating an IBS Report}

Exiting after report creation is the same procedure for all reports:

1. To exit normally (with prompt for approval): press RETURN in the last field of the form (or GOLD $Z$ in any field). You then see this prompt for approving transmittal of the report:

Send report to onpost system? ( $Y / N<C t r l-z>=A b o r t) ~=m$

- $\quad$ : If you approve transmittal, the report is generated, logged, and sent to the onpost system after you specify the onpost computer name, username, and password. The IBS then returns to the CREATE IBS$>$ POST REPORTS menu and displays a message confirming the report was generated and sent.

After the file is transmitted, the system will display the following prompt:

View the ETP.OUT file? ( $Y / N<C t x l-Z=A b o r t)=>$

Type a $Y$ (yes) if you want to see if the transfer was successful.

If graphic files are attached to the report, the system will prompt:

Send overlay to ONPOST? ( $(Y / N<C t r l-Z>=A b o r t)=2>$

When you reply $Y$ (yes) to this prompt, the system will again prompt you to type the onpost computer name, username, and password. The system will display messages confirming each graphic file sent to the post.

After the graphic file is transmitted, the system will display the following prompt:

View the FTP.OUT filef ( $Y / N<C t r l-Z=A b o r t)=\equiv$

Type a $Y$ (yes) if you want to see if the transfer was successful.

- N: If you do NOT approve transmittal, the IBS returns to the CREATE IBS->POST REPORTS menu and displays a message indicating the report was NOT generated.

2. To cancel the report directly (with no prompt for approval): press GOLD Y at any time. Then the report is NOT sent, no prompt appears, and the IBS returns to the CAEATE IBS->POST REPOATS menu with a message confirming the report was NOT generated. 


\section{COORDINATE CODE TABLE}

This option displays the following form, which identifies a map file containing nodes, reception centers, and control points:

- Nodes generally refer to point locations on a roadway network (such as irtersections and traffic loading points).

- Reception centers are point locations that serve as destinations for evacuees.

- Conted points are point locations where an emergency management official might be sent or located.

Nodes, reception centers, and control points are associated on a node overlay, a graphic map supplied to the onpost system as a map graphics file.

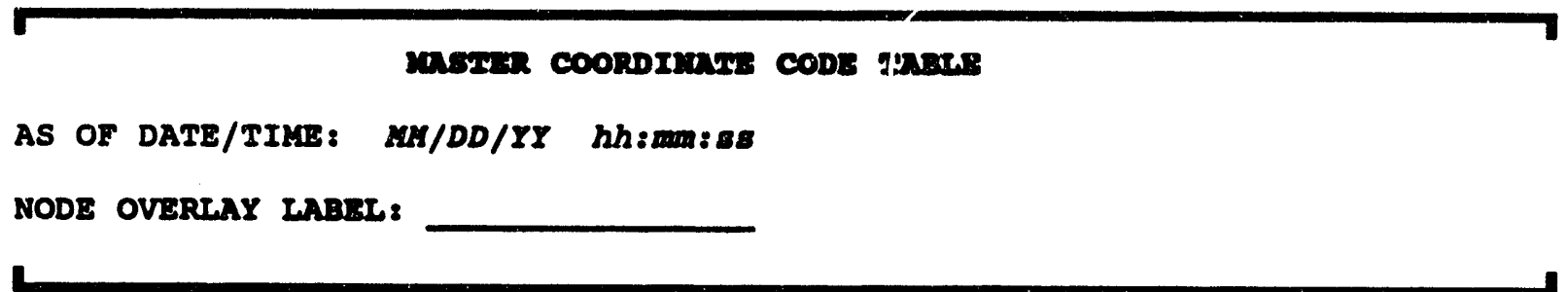

The date and time fields are filled with the current system time. The only information to be entered is the node overlay label:

- NODE OVERLAY LABEL: the name of the IBS map graphics file that shows the listed point locations.

Approve and send the information (as shown on the previous page) or cancel it (GOLD-Y). 


\section{EVAC ROUTE ANNOUNCEMENT}

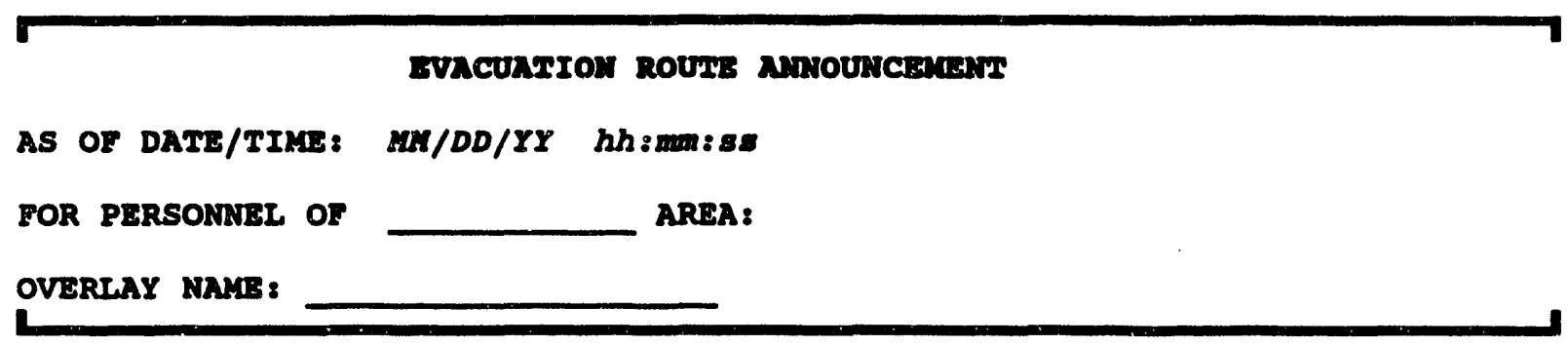

The date and time fields are filled with the system time.

Approve and send the information (as shown under the heading, Exiting After Creating an IBS Report) or cancel it (GOLD-Y). 


\section{EVACUATION ORDER}

Creating an Evacuation Order requires two screens of information:

\section{Evcungros orom}

(l of 2 screens)

Areas Ordered Fvacuated:

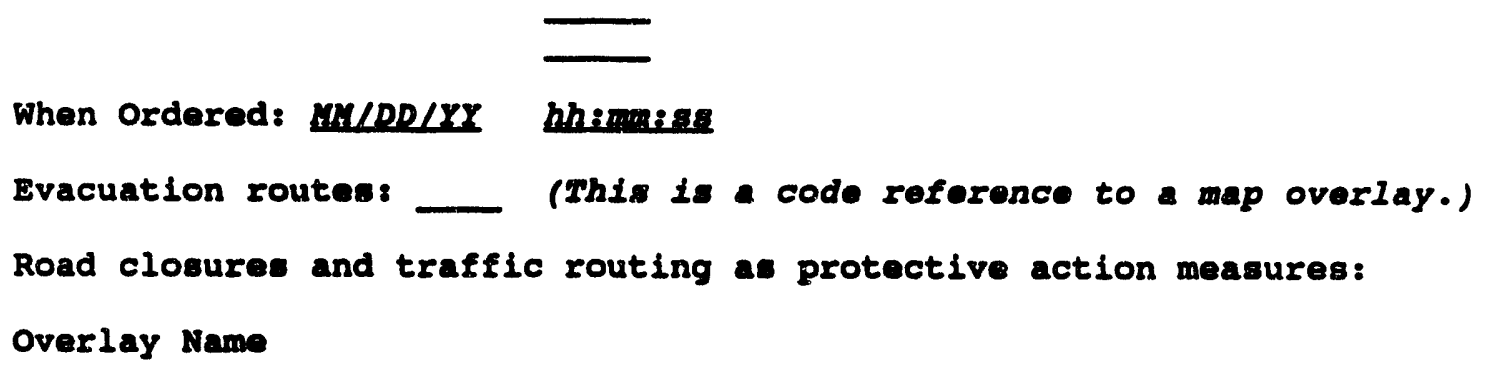

- Road closures and trallic routing: descriptions of road closures or special routings. Each description includes a) the name of a file that contains a visual representation of the affected roadways and 2) a textual explanation.

Press Gold-Z to move to the next screen of the form. Use Gold-Y to exit the form without sending it.

After the explanation of closure or routing, the following screen lists emergency resources, services, and reception centers related to the evacuation. 


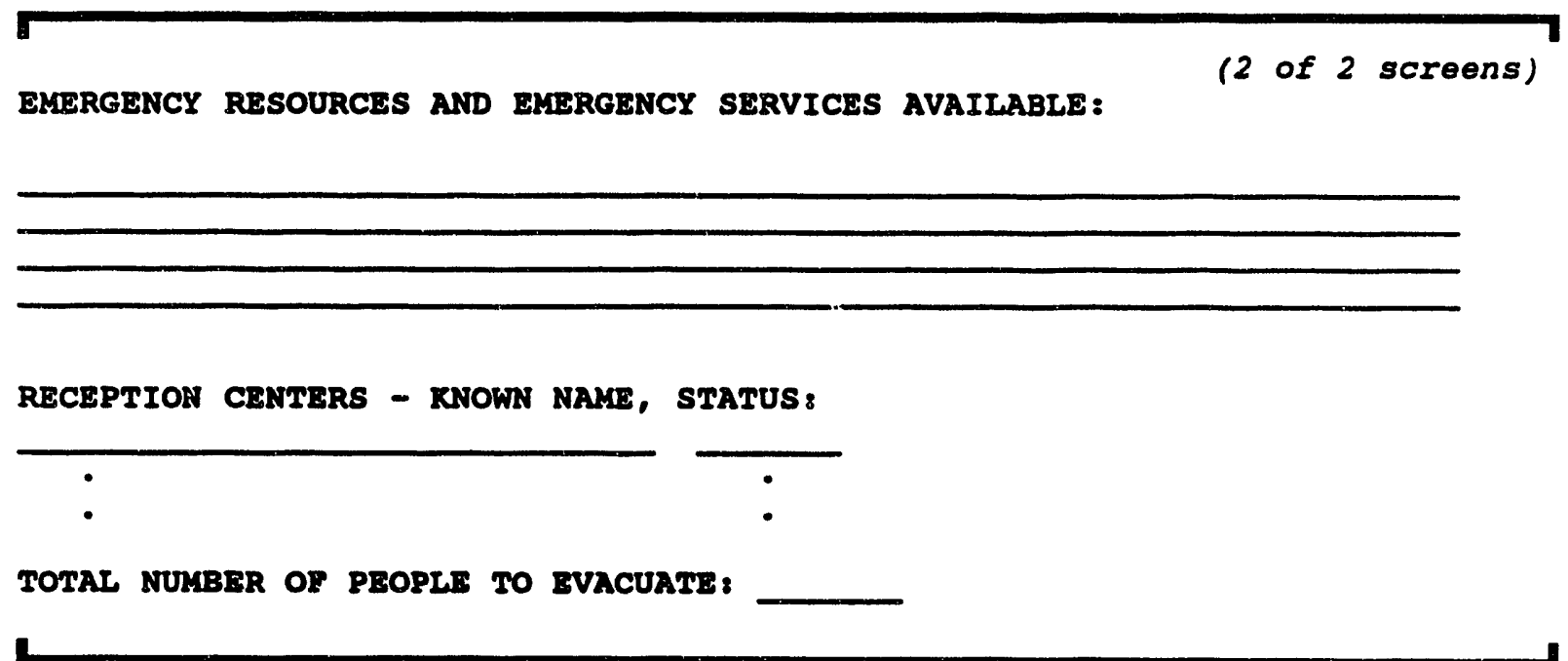

Emergency resources and emergency services available and Reception centers are both scrolled regions of the form.

Approve and send the information (as shown under the heading, Exiting After Creating an IBS Report) or cancel it (GOLD-Y). 


\section{EVACUATION ROUTE TABLE}

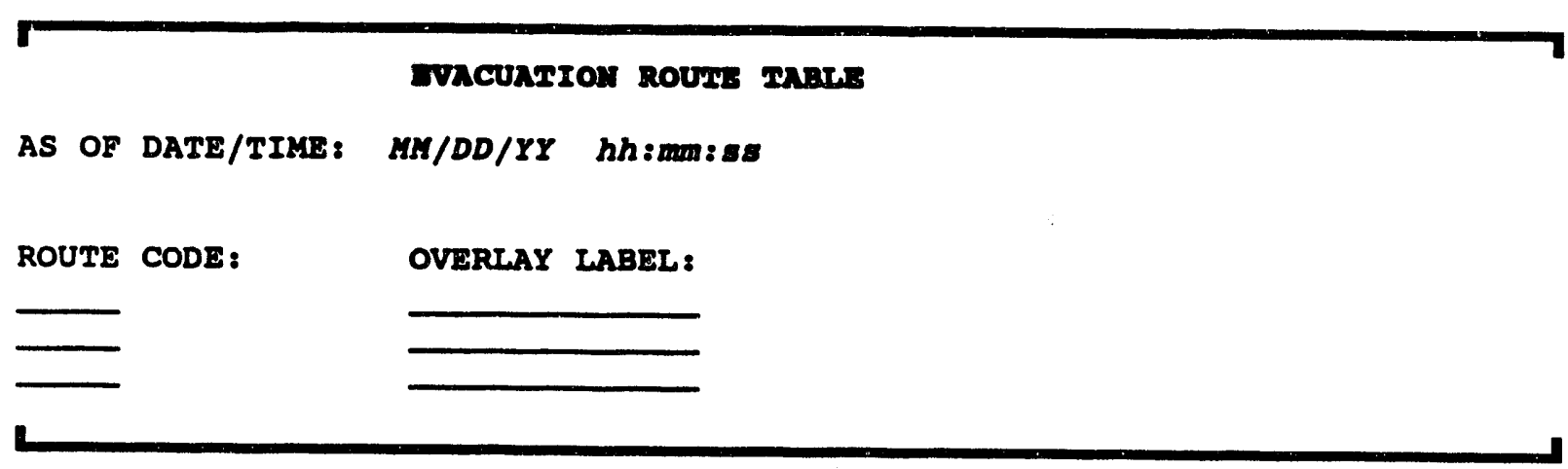

EVACUATION ROUTE TABLE automatically assembles and displays route data. The evacuation route codes and overlay labels are listed by route code in alphabetical ascending order. To look through this information, scroll it up and down on the screen with the arrow keys.

Approve and send the information (as shown under the heading, Exiting After Creating an IBS Report) or cancel it (GOLD-Y). 


\section{INCOMING MILITARY ROUTES}

This option displays a form that describes the route(s) proposed for incoming military response teams. Each route description consists of a source, a destination, and a reference to a map overlay describing the route.

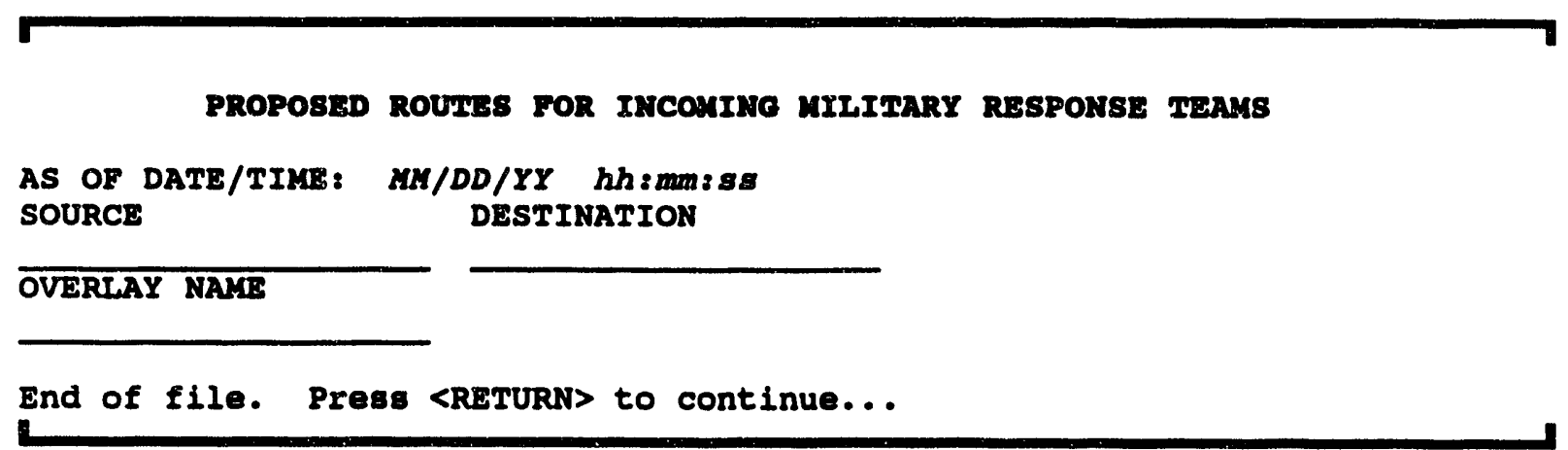

The date and time are filled with the current system time.

Approve and send the information (as shown under the heading, Exiting After Creating an IBS Report) or cancel it (GOLD-Y). 


\section{OFFPOST CASUALTY SUMMARY}

This option automatically displays casualty information that is available in the current database. This information is contained in two forms.

A ? (question mark) in a field means that the information was not available. You can enter values in those fields.

The first form displays as shown.

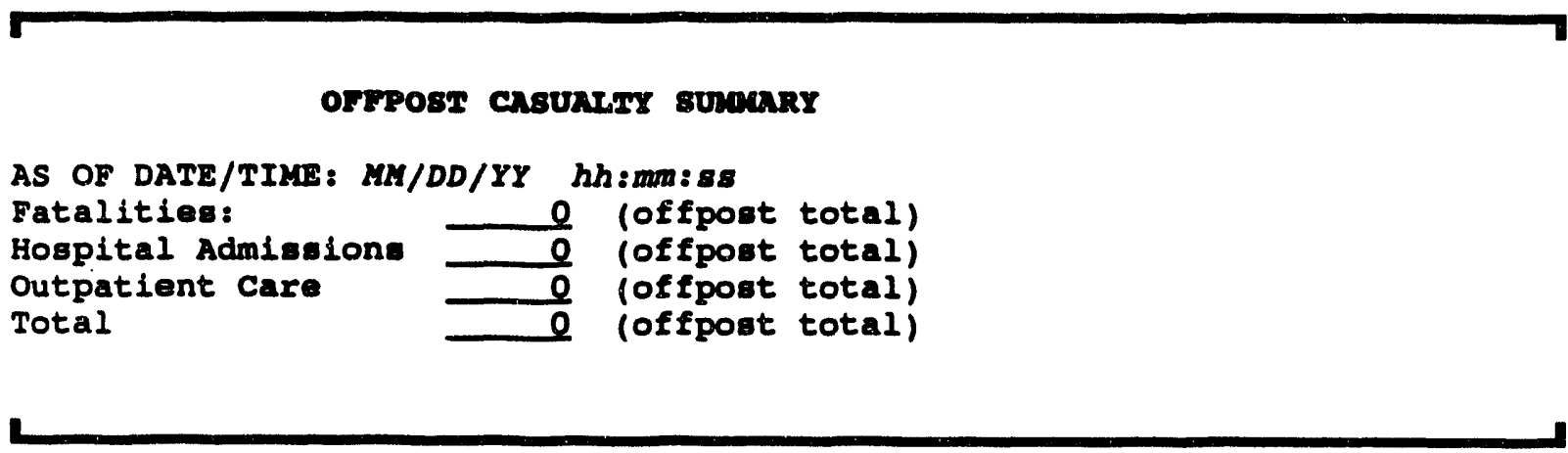

After you go through the first form, the second form displays as shown.

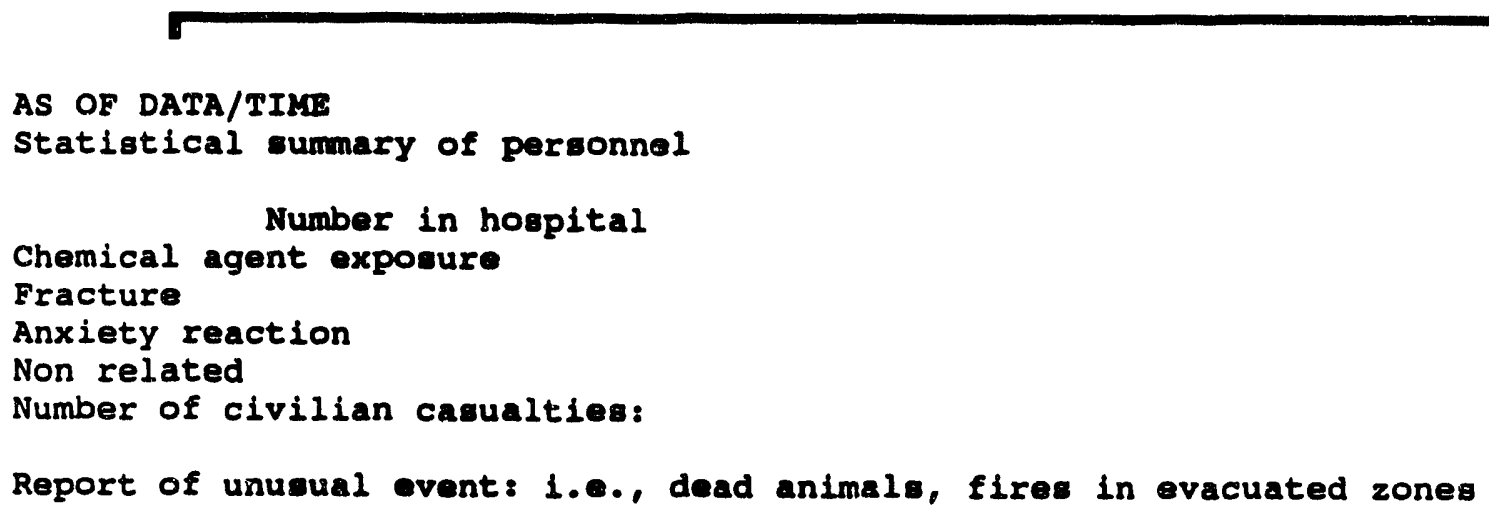

The date and time fields are filled using the current system time.

Approve and send the information (as shown under the heading, Exiting After Creating an IBS Report) or cancel it (GOLD-Y). 


\section{IIE POLYGON CODE TABLE}

This option automatically displays information about the polygonal boundaries that have been created to represent specific areas. The following form lists this information in alphabetical ascending order by area code.

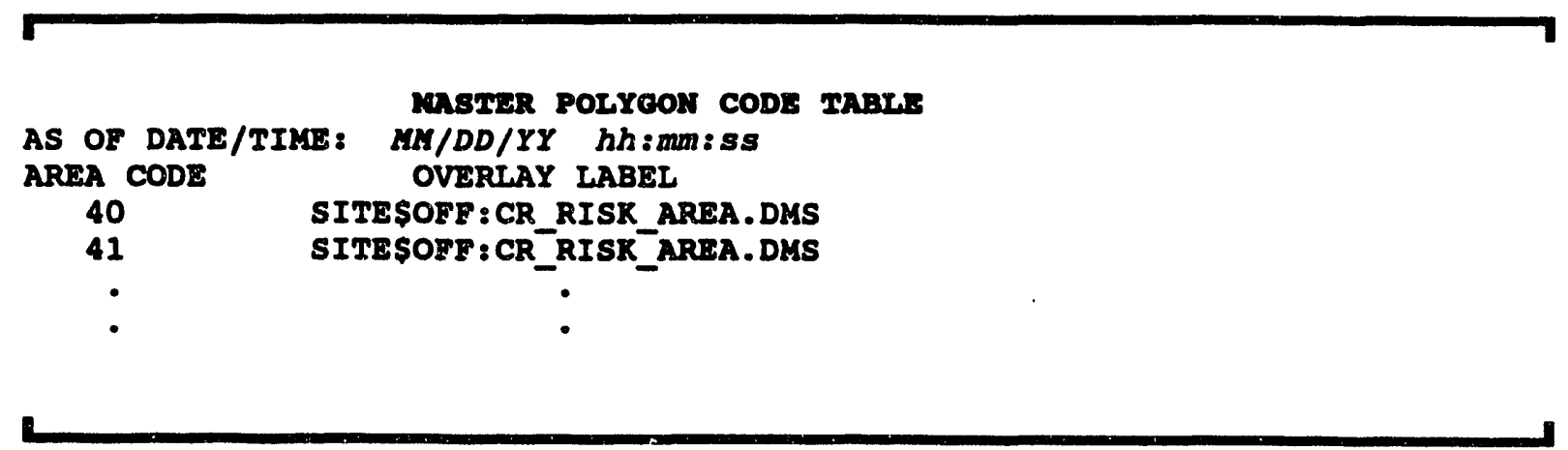

The date and time fields are filled with the current system time.

Approve and send the information (as shown under the heading, Exiting After Creating an IBS Report) or cancel it (GOLD-Y). 


\section{PROTECTIVE ACTION ORDER}

This option displays information on the issuance of a protective action order.

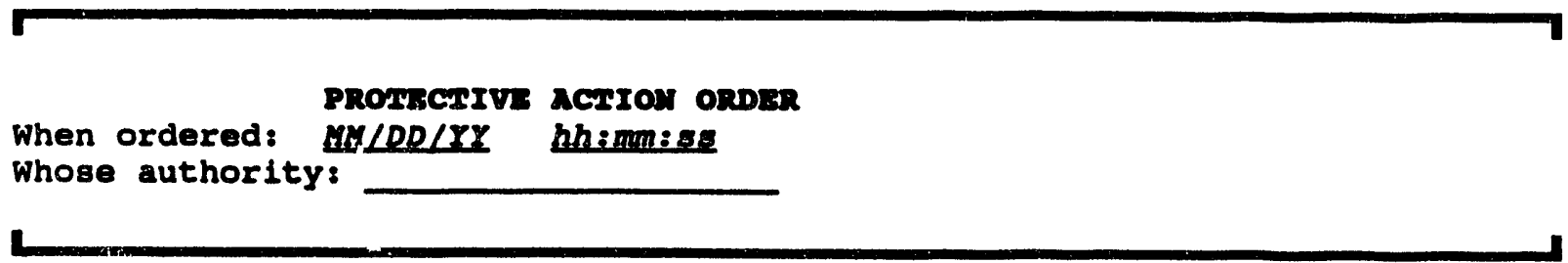

Approve and send the information (as shown under the heading, Exiting After Creating an IBS Report) or cancel it (GOLD-Y). 


\section{II: RECEPTION CTR DIRECTORY}

This option presents a scrolling form that enables you to enter descriptions of many reception centers.

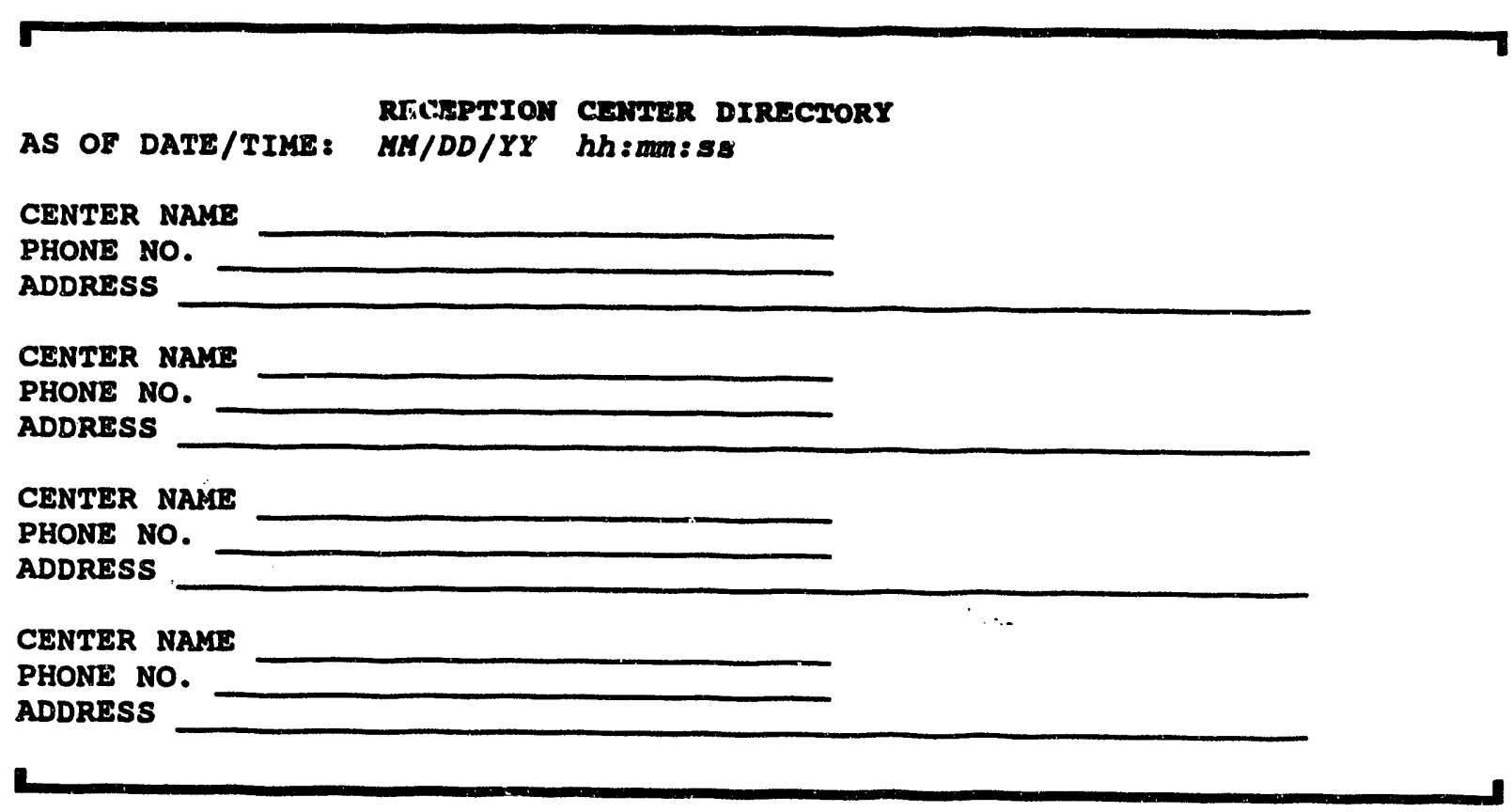

The date and time fields are filled using the current system time.

Approve and send the information (as shown under the heading, Exiting After Creating an IBS Report) or cancel it (GOLD-Y). 


\section{RECEPTION CTR SUMMARY}

This option automatically displays information about reception centers in the current database.

A ? (question mark) in a field means that the information was not available. You can enter values in those fields.

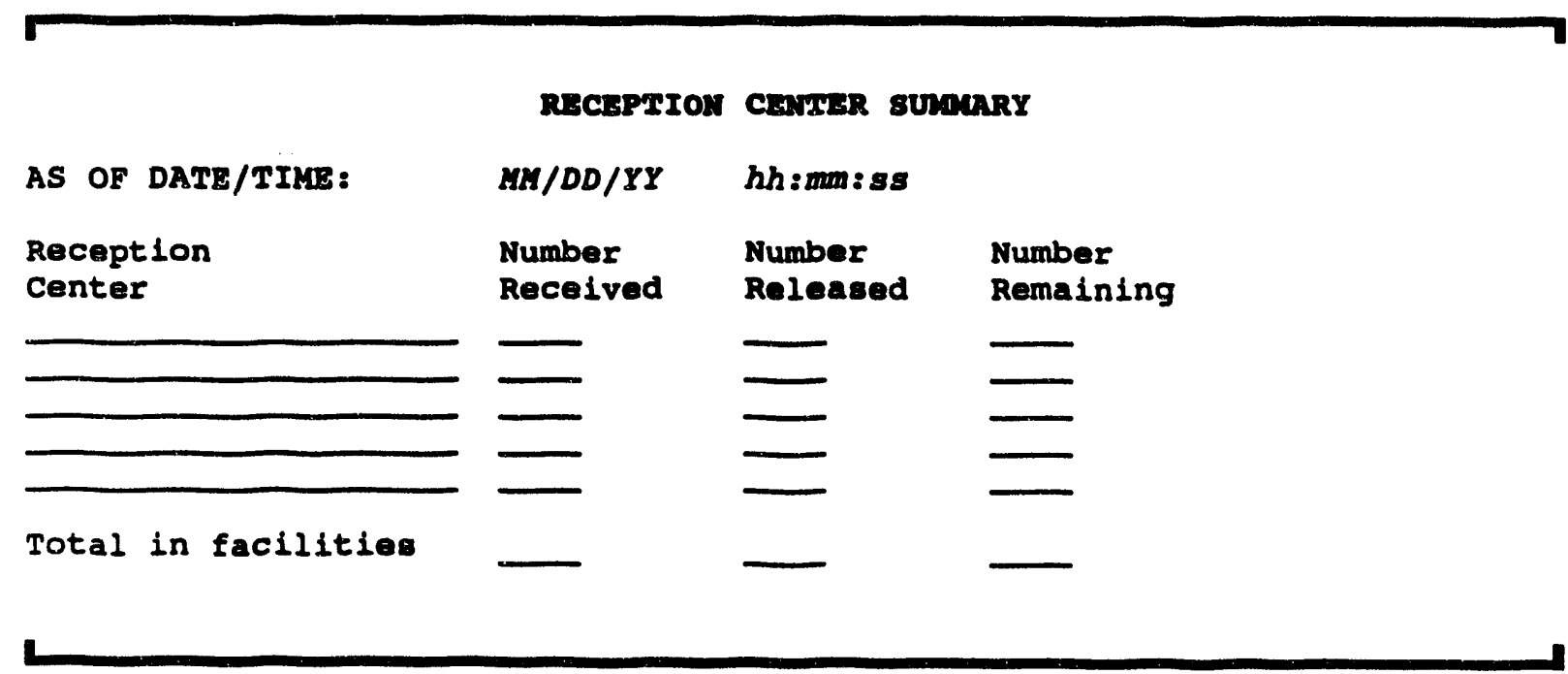

The date and time fields are filled using the current system time.

Approve and send the information (as shown under the heading, Exiting After Creating an IBS Report) or cancel it (GOLD-Y). 


\section{SET IBS ONPOST HEADER}

This option enables you to set the header on reports sent from IBS to the onpust system. Selecting this option causes the following menu to appear.

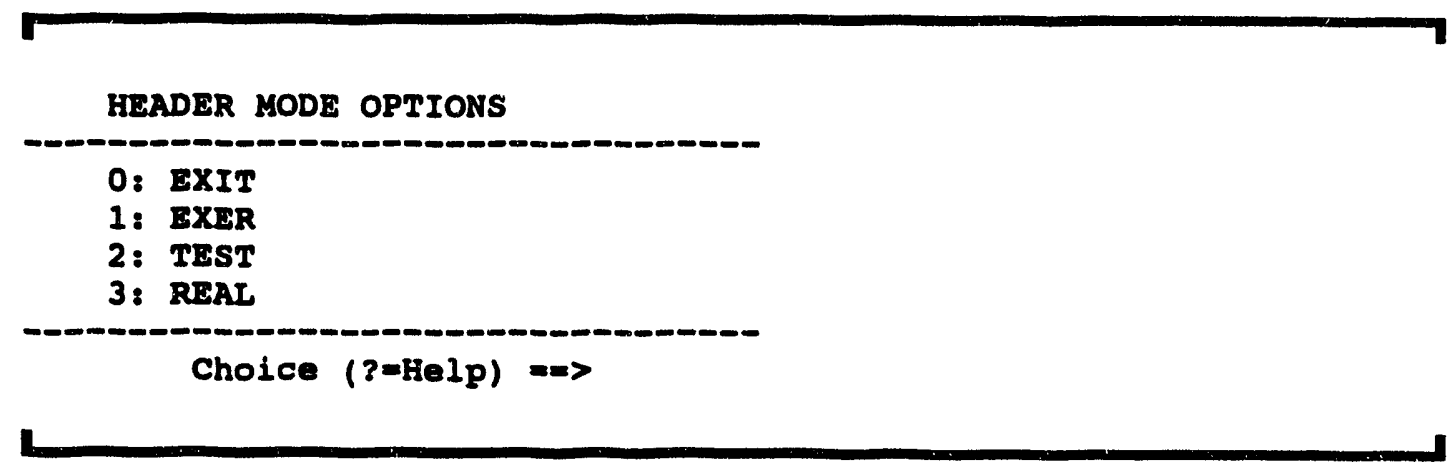

Select the option that describes your reports:

1. Exercise

2. Test

3. Real

After you select a header option, the following menu appears. HEADER DEPOT OPTIONS

0: EXIT
1: ANAD
2: APG
3: IBAD
4: NAAP
5: PBA
6: PUDA
7: TEAD
8: UADA
Choice $(3=$ Help) $=>$

\section{1}

Select the option that describes the depot. After you select a depot option, the following prompt appears.

Enter description $==>$ Test Reports for June

Type a header description and press the Return key. The system applies this header to all following reports from IBS to onpost. 


\section{SHELTER AREA REPORT}

This option enables you to enter the name of a graphic file to show shelter areas in the following form.

AS OF 06/17/92 19:00:52

BaglyoR ARE RGPORT

Overlay name

Approve and send the information (as shown under the heading, Exiting After Creating an IBS Report) or cancel it (GOLD-Y). 


\section{SHELTERING SUMMARY}

This option displays a table of emergency shelter information.

A ? (question mark) in a field means that the information was not available. You can enter values in those fields.

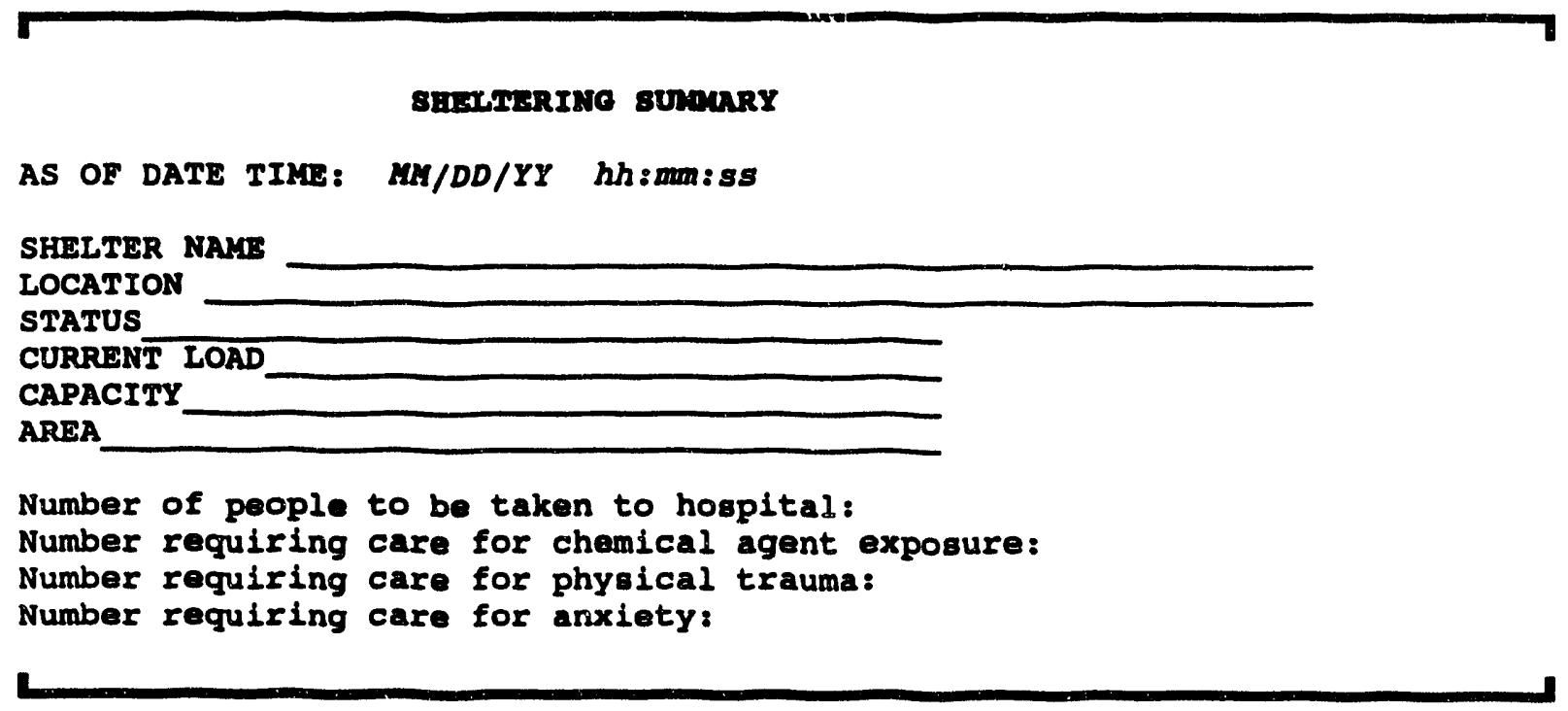

The date and time fields are filled using the current system time.

Approve and send the information (as shown under the heading, Exiting After Creating an IBS Report) or cancel it (GOLD-Y). 


\section{TRAFFIC CONTROL REPORT}

This option displays information from the current Law Enforcement tasks in the current Implementing Procedure and event database. The Traffic Control facilities are listed.

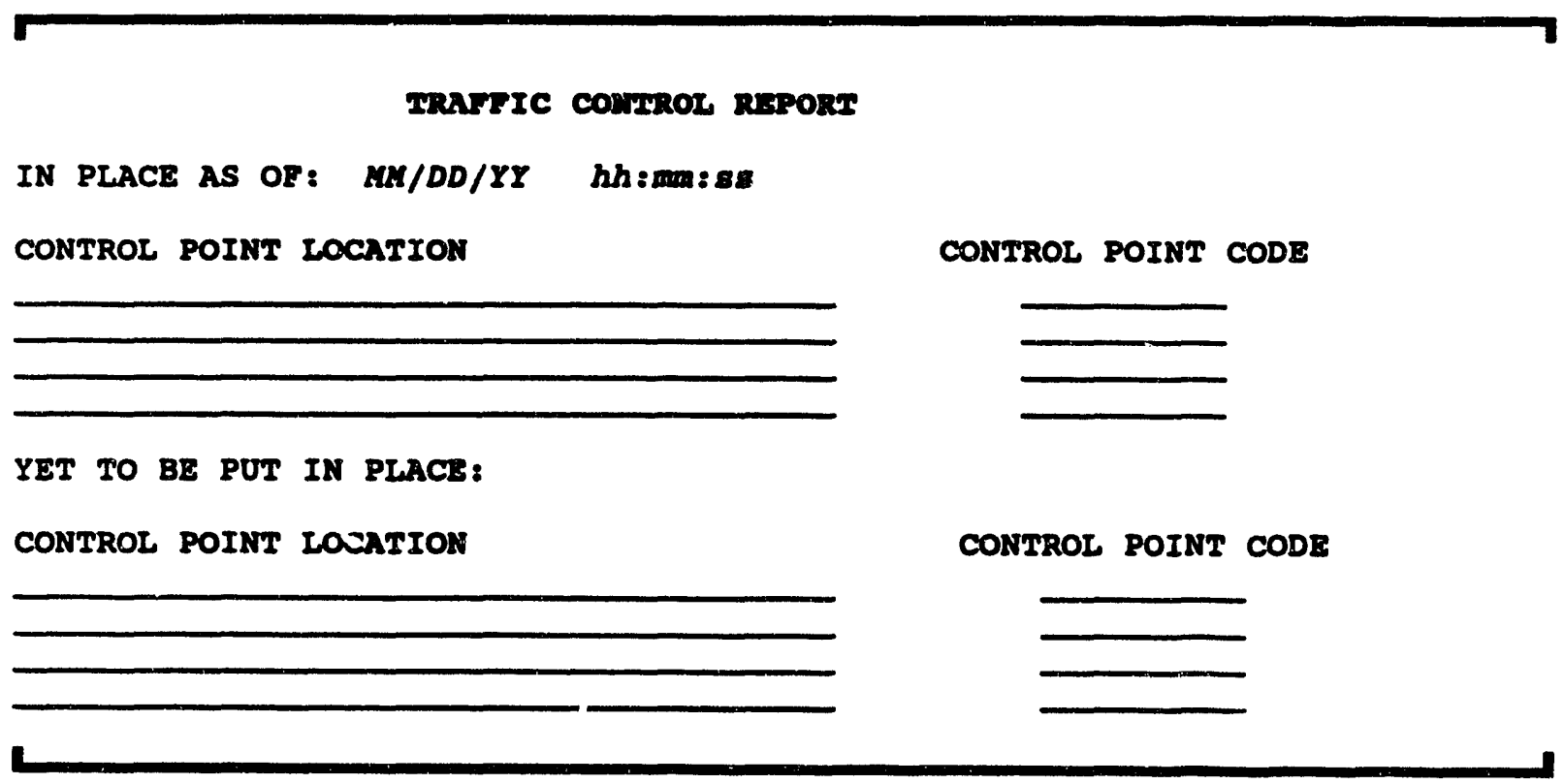

The date and time blanks are filled in with the current system time.

The portions of the form labeled IN PLACE and YET TO BE PUT IN PLACE are both sciolled regions.

Approve and send the information (as shown under the heading, Exiting After Creating an IBS Report) or cancel it (GOLD-Y). 


\section{Reports from the Onpost EOC System}

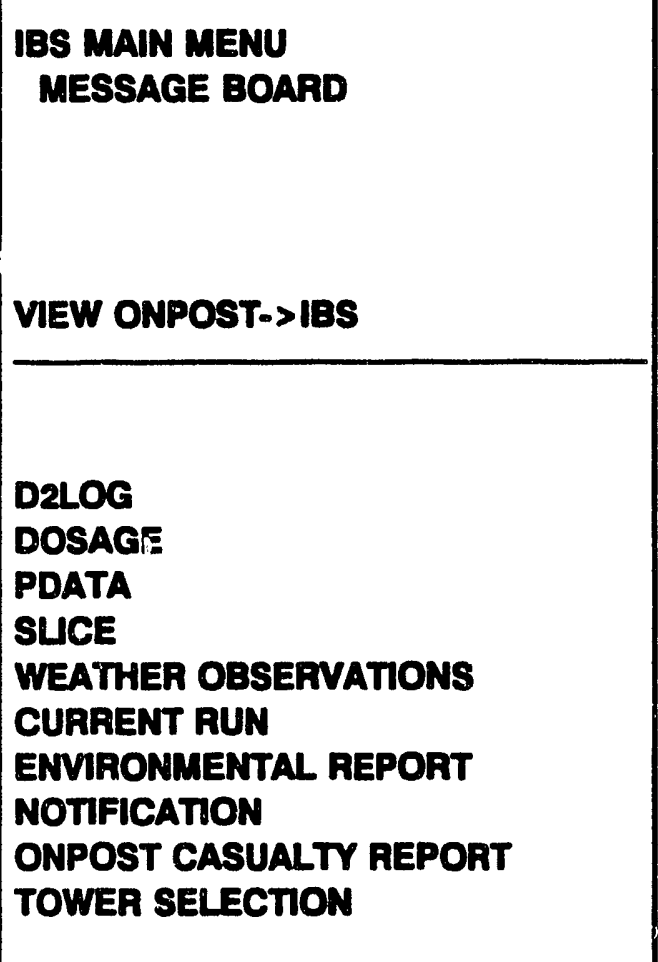

VIEW ONPOST->IBS RPT displays this menu for reviewing reports (messages) that have been transmitted from the onpost system to the IBS.

Each menu item corresponds to one type of report. You can select one or more types of report to review.

After selecting one or more types of reports, you are able to restrict the instances of those reports to reports that contain a key word, reports that apply to a certain time range, or reports that have a specific sequence number. (This is as described for VIEW IBS-> ONPOST RPT, in Section 2, Message Board.)

In the final step, you can specify how the report(s) are output: displayed on the screen or sent to a printer.

The formats for reports from the onpost system are shown on the following pages in alphabetical order by menu item name. Additional interactions with the system are also described. See the heading, Using the Report Selection Method Menu for instructions for using the Report Selection Method menu that initially displays when you select a report. 


\section{II] CURRENT RUN}

CURAENT RUN displays the following fixed-format report with up to three current run information sets describing onpost activities involving chemical agents.

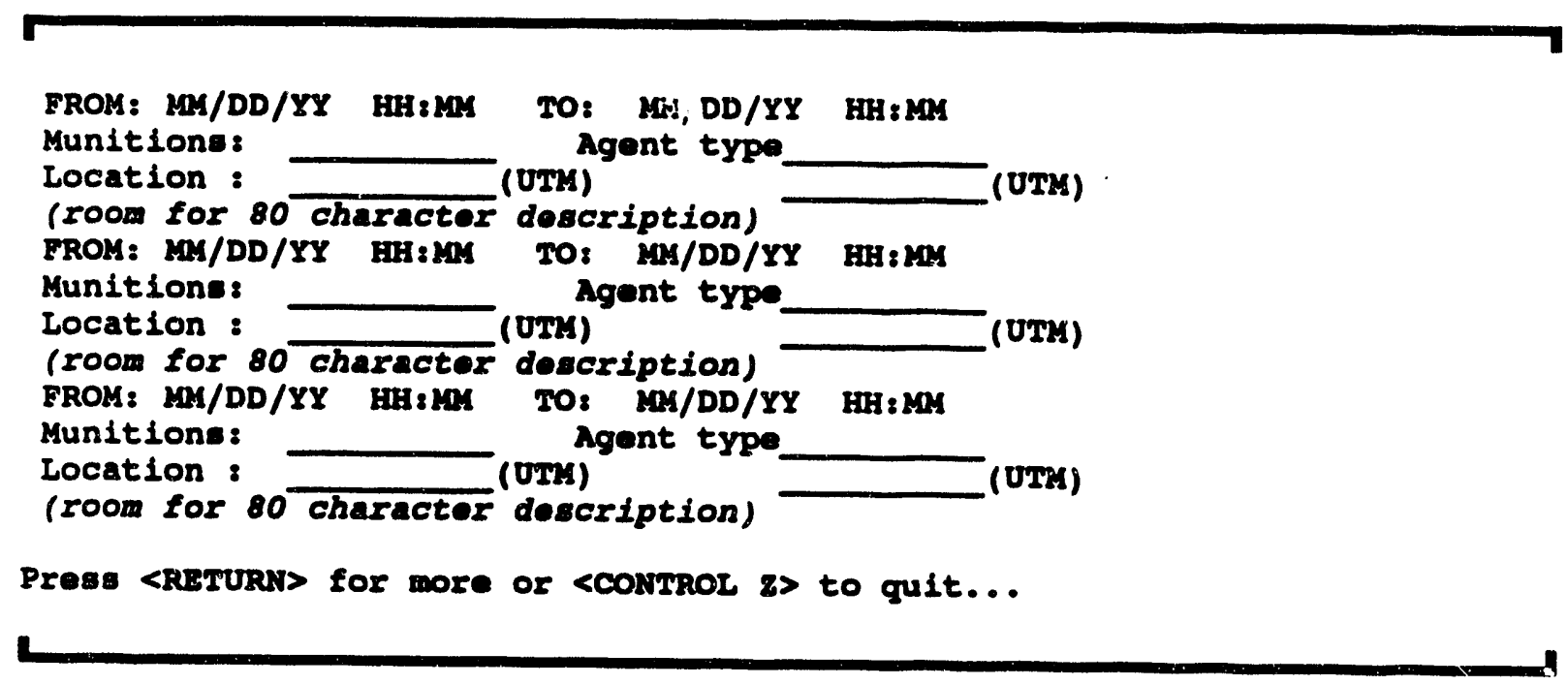




\section{D2LOG}

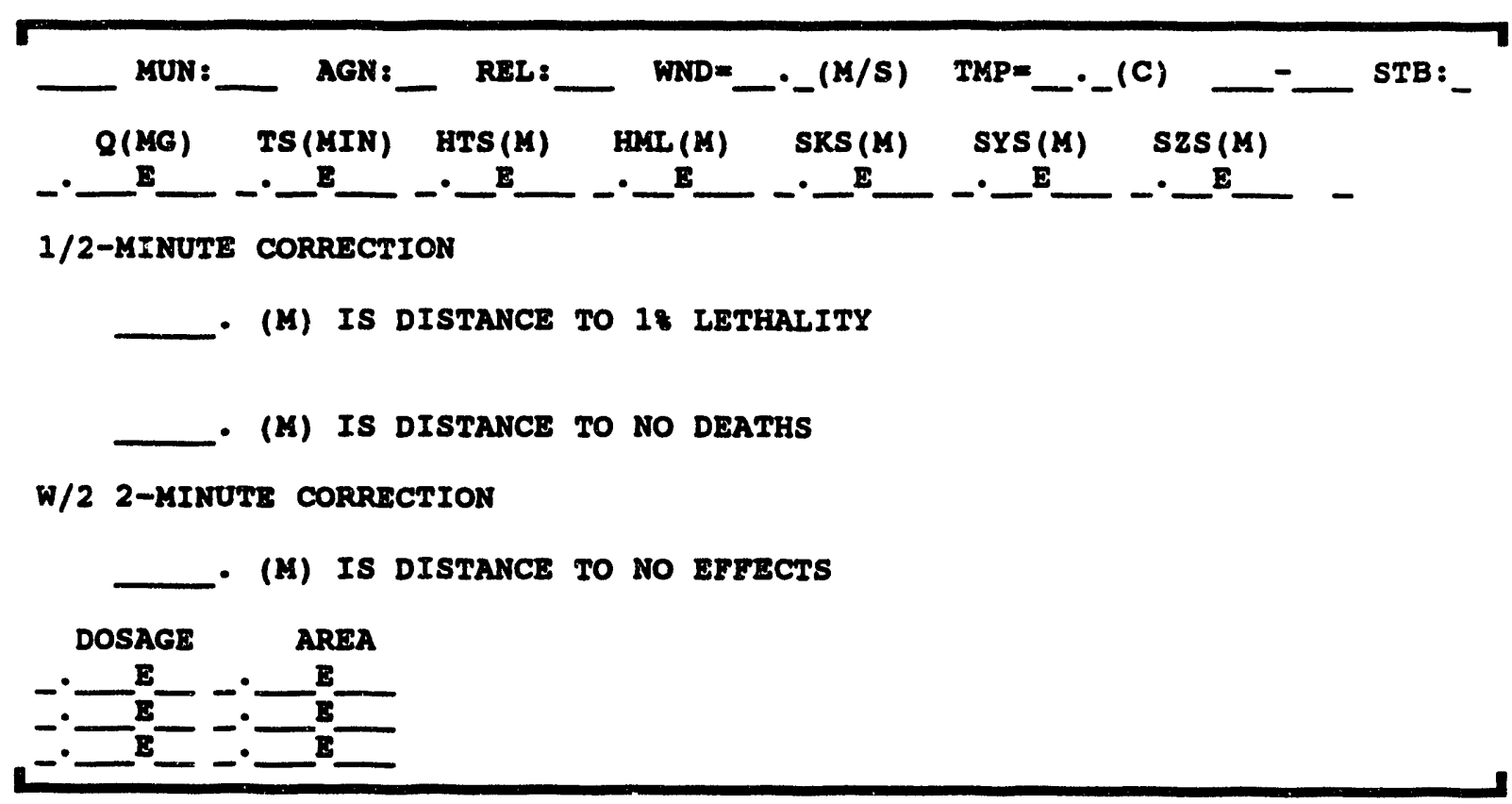

The first field in the form is for the number of munitions.

Note: The two unlabeled fields near the end of the first record are for location and season (LOC and SEA, respectively, in D2 terms). 


\section{DOSAGE}

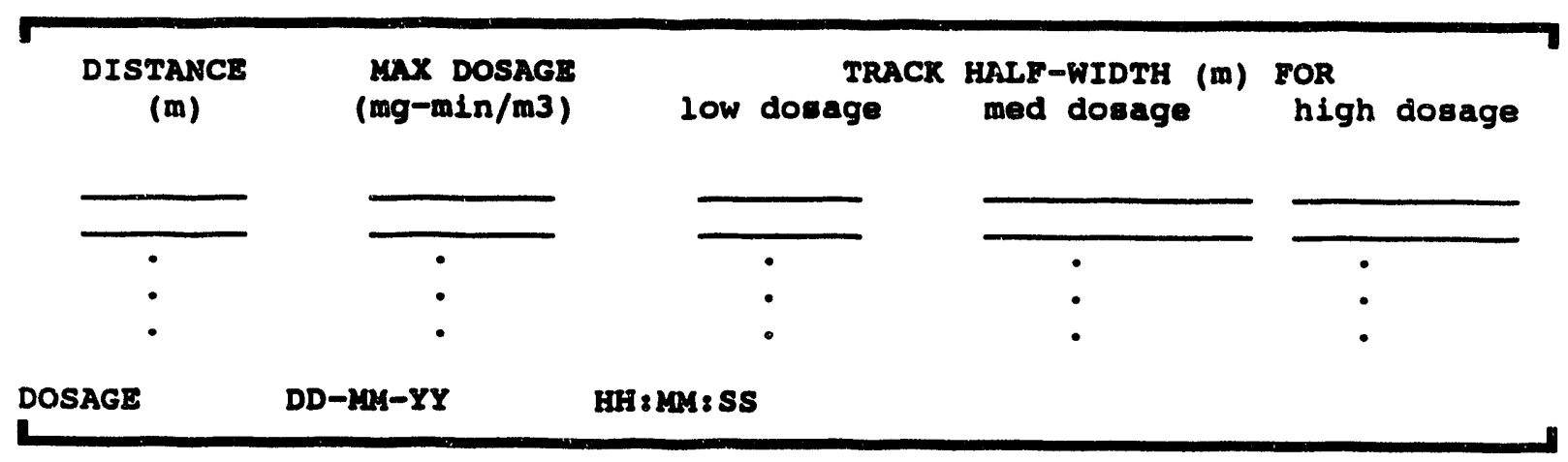

Note: The content of this report can vary if the selected D2 output was concentration rather than dasage.

You can scroll the information in this report. 


\section{ENVIRONMENTAL REPORT}

ENVIRONMENTAL REPORT displays a summary report of information gathered from various types of on-site detectors or human observations. The report format follows.

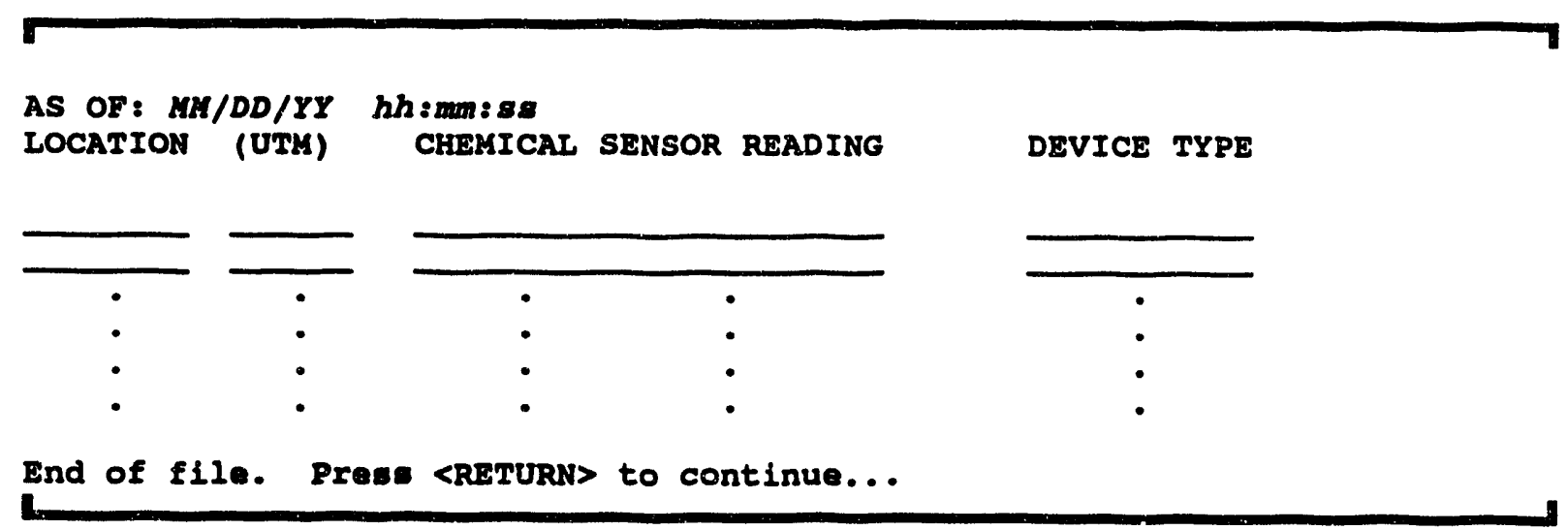




\section{NOTIFICATION}

\section{HOTIFICATION}

AS OF: $M M / D D / Y Y$ hhimmsas

EVENT REFERENCE DATE/TIKE: MM/DD/YY hh:mm:sg

EVENT CLASSIFICATION:

ONPOST SYSTEM EVENT ID:

(comments)

An optional free-form comments section is included on the form: onpost personnel may wish to recommend a specific IBS scenario or recommend protective actionson this form. 


\section{HD ONPOST CASUALTY REPORT}

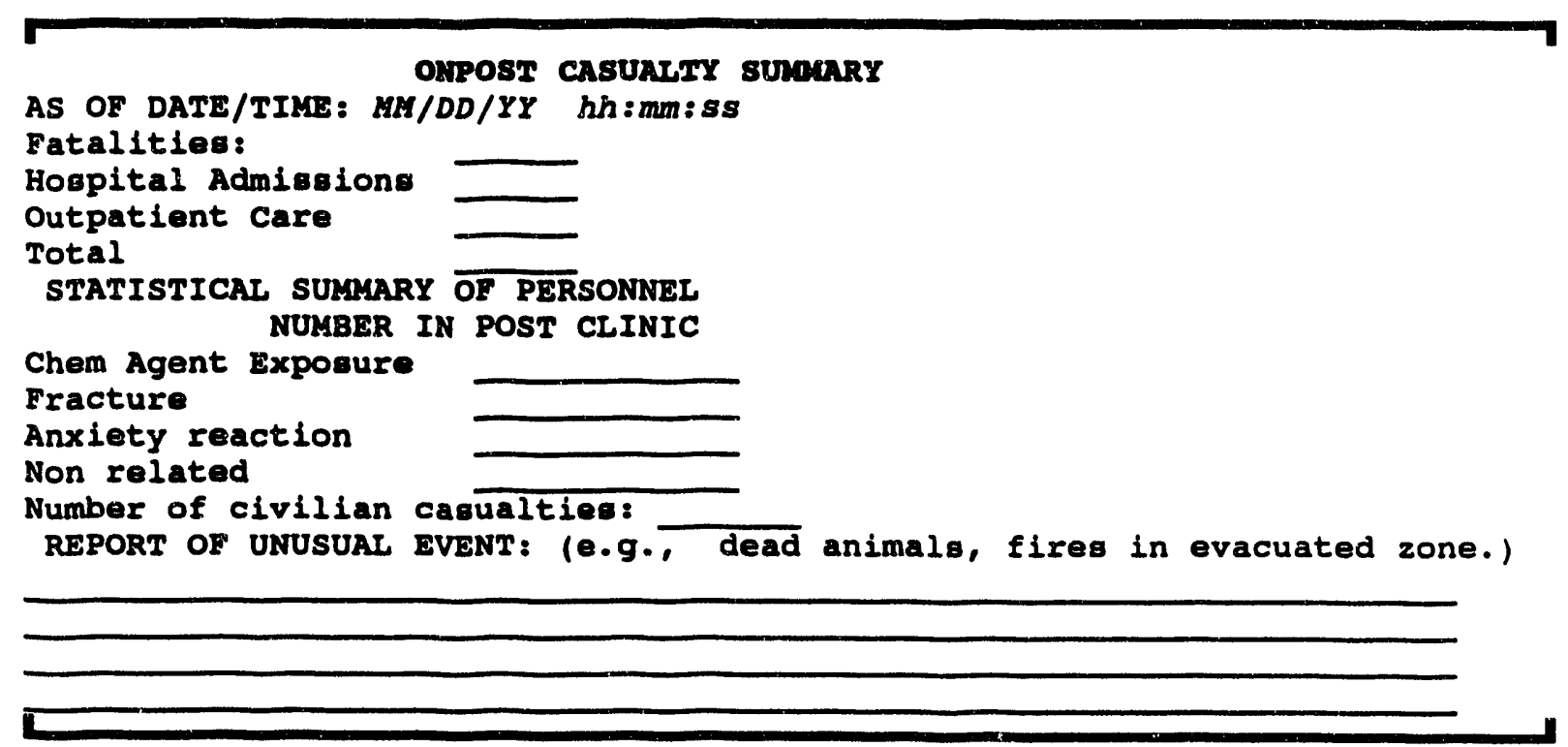




\section{PDATA}

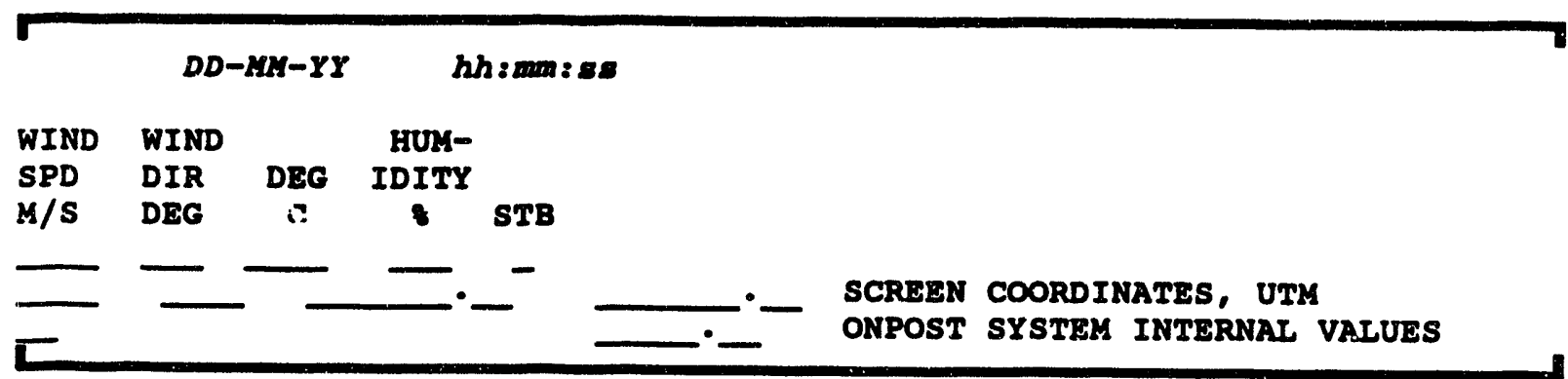




\section{SLICE}

The format of the report can vary, depending on the D2 input.

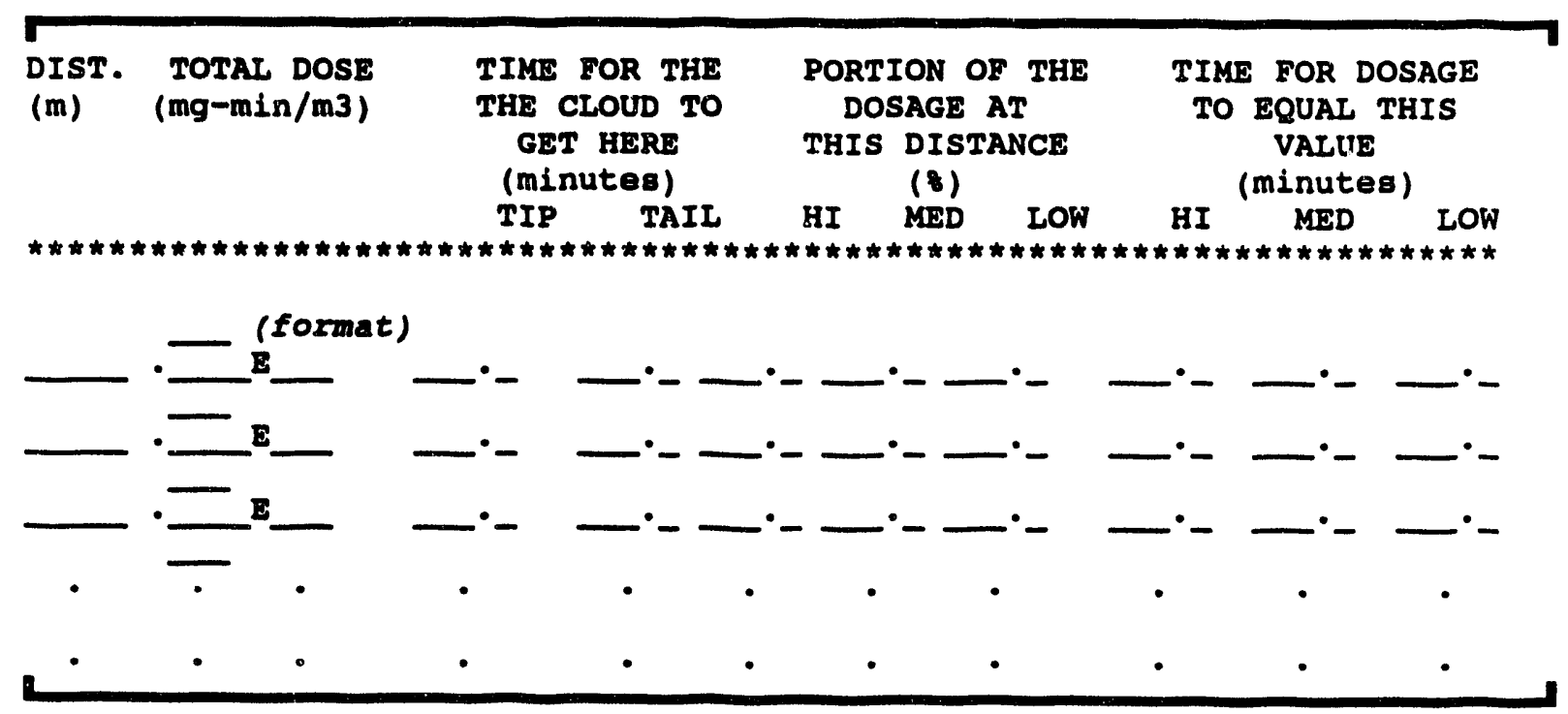


III TOWER SELECTION

TOWER SELECTION displays the following report. This report identifies the meteorological data that is fed into the D2 model in IBS.

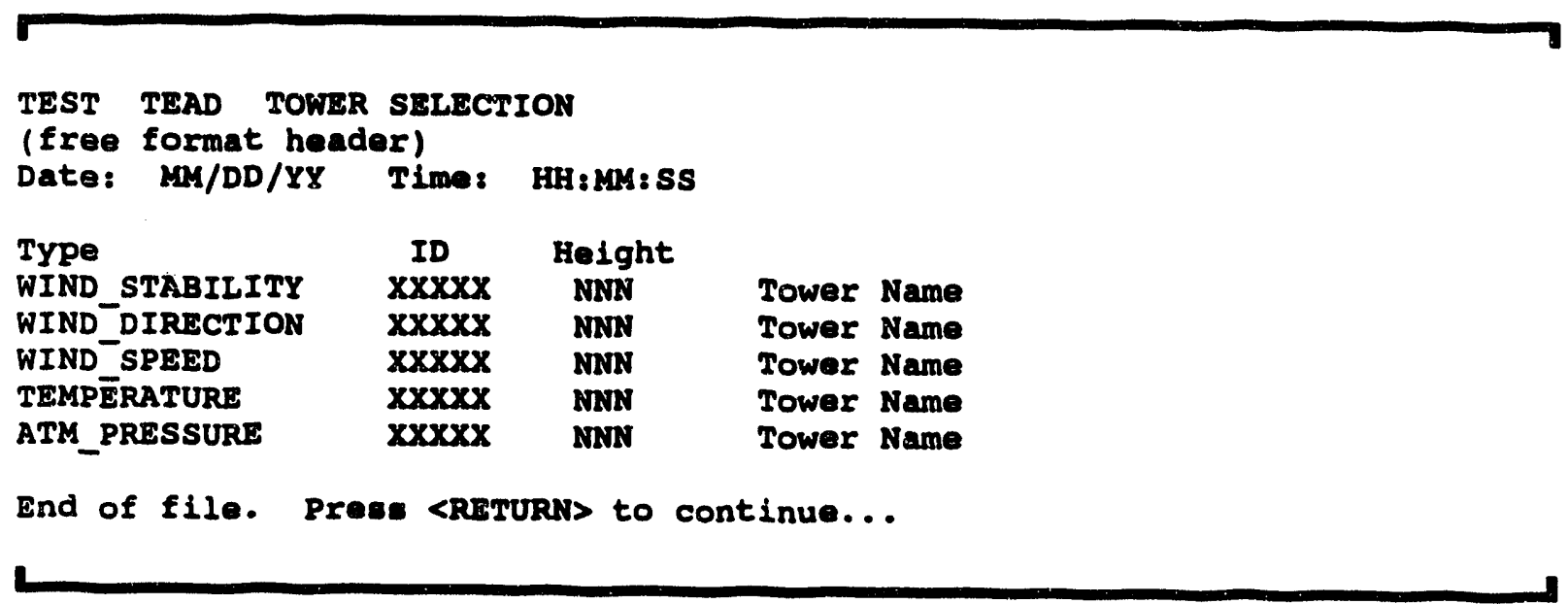




\section{WEATHER OBSERVATIONS}

WEATHER OBSERVATIONS displays the following report. If any values are known to be incorrect, those fields are filled with * (asterisks).

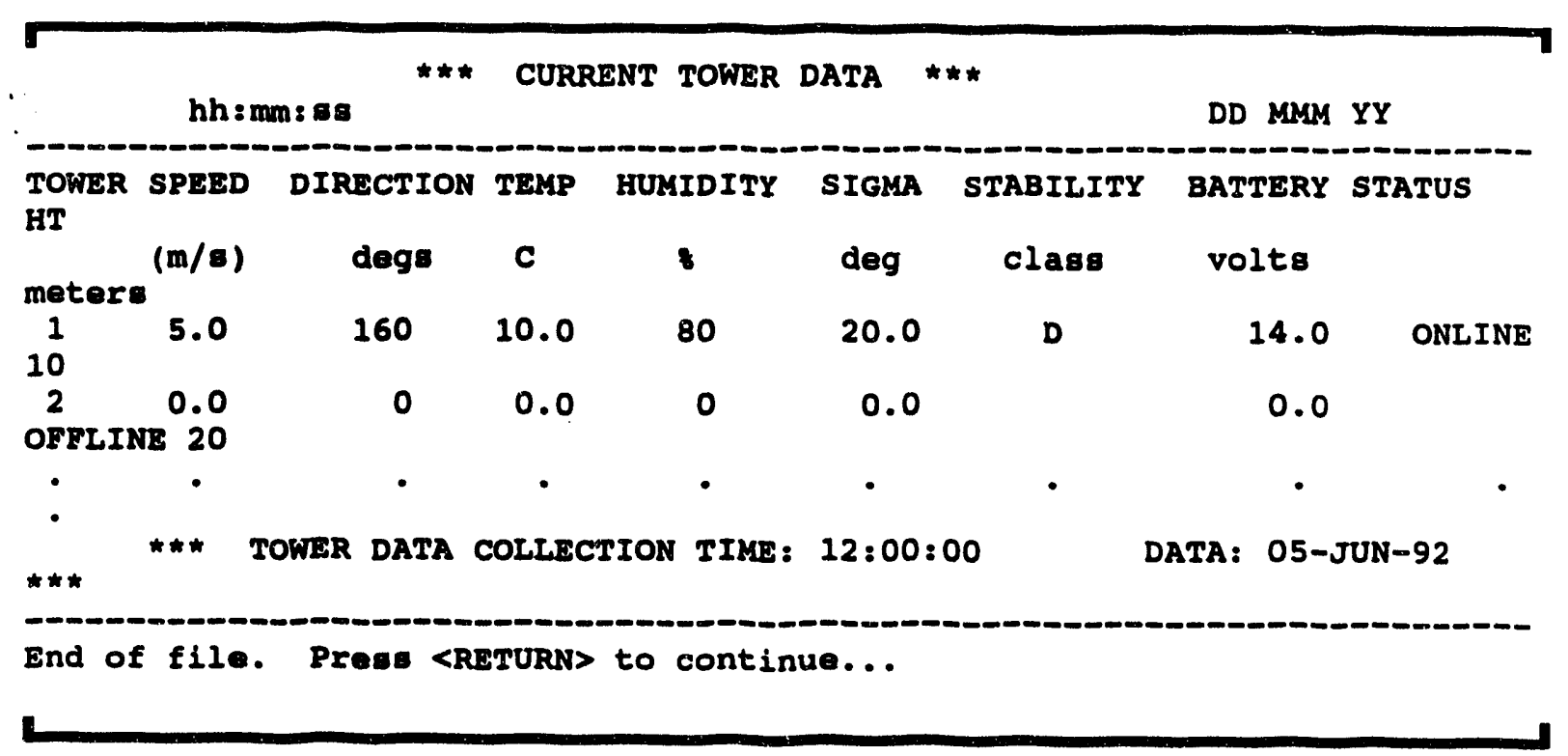




\section{Appendix $F$ IBS Icons}

Icons are symbols used in the IBS to graphically depict the location and availability of features stch as facilities, resources, services, and physical landmarks. Each icon is represented by a symbol which can be drawn on the topographic map display. This appendix provides a listing of the current set of icons available in IBS, together with their type.

The current set of icons has been divided into three categories within this appendix. These categories are:

- Facillty Icons: Represent the location of facilities such as schools, churches, and food distribution centers.

- Resource Icons: Used to depict a major resource type, such as communication equipment, food, and medical equipment.

- Non-Facility/Resource Icons: Represent items which do not fall within the facility or resource categories. Examples of non-facility/resource icons are:
- City
- Flood
- Earthquake

The following pages contain the icon lists for the IBS. The icon listings contain two fields describing the icons. These fields are:

- Symbol: This is the graphic symbol used for displaying the icon. Because the symbols shown are drawings of the actual icons, and are not in color (some icons contain multiple colors), some minor differences in appearance may exist between the symbols and the actual icon display. Listed above each symbol in parentheses is the icon color. If the icon contains multiple colors, more than one color is listed.

- Type: This is an icon descriptive text field. In addition to type, resources require a second parameter, resource description, when resources are defined in IBS. A resource description is a descriptive character text string entered by the system user and assigned to a resource type, within the IBS Define Resources menu function. The user will require special privileges to define resources. For example, Ambulances and Fire Trucks are two possible resource descriptions which can be assigned to the resource type Emergency Equipment to specify these resources. Both Ambulances and Fire Trucks 
would be represented by the same resource icon (Emergency Equipment), they both belong to the same resource type. However, each resource description must be unique. For example, only one Ambulance resource description can be assigned to the resource type, Emergency Equipment. The resource type and description fields are 8 and 32 characters in length, respectively. Facility and non-facility/resource type fields are 25 characters in length. See Section 6, Resource Management for more information on defining resources and facilities. 


\section{Facility Icons}
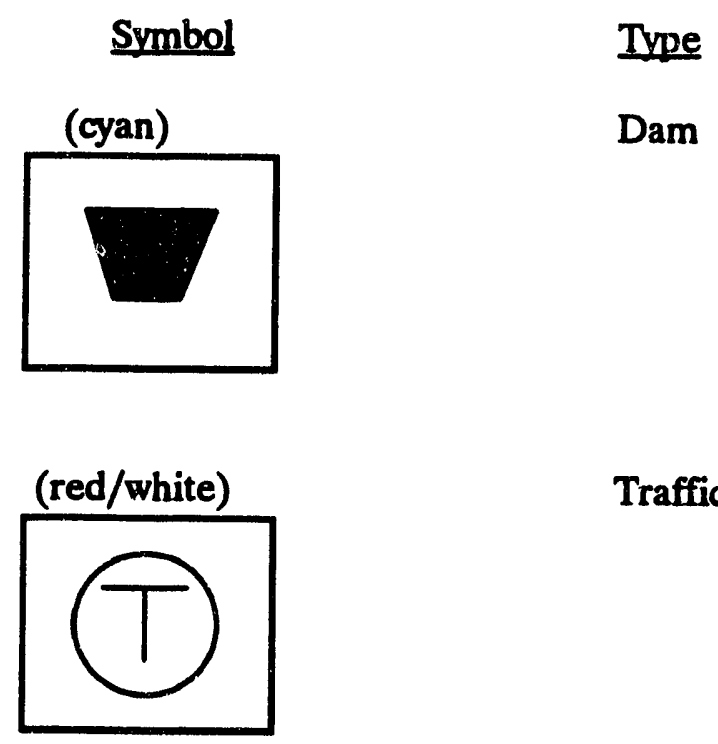

Traffic Control

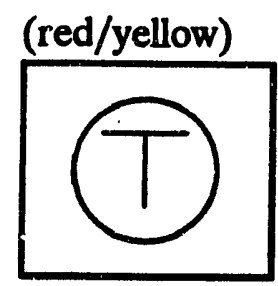

Traffic Control (Inactive)

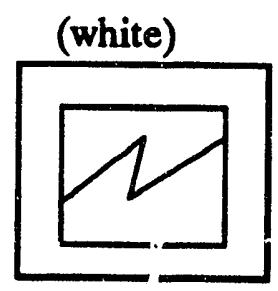

Power Station

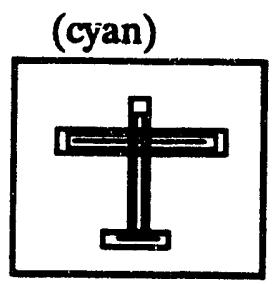

Airpor 
Symbol

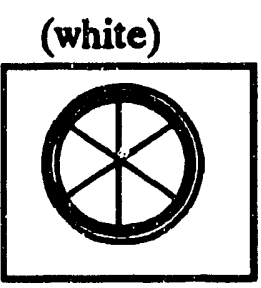

(white)

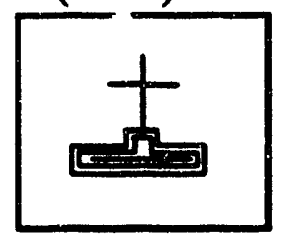

(white)

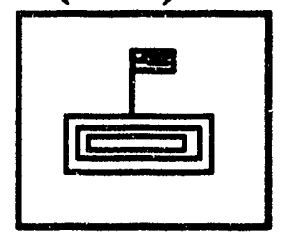

(white)

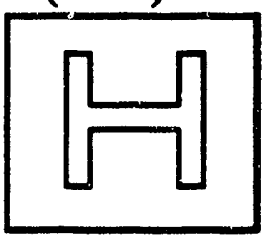

(cyan)

$\square \square$
Type

Transportation facility

Church

School

Hospital

Public Utility 


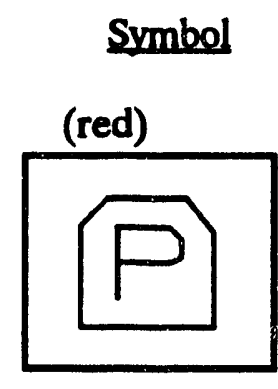

Type

Private Business

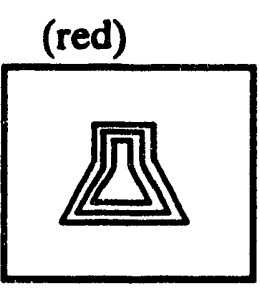

Nuclear Plant

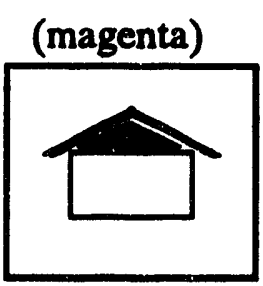

Shelter

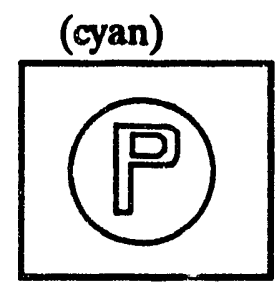

Police Station

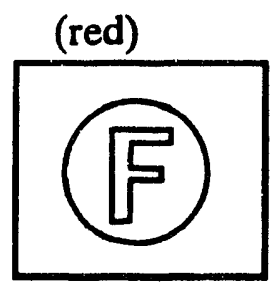

Fire Station 


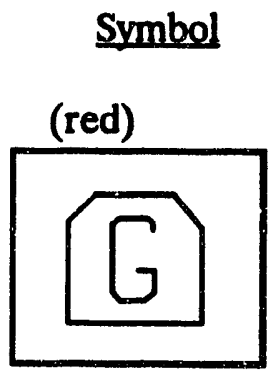

Type

Government Building

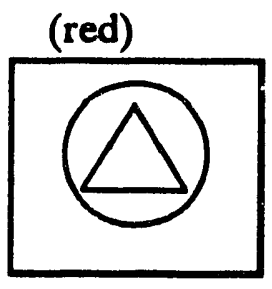

EOC

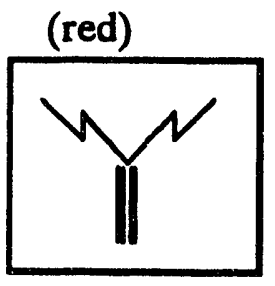

Communications Facility

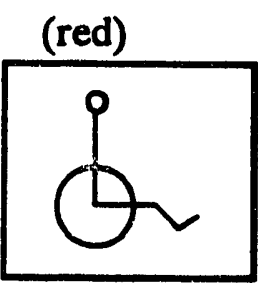

Special Population

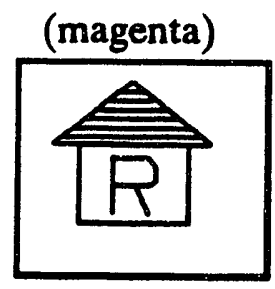

Reception Center 
Symbol

(magenta/green) M

(white)

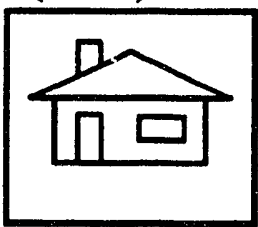

(red)

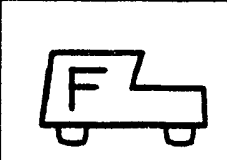

(white)

49
Type

Mobile Medical Unit

Private Residence

Food Distribution

Food Production 


\section{Resource Icons}

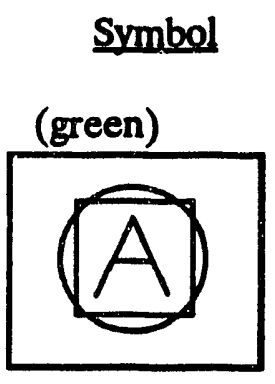

Type

1st Aid

(green)

Barricade (Barricad in the system)

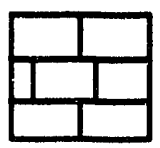

(green)

Cars
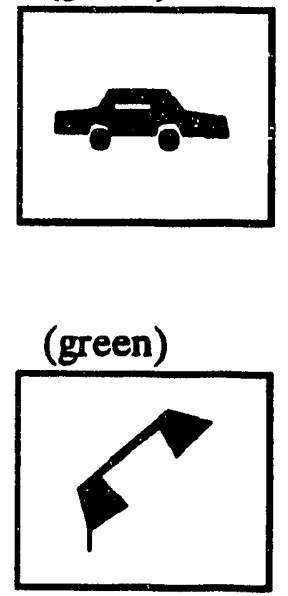

Communications Equipment (Comm Eq)

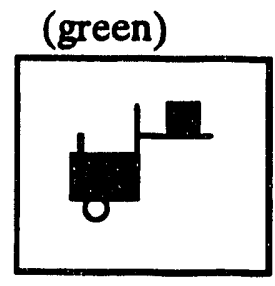

Construction Equipment (Const Eq) 


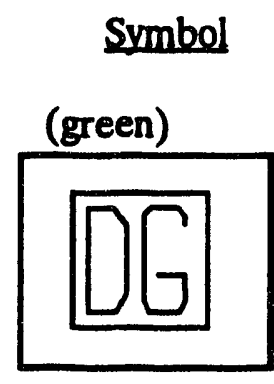

Type

Dry Goods (Dry Good)

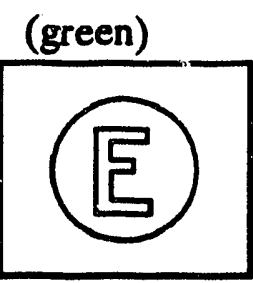

Emergency Equipment (İmerg Eq)..

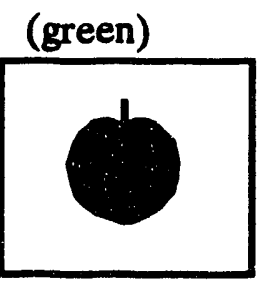

Food

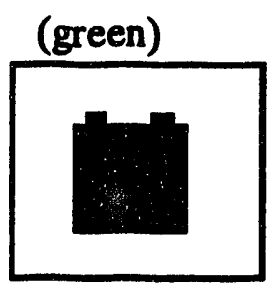

Generator (Generatr)

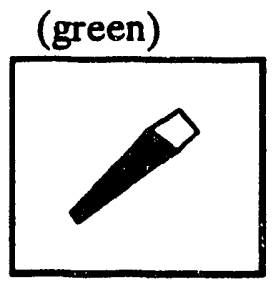

Hand Tool (Hand Tl) 


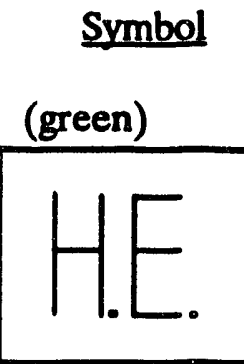

\section{Type}

Heavy Equipment (Heavy Eq)

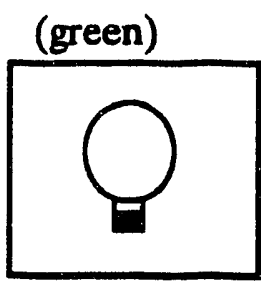

Lights

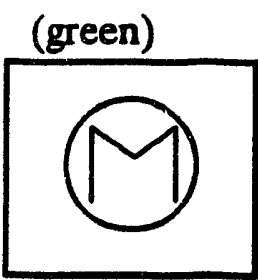

Medical Equipment (Medic Eq)

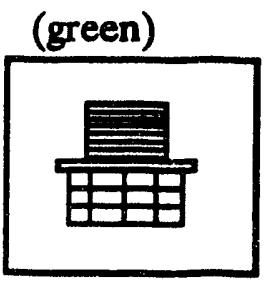

Office Machine (Office M)

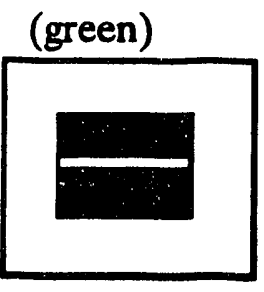

Paving Equipment (Pave Eq) 


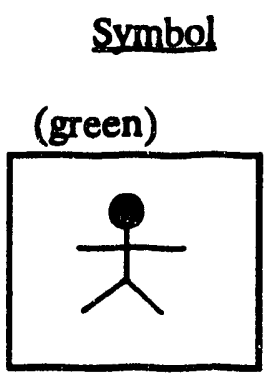

\section{Type}

People

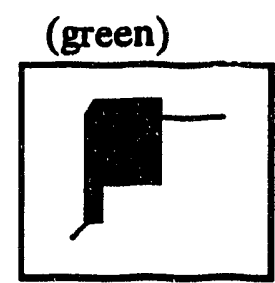

Power Tool (Power Tl)

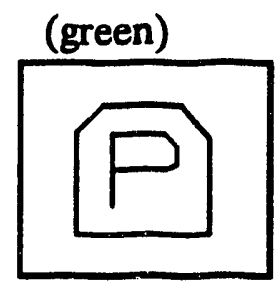

Prefabricated Building (Prefab B)

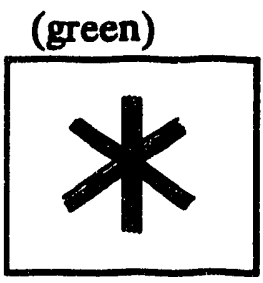

Rescue

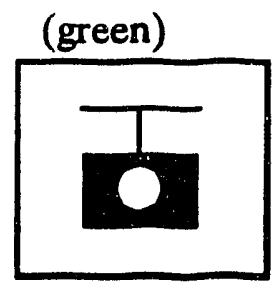

Scales 


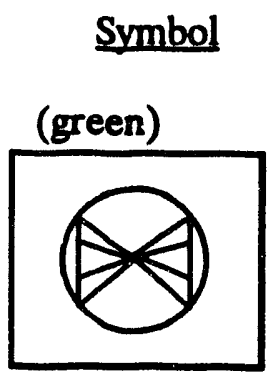

Type

Non-rotating Siren (Siren-NR)

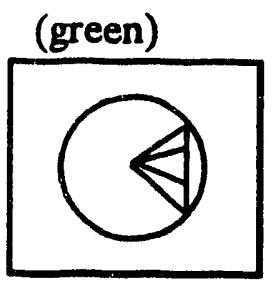

Rotating Siren (Siren-R)

(green/white)

Transport Vehicles (Transprt)

مـ

(green/white)

Trucks

$\frac{0}{0}$

(green/white)

Water

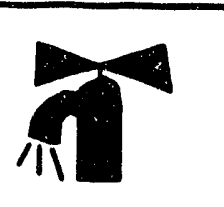


Sumbol

(green)
Type

Weapons 


\section{Non-Facility/Resource Icons}

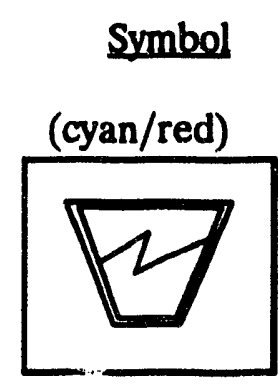

Type

Hydroelectric Plant

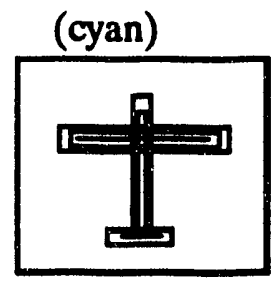

Civilian Airport

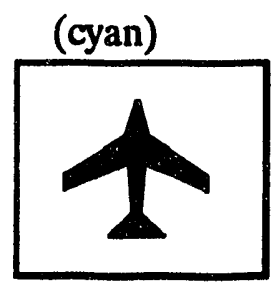

Civilian Air Hub

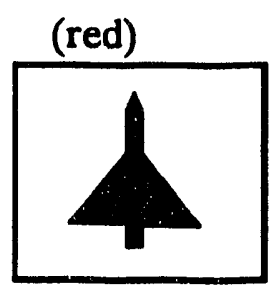

Military Airport

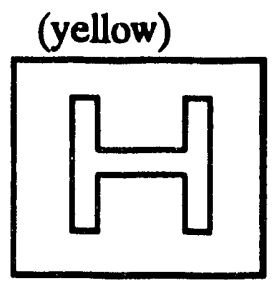

Hospital (Inactive) 


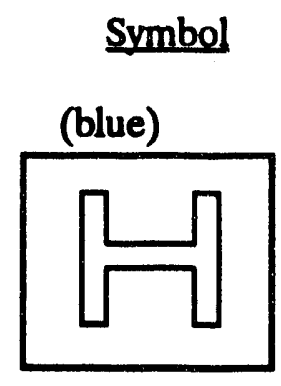

(red)

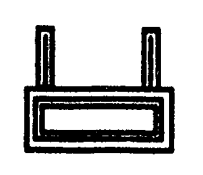

(red)
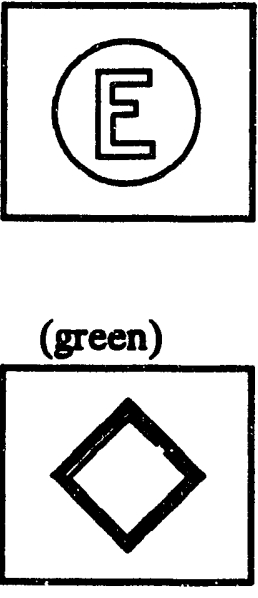

(magenta/yellow)

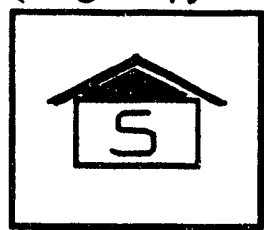

Type

VMAC Hospital

Industrial Park

Emergency Equipment

\author{
Hazmat Site
}

Shelter - CSEPP 


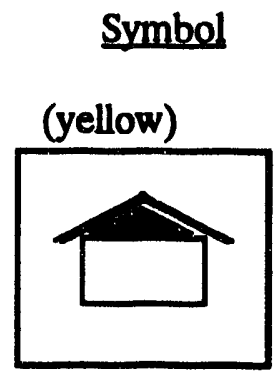

\section{Type}

Shelter (Inactive)

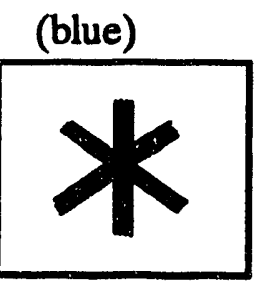

Rescue Squad

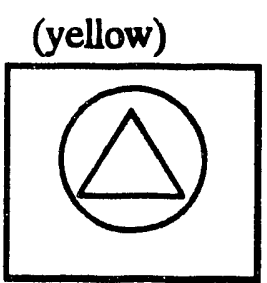

EOC (Inactive)

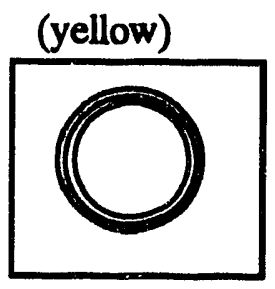

Tank Farm (Fuel)

(blue/blink white)

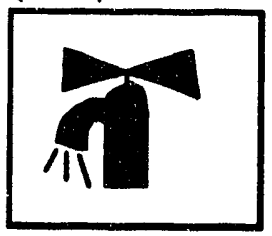

Water Supply 

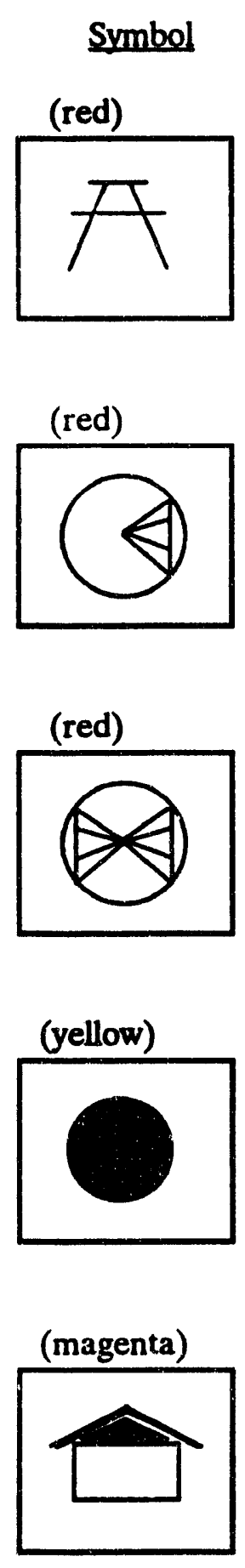

Type

Recreation Area (Rec Area)

Siren - Nonrotating

Other Control Point

Evacuation Shelter 


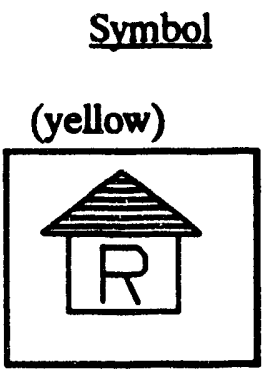

\section{Type}

Reception Center (Inactive)

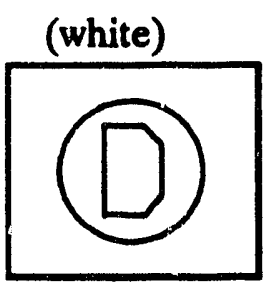

\section{Decontamination Center}

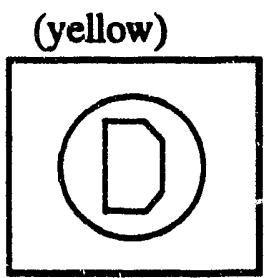

Decontamination Center (Inactive)

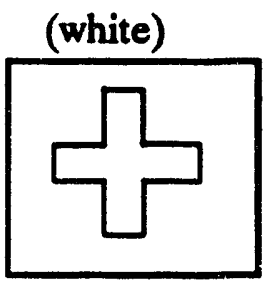

\section{Morgue}

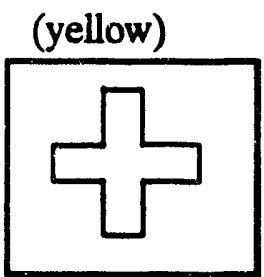

Morgue (Inactive) 

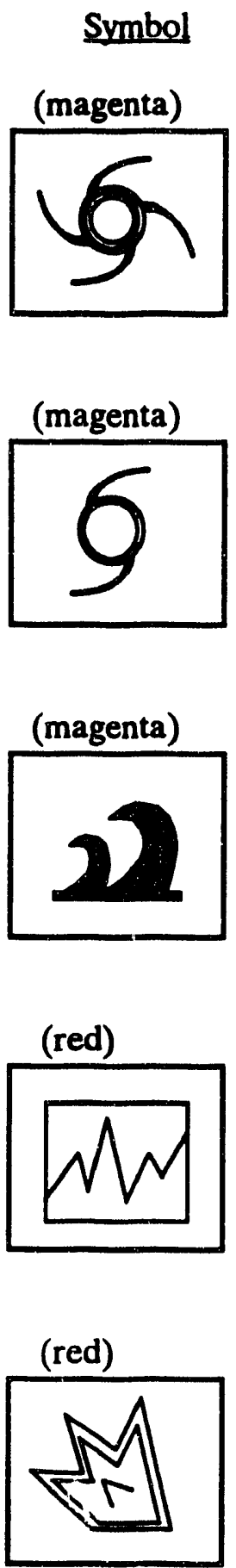

Type

Hurricane

Tropical Storm

Tsunami

Earthquake

Fire 


\begin{tabular}{c} 
Symbol \\
(white) \\
\hline
\end{tabular}

Type

Blizzard

(blue)

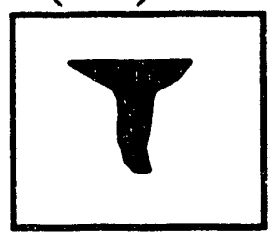

(cyan)

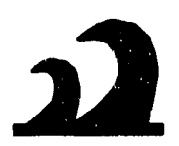

(red)

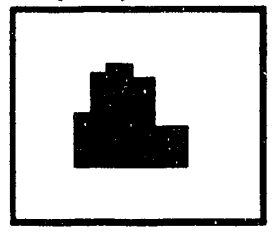

(cyan)

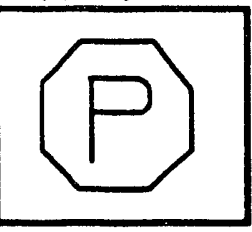

Tornado

Flood

City

CSEPP Police Station 

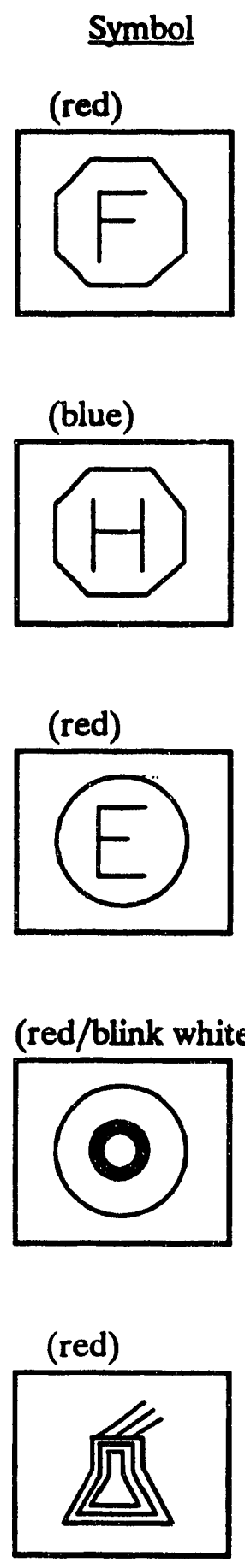

\section{Type}

CSEPP Fire Station

Hospital Resource

Equipment

NAPB Target

Refinery 


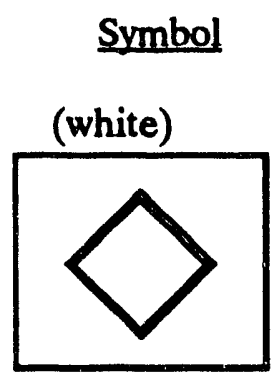

\section{Type}

Coal Mine .

(red/white)
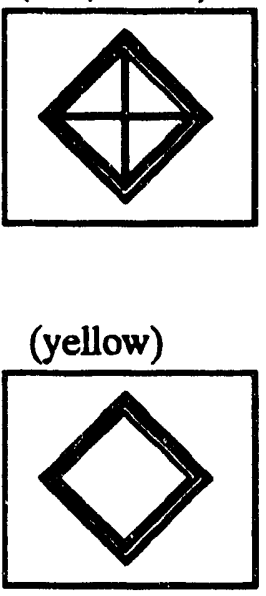

(blue)

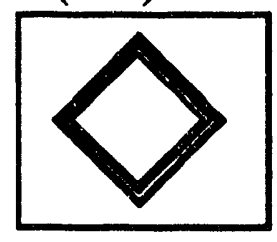

(white/yellow)

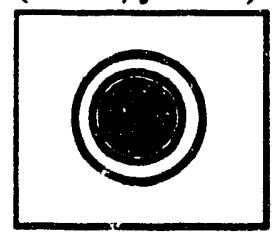

Coke Producer

Natural Gas Pressure Plant (Nat Gas P. P.)

\section{Natural Gas Underground Storage \\ (Nat Gas Under St.)}

Petroleum Import Facility (Petrol Import Fac.) 


\section{Symbol}

(blue)

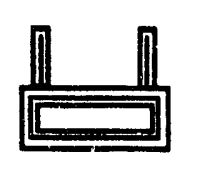

(white)

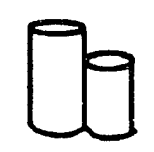

(white)

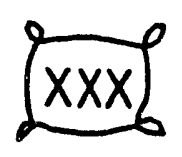

(white)
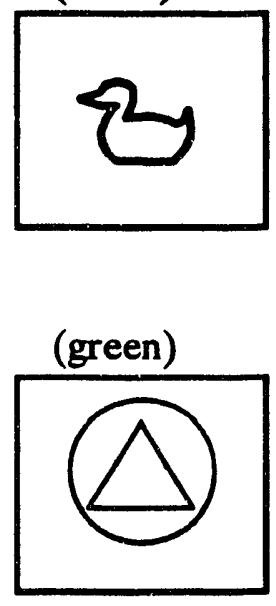

Type

Port Facility

Grain Storage

Flour Mills

Poultry Production

Agriculture EOC 
Symbol Type

(white)

Egg Producers

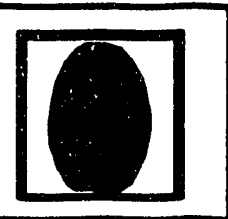



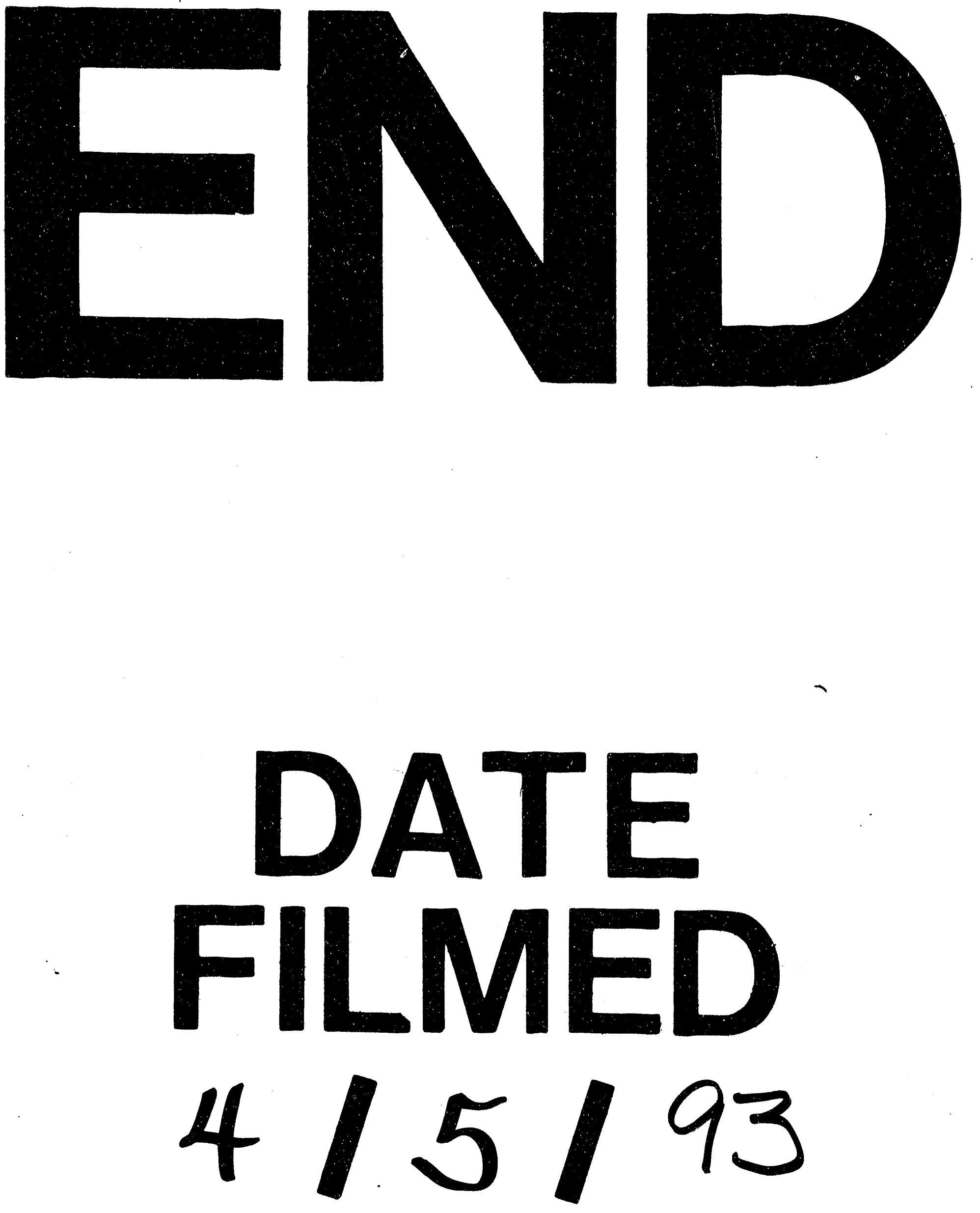

1 
